\title{
EXPERIMENT DATA REPORT FOR SEMISCALE MOD-1 TEST S-05-1 (ALTERNATE ECC INJECTION TEST)
}

\author{
EDGAR M. FELDMAN MORRIS L. PATTON, JR.
}

KENNETH E. SACKETT

February 1977

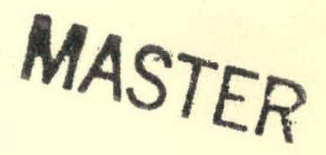

EG\&G Idaho, Inc.

IDAHO NATIONAL ENGINEERING LABORATORY

\section{ENERGY RESEARCH AND DEVELOPMENT ADMINISTRATION}




\section{DISCLAIMER}

This report was prepared as an account of work sponsored by an agency of the United States Government. Neither the United States Government nor any agency Thereof, nor any of their employees, makes any warranty, express or implied, or assumes any legal liability or responsibility for the accuracy, completeness, or usefulness of any information, apparatus, product, or process disclosed, or represents that its use would not infringe privately owned rights. Reference herein to any specific commercial product, process, or service by trade name, trademark, manufacturer, or otherwise does not necessarily constitute or imply its endorsement, recommendation, or favoring by the United States Government or any agency thereof. The views and opinions of authors expressed herein do not necessarily state or reflect those of the United States Government or any agency thereof. 


\section{DISCLAIMER}

Portions of this document may be illegible in electronic image products. Images are produced from the best available original document. 
Printed in the United States of America

Available from

National Technical Information Service

U.S. Department of Commerce

5285 Port Royal Road

Springfield, Virginia 22161

Price: Printed Copy $\$ 7.75$; Microfiche $\$ 3.00$

"The NRC will make available data tapes and operational computer codes on research programs dealing with postulated loss-of-coolant accidents in light water reactors. Persons requesting this information must reimburse the NRC contractors for their expenses in preparing copies of the data tapes and the operational computer codes. Requests should be submitted to the Research Applications Branch, Office of Nuclear Regulatory Research, Nuclear Regulatory Commission, Washington, D.C. 20555."

\section{NOTICE}

This report was prepared as an account of work sponsored by the United States Government. Neither the United States nor the Energy Research and Development Administration, nor the Nuclear Regulatory Commission, nor any of their employees, nor any of their contractors, subcontractors, or their employees, makes any warranty, express or implied, or assumes any legal liability or responsibility for the accuracy, completeness or usefulness of any information, apparatus, product or process disclosed, or represents that its use would not infringe privately owned rights. 
TREE-NUREG-1050

EXPERIMENT DATA REPORT FOR SEMISCALE MOD-1

TEST S-05-1

\section{(ALTERNATE ECC INJECTION TEST)}

Approved:

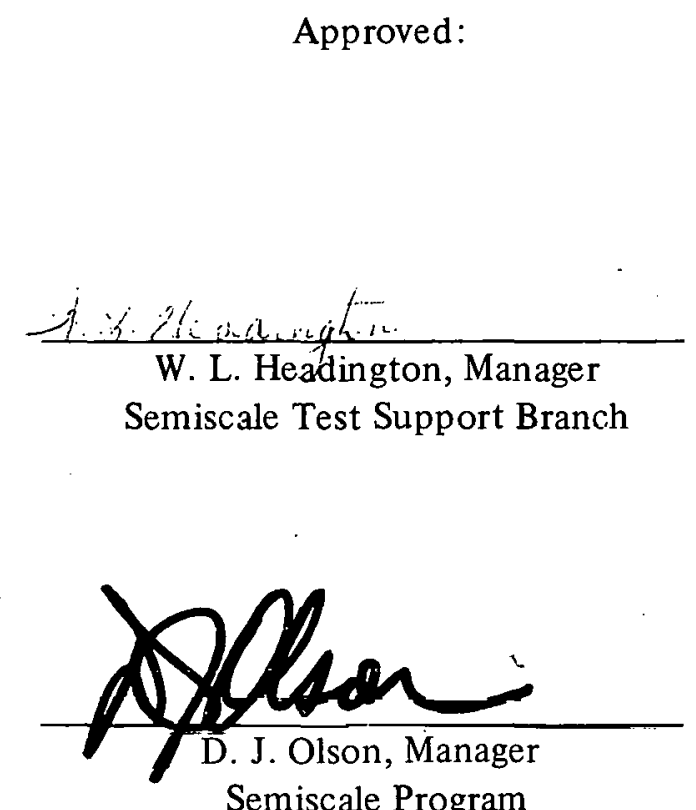

Semiscale Program

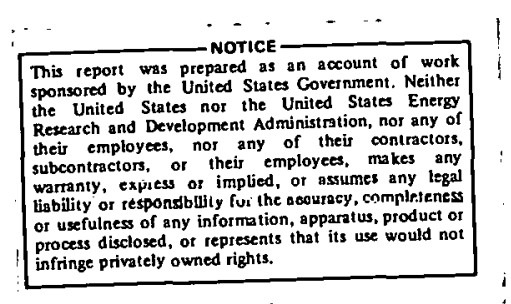




\title{
EXPERIMENT DATA REPORT FOR SEMISCALE MOD-1 \\ TEST S-05-1 \\ (ALTERNATE ECC INJECTION TEST)
}

by

\author{
Edgar M. Feldman \\ Morris L. Patton, Jr. \\ Kenneth E. Sackett
}

EG\&G IDAHO, INC.

February 1977

PREPARED FOR THE U.S. NUCLEAR REGULATORY COMMISSION AND ENERGY RESEARCH AND DEVELOPMENT ADMINISTRATION IDAHO OPERATIONS OFFICE UNDER CONTRACT NO. EY-76-C-07-1570 


\begin{abstract}
Recorded test data are presented for Test S-US-1 of the Semiscale Mod-1 alternate ECC injection test series. These tests are among several Semiscale Mod-1 experiments conducted to investigate the thermal and hydraulic phennmena acsompanying a hypothesized loss-of-coolant accident in a pressurized water reactor (PWR) system.
\end{abstract}

Test S-05-1 was conducted from initial conditions of 2263 psia and $544^{\circ} \mathrm{F}$ to investigate the response of the Semiscale Mod-1 system to a depressurization and reflood transient following a simulated double-ended of fset shear of the cold leg broken loop piping. During the test, cooling water was injected in to the vessel lower plenum to simulate emergency core coolant injection in a PWR, with the flow rate based on system volume scaling.

The purpose of this report is to make available the uninterpreted data from Test S-05-1 for future data analysis and test results reporting activities. The data, presented in the form of graphs in engineering units, have been analyzed only to the extent necessary to assure that they are reasonable and consistent. 


\section{SUMMARY}

Test S-05-1 was performed as part of the Semiscale Mod-1 portion of the Semiscale Program conducted by EG\&G Idaho, Inc., for the United States Government. This test was part of the alternate ECC injection test series (Test Series 5) performed to investigate the response of the Mod-1 system to specific variations in coolant injection location. The test objective specific to Test S-05-1 was to provide data which can be used to assess the influence of lower plenum injection on the core and system response. Hardware configuration and test parameters were selected to yield a system response that simulates the response of a pressurized water reactor (P.WR) to a hypothesized loss-of-coolant accident (LOCA) with subsequent retill and reflood.

Test S-05-1 utilized the Semiscale Mod-1 system equipped with a pressure vessel with a 40-rod electrically heated core; an intact loop with active pump, steam generator, and pressurizer; a broken loop with simulated pump, simulated steam generator, and rupture assemblies; and a pressure suppression system with header, pressure suppression tank, and a heated steam supply system. High and low pressure coolant injection pumps and a coolant injection accumulator were provided for the vessel lower plenum only. The vessel lower plenum volume, coolant flow rate, and total accumulator nitrogen flow were volumetrically scaled to that of a PWR. In addition, for Test S-05-1, four heater rods were intentionally unpowered to simulate the effects of control rod guide tubes and the power in three heater rods was increased to produce a slightly peaked profile.

The test was conducted from initial conditions of 2263 psia and $544^{\circ} \mathrm{F}$ (at the intact loop cold leg vessel inlet) with a simulated full size (200\%) double-ended offset shear of the cold leg broken loop piping at an initial core power level of $1.49 \mathrm{MW}$, and an initial core inlet flow rate of $143 \mathrm{gpm}$. The instantaneous offset shear of the broken loop cold leg piping was simulated by simultaneous (within $10 \mathrm{msec}$ ) actuation of the rupture assemblies. After initiation of blowdown, power to the heated core was reduced to simulate the predicted heat flux response of nuclear fuel rods during a LOCA. Blowdown was accompanied by simulated emergency core coolant injected directly in to the vessel lower plenum.

Test S-05-1 was generally conducted as specified. Conditions which did not conform to the specified test configuration were considered acceptable for analysis purposes within the test objectives. The instrumentation used generally functioned as intended. Of 213 measurements taken, 210 produced usable data. 


\section{CONTENTS}

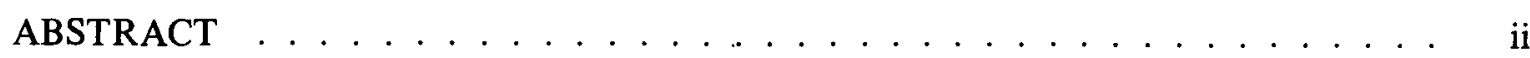

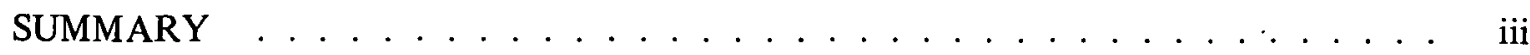

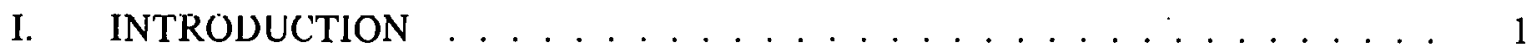

II. SYSTEM, PROCEDURES, CONDITIONS, AND EVENTS FOR TEST S-05-1 2

1. SY'STEM CONFIGURATION AND TEST PROCEDURES . . . . . . . 2

2. INITIAL TEST CONDITIONS AND SEQUENCE OF EVENTS . . . . . . 5

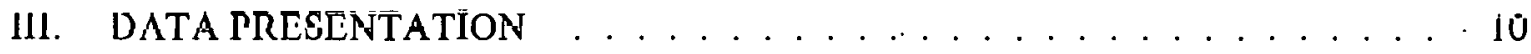

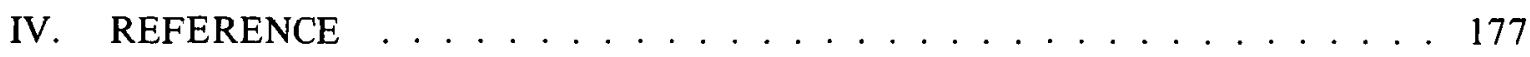

APPENDIX A - POSTTEST ADJUSTMENTTS TO DATA FROM

SEMISCALE MOD-1 TEST S-05-1 . . . . . . . . . . . . . 179

1. PRESSURE MEASUREMENTS ................. 181

2. DIFFERENTIAL PRESSURE MEASUREMENTS . . . . . . . . . . . 182

3. MOMENTUM FLUX MEASUREMENTS (DRAG DISCS) . . . . . . . . 185

4. DENSITY MEASUREMENTS . . . . . . . . . . . . . 186

5. CORE POWER MEASUREMENTS . . . . . . . . . . . . . . . . 189

\section{FIGURES}

1. Semiscale Mod-1 system for cold leg break configuration - schematic . . . . . . . . . . . . . . . 3

2. Cross section of vessel with lower plenum filler . . . . . . . . . . . . 4

3. - Semiscale Mod-1 system and instrumentation for cold leg break configuration - isometric . . . . . . . . . . . . 11

4. Semiscale Mod-1 system and instrumentation for cold leg break configuration - schematic 
5. Semiscale Mod-1 pressure vessel - cross

section showing instrumentation . . . . . . . . . . . . . . . . 13

6. Semiscale Mod-1 pressure vessel - ịsometric

showing instrumentation . . . . . . . . . . . . . . . . . . 14

7. Semiscale Mod-1 pressure vessel - penetration

and instrumentation . . . . . . . . . . . . . . . 15

8. Semiscale Mod-1 heated core - plan view . . . . . . . . . . . . 16

9. Fluid temperature in intact loop hot leg

(RBU-2), from -20 to 300 seconds . . . . . . . . . . . . . . . 28

10. Fluid temperature in in tact loop hot leg

(RBU-2), from -6 to 42 seconds . . . . . . . . . . . . . . . . 28

11. Fluid temperature in intact loop cold leg (TFU-10,

RBU-14A, and TFU-14B), from -20 to 300 seconds . . . . . . . . . . . 29

12. Fluid temperature in in tact loop cold leg (TFU-10,

RBU-14A, and TFU-14B), from -6 to 42 seconds . . . . . . . . . . . . . .

13. Fluid temperature in broken loop, vessel side

(TFB-20 and TFB-23), from -20 to 300 seconds . . . . . . . . . . 30

14. Fluid temperature in broken loop, vessel side

(TFB-20 and TFB-23), from -6 to 42 seconds . . . . . . . . . . . . . . . 30

15. Fluid temperature in broken loop, pump side (TFB-30,

TFB-37, and TFB-42), from -20 to 300 seconds

16. Fluid temperature in broken loop, pump side (TFB-30,

TFB-37, and TFB-42), from -6 to 42 seconds . . . . . . . . . . . . 31

17. Fluid temperature in inlet anmulus (TFV-ANN-4A

and TFV-ANN-4M), from -20 to 300 seconds.

18. Fluid temperature in inlet annulus (TFV-ANN-4A

and TFV-ANN-4M), from -6 to 42 seconds

19. Fluid temperature in downcomer annulus (TFV-ANN-35A, TFV-ANN-70A, TFV-ANN-115A, and TFV-ANN-156A), from -20 to 300 seconds . . . . . . . 33

20. Fluid temperature in downcomer annulus (TFV-ANN-35A, TFV-ANN-70A, TFV-ANN-115A, and TFV-ANN-156A), from -6 to 42 secunds . . . . . . . . 
21. Fluid temperature in upper plenum

(TFV-UP+13), from -20 to 300 seconds . . . . . . . . . . . . 34

22. Fluid temperature in upper plenum

(TFV-UP+13), from -6 to 42 seconds . . . . . . . . . . . . . . . . 34

23. Fluid temperature in lower plenum (TFV-LP-2,

TFV-LP-4, and TFV-LP-7), from -20 to 300 seconds . . . . . . . . . . 35

24. Fluid temperature in lower plenum (TFV-LP-2,

TFV-LP-4, and TFV-LP-7), from -6 to 42 seconds . . . . . . . . . . 35

25. Fluid temperature in core inlet

(TFV-CORE-IN), from -20 to 300 seconds . . . . . . . . . . . . . 36

26. Fluid temperature in core inlet

(TFV-CORE-IN), from -6 to 42 seconds . . . . . . . . . . . . 36

27. Fluid temperature in core barrel insulation

gap (TFV-CIG-70A), from -20 to 300 seconds . . . . . . . . . . . . . 37

28. Fluid temperature in core barrel insulation

gap (TFV-CIG-70A), from -6 to 42 seconds . . . . . . . . . . . . . . 37

29. Fluid temperature in vessel filler insulation

gap (TFV-FIG-156A), from -20 to 300 seconds . . . . . . . . . . . . 38

30. Fluld temperature in vessel filler insulation

gap (TFV-FIG-156A), from -6 to 42 seconds . . . . . . . . . . . 38

31. Fluid temperature in lower plenum

(TFV-ECC-165), from -20 to 300 seconds . . . . . . . . . . . . . 39

32. Fluid temperature in lower plenum

(TFV-ECC-165), from -6 to 42 seconds . . . . . . . . . . . . . . . . 39

33. Fluid temperature in steam generator (TFIJ-SGFW

and TFU-SGSD), from -20 to 300 seconds . . . . . . . . . . . . . 40

34. Fluid temperature in steam generator (TFU-SGFW

and TFU-SGSD), from -6 to 42 seconds . . . . . . . . . . . . . . . 40

35. Fluid temperature in pressurizer surge line

(TFU-PRIZE), from -20 to 300 seconds 
36. Fluid temperature in pressurizer surge line

(TFU-PRIZE), from -6 to 42 seconds

37. Fluid temperature in pressure suppression tank

(T.F-PSS-33 and TF-PSS-130), from -20 to 300 seconds

38. Fluid temperature in pressure suppression tank

(TF-PSS-33 and TF-PSS-130), from -6 to 42 seconds

39. Material temperature in intact loop (TMU-1T16,

TMU-15B16, and TMU-15T16); from -20 to 300 seconds

40. Material temperature in in tact loop (TMU-1T16,

TMU-15B16, and TMU-15T16), from -6 to 42 seconds

41. Material temperature in broken loop (TMB-20B16, and

TMB-30T 16), from -20 to 300 seconds

42. Material temperature in broken loop (TMB-20B16, and

TMB-30T 16), from -6 to 42 seconds . . . . . . . . . . . . . .

43. Material temperature in vessel filler (TMV-FI-4M,

TMV-FI-15A, and TMV-FI-35A), from -20 to 300 seconds

44. Material temperature in vessel filler (TMV-FI-4M,

TMV-FI-15A, and TMV-FI-35A), from -6 to 42 seconds

45. Material temperature in vessel filler (TMV-FI-70A,

TMV-FI-115A, and TMV-FI-156A), from -20 to 300 seconds

46

46. Material temperature in vessel filler (TMV-FI-70A,

TMV-FI-115A, and TMV-FI-156A), from -6 to 42 seconds

47. Material temperature in vessel filler

(TMV-FO-156A), from -20 to 300 seconds

48. Material temperature in vessel filler

(TMV-FO-156A), from -6 to 42 seconds

49. Material temperature in vessel filler insulator (TIV-FO-35A,

TIV-FO-35M, TIV-FO-70A, and TIV-FO-115A), from -20 to 300 seconds.

50. Material temperature in vessel filler insulator (TIV-FO-35A,

TIV-FO-35M, TIV-FO-70A, and TIV-FO-115A), from -6 to 42 seconds $\because .$. . 
51. Material temperature in core barrel inner diameter

(TMV-CI-70A and TMV-CI-1 15A), from -20 to 300 seconds

52. Material temperature in core barrel inner diameter

(TMV-CI-70A and TMV-CI-1 15A), from -6 to 42 seconds . . . . . . . . . . 49

53. Material temperature in core barrel outer diameter

(TMV-CO-70A and TMV-CO-115A), from -20 to 300 seconds . . . . . . . . 50

54. Material temperature in core barrel outer diameter

(TMV-CO-70A and TMV-CO-115A), from -6 to 42 seconds . . . . . . . . . . 50

55. Material temperature in core housing filler (TMV-HF-115W,

TMV-HF-12/W, and IMV-HF-138W). from -20 to 300 se.snnds f . . . . 51

56. Material temperature in core housing filler (TMV-HF-115W,

TMV-HF-127W, and TMV-HF-138W), from -6 to 42 seconds . . . . . . . . 51

57. Core heater temperature, Rod D-4 (TH-D4-14

and TH-D4-29), from -20 to 300 seconds . . . . . . . . . . . 52

58. Core heater temperature, Rod D-4 (TH-D4-14

and TH-D4-29), from -6 to 42 seconds . . . . . . . . . . . . . . . 52

59. Core heater temperature, Rod D-5 (TH-D5-29),

from -20 to 300 seconds . . . . . . . . . . . . . . . . . . 53

60. Core heater temperature, Rod D-5 (TH-D5-29),

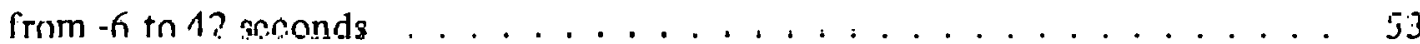

61. Core heater temperature, Rod E-4 (TH-E4-09, TH-E4-28G,

TH-E4-28T, and TH-E4-55), from -20 to 300 seconds . . . . . . . . . . . . 54

62. Core heater temperature, Rod E-4 (TH-E4-09, TH-E4-28G,

TH-E4-28T, and TH-E4-55), from -6 to 42 seconds . . . . . . . . . . . . 54

63. Core heater temperature, Rod E-5 (TH-E5-21 and

I'H-E5-25), frum -20 to 300 seconds . . . . . . . . . . . . . 55

64. Core heater temperature, Rod E-5 (TH-E5-21 and

TH-E5-25), from -6 to 42 seconds . . . . . . . . . . . . . . . 55

65. Core heater temperature, Rod A-4 (TH-A4-09, TH-A4-29,

and TH-A4-39), from -20 to 300 seconds 
66. Core heater temperature, Rod A-4 (TH-A4-09, TH-A4-29, and TH-A4-39), from -6 to 42 seconds . . . . . . . . . . . . . 56

67. Core heater temperature, Rod A-5 (TH-A5-29 and TH-A5-45), from -20 to 300 seconds

68. Core heater temperature, Rod A-5 (TH-A5-29

and TH-A 5-45), from -6 to 42 seconds . . . . . . . . . . . . . . . 57

69. Core heater temperature, Rod B-3 (TH-B3-32),

from -20 to 300 seconds . . . . . . . . . . . . . . . . . 58

70. Core heater temperature, Rod B-3 (TH-B3-32),

from -6 to 42 seconds . . . . . . . . . . . . . . . . . . . . . . . . 58

71. Core heater temperature, Rod B-5 (TH-B5-29

and TH-B5-33), from -20 to 300 seconds . . . . . . . . . . . . . . . . 59

72. Core heater temperature, Rod B-5 (TH-B5-2.9

and TH-B5-33), from -6 to 42 seconds. . . . . . . . . . . . . . . . . . . . . . . 59

73. Core heater temperature, Rod B-6 (TH-B6-29),

from -20 to 300 seconds . . . . . . . . . . . . . . . . . . 60

74. Core heater temperature, Rod B-6 (TH-B6-29),

from -6 to 42 seconds . . . . . . . . . . . . . . . . . . . . . 60

75. Core heater temperature, Rod C-2 (TH-C2-38),

from -20 to 300 seconds . . . . . . . . . . . ........... . . 61

76. Core heater temperature, Rod C-2 (TH-C2-38),

from -6 to 42 seconds

77. Core heater temperature, Rod C-4 (TH-C4-20, TH-C4-26, and TH-C4-53), from -20 to 300 seconds . . . . . . . . . . . . 62

78. Core heater temperature, Rod C-4 (TH-C4-20, TH-C4-26, and TH-C4-53), from -6 to 42 seconds . . . . . . . . . . . . . . . . 62

79. Core heater temperature, Rod C-5 (TH-C5-28), from -20 to 300 seconds . . . . . . . . . . . . . . . . . 63

80. Core heater temperature, Rod C-5 (TH-C5-28), from -6 to 42 seconds 
81. Core heater temperature, Rod C-6 (TH-C6-32

and TH-C6-53), from -20 to 300 seconds . . . . . . . . . . . . . . 64

82. Core heater temperature, Rod C-6 (TH-C6-32

and TH-C6-53), from -6 to 42 seconds . . . . . . . . . . . . . . . . 64

83. Core heater temperature, Rod C-7 (TH-C7-07

and TH-C7-15), from -20 to 300 seconds . . . . . . . . . . . . 65

84. Core heater temperature, Rod C-7 (TH-C7-07

and TH-C7-15), from -6 to 42 șeconds . . . . . . . . . . . . . . . 65

85. Core heater temperature, Rod D-1 (TH-D1-21),

from -20 to 300 seconds . . . . . . . . . . . . . . . . . . 66

86. Core heater temperature, Rod D-1 (TH-D1-21),

from -6 to 42 seconds . . . . . . . . . . . . . . . . . . 66

87. Core heater temperature, Rod D-2 (TH-D2-14

and TH-D2-61), from -20 to 300 seconds . . . . . . . . . . . . . . 67

88. Core heater temperature, Rod D-2 (TH-D2-14

and TH-D2-61), from -6 to 42 seconds . . . . . . . . . . . . . 67

89. Core heater temperature, Rod D-3 (TH-D3-29

and TH-D3-39), from -20 to 300 seconds . . . . . . . . . . . . 68

90. Core heater temperature, Rod D-3 (TH-D3-29

and TH-D3-39), from -6 to 42 seconds . . . . . . . . . . . . . . . 68

91. Core heater temperature, Rod D-6 (TH-D6-25),

from -20 to 300 seconds : . . . . . . . . . . . . . . . . . . . 69

92. Core heater temperature. Rod D-6 (TH-D6-25),

from -6 to 42 seconds . . . . . . . . . . . . . . . . . . . . . . . 69

93. Core heater temperature, Rod D-7 (TH-D7-20),

from -20 to 300 seconds . . . . . . . . . . . . . . . . . . . . 70

94. Core heater temperature, Rod D-7 (TH-D7-20),

from -6 to 42 seconds . . . . . . . . . . . . . . . . . . 70

95. Core heater temperature, Rod D-8 (TH-D8-27

and TH-D8-57), from -20 to 300 seconds 
96. Core heater temperature, Rod D-8 (TH-D8-27

and TH-D8-57), from -6 to 42 seconds . . . . . . . . . . . . . 71

97. Core heater temperature, Rod E-1 (TH-E1-21

and TH-E 1-33), from -20 to 300 seconds . . . . . . . . . . . . 72

98. Core heater temperature, Rod E-1 (TH-E1-21

and TH-E 1-33), from -6 to 42 seconds . . . . . . . . . . . . . . . 72

99. Core heater temperature, Rod E-2 (TH-E2-20

and TH-E2-33), from -20 to 300 seconds . . . . . . . . . . . . 73

100. Core heater temperature, Rod E-2 (TH-E2-20

and TH-E2-33), from -6 to 42 seconds . . . . . . . . . . . . . . . 73

101. Core heater temperature, Rod E-3 (TH-E3-05,

TH-E3-20, and TH-E3-24), from -20 to 300 seconds . . . . . . . . . . . . . 74

102. Core heater temperature, Rod E-3 (TH-E3-05,

TH-E3-20, and TH-E3-24), from -6 to 42 seconds $\ldots . . . . . . . \quad 74$

103. Core heater temperature, Rod E-6 (TH-E6-08,

TH-E6-28, and TH-E6-37), from -20 to 300 seconds . . . . . . . .

104. Core heater temperature, Rod E-6 (TH-E6-08,

TH-E6-28, and TH-E6-37), from -6 to 42 seconds

105. Core heater temperature, Rod E-7 (TH-E7-44),

from -20 to 300 seconds $\therefore \ldots \ldots \ldots \ldots \ldots \ldots$

106. Core heater temperature, Rod E-7 (TH-E7-44),

from -6 to 42 seconds . . . . . . . . . . . . . . . . . . 76

107. Core heater temperature, Rod E-8 (TH-E8-14,

TH-E8-29, and TH-E8-45), from -20 to 300 seconds . . . . . . . . . . 77

108. Core heater temperature, Rod E-8 (TH-E8-14,

TH-E8-29, and TH-E8-45), from -6 to 42 seconds . . . . . . . . . . . . 77

109. Core heater temperature, Rod F-2 (TH-F2-07,

TH-F2-22, and TH-F2-25), from -20 to 300 seconds . . . . . . . . . . . $/ 8$

110. Core heater temperature, Rod F-2 (TH-F2-07,

TH-F2-22, and TH-F2-25), from -6 to 42 seconds . . . . . . . 78 
111. Core heater temperature, Rod F-4 (TH-F4-14, TH-F4-29, and TH-F4-44), from -20 to 300 seconds

112. Core heater temperature, Rod F-4 (TH-F4-14,

TH-F4-29, and TH-F4-44), from -6 to 42 seconds

113. Core heater temperature, Rod F-5 (TH-F5-20, TH-F5-26,

TH-F5-33, and TH-F5-53), from -20 to 300 seconds . . . . . . . . . . 80

114. Core heater temperature, Rod F-5 (TH-F5-20, TH-F5-26,

TH-F5-33, and TH-F5-53), from -6 to 42 seconds

115. Core heater temperature, Kod F'-6 ('TH-F6-08),

from -20 to 300 seciunds

116. Core heater temperàture, Kod F-6 (TH-F6-08),

from -6 to 42 seconds

117. Core heater temperature, Rod G-3 (TH-G3-13),

from -20 to 300 seconds

118. Core heater temperature, Rod G-3 (TH-G3-13),

from -6 to 42 seconds

119. Core heater temperature, Rod G-4 (TH-G4-29, TH-G4-33,

and TH-G4-38), from -20 to 300 seconds

120. Core heater temperature, Rod G-4 (TH-G4-29, TII-G4-33,

and TH-G4-38), from -6 to 42 seconds

121. Core heater temperature, Rod G-5 (TH-G5-14 and

TH-G5-24), from -20 to 300 seconds

122. Core heater temperature, Rod G-5 (TH-G5-14 and

TH-G5-24), from -6 to 42 seconds

123. Core heater temperature, Rod H-5 (TH-H5-32),

from -20 to 300 seconds

124. Core heater temperature, Rod H-5 (TH-H5-32),

from -6 to 42 seconds

125. Pressure in intact loop, Spool 13 PU:13(F),

from -20 to 300 seconds 
126. Pressure in intact loop, Spool $13 \mathrm{PU}-13(\mathrm{~F})$,

from -6 to 42 seconds

127. Pressure in intact loop, Spool 15, low range,

(PU-15L), from -20 to 300 seconds

128. Pressure in in tact loop, Spool 15 , low range, (PU-15L), from -6 to 42 seconds

129. Pressure in broken loop, vessel side,

Spool 23 (PB-23), from -20 to 300 seconds

130. Pressure in broken loop, vessel side,

Spool 23 (PB-23), from -6 to 42 seconds

131. Pressure in broken loop, pump side (PB-37

and PB-42), from -20 to 300 seconds

132. Pressure in broken loop, pump side (PB-37

and PB-42), from -6 to 42 seconds

133. Pressure in broken loop, pump-side nozzle

(PB-HN1), from -20 to 300 seconds

134. Pressure in broken loop, pump-side nozzle

(PB-HN1), from -6 to 42 seconds

135. Prcssure in broken loop, vessel-side nozzle

(PB-CN1), from -20 to 300 seconds

136. Pressure in broken loop, vessel-side nozzle

(PB-CN1), from -6 to 42 seconds

137. Pressure in vessel (PV-UP+10 and

PV-LP-166), from -20 to 300 seconds

138. Pressure in vessel (PV-UP+10 and

PV-LP-166), from -6 to 42 seconds

139. Pressure in vessel accumulator

(PV-ACC), from -20 to 300 seconds

140. Pressure in vessel accumulator

(PV-ACC), from -6 to 42 seconds 
141. Pressure in steam generator, secondary side (PU-SGSD), from -20 to 300 seconds

142. Pressure in steam generator, secondary side (PU-SGSD), from -6 to 42 seconds

143. Pressure in pressurizer (PU-PRIZE), from -20 to 300 seconds . . . . . . . . . . . . . . . . . . 95

144. Pressure in pressurizer (PU-PRIZE), from -6 to 42 seconds

145. Pressure in pressure suppression tank (P-PSS), trom-2U to 300 seconds

146. Pressure in pressure suppression tank (P-PSS), from -6 to 42 seconds

147. Differential pressure in in tact loop (DPU-UP-3), from -20 to 300 seconds

148. Differential pressure in in tact loop (DPU-UP-3), from -6 to 42 seconds

149. Differential pressure in intact loop (DPU-3-7), from-20 to 300 seconds

150. Differential pressure in in tact loop (DPU-3-7), from -6 to 42 seconds

151. Differential pressure in in tact loop (DPU-7-10), from -20 to 300 seconds

152. Differential pressure in intact loop (DPU-7-10), from -6 to 42 seconds

153. Differential pressure in intact loop (DPU-12-10), from -20 to 300 seconds

154. Differential pressure in intact loop (DPU-12-10), from -6 to 42 seconds $-100$

155. Differential pressure in in tact loop, low range (DPU-12-10L), from -20 to 300 seconds 
156. Differential pressure in intact loop, low

range (DPU-12-10L), from -6 to 42 seconds

157. Differential pressure in intact loop,

(DPU-12-15), from -20 to 300 seconds

158. Differential pressure in intact loop,

(DPU-12-15), from -6 to 42 seconds

159. Differential pressure in intact loop

(DPU-15-IANN), from -20 to 300 seconds . . . . . . . . . . . . 103

160. Differential pressure in intact loop

(DPU-15-IANN), from -6 to 42 seconds

161. Differential pressure in in tact loop

(DPU-15-1), from -20 to 300 seconds

162. Differential pressure in in tact loop (DPU-15-1), from -6 to 42 seconds

163. Differential pressure in in tact loop, low range

(DPU-15-1L), from -20 to 300 seconds

164. Differential pressure in in tact loop, low range

(DPU-15-1L), from -6 to 42 seconds

165. Differential pressure in intact loop (DPU-PRESLL), from -20 to 300 seconds . . . . . . . . . . . . . . 106

166. Differential pressure in in tact loop

(DPU-PRESLL), from -6 to 42 seconds

167. Differential pressure in in tact loop

(DPU-PR-4), from -20 to 300 seconds

168. Differential pressure in intact loop

(DPU-PR-4), from - 6 to 42 seconds

169. Differential pressure in broken loop

(DPB-UP-30), from -20 to 300 seconds

170. Differential pressure in broken loop (DPB-UP-30), from -6 to 42 seconds 
171. Differential pressure in broken loop

(DPB-2 1-IANN), from -20 to 300 seconds . . . . . . . . . . . . . . 109

172. Differential pressure in broken loop (DPB-2 1-IANN), from -6 to 42 seconds

173. Differential pressure in broken loop

(DPB-23-CN1), from -20 to 300 seconds . . . . . . . . . . . . . . 110

174. Differential pressure in broken loop (DPB-23-CN1), from - 6 to 42 seconds

175. Differential pressure in broken loop (DPB-30-36L), from 20 to 300 sccond 3

176. Differential pressure in broken loop (DPB-30-36L), from -6 to 42 seconds

177. Differential pressure in broken loop (DPB-32U-36L), from -20 to 300 seconds

178. Differential pressure in broken loop (DPB-32U-36L), from -6 to 42 seconds

179. Differential pressure in broken loop (DPB-36L-37), from -20 to 300 seconds

180. Differential pressure in broken loop (DPB-36L-37), from -6 to 42 seconds

181. Differential pressure in broken loop

(DPB-37-38), from -20 to 300 seconds

182. Differential pressure in broken loop (DPB-37-38), from -6 to 42 seconds

183. Differential pressure in broken lonp

(DPB-38-40), from -20 to 300 seconds

184. Differential pressure in broken loop (DPB-38-40), from -6 to 42 seconds

185. Differential pressure in broken loop

(DPB-40-42), from -20 to 300 seconds 
186. Differential pressure in broken loop

(DPB-40-42), from -6 to 42 seconds . . . . . . . . . . . . . . 116

187. Differential pressure in vessel.

(DPV-UP-IANN), from -20 to 300 seconds ... . . . . . . . . 117

188. Differential pressure in vessel

(DPV-UP-IANN), from -6 to 42 seconds . . . . . . . . . . 117

189. Differential pressure in vessel

(DPV-0-9GQ), from -20 to 300 seconds . . . . . . . . . . . . 118

190. Differen (ial pressure in vessel

(DPV-0-9GQ), from -6 to 42 seconds . . . . . . . . . . . . 118

191. Differential pressure in vessel

(DPV-9-26QQ), from -20 to 300 seconds . . . . . . . . . . . . . 119

192. Differential pressure in vcssel

(DPV-9-26QQ), from -6 to 42 seconds . . . . . . . . . . . . . . . 119

193. Differential pressure in vessel

(DPV-9-166QQ), from -20 to 300 seconds . . . . . . . . . . . . . . 120

194. Differential pressure in vessel

(DPV-9-166QQ), from -6 to 42 seconds . . . . . . . . . . . . . 120

195. Differential pressure in vessel

(DPV-26-55QM), from -20 to 300 seconds . . . . ........... . 121

196. Differential pressure in vessel

(DPV-26-55QM), from -6 to 42 seconds . . . . . . . . . . . . . 121

197. Differential pressure in vessel

(DPV-55-110MM), from -20 to 300 seconds . . . . . . . . . . . . 122

198. Differential pressure in vessel

(DPV-55-1 10MM), from -6 to 42 seconds . . . . . . . . . . . . . . . 122

199. Differential pressure in vessel

(DPV-1 10-1 56MQ), from -20 to 300 seconds . . . . . . . . . . 123

200. Differential pressure in vessel

(DPV-110-156MQ), from -6 to 42 seconds . . . . . . . . . . . . . 123 
201. Differential pressure in vessel

(DPV-166-173QQ), from -20 to 300 seconds . . . . . . . . . . . . . . 124

202. Differential pressure in vessel

(DPV-166-173QQ), from -6 to 42 seconds . . . . . . . . . . . . . . . 124

203. Differential pressure in vessel

(DPV-166Q-UP), from -20 to 300 seconds . . . . . . . . . . . . 125

204. Differential pressure in vessel

(DPV-166Q-UP), from -6 to 42 seconds . . . . . . . . . . . . . . 125

205. Differential pressure in vessel core

(DPVC-89W-UP), from -20 to 300 seconds . . . . . . . . . . . 126

206. Differential pressure in vessel core

(DPVC-89W-UP), from -6 to 42 seconds . . . . . . . . . . . . 126

207. Differential pressure in vessel core

(DPVC-89-106WQ), from -20 to 300 seconds . . . . . . . . . . . . 127

208. Differential pressure in vessel core

(DPVC-89-106WQ), from -6 to 42 seconds . . . . . . . . . . . . 127

209: Differential pressure in vessel core

(DPVC-106-122QJ), from -20 to 300 seconds . . . . . . . . . . . . . 128

210. Differential pressure in vessel core

(DPVC-106-122QJ), from -6 to 42 seconds . . . . . . . . . . . . . 128

211. Differential pressure in vessel core

(DPVC-122-140JD), from -20 to 300 seconds . . . . . . . . . . . . . . 129

212. Differential pressure in vessel core

(DPVC-122-140JD), from -6 to 42 seconds . . . . . . . . . . . . . 129

213. Differential pressure in vessel accumulator

(DPV-ACC-TB), from -20 to 300 seconds . . . . . . . . . . . . . 130

214. Differential pressure in vessel accumulator

(DPV-ACC-TB), from -6 to 42 seconds . . . . . . . . . . . . 130

215. Differential pressure in steam generator secondary

(DPU-SG-SEC), from -20 to 300 seconds . . . . . . . . . . . . . . . 131 
216. Differential pressure in steam generator secondary (DPU-SG-SEC), from -6 to 42 seconds . . . . . . . . . . . . . . . 131

217. Differential pressure across steam generator outlet orifice (DPU-SG-DISC), from -20 to 300 seconds

218. Differential pressure across steam generator outlet orifice (DPU-SG-DISC), from -6 to 42 seconds

219. Volumetric flow in intact loop (FTU-1. and FTU-9), from -20 to 300 seconds

220. Volumetric flow in in tact loop (FTU-1 and FTU-9), from -6 to 42 seconds

221. Volumetric flow in in tact loop (FTU-13 and FTU-15), from -20 to 300 seconds

222. Volumetric flow in intact loop (FTU-13 and FTU-15), from -6 to 42 seconds

223. Volumetric flow in broken loop (FTB-21), from -20 to 300 seconds

224. Volumetric flow in broken loop (FTB-21), from -6 to 42 seconds

225. Volumetric flow in broken loop (FTB-30 and FTB-37), from -20 to 300 seconds

226. Volumetric flow in broken loop (FTB-30 and FTB-37), from -6 to 42 seconds

227. Volumetric flow in core entrance (FTV-CORE-IN), from -20 to 300 seconds . . . . . . . . . . . . . . . . .

228. Volumetric flow in core entrance (FTV-CORE-IN), from -6 to 42 seconds

229. Volumetric flow in intact loop high pressure injection line, to vessel (FTU-HPIS), from -20 to 300 seconds

230. Volumetric flow in intact loop high pressure injection line, to vessel (FTU-HPIS), from -6 to 42 seconds 
231. Volumetric flow in in tact loop low pressure injection line, to vessel (FTU-LPIS), from -20 to 300 seconds

232. Volumetric flow in intact loop low pressure injection line, to vessel (FTU-LPIS), from -6 to 42 seconds

233. Volumetric flow from pressurizer (FTU-PRIZE), from -20 to 300 seconds

234. Volumetric flow from pressurizer (FTU-PRIZE), from -6 to 42 seconds

235. Fluid velocity in vessel (FTV-40A and FTV-40M), from -20 to 300 seconds

236. Fluid velocity in vessel (FTV-40A and

FTV-40M), from -6 to 42 seconds

237. Momentum flux in in tact loop (FUU-1), from -6 to 42 seconds

238. Momentum flux in intact loop (FDU-10), from -6 to 42 seconds

239. Momentum flux in in tact loop (FDU-13), from -6 to 42 seconds

240. Momentum flux in intact loop (FDU-15), l'rum -6 lo 42 seconds

241. Momentum flux in broken loop (FDB-21), from -6 to 42 seconds

242. Momentum flux in broken loop (FDB-30), from -6 to 42 seconds

243. Momentum flux in broken loop (FDB-37), from -6 to 42 seconds

244. Momentum flux in broken loop (FDB-42), from -20 to 300 seconds

245. Momentum flux in broken loop (FDB-42), from -6 to 42 seconds 
246. Momentum flux in core entrance (FDV-CORE-IN),

from -20 to 300 seconds . . . . . . . . . . . . . . . . . . . . 147

247. Momentum flux in core entrance (FDV-CORE-IN),

from -6 to 42 seconds . . . . . . . . . . . . . . . . . 147

248. Density in in tact loop (GU-1VR and

GU-1HZ), from -20 to 300 seconds

249. Density in intact loop (GU-1VR and GU-1HZ), from -6 to 42 seconds . . . . . . . . . . . . . . . . 148

250. Density in intact loop (GU-5VR and GU-10VR), from -20 to 300 seconds

251. Density in intact loop (GU-5VR and GU-10VR), from -6 to 42 seconds

252. Density in intact loop (GU-13VR), from -20 to 300 seconds

253. Density in intact loop (GU-13VR), from -6 to 42 seconds

254. Density in intact loop (GU-15VR and GU-15HZ), from -20 to 300 seconds

255. Density in intact loop (GU-15VR and GU-15HZ), from -6 to 42 seconds

256. Density in broken loop (GB-2lVR), from

-20 to 300 seconds

257. Density in broken loop (GB-2 IVR and GB-23VR), from -6 to 42 seconds

258. Density in broken loop (GB-30VR and GB-4.2VR), from -20 to 300 seconds

259. Density in broken loop (GB-30VR and GB-42VR), from -6 to 42 seconds

260. Density in vessel (GV-COR-150HZ), from -20 to 300 seconds 
261. Density in vessel (GV-COR-150HZ),

from -6 to 42 seconds . . . . . . . . . . . . . . . . . 154

262. Density in vessel (GVLP-165HZ and

GVLP-172HZ), from -20 to 300 seconds . . . . . . . . . . . . 155

263. Density in vessel (GVLP-165HZ and

GVLP-172HZ), from -6 to 42 seconds . . . . . . . . . . . . . 155

264. Density in pressurizer (GU-PRIZE),

from -20 to 300 seconds . . . . . . . . . . . . . . . 156

265. Density in pressunzer (GU-PRILE),

from -6 to 42 seconds . . . . . . . . . . . . . . . . . . 156

266. Mass tlow in intact loop (FUU- 1 and

GU-1VR), from -6 to 42 seconds

267. Mass flow in in tact loop (FTU-1 and

GU-1VR), from -20 to 300 seconds

268. Mass flow in intact loop (FTU-1 and

GU-1VR), from -6 to 42 seconds

269. Mass flow in in tact loop (FTU-9 and

GU-10VR), from -20 to 300 seconds

2\%. Mass flow in intact loop (FTU-9 and GU-10VR), from -6 to 42 seconds . . . . . . . . . . . . . . . . . . . . 159

271. Mass flow in intact loop (FDU-10 and

GU-10VR), from -6 to 42 seconds

272. Mass flow in intact loop (FDU-13 and GU-13VR), from -6 to 42 seconds

273. Mass flow in intact loop (FTU-13 and GU-13VR), from -20 to 300 seconds

274. Mass flow in intact loop (FTU-13 and GU-13VR), from -6 to 42 seconds

275. Mass flow in intact loop (FDU-15 and GU-15VR), from -6 to 42 seconds 
276. Mass flow in intact loop (FTU-15 and GU-15VR), from -20 to 300 seconds

277. Mass flow in intact loop (FTU-15 and

GU-15VR), from -6 to 42 seconds

278. Mass flow in broken loop (FDB-21 and

GB-2 1VR), from -6 to 42 seconds

279. Mass flow in broken loop (FTB-21 and

GB-2.1VR), from -20 to 300 seconds

280. Mass tlow in broken loop (FTB-2.1 and

GB-2.IVR), from -6 to 4.2 seconds

281. Mass flow in broken loop (FDB-30 and

GB-30VR), from -6 to 42 seconds

282. Mass flow in broken loop (FTB-30 and

GB-30VR), from -20 to 300 seconds

283. Mass flow in broken loop (FTB-30 and

GB-30VR), from -6 to 42 seconds

284. Mass flow in broken loop (FDB-42 and

GB-42VR), from -6 to 42 seconds

285. Mass flow in vessel (FDV-CORE-IN and

GV-COR-150HZ), from -20 to 300 seconds

286. Mass flow in vessel (FDV-CORE-IN and

GV-COR-150HZ), from -6 to 42 seconds

287. Mass flow in vessel (FTV-CORE-IN and

GV-COR-150HZ), from -20 to 300 seconds

288. Mass flow in vessel (FTV-CORE-IN and

GV-COR-150HZ), from -6 to 42 seconds

289. Mass flow in pressurizer surge line (FTU-PRIZE

and GU-PRIZE), from -20 to 300 seconds

290. Mass flow in pressurizer surge line (FTU-PRIZE

and GU-PRIZE), from -6 to 42 seconds 
291. Corc heater pin total power (PWRCOR T-1 and PWRCOR T-2), from -20 to 300 seconds

292. Core heater pin total power (PWRCOR T-1 and PWRCOR T-2), from -6 to 42 seconds

293. Core heater voltage (VOLTCOR-T), from -20 to 300 seconds . . . . . . . . . . . . . . . . . . . . 173

294. Core heater voltage (VOLTCOR-T), from -6 to 42 seconds

295. Core heater total current (AMPCOR-T), from -20 to 300 seconds . . . . . . . . . . . . . . . . . . 174

296. Core heater total current (AMPCOR-T), from -6 to 42 seconds 174

297. Primary pump speed (PUMPU-RPM), from -20 to 300 seconds

298. Primary pump speed (PUMPU-RPM), from -6 to 42 seconds

299. Primary pump current (PUMPU-CUR), from -20 to 300 seconds . . . . . . . . . . . . . . . . . . . 176

300. Primary pump current (PUMPU-CUR), from -6 to 42 seconds

\section{TADLES}

I. Conditions at Blowdown Initiation $\ldots \ldots \ldots \ldots \ldots$

II. Primary Coolant Temperature Distribution

Prior to Rupture . . . . . . . . . . . . . . . . . . . . 7

III. Water Chemistry Prior to Blowdown $\ldots \ldots \ldots \ldots \ldots$

IV. Sequence of Events During Test $\ldots \ldots \ldots \ldots \ldots$

V. Data Presentation for Semiscale Mod-1 Test S-05-1 . . . . . . . . 17 
A-I. Constants for Pressure Measurement

Corrections (Test S-05-1) f . . . . . . . . . . . . . . . . . 1 182

A-II. Constants for Differential Pressure

Measurement Corrections (Test S-05-1) . . . . . . . . . . . . . . . . . . 184

A-HII. Constants for Momentum Flux

Me asurement Corrections (Test S-05-1) . . . . . . . . . . 186

A-IV. Constants for Density Measurement Conversions

to Engineering Units (Test S-05-1) . . . . . . . . . . . . . . . 188 


\title{
EXPERIMENT DATA REPORT FOR SEMISCALE MOD-1
}

\author{
TEST S-05-1
}

\section{(ALTERNATE ECC INJECTION TEST)}

\section{INTRODUCTION}

The Semiscale Mod-1 experiments represent the current phase of the Semiscale Program conducted by EG\&G Idaho, Inc., ${ }^{[a]}$ for the United States Government. The program, which is sponsored by the Nuclear Regulatory Commission through the Energy Research and Development Administration, is part of the overall program designed to investigate the response of a pressurized water reactor system to a hypothesized loss-of-coolant accident (LOCA). The underlying objectives of the Semiscale program are to quantify the physical processes controlling system behavior during a LOCA and to provide an experimental data base for assessing reactor safety evaluation models. The Semiscale Mod-1 program has the further objective of providing support to other experimental programs in the form of instrumentation assessment, optimization of test series, selection of test parameters, and evaluation of test results.

Test S-05-1 was conducted September 28, 1976 in the Semiscale Mod-1 system as part of the alternate ECC injection test series, which was designed to obtain thermal-hydraulic response data from blowdown, refill, and reflood transients in a simulated nuclear reactor with a heated core, to study system response to change in ECC injection location.

The purpose of this report is to present the test data in an uninterpreted but readily usable form for use by the nuclear community in advance of detailed analysis and interpretation. Section II briefly describes the system configuration, procedures, initial test conditions, and events that are applicable to Test S-05-1; Section III presents the data graphs and provides comments and supporting information necessary for in terpretation of the data. A description of the overall Semiscale Program and test series, a more detailed description of the Semiscale Mod-1 system, and a description of the measurement and data processing techniques and uncertainties can be found in Reference 1.

[a] Test S-05-1 was conducted by Aerojet Nuclear Company under Contract No. E(10-1)-1375. As of October 1, 1976, the Semiscale Program is being conducted by EG\&G Idaho, Inc. 


\section{SYSTEM, PROCEDURES, CONDITIONS, AND EVENTS FOR TEST S-05-1}

The following system configuration, procedures, initial test conditions, and events are specific to Test S-05-1 as indicated.

\section{SYSTEM CONFIGURATION AND TEST PROCEDURES}

The Semiscale Mod-1 system used for this test consisted of a pressure vessel with internals, including a 40-rod core with 36 electrically heated rods; an intact loop with steam generator, pump, and pressurizer; a broken loop with simulated steam generator, simulated pump, and iwo rupture assemblies; a coolant injection accumulator for the vessel lower plenum; high and low pressure injection pumps for the vessel lower plenum; and a pressure suppression system with a suppression tank, header, and a heated steam supply system. For Test S-05-1, the volume of the lower plenum was reduced to $0.529 \mathrm{ft}^{3}$ by the addition of a metal filled piece. System configuration information is provided in Reference 1. Figures 1 and 2 provide the system configuration for Test S-05- 1 .

For Test S-05-1, 33 rods of the 40-rod electrically heated core were operated at a peak power density of approximately $11.5 \mathrm{~kW} / \mathrm{ft}$, three rods (Rods D-4, E-4, and E-5) were operated at a peak power density of $12.1 \mathrm{~kW} / \mathrm{ft}$ to yield a slightly peaked power profile, and four rods (Rods C-3, D-5, F-3, and F-6) were unpowered to simulate the effect of control rod guide tubes. The resulting total core power was approximately $1.49 \mathrm{MW}$.

In preparation for the test, the vessel accumulator was filled with treated demineralized water, drained to the specified initial level, and pressurized with nitrogen to 600 psig. The system was filled with treated demineralized water and vented at strategic points to assure a liquid full system. Prior to warmup the system was pressurized to check for leakage, system instrumentation was checked, and transducer readings were initialized. Warmup to initial test conditions was accomplished with the heaters in the vessel core. Heatup of the broken loop piping was accomplished with bypass lines which served to allow circulation through the broken loop. During warmup, the purification and sampling systems were valved into the primary system to maintain water chemistry requirements and to provide a water sample at system conditions for subsequent analysis. At $100^{\circ} \mathrm{F}$ temperature intervals during warmup, detector readings were sampled to allow the integrity of the measurement instrumentation and the operability of the data acquisition system to be checked.

Prior to establishing the initial core power level, the pressure suppression system was pressurized to 35 psia with saturated steam from the steam supply system. After the core power was increased to $1.49 \mathrm{MW}$, initial test conditions were held for 6 minutes to establish equilibrium in the system. At the end of this period all auxiliary systems including the bypass lines were isolated to prevent blowdown through those systems. 


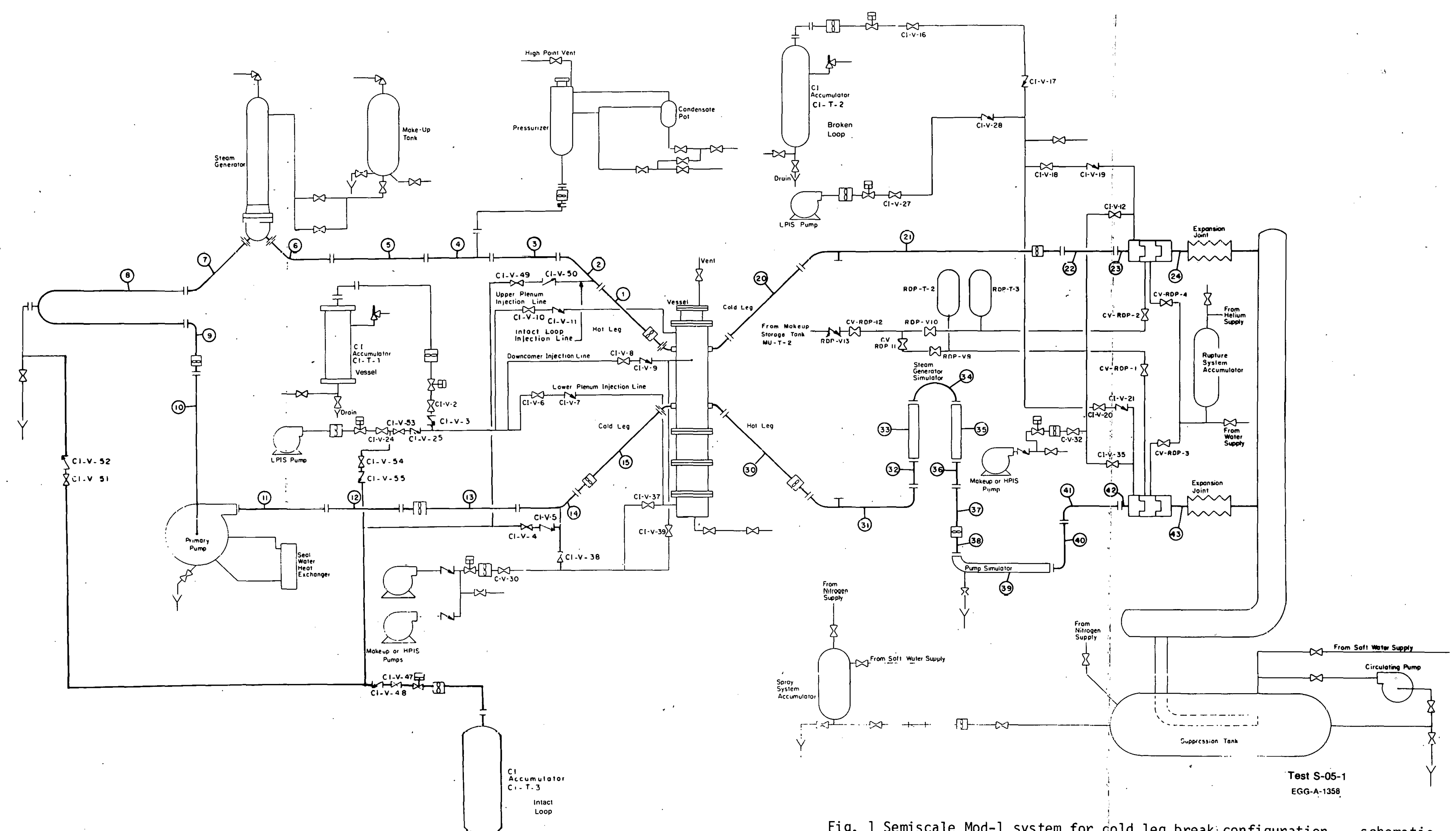

Fig. 1 Semiscale Mod-1 system for cold leg break: configuration -- schematic. 


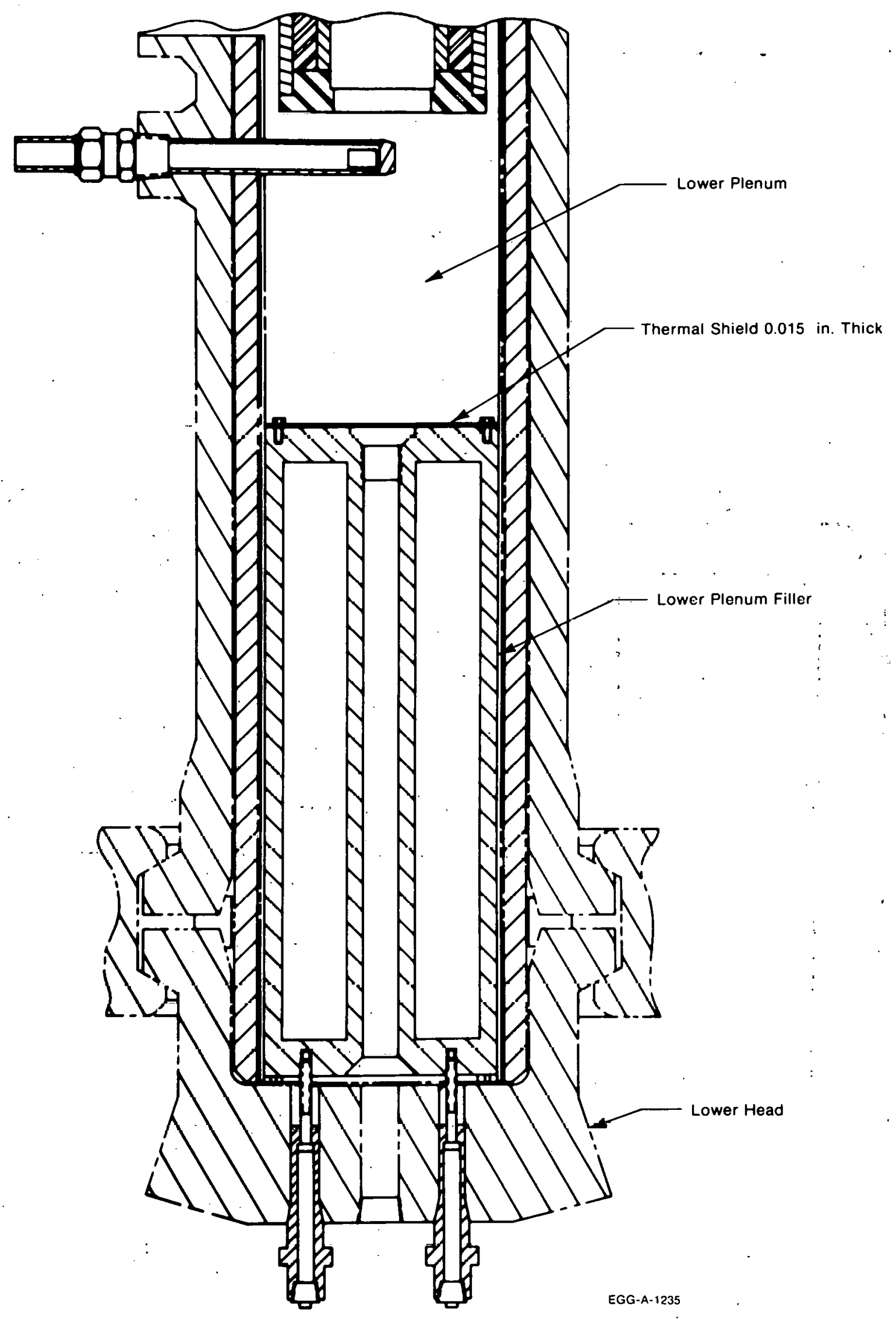

Fig. 2 Cross section of vessel with lower plenum filler. 
The system was successfully subjected to a simulated double-ended cold leg break through two rupture assemblies and two blowdown nozzles, each having a break area of $0.00262 \mathrm{ft}^{2}$. Pressure to operate the rupture assemblies and initiate blowdown was taken from an accumulator system filled with water and pressurized to 2250 psig with gaseous nitrogen. Immediately (within 0.02 second) after initiation of blowdown, the lines to the accumulator were again isolated. The effluent from the primary system was ejected into the pressure suppression system which was vented to maintain a constant pressure of $35 \mathrm{psia}$. At blowdown, power to the primary coolant circulation pump was reduced and the pump was allowed to coast down to a speed of $1520 \mathrm{rpm}$ which was maintained for the duration of the test. During the blowdown transient, power to the electrically heated core was automatically controlled to simulate the thermal response of nuclear heated fuel rods.

For Test S-05-1, the coolant injection systems were arranged to discharge only into the lower plenum. Coolant injection started immediately after initiation of blowdown with manual activation of the high pressure injection pump. Coolant injection was then initiated from the vessel accumulator after the system was depressurized to $600 \mathrm{psig}$. At 150 psig the low pressure injection pump was also started. Coolant injection was continued until the test was terminated at 300 seconds after initiation of blowdown.

\section{INITIAL TEST CONDITIONS AND SEQUENCE OF EVENTS}

Conditions in the Semiscale Mod-1 system at initiation of blowdown are given in Tables I and II; the primary system water chemistry prior to blowdown is given in Table III; and the scquence of events relative to rupture is given in Table IV. 


\section{TABLE I}

CONDITIONS AT BLOWDOWN INITIATION

\begin{tabular}{|c|c|c|}
\hline & \multicolumn{2}{|c|}{ Test $\mathrm{S}-05-1$} \\
\hline & Measured $^{[\mathrm{a}]}$ & Specified \\
\hline Core power (MW) & 1.486 & $1.444 \pm 0.03$ \\
\hline Intact loop cold leg fluid temperature $\left({ }^{\circ} \mathrm{F}\right)$ & 544 & $544 \pm 2$ \\
\hline $\begin{array}{l}\text { Hot leg to cold leg temperature } \\
\left.\text { differential ( }{ }^{\circ} \mathrm{F}\right)\end{array}$ & 65 & $66 \pm 1$ \\
\hline Pressurizer pressure (psia) & 2263 & $2263 \pm 25$ \\
\hline Pressurizer water ievel (in.) ${ }^{[b]}$ & $24.1^{[c]}$ & 27.1 \\
\hline Steam generator feedwater temperature $\left({ }^{\circ} \mathrm{F}\right)$ & 440 & $435 \pm 10$ \\
\hline $\begin{array}{l}\text { Steam generator liquid level (from bottom } \\
\text { of tube sheet) (in.) }\end{array}$ & 116 & $116 \pm 2$ \\
\hline $\begin{array}{l}\text { Fluid temperature in broken loop } \\
\text { (pump side) }\left({ }^{\circ} \mathrm{F}\right)\end{array}$ & 572 & 572 \\
\hline $\begin{array}{l}\text { Fluid temperature in broken loop } \\
\left.\text { (vessel side) ( }{ }^{\circ} \mathrm{F}\right)\end{array}$ & 540 & $\begin{array}{l}\text { Not } \\
\text { Specified }\end{array}$ \\
\hline Intact loop cold leg flow (gpm) & 143 & {$[d]$} \\
\hline Pressure suppression tank water level (in.) & 47.5 & $47.5 \pm 0.5$ \\
\hline Pressure suppression tank pressure (psia) & 22.5 & $22.5 \pm 1$ \\
\hline $\begin{array}{l}\text { Pressure suppressign tank water } \\
\text { temperature }\left({ }^{\circ} \mathrm{F}\right)[\mathrm{e}]\end{array}$ & 60 & Ambient \\
\hline
\end{tabular}

[a] Measured initial conditions are taken from process instrumentation read just prior to blowdown. Those measured conditions which did not meet the specified initial conditions were considered acceptable for analysis purposes within the test objectives.

[b] Pressurizer water level measured down from inside of top head. l.evel was specified in terms of differential pressure in the liquid level measuring system.

[c] Level shown corresponds to a pressurizer system volume of $0.61 \mathrm{ft}^{3}$ (including surge line).

[d] Flow is not specified, since it must be adjusted to achieve the required differential temperature across the core.

[e] Process instrumentation not used. Data taken from last digital scan 138 seconds prior to blowdown initiation. 


\section{TABLE II}

PRIMARY COOLANT TEMPERATURE DISTRIBUTION PRIOR TO RUPTURE[a]

Test S-05-1

\begin{tabular}{llc}
\hline & \multicolumn{1}{c}{ Test S-05-1 } \\
$\begin{array}{l}\text { Vessel lower plenum (upper portion } \\
\text { above filler block) }\end{array}$ & Detector & Temperature ( $\left.{ }^{\circ} \mathrm{F}\right)$ \\
Intact loop hot leg (near vessel) & TFV-LP-7 & 546 \\
Intact loop cold leg (near pump inlet) & RBU-2 & 609 \\
Intact loop cold leg (near vessel) & RBU-14A & 541 \\
Broken loop cold leg (near nozzle) & TFB-23 & 543 \\
Broken loop hot leg (near vessel) & TFB-30 & 504 \\
Broken loop cold leg (near nozzle) & TFB-42 & 596 \\
\hline [a] Data taken from final digital scan 138 seconds before blowdown. \\
\hline
\end{tabular}


TABLE III.

WATER CHEMISTRY PRIOR TO BLOWDOWN ${ }^{\text {[a] }}$

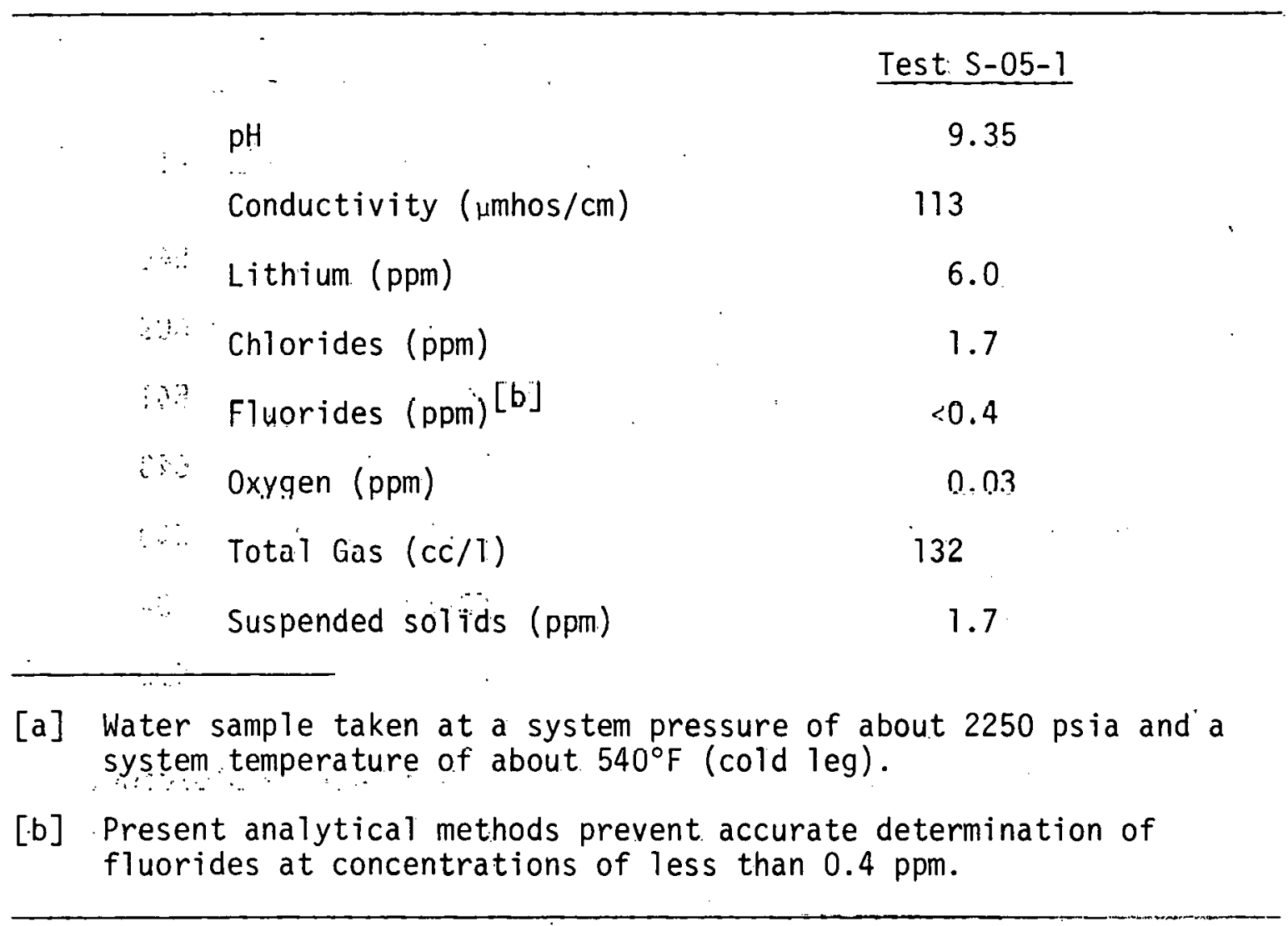


TABLE IV

SEQUENCE OF EVENTS DURING TEST ${ }^{[a]}$

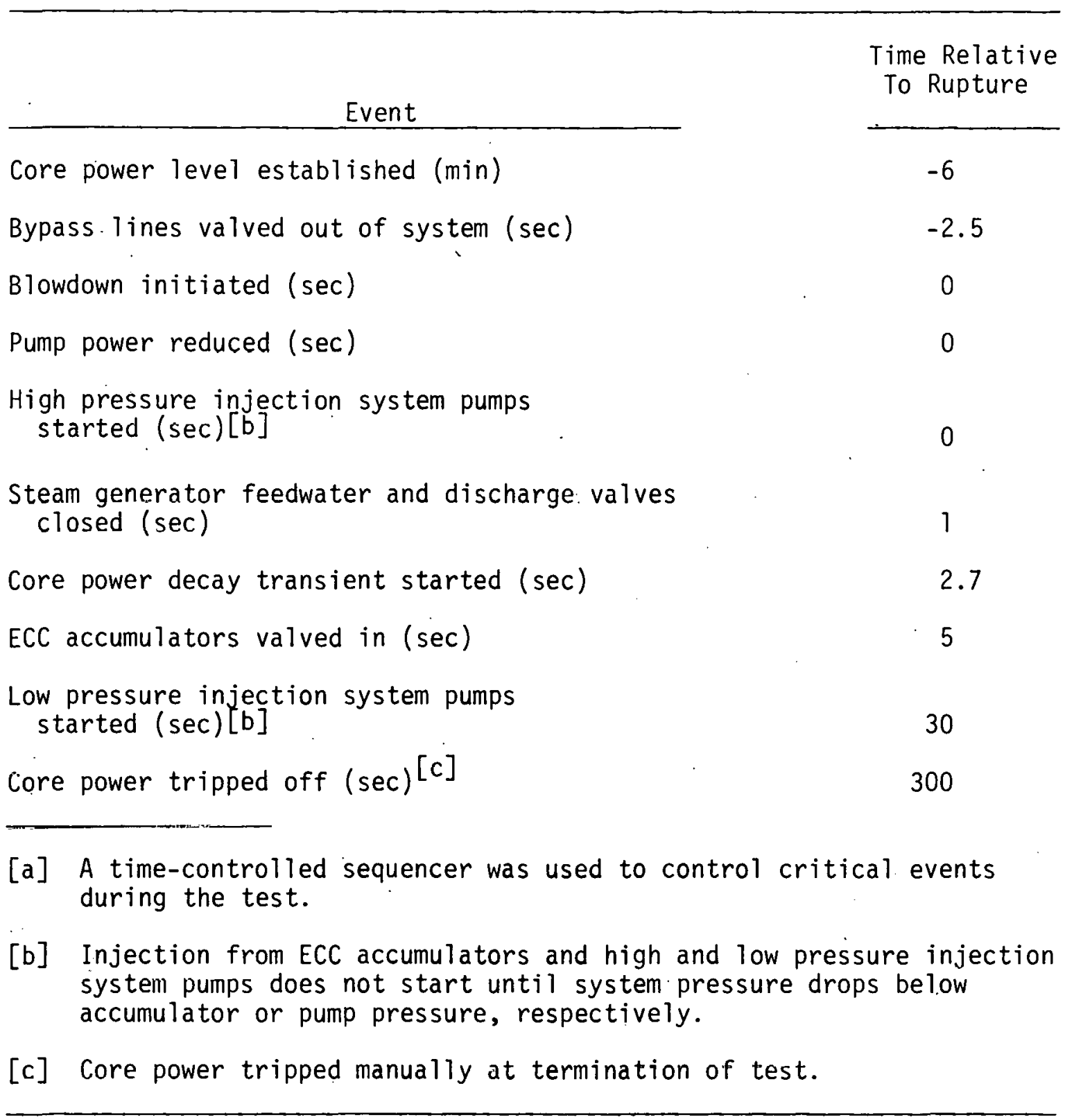




\section{DATA PRESENTATION}

The data from Semiscale Mod-1 Test S-05-1 are presented with brief comment. Processing analysis has been performed only to the ex tent necessary to obtain appropriate engineering units and to assure that the data are reasonable and consistent. In all cases, in converting transducer output to engineering units, a homogeneous fluid was assumed. Further interpretation and analysis should consider that sudden decompression processes such as those occurring during blowdown may have subjected the measurement devices to nonhomogeneous fluid conditions.

The performance of the system during Test S-05-1 was monitored by 213 detectors. The data obtained were recorded on both digital and analog data acquisition systems. The digital system uas used to process the data presented in this report. The digital data were recorded at a sample rate of $3 \%$ points per second. Lung temin plots ( -20 to 300 sovonds) were compressed at a 20 to 1 ratio giving an effective sample rate of 2.875 points per second. Short term plots ( -6 to 42 seconds) were compressed at a 3 to 1 ratio glving :atr effective sample rate of 19.17 points per second. The analog system was used to provide better resolution capability (needed as input to various data analysis codes) and to provide redundancy.

The data are presented, in some instances, in the form of composite graphs to facilitate comparison of the values of given variables at several locations. The scales selected for the graphs do not reflect the obtainable resolution of the data. (The data-processing techniques are described further in Reference 1.)

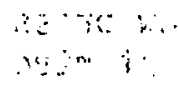

Figures 3 through 8 and Table V provide supporting information for interpretation of the data graphs shown in Figures 9 through 300, and pruvide relative locations of all detectors used during Test S-05-1. Table V groups the measurements accorcling to measurement type; identifies and specific measurement location and range of the detector and actual recording range of the data acquisition system; provides; brief: comments regarding the data; and references the measurements and comments to the corresponding figure. Figures 9 through 300 present all the blowdown and reflood data obtained. Time zero on the graphs is the time of rupture initiation: Appendix A provides information explaining posttcst data processing for data conversion into engineering units and data adjustments. 


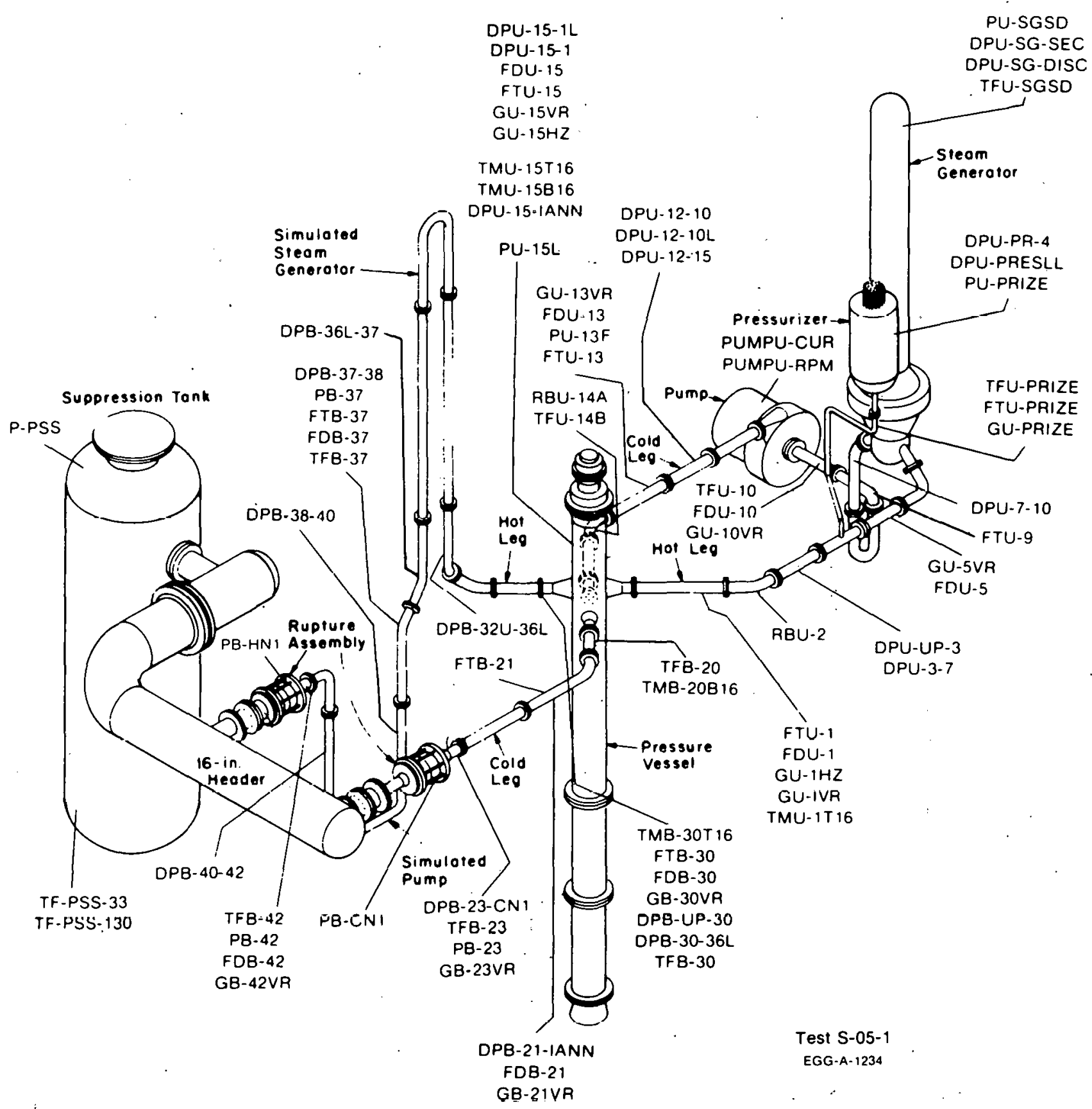

Fig. 3 Semiscale Mod-l system and instrumentation for cold leg break configuration -- isometric. 


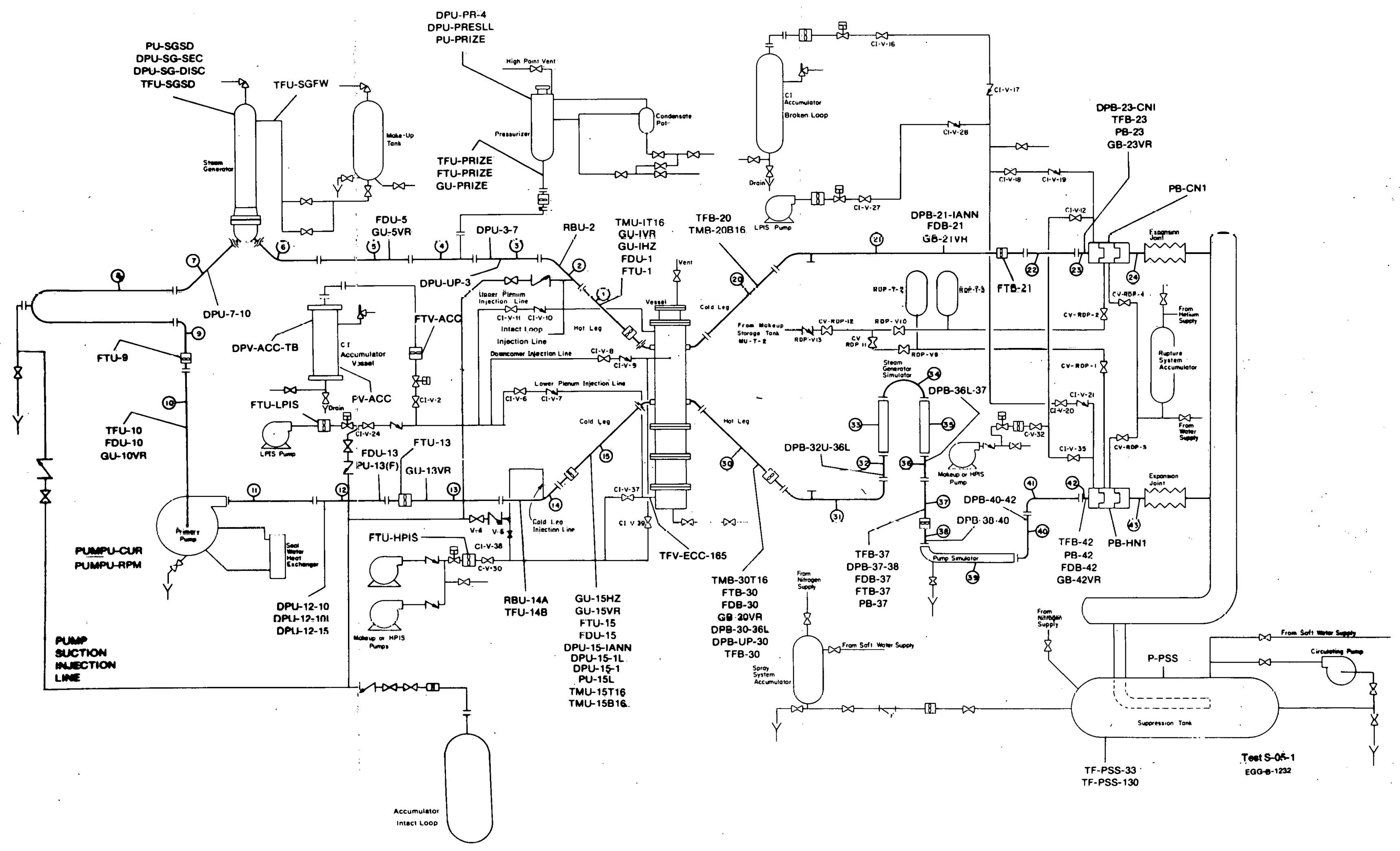

Fig. 4 Semiscale Mod-l system and instrumentation for cold leg break configuration -- schematic. 


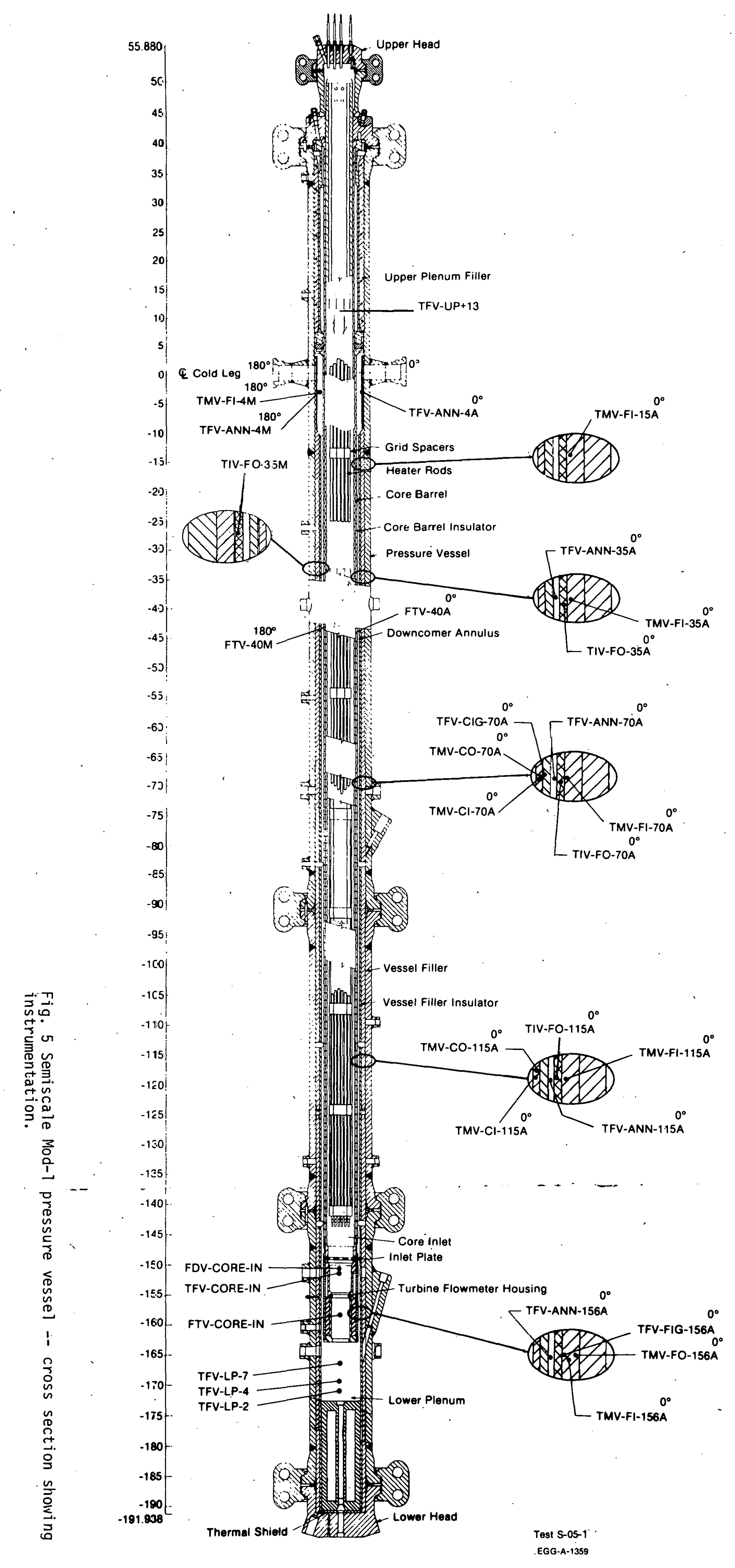



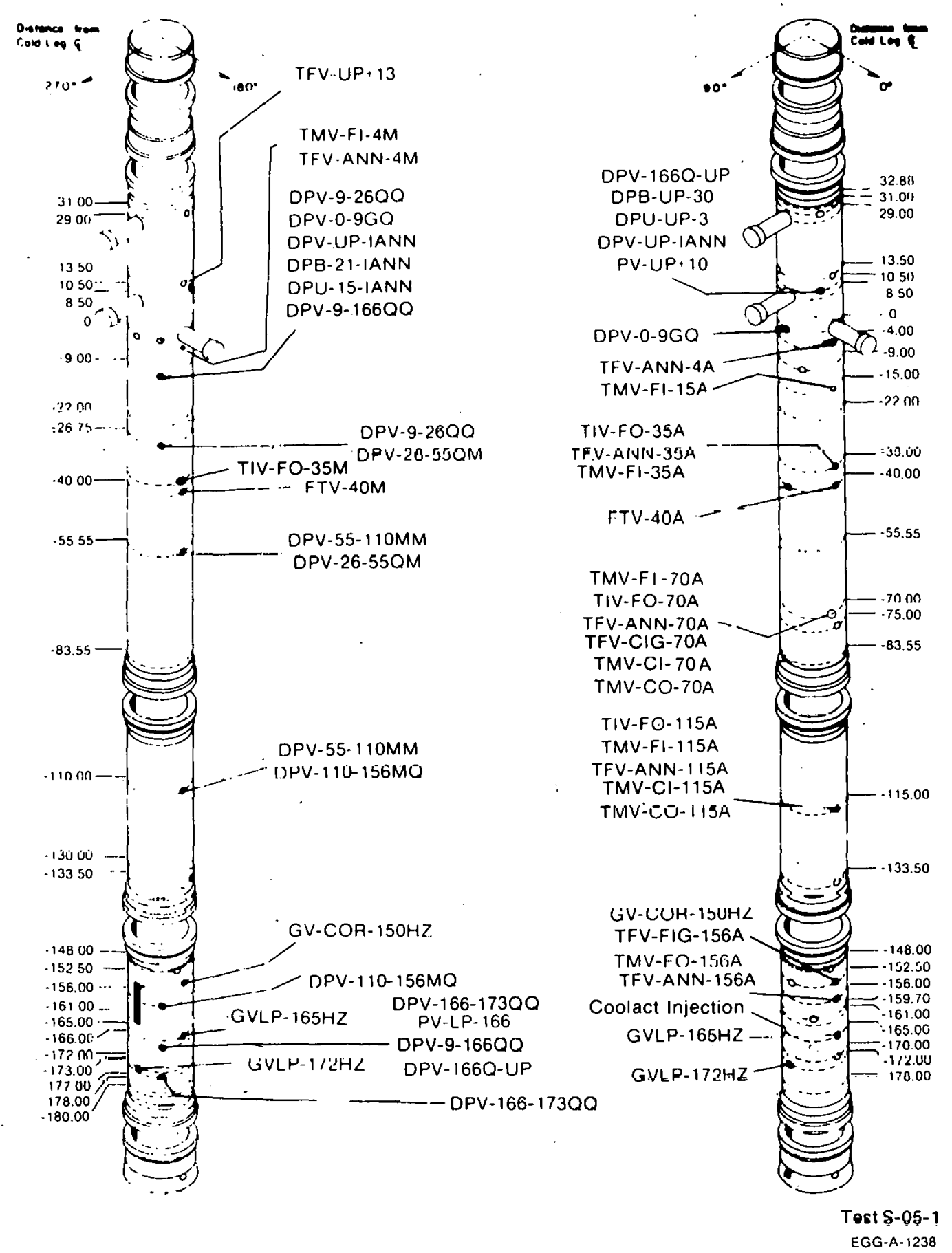

Fig. 6 Semiscale Mod-1 pressure vessel -- isometric showing instrumentation. 


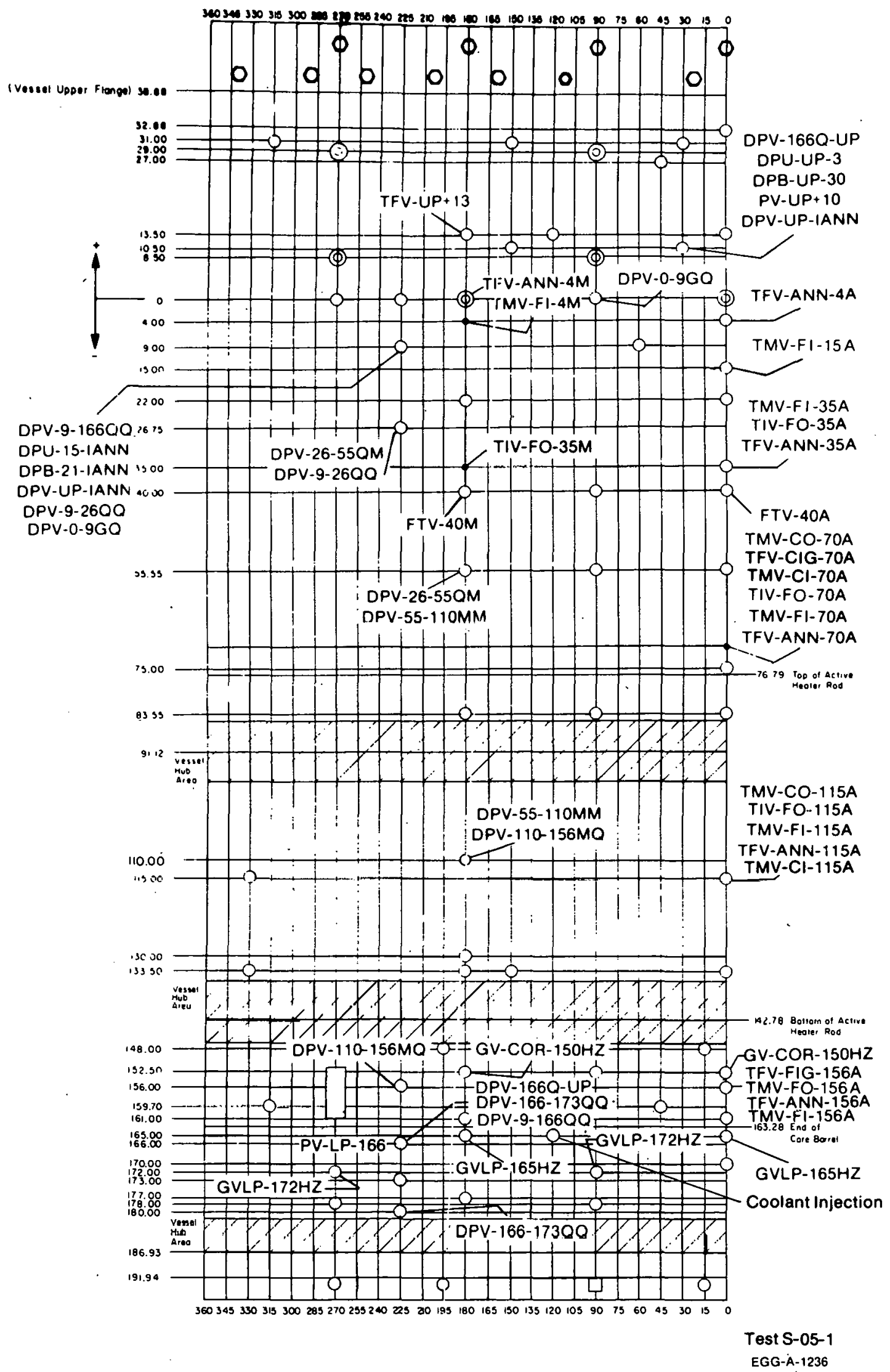

Fig. 7 Semiscale Mod-1 pressure vessel -- penetrations and instrumentation. 


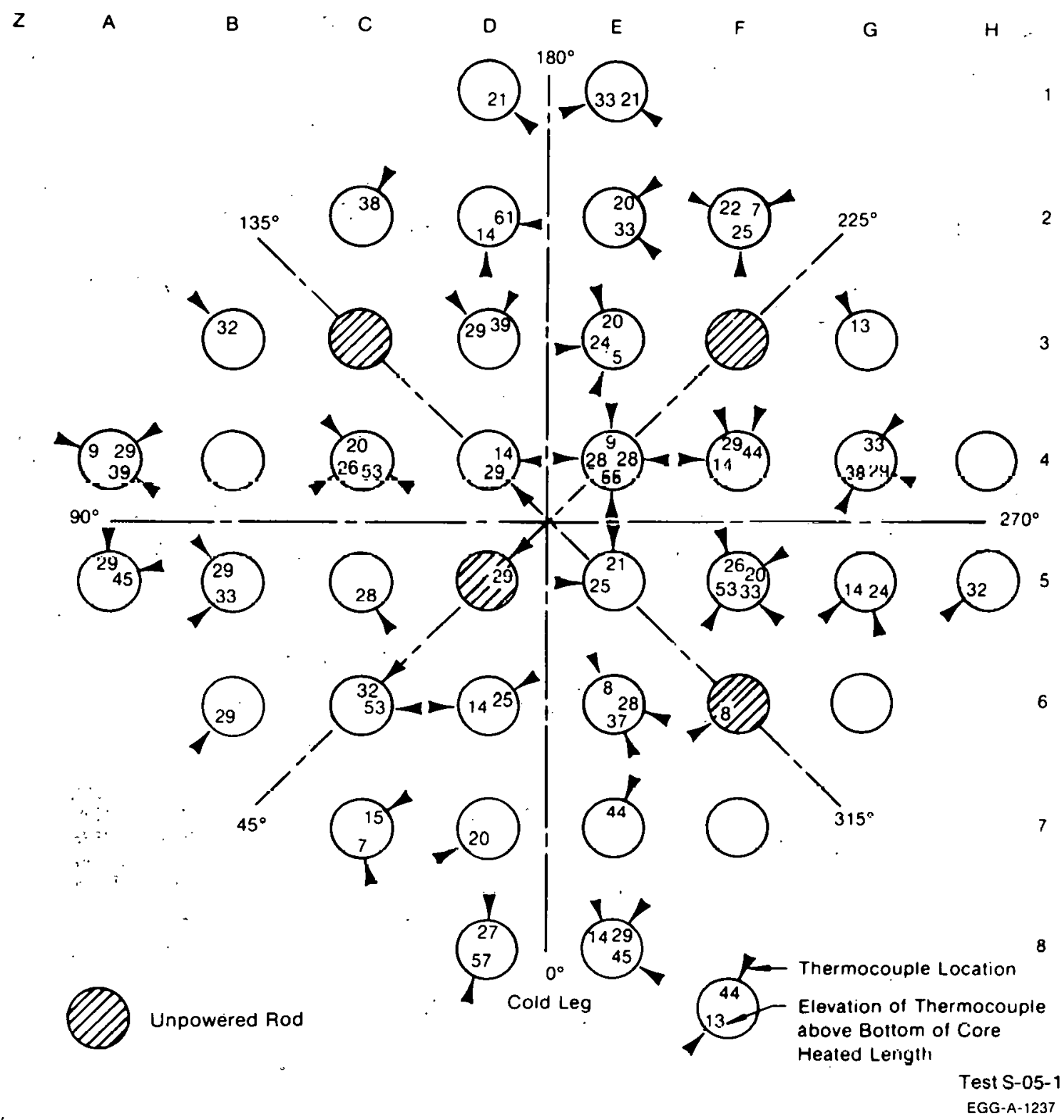

Fig. 8 Semiscale Mod- 7 heated core -- plan view. 
TABLE V

DATA PRESENTATION FOR SEMISCALE MOD- 1 TEST S-05- 1

\begin{tabular}{|c|c|c|c|c|c|}
\hline & & & Range $\left[\mathrm{a} .^{-}\right.$ & & \\
\hline Measurement & Location and Comments ${ }^{[a]}$ & Detector & $\begin{array}{l}\text { Data Acquisition } \\
\text { System }\end{array}$ & Figure $^{[\mathrm{a}]}$ & Measurement Comments ${ }^{[b]}$ \\
\hline FLUID TEMPERATURE & $\begin{array}{l}\text { Chromel-Alumel thernocouples uniess } \\
\text { specified otherwise. }\end{array}$ & & & & . \\
\hline intact loop & & 0 to $2300^{\circ} \mathrm{F}$ & 0 to $591^{\circ} \mathrm{F}$ & & \\
\hline RBU-2 & $\begin{array}{l}\text { Hot leg, Spool } 2,46 \text { in. from vessel } \\
\text { center (platinum resistance bulb). }\end{array}$ & 0 to $1000^{\circ} \mathrm{F}$ & 0 to $1000^{\circ} \mathrm{F}$ & 9,10 & \\
\hline TFU -10 & $\begin{array}{l}\text { Cold leg, Spool 10, } 144 \text { in. from } \\
\text { vessel center. }\end{array}$ & & & 11,12 & \\
\hline RBU-14A & $\begin{array}{l}\text { Cold leg, Spool } 14,43 \text { in. from } \\
\text { vessel center, upstream of cold leg } \\
\text { injection port (piatinum resistance } \\
\text { bulb). }\end{array}$ & 0 to $1000^{\circ} \mathrm{F}$ & 0 to $1000^{\circ} \mathrm{F}$ & 11,12 & \\
\hline TFU-148 & $\begin{array}{l}\text { Cold leg. Spool } 14,39 \text { in. from } \\
\text { vessel center, downstream of cold } \\
\text { leg injection port. }\end{array}$ & & & 11,12 & \\
\hline Broken Loop & & 0 to $2300^{\circ} \mathrm{F}$ & 0 to $1017^{\circ} \mathrm{F}$ & & \\
\hline TFB-20 & $\begin{array}{l}\text { Cold leg, Spool } 20,21 \text { in. from } \\
\text { véssel center. }\end{array}$ & & & 13,14 & \\
\hline TFB-23 & $\begin{array}{l}\text { Cold leg. Spool } 23,91 \text { in. from } \\
\text { vessel center, upstream of vessel- } \\
\text { side nozzle. }\end{array}$ & & & 13,14 & \\
\hline TFB-30 & $\begin{array}{l}\text { Hot leg, spool } 30,36 \mathrm{in} \text {. Prom } \\
\text { vessel center. }\end{array}$ & & & 15,16 & \\
\hline TFB-37 & $\begin{array}{l}\text { Cold leg, Spool } 37,276 \text { in. from } \\
\text { vessel center along hot leg, dis. } \\
\text { charge of simulated steam generator. }\end{array}$ & & & 15,16 & ' \\
\hline TFB-42 & $\begin{array}{l}\text { Cold leg, Spool } 42,414 \text { in. from } \\
\text { vessel center along hot leg, upstream } \\
\text { of pump-side nozzle. }\end{array}$ & & & 15,16 & \\
\hline Inlet Annulus & $\begin{array}{l}4 \text { in. below cold leg centerline, } \\
0.2 \text { in. from vessel wall. Type } j \\
\text { iron-constantan thermocouples. }\end{array}$ & 0 to $1400^{\circ} \mathrm{F}$ & 0 to $803^{\circ} \mathrm{F}$ & & \\
\hline IFV-ANN- $4 A$ & $0^{\circ}$. & & & 17,18 & \\
\hline TFV-ANN-4M & $180^{\circ}$. & . & & & \\
\hline Downcomer Annulus & $\begin{array}{l}\text { Centered in annulus, Type } \mathrm{J} \text { iron- } \\
\text { constantan thermocouplec. }\end{array}$ & 0 to $1400^{\circ} \mathrm{F}$ & 0 to $803^{\circ} \mathrm{F}$ & - & \\
\hline TFV-ANM-35A & $\begin{array}{l}35 \text { in. below cold leg centerline, } \\
0^{\circ} \text {. }\end{array}$ & . & & 19,20 & \\
\hline TFV-ANN-70A & $\begin{array}{l}70 \text { in. below coid leg centerline, } \\
0^{\circ} \text {. }\end{array}$ & & & 19,20 & \\
\hline TFV-ANN-115A & $\begin{array}{l}115 \text { in. below cold leg centerline, } \\
0^{\circ} \text {. }\end{array}$ & & & 19,20 & \\
\hline TFV-AHN-156A & $\begin{array}{l}156 \text { in. below cold leg centerline, } \\
0^{\circ} \text {. }\end{array}$ & 0 to $2300^{\circ} \mathrm{F}$ & 0 to $597^{\circ} \mathrm{F}$ & 19,20 & \\
\hline Upper Pl enum & & U tó $2300=r$ & $u$ to $i v i 7^{\circ} p$ & & \\
\hline IFV-UP+13 & $\begin{array}{l}\text { In upper plenum, } 13.5 \text { in. above } \\
\text { cold leg centerline at } 180^{\circ} \text {. }\end{array}$ & & & 21,22 & \\
\hline Lower Plenum & $\begin{array}{l}\text { On fluid thermocouple rack, } 1 \text { in. } \\
\text { from vessel center, } 45^{\circ} \text {. }\end{array}$ & 0 to $2300^{\circ} \mathrm{F}$ & 0 to $1017^{\circ} \mathrm{F}$ & & \\
\hline IFV $=L P-2$ & $\begin{array}{l}\text { 2.0 in. above top of lower plenum } \\
\text { filler. }\end{array}$ & & & 23,24 & \\
\hline TFV-LP-4 & $\begin{array}{l}4.0 \mathrm{in.} \text { above top of lower plenum } \\
\text { filler. }\end{array}$ & & & 23.24 & \\
\hline$T F V-L P-7$ & $\begin{array}{l}7.0 \mathrm{in} \text {. above top of lower plenum } \\
\text { filler. }\end{array}$ & & & 23,24 & \\
\hline Core & & & & & \\
\hline TFV-CORL-III & $\begin{array}{l}\text { In coine flow miser bax, } 160 \text { in. } \\
\text { below cold leg centerline (a } \\
\text { part of FOV-CORE-IN). }\end{array}$ & 0 to $2300^{\circ} \mathrm{F}$ & $n \ln 1017^{\circ} \mathrm{F}$ & 25.26 & \\
\hline$\frac{\text { Core Barrel }}{\text { Insulation Gap }}$ & & & & & \\
\hline TFV-C1G-70A & $\begin{array}{l}70 \text { in. below cold } \\
\text { leg centerline, } 0^{\circ} \text {. }\end{array}$ & 0 to $1400^{\circ} \mathrm{F}$ & ก t. $803^{\circ} \mathrm{F}$ & 27,28 & \\
\hline
\end{tabular}




\section{TABLE V (continued)}

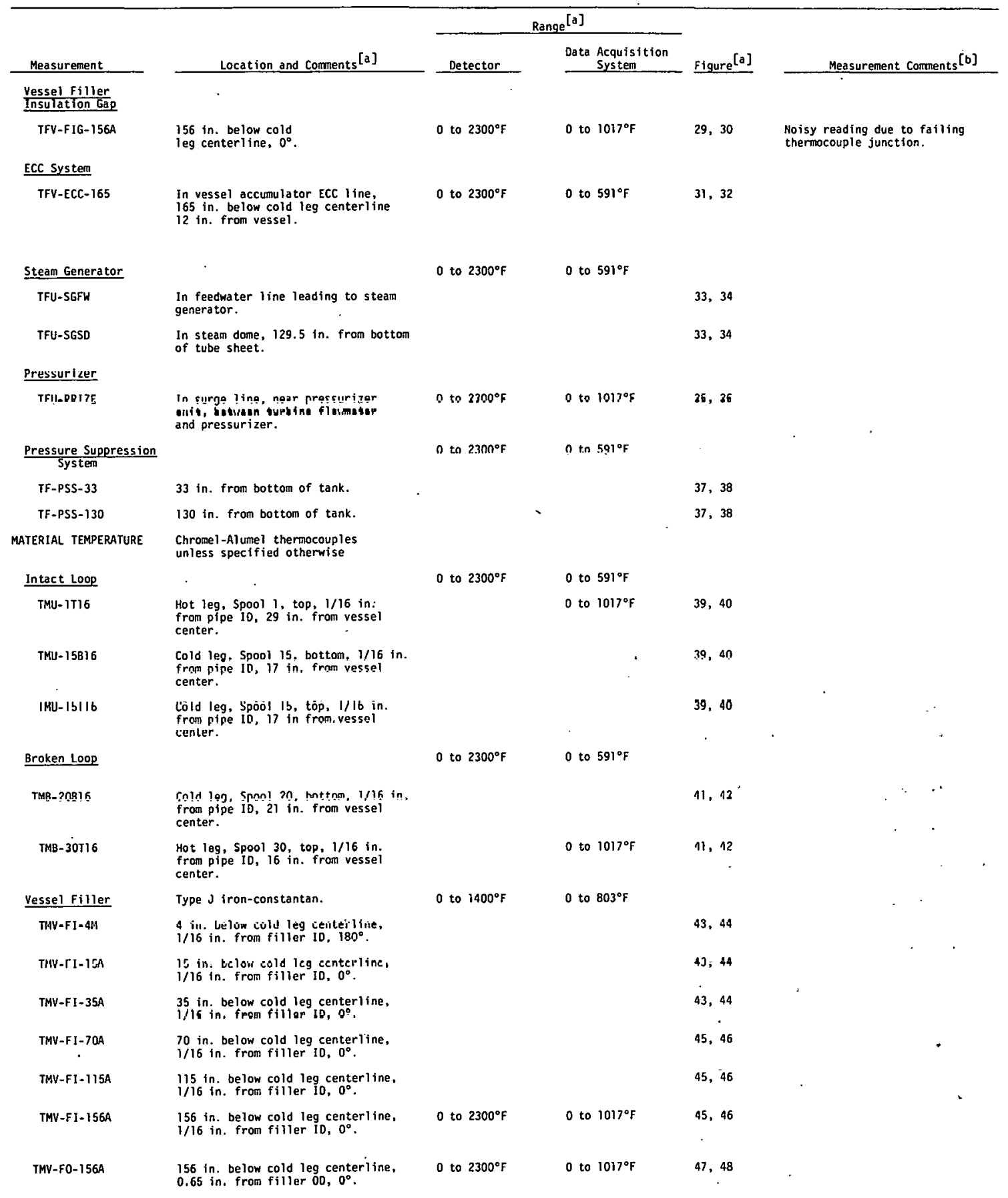




\section{TABLE V (continued)}

\begin{tabular}{|c|c|c|c|c|c|}
\hline \multirow[b]{2}{*}{ Measurement } & \multirow[b]{2}{*}{ Location and Comments ${ }^{[a]}$} & \multicolumn{2}{|c|}{ Range $^{[a]}$} & \multirow{3}{*}{ Eigure ${ }^{[a]}$} & \multirow[b]{2}{*}{ Measurement Corments $[\mathrm{b}]$} \\
\hline & & Detector & $\begin{array}{c}\text { Data Acquisition } \\
\text { System }\end{array}$ & & \\
\hline$\frac{\text { Vessel Filler }}{\text { Insulator }}$ & $\begin{array}{l}\text { Outer surface of insulator. Type } \\
\mathrm{J} \text { iron-constantan thermocouples. }\end{array}$ & O to $1400^{\circ} \mathrm{F}$ & 0 to $803^{\circ} \mathrm{F}$ & & \\
\hline TIV-F0-35A & $\begin{array}{l}35 \text { in. below cold leg centerline, } \\
0^{\circ} .\end{array}$ & & & 49,50 & \\
\hline TIV-F0-35M & $\begin{array}{l}35 \text { in. below cold leg centerline, } \\
180^{\circ} \mathrm{F} \text {. }\end{array}$ & & & 49,50 & \\
\hline TIV-FO-70A & $\begin{array}{l}70 \text { in. below cold leg centerline, } \\
0^{\circ} \text {. }\end{array}$ & & & 49, 50 & \\
\hline$T I V-F 0-115 A$ & $\begin{array}{l}115 \text { in. below cold leg center } 3 \text { ine, } \\
0^{\circ} \text {. }\end{array}$ & & & 49,50 & \\
\hline Gore Barrel & Type $\mathrm{J}$ iron-constantan thermocouples & 0 to $1400^{\circ} \mathrm{F}$ & 0 to $803^{\circ} \mathrm{F}$ & & \\
\hline TMV-CI-70A & $\begin{array}{l}70 \text { in. below cold leg centeri ine, } \\
1 / 16 \text { in. from core barrel } 10,0^{\circ} \text {. }\end{array}$ & & & 51,52 & \\
\hline TAV-CI-115A & $\begin{array}{l}115 \text { in. below cold leg centerline } \\
1 / 16 \text { in. from core barrel } 10.0^{\circ} \text {. }\end{array}$ & & & 51,52 & \\
\hline TMV- $-00-70 A$ & $\begin{array}{l}70 \text { in. below cold leg centerinine. } \\
1 / 16 \text { in. Prom core barrel ob, } 0^{n} \text {. }\end{array}$ & & & 53,54 & \\
\hline THV-CO-115A & $\begin{array}{l}115 \text { in. below cold leg centerline. } \\
1 / 16 \text { in. from core barrel } 00,0^{\circ} \text {. }\end{array}$ & & & 53,54 & - \\
\hline Core Housing Filler & , & 0 to $2300^{\circ} \mathrm{F}$ & 0 to $1017^{\circ} \mathrm{F}$ & & \\
\hline TiYV-HF-115W & $\begin{array}{l}\text { On core housing filler, } 115 \text { in. } \\
\text { below cold leg centerline, } 0.20 \mathrm{n} \text {. } \\
\text { from outer surface, } 315^{\circ} \text {. }\end{array}$ & & & 55,56 & \\
\hline TMV-HF-127W & $\begin{array}{l}\text { On core housing filier, } 127 \text { in. } \\
\text { below cold leg centerline, } 0.20 \text { in. } \\
\text { from outer surface, } 315^{\circ} \text {. }\end{array}$ & & & 55,56 & - \\
\hline TMV-HF-1 38W & $\begin{array}{l}\text { On core housing filler, } 138 \text { in. } \\
\text { below cold leg centerifine, } 0.20 \text { in. } \\
\text { from outer surface, } 315^{\circ} \text {. }\end{array}$ & & & 55,56 & \\
\hline $\begin{array}{l}\text { CORE HEATER } \\
\text { CLADDING TEMPERATURES }\end{array}$ & Chrome I-Al unel thermocouples. & & & & \\
\hline High Power Heaters & & 0 to $2300^{\circ} \mathrm{F}$ & 0 to $2382^{\circ} \mathrm{F}$ & $\cdot$ & \\
\hline $\begin{array}{l}\text { TH- } 04-14 \\
\text { TH }-04-29\end{array}$ & 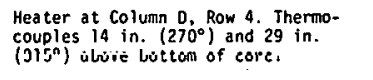 & & & 57,58 & \\
\hline TH-05-29 & $\begin{array}{l}\text { Heater at column } 0, \text { Row } 5 \text {. Thermo- } \\
\text { couple } 29 \text { in. }\left(225^{\circ}\right) \text { above bottom } \\
\text { of core. }\end{array}$ & & & 59,60 & 冫 \\
\hline $\begin{array}{l}T H-E 4-09 \\
T H-44-286 \\
T H-4-289 \\
T H-E 4-55\end{array}$ & $\begin{array}{l}\text { Heater at colunn E, Row } 4 \text {. Theruo- } \\
\text { couples } 9 \text { in }\left(180^{\circ}\right), 28 \text { inh }\left(90^{\circ}\right), \\
28 \text { in. }\left(27^{\circ}\right) \text {, and } 55 \text { in. }\left(0^{\circ}\right) \\
\text { above bottom of core. }\end{array}$ & & & 61,62 & \\
\hline $\begin{array}{l}\text { TH-E5-21 } \\
T H-E 5-25\end{array}$ & $\begin{array}{l}\text { Heater at column E, Row } 5 \text {. Thermo- } \\
\text { couples } 21 \mathrm{in}\left(180^{\circ}\right) \text { and } 25 \text { in. } \\
\left(90^{\circ}\right) \text { above bottom of core. }\end{array}$ & & & 63, 64 & \\
\hline Low Power Heaters & & 0 to $2300^{\circ} \mathrm{F}$ & 0 to $2382^{\circ} \bar{F}$ & & \\
\hline $\begin{array}{l}\text { TH-MM-09 } \\
\text { TH-A4-29 } \\
\text { TH-A4-39 }\end{array}$ & 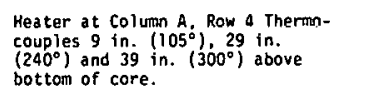 & & & 65.66 & $\begin{array}{l}\text { Notsy reading due to failing } \\
\text { thermocouple junction }\end{array}$ \\
\hline $\begin{array}{l}\text { TH-A5-29 } \\
\text { TH-A5-45 }\end{array}$ & 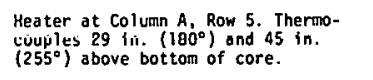 & & & 67.68 & \\
\hline$T H-83-32$ & $\begin{array}{l}\text { Heater at Column } 8, \text { Row 3. Thermo- } \\
\text { couple } 32 \text { in. }\left(135^{\circ}\right) \text { above bottom } \\
\text { of core. }\end{array}$ & & & 69,70 & . \\
\hline $\begin{array}{l}T H-B 5-29 \\
T H-85-33\end{array}$ & $\begin{array}{l}\text { Heater at Column B, Row 5. Thermo- } \\
\text { couples } 29 \text { in. }\left(150^{\circ}\right) \text { and } 33 \text { in. } \\
\left(45^{\circ}\right\rangle \text { above bottom of core. }\end{array}$ & & ' & 71,72 & \\
\hline IH-вb-¿̌y & $\begin{array}{l}\text { Hearer at culuman Be Ruw o. Therinu- } \\
\text { couple ig in. }\left(45^{\circ}\right) \text { above bottoria } \\
\text { of core. }\end{array}$ & & & 73,74 & \\
\hline$T H-6 ?-38$ & $\begin{array}{l}\text { Heater at Columinn C. Row 2. Thermo- } \\
\text { couple } 38 \text { in. }\left\{225^{\circ}\right\rangle \text { above bottom } \\
\text { of core. }\end{array}$ & & & 75,76 & \\
\hline $\begin{array}{l}T H-C 4-20 \\
T H-C 4-25 \\
T H-C 4-53\end{array}$ & $\begin{array}{l}\text { Heater at Column C, Row 4. Therno- } \\
\text { couples } 200 \text { in. }\left(150^{\circ}\right) \text {, } 26 \text { in. }\left(75^{\circ}\right) \\
\text { and } 53 \text { in. }\left(300^{\circ}\right) \text { above bottom of } \\
\text { core. }\end{array}$ & - & & 77,78 & \\
\hline$T H-C 5-28$ & $\begin{array}{l}\text { Heater at C.olumn C. Rnw 5. Thermo- } \\
\text { couple } 28 \text { in. }\left(315^{n}\right) \text { abuve lot tom } \\
\text { of core. }\end{array}$ & & & 79,80 & \\
\hline $\begin{array}{l}\text { TH-C6-32 } \\
\text { TH-C6-53 }\end{array}$ & $\begin{array}{l}\text { Heater at Column } C \text {, Row } 6 \text {. Thermo- } \\
\left.\text { couples } 32 \text { in ( } 225^{\circ}\right) \text { and } 53 \text { in } \\
\left(270^{\circ}\right) \text { above bottom of core. }\end{array}$ & & & 81,82 & $\cdot$ \\
\hline
\end{tabular}


TABLE V (continued)

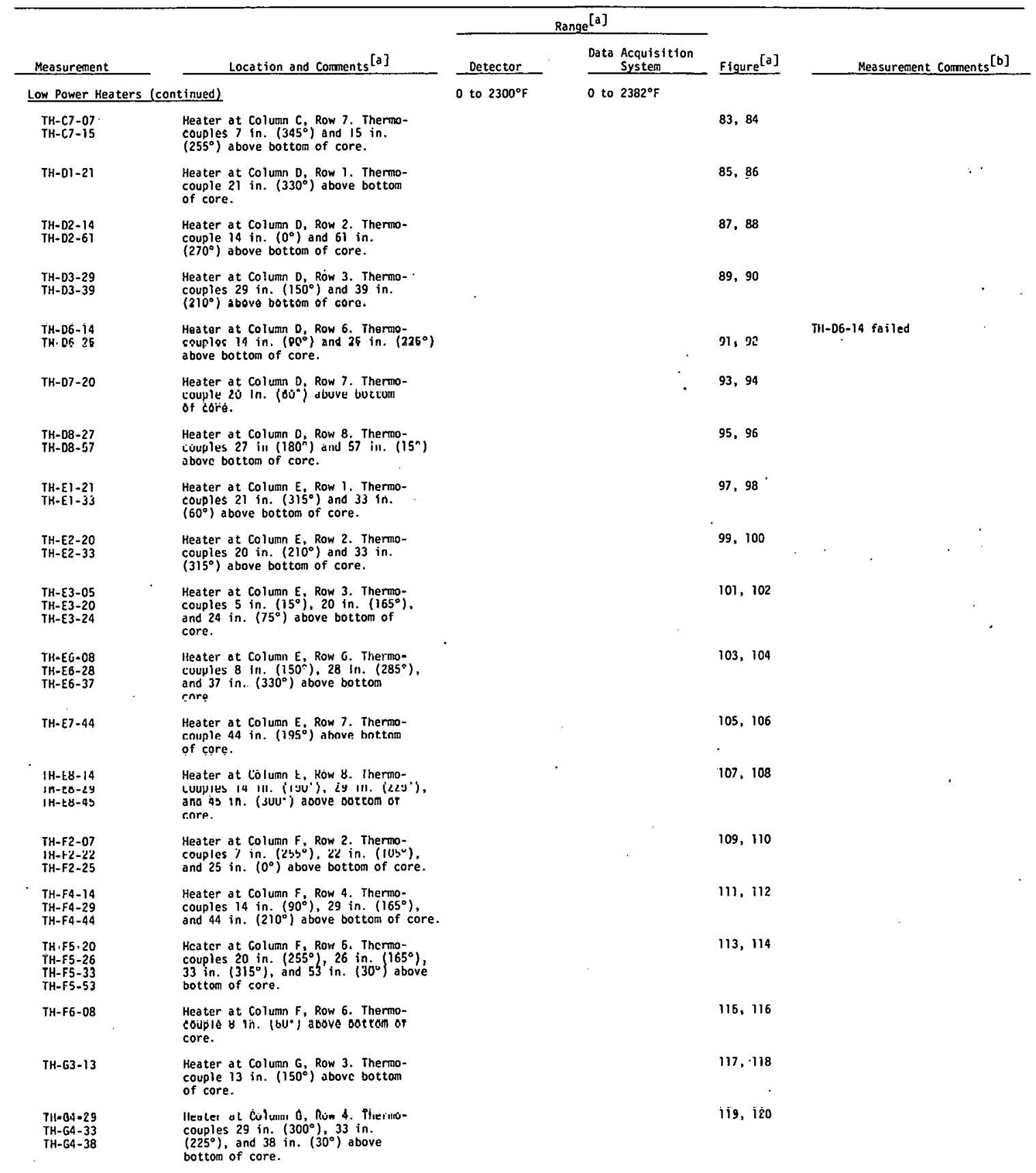




\section{TABLE $\vee$ (continued)}

\begin{tabular}{|c|c|c|c|c|c|}
\hline \multirow[b]{2}{*}{ Measurement } & \multirow[b]{2}{*}{ Location and Comments $[\mathrm{a}]$} & \multicolumn{2}{|c|}{ Range $^{[\mathrm{a}]}$} & \multirow{3}{*}{ Eigure ${ }^{[a]}$} & \\
\hline & & \multirow{2}{*}{$\begin{array}{l}\text { Detector } \\
\text { O to } 2300^{\circ} \mathrm{F}\end{array}$} & \multirow{2}{*}{$\begin{array}{l}\text { Data Acquisition } \\
\text { System }\end{array}$} & & Measurement Comments ${ }^{[\mathrm{b}]}$ \\
\hline \multicolumn{2}{|c|}{ Low Power Heaters (continued) } & & & & \\
\hline $\begin{array}{l}\text { TH-65-14 } \\
\text { TH-65-24 }\end{array}$ & $\begin{array}{l}\text { Heater at column } 6, \text { Row } 5 \text { Thermo- } \\
\text { coup les. } 14 \text { in. }\left(45^{\circ}\right) \text { and } 24 \text { in } \\
\left(330^{\circ}\right) \text { above bot tom of core. }\end{array}$ & & & 121,122 & \\
\hline TH-H5-32 & $\begin{array}{l}\text { Heater at column } 4, \text { Row 5. Thermo- } \\
\text { coupple } 32 \text { in. } 144^{\circ} ; \text { above bottom of } \\
\left(330^{\circ}\right) \text { above bot tom of core. }\end{array}$ & & & 123,124 & \\
\hline \multicolumn{6}{|l|}{ PRESSURE } \\
\hline Intact Loop & & $\begin{array}{l}0 \text { to } 3000 \\
\text { psi }\end{array}$ & & & \\
\hline$P U-13(F)$ & $\begin{array}{l}\text { Cold leg, spool 13, } 54 \text { in. from } \\
\text { vessel center (flush mount). }\end{array}$ & & o to 4497 psia & 125.126 & \\
\hline PU-15L & $\begin{array}{l}\text { Cold log, Spool } 15,16 \text { in. from } \\
\text { vessel center, to atmosphere }\end{array}$ & 0 to $600 \mathrm{psi}$ & 0 to 553 psis & 127,128 & \\
\hline Broken Loop & & $\begin{array}{l}0 \text { to } 3,000 \\
\text { psi }\end{array}$ & & & \\
\hline PB-23 & $\begin{array}{l}\text { Cold leg, Spool 23, } 92 \text { in. from } \\
\text { vessel center, upstream of nozzle } \\
\text { (tee off } 0 P \text { tap). }\end{array}$ & & 0 to $4364 \mathrm{psia}$ & 129,130 & \\
\hline PB-37 & $\begin{array}{l}\text { Cold leg, Spool } 37,282 \text { in. from } \\
\text { vessel ceenter along hat leg. }\end{array}$ & & 0 to $4402 \mathrm{psta}$ & 131,132 & \\
\hline PB-42 & $\begin{array}{l}\text { cold leg, Spool } 42,415 \text { in. from } \\
\text { vessel center along hot leg, up- } \\
\text { stream of pump-side nozzle (tee } \\
\text { off op tap). }\end{array}$ & & 0 to 4832 psta & 131.132 & \\
\hline PB-HNI & $\begin{array}{l}\text { Pump-side nozzle, nozzle throat, } \\
\text { alg in. from vessel center along } \\
\text { hot leg (tee off op tap). }\end{array}$ & & 0 to 4666 psia & 133,134 & \\
\hline $\mathrm{PB}-\mathrm{CNI}$ & $\begin{array}{l}\text { Cold leg, Spool 23, vessel-side } \\
\text { nozzie, nozile throat, } 96 \text { in. } \\
\text { from, vessel center aiong cold } \\
\text { leg, } 45^{\circ} \text {. }\end{array}$ & & 0 to 2509 psia & 135,136 & . \\
\hline \multicolumn{6}{|l|}{ Vessel } \\
\hline PV-UP+10 & $\begin{array}{l}\text { In upper plenum, } 10 \text { in. above cold } \\
\text { leg centerline, mounted on standoff, } \\
30^{\circ} \text {. }\end{array}$ & $\begin{array}{l}\text { o to } 2500 \\
\text { psi }\end{array}$ & 0 to $3110 \mathrm{psia}$ & 137,138 & \\
\hline PV-LP-166 & $\begin{array}{l}\text { In upper part of lower plenum, } 166 \\
\text { in. be low cold leg centerline, } \\
\text { mounted on standifff, } 225^{\circ} \text {. }\end{array}$ & $\begin{array}{l}\text { o to } 3000 \\
\text { psi }\end{array}$ & 0 to 2503 psta & 137,138 & . \\
\hline ECC System & & 0 to $750 \mathrm{psi}$ & & & \\
\hline PV-ACC & In vessel accumuiator. & & 0 to 743 psia & 139,140 & \\
\hline \multicolumn{6}{|c|}{ Steam Generator } \\
\hline PU-SGSD & Secondary side steam dome. & $\begin{array}{l}0 \text { to } 3000 \\
\text { psi }\end{array}$ & 0 to 1811 psia & 141,142 & \\
\hline \multicolumn{6}{|l|}{ Presgurieer } \\
\hline PU-PRI2E & Pressurizer steam dome. & $\begin{array}{l}0 \text { to } 2500 \\
\text { psit }\end{array}$ & 0 to 3210 psia & 143,144 & \\
\hline \multicolumn{6}{|c|}{$\frac{\text { Pressure Suppression }}{\underline{\text { yystem }}}$} \\
\hline P-psS & Suppression tank top. & 0 to $250 \mathrm{psi}$ & O to 347 psia & 145,146 & \\
\hline
\end{tabular}


TABLE V (continued)

\begin{tabular}{|c|c|c|c|c|c|}
\hline \multirow[b]{2}{*}{ Measurement } & \multirow[b]{2}{*}{ Location and Comments $^{\text {[a] }}$} & \multicolumn{2}{|c|}{ Range $^{[\mathrm{a}]}$} & \multirow{3}{*}{ Figure ${ }^{[a]}$} & \multirow[b]{2}{*}{ Measurement Comments ${ }^{[\mathrm{b}]}$} \\
\hline & & Detector & $\begin{array}{l}\text { Data } \begin{array}{c}\text { Acquisition } \\
\text { System }\end{array} \\
\end{array}$ & & \\
\hline DIFFERENTIAL PRESSURE & $\begin{array}{l}\text { Elevation oifference between } \\
\text { transsducer taps is zero unless } \\
\text { otherwise specified. }\end{array}$ & & & & \\
\hline \multicolumn{6}{|l|}{ Intact Loop } \\
\hline DPU-UP-3 & $\begin{array}{l}\text { Upper plenum } 10.5 \text { in. above } \\
\text { cold leg centeri ine at } 30^{\circ} \text { to } \\
\text { hot leg, spool } 3 \text {, } 62 \text { in. from } \\
\text { vessel center. Upper plenum tap } \\
\text { is approximately } 2 \text { in. above Spool } \\
3 \text { tap. }\end{array}$ & $\begin{array}{l} \pm 50 \text { in. } \\
\text { water }\end{array}$ & \pm 2.4 psid & $\begin{array}{r}147,148 \\
-\end{array}$ & $\begin{array}{l}\text { Data acquisition system } \\
\text { or detector saturated near } \\
\text { t=0 sec. }\end{array}$ \\
\hline DPU-3-7 & 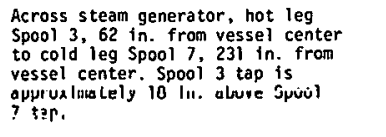 & $\frac{ \pm 500 \text { in. }}{\text { water }}$ & \pm 25 psid & 149,150 & \\
\hline UPU-1-IU & 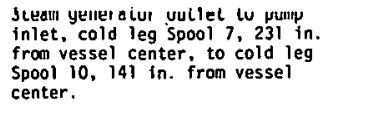 & $\frac{150 \text { ini. }}{\text { water }}$ & IC, pos pid & 161.162 & \\
\hline$O P U-12-10$ & $\begin{array}{l}\text { Pump outlet to pump inlet, cold } \\
\text { leg spool } 12,75 \text { in. from vessel } \\
\text { center, to cold leg spool } 10,141 \\
\text { in. from vessel center. } 5 p 00110 \\
\text { tap is } 10 \text { in. below Spool } 12 \text { tap. }\end{array}$ & \pm 50 psi & \pm 50 psid & 153.154 & 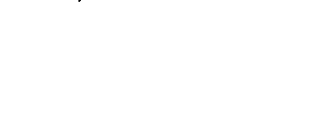 \\
\hline DPU-12-10L & $\begin{array}{l}\text { Pump outlet to pump inlet, cold } \\
\text { leg spool 13, } 75 \text { in. from vessel } \\
\text { center, to cold leg spool } 10,141 \\
\text { in. from vessel center. Spool } 10 \\
\text { tap is } 10 \text { in. below Spool } 12 \text { tap } \\
\text { (low range). }\end{array}$ & $\underset{\text { water }}{ \pm 100 \mathrm{in} .}$ & $\pm 4.9 \mathrm{ps}$ id & 155,156 & $\begin{array}{l}\text { Uetector saturated to } t=7 \\
\text { sec. }\end{array}$ \\
\hline OPU-12-15 & 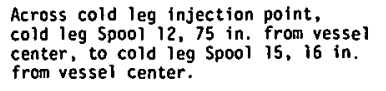 & $\frac{ \pm 100 \text { in. }}{\text { water }}$ & $\pm 4.8 \mathrm{ps}$ id & 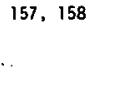 & \\
\hline DPU-15-1 & 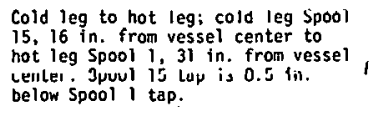 & $\frac{+500}{\text { in. }}$ inater & \pm 25 ps 10 & 161,162 & 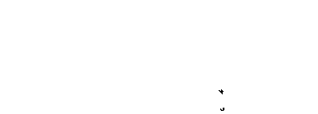 \\
\hline OPU-15-1L & 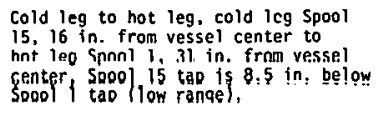 & $\stackrel{ \pm}{\text { water }}^{ \pm 100 \mathrm{in} .}$ & \pm 4.8 ps id & 163,164 & $\begin{array}{l}\text { neterer.t.n saturated prior to t=0 } \\
\text { sec. }\end{array}$ \\
\hline DPU-15- IANM & $\begin{array}{l}\text { Cold leg Spool } 15,16 \text { in. from } \\
\text { vessel center, to inlet annulus, } \\
\text { in below cold leg centerline at } \\
225^{n} \text {. Spool is tap is } 9 \text { in. obove } \\
\text { inlet atmulus tep. }\end{array}$ & $\frac{ \pm 100 \mathrm{in}}{\text { water }}$ & \pm 4.8 ps id & 159.160 & . \\
\hline DPU-PRESLL & $\begin{array}{l}\text { Pressurizer water level. Eleva- } \\
\text { tion difference between taps is } \\
53 \text { in. Lower tap is } 3.5 \text { in. above } \\
\text { pressurizer exit. }\end{array}$ & $\begin{array}{l}+50 \mathrm{in} . \\
\text { water }\end{array}$ & \pm 2.5 ps id & 165,166 & 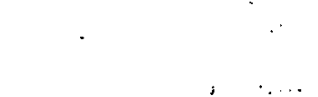 \\
\hline DPII-PR-4 & 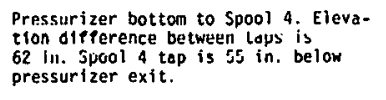 & \pm 1000 psi & +1357 psid & 167,168 & . \\
\hline \multicolumn{6}{|l|}{ Broken Luup } \\
\hline DPB-UP-30 & $\begin{array}{l}\text { Vessel upper plenum, } 10.5 \text { in. above } \\
\text { cold leg centerline at } 30^{\circ} \text {. to hot } \\
\text { leg Spool } 30,18 \text { 1n. from vessel } \\
\text { center. Upper plenum tap is } 2 \text { in. } \\
\text { above Spool } 30 \text { tap. }\end{array}$ & $\underset{\text { water }}{ \pm 100 \mathrm{in}}$ & \pm 4.8 psid & 169,170 & \\
\hline DPB-21-IANM & $\begin{array}{l}\text { Cold leg Spool } 21,49 \text { in. from } \\
\text { vessel center, to vessel inlet } \\
\text { annulus, } 9 \text { in. below cold leg } \\
\text { centerline at } 225^{\circ} \text {. Inlet annulus } \\
\text { tap is } 9 \text { in. below spool } 21 \text { tap. }\end{array}$ & ${ }_{\text {water }}^{ \pm 100 \mathrm{in}}$ & $\pm 4.8 \mathrm{psid}$ & 171,172 & \\
\hline DPB-23-CN1 & $\begin{array}{l}\text { Cold leg Spool 23, } 92 \text { in. from } \\
\text { vessel center, to vessel-side } \\
\text { nozzle throat, } 96 \text { in. from vessel } \\
\text { cunter. }\end{array}$ & $\pm 1000 \mathrm{psi}$ & \pm 1336 psid & 173,174 & \\
\hline DPB-30-36L & $\begin{array}{l}\text { Across entire simulated steam gen- } \\
\text { erator assembly, hot leg spool } 30, \\
18 \text { in. from vessel center, to cold } \\
\text { leg Spool } 36 \text { lower tap, } 24 \text { in. } \\
\text { from vessel center. Sppool } 30 \text { tap is } \\
\text { 19. below Spool } 36 \text { lower tap. }\end{array}$ & $\pm 500 \mathrm{ps} 1$ & \pm 500 psid & 175,176 & \\
\hline
\end{tabular}




\section{TABLE V (continued)}

\begin{tabular}{|c|c|c|c|c|c|c|c|}
\hline \multirow[b]{2}{*}{ Measurement } & \multirow[b]{2}{*}{ Location and Comments $[\mathrm{a}]$} & \multicolumn{2}{|c|}{ Range $[\mathrm{a}]$} & \multirow[b]{2}{*}{ Figure ${ }^{[a]}$} & \multirow{2}{*}{\multicolumn{3}{|c|}{ Measurement Comments ${ }^{[b]}$}} \\
\hline & & Detector & $\begin{array}{l}\text { Data Acquisition } \\
\text { System }\end{array}$ & & & & \\
\hline \multicolumn{8}{|c|}{ Broken Loop (contínued) } \\
\hline$D P B-32 U-36 L$ & $\begin{array}{l}\text { Across simulated steam generator } \\
\text { orifice assembly, hot leg Spool } 32 \\
\text { upper tap, } 73 \text { in. fram vessel center. } \\
\text { to Spool } 36 \text { lower tap, } 242 \text { in. from } \\
\text { vessel center. Spool } 32 \text { upper tap } \\
\text { is } 16 \text { in. above Spool } 36 \text { lower tap. }\end{array}$ & \pm 500 psi & $\pm 500 \mathrm{psid}$ & 177,178 & . & & \\
\hline DPB-36L-37 & $\begin{array}{l}\text { Across nozzle assembly, Spool } 36 \\
\text { lower tap. } 242 \text { in. from yessel } \\
\text { center a long hot leg, to Spool } 37 \text {, } \\
282 \text { in. from vessel center along } \\
\text { hot leg. Spool } 37 \text { tap is } 40 \text { in. } \\
\text { below spool } 36 \text { lower tap. }\end{array}$ & $\pm 50 \mathrm{psi}$ & \pm 50 psid & 179. 180 & & v & \\
\hline$O P B-37-38$ & $\begin{array}{l}\text { Across turbine flowneter and drag } \\
\text { disc, cold leg Spool } 37,282 \text { in. } \\
\text { from vessel center along hot leg, to } \\
\text { cold leg Spool } 38,305 \text { in. from } \\
\text { vessel center along hot leg. Spool } \\
37 \text { tap is } 23 \text { in. above Spool } 38 \text { tap. }\end{array}$ & $\begin{array}{l} \pm 50 \mathrm{in} . \\
\text { water }\end{array}$ & $\pm 2.5 \mathrm{psid}$ & 181,102 & & & \\
\hline . DPB-38-40 & $\begin{array}{l}\text { Across simulated pump, cold leg } \\
\text { Spool } 38,305 \text { in. from vessei center } \\
\text { along hot leg, to cold leg Spool } 40 \text {, } \\
365 \text { in. from vessel center along hot } \\
\text { log. }\end{array}$ & \pm 1000 psi & \pm 1353 psid & 183.184 & . & & \\
\hline $\mathrm{DPB}-40-42$ & $\begin{array}{l}\text { Across elbow leading to spool up- } \\
\text { strean of pump-side nozzle. cold } \\
\text { leg Spool } 40,365 \text { in. from vessel } \\
\text { center along hot leg, to Spool } 42 \text {. } \\
415 \text { in. from vessel center along } \\
\text { hot leg. Spool } 40 \text { tap is } 40 \text { in. } \\
\text { below spool } 42 \text { tap. }\end{array}$ & $\begin{array}{l}+50 \mathrm{in} \\
\text { water }\end{array}$ & $\pm 2.5 \mathrm{psid}$ & 185,186 & $\begin{array}{l}\text { Data } \\
\text { from }\end{array}$ & $\begin{array}{l}\text { acquisition system } \\
t=0 \text { to } t=1 \text { sec. }\end{array}$ & n saturated \\
\hline \multicolumn{8}{|l|}{ Vessel } \\
\hline DPV-UP-IANH & $\begin{array}{l}\text { Upper plenum, } 10.5 \text { in. above cold } \\
\text { leg centerline at } 30^{\circ} \text { to inlet } \\
\text { annulus, } 9 \text { in. below cold leg center- } \\
\text { line at } 225^{\circ} \text {. Elevation difference } \\
\text { between taps is } 19 \text { in. }\end{array}$ & $\begin{array}{l}+300 \text { in } \\
\text { water }\end{array}$ & \pm 14.7 psid & 187,188 & & & \\
\hline DPV-0-9GQ & $\begin{array}{l}\text { Inlet annulus cold leg centerline at } \\
90^{\circ} \text {, to } 9 \text { in. below cold leg center- } \\
\text { line at } 225^{\circ} \text {. Elevation difference } \\
\text { between taps is } 9 \text { in. }\end{array}$ & $\begin{array}{l}+50 \mathrm{in} . \\
\text { water }\end{array}$ & $\pm 2.5 \mathrm{psid}$ & 189,190 & & . & $\therefore \cdots$ \\
\hline OPV-9-260Q & $\begin{array}{l}\text { Inlet annulus, } 9 \text { in. below cold leg } \\
\text { centerline at } 225^{\circ} \text {, to downcomer gap. } \\
26 \text { in. below cold ieg centerline at } \\
225^{\circ} \text {. Elevation difference between } \\
\text { taps is } 17 \text { in. }\end{array}$ & water & \pm 2.4 psid & 191,192 & & & , \\
\hline OPV-9-166QQ & $\begin{array}{l}\text { Inlet annulus, } 9 \text { in. below cold leg } \\
\text { centerline at } 225^{\circ} \text {. to lower plenum, } \\
166 \text { in. below cold leg centerline } \\
\text { at } 225^{\circ} \text {. Elevation difference be- } \\
\text { tween taps is } 157 \text { in. }\end{array}$ & $\underset{\text { water }}{+300 \text { in. }}$ & \pm 14.4 psid & 193,194 & & & . \\
\hline DPY-20-550M & 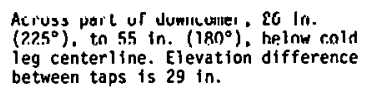 & $\begin{array}{l}\text { I } 50 \mathrm{ill} . \\
\text { wat.er }\end{array}$ & $\pm 2.0 \mathrm{psid}$ & 195,190 & & & \\
\hline DPV-55-11OMM & $\begin{array}{l}\text { Across part of downcomer, } 55 \text { in. } \\
\left(180^{\circ}\right) \text {, to } 110 \text { in. }\left(180^{\circ}\right) \text {, below } \\
\text { cold ieg centerline. Elevation } \\
\text { difference between taps is } 55 \text { in. }\end{array}$ & $\begin{array}{l}+100 \mathrm{in.} \\
\text { water }\end{array}$ & \pm 4.9 psid & 197,198 & $\therefore$ & & \\
\hline OPV-110-156MQ & $\begin{array}{l}\text { Across part of downcomer, } 110 \text { in. } \\
\left(180^{\circ}\right) \text {, to } 156 \text { in. }\left(225^{\circ}\right) \text {, below colo } \\
\text { leg centerline. Elevation difference } \\
\text { between taps is } 46 \text { in. }\end{array}$ & $\underset{\text { water }}{ \pm 100 \mathrm{in.}}$ & $\pm 4.9 \mathrm{psid}$ & 199,200 & & ‘ & \\
\hline DPV-16C-173QQ & $\begin{array}{l}\text { Across port of lowicy pleitim, } 16 \mathrm{c} \text { in. } \\
\left(225^{\circ}\right) \text {, to } 173 \text { in. }\left(225^{\circ}\right) \text {, below cold } \\
\text { leg centerline. Elevation difference } \\
\text { between taps is } 7 \text { in. }\end{array}$ & $\frac{120 \mathrm{in} .}{\text { water }}$ & I1.0 posis & 207,202 & & & \\
\hline DPV-1650-UP & $\begin{array}{l}\text { Lower plenum, } 166 \text { in. be low cold } \\
\text { leg centerline at } 225^{\circ} \text {, to upper } \\
\text { plenum, } 10.5 \text { in. above cold leg } \\
\text { centerine at } 30^{\circ} \text {. Elevation dif- } \\
\text { ference between taps is } 177 \text { in. }\end{array}$ & $\underset{\text { water }}{+300 \text { in. }}$ & \pm 14.7 psid & 203, 204 & & & \\
\hline
\end{tabular}


TABLE $\vee$ (continued)

\begin{tabular}{|c|c|c|c|c|c|}
\hline \multirow[b]{2}{*}{ Measurement ${ }^{\circ}$} & \multirow[b]{2}{*}{ Location and Coments ${ }^{[a]}$} & \multicolumn{2}{|c|}{ Range $^{[a]}$} & \multirow[b]{2}{*}{ Figure ${ }^{[a]}$} & \multirow[b]{2}{*}{ Measurement comments ${ }^{[b]}$} \\
\hline & & Detector & $\begin{array}{l}\text { Data Acquisition } \\
\text { System }\end{array}$ & & \\
\hline Vessel (continued) & & & & & . \\
\hline DPU-UP-3 & $\begin{array}{l}\text { Vessel upper plenum, } 10.5 \text { in. above } \\
\text { cold leg centerline at } 300^{\circ} \text {, to intact } \\
\text { oop hot leg Spool } 3 \text {, } 62 \text { in. from } \\
\text { vessel center. Upper plenum tap is } \\
\text { v2 in. above Spool } 3 \text { tap. }\end{array}$ & $\underset{+50 \text { in. }}{+2}$ & \pm 2.4 psid & 147,148 & \\
\hline DPB-21-IANN & $\begin{array}{l}\text { Cold leg Spool } 21,49 \text { in. } \text {. from vessel } \\
\text { center, to vessel inlet annulus. } 9 \text { in. } \\
\text { below cold leg centerline at } 2255^{\circ} \text {. } \\
\text { Inlet annulus tap is } 9 \text { in. below Spool } \\
21 \text { tap. }\end{array}$ & $\underset{\text { water }}{ \pm 100 \text { in. }}$ & \pm 4.8 psid & 171,172 & \\
\hline Vessel Core & & & & . & . \\
\hline OPVC-89W-UP & 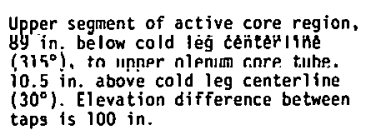 & 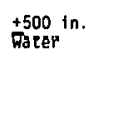 & \pm 25 psid & 205.206 & $\begin{array}{l}\text { Liquid may have boiled from } \\
\text { sellss illes; ques Liviladie } \\
\text { data. }\end{array}$ \\
\hline DPVC-89-105KQ & 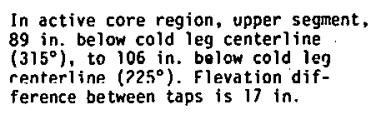 & $\begin{array}{l}+50 \text { in. } \\
\text { water }\end{array}$ & $\pm 2.5 \mathrm{ps} t \mathrm{dd}$ & 207,208 & . \\
\hline DPVC-105-122QJ & $\begin{array}{l}\text { Across center segment of active corc } \\
\text { region, } 106 \text { ine below cold leg; } \\
\text { centerine }\left(225^{\circ}\right) \text {, to to } 122 \text { in. } \\
\text { below cold leg centerline }\left(135^{\circ}\right) \text {. } \\
\text { Elevation difference between taps } \\
\text { is } 16 \text { in. }\end{array}$ & $\underset{\text { water }}{+100 \mathrm{in} .}$ & $\pm 4.8 \mathrm{ps} 10$ & 209.210 & . \\
\hline DPVC-122-140J0 & $\begin{array}{l}\text { In active core region, lower segment, } \\
\text { ind in. below cold leg centerline } \\
\left(135^{\circ}\right) \text { to } 140 \text { in. be cow cold leg } \\
\text { centerline }\left(40^{\circ}\right) \text {. Elevation dif- } \\
\text { ference between taps is } 18 \text { in. }\end{array}$ & $\frac{+700 \text { in. }}{\text { water }}$ & \pm 4.9 psid & 211,212 & \\
\hline \multicolumn{6}{|l|}{ LCC SYSTLM } \\
\hline Vesspel & * & & & & \\
\hline DPV-ACC-TB & $\begin{array}{l}\text { Top to bottom of broken loop accumu- } \\
\text { lator tank. Elevation difference be- } \\
\text { tween taps is } 177 \text { in. }\end{array}$ & $\frac{\text { troo in. }}{\text { water }}$ & $\pm 4.9 \mathrm{psid}$ & 213,214 & . \\
\hline \multicolumn{6}{|l|}{ 3Ledil G̈tneraiur } \\
\hline DPU $=3 Q-J E C$ & $\begin{array}{l}\text { secondary } 3 \text { ide, differential pressurc } \\
\text { taps at } 45 \text { in. and } 126 \text { in. above } \\
\text { oottom of tube sheet. Elevation } \\
\text { difference between taps is } 81 \text { in. }\end{array}$ & $\frac{+100 \mathrm{in}}{\text { water }}$ & $\pm 4.8 \mathrm{psids}$ & 215.215 & . \\
\hline DPU-SG-DISC & $\begin{array}{l}\text { Across venturi tube, } 66 \text { in. down- } \\
\text { stream from stream generator dis- } \\
\text { charge. }\end{array}$ & $\pm 500 \mathrm{in}$. & $\pm 24 . b$ psid & $21 \%, 218$ & . \\
\hline VOLUMETRIC FLOW RATE & Turbine flommeter, bidirectional. & & . & . & 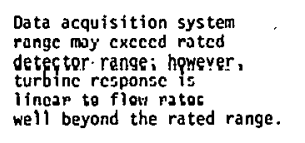 \\
\hline Intact Lonp & 3 -in. Schedule 160 pipe. & & - & & . \\
\hline FTU-1 & $\begin{array}{l}\text { Hot leg, Spool 1, } 18 \text { in. from } \\
\text { vessel center. }\end{array}$ & $\frac{+20}{\mathrm{gpm}}$ to +400 & $\pm 1200 \mathrm{gpm}$ & 219,220 & \\
\hline \&тU-9 & $\begin{array}{l}\text { Cold leg, Snnol 9, } 154 \text { in. from } \\
\text { vessel center. }\end{array}$ & $\frac{+80}{9 p m}$ to \pm 800 & $\pm 1200 \mathrm{gpm}$. & 219,220 & \\
\hline PTU. 13 & $\begin{array}{l}\text { cold log, jponi is, an in trim } \\
\text { vessel center. }\end{array}$ & 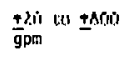 & 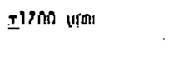 & โ21. โ\&ะ & $\cdot \cdot$ \\
\hline FTU-15 & $\begin{array}{l}\text { Cold leg, Spool 15, } 29 \mathrm{in.} \text { from } \\
\text { vessel center. }\end{array}$ & $\frac{+20}{\mathrm{gpm}}$ to \pm 800 & $\pm 1000 \mathrm{gpm}$ & 221,222 & \\
\hline Brukell Luup & Schedule 160 pipe. & & & & \\
\hline FTB-21 & $\begin{array}{l}\text { Cold leg, Spool 21, } 58 \text { in. from } \\
\text { vessel center; 3-in. pipe. }\end{array}$ & $\frac{ \pm 200}{\mathrm{gpm}}$ to \pm 400 & $\pm 1200 \mathrm{gpm}$ & 223,224 & \\
\hline FT8-30 & $\begin{array}{l}\text { Hot leg, Spool } 30,25 \text { in. from } \\
\text { vessel centery } 3 \text {-in. pipe. }\end{array}$ & $\frac{ \pm 20}{9 \mathrm{pm}}$ to \pm 400 & $\pm 800 \mathrm{gpm}$ & 223,2226 & $\begin{array}{l}\text { liripline poometer } \\
\text { mal function to } \\
t=4.6 \text { seconds. }\end{array}$ \\
\hline
\end{tabular}




\section{TABLE $\vee$ (continued)}

\begin{tabular}{|c|c|c|c|c|c|}
\hline \multirow[b]{2}{*}{ Measurement } & \multirow[b]{2}{*}{ Location and Comments ${ }^{[a]}$} & \multicolumn{2}{|c|}{ Range $^{[a]}$} & \multirow[b]{2}{*}{ Figure $^{[\mathrm{a}]}$} & \multirow[b]{2}{*}{ Measurement Comments ${ }^{[\mathrm{b}]}$} \\
\hline & & Detector & $\begin{array}{c}\text { Data Acquisition } \\
\text { System }\end{array}$ & & \\
\hline \multicolumn{6}{|c|}{ Broken Loop (continued) } \\
\hline FTB-37 & $\begin{array}{l}\text { Cold leg, Spool } 37,290 \text { in. from } \\
\text { vessel center along hot leg; } 2-\text { in. } \\
\text { pipe. }\end{array}$ & $\frac{ \pm 20}{9 p m}$ to \pm 800 & $\pm 800 \mathrm{gpm}$ & 225. 226 & \\
\hline \multicolumn{6}{|l|}{ Core } \\
\hline FTV-CORE-IN & $\begin{array}{l}\text { Entrance to core, } 2158 \mathrm{sn} \text {. below } \\
\text { cold leg centerline. }\end{array}$ & $\frac{ \pm 2}{\mathrm{~g} p m}$ to \pm 200 & $\pm 900 \mathrm{gpm}$ & 227,228 & \\
\hline \multicolumn{6}{|l|}{ ECC System } \\
\hline FTU-HPIS & $\begin{array}{l}\text { In line immediately after HPIS } \\
\text { pump for broken loop, } 1 / 2-i n \text {. Iine } \\
\text { Pump discharge routed to vessel } \\
\text { lower plenum. }\end{array}$ & $\frac{ \pm 0.75}{9 p \pi m}$ to \pm 7.5 & $\pm 2 \mathrm{gpm}$ & 229,230 & $\begin{array}{l}\text { Data acquisition sys tem saturated } \\
\text { intermittentiy. }\end{array}$ \\
\hline FTU-LPIS & $\begin{array}{l}\text { In } 1 \text { ine leading from LPIS for } \\
\text { intact loop; } 1 / 2-1 \text { in. Iine. Pump } \\
\text { discharge routed to vessel lower } \\
\text { Dlenum. }\end{array}$ & $\frac{ \pm 0.75}{9 \mathrm{pm}}$ to \pm 7.5 & $\pm 10 \mathrm{gpm}$ & 231,232 & $\begin{array}{l}\text { Data acquifition system saturated } \\
\text { near } t=24 \mathrm{sec} \text {. }\end{array}$ \\
\hline FIV-ACC & $\begin{array}{l}\text { In line leading from vessel } \\
\text { accumulator; l-in. line. }\end{array}$ & $\frac{+5}{\mathrm{~g} p m}$ to \pm 50 & $\pm 75 \mathrm{gpm}$ & 421,422 & Turbine flowneter falled. \\
\hline Pressurizer & $1-1 / 2-1$ in. turbine. & & & & \\
\hline FTU-PRIZE & Surge line. & $\frac{+2}{9}$ to \pm 20 & $\pm 80 \mathrm{gpm}$ & 233,234 &. \\
\hline FLUIO VELOCITY & Turbine flometer, bidírectional. & & - & & \\
\hline \multicolumn{6}{|l|}{ Downcomer } \\
\hline FTV-40A & $\begin{array}{l}40 \text { in. below coid leg centerline, } \\
0^{\circ} \text {. }\end{array}$ & $\begin{array}{l}+2.5 \text { to } 50 \\
\mathrm{ft} / \mathrm{sec}\end{array}$ & $\pm 50 \mathrm{ft} / \mathrm{sec}$ & 235,236 & Unidirectional measurement \\
\hline FTV- $40 \mathrm{CH}$ & $\begin{array}{l}40 \text { in. below cold leg centerline, } \\
180^{\circ} \text {. }\end{array}$ & $\begin{array}{l}+2.5 \text { to } 50 \\
\text { ft } / \mathrm{sec}\end{array}$ & $\pm 50 \mathrm{ft} / \mathrm{sec}$ & & \\
\hline MOMENTUM FLUX & Drag dise, bidirectional. & & & - & $\begin{array}{l}\text { Momentum flux reported only } \\
\text { for }-6 \text { to } 42 \text { sec, except as } \\
\text { noted. Drag disc data may } \\
\text { exhibit significant tempera- } \\
\text { ture dependence. Drag disc data } \\
\text { should be used only for short- } \\
\text { term transient response. }\end{array}$ \\
\hline Intact Loop & 3-in. pipe. & & & & \\
\hline FOU-1. & $\begin{array}{l}\text { Hot } l \text { leg, Spool } 1,29 \text { in. from } \\
\text { vessel center: target size } \\
0.875 \text { in. }\end{array}$ & $\begin{array}{l} \pm 200 \text { to } \pm 11,500 \\
16 \mathrm{bm} / \mathrm{ft}-\mathrm{sec}^{2}\end{array}$ & $\begin{array}{l} \pm 22,400 \\
1 \mathrm{bm} / \mathrm{ft}-\sec ^{2}\end{array}$ & 237 & $\vdots$ \\
\hline FDU -5 & $\begin{array}{l}\text { Hot leg, Spool 5, } 100 \text { in. from } \\
\text { vessel center; target size } \\
\text { l.0 in. }\end{array}$ & $\begin{array}{l} \pm 1 \text { to } \pm 2000 \\
1 \mathrm{bm} / \mathrm{ft}-\mathrm{sec}^{2}\end{array}$ & $\begin{array}{l} \pm 4750 \\
1 \mathrm{bm} / \mathrm{ft}-\mathrm{sec}^{2}\end{array}$ & & Detector failed. \\
\hline FDU-10 & $\begin{array}{l}\text { Cold leg, Spool } 10,137 \text { in. from } \\
\text { vessel center; target size } 0.875 \text { in. }\end{array}$ & $\begin{array}{l} \pm 200 \text { to } \pm 104,000 \\
1 \mathrm{bm} / \mathrm{ft}-\sec ^{2}\end{array}$ & $\begin{array}{l} \pm 23,750 \\
1 \mathrm{bm} / \mathrm{ft}-\sec ^{2}\end{array}$ & 238 & \\
\hline Foll-13. & $\begin{array}{l}\text { Cold leg. } 5 p o o l 13.54 \text { in. from } \\
\text { vessel center; target size } 0.875 \text { in. }\end{array}$ & $\begin{array}{l} \pm 200 \text { to } \pm 14,800 \\
1 \operatorname{lxi} / \mathrm{fl}-\mathrm{sec}^{2}\end{array}$ & $\begin{array}{l} \pm ? n \cdot \mathrm{nan} \\
1 \mathrm{bm} / \mathrm{ft}-\sec ^{2}\end{array}$ & 239 & . \\
\hline FDU-15 & $\begin{array}{l}\text { Cold leg, Spool } 15,19 \text { in. from } \\
\text { vessel center; target size } 0.875 \text { in. }\end{array}$ & $\begin{array}{l} \pm 200 \text { to } \pm 14,500 \\
16 \mathrm{~m} / \mathrm{ft}-\sec ^{2}\end{array}$ & $\begin{array}{l} \pm 20,250 \\
i \mathrm{bm} / \mathrm{ft}-\sec ^{2}\end{array}$ & 240 & \\
\hline \multicolumn{6}{|l|}{ Broken Loop } \\
\hline FDB-21 & $\begin{array}{l}\text { Cold leg, Spool } 21,53 \text { in. from } \\
\text { vessel center, 3-in. pipe; target } \\
\text { size } 0.875 \text { in. }\end{array}$ & $\begin{array}{l} \pm 200 \text { to } \pm 70,500 \\
1 \mathrm{bm} / \mathrm{ft}-\mathrm{sec}^{2}\end{array}$ & $\begin{array}{l} \pm 25,000 \\
1 \mathrm{bm} / \mathrm{ft}-\mathrm{sec}^{2}\end{array}$ & 241 & \\
\hline FDB- 30 & $\begin{array}{l}\text { Hot leg, Spool } 30,21 \text { in. from } \\
\text { vessel center, 3-in. pipe; target } \\
\text { stze 0 } 0.56 \text { in. }\end{array}$ & $\begin{array}{l} \pm 200 \text { to } \pm 60,000 \\
10 \mathrm{x} / \mathrm{tt}-\sec ^{2}\end{array}$ & 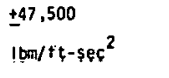 & 242 & \\
\hline FOB-37 & $\begin{array}{l}\text { Cold leg, Spool } 37,284 \text { in. from } \\
\text { vessel center along hot leg, steam } \\
\text { generator outlet, vertical pipe, } \\
\text { 2-In. pipe; target size } 0.406 \text { in. }\end{array}$ & $\begin{array}{l} \pm 200 \text { to } \pm 121,000 \\
1 \mathrm{tm} / \mathrm{ft}-\mathrm{sec}^{2}\end{array}$ & $\begin{array}{l} \pm 248,000 \\
1 \mathrm{bm} / \mathrm{ft}-\sec ^{2}\end{array}$ & 243 & \\
\hline
\end{tabular}




\section{TABLE V. (continued)}

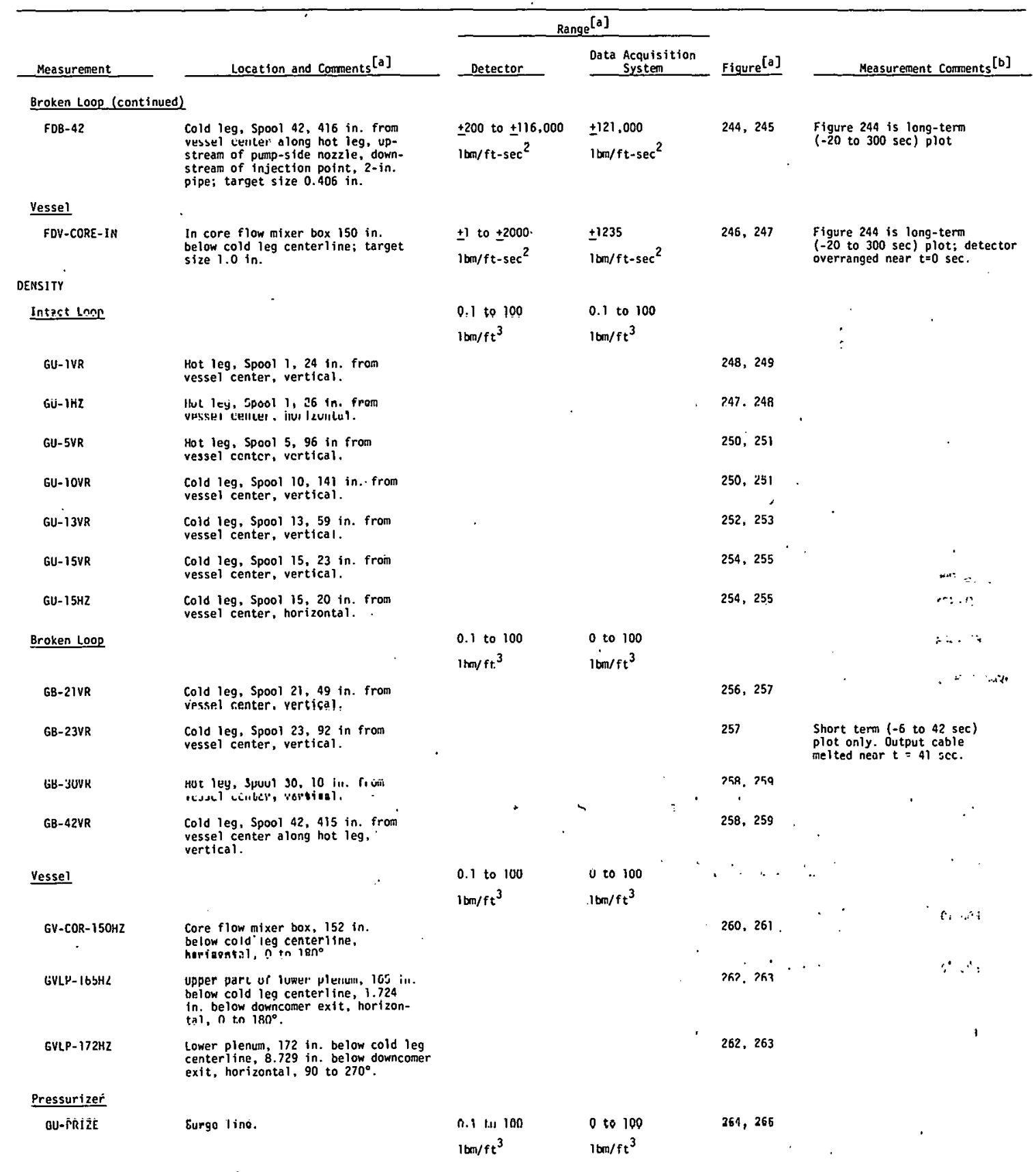




\section{TABLE V (continued)}

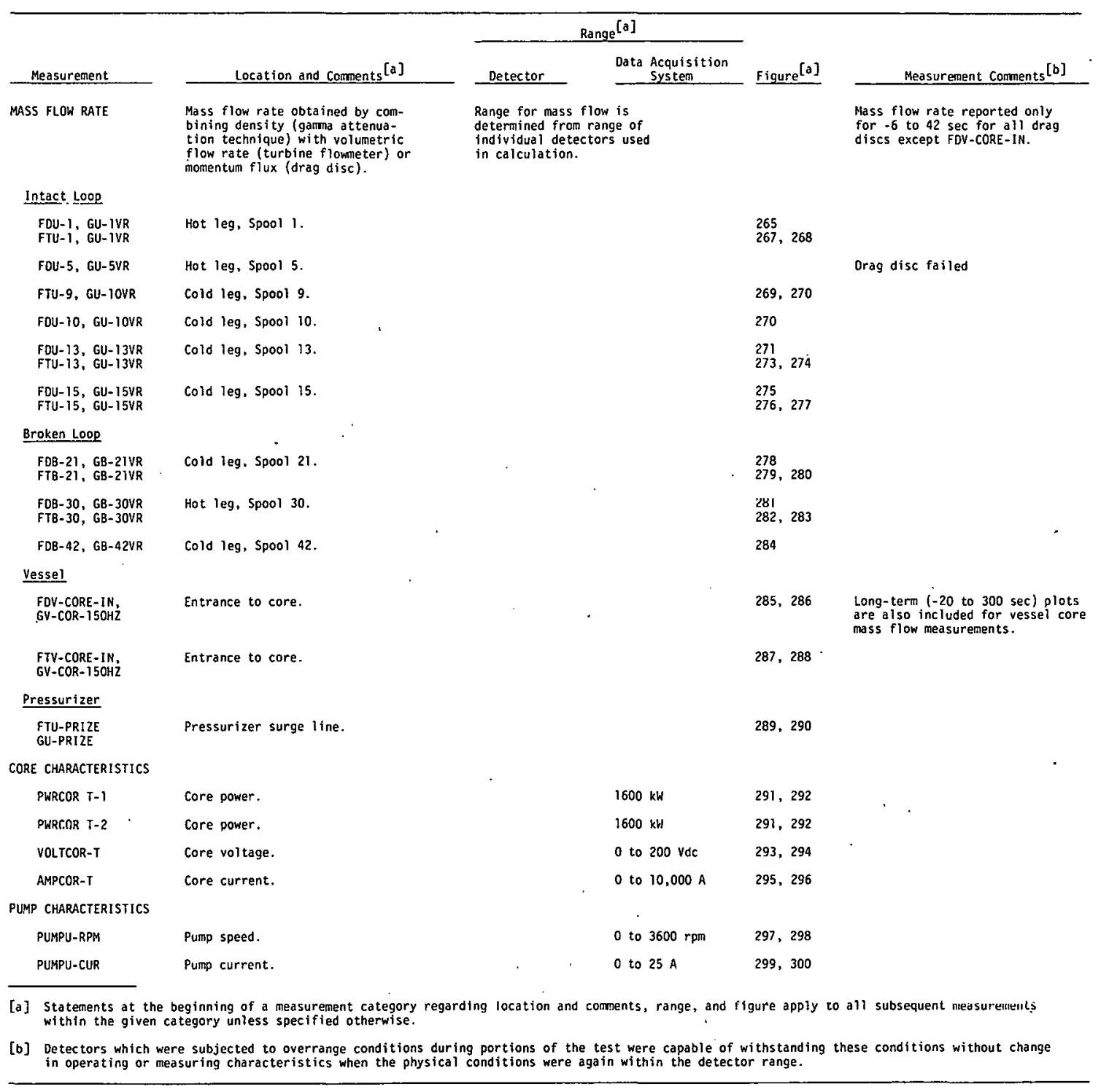




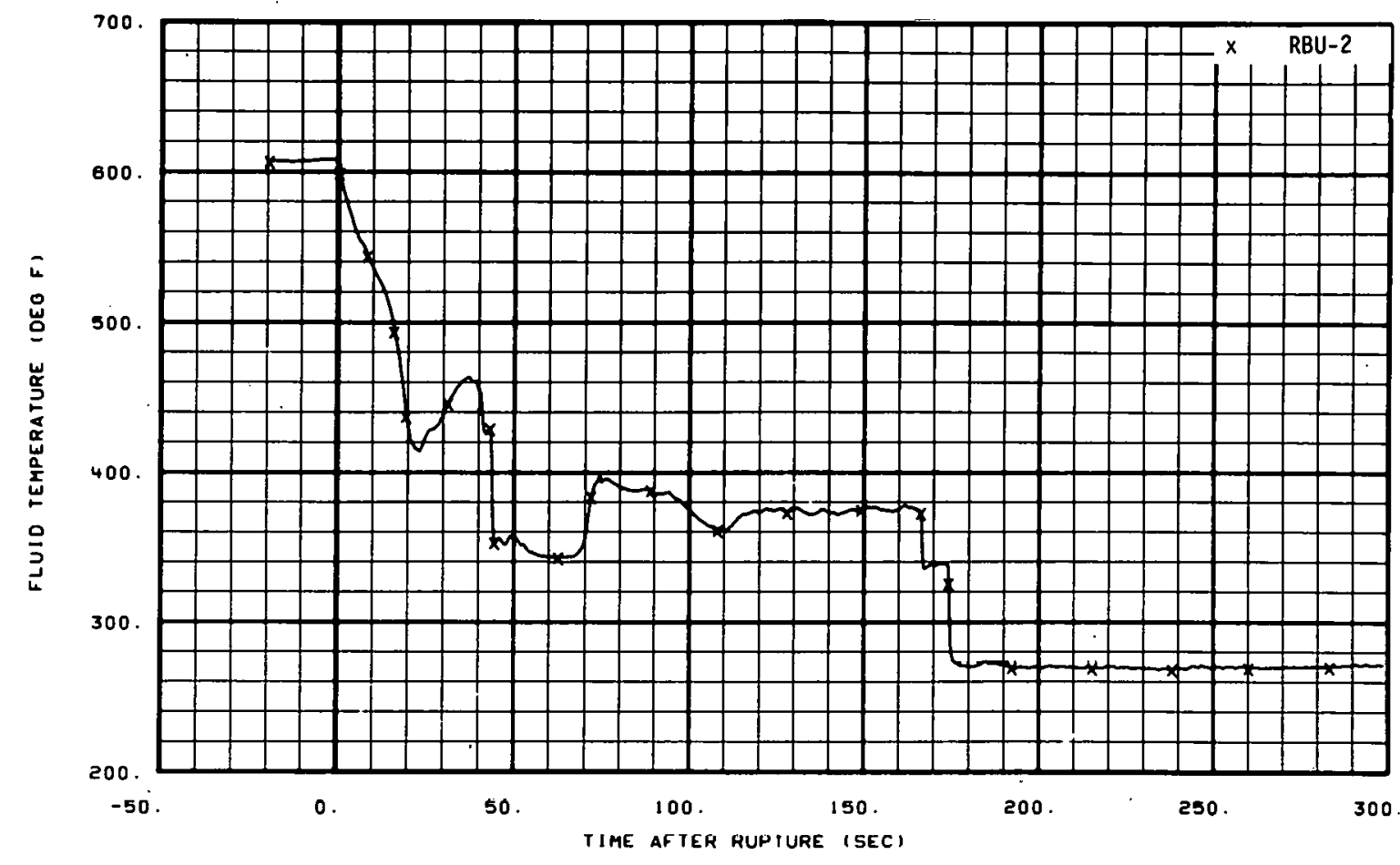

Fig. 9 Fluid temperature in intact loop hot leg (RBU-2), from -20 to 300 seconds.

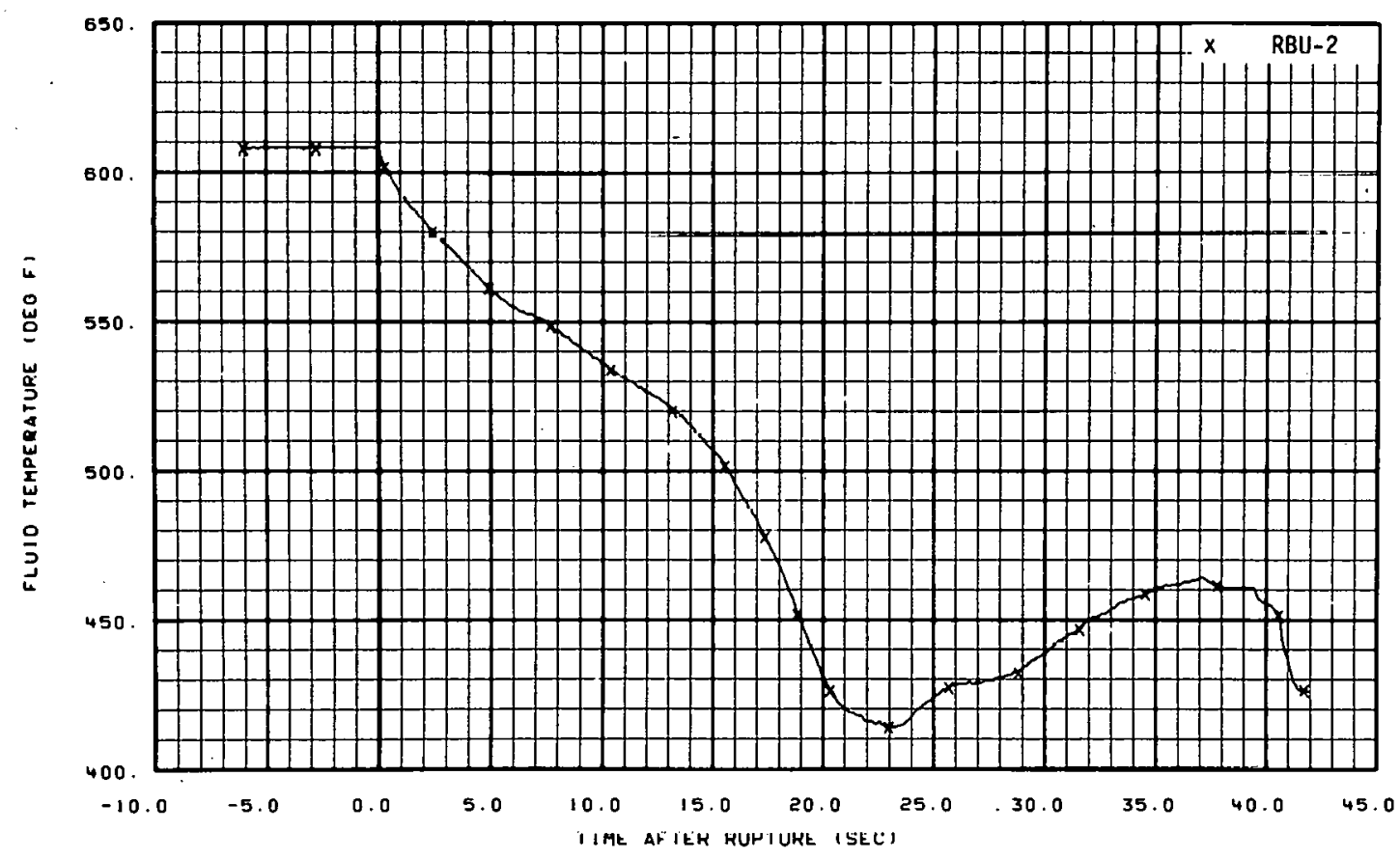

Fig. 10 Fluid temperature in intact loop hot leg (RBU-2), from -6 to 42 seconds. 


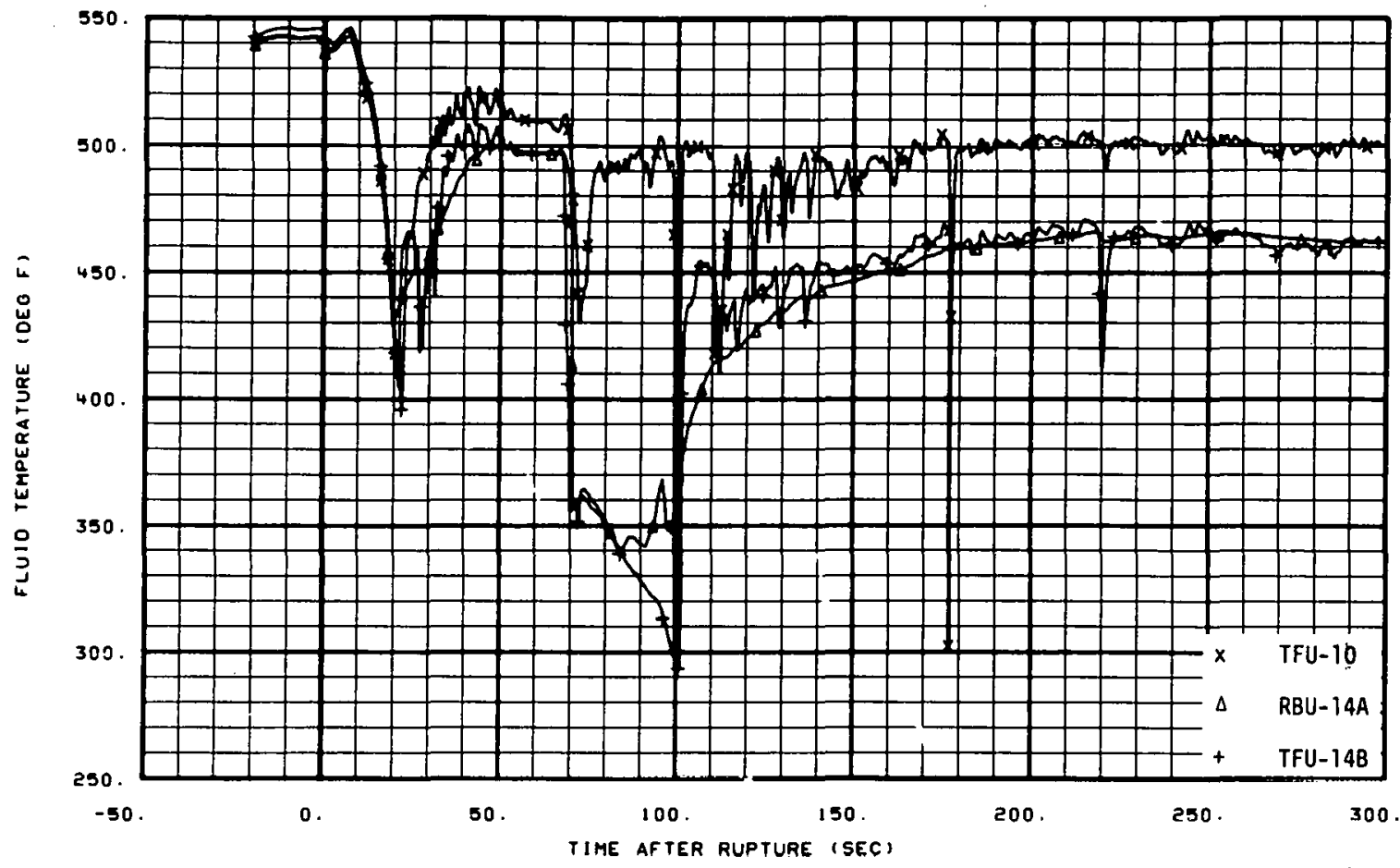

Fig. $11 \mathrm{Fluid}$ temperature in intact loop cold leg (TFU-10, RBU-14A, and TFU-14B), from -20 to 300 seconds.

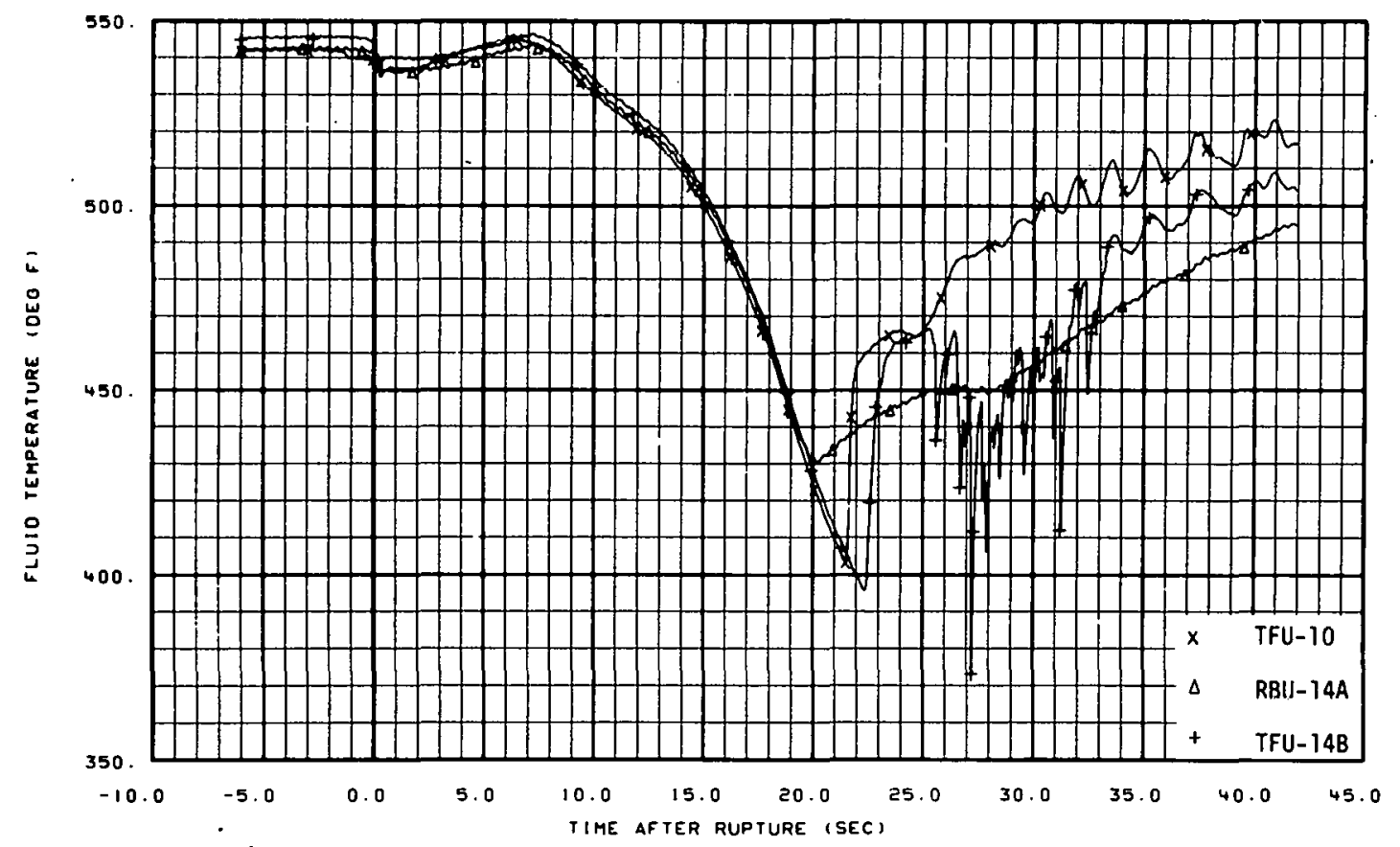

Fig. 12 Fluid temperature in intact loop cold leg (TFU-10, RBU-14A, and TFU-14B), from -6 to 42 seconds. 


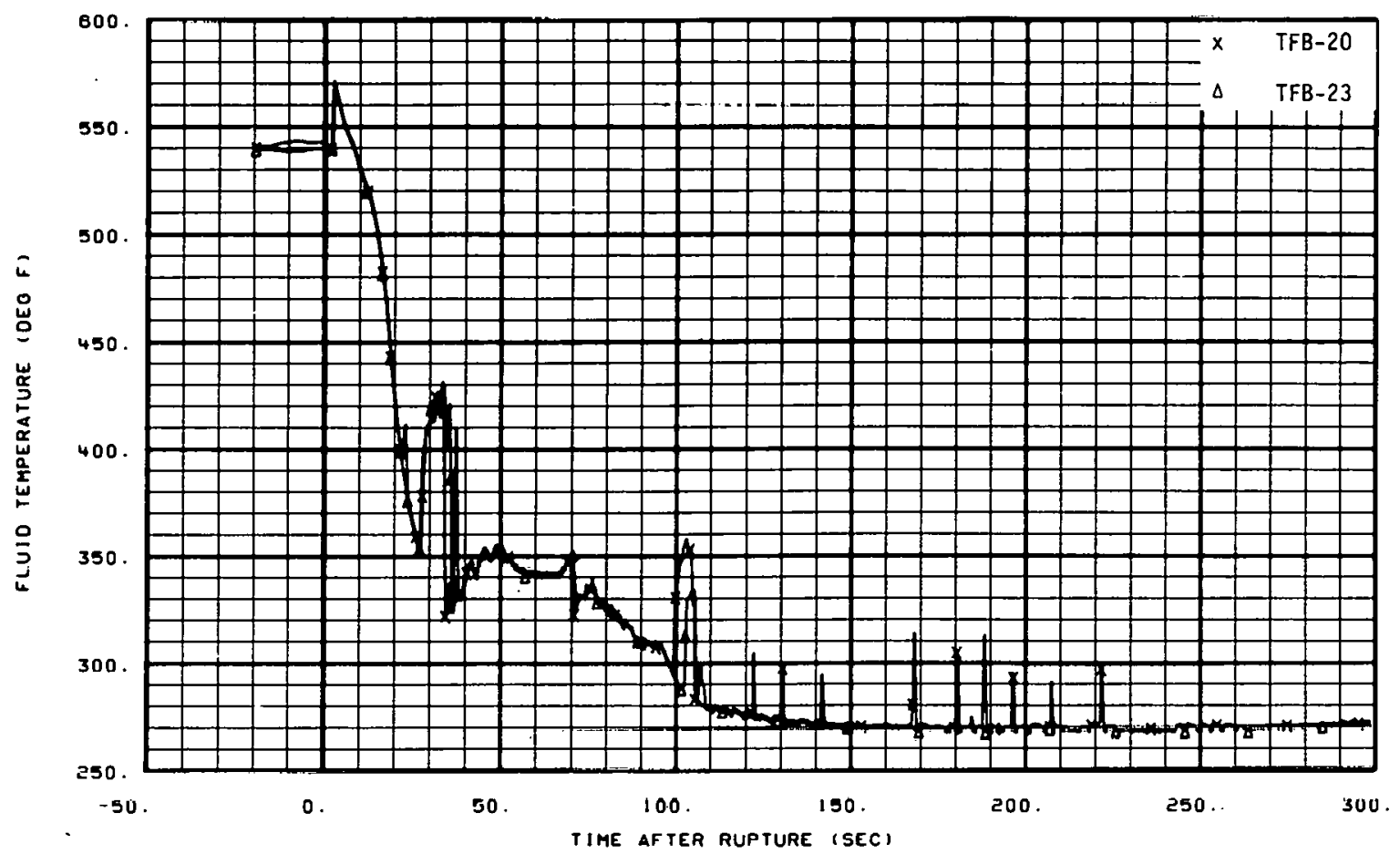

Fig. 13 Fluid temperature in broken loop, vessel side (TFB-20 and $T F B-23$ ), from -20 to 300 seconds.

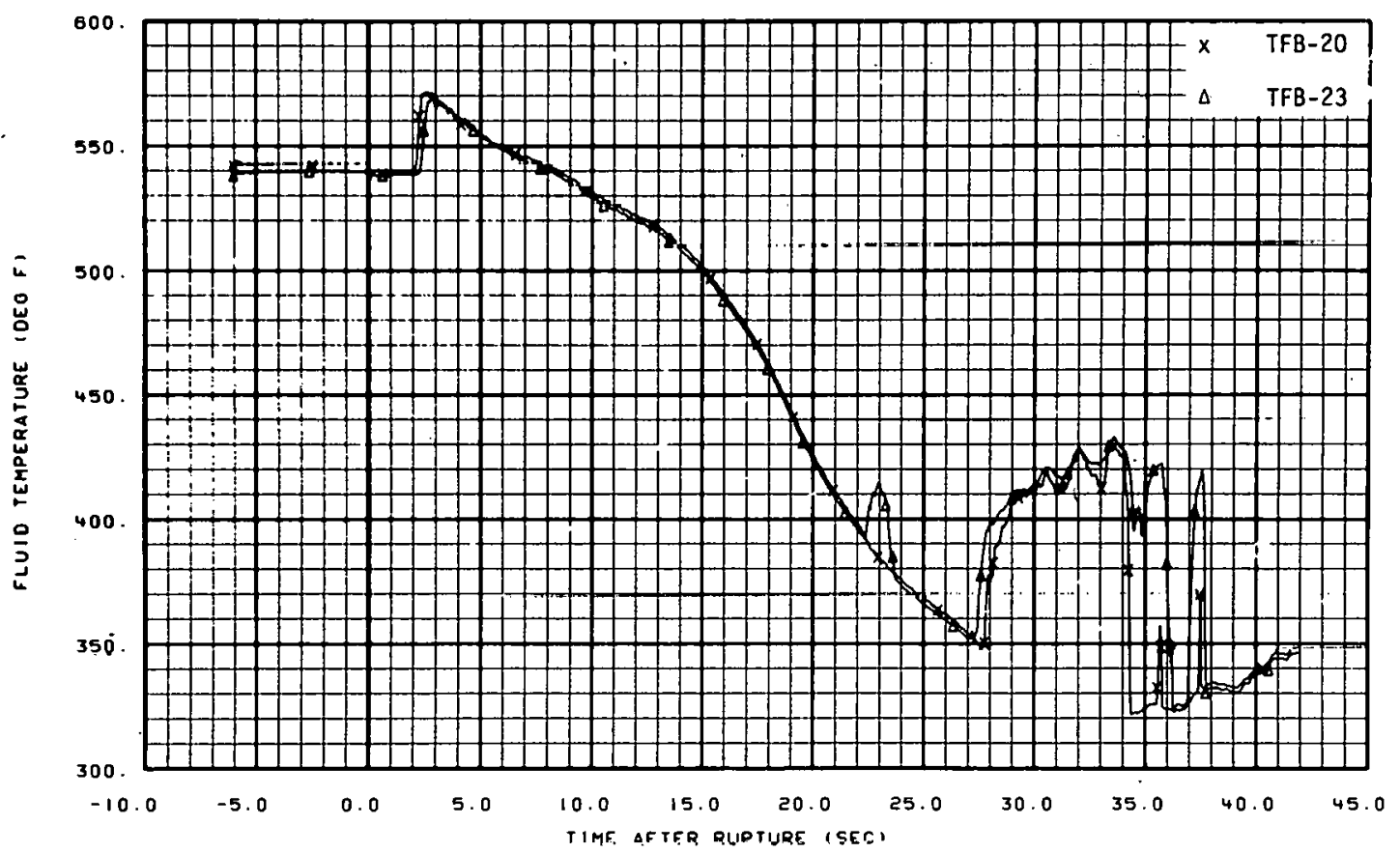

Fig. 14 Fluid temperature in broken loop, vessel side (TFB-20 and TFB-23), from -6 to 42 seconds. 


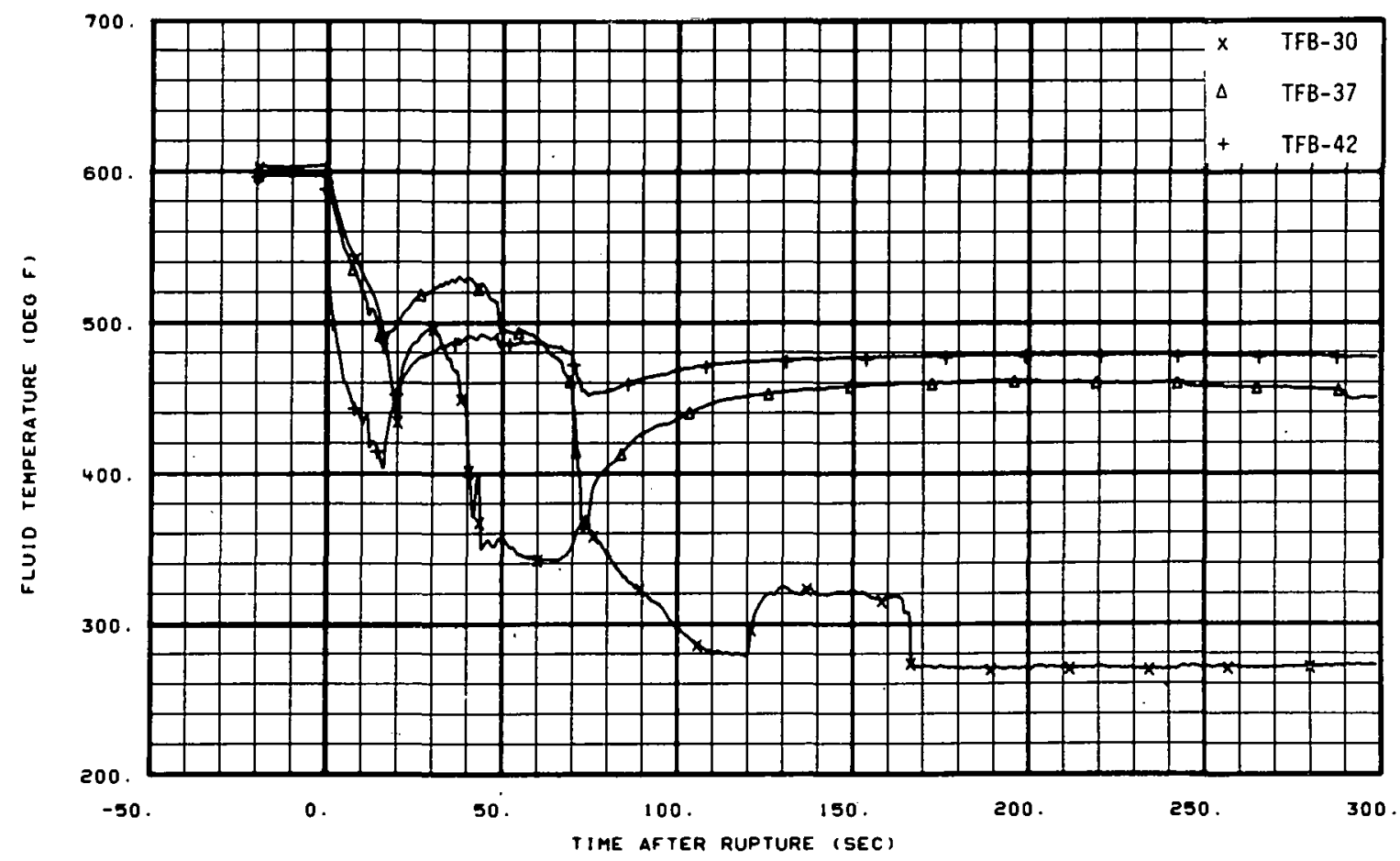

Fig. 15 Fluid temperature in broken loop, pump side (TFB-30, TFB-37; and $T F B-42)$, from -20 to 300 seconds.

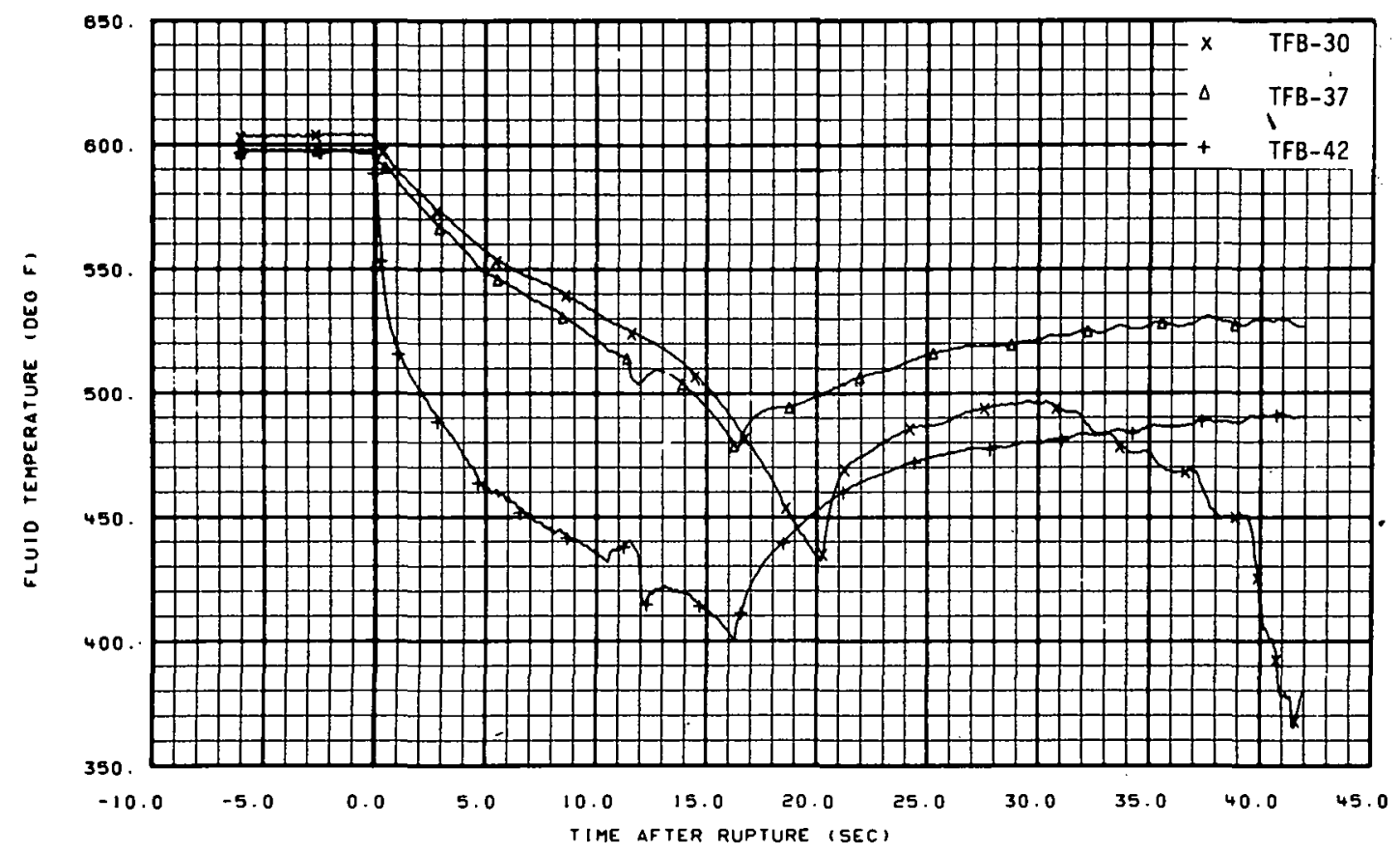

Fig. 16 Fluid temperature in broken loop, pump side (TFB-30, TFB-37, and $T F B-42)$, from -6 to 42 seconds. 


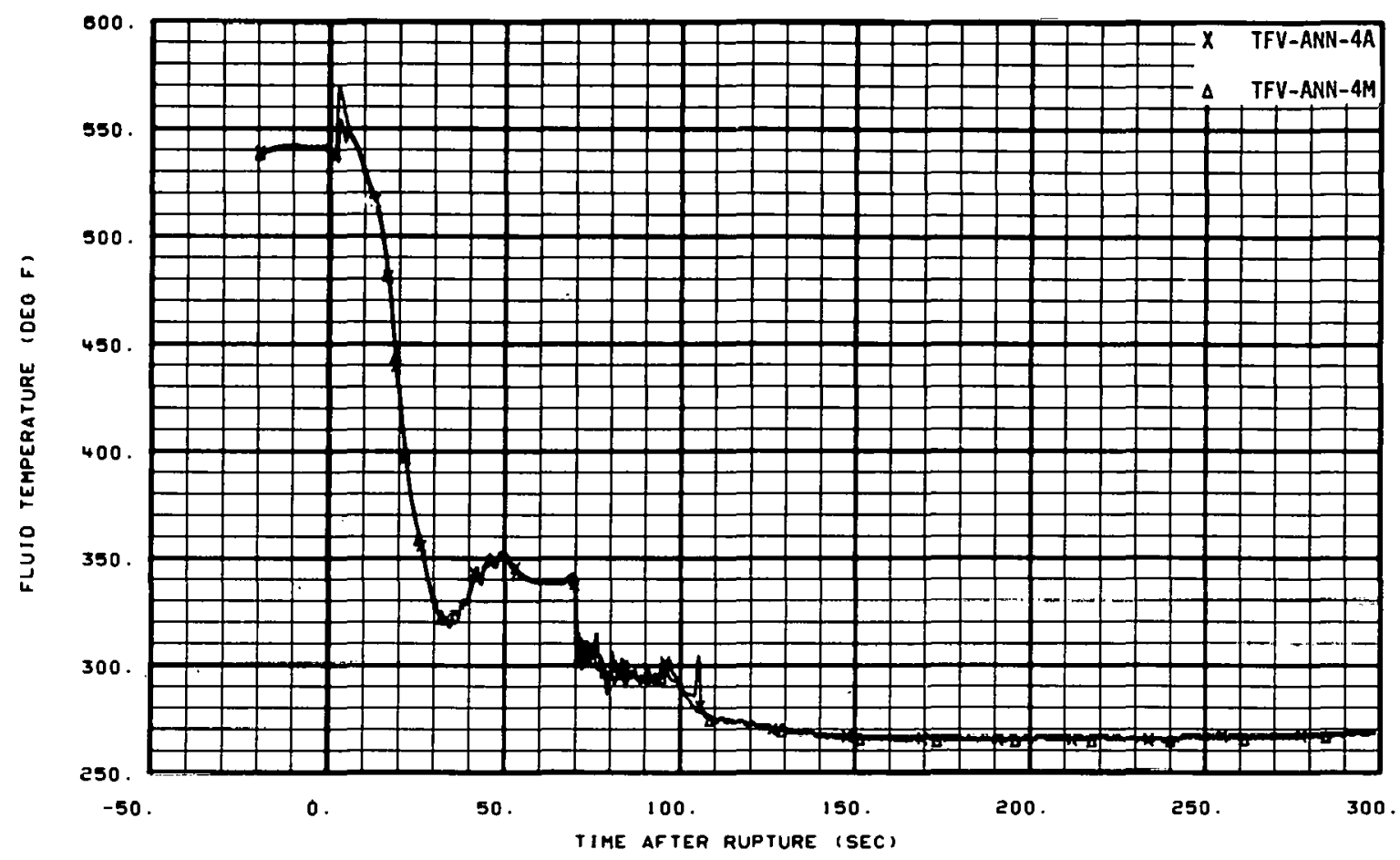

Fig. 17 Fluid temperature in inlet annulus (TFV-ANN-4A and TFV-ANN-4M), from -20 to 300 seconds.'

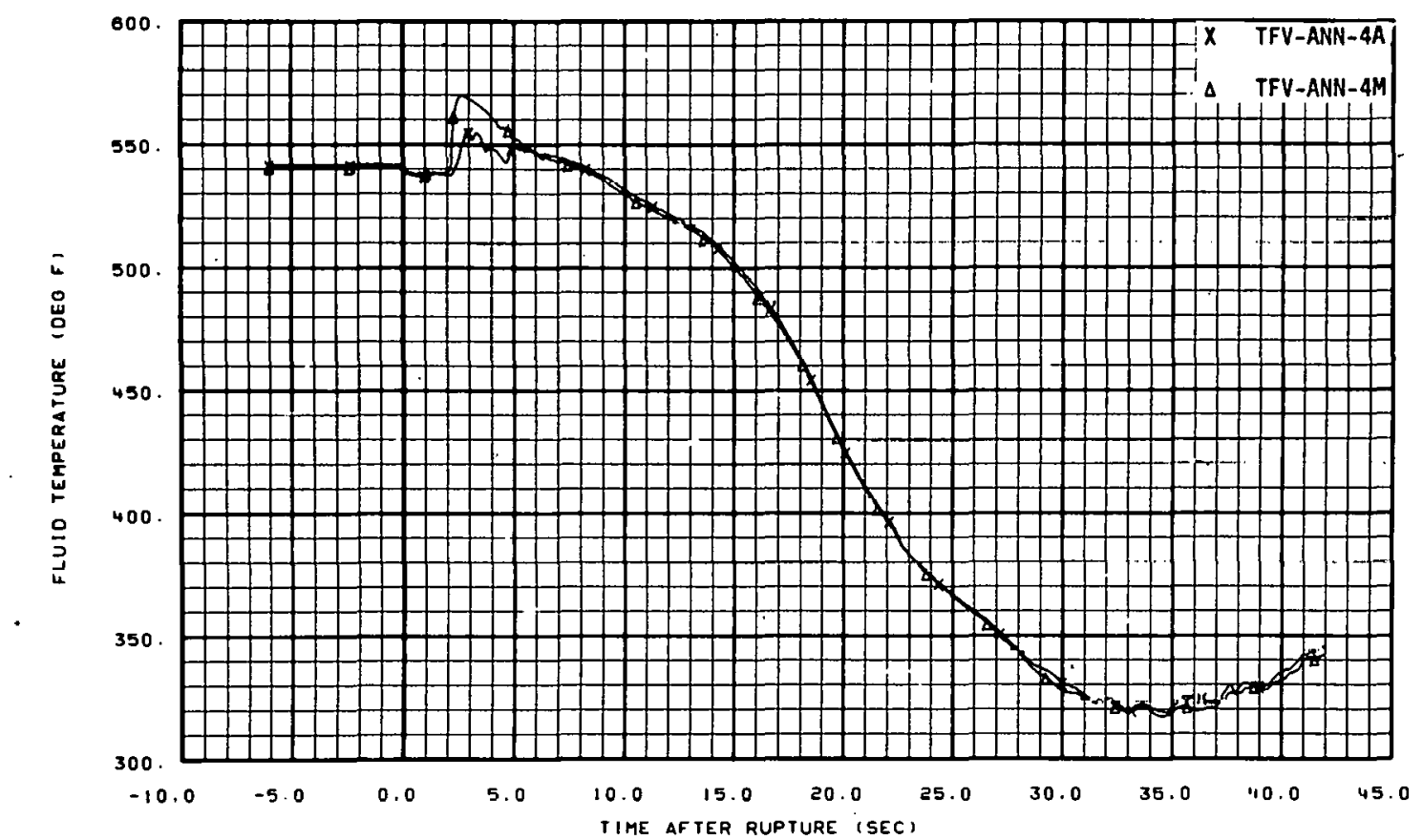

Fig. 18 Fluid temperature in inlet annulus (TFV-ANN-4A and TFV-ANN-4P1), from -6 to 42 seconds. 


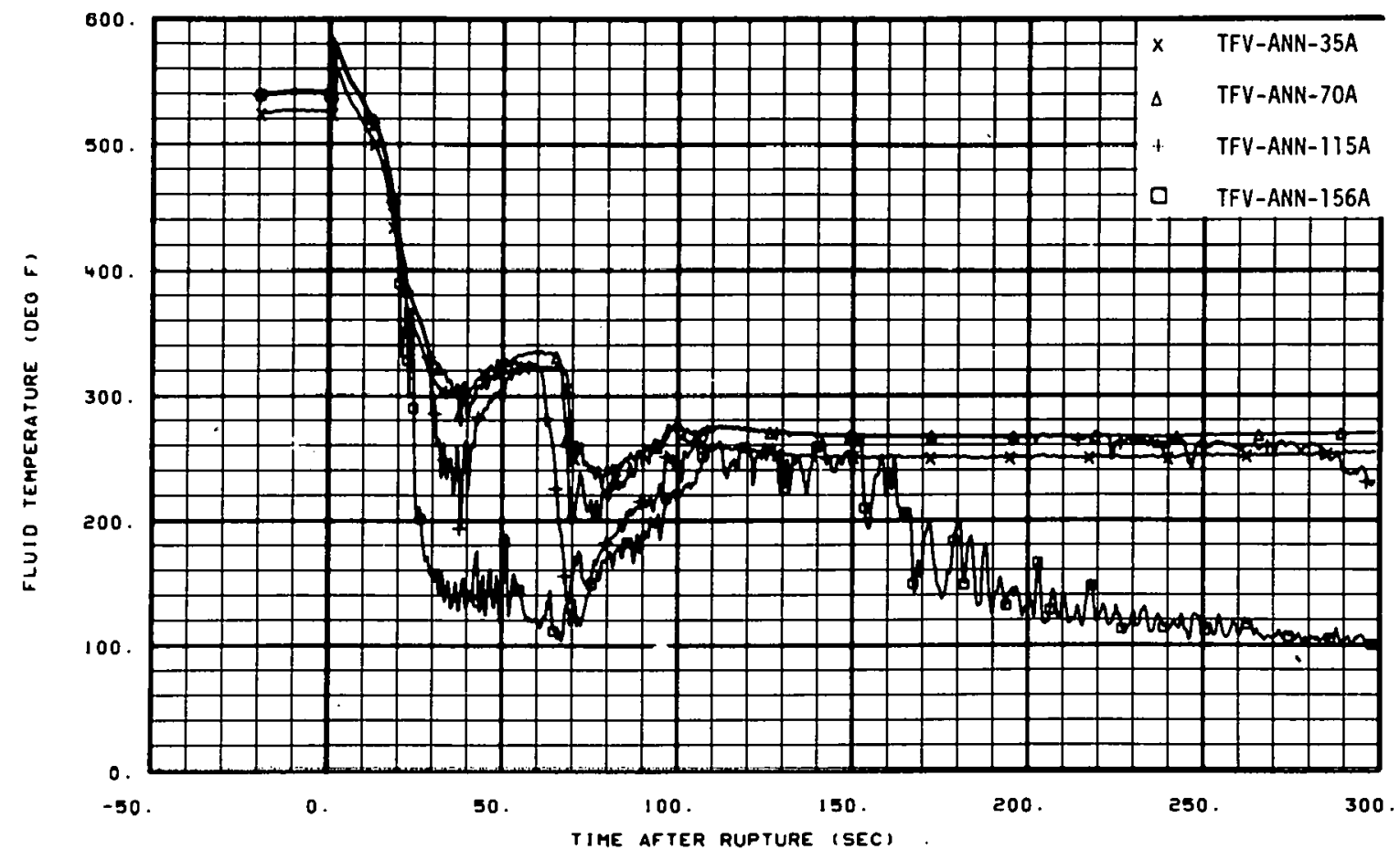

Fig. 19 Fluid temperature in downcomer annulus (TFV-ANN-35A, TFV-ANN-70A, TFV-ANN-115A, and TFV-ANN-156A), from -20 to 300 seconds.

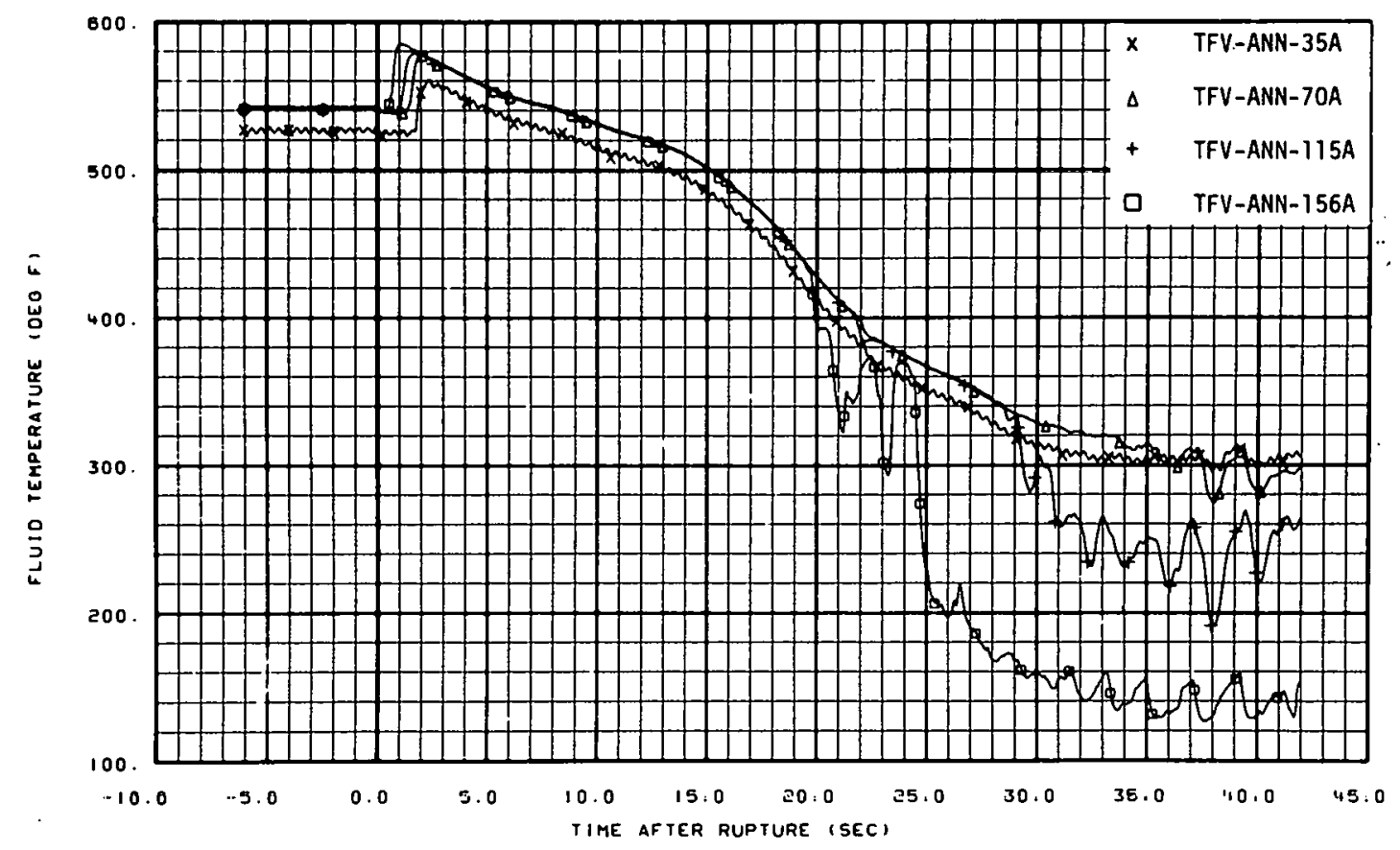

Fig. 20 Fluid temperature in downcomer annulus (TFV-ANN-35A, TFV-ANN-70A, TFV-ANN-115A, and TFV-ANN-156A), from -6 to 42 seconds. 


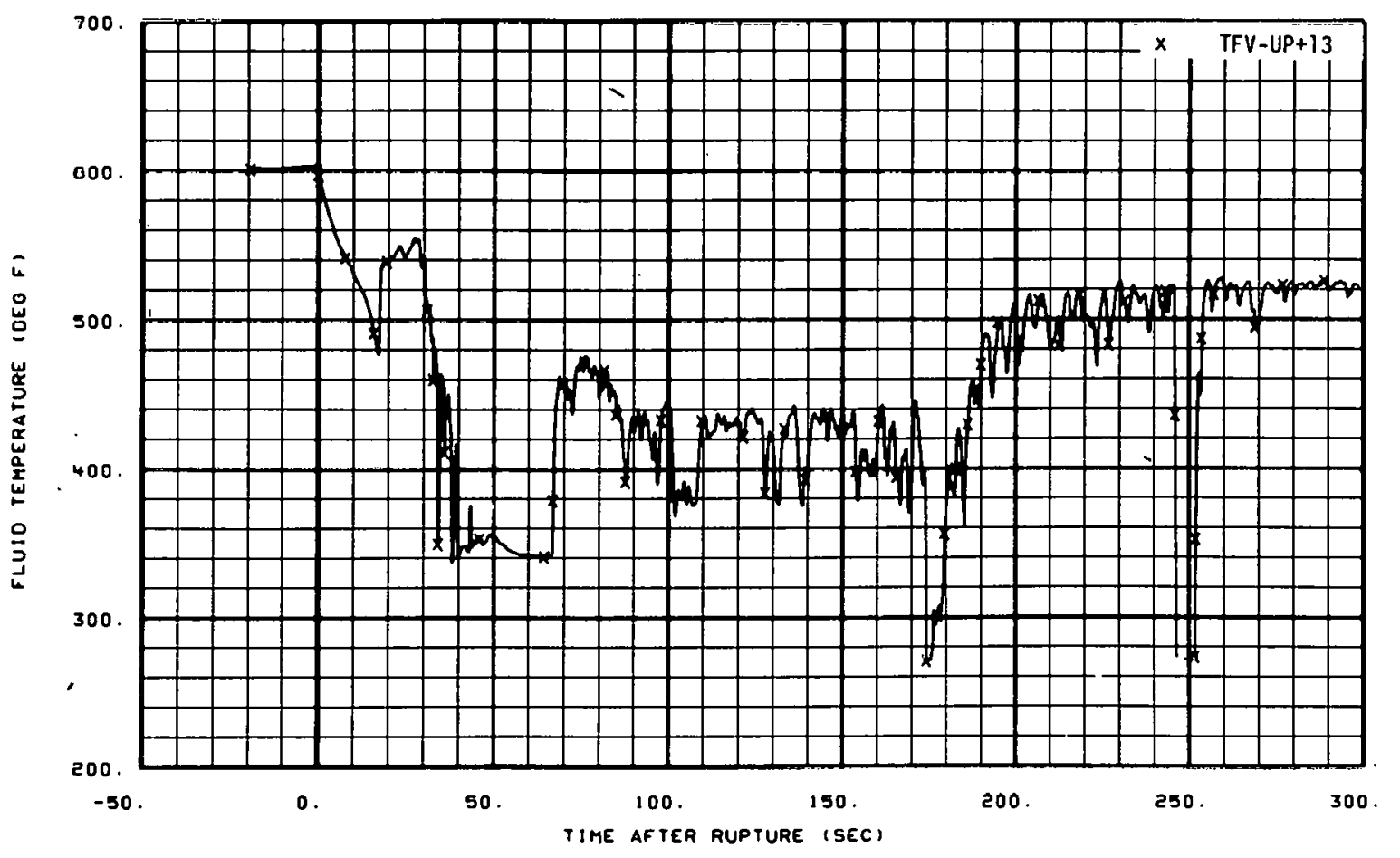

Fig. 21 Fluid temperature in upper plenum (TFV-UP+13), from -20 to 300 seconds.

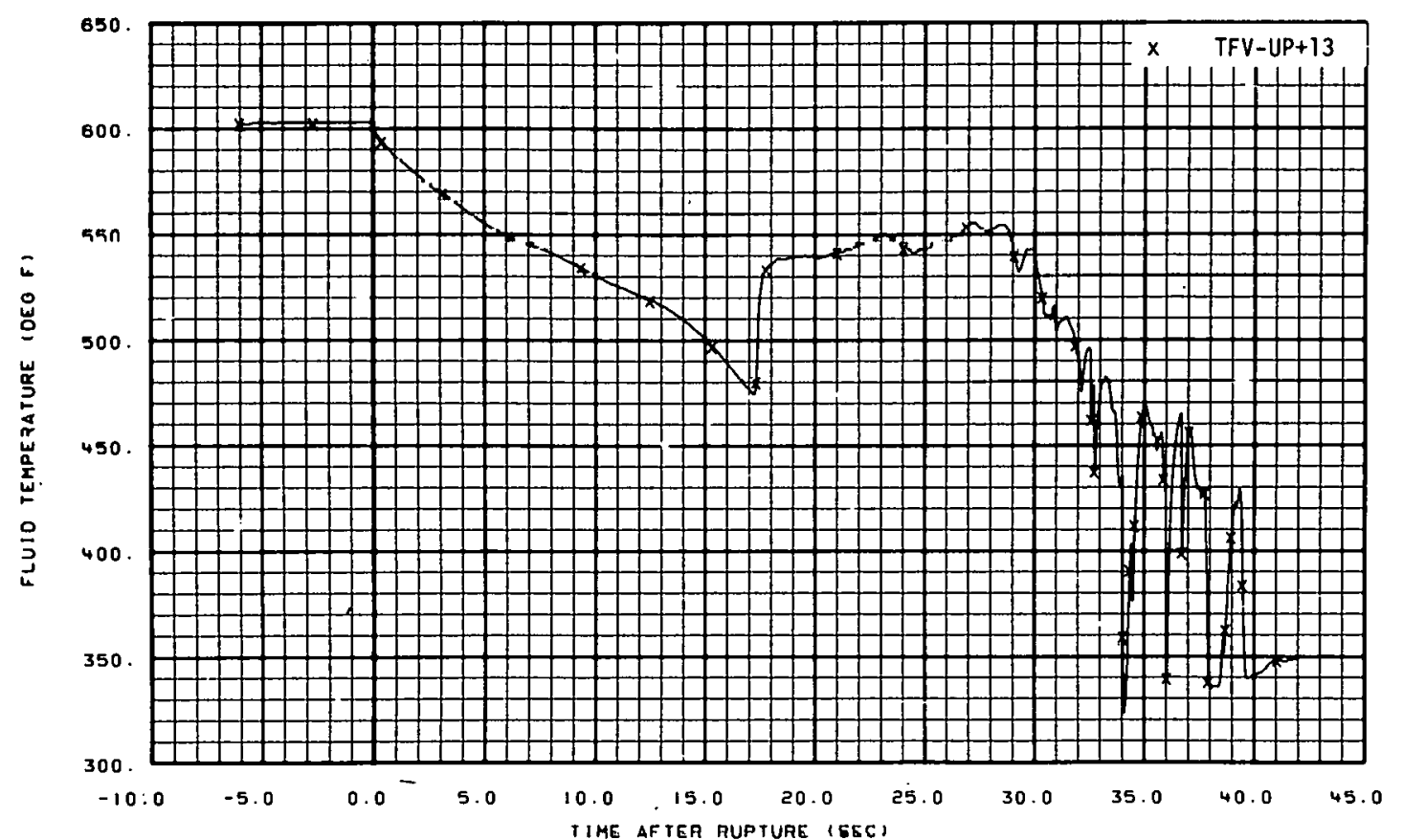

Fig. 22 Fluid temperature in upper plenum $(T F V-U P+13)$, from -6 to 42 seconds. 


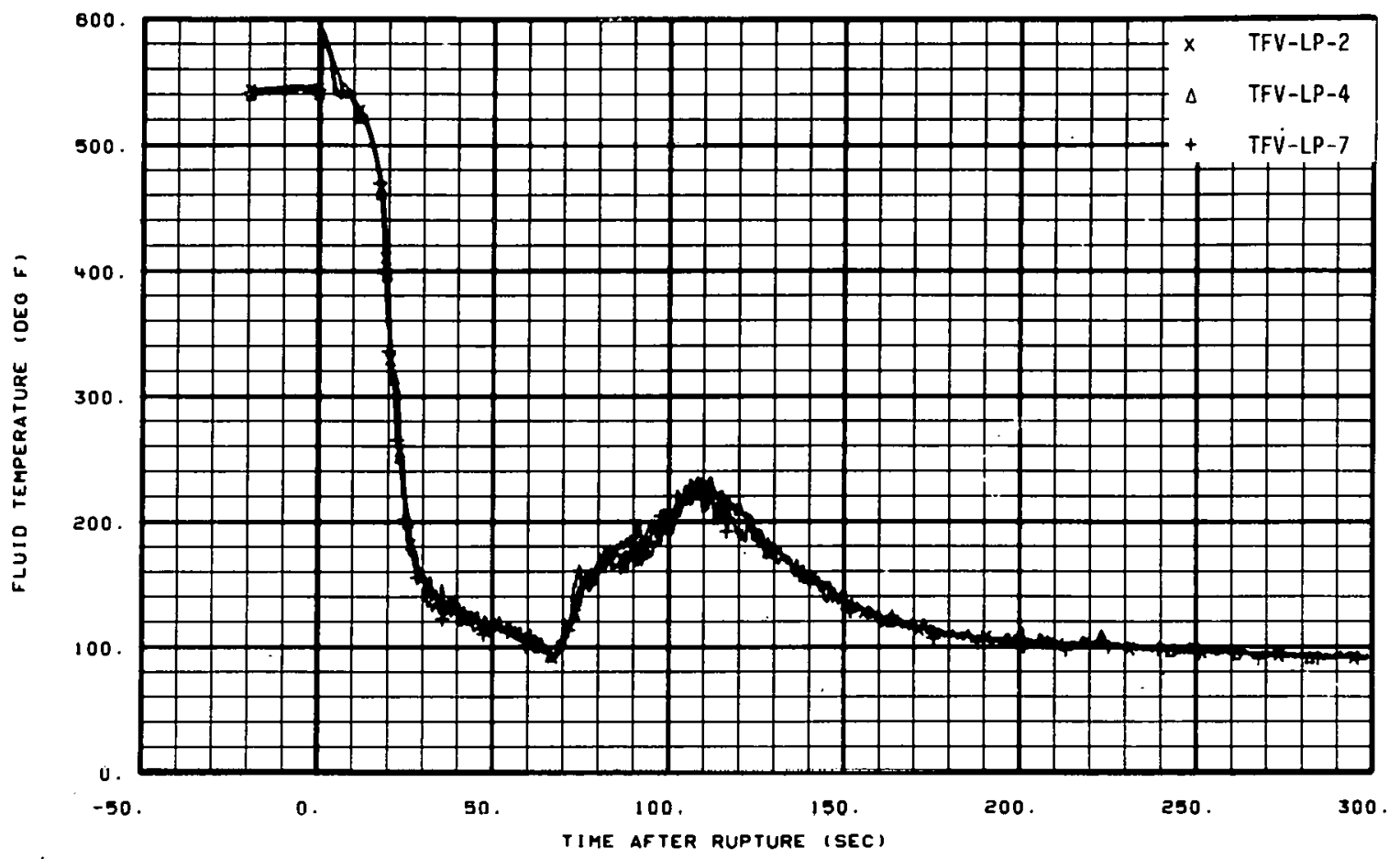

Fig. 23 Fluid temperature in lower plenum (TFV-LP-2, TFV-LP-4, and TFV-LP-7), from -20 to 300 seconds.

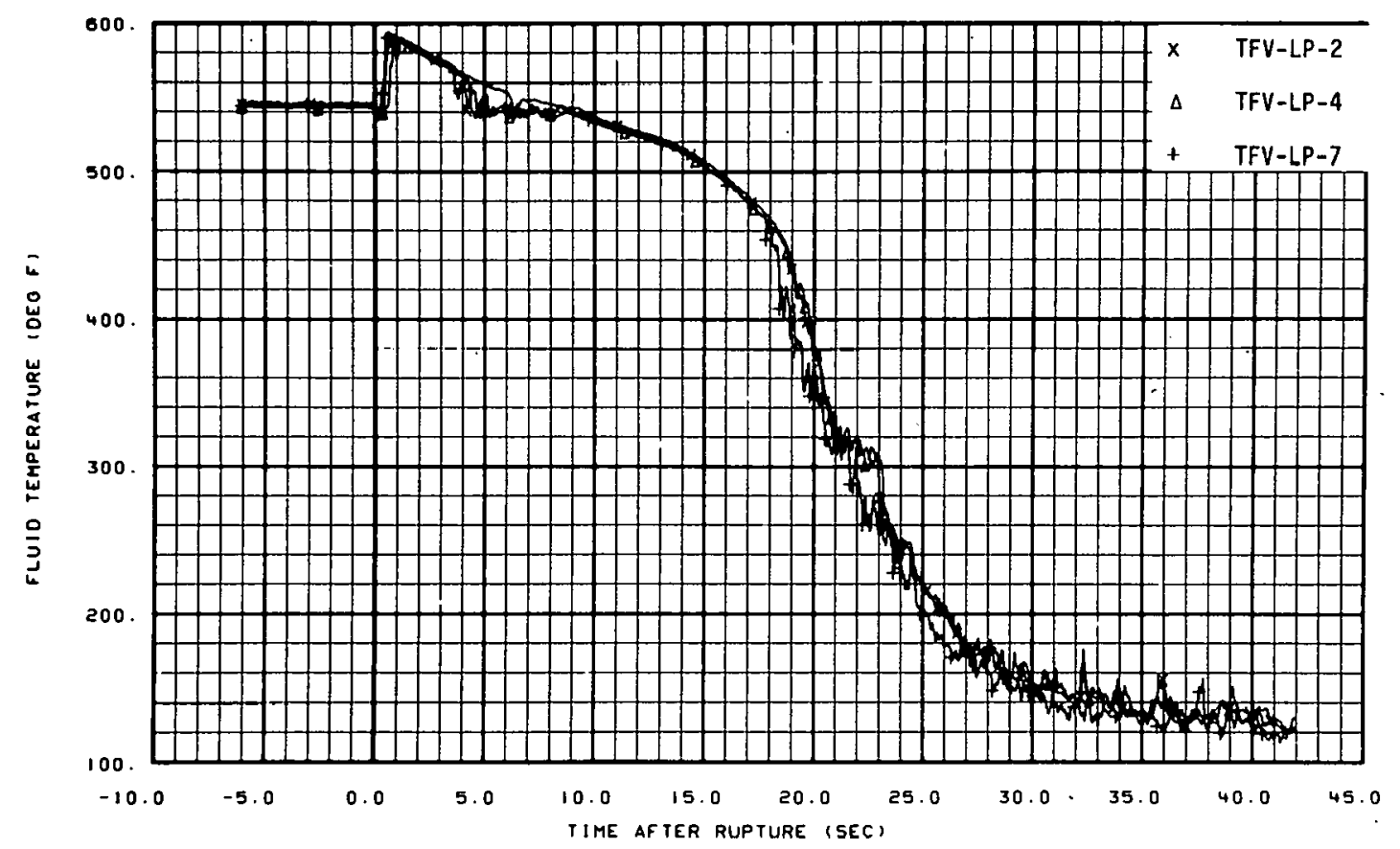

Fig. 24 Fluid temperature in lower plenum (TFV-LP-2, TFV-LP-4, and TFV-LP-7), from -6 to 42 seconds. 


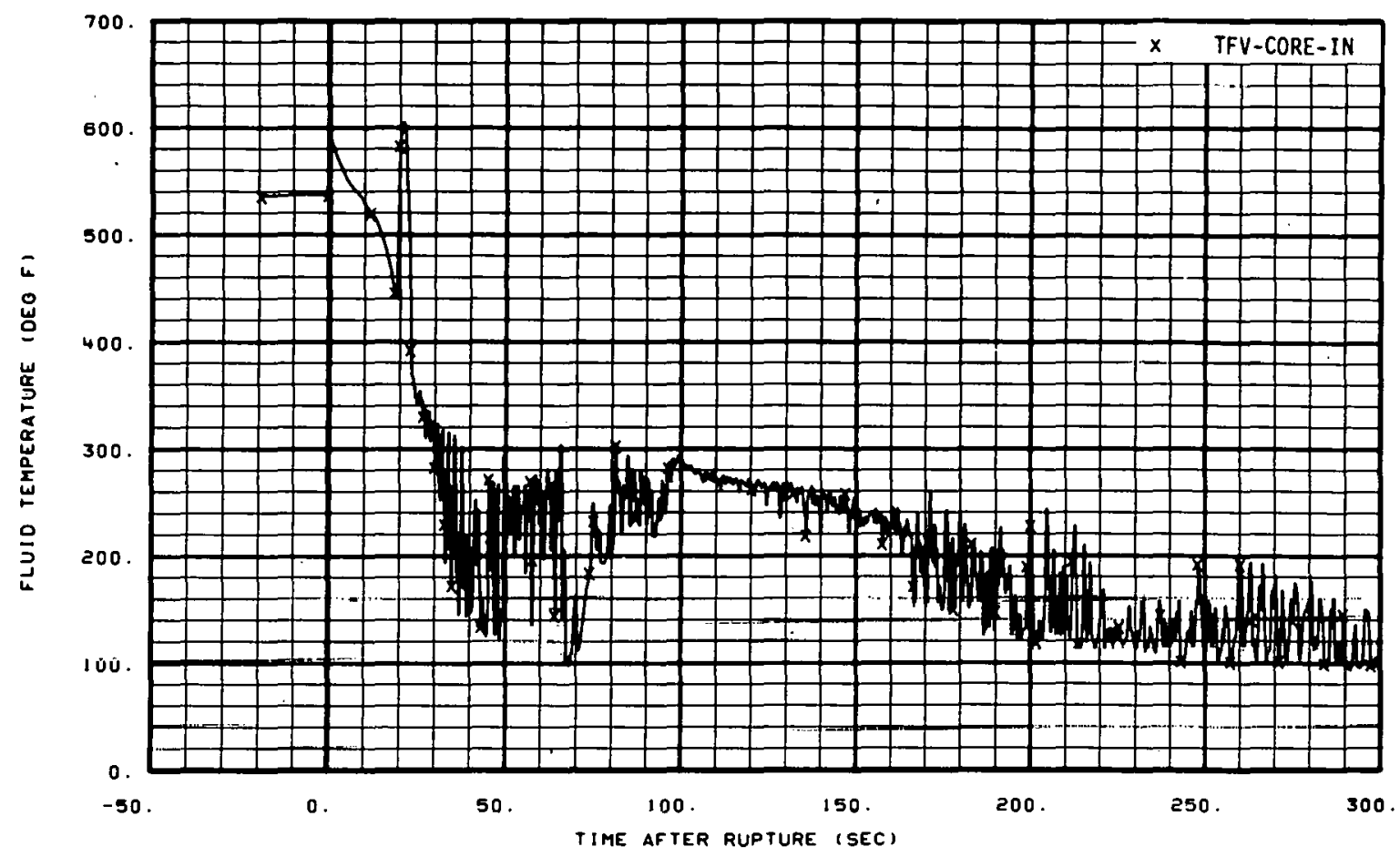

Fig. 25 Fluid temperature in core inlet (TFV-CORE-IN), from -20 to 300 seconds.

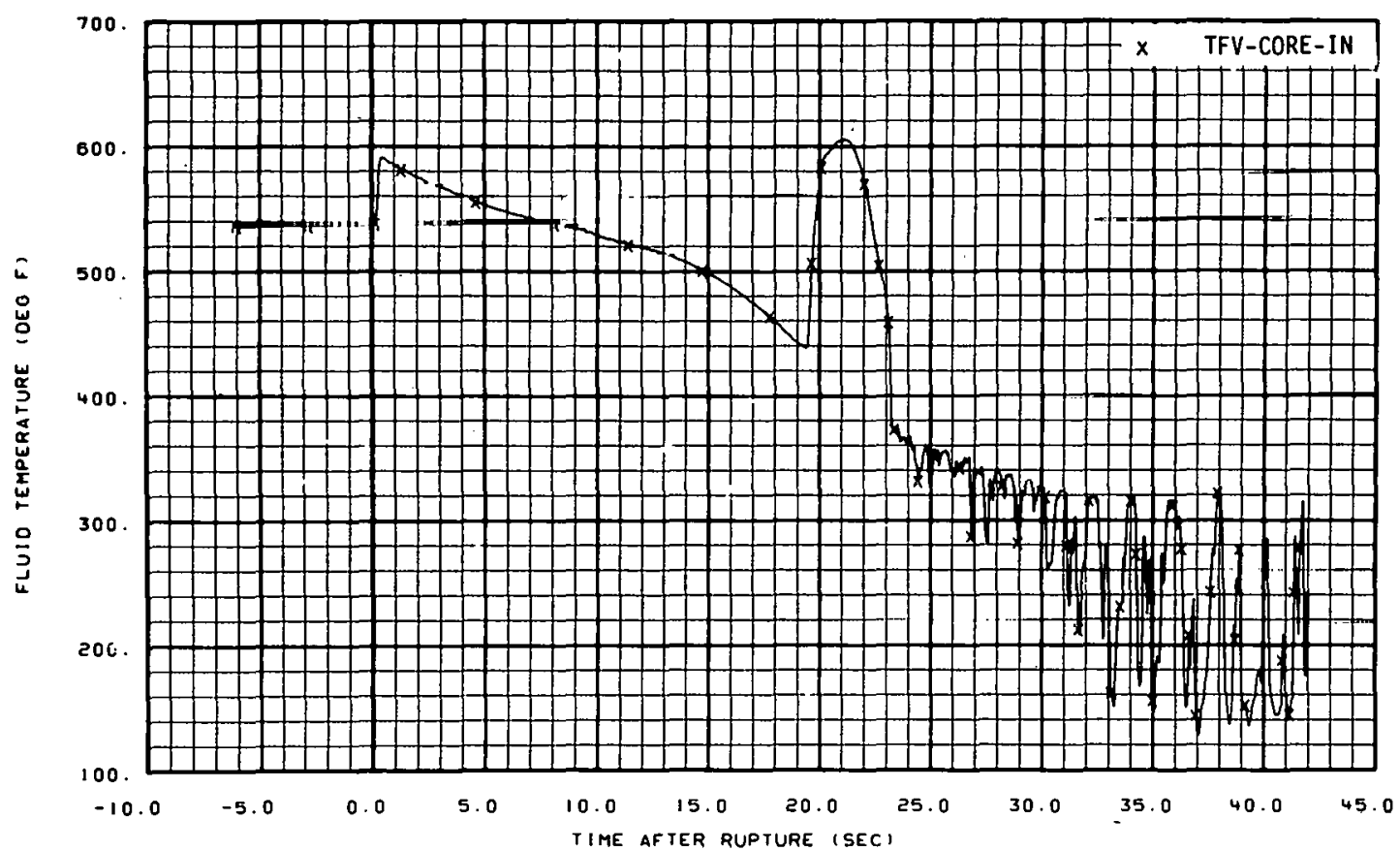

Fig. 26 Fluid temperature in core inlet (TFV-CORE-IN), from -6 to 42 seconds. 


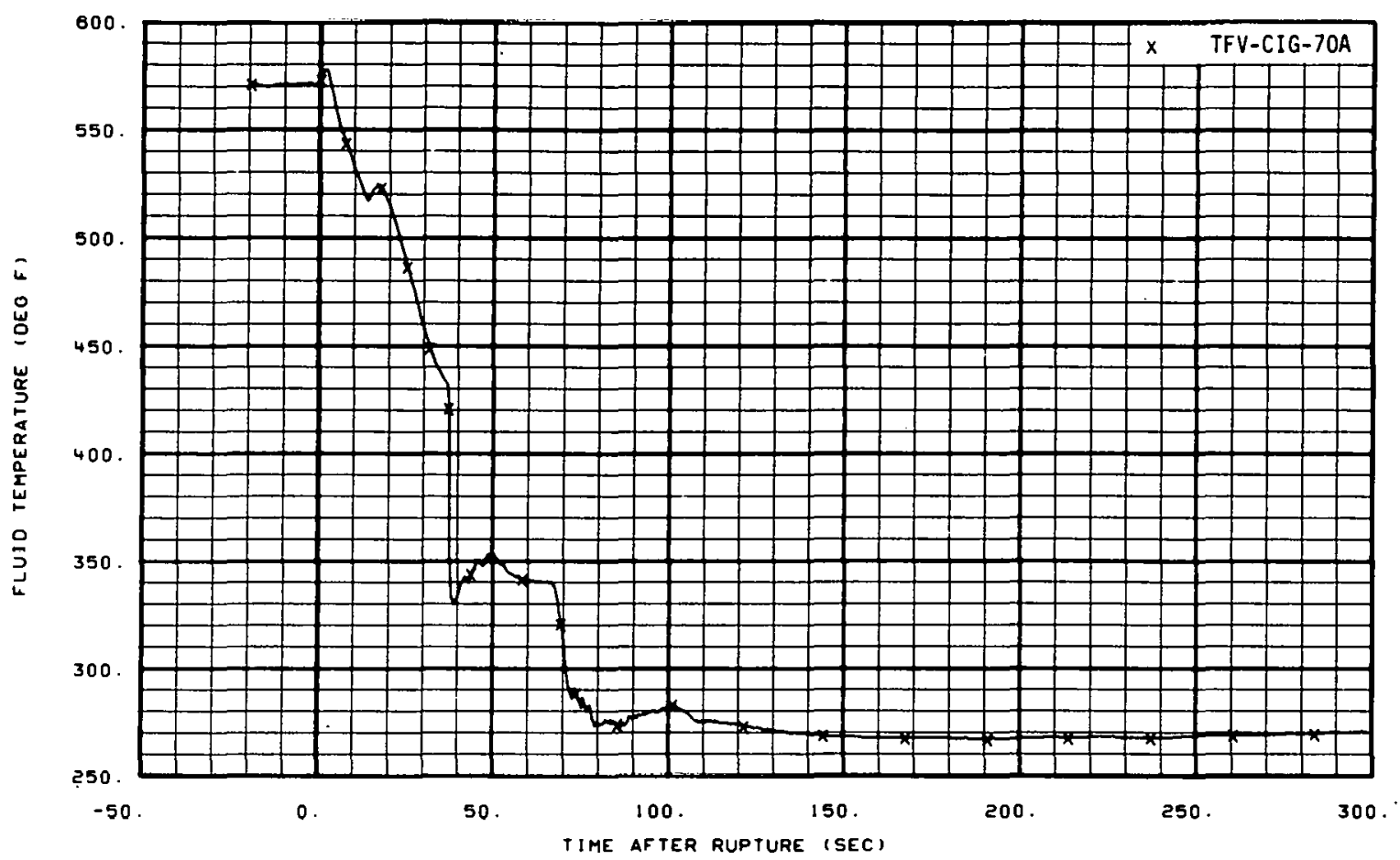

Fig. 27 Fluid temperature in core barrel insulation gap (TFV-CIG-70A), from -20 to 300 seconds.

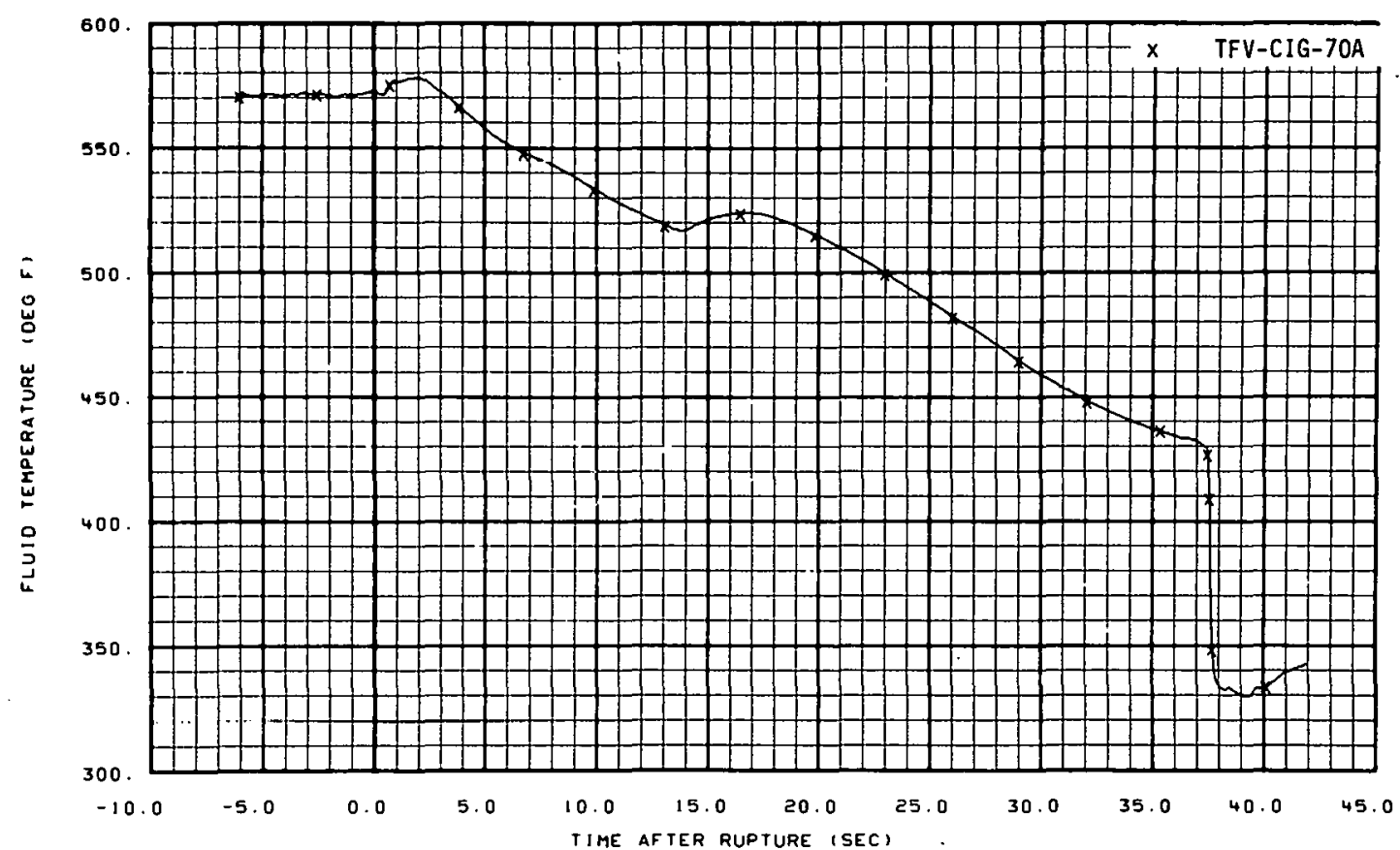

Fig. 28 Fluid temperature in core barrel insulation gap (TFV-CIG-70A), from -6 to 42 seconds. 


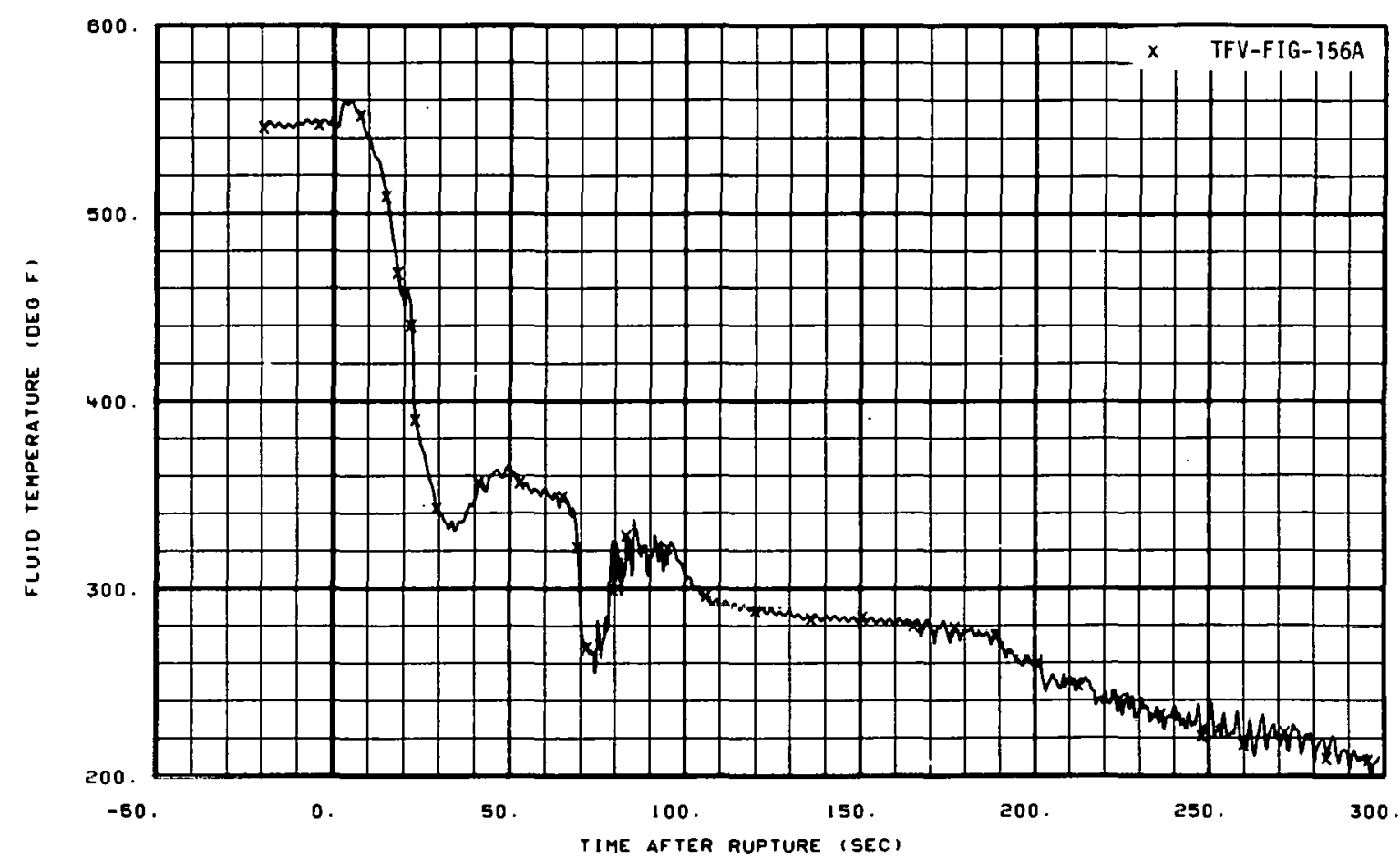

Fig. 29 Fluid temperature in vessel filler insulation gap (TFV-FIG-156A), from -20 to 300 seconds.

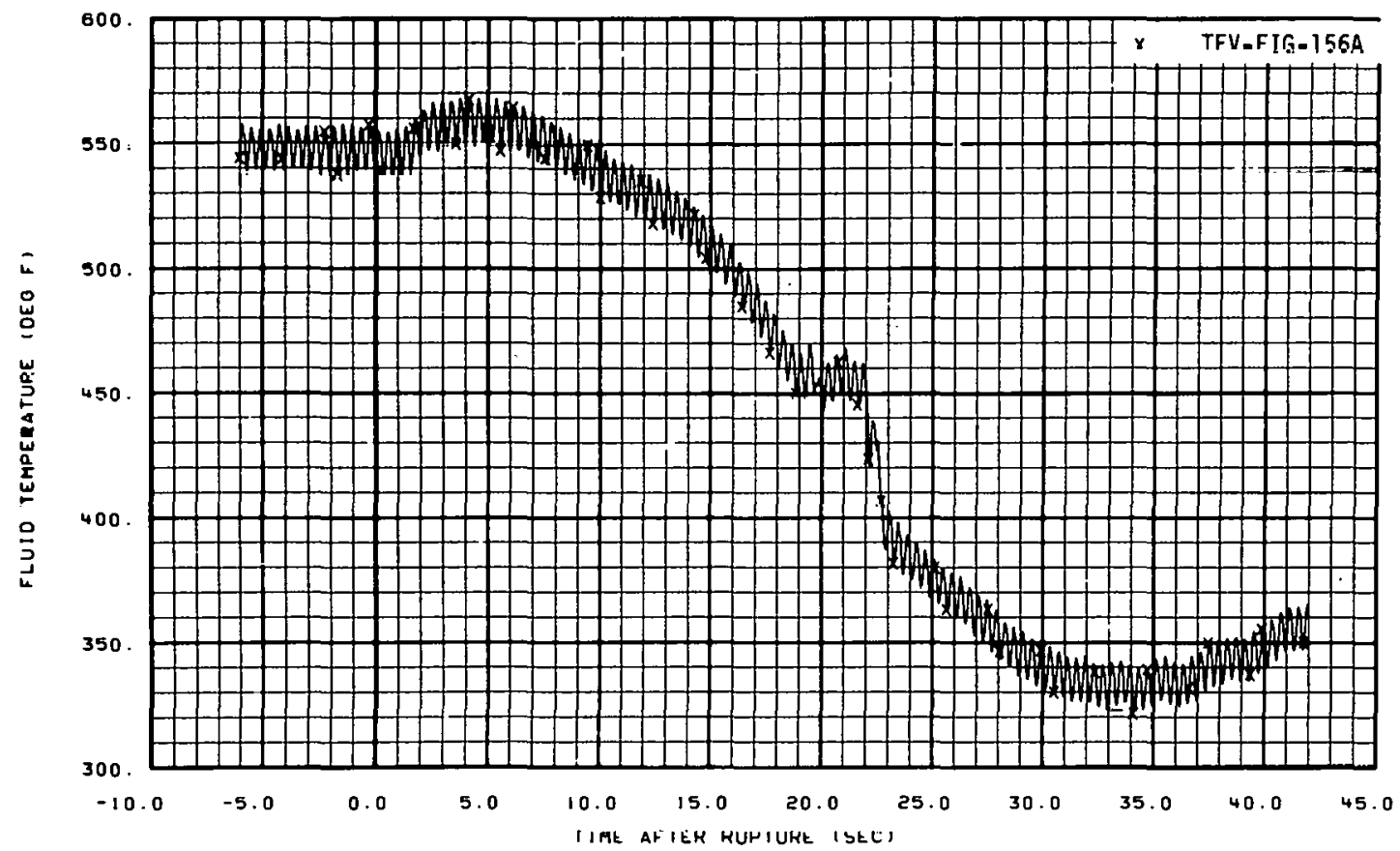

Fig. 30 Fluid temperature in vessel filler insulation gap (TFV-FIG-156A), from -6 to 42 seconds. 


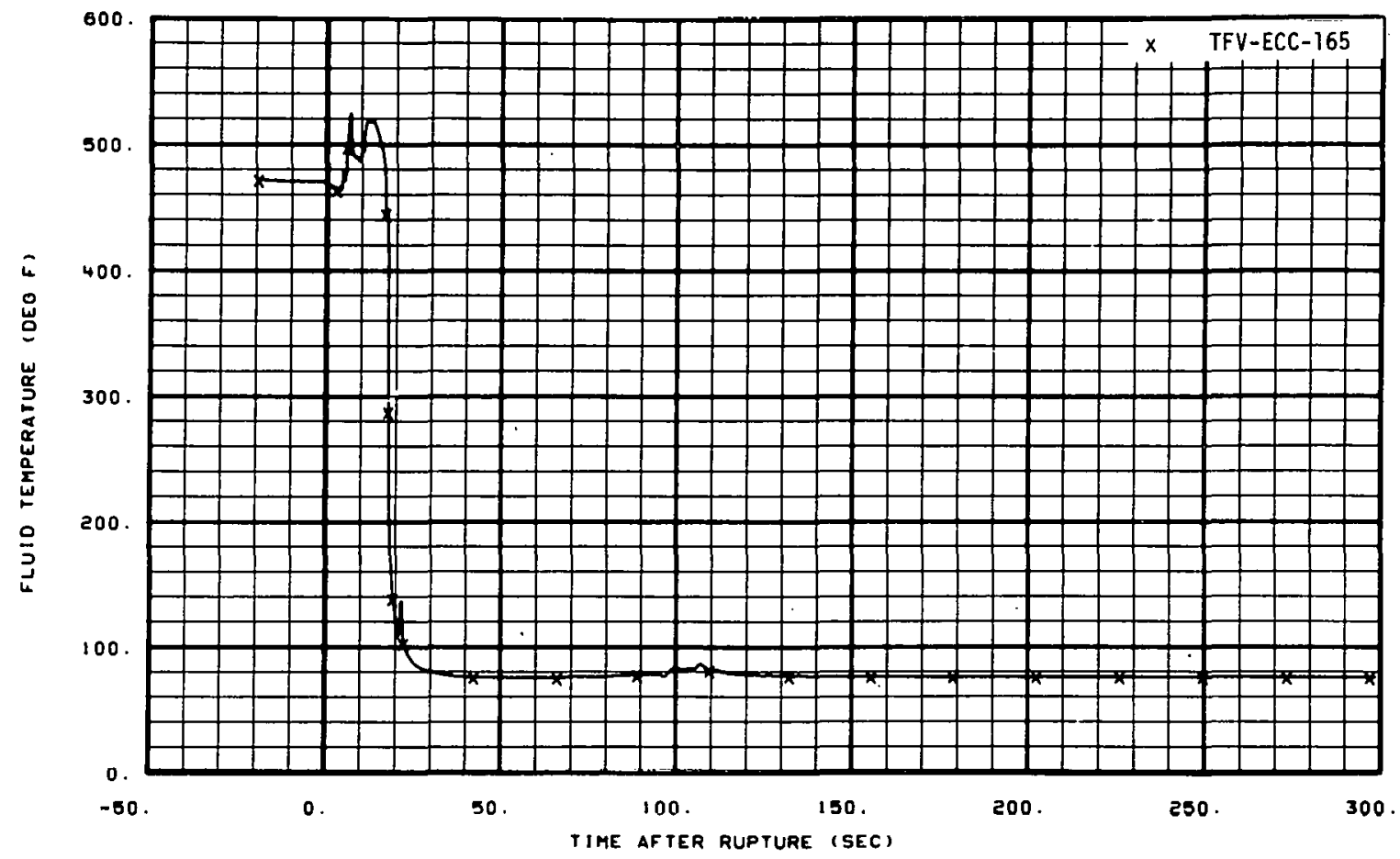

Fig. 31 Fluid temperature in lower plenum (TFV-ECC-165), from -20 to 300 seconds.

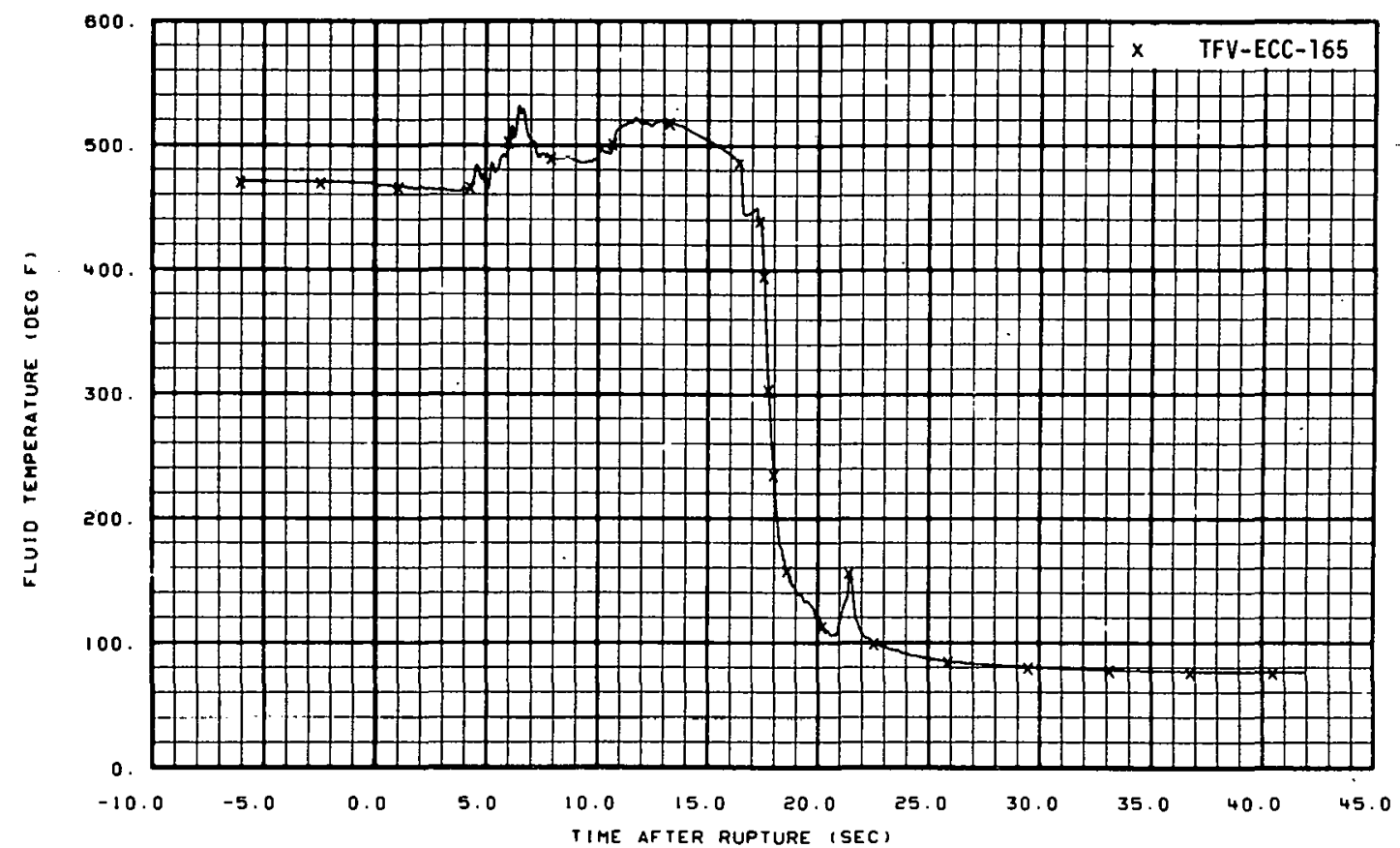

Fig. 32 Fluid temperature in lower plenum (TFV-ECC-165), from -6 to 42 seconds, 


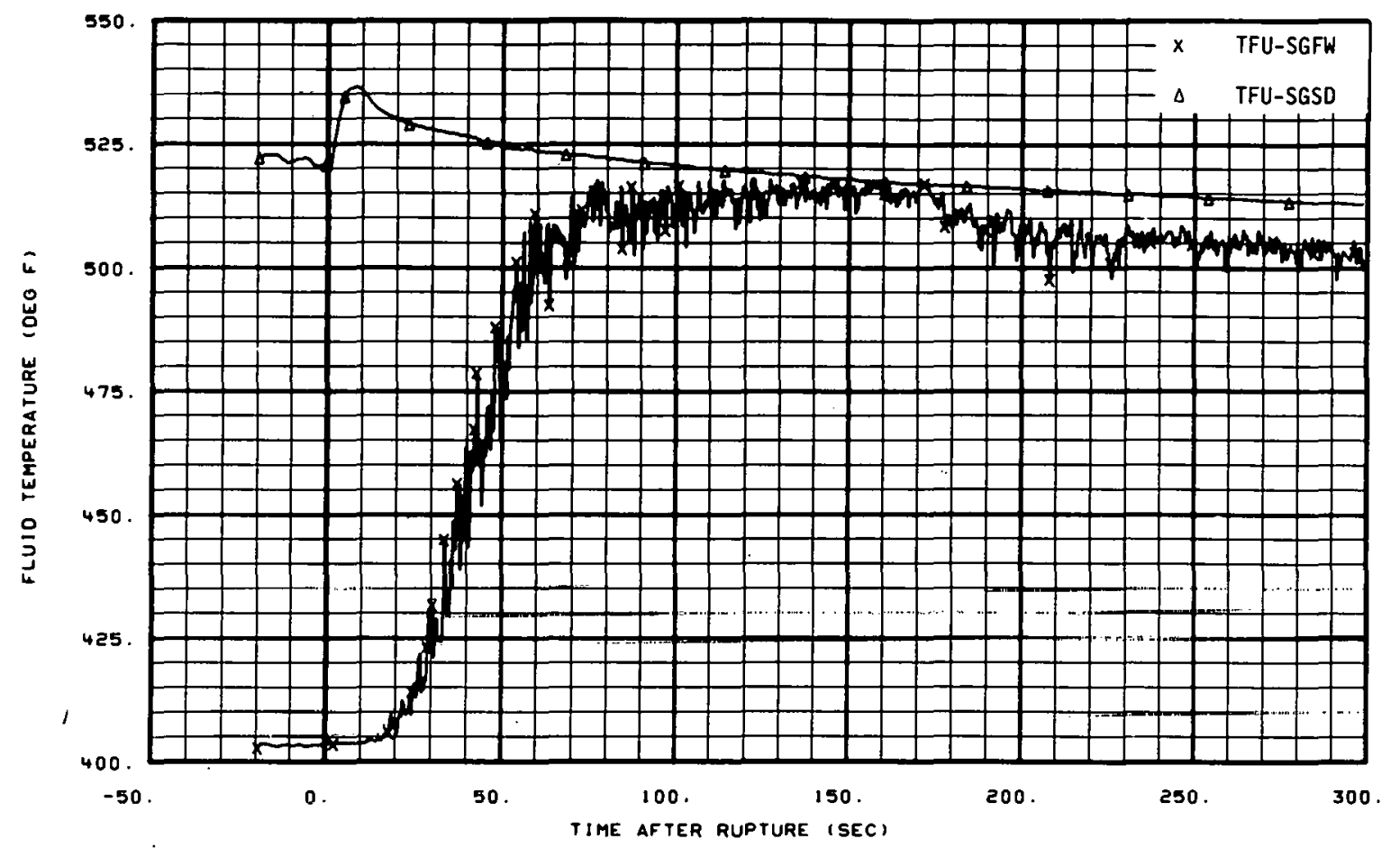

Fig. 33 Fluid temperature in steam generator (TFU-SGFW and TFU-SGSD), from -20 to 300 seconds.

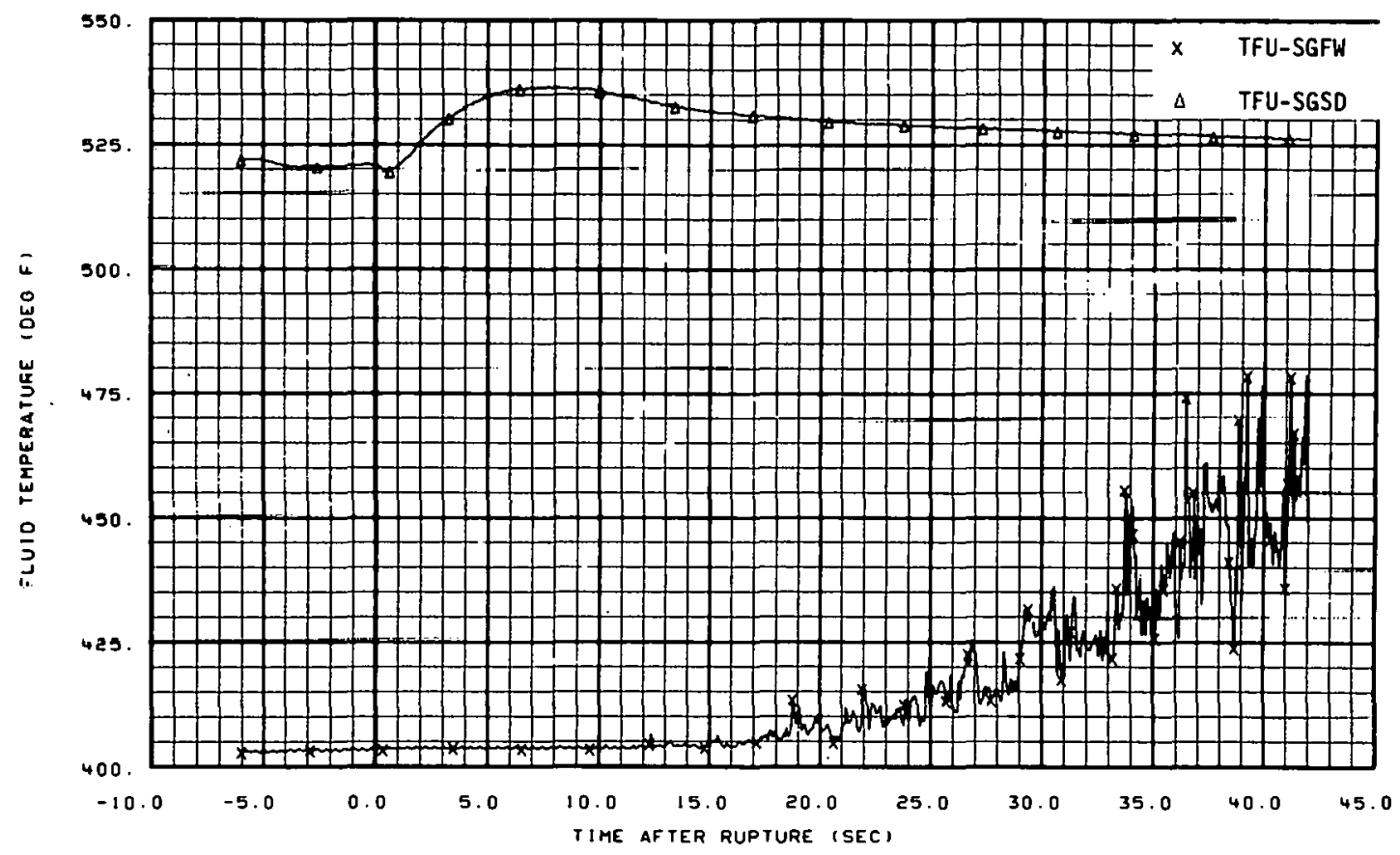

Fig. 34 Fluid temperature in steam generator (TFU-SGFW and TFU-SGSD), from -6 to 42 seconds. 


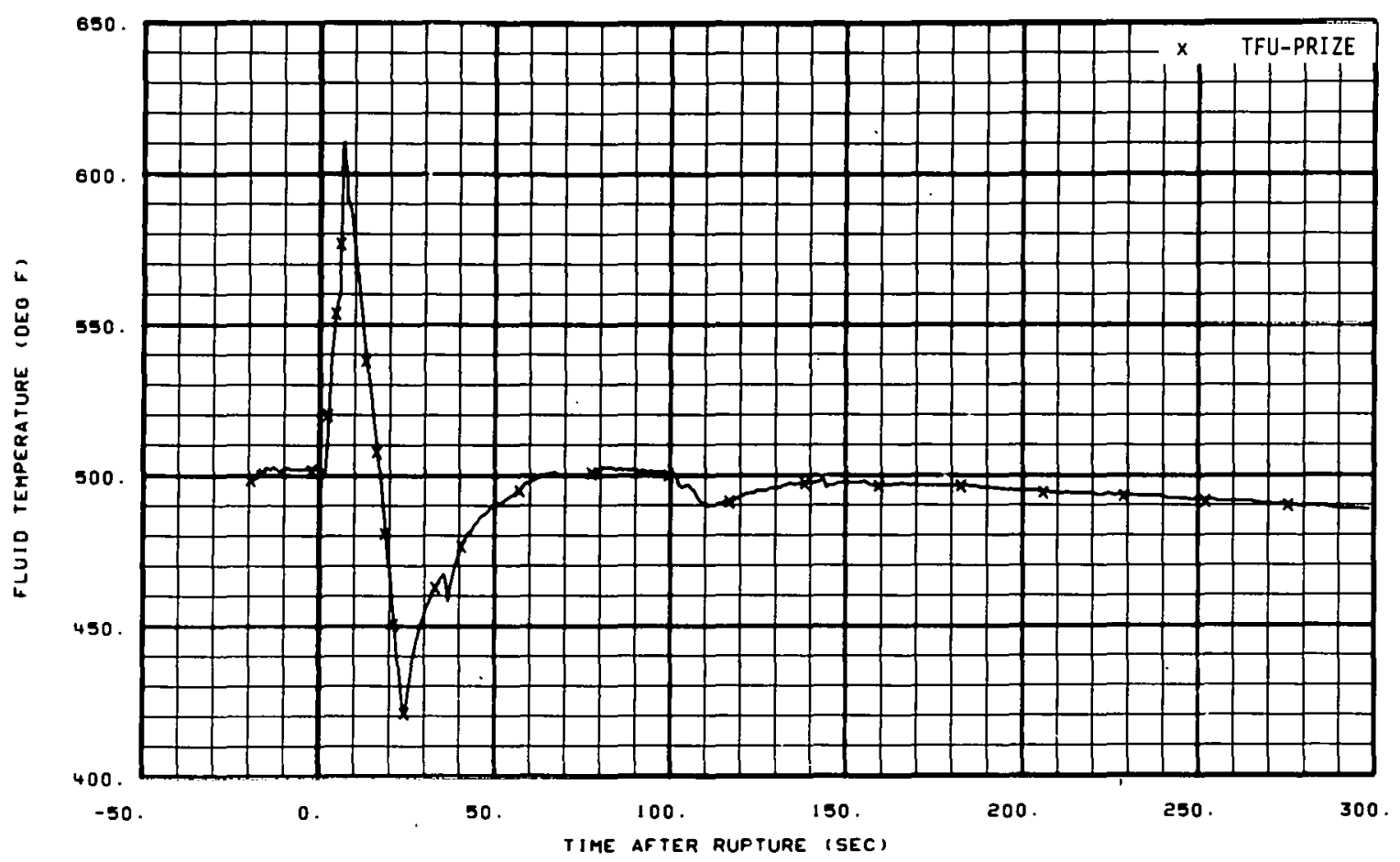

Fig. 35 Fluid temperature in pressurizer surge line (TFU-PRIZE), from -20 to 300 seconds.

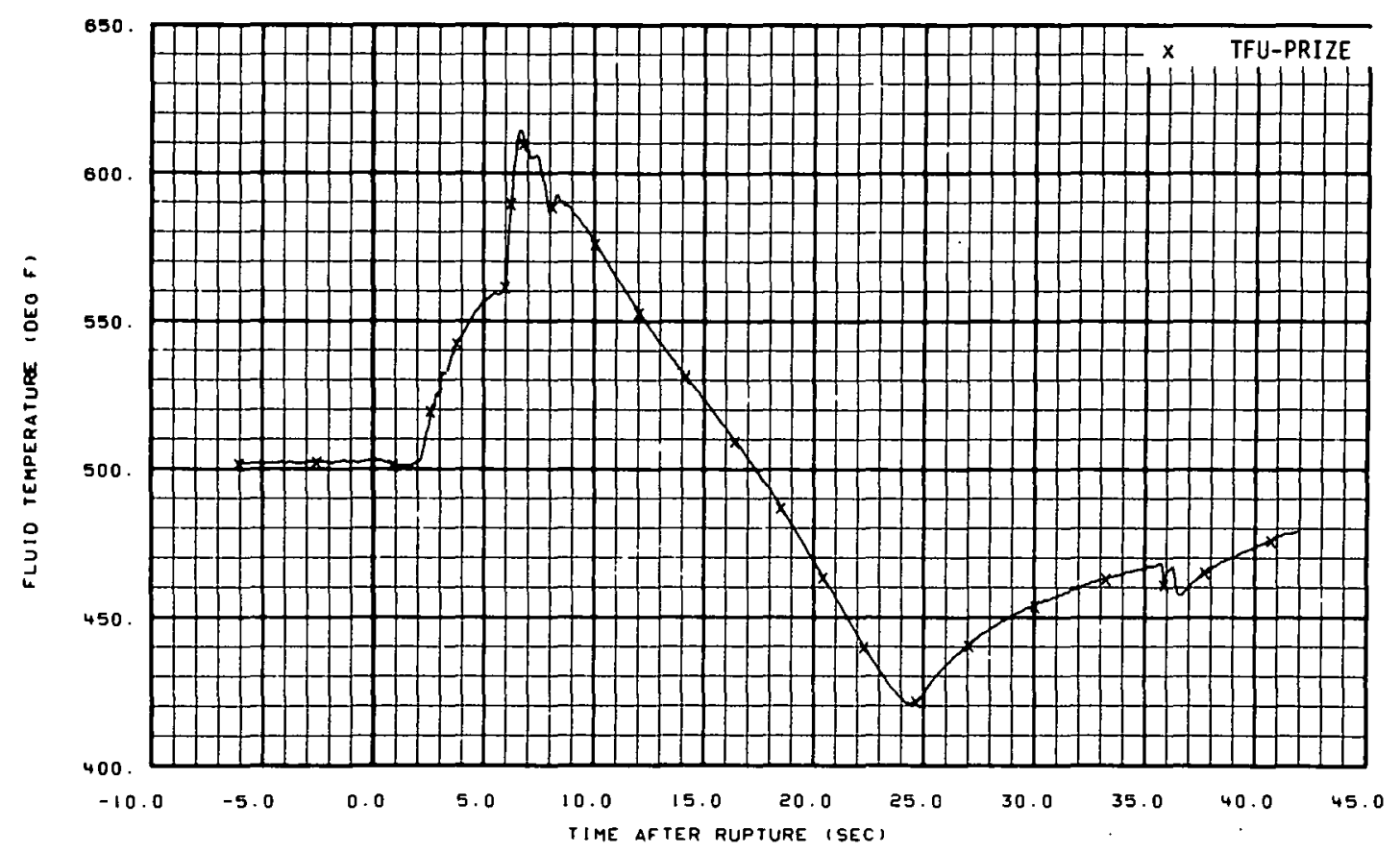

Fig. 36 Fluid temperature in pressurizer surge line (TFU-PRIZE), from -6 to 42 seconds. 


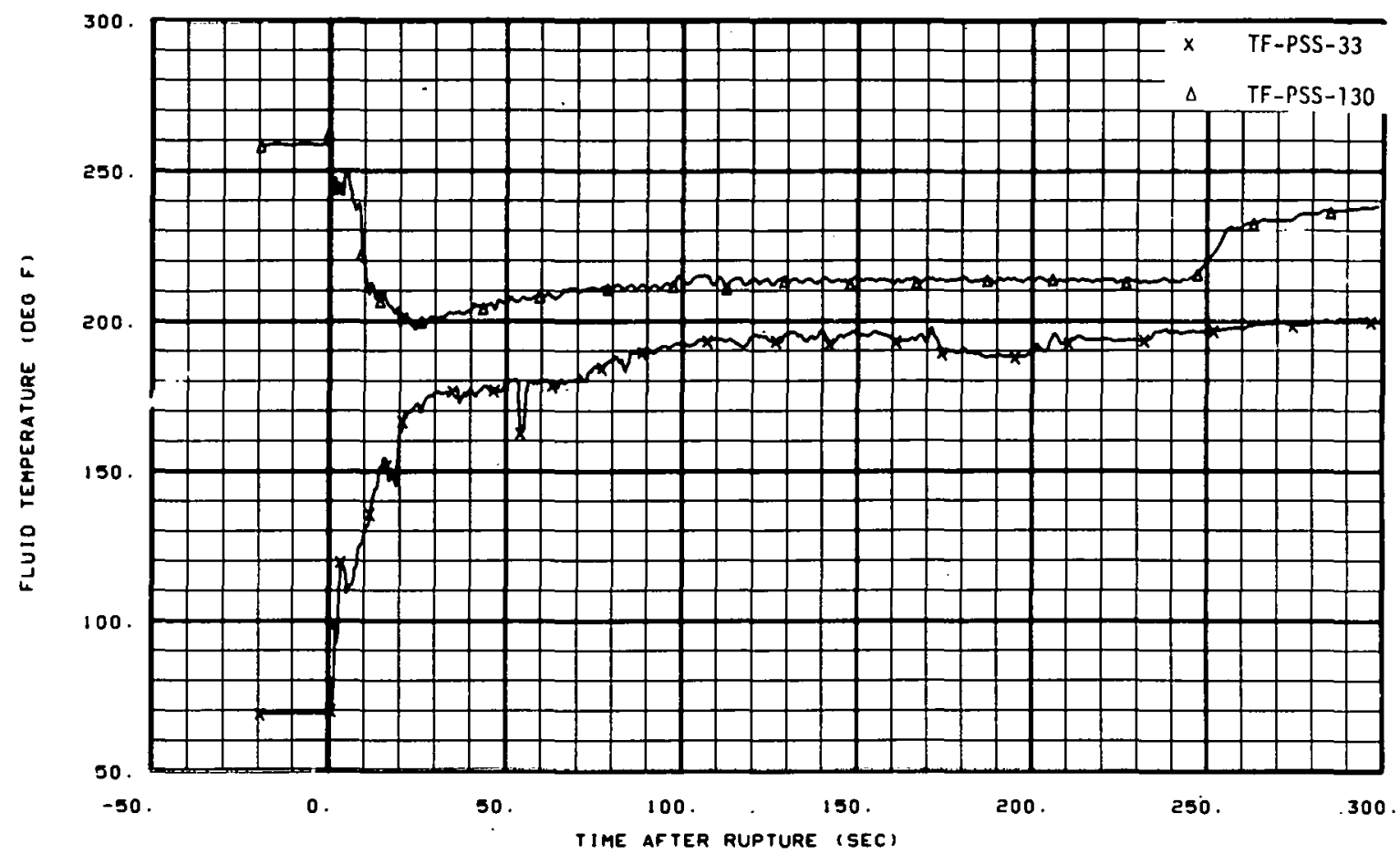

Fig. 37 Fluid temperature in pressure suppression tank (TF-PSS-33 and TF-PSS-130), from -20 to 300 seconds.

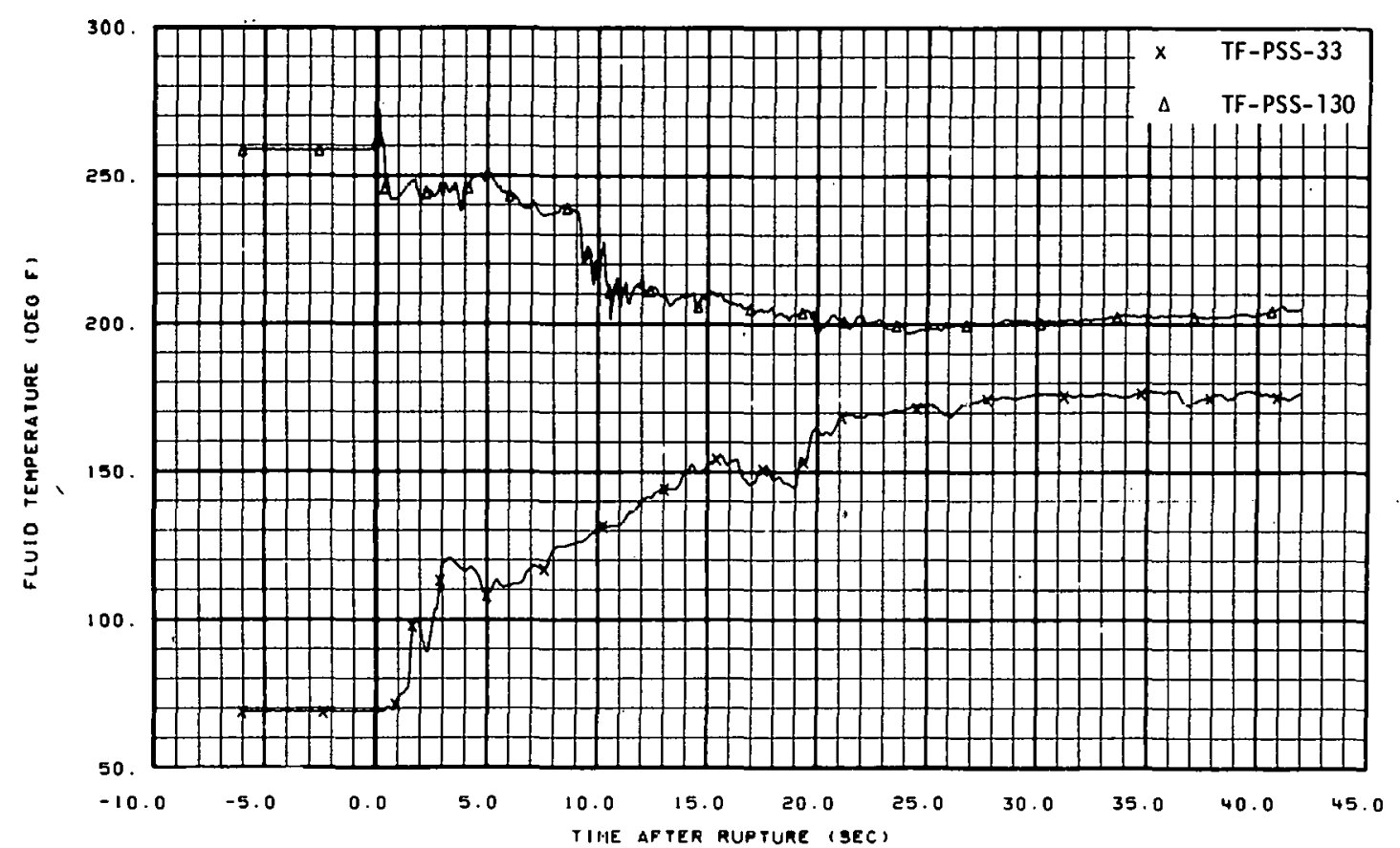

Fig. 38 Fluid temperature in pressure suppression tank (TF-PSS-33 and TF-PSS-130), from -6 to 42 seconds. 


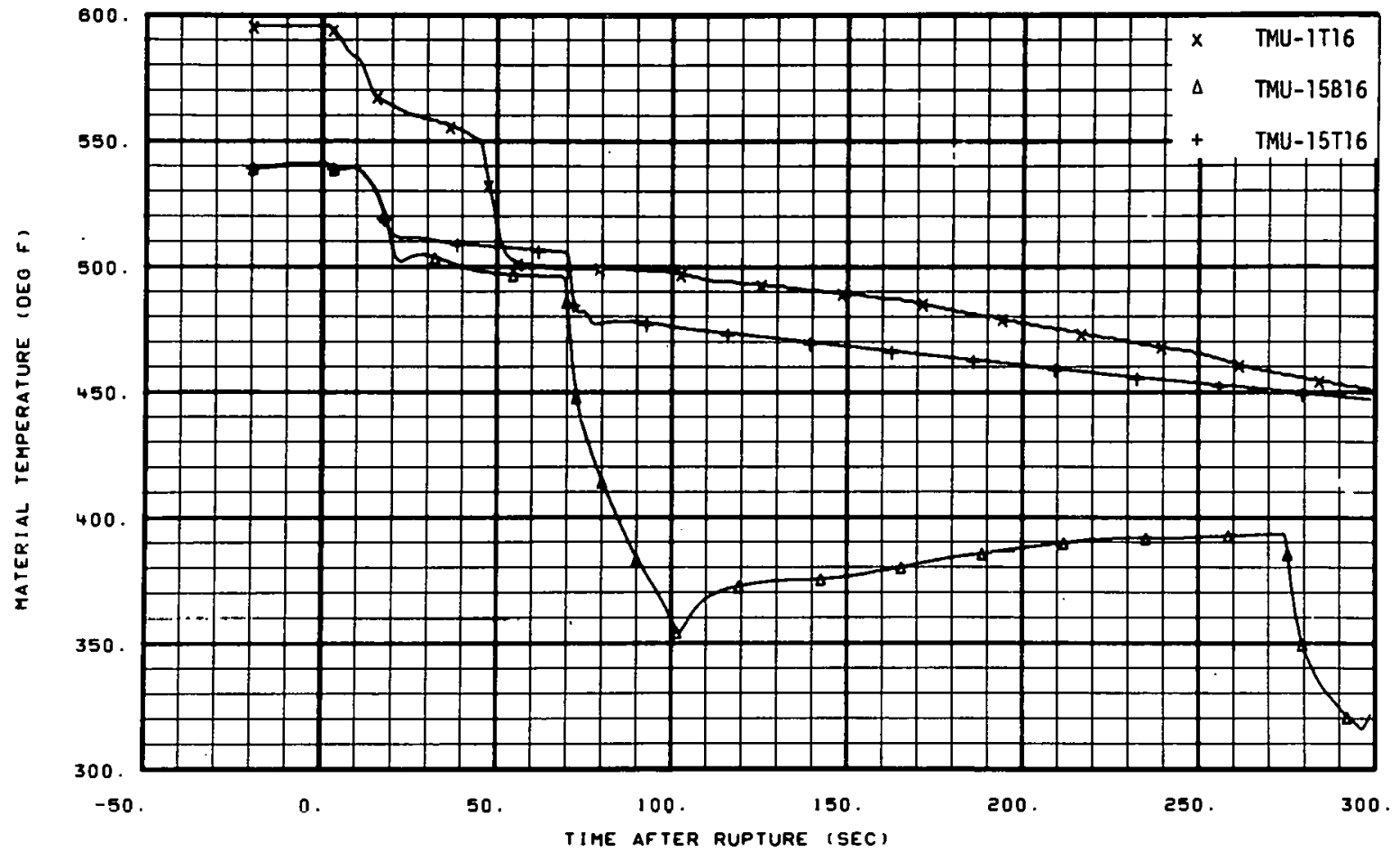

Fig. 39 Material temperature in intact loop (TMU-1T16, TMU-15B16, TMU-15T16), from -20 to 300 seconds.

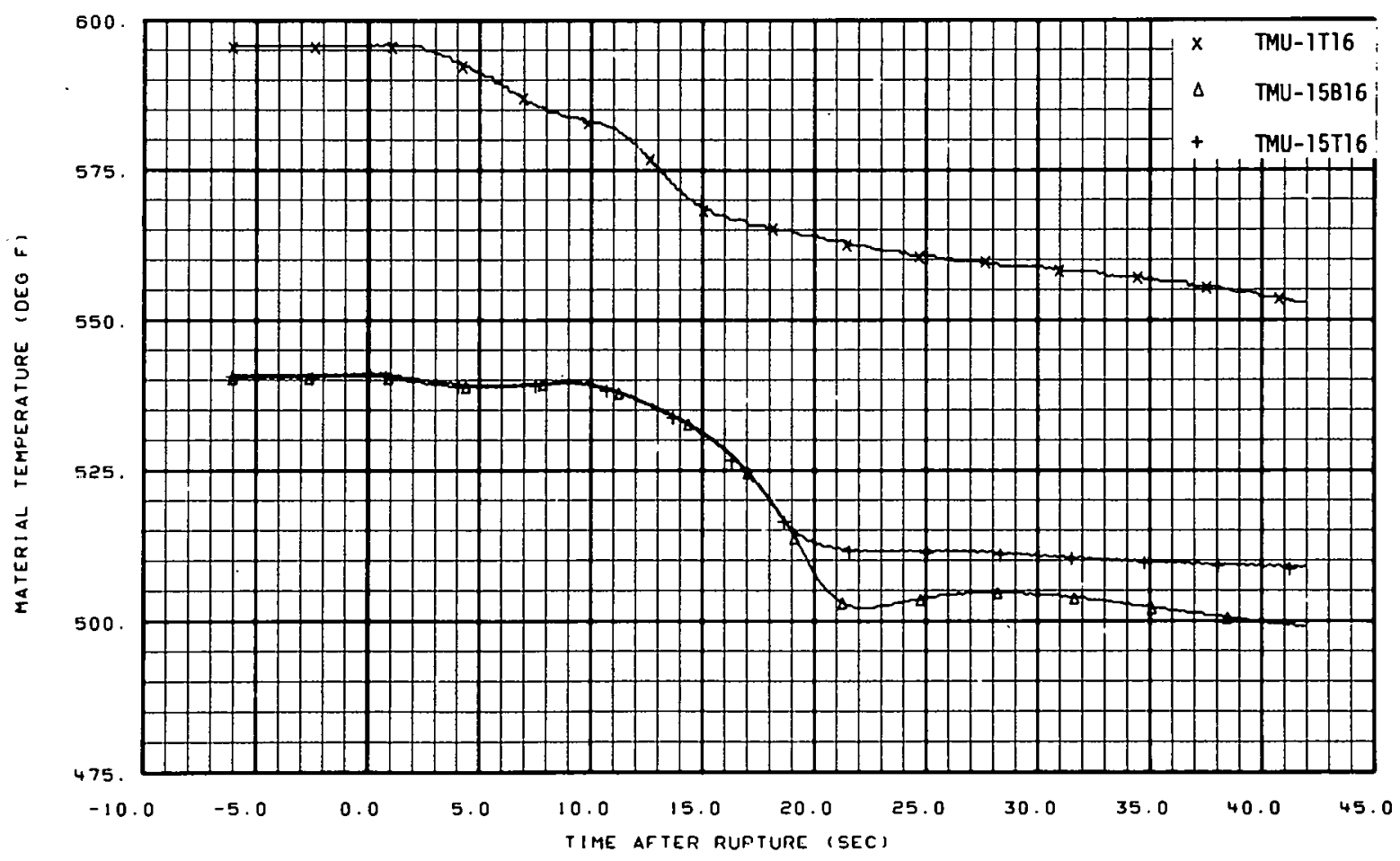

Fig. 40 Material temperature in intact loop (TMU-1T16, TMU-15B16, TMU-15T16), from -6 to 42 seconds. 


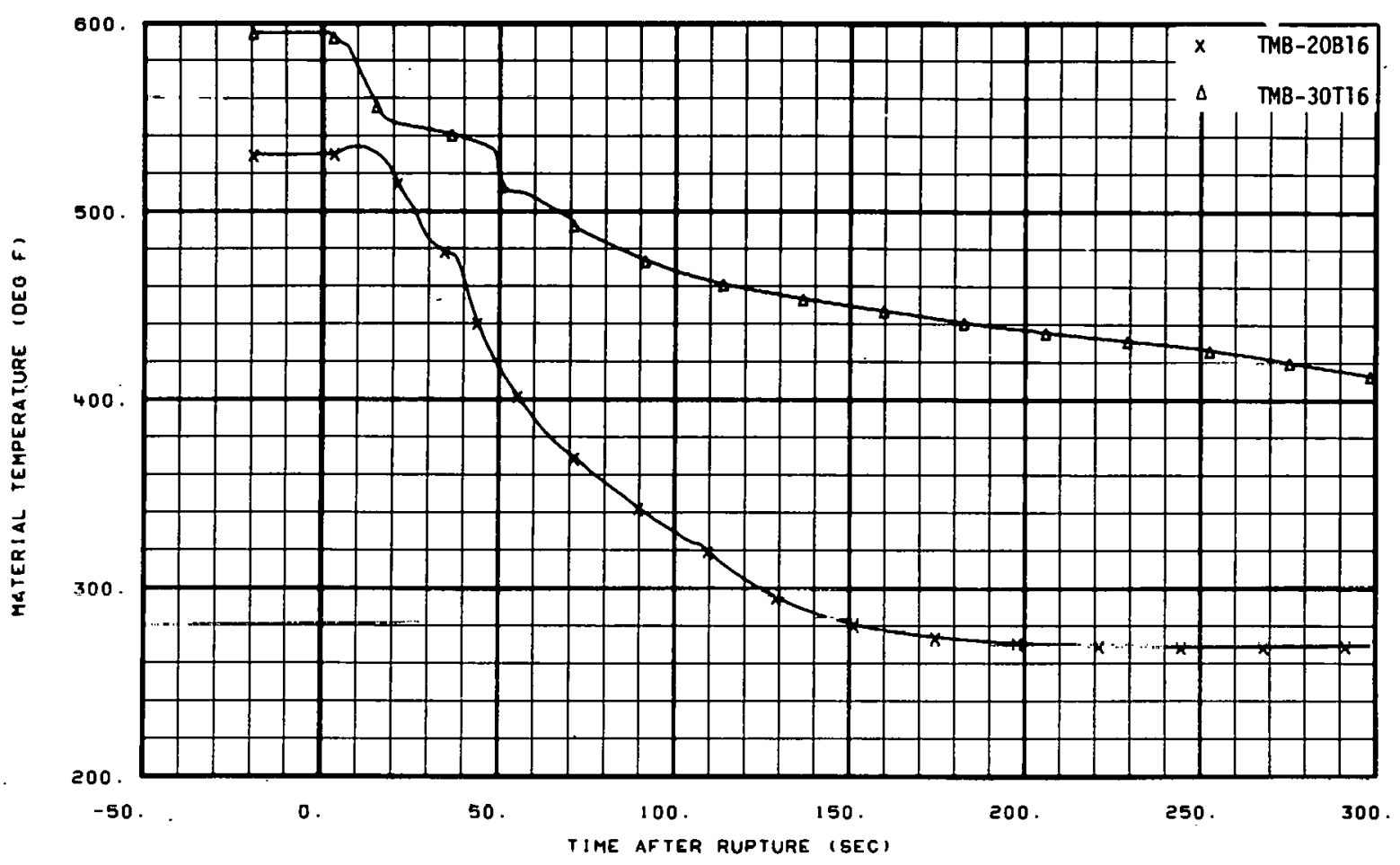

Fig. 41 Material temperature in broken loop (TMB-20B16 and TMB-30T16), from -20 to 300 seconds.

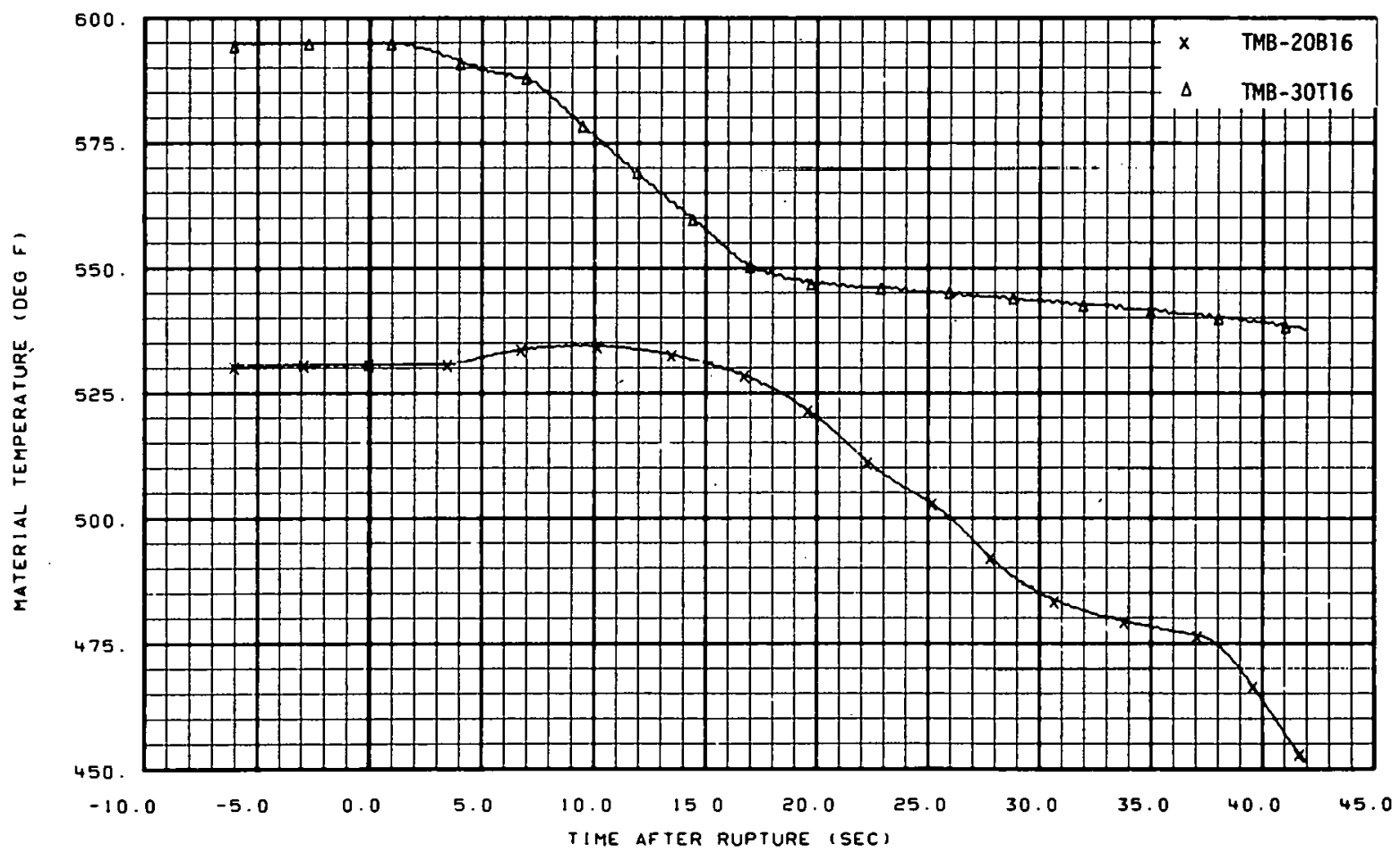

Fig. 42 Material temperature in broken loop (TMB-20B16 and TMB-30T16), from -6 to 42 seconds. 


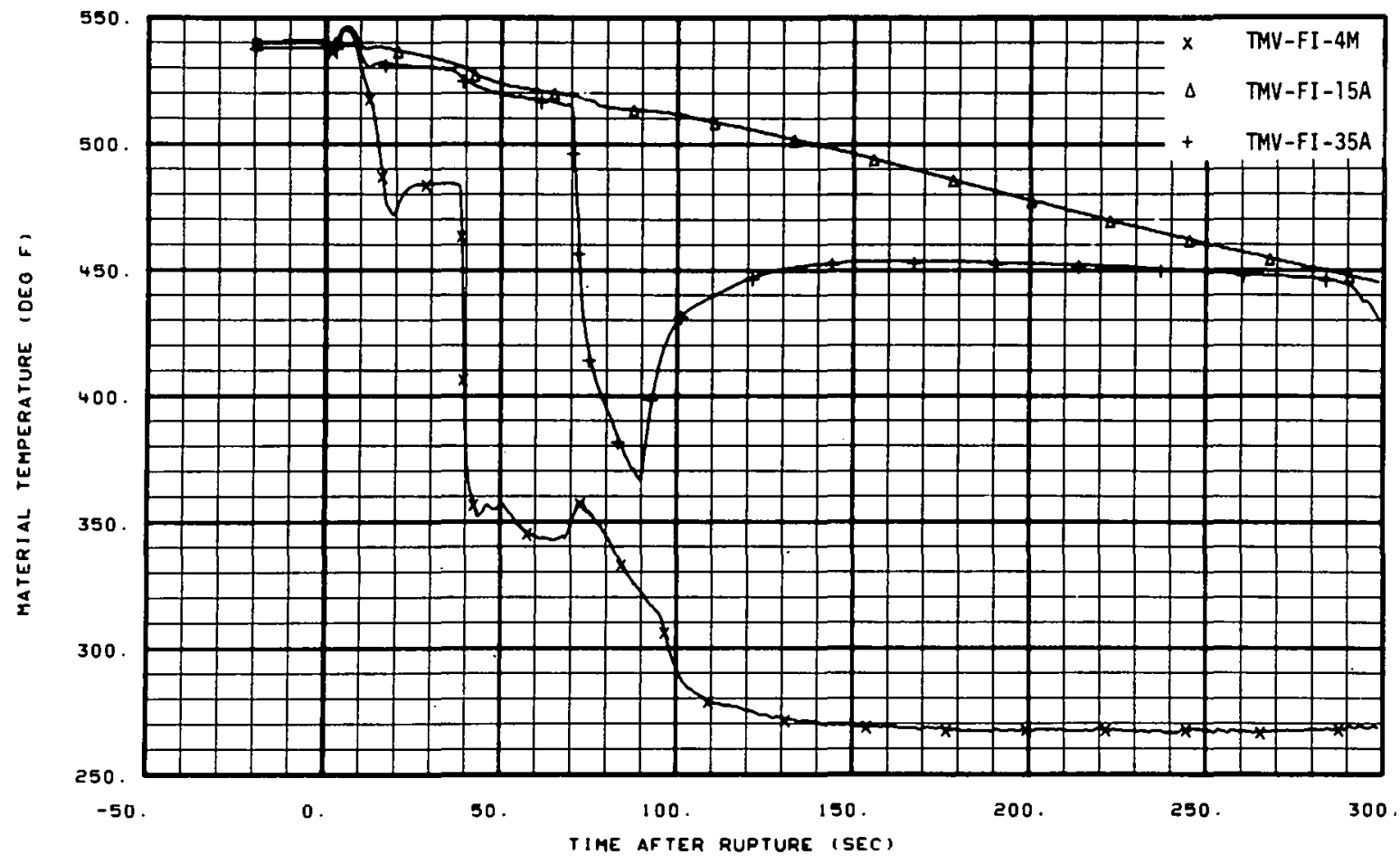

Fig. 43 Material temperature in vessel filler (TMV-FI-4M, TMV-FI-15A, and TMV-FI-35A), from -20 to 300 seconds.

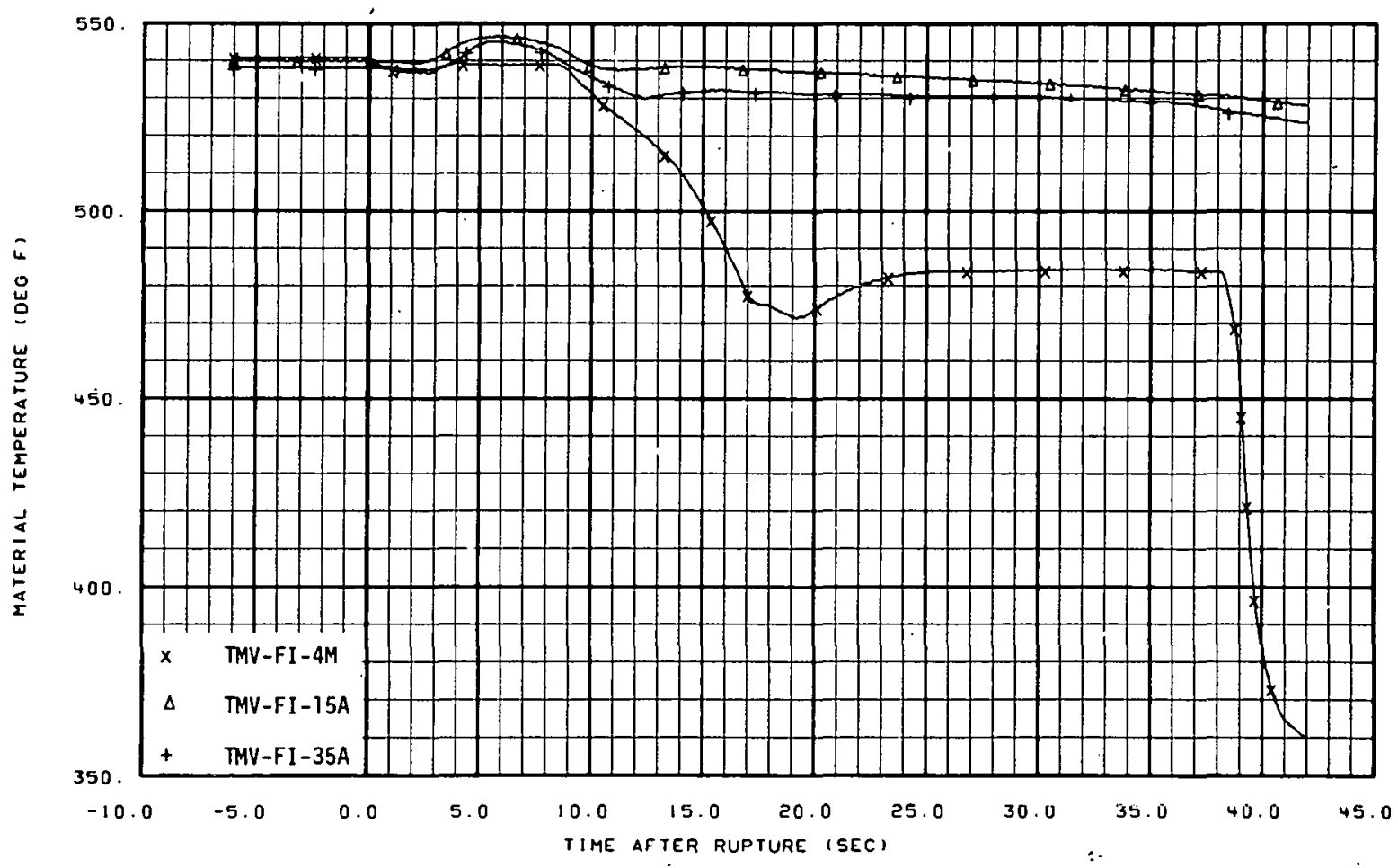

Fig. 44 Material temperature in vessel filler (TMV-FI-4M, TIMV-FI-15A, and TMV-FI-35A), from -6 to 42 seconds. 


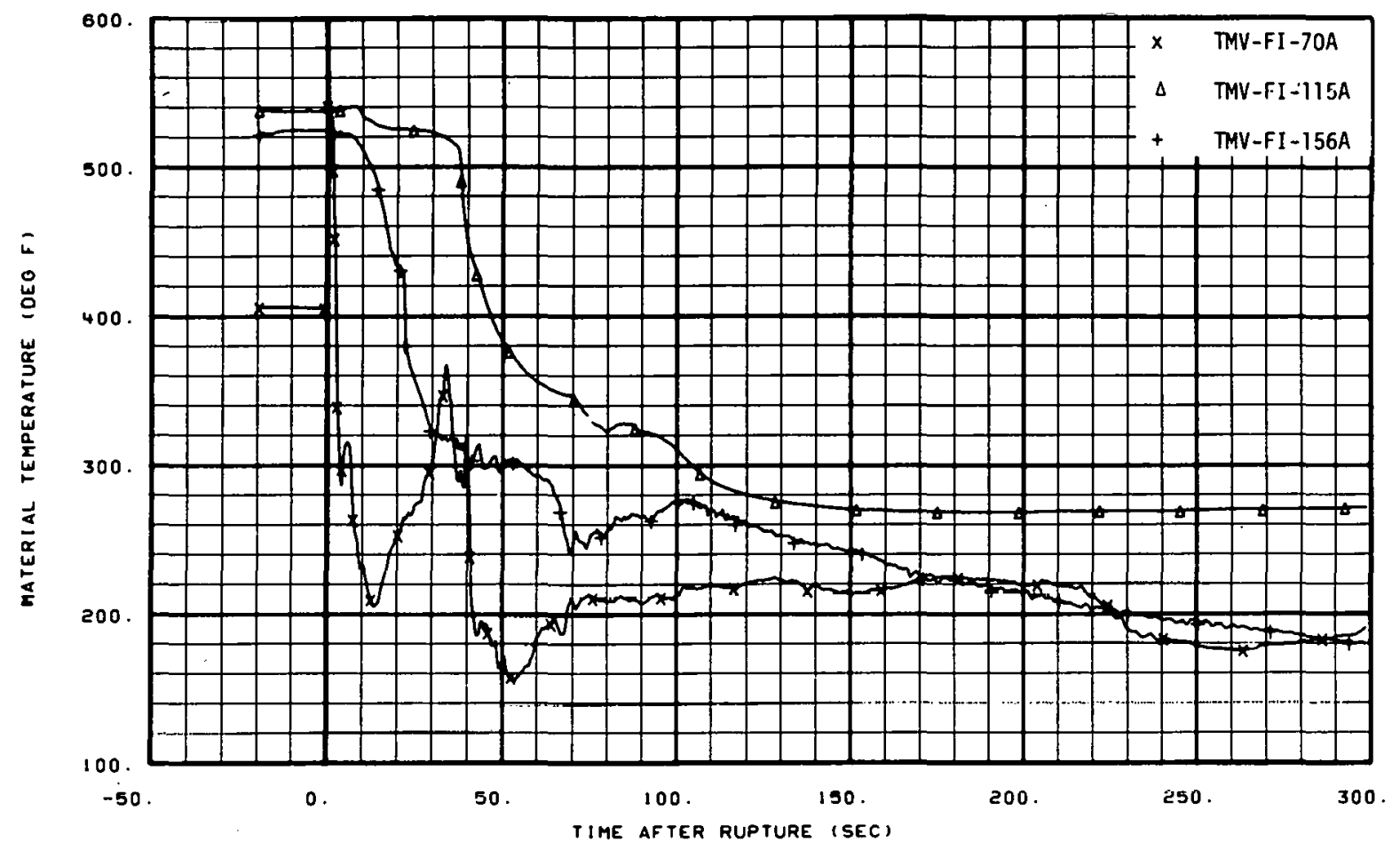

Fig. 45 Material temperature in vessel filler (TMV-FI-70A, TMV-FI-115A, and TMV-FI-156A), from -20 to 300 seconds.

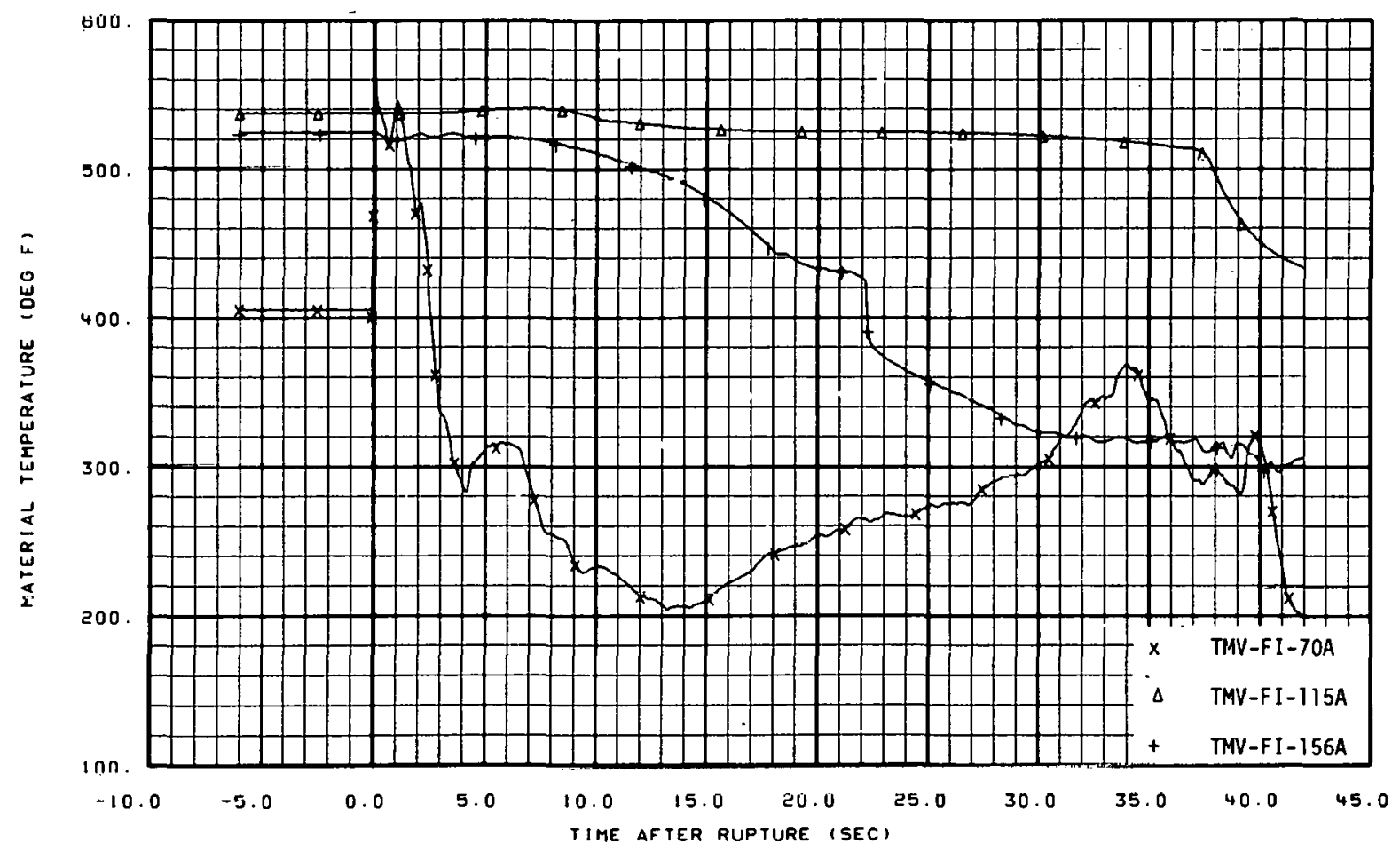

Fig. 46 Material tempèrature in vessel filler (TMV-FI-70A, TMV-FI-115A, and TMV-FI-156A), from -6 to 42 seconds. 


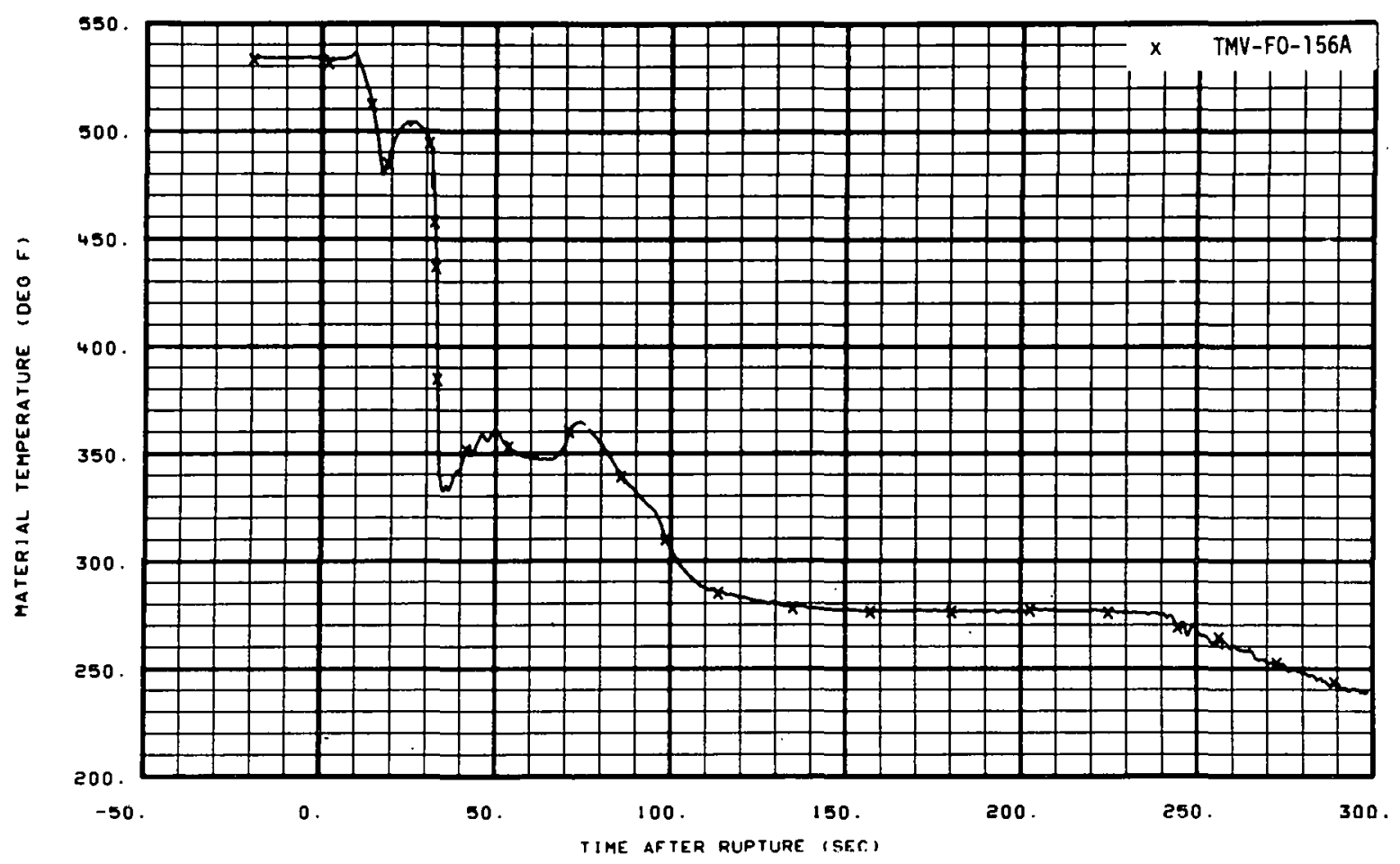

Fig. 47 Material temperature in vessel filler (TMV-F0-156A), from -20 to 300 seconds.

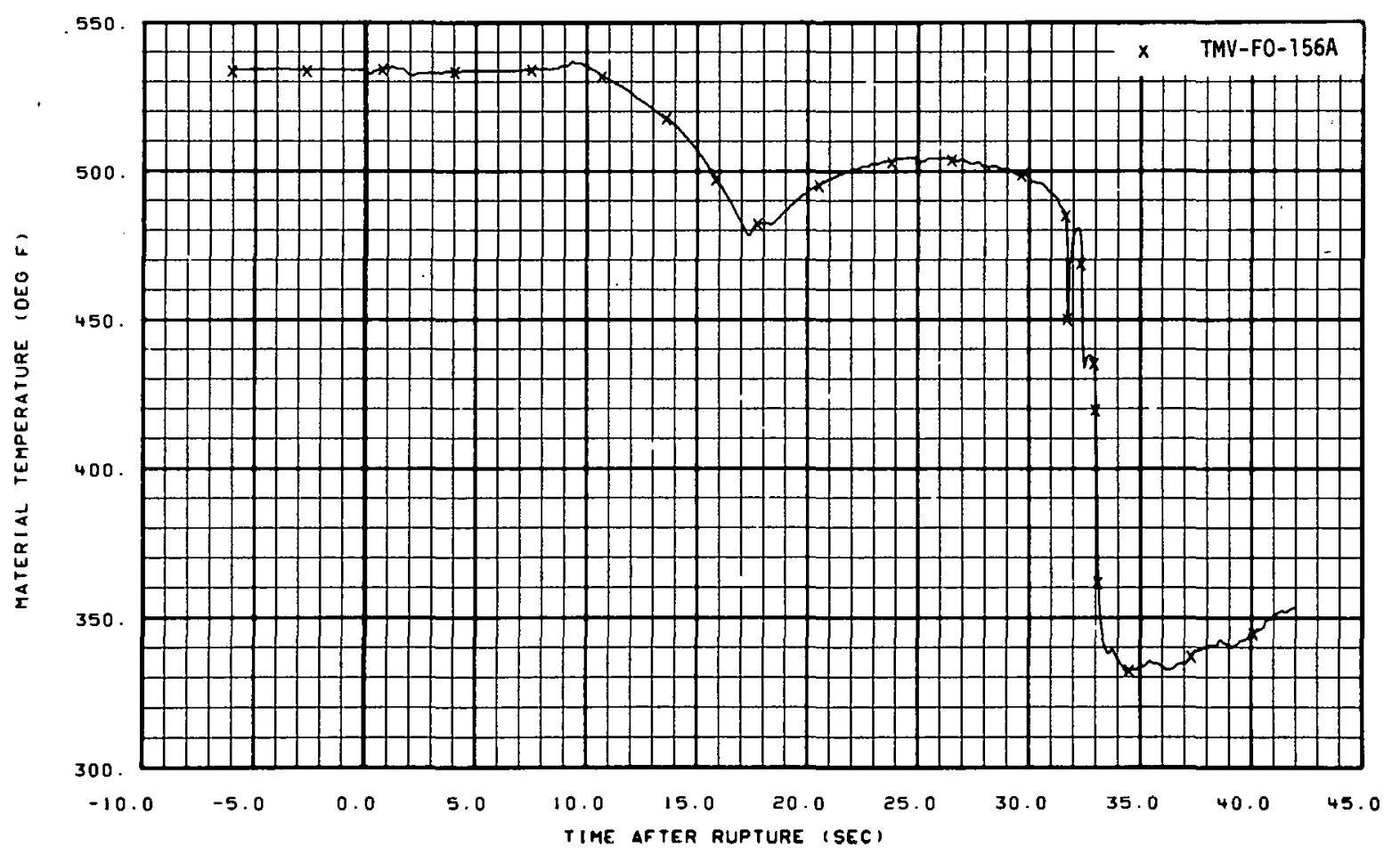

Fig, 48 Material temperature in vessel filler (TMV-F0-156A), from -6 to 42 seconds. 


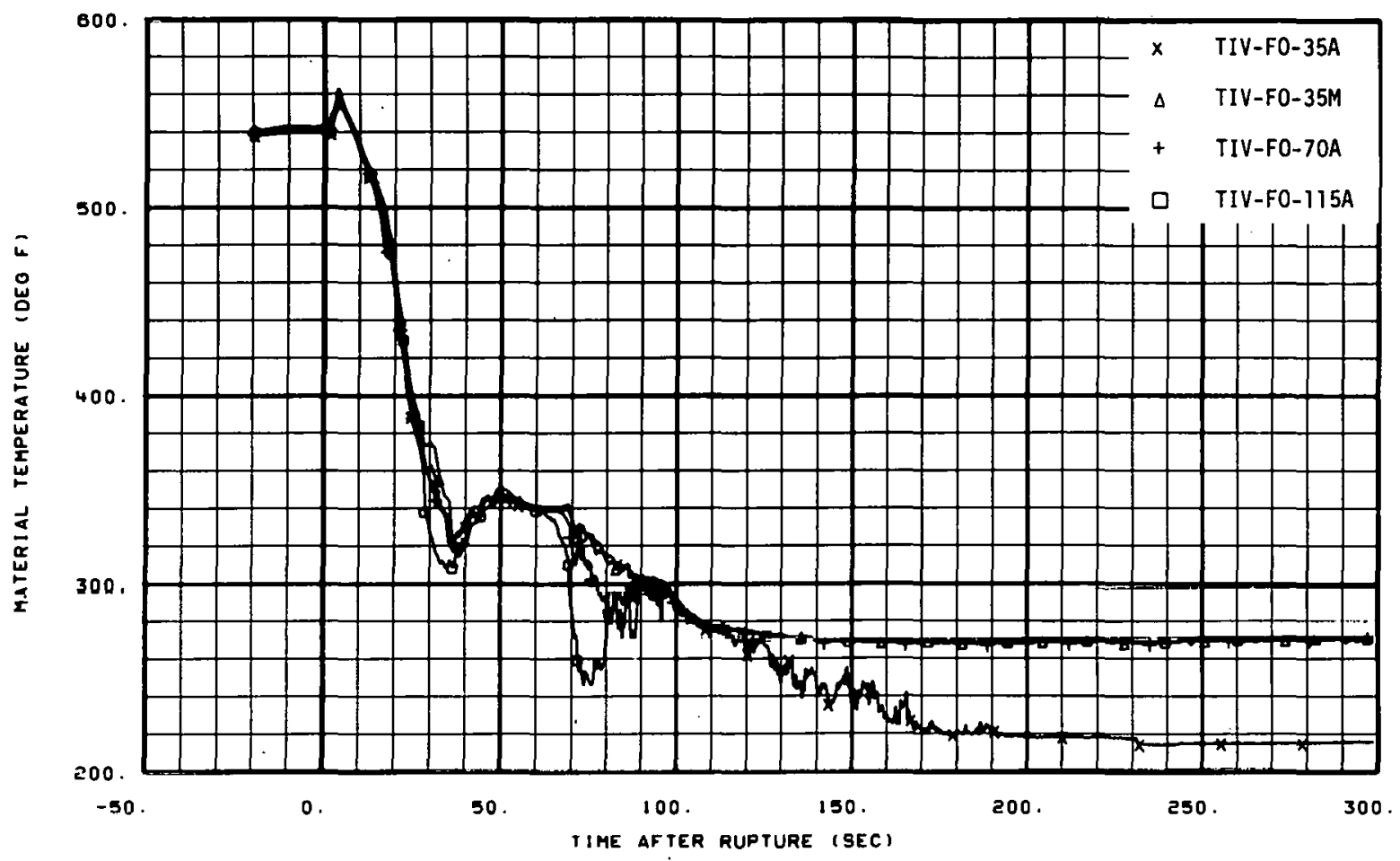

Fig. 49 Material temperature in vessel filler insulator (TIV-F0-35A, TIV-F0-35I, TIV-FO-70A, and TIV-F0-115A), from -20 to 300 seconds.

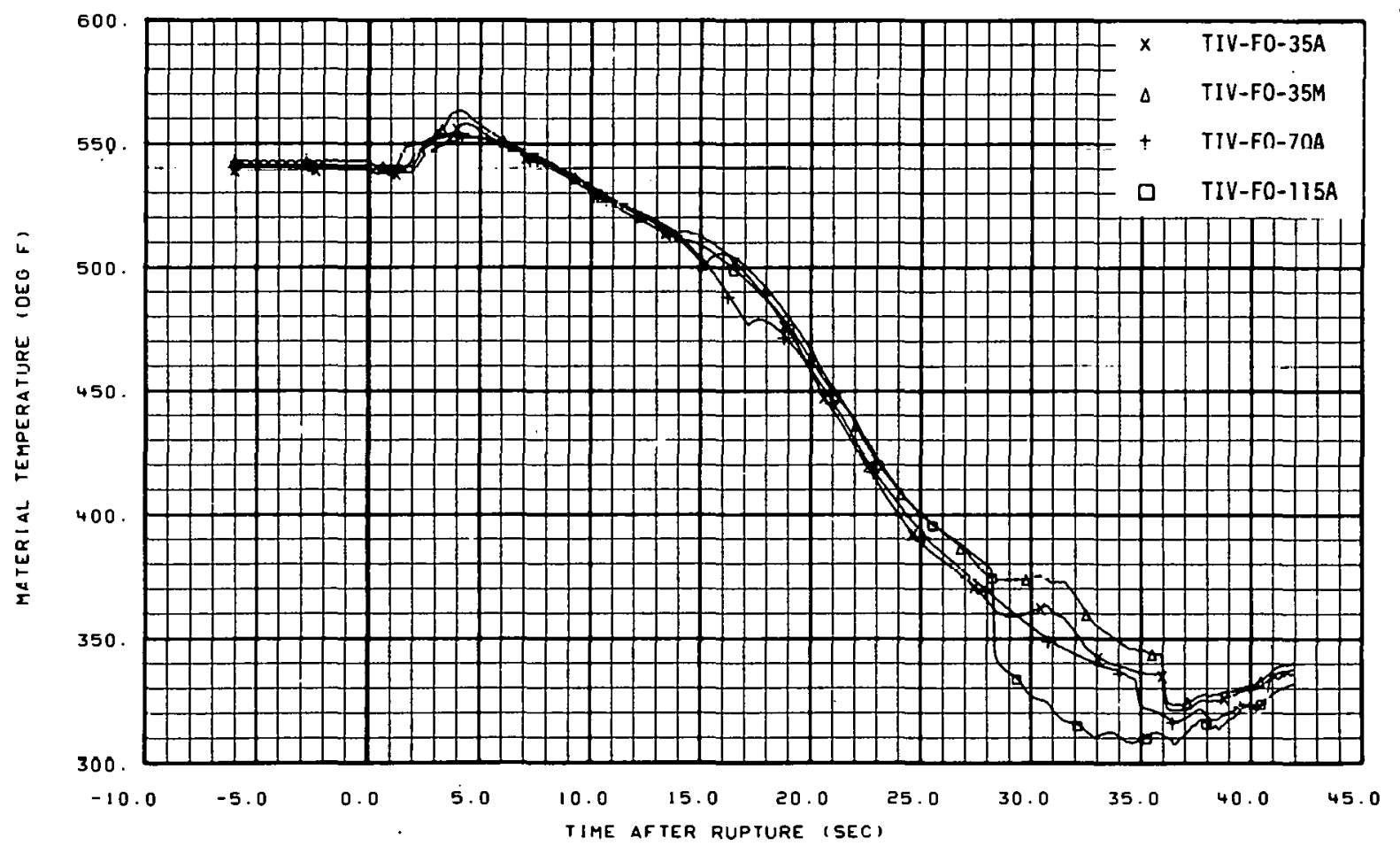

Fig. 50 Material temperature in vessel filler insulator (TIV-F0-35A, TIV-F0-35I, TIV-F0-70A, and TIV-F0-115A), from -6 to 42 seconds. 


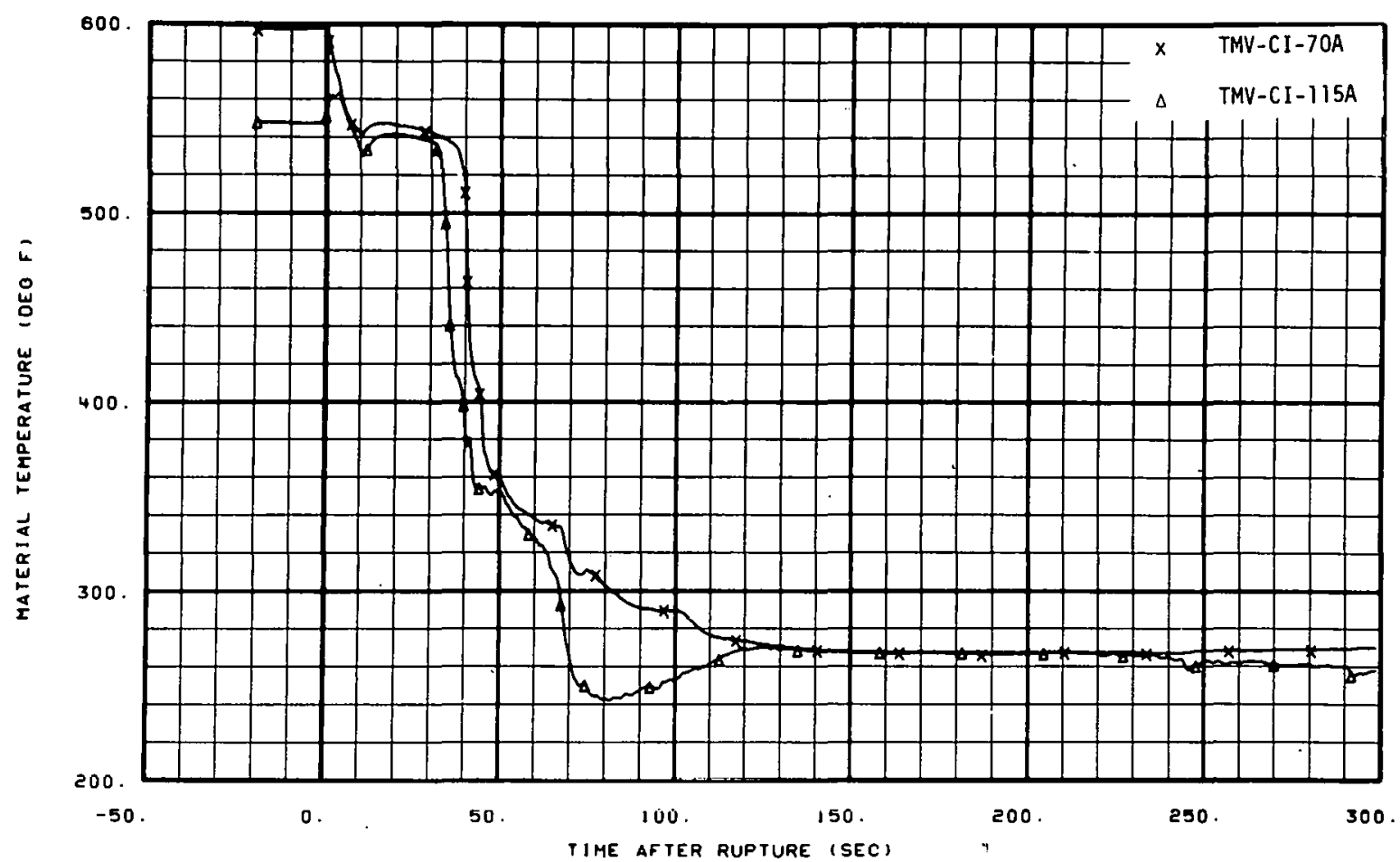

Fig. 51 Materiāl temperature in core barrel inner diameter (TMV-CI-70A and TMV-CI-115A), from -20 to 300 seconds.

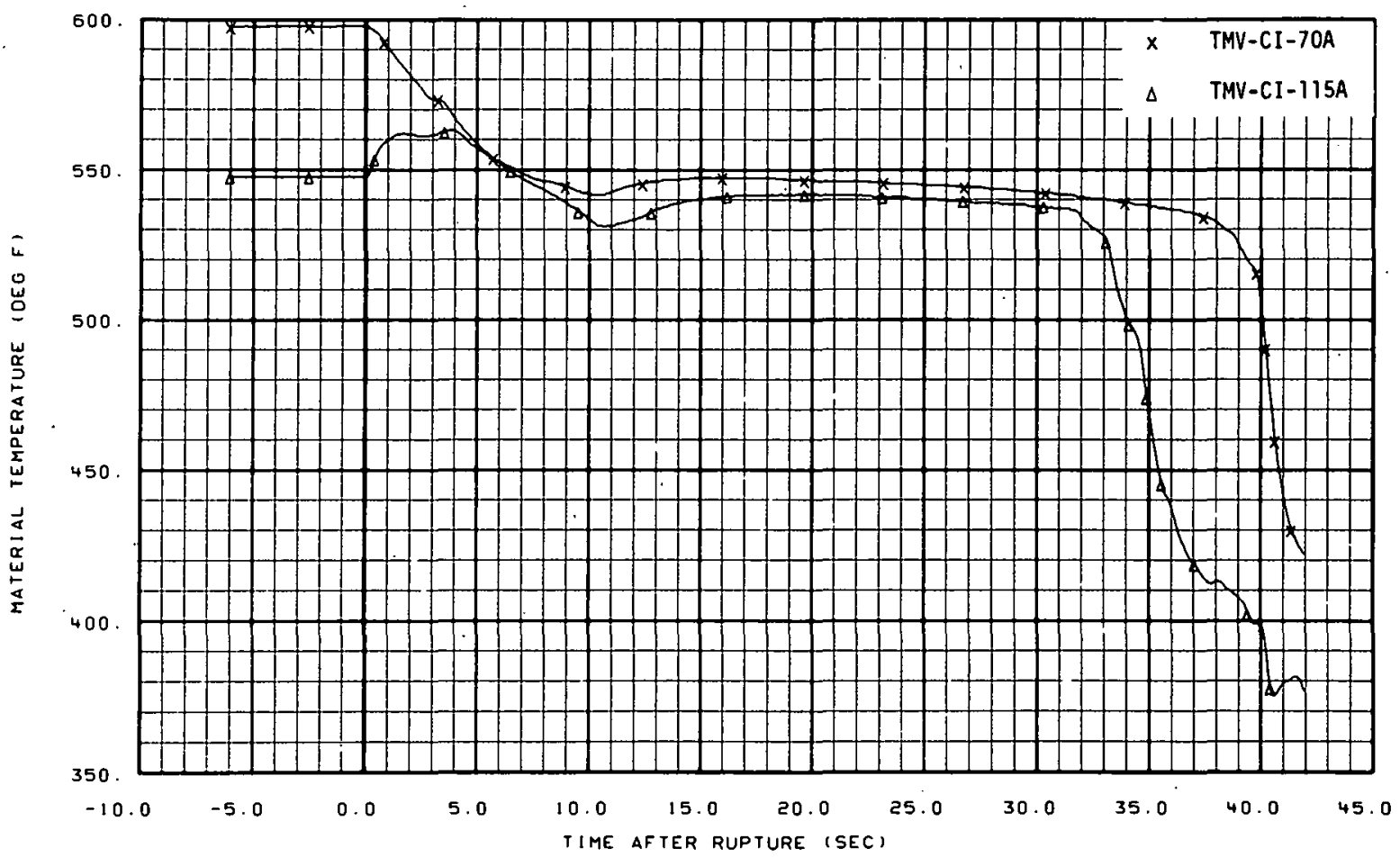

Fig. 52 Material temperature in core barrel inner diameter (TMV-CI-70A and TMV-CI-115A), from -6 to 42 seconds. 


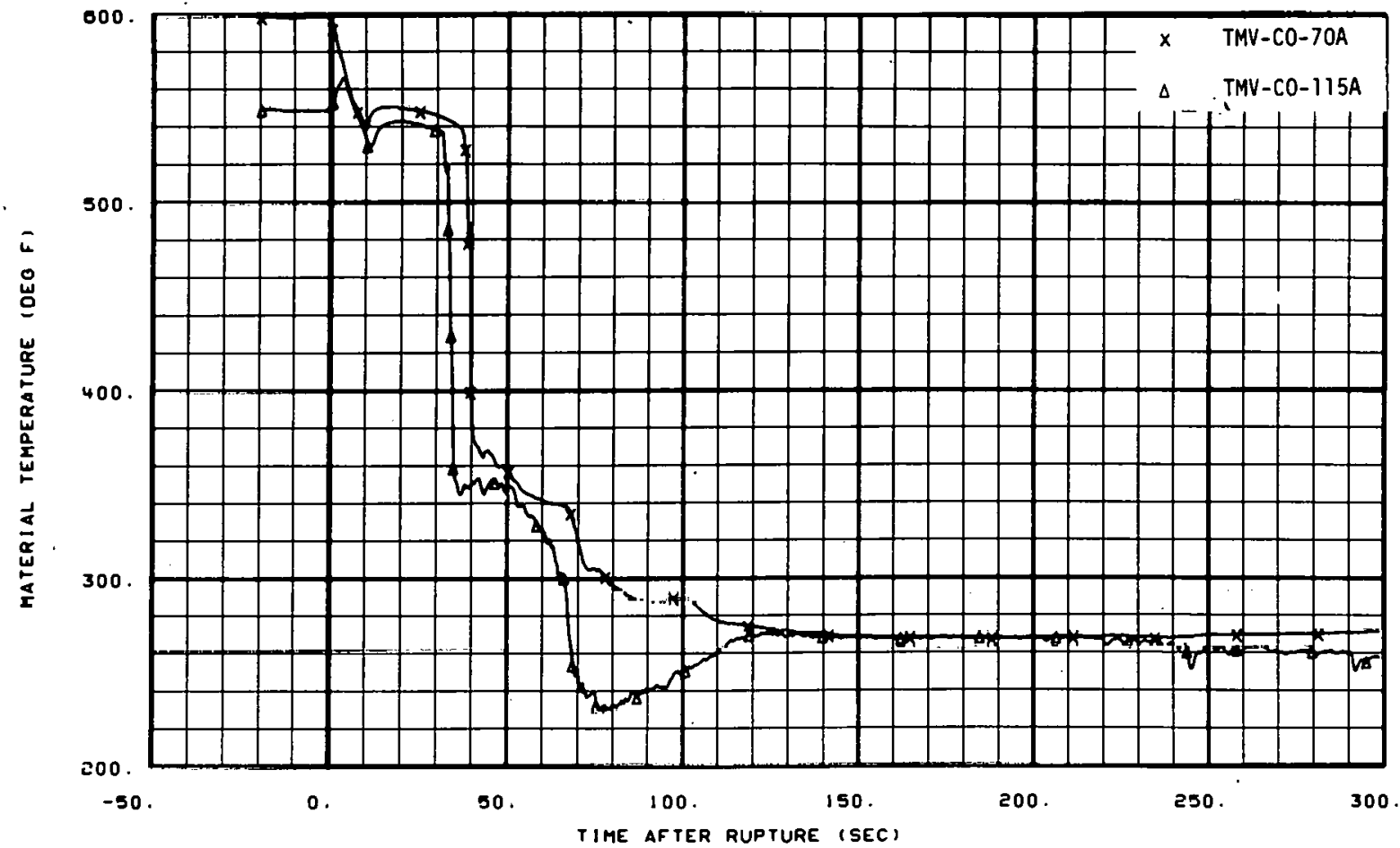

Fig. 53 Material temperature in core barrel outer diameter (TMV-CO-70A and TMV-C0-115A), from -20 to 300 seconds.

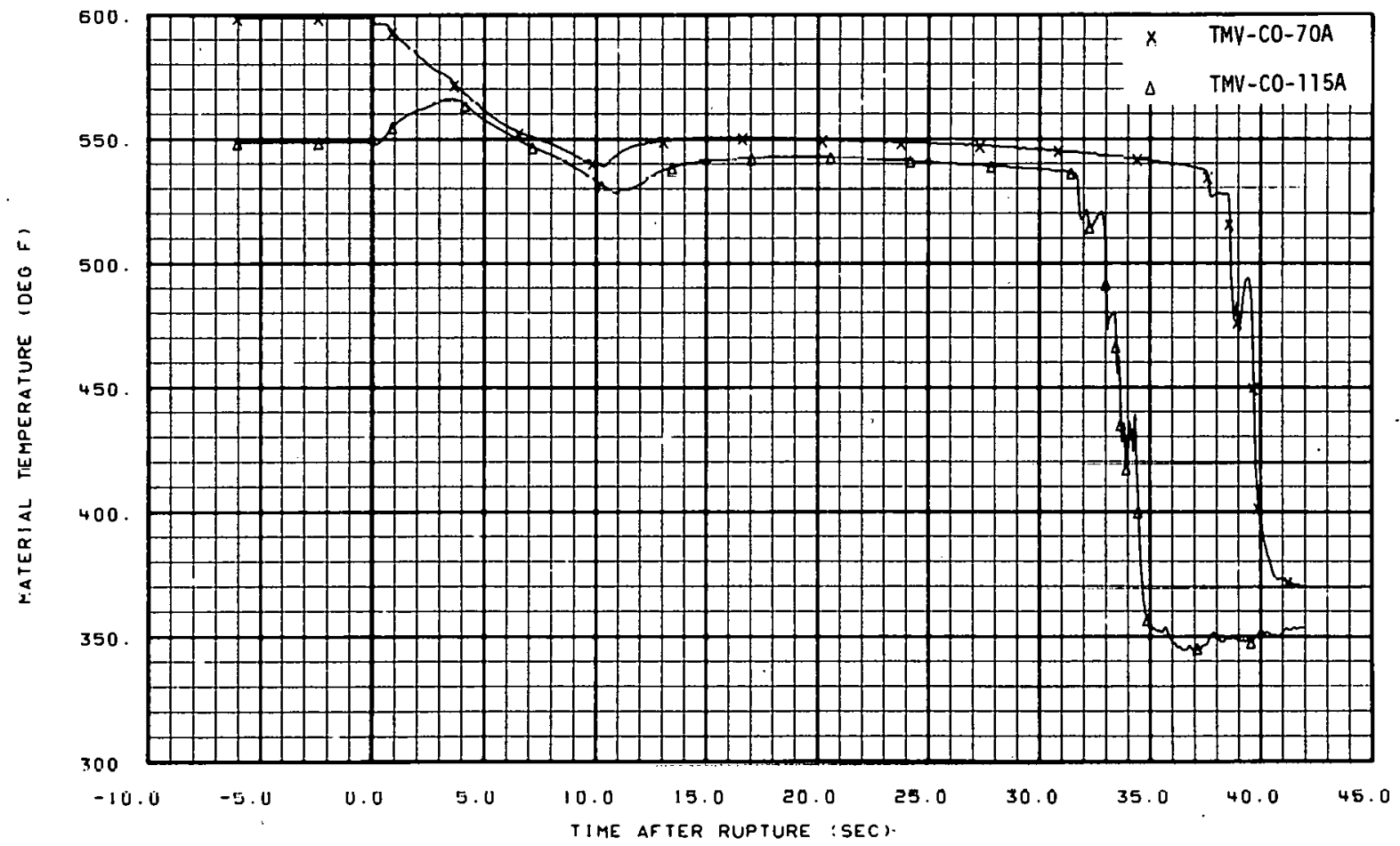

Fig. 54 Material temperature in core barrel outer diameter (TMV-C0-70A and TMV-C0-115n), from -6 to 42 seconds. 


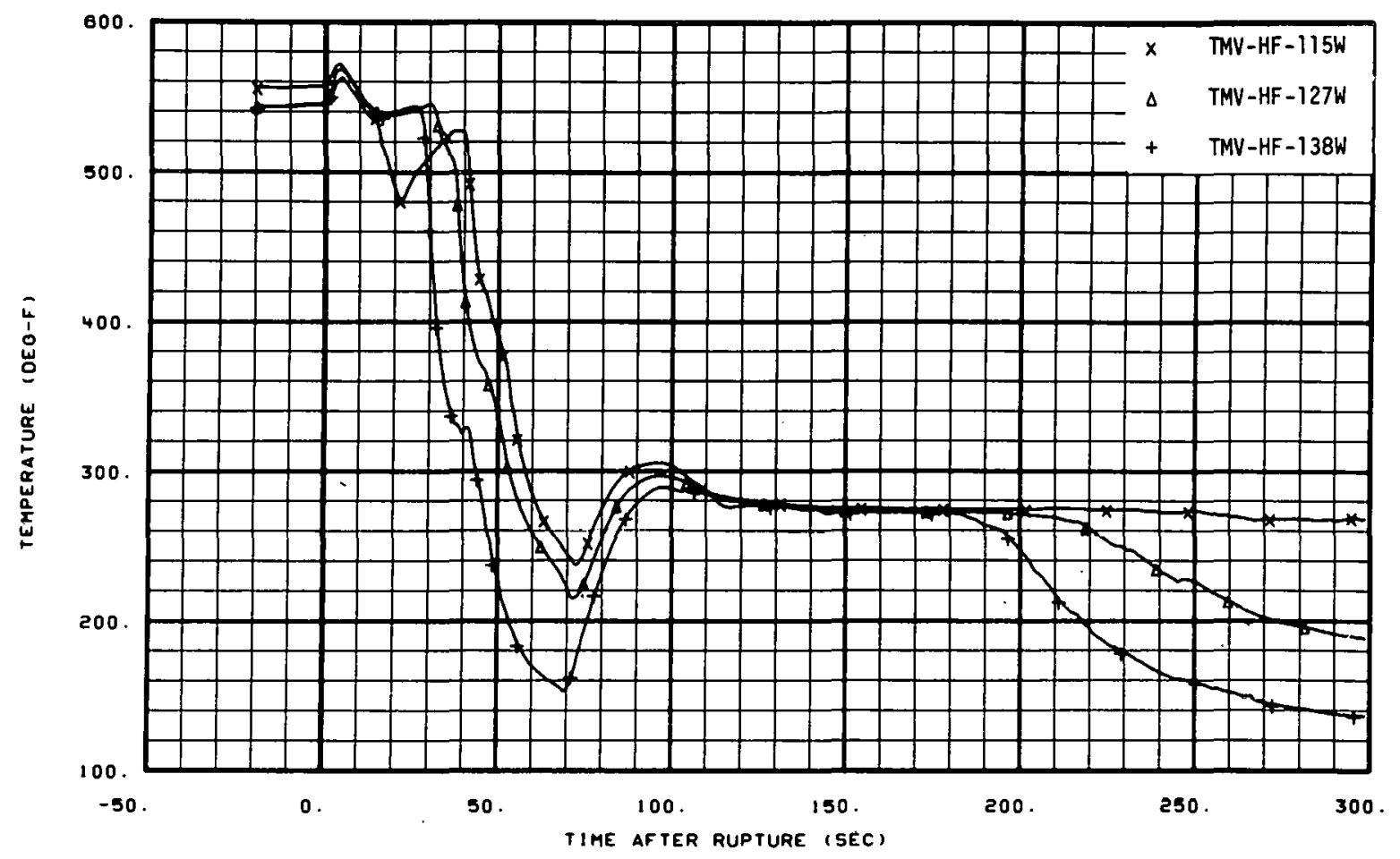

Fig. 55 Material temperature in core housing filler. (TH. V-HF-115W, TMV-HF-127W, and TMV-HF-138W), from -20 to 300 seconds.

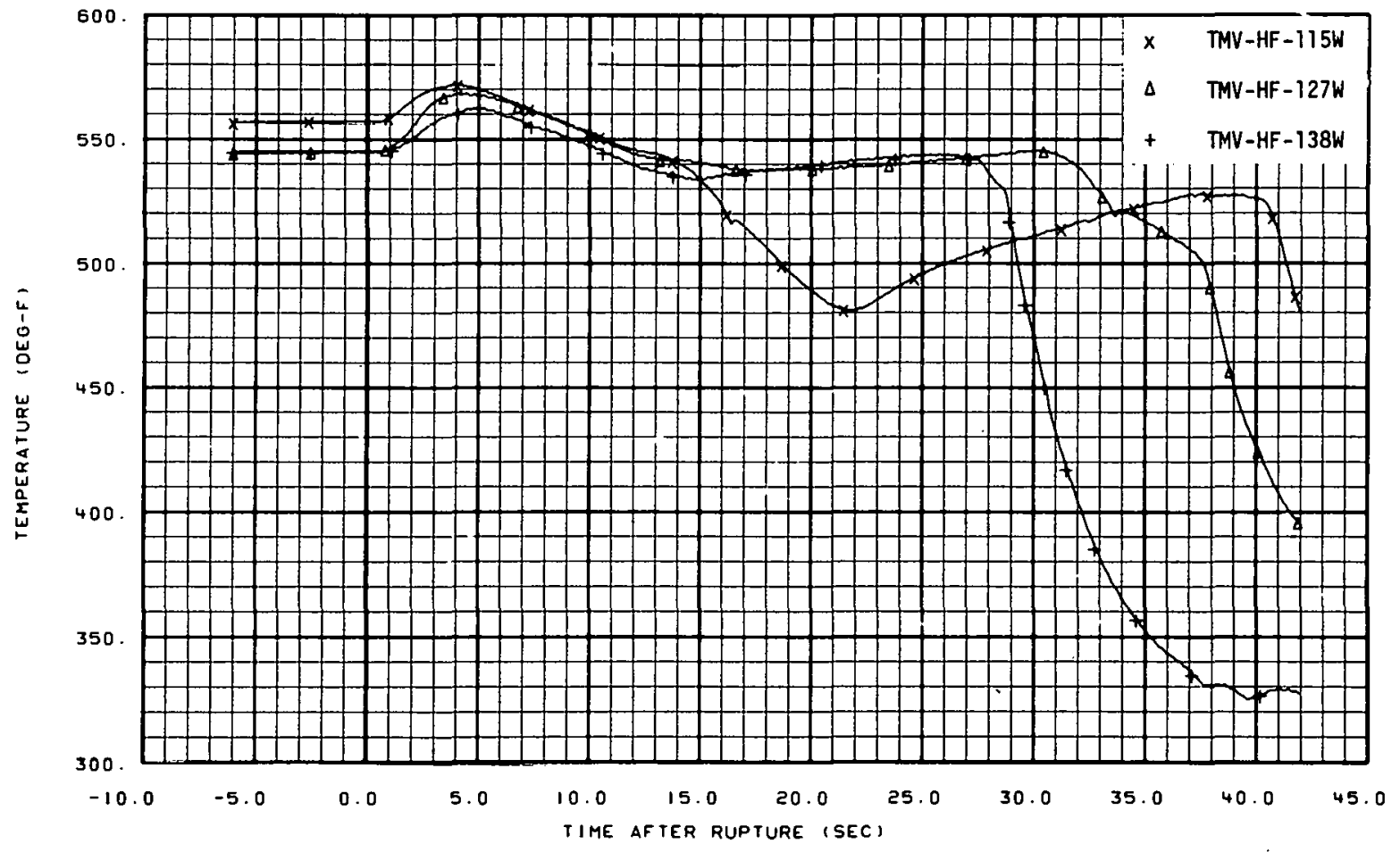

Fig. 56 Material temperature in core housing filler (IMV-HF-115W, TMV-HF-127W, and TMV-HF-138W), from -6 to 42 seconds. 


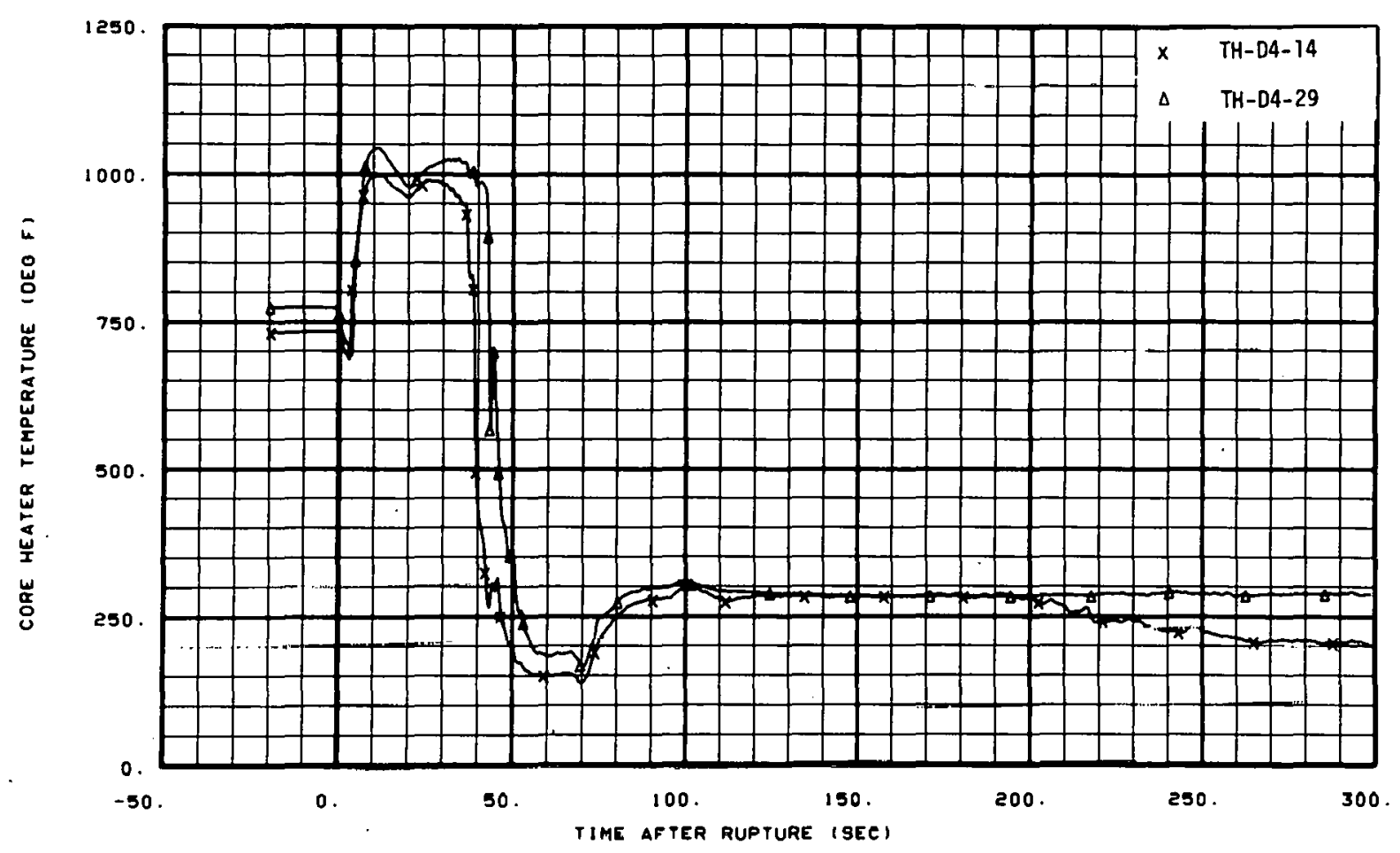

Fig. 57 Core heater temperature, Rod D-4 (TH-D4-14 and TH-D4-29), from -20 to 300 seconds.

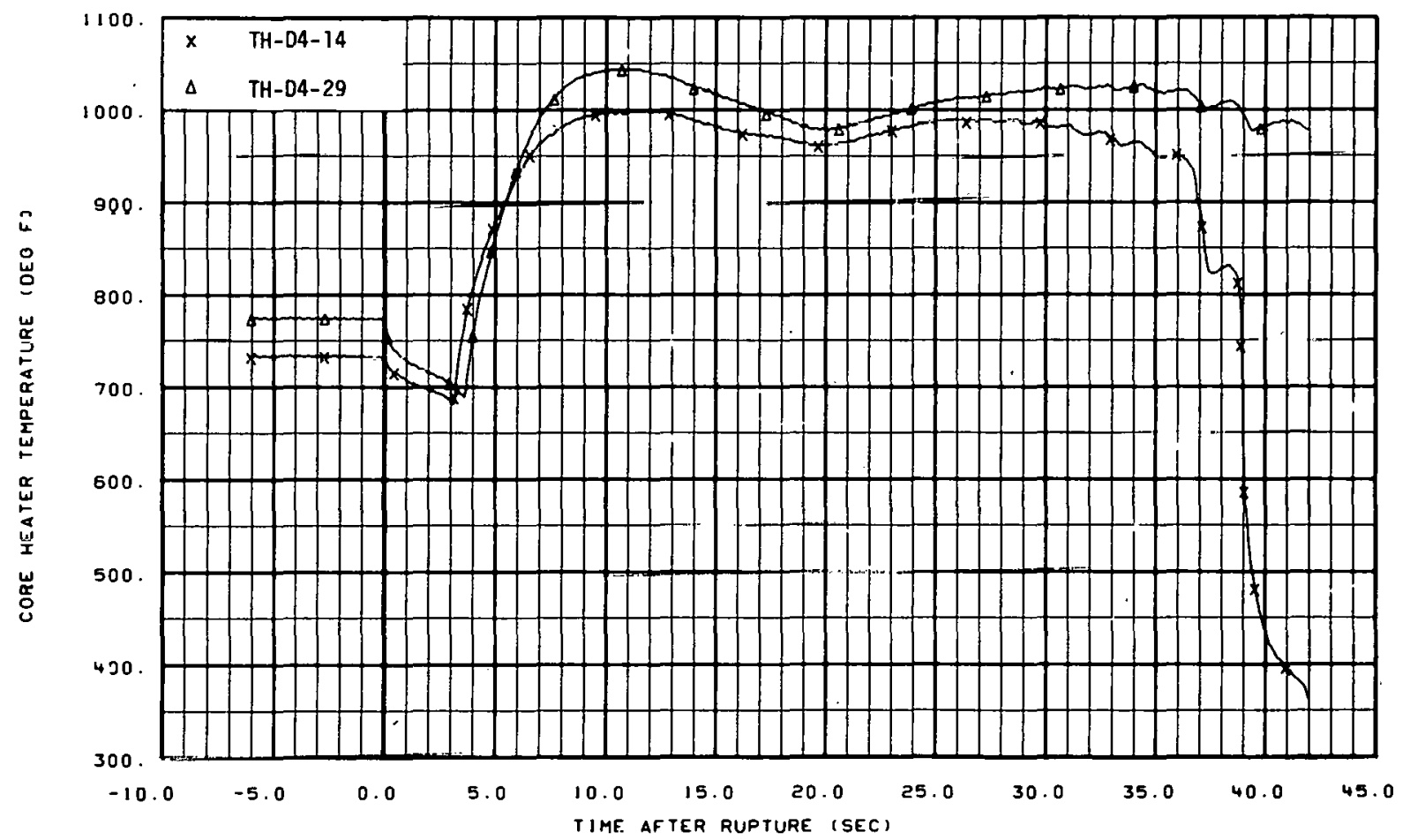

Fig. 58 Core heater temperature, Rod D-4 (TH-D4-14 and TH-D4-29), from -6 to 42 seconds. 


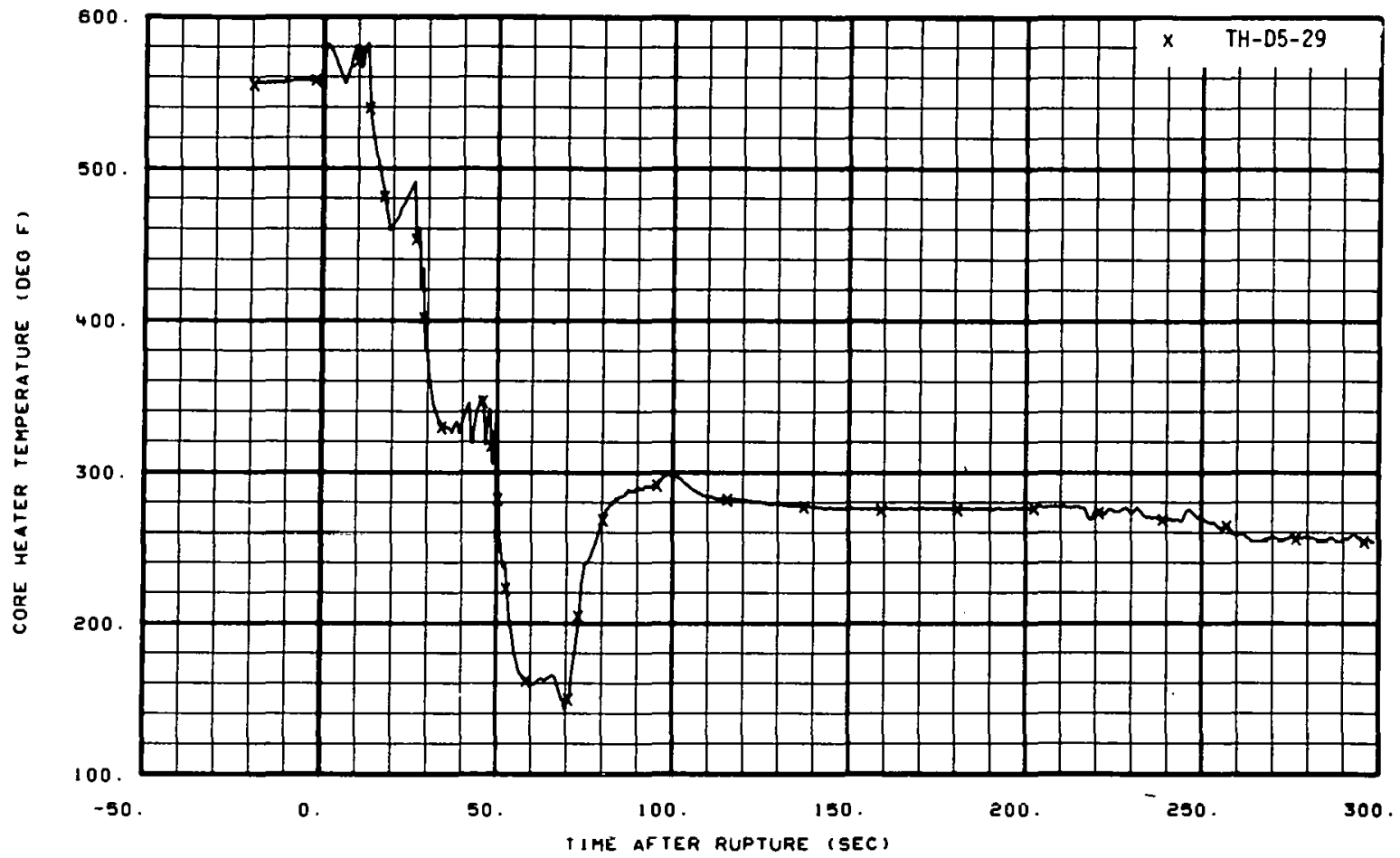

Fig. 59 Core heater temperature, Rod D-5 (TH-D5-29), from -20 to 300 seconds.

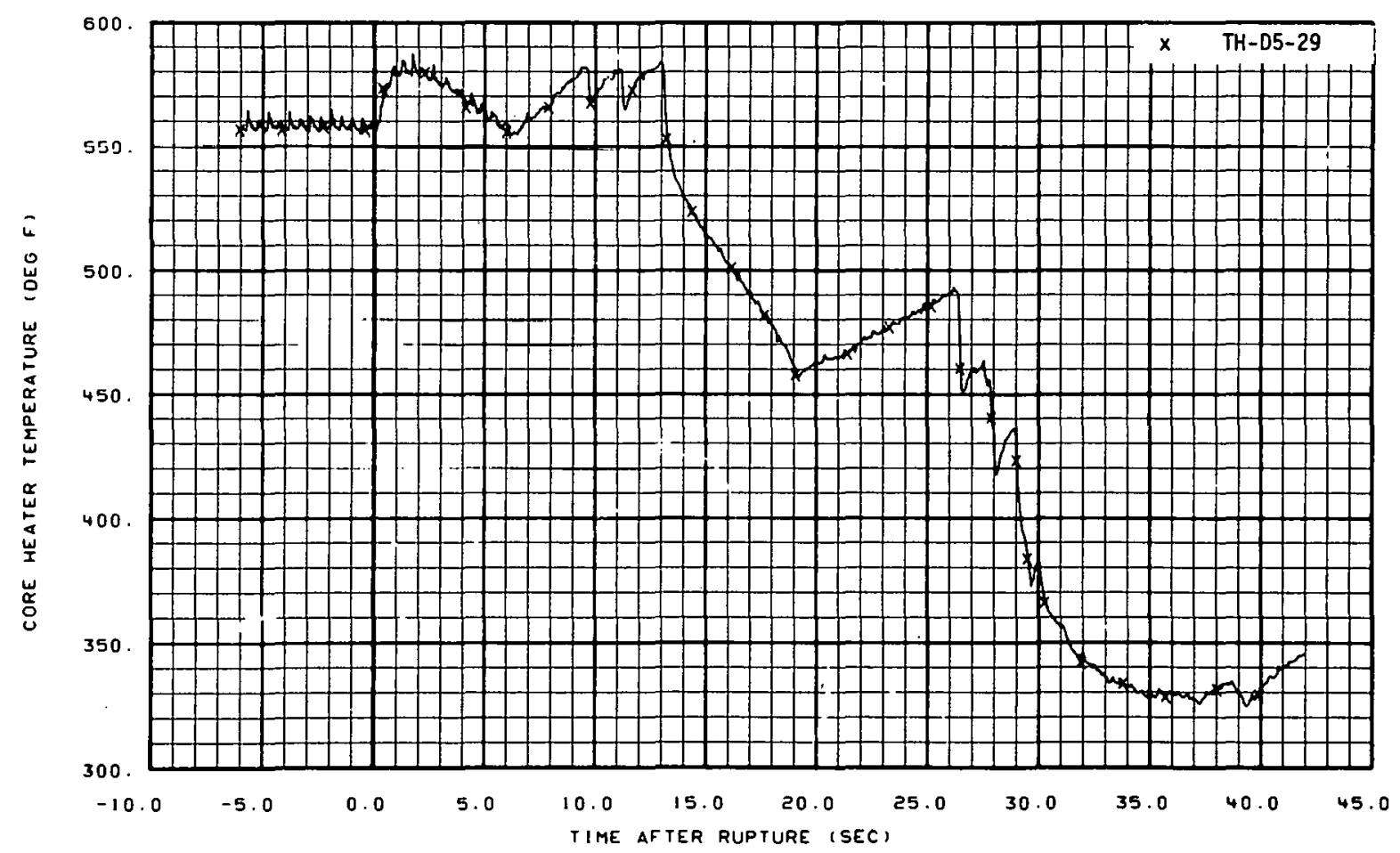

Fig. 60 Core heater temperature, Rod D-5 (TH-D5-29), from -6 to 42 seconds. 


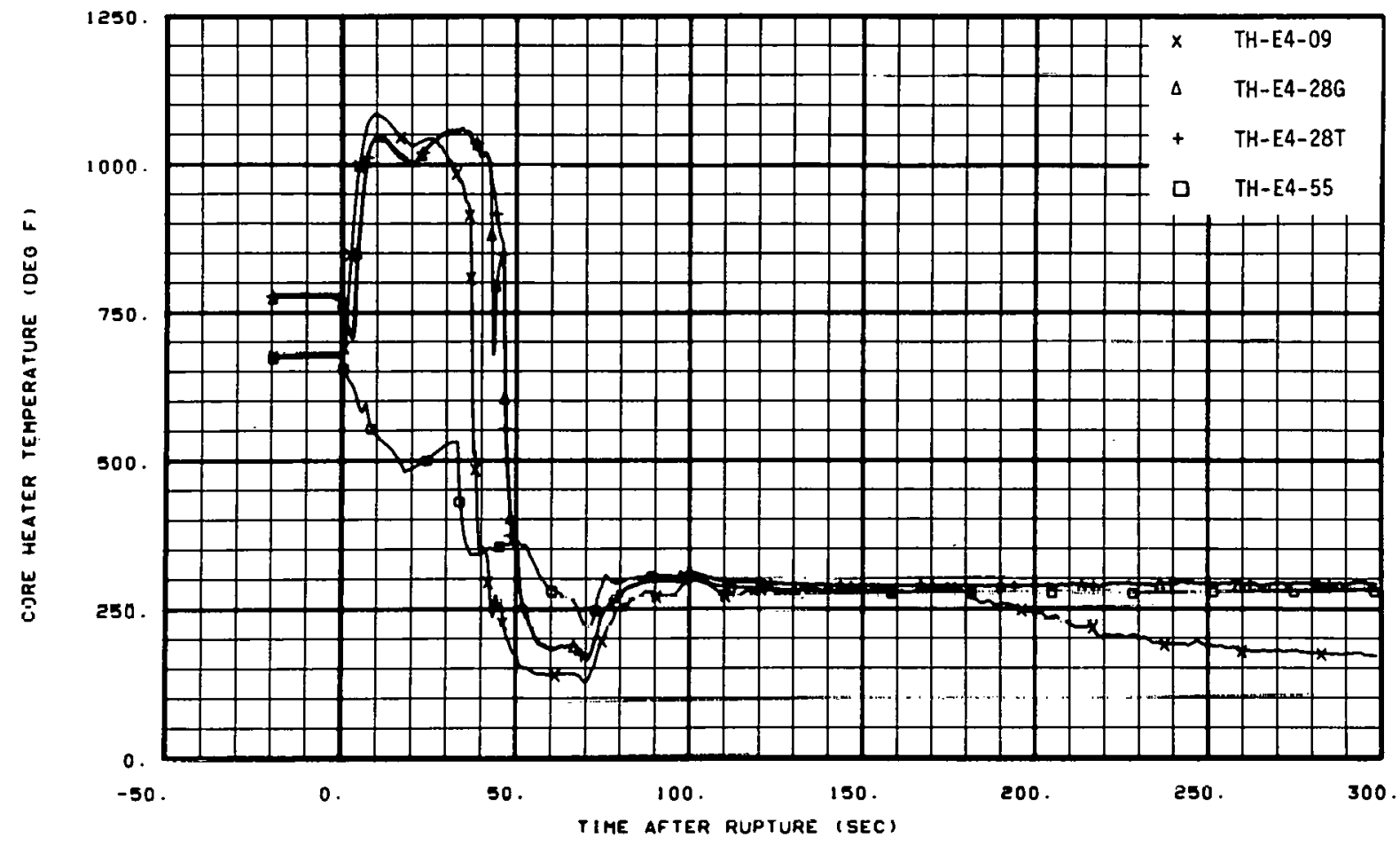

Fig. 61 Core heater temperature, Rod E-4 (TH-E4-09, TH-E4-28G, TH-E4-28T, and $\mathrm{TH}-\mathrm{E} 4-55)$, from -20 to 300 seconds.

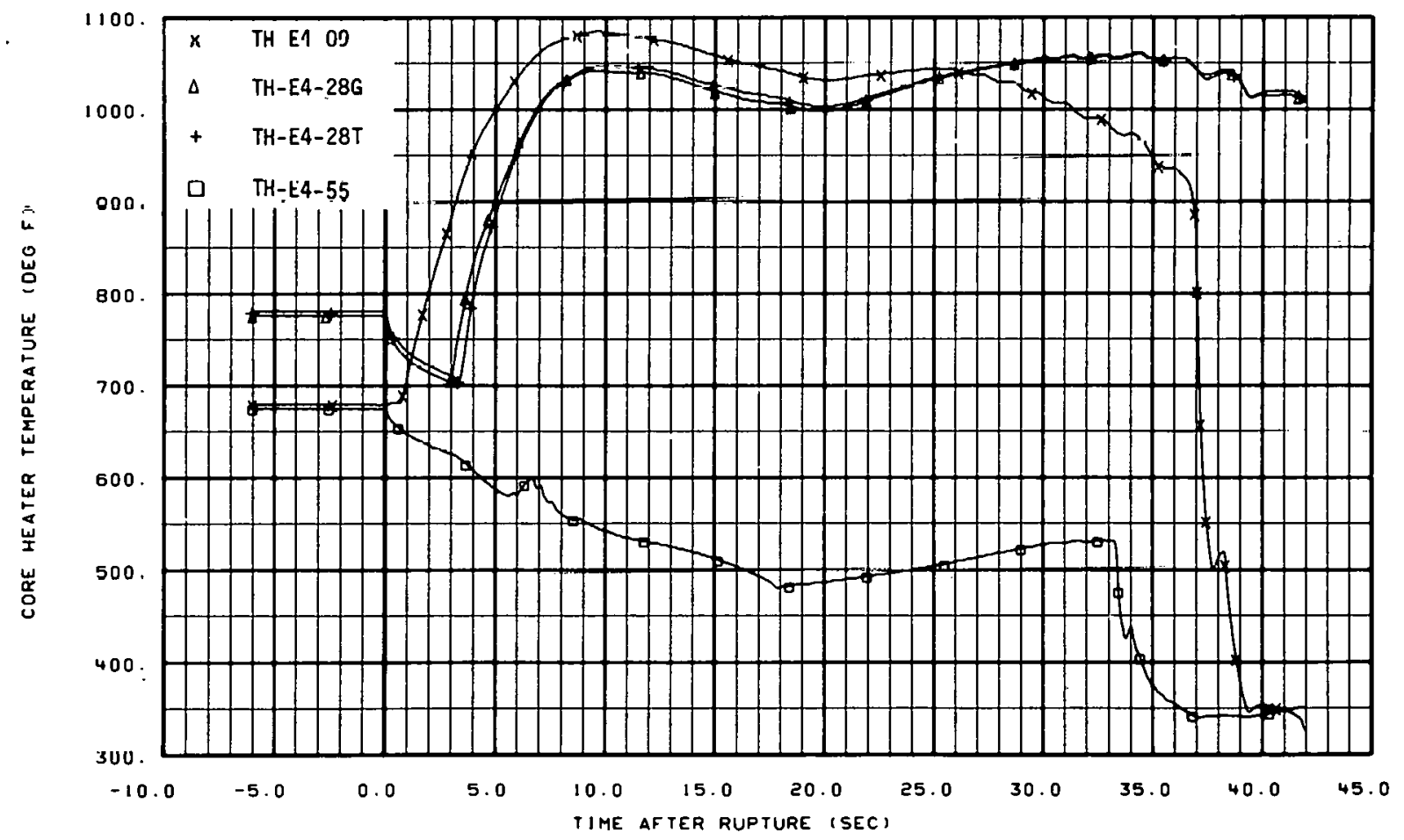

Fig. 62 Core heater temperature, Rod E-4 (TH-E4-09, TH-E4-28G, TH-E4-28T, and $\mathrm{TH}-\mathrm{E} 4-55)$, from -6 to 42 seconds. 


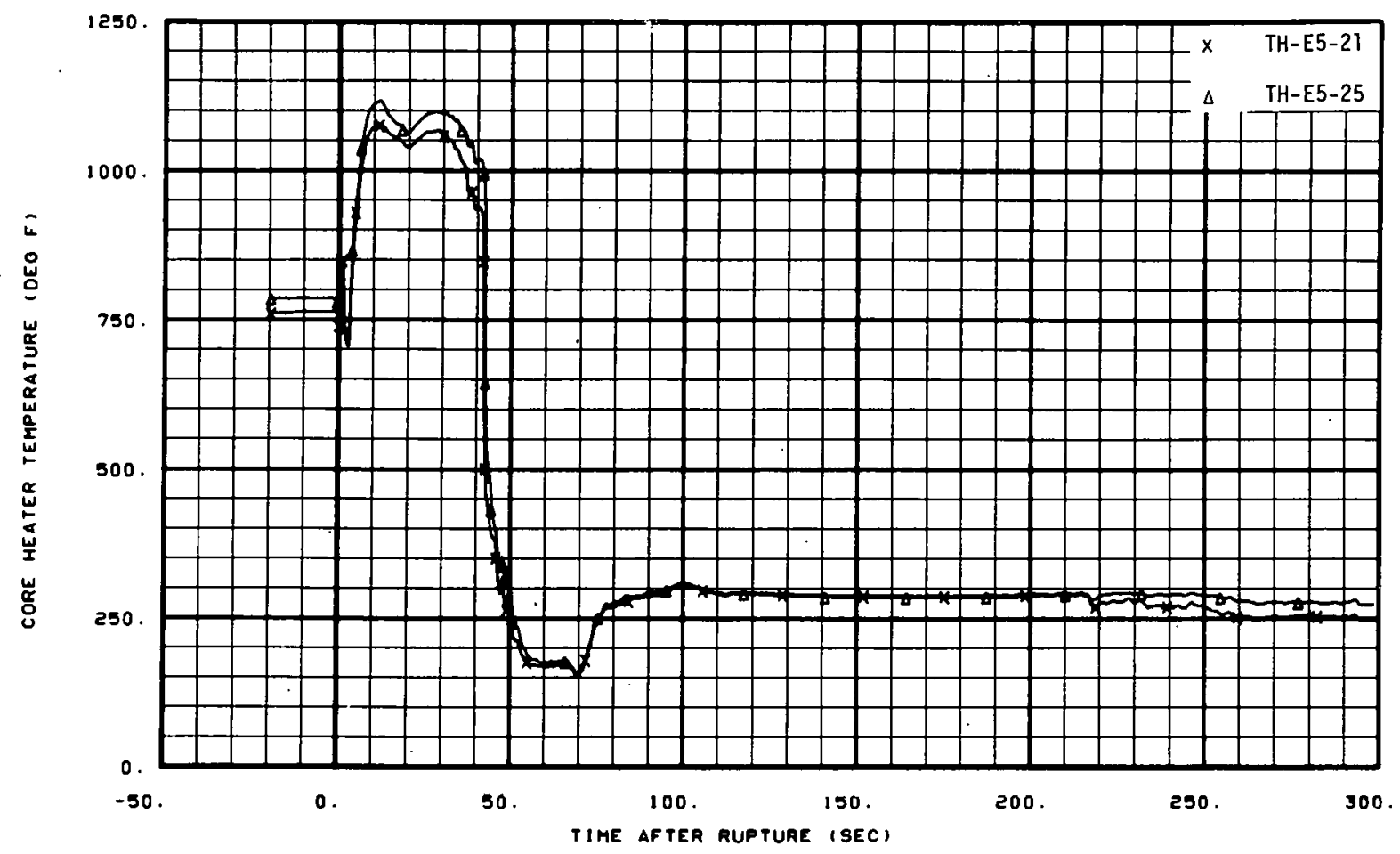

Fig. 63 Core heater temperature, Rod E-5 (TH-E5-21 and TH-E5-25), from -20 to 300 seconds.

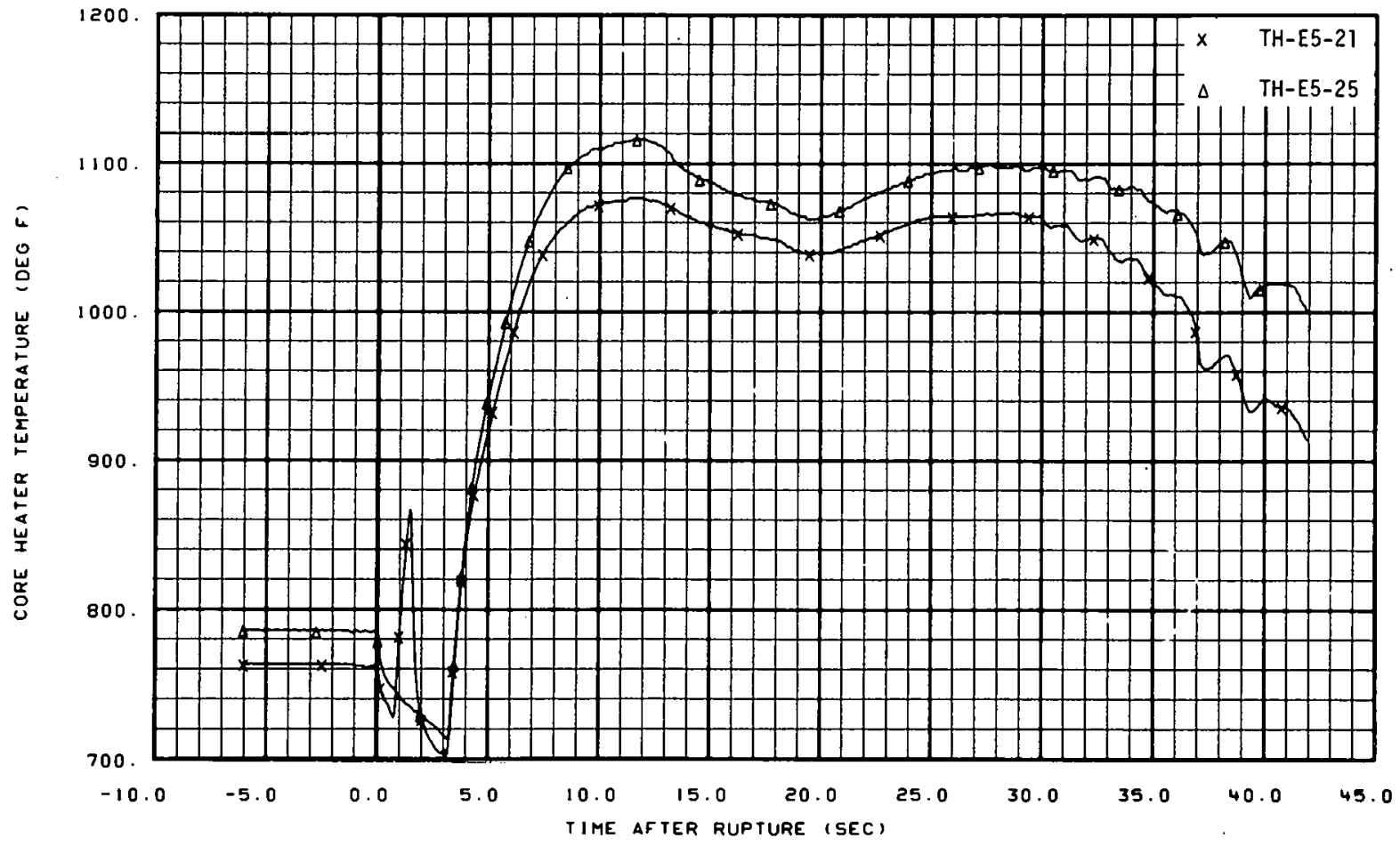

Fig. 64 Core heater temperature, Rod E-5 (TH-E5-2l and $\mid \mathrm{H}-\mathrm{E}-5-25)$, from -6 to 42 seconds. 


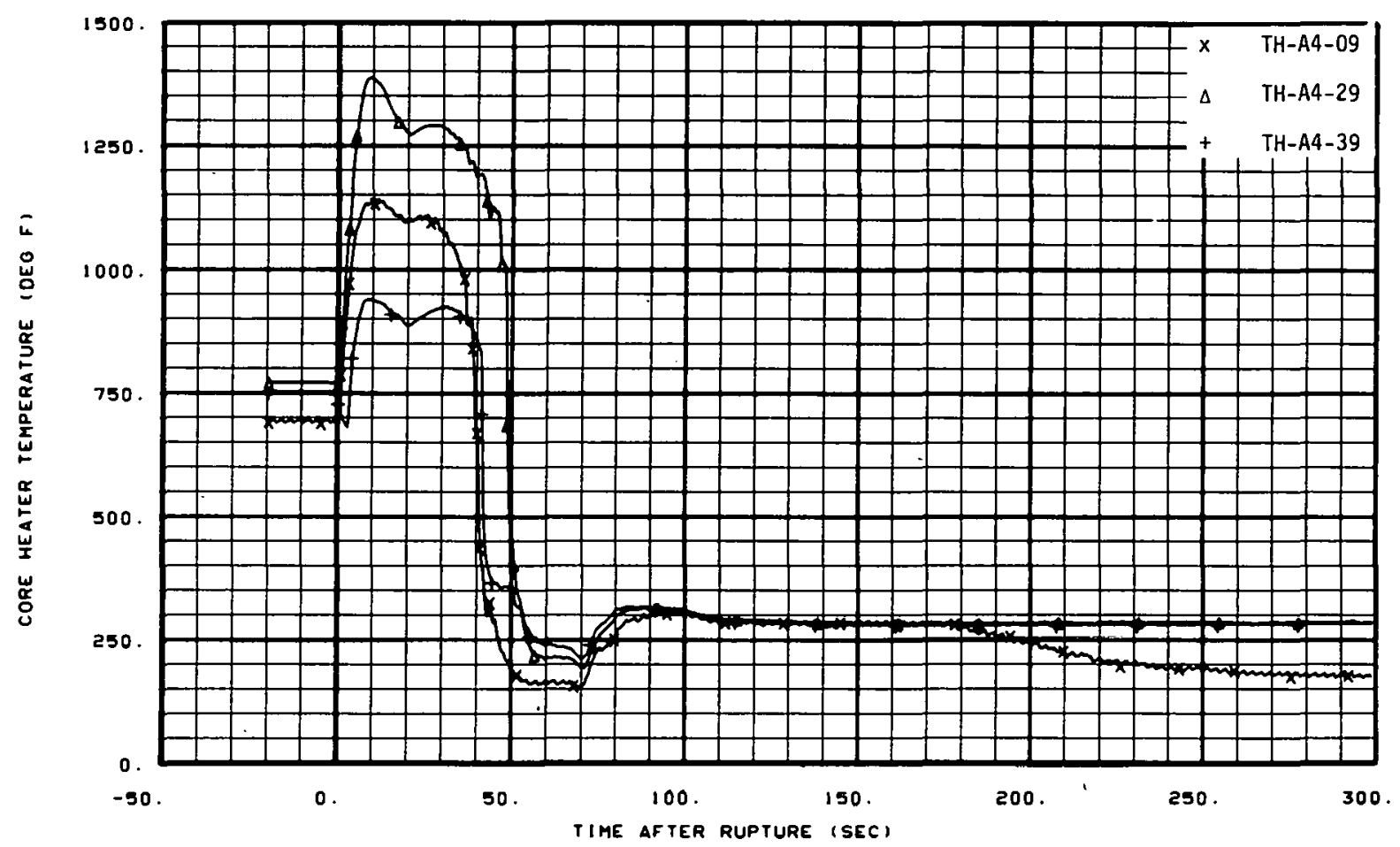

Fig. 65 Core heater temperature, Rod A-4 (TH-A4-09, TH-A4-29, and TH-A4-39), from -20 to 300 seconds.

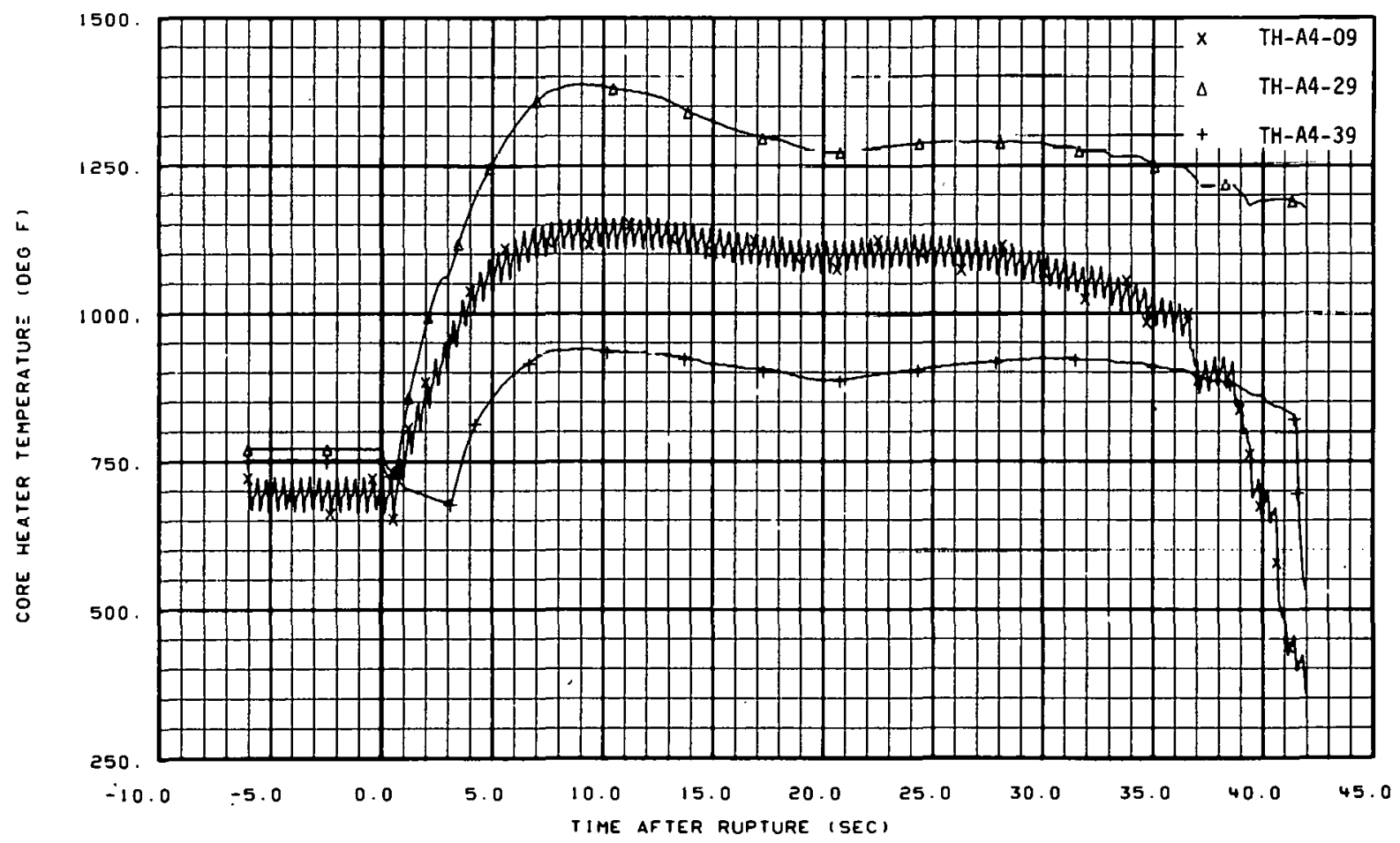

Fig. 66 Core heater temperature, Rod A-4 (TH-A4-09, TH-A4-29, and TH-A4-39), from -6 to 42 seconds. 


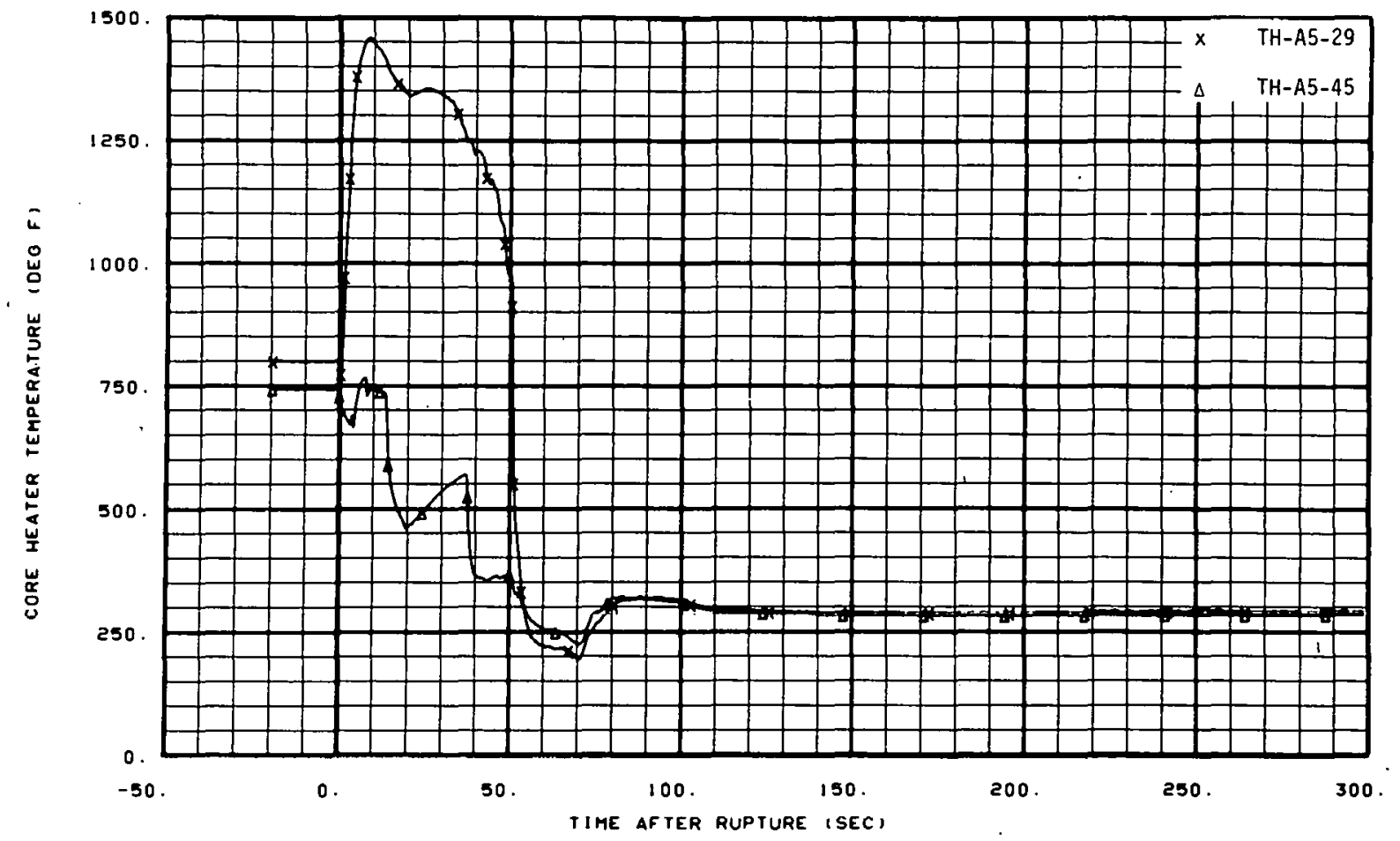

Fig. 67 Core heater temperature, Rod A-5 (TH-A5-29 and TH-A5-45), from -20 to 300 seconds.

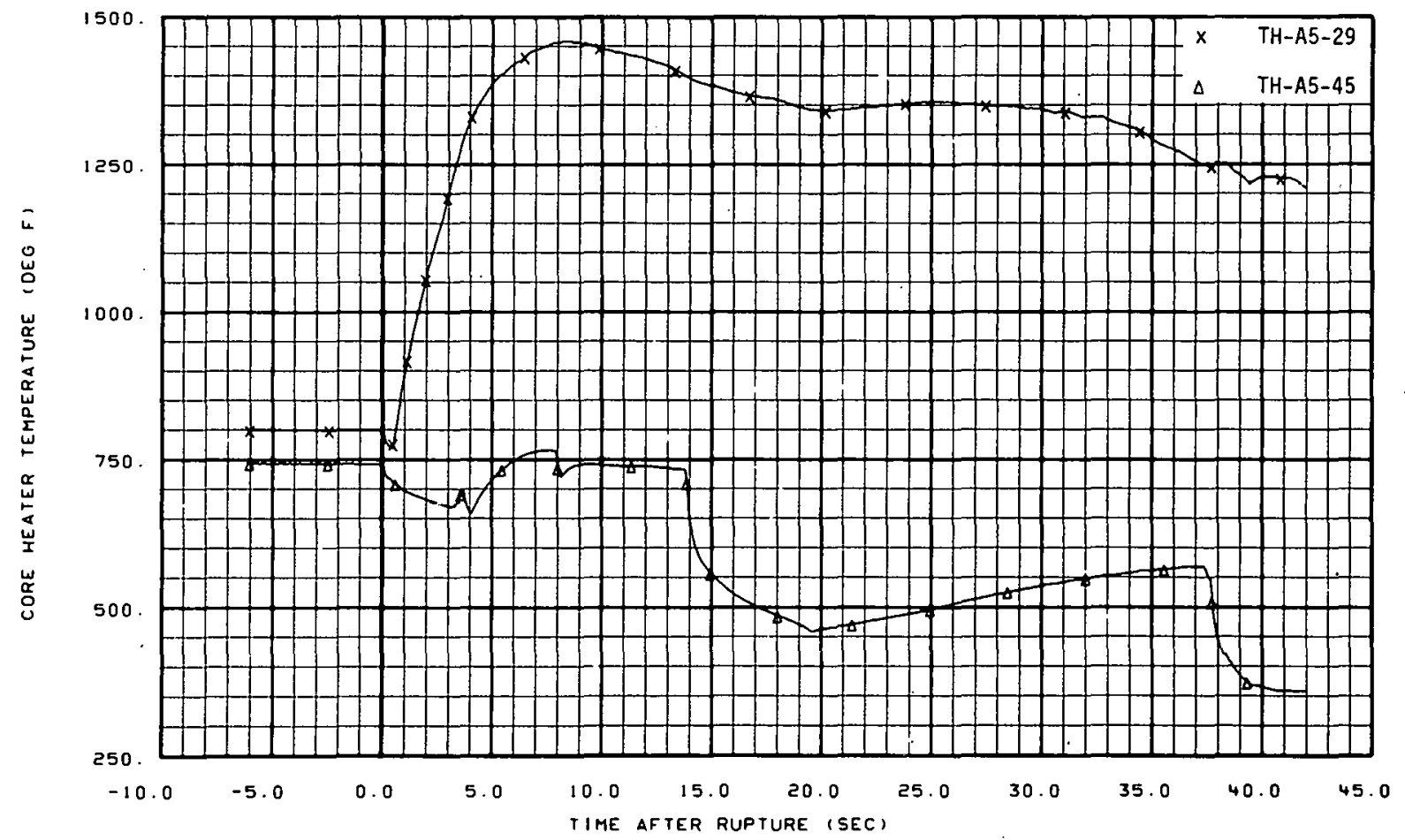

Fig. 68 Core heater temperature, Rod A-5 (TH-A5-29 and TH-A5-45), from -6 to 42 seconds. 


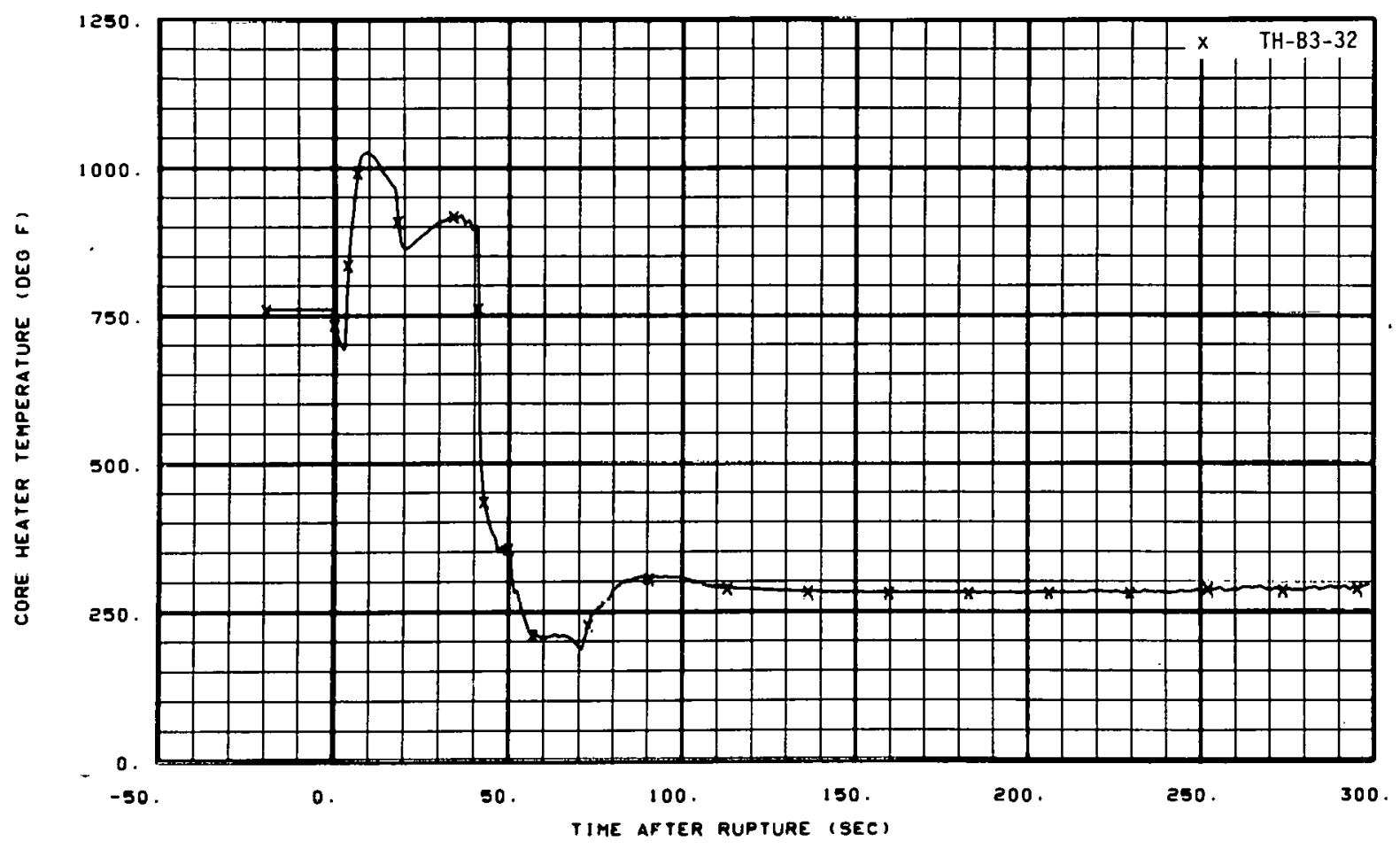

Fig. 69 Core heater temperature, Rod B-3 (TH-B3-32), from -20 to 300 seconds.

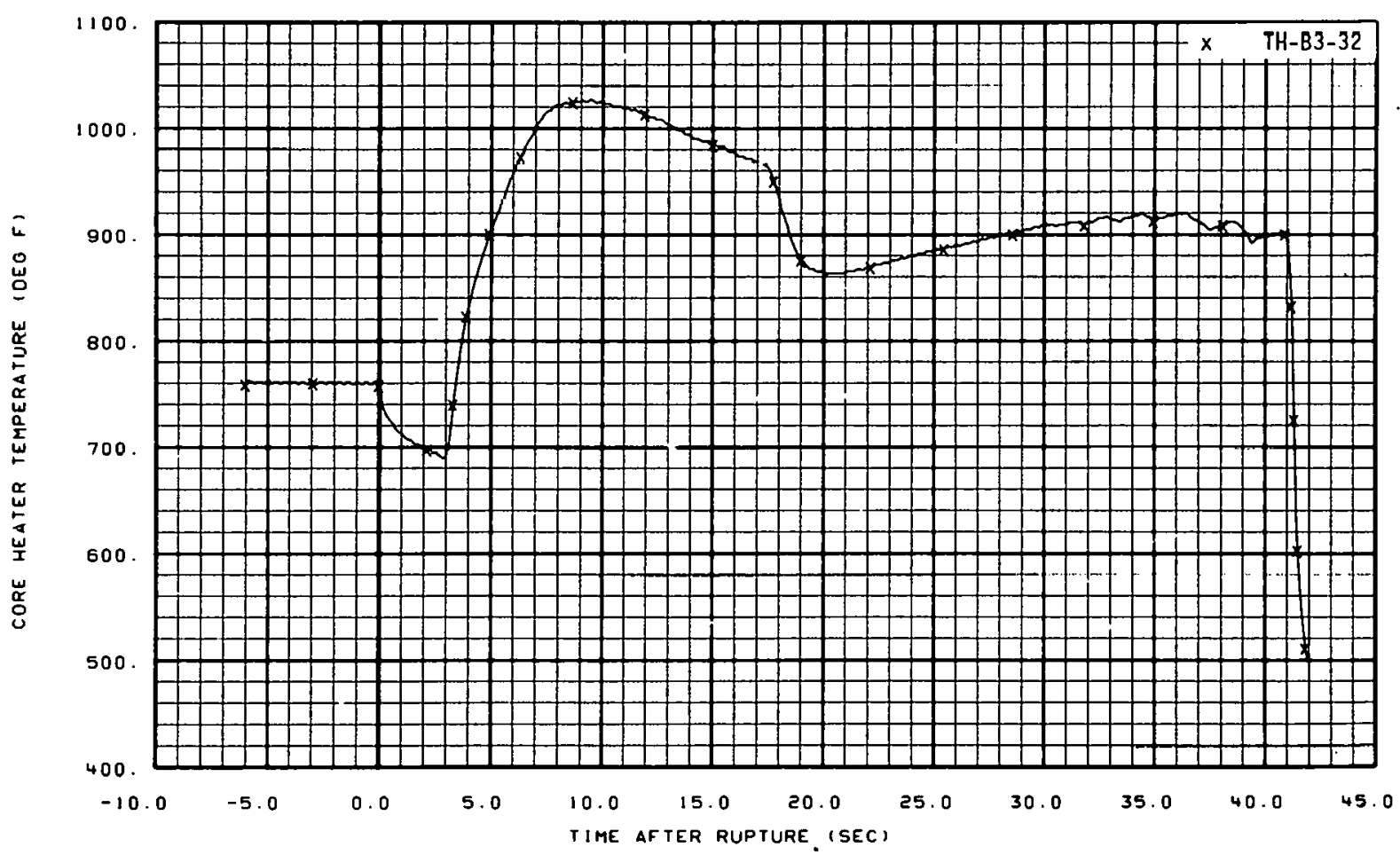

Fig. 70 Core heater temperature, Rod B-3 (TH-B3-32), from -6 to 42 seconds. 


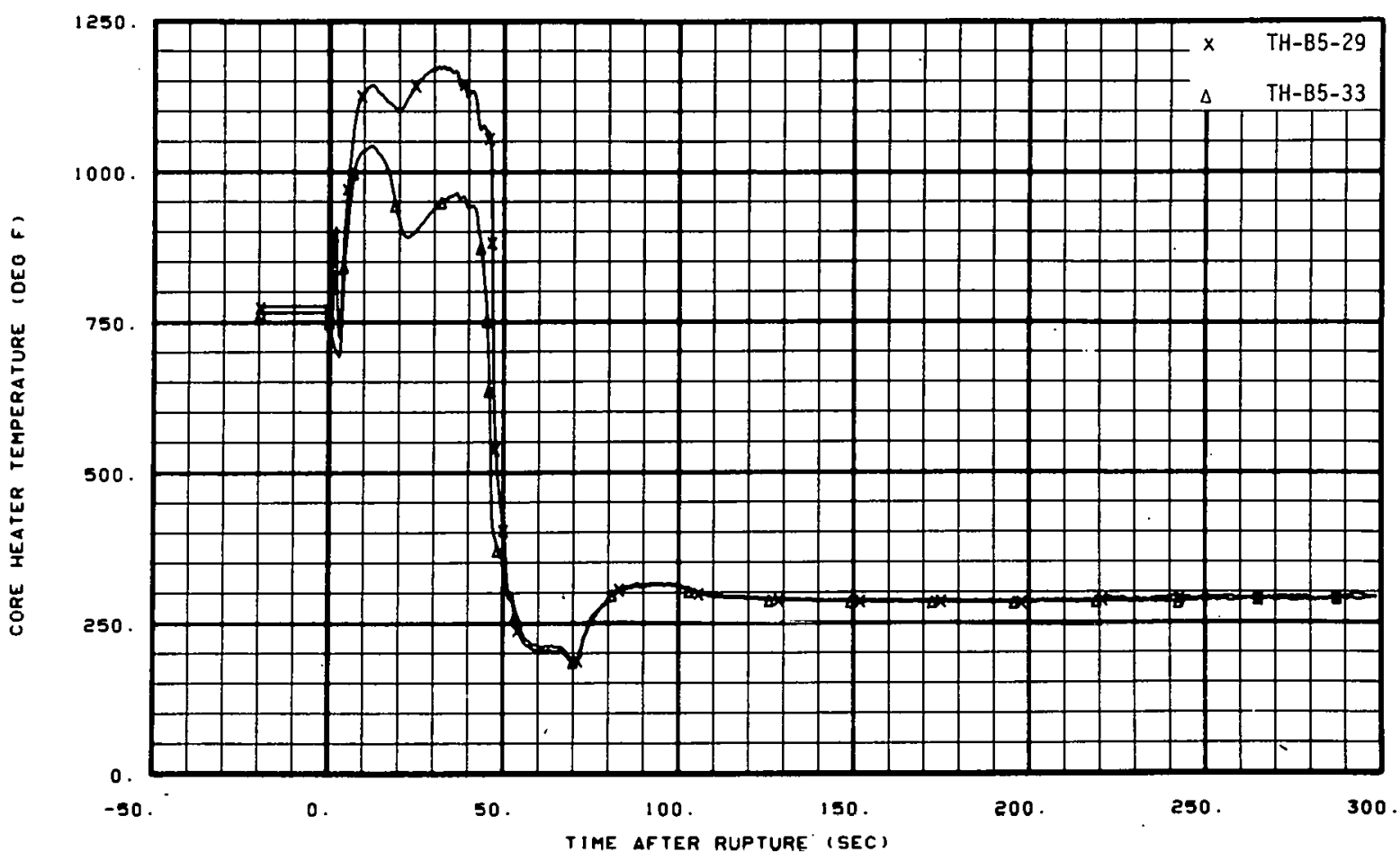

Fig. 71 Core heater temperature, Rod B-5 (TH-B5-29 and TH-B5-33), from -20 to 300 seconds.

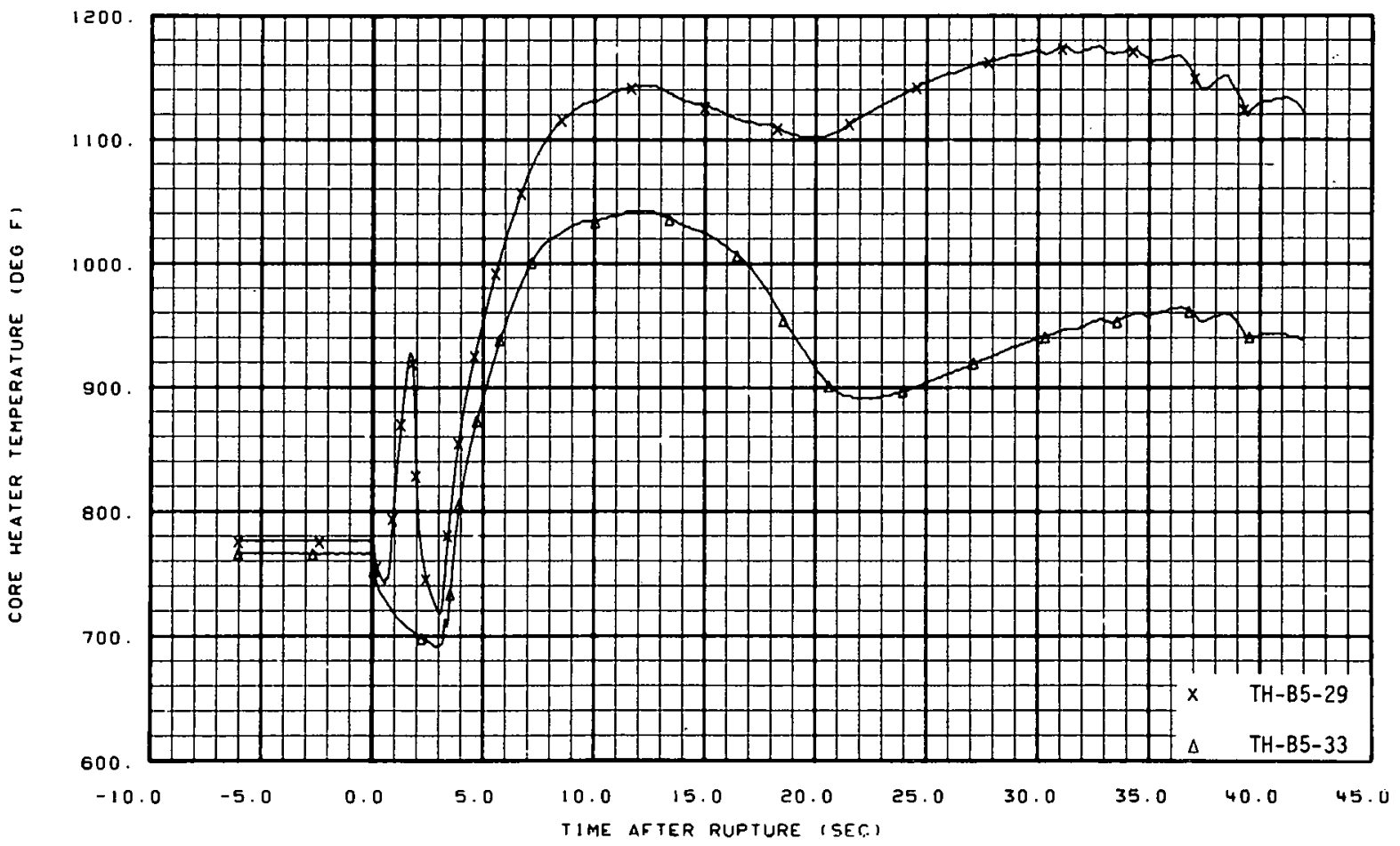

Fig. 72 Core heater temperature, Rud B-5 (TH-B5-29 and TH-B5-33), from -6 to 42 seconds. 


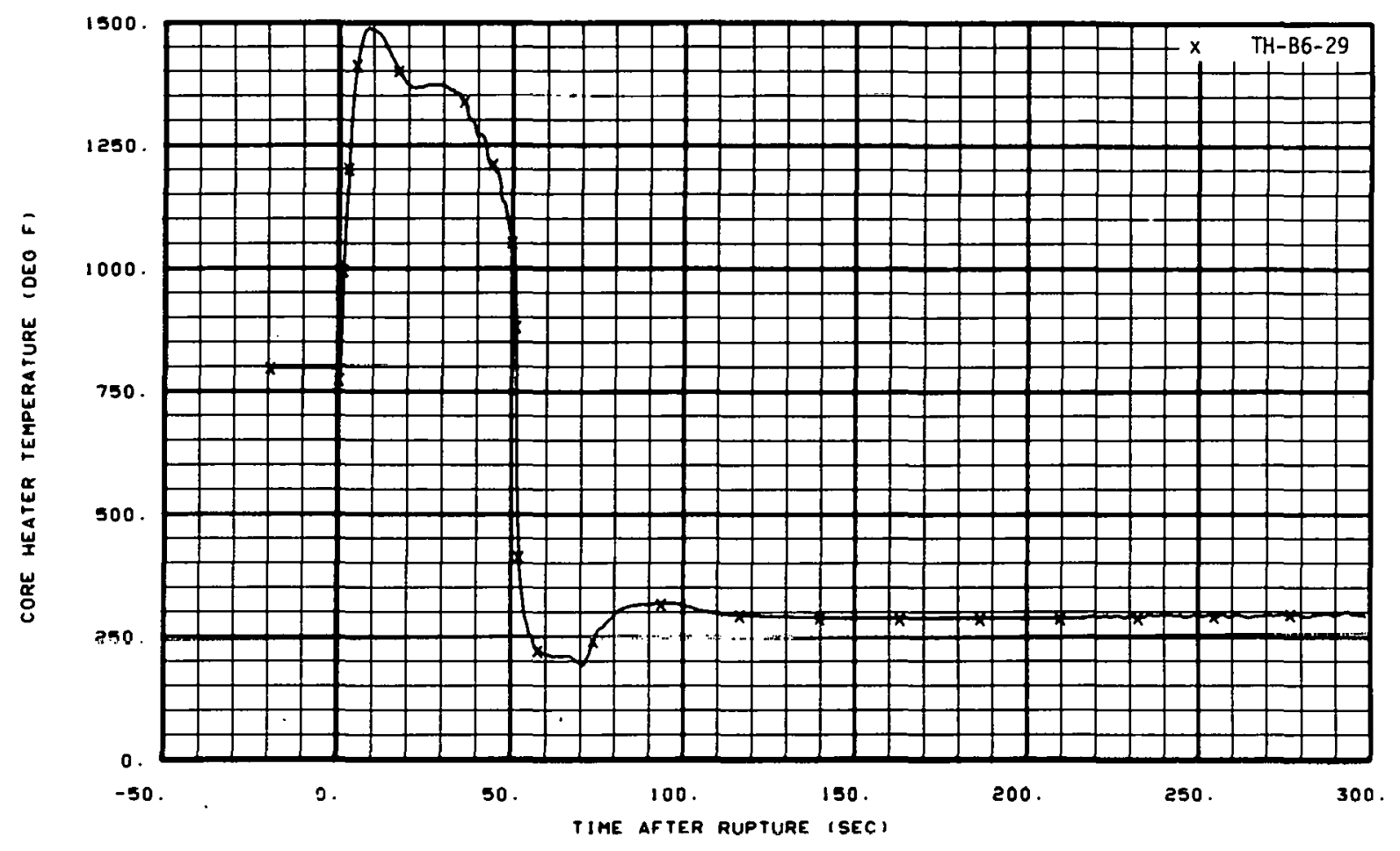

Fig. 73 Core heater temperature, Rod B-6 (TH-B6-29), from -20 to 300 seconds.

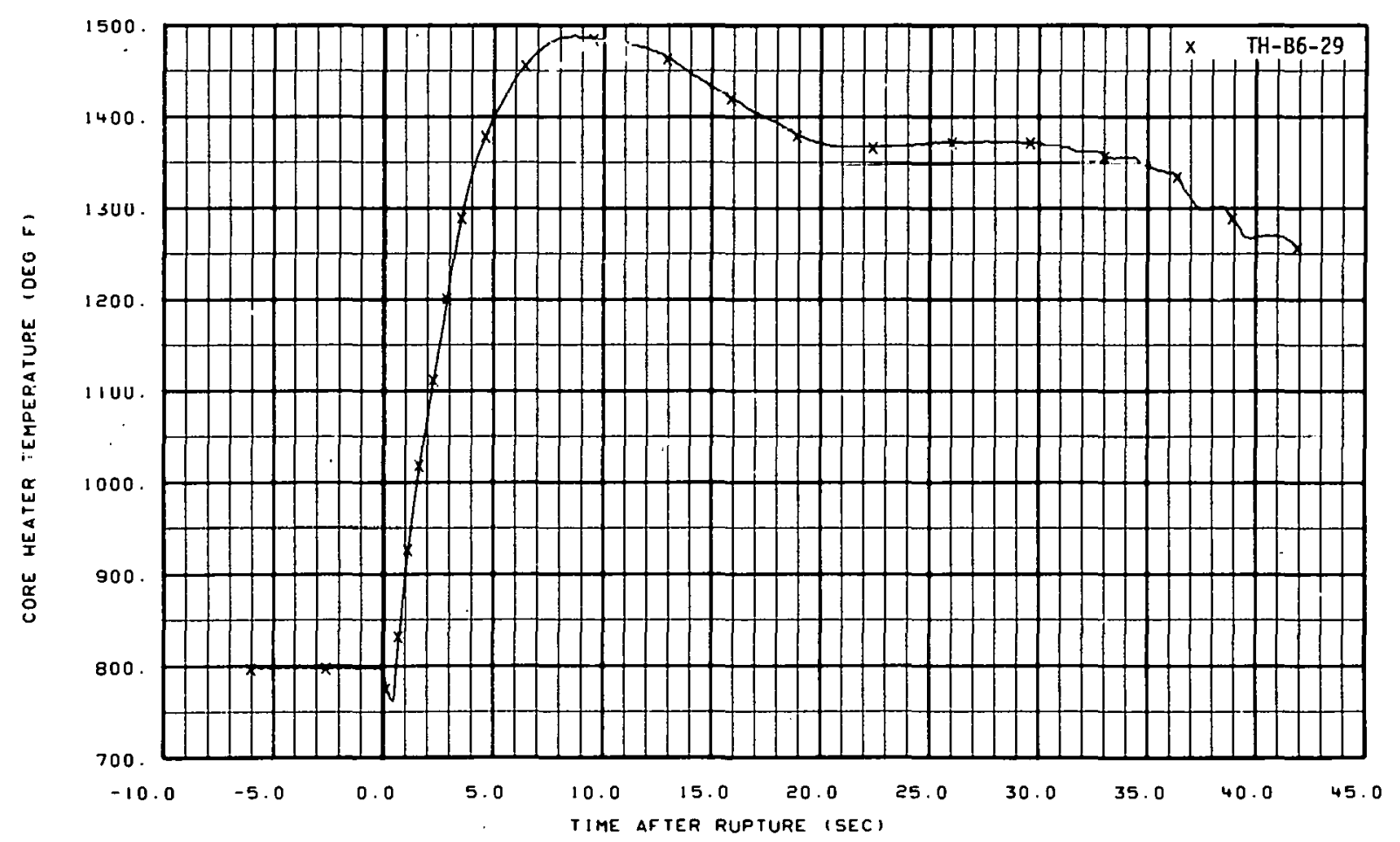

Fig. 74 Core heater temperature, Rod B-6 (TH-B6-29), from -6 to 42 seconds. 


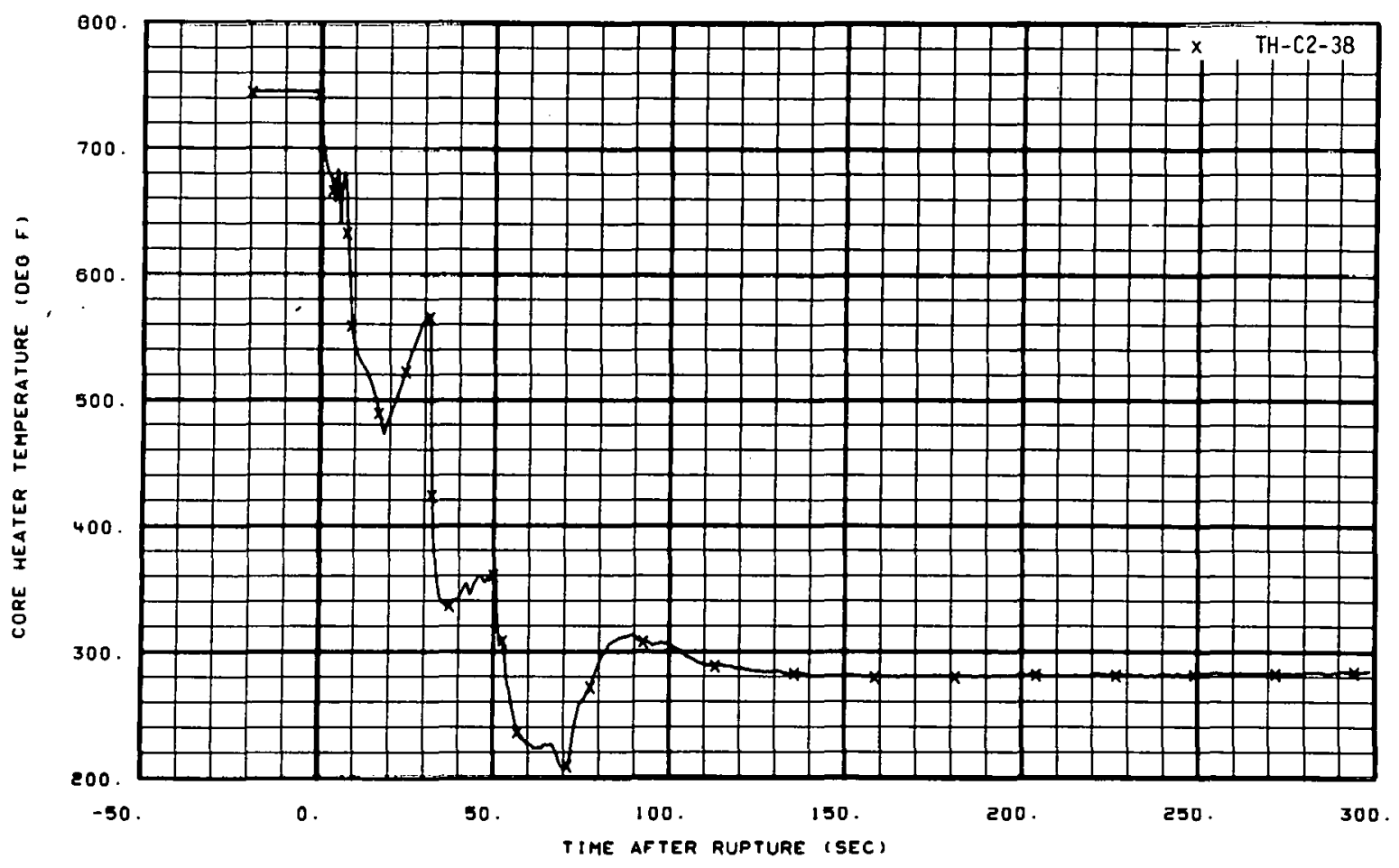

Fig. 75 Core heater temperature, Rod $\mathrm{C}-2$ ( $\mathrm{TH}-\mathrm{C} 2-38)$, from -20 to 300 seconds.

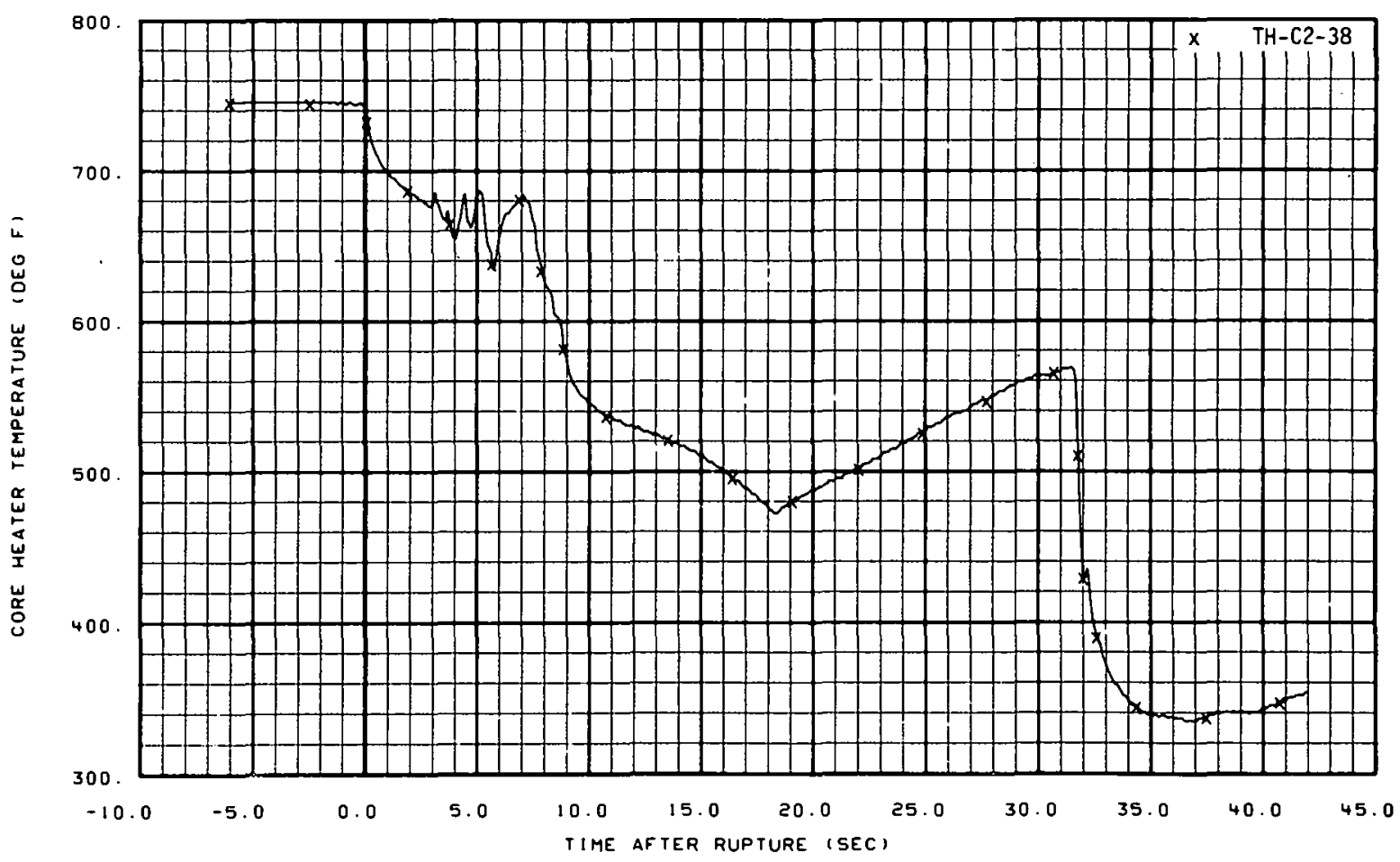

Fig. 76 Core heater temperature, Rod $\mathrm{C}-2$ ( $\mathrm{TH}-\mathrm{C} 2-38)$, from -6 to 42 seconds. 


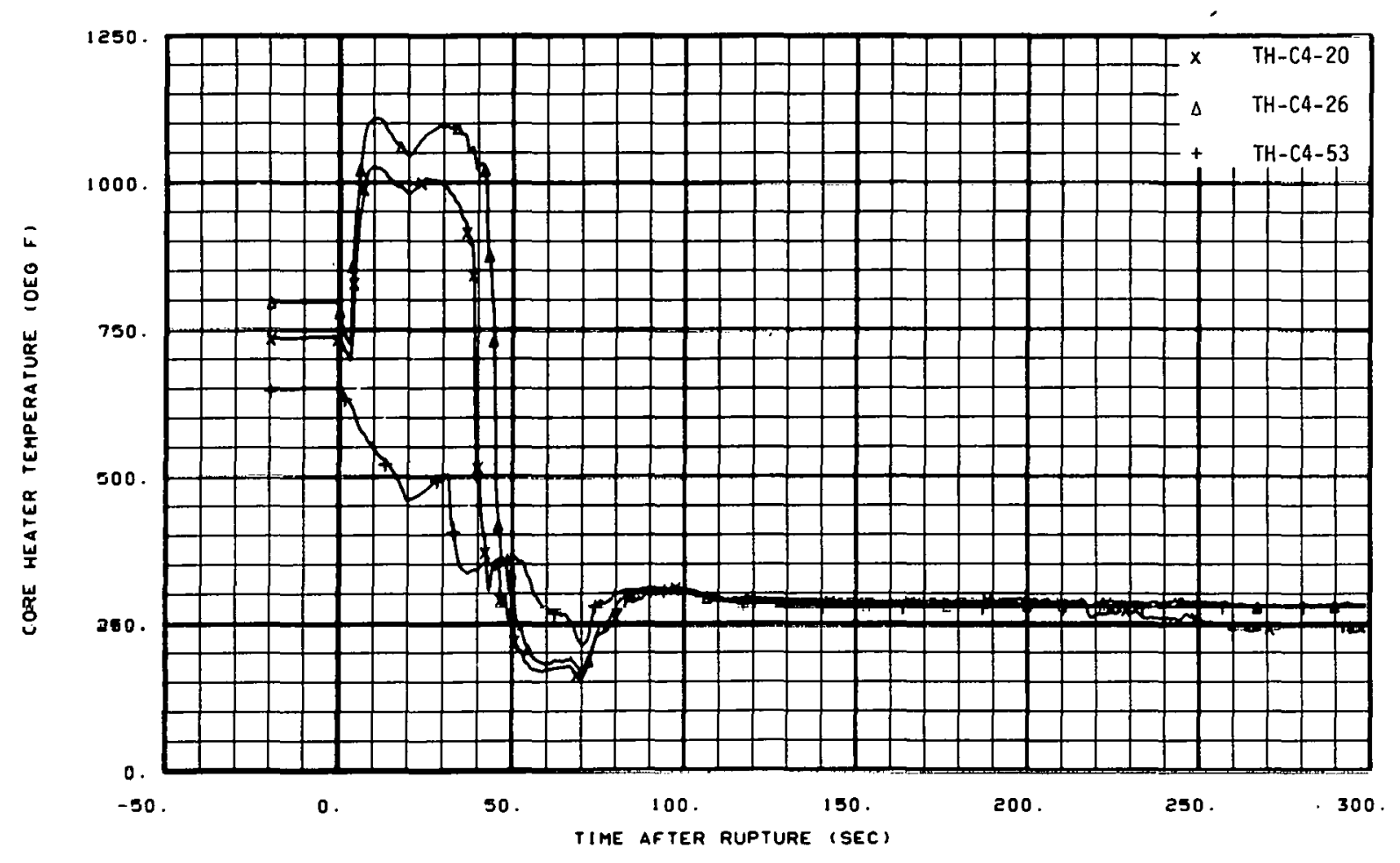

Fig. 77 Core heater temperature, Rod C-4 (TH-C4-20, TH-C4-26, and $\mathrm{TH}-\mathrm{C4}-53$ ), from -20 to 300 seconds.

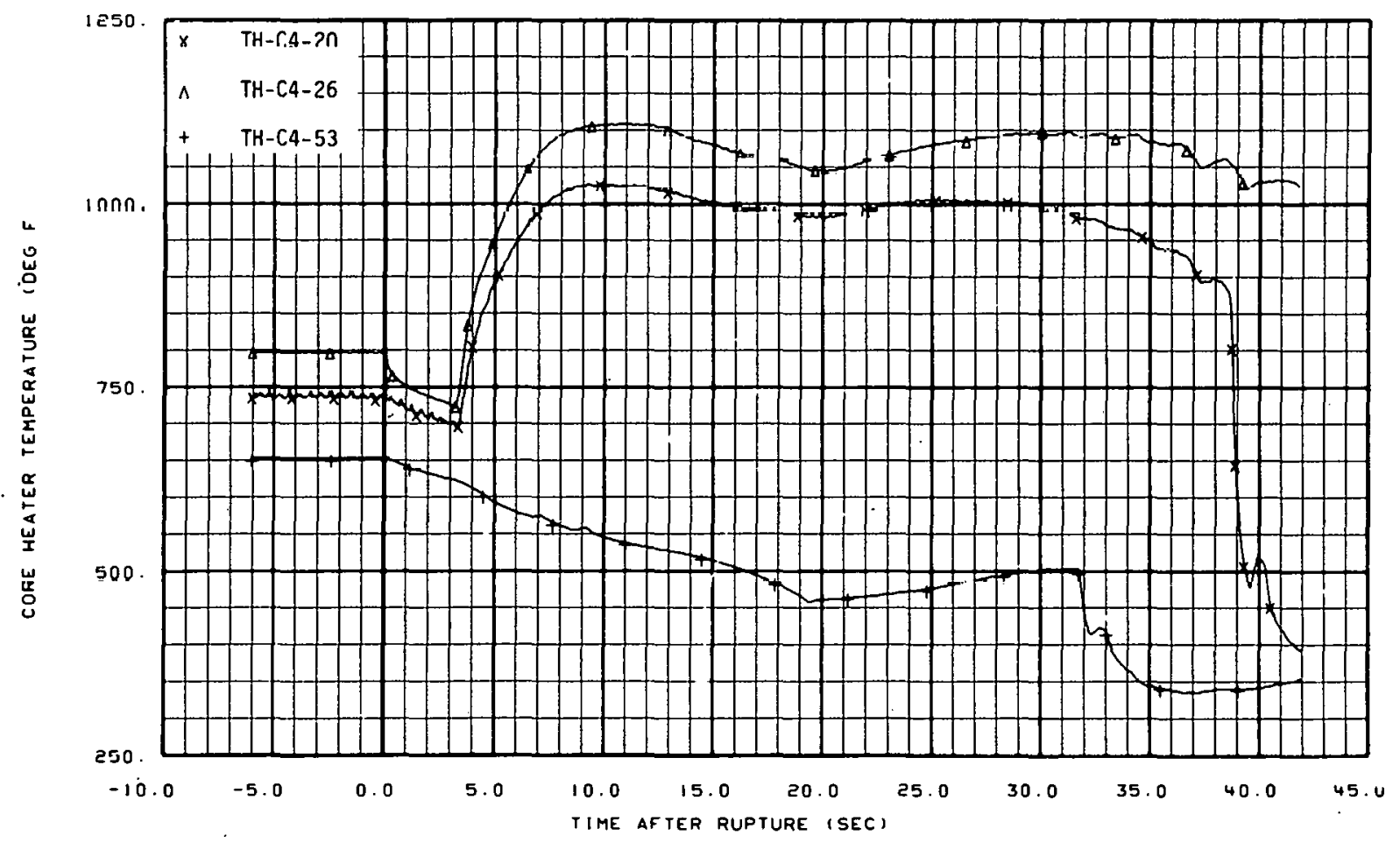

Fig. 78 Core heater temperature, Rod $\mathrm{C}-4$ (TH-C4-20, TH-C4-26, and $\mathrm{TH}-\mathrm{C} 4-53)$, from -6 to 42 seconds. 


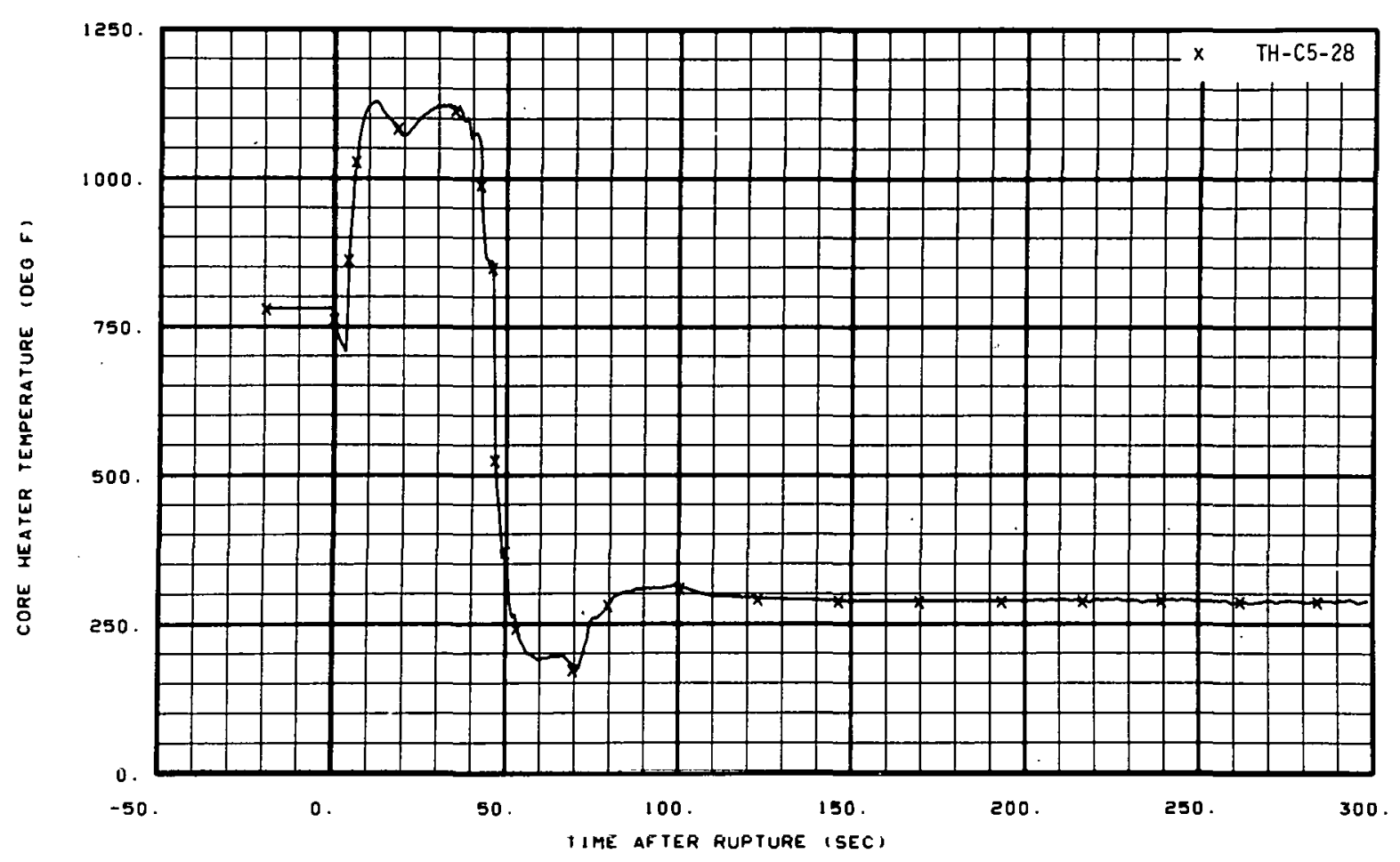

Fig. 79 Core heater temperature, Rod C-5 (TH-C5-28), from -20 to 300 seconds.

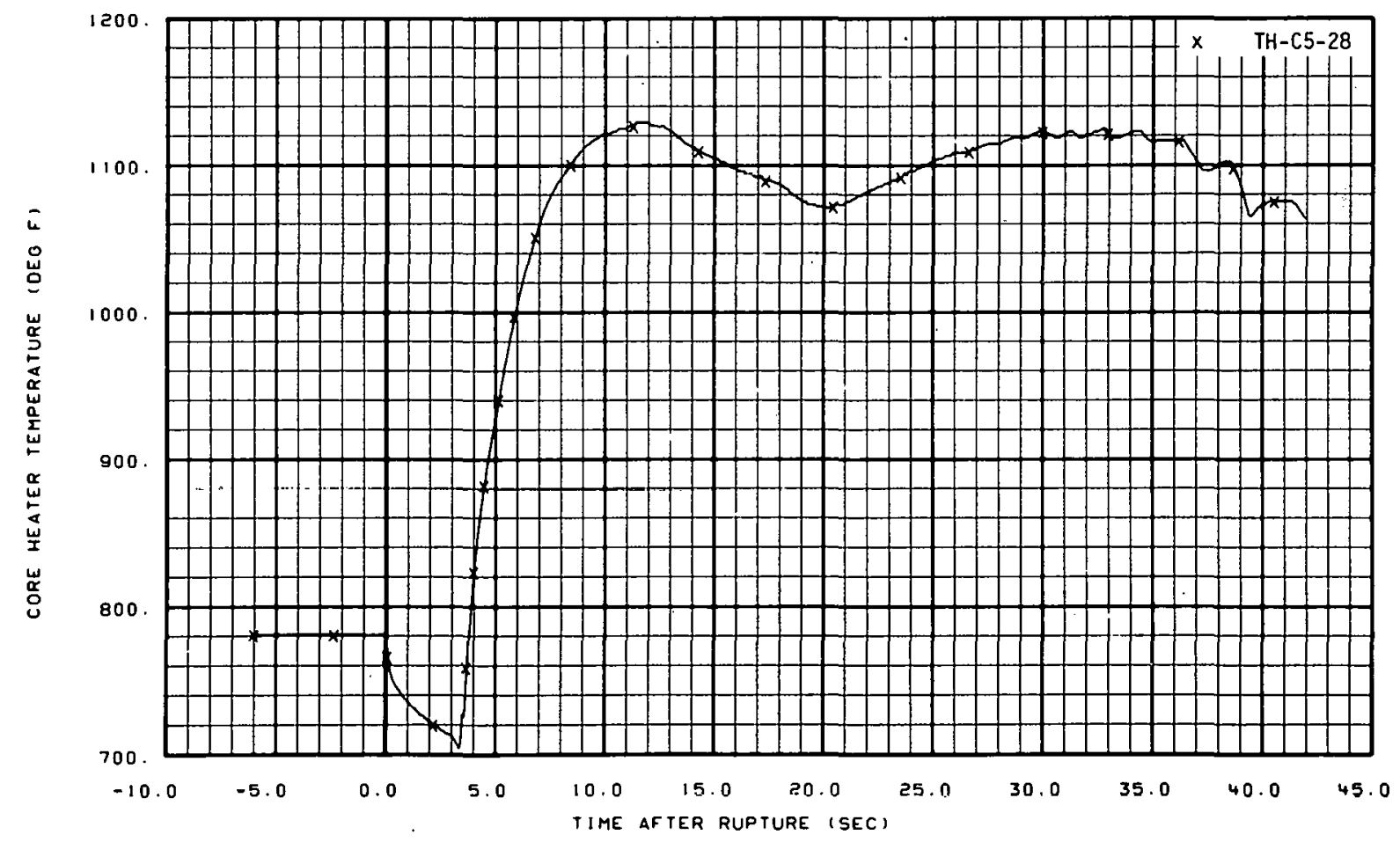

Fig. 80 Core heater temperature, Rod $\mathrm{C}-5$ ( TH-C5-28), from -6 to 42 seconds. 


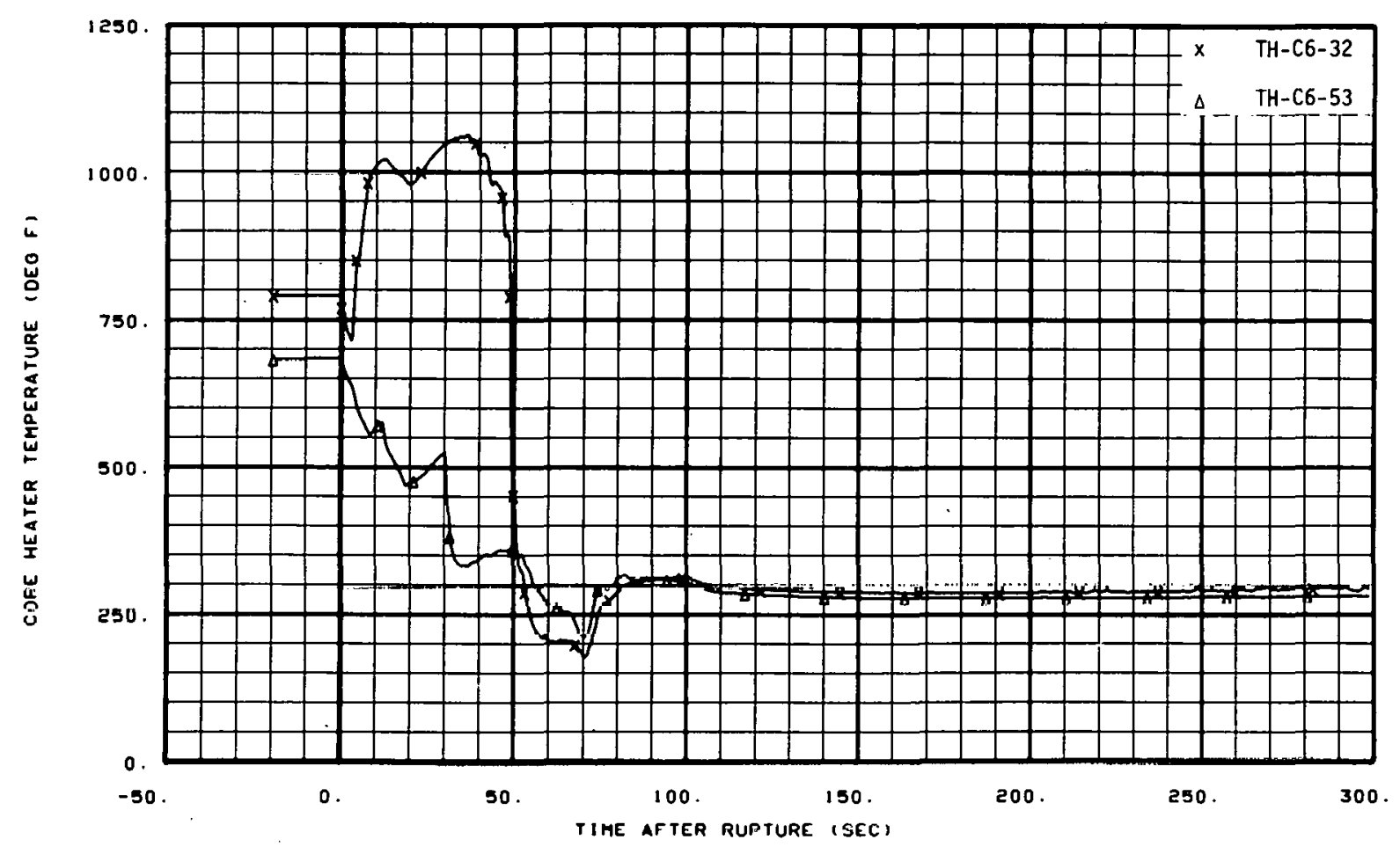

Fig. 81 Core heater temperature, Rod C-6 (TH-C6-32 and TH-C6-53), from -20 to 300 seconds.

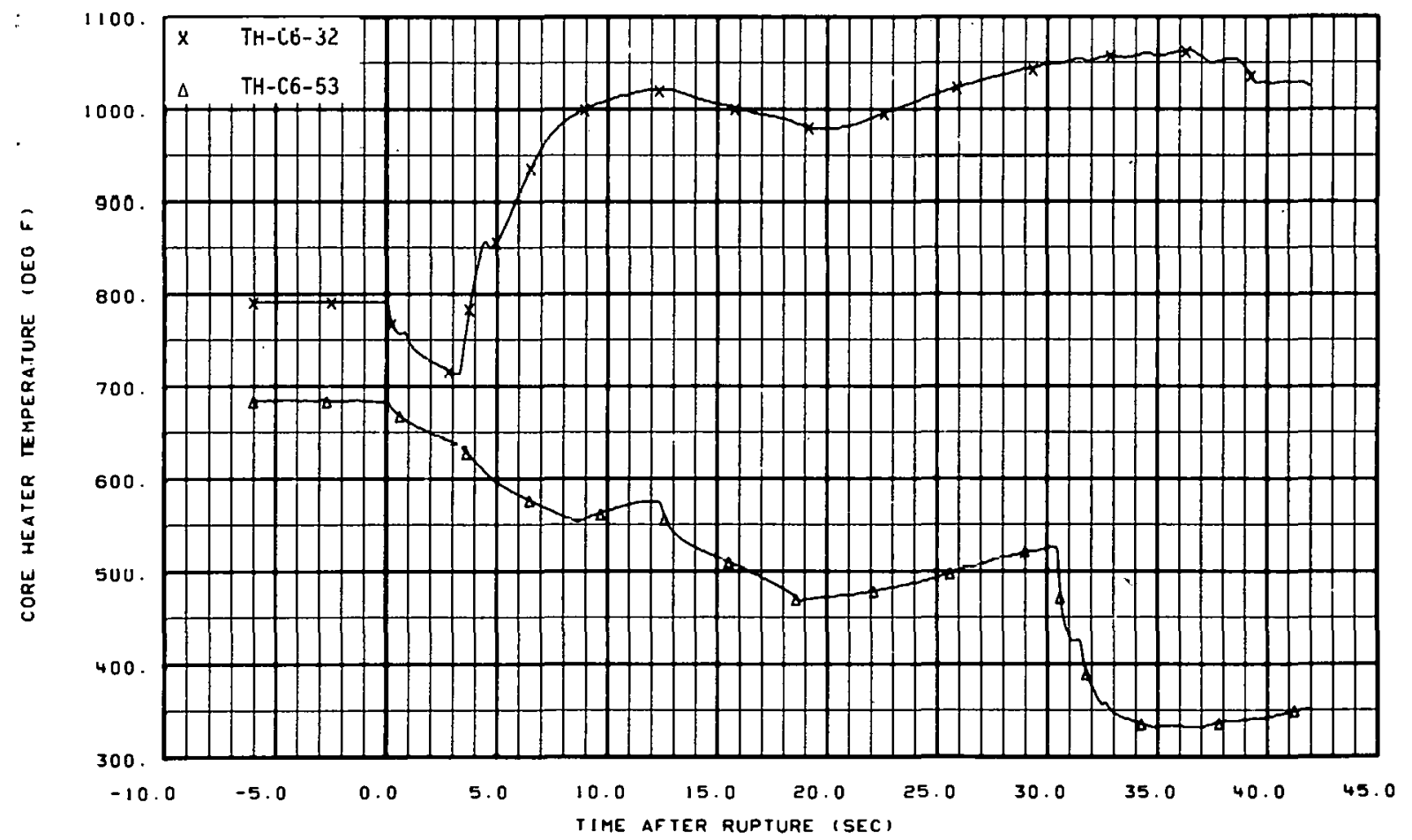

Fig. 82 Core heater temperature, Rod C-6 (TH-C6-32 and TH-C6-53), from -6 to 42 seconds. 


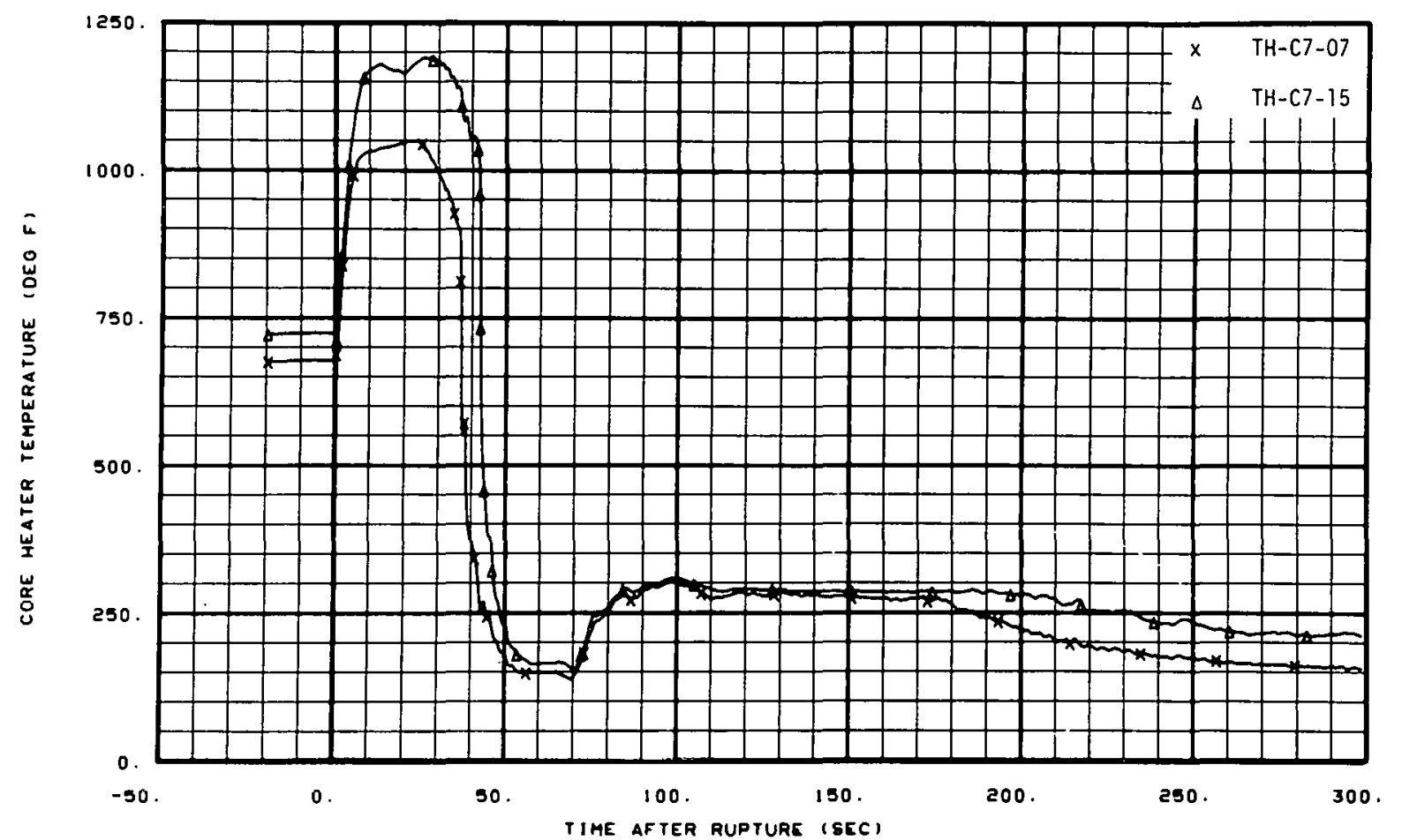

Fig. 83 Core heater temperature, Rod $\mathrm{C}-7$ (TH-C7-07 and TH-C7-15), from -20 to 300 seconds.

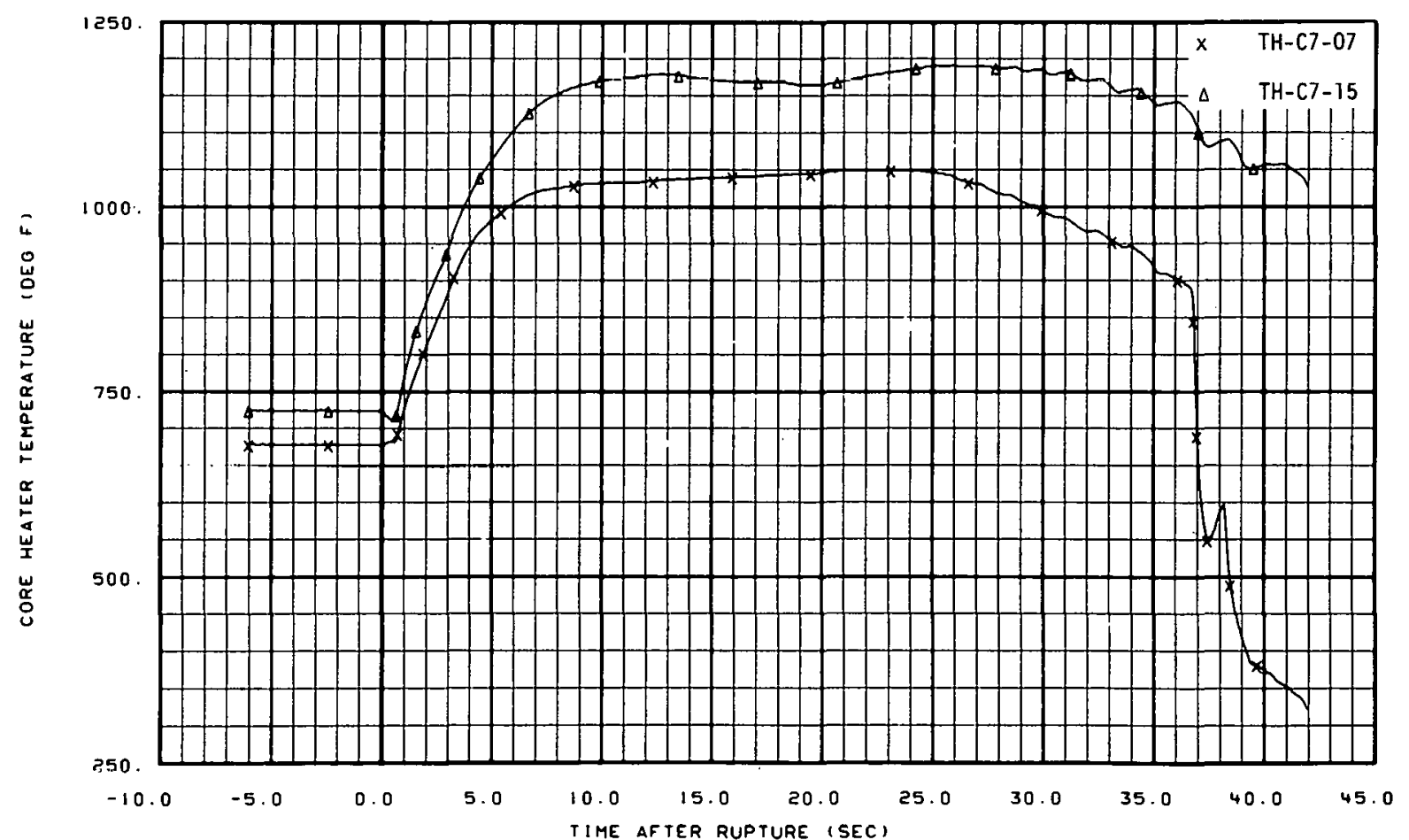

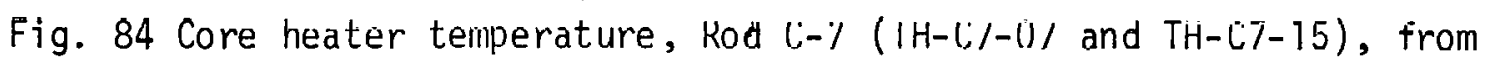
-6 to 42 seconds. 


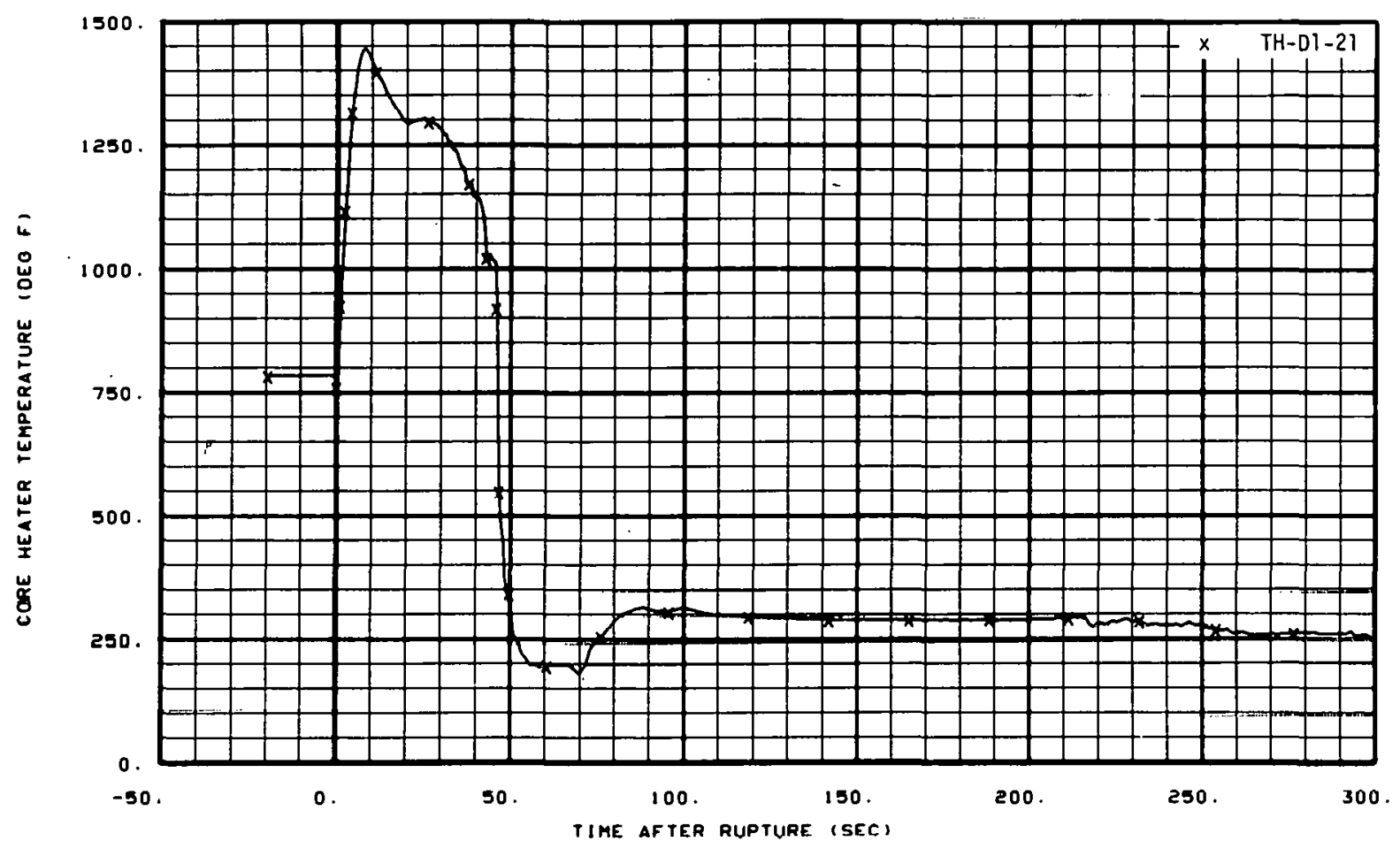

Fig. 85 Core heater temperature, Rod D-1 (TH-DI-21), from -20 to 300 seconds.

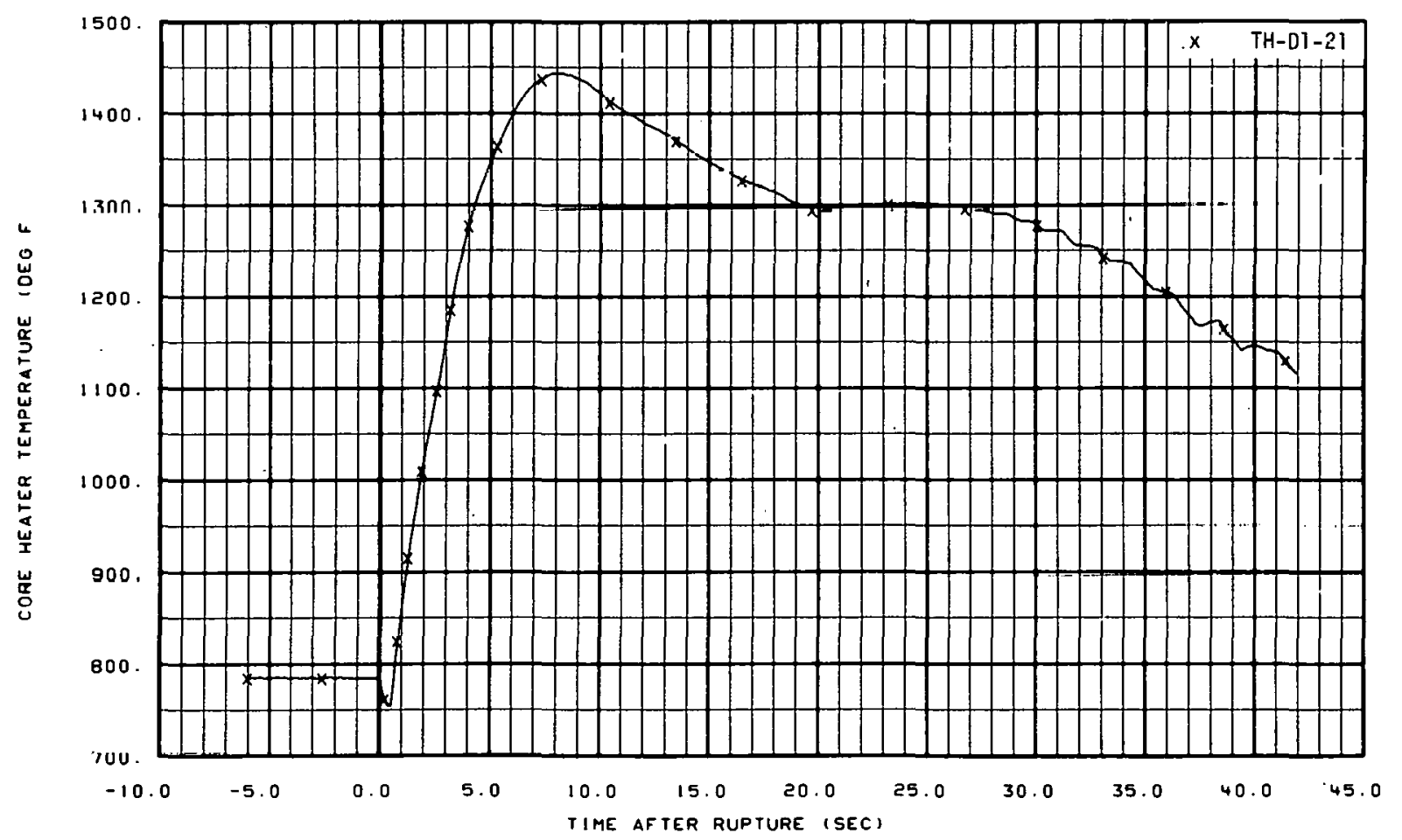

Fig. 86 Core heater temperature, Rod D-1 (TH-DI-21), from -6 to 42 seconds. 


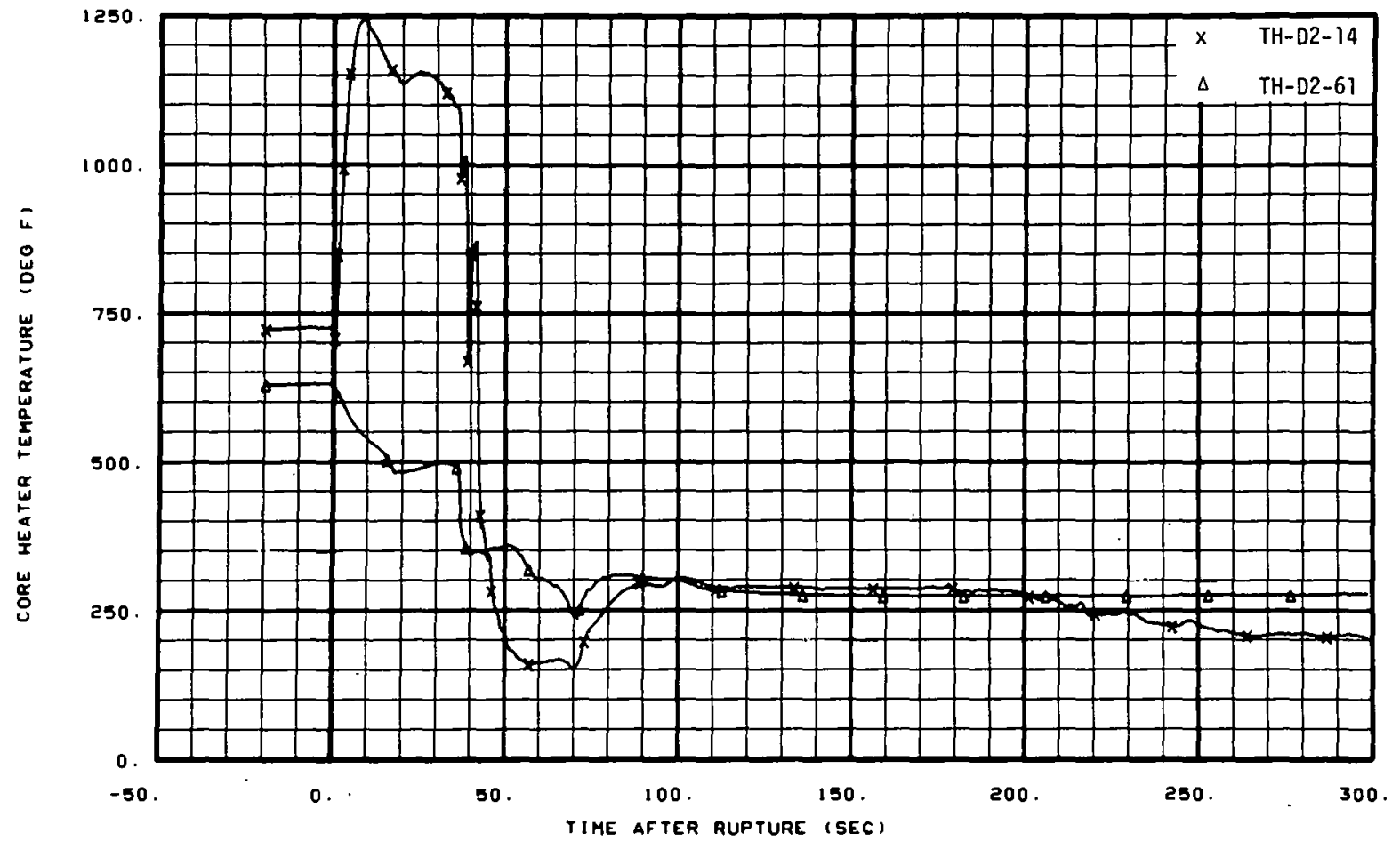

Fig. 87 Core heater temperature, Rod D-2 (TH-D2-14 and TH-D2-61), from -20 to 300 seconds.

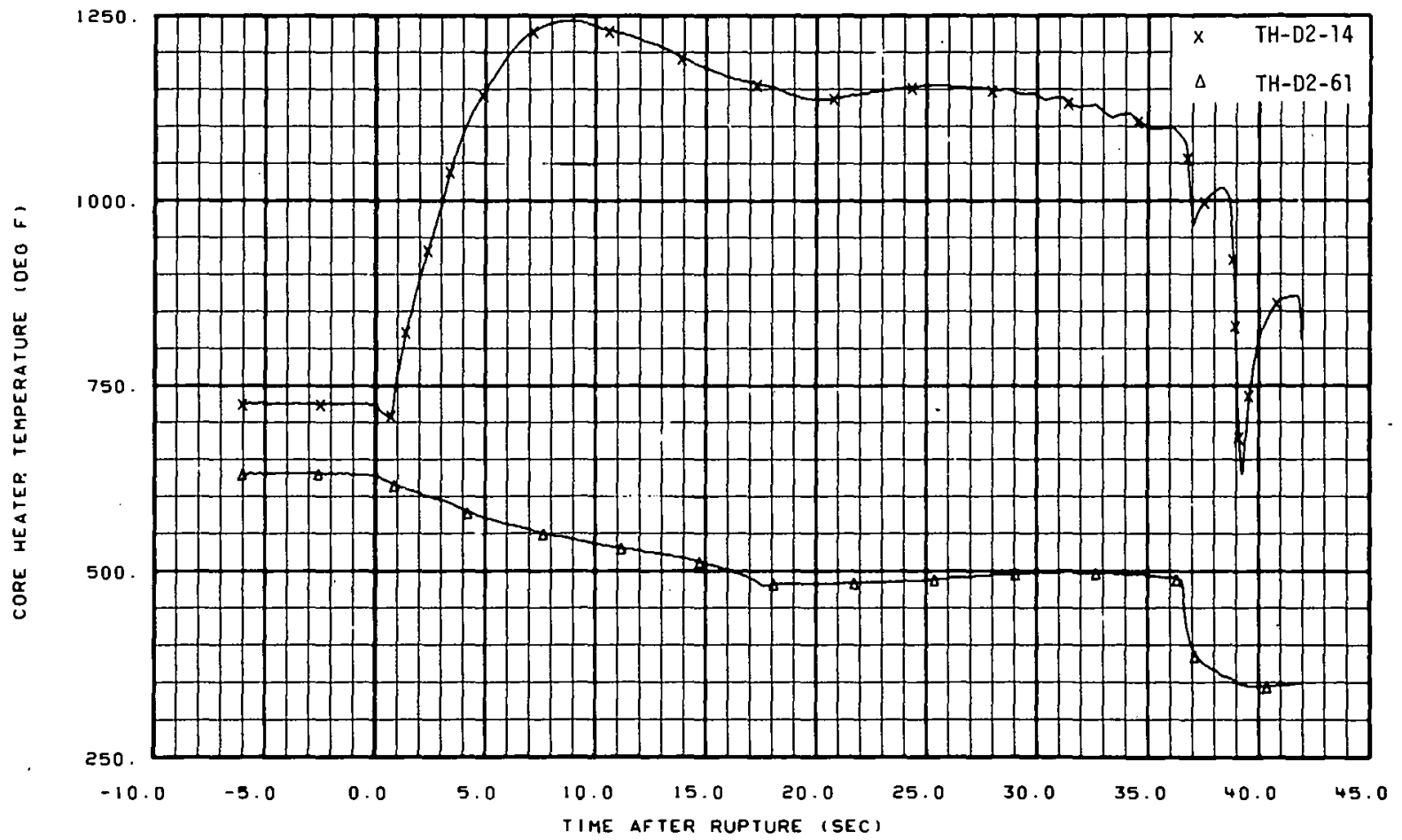

Fig. 88 Core heater temperature, Rod D-2 (TH-D2-14 and TH-D2-61), from -6 to 42 seconds. 


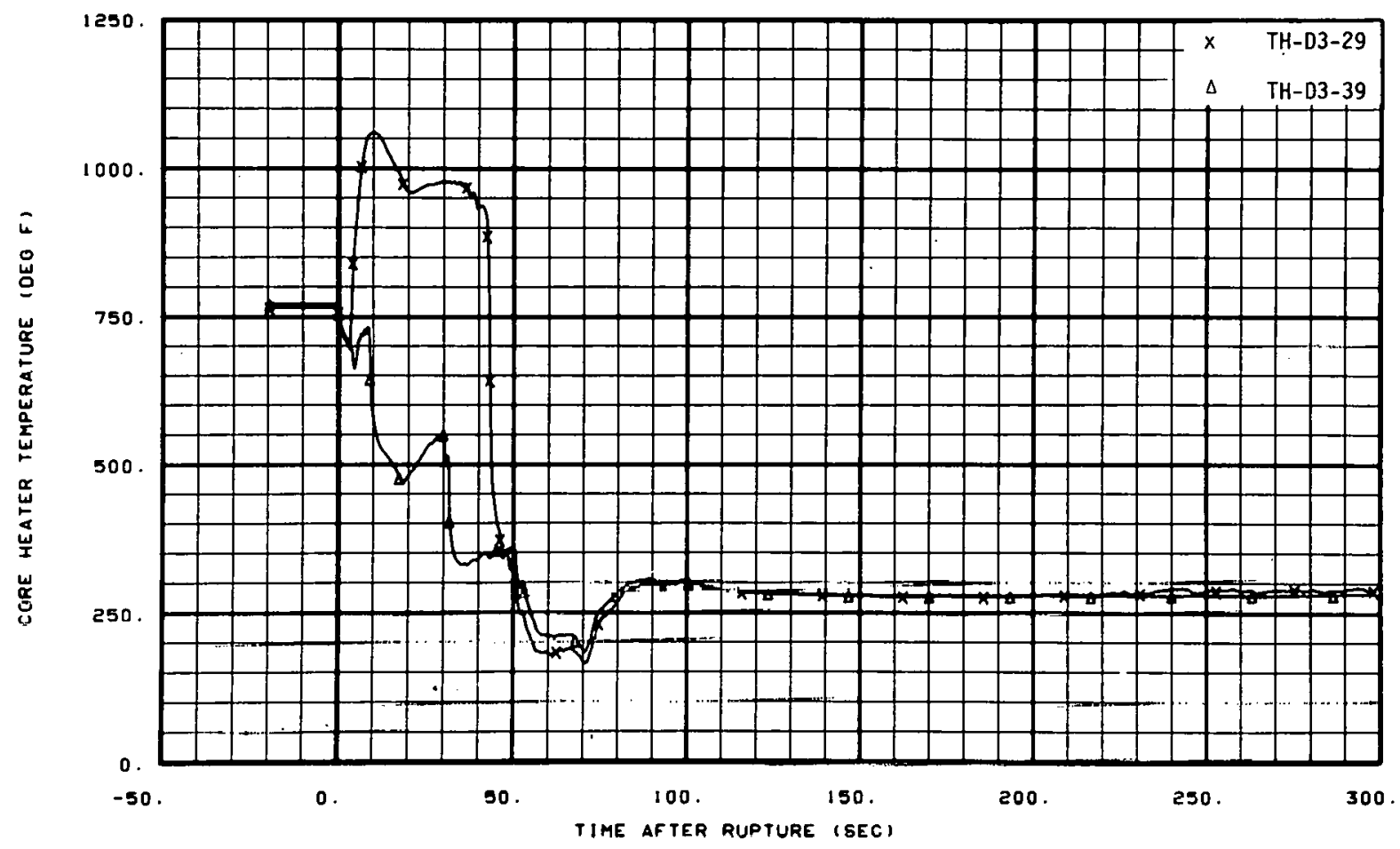

Fig. 89 Core heater temperature, Rod D-3 (TH-D3-29 and TH-D3-39), from -20 to 300 seconds.

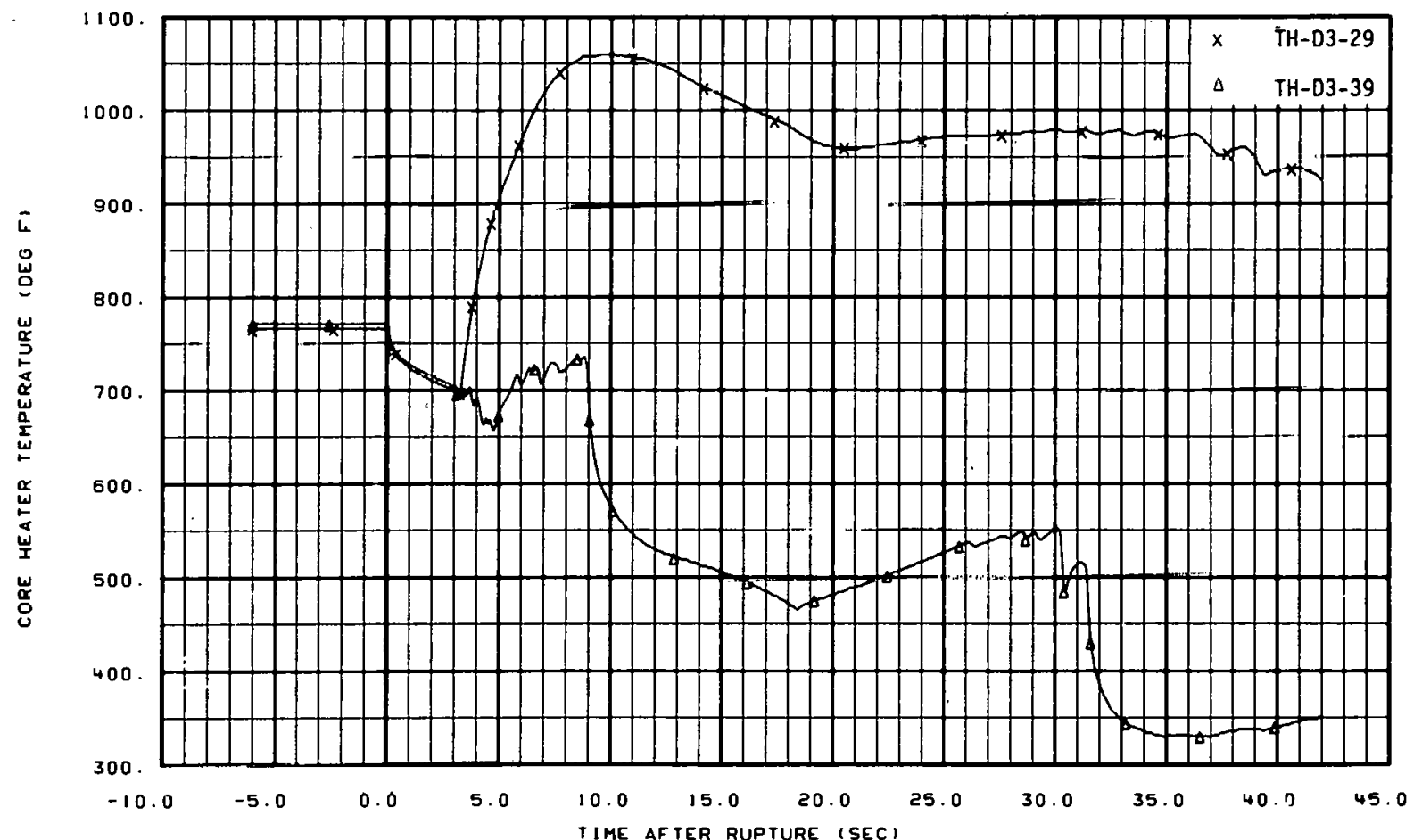

Fig. 90 Core heater temperature, Rod D-3 (TH-D3-29 and TH-D3-39), from -6 to 42 seconds. 


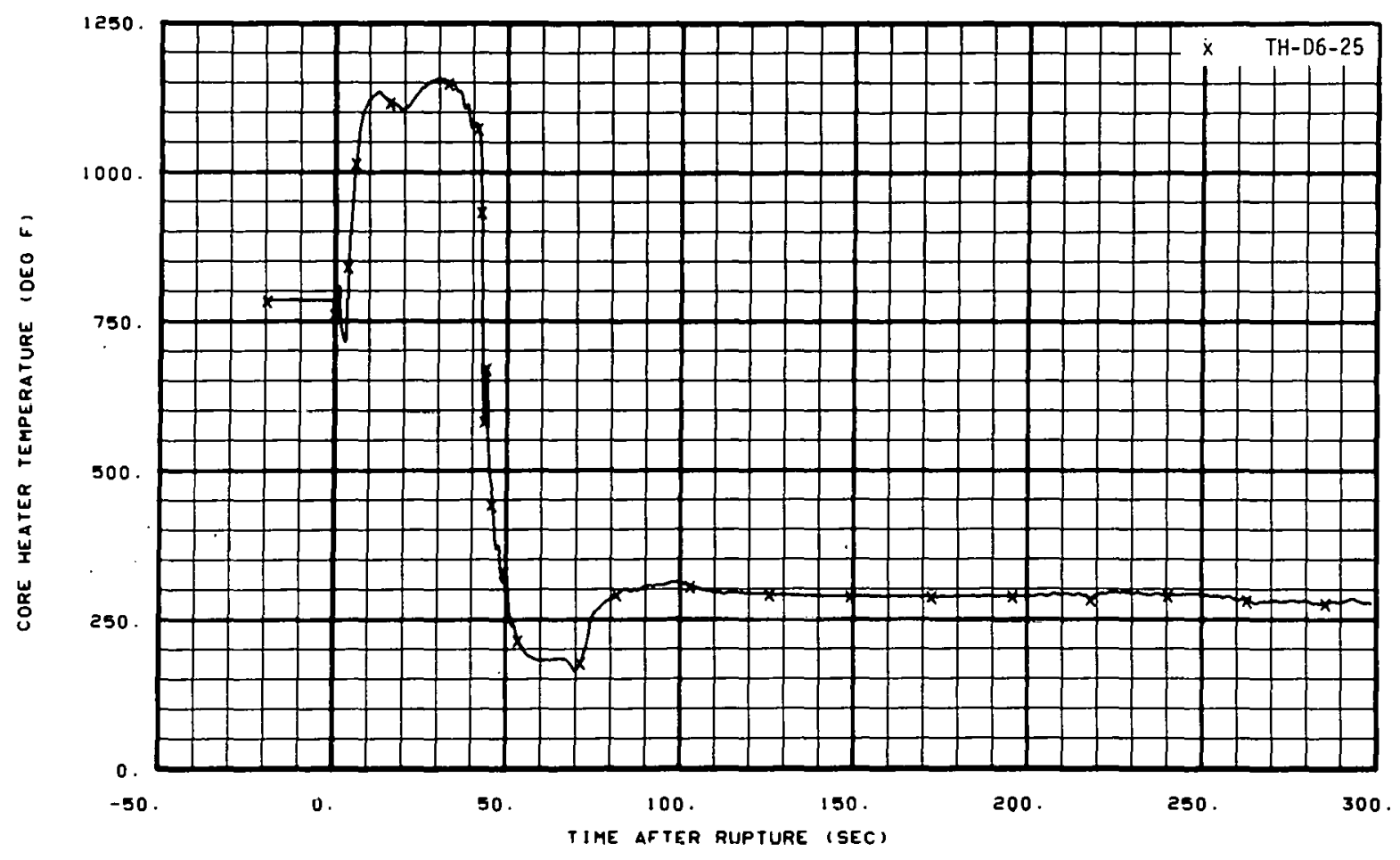

Fig. 91 Core heater temperature, Rod D-6 (TH-D6-25), from -20 to 300 seconds.

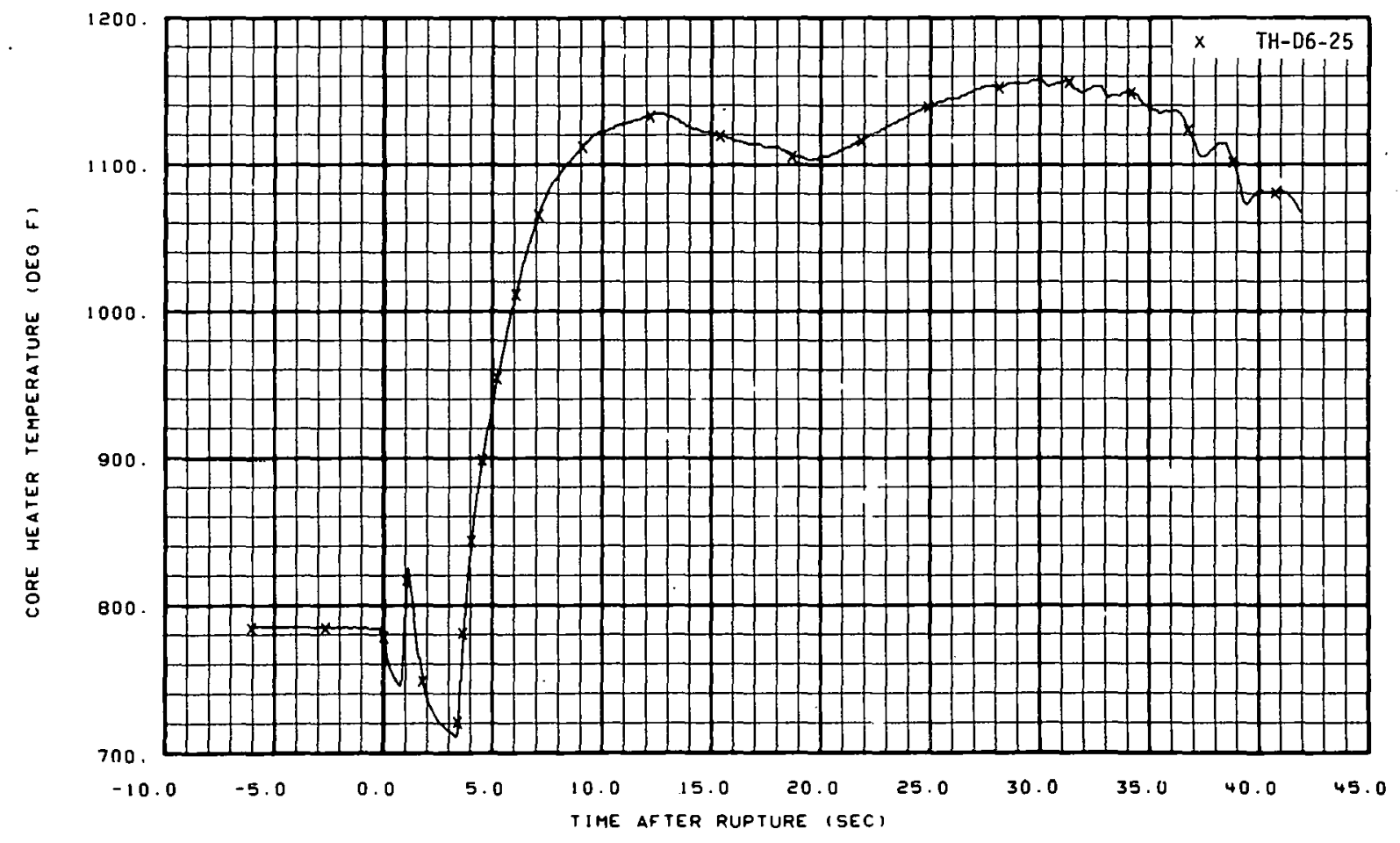

Fig. 92 Core heater temperature, Rod D-6 (TH-D6-25), from -6 to 42 seconds. 


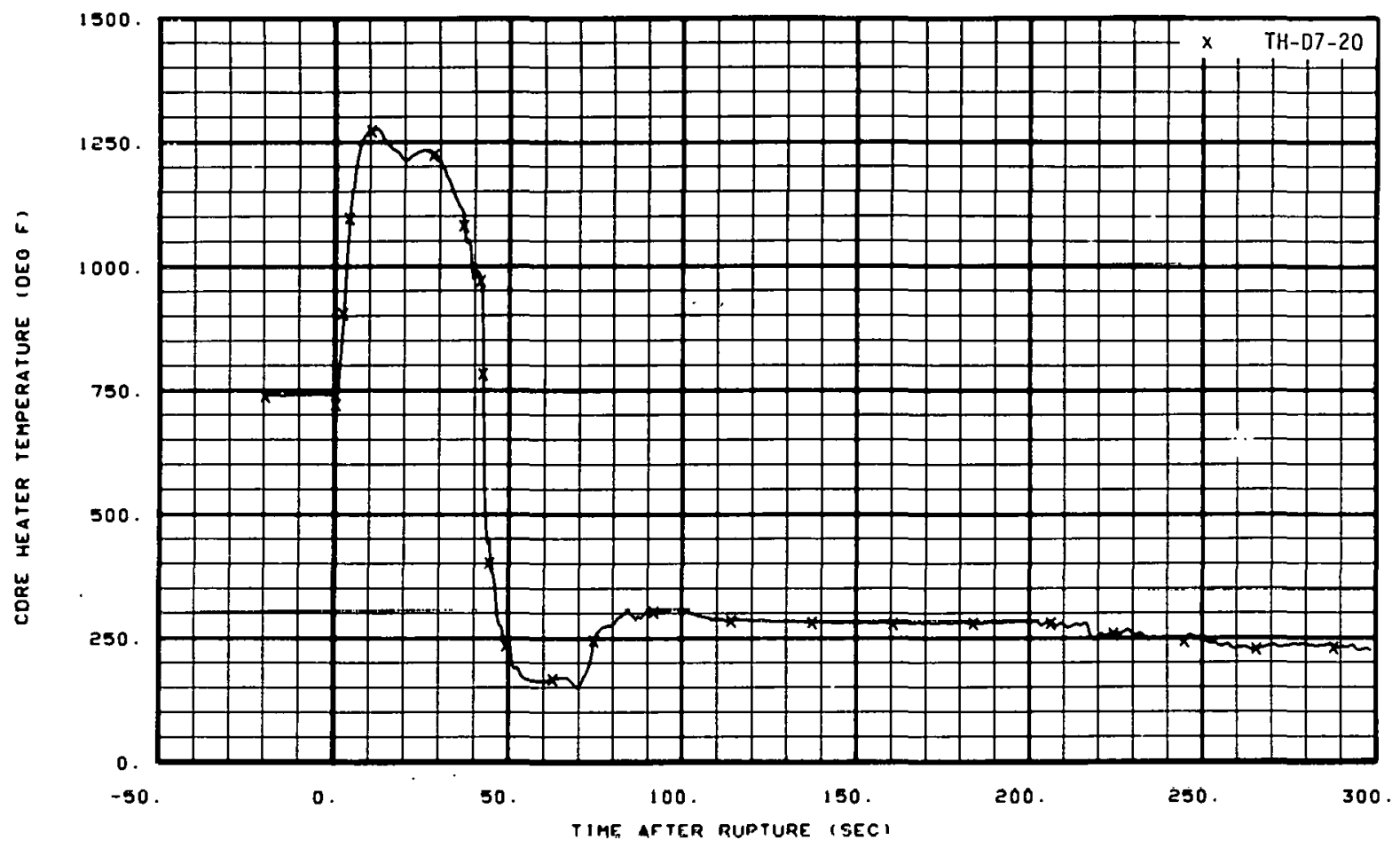

Fig. 93 Core heater temperature, Rod D-7 (TH-D7-20), from -20 to 300 seconds.

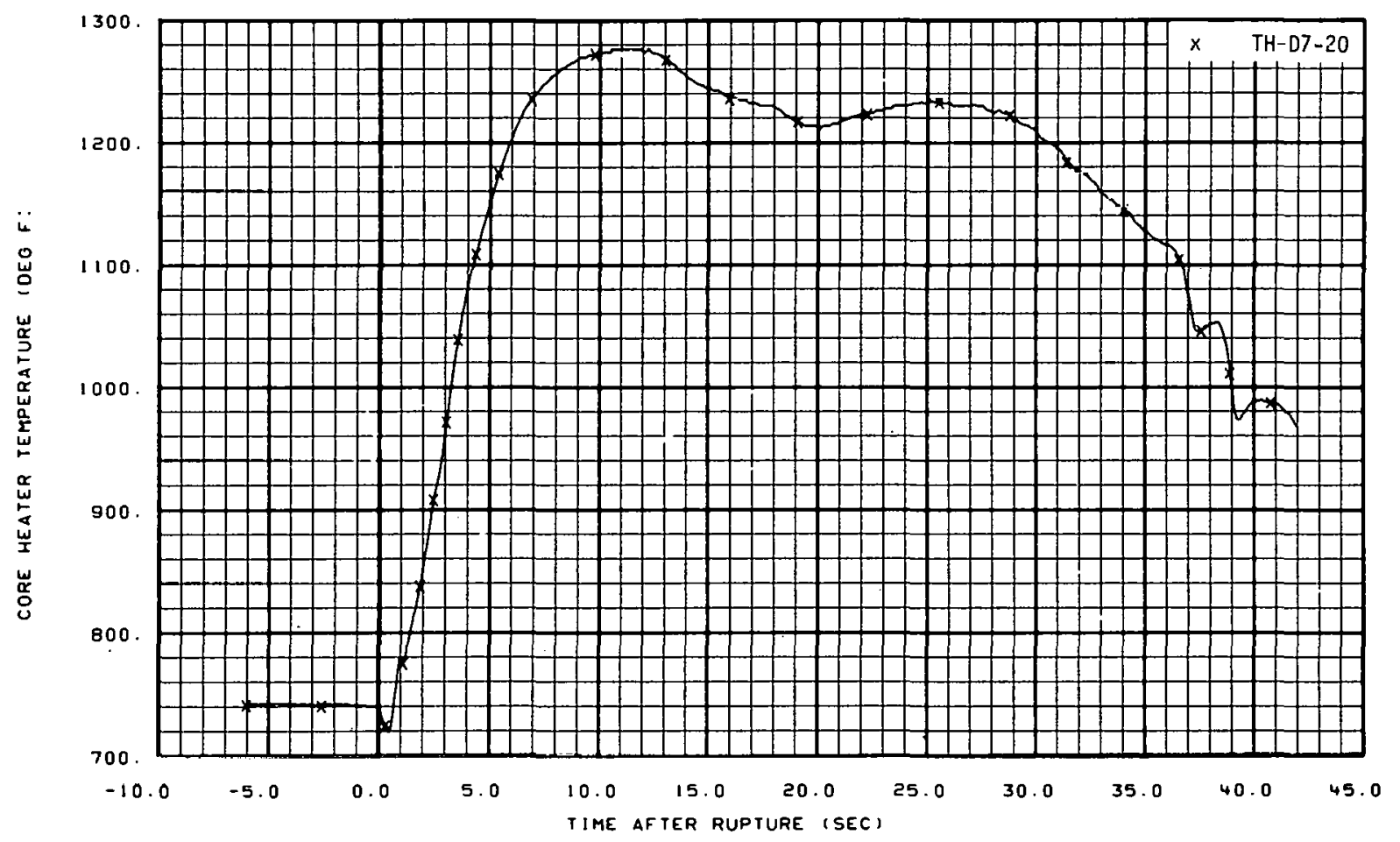

Fig. 94 Core heater temperature, Rod D-7 (TH-D7-20), from -6 to 42 seconds. 


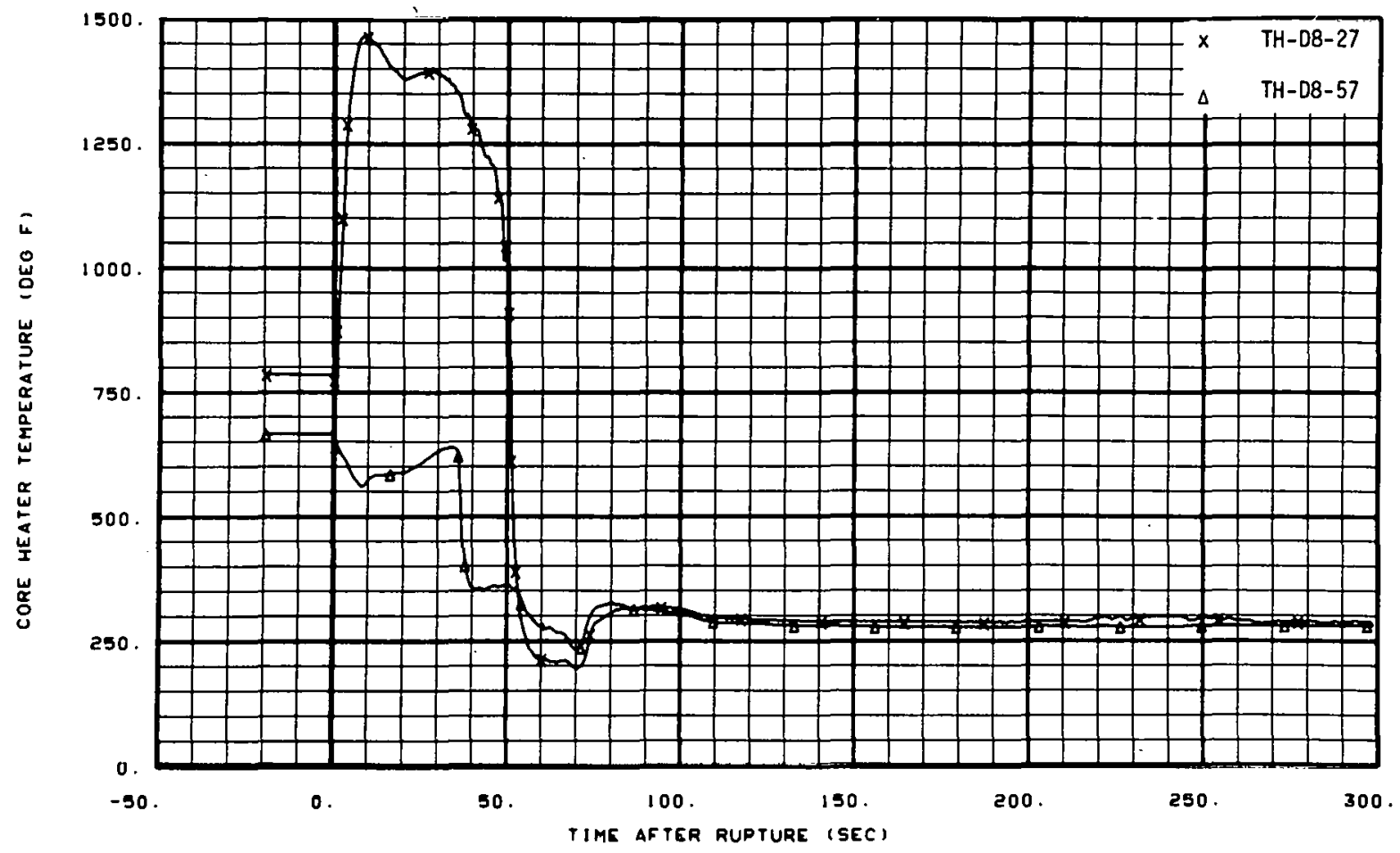

Fig. 95 Core heater temperature, Rod D-8 (TH-D8-27 and TH-D8-57), from -20 to 300 seconds.

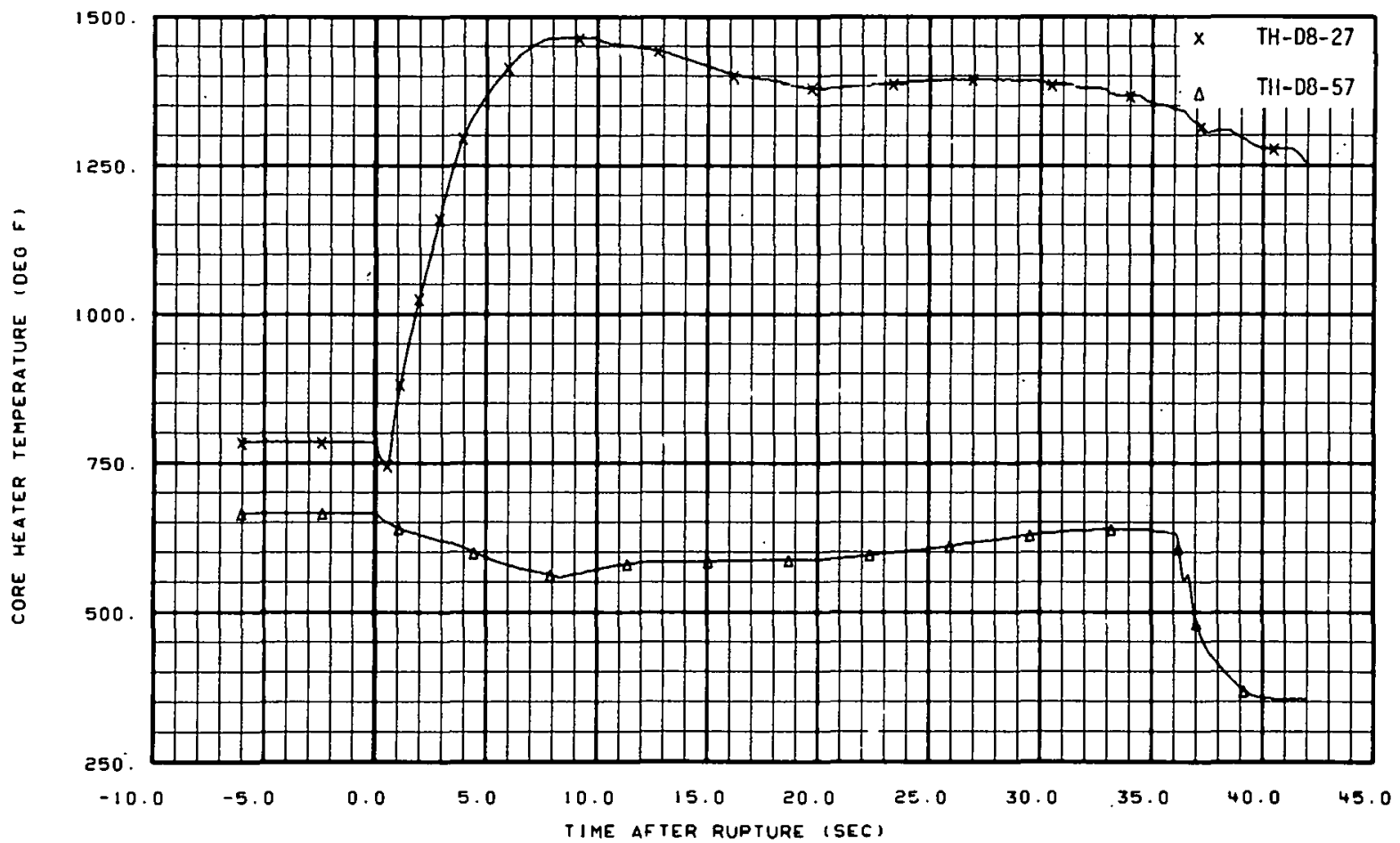

Fig. 96 Core heater temperature, Rod D-8 (TH-D8-27 and TH-D8-57), from -6 to 42 seconds. 


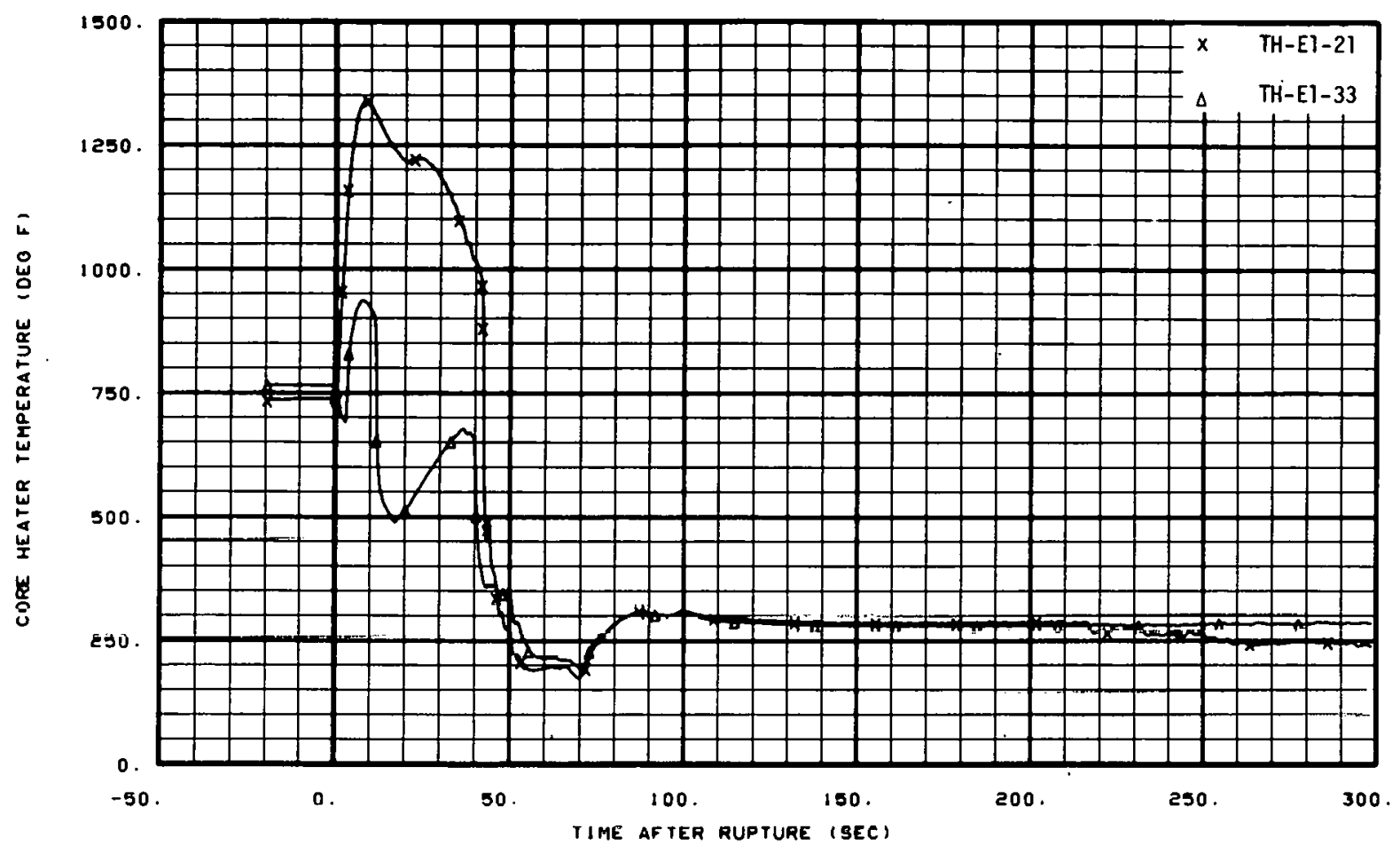

Fig. 97 Core heater temperature, Rod E-1 (TH-El-21 and $\mathrm{TH}-\mathrm{E}]-33$ ), from -20 to 300 seconds.

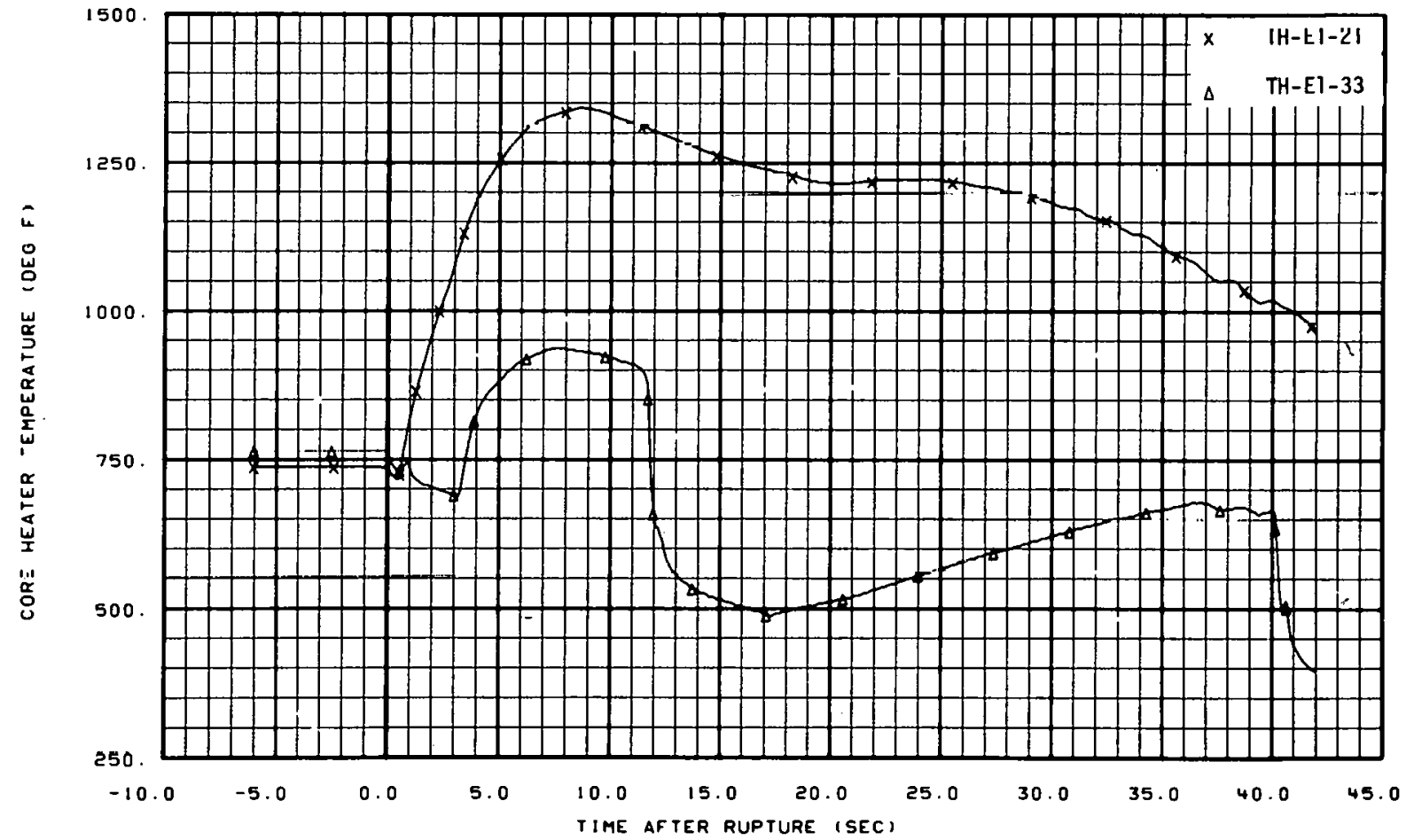

Fig. 98 Core heater temperature, Rod E- 7 (TH-ET-21 and TH-El-33), from -6 to 42 seconds. 


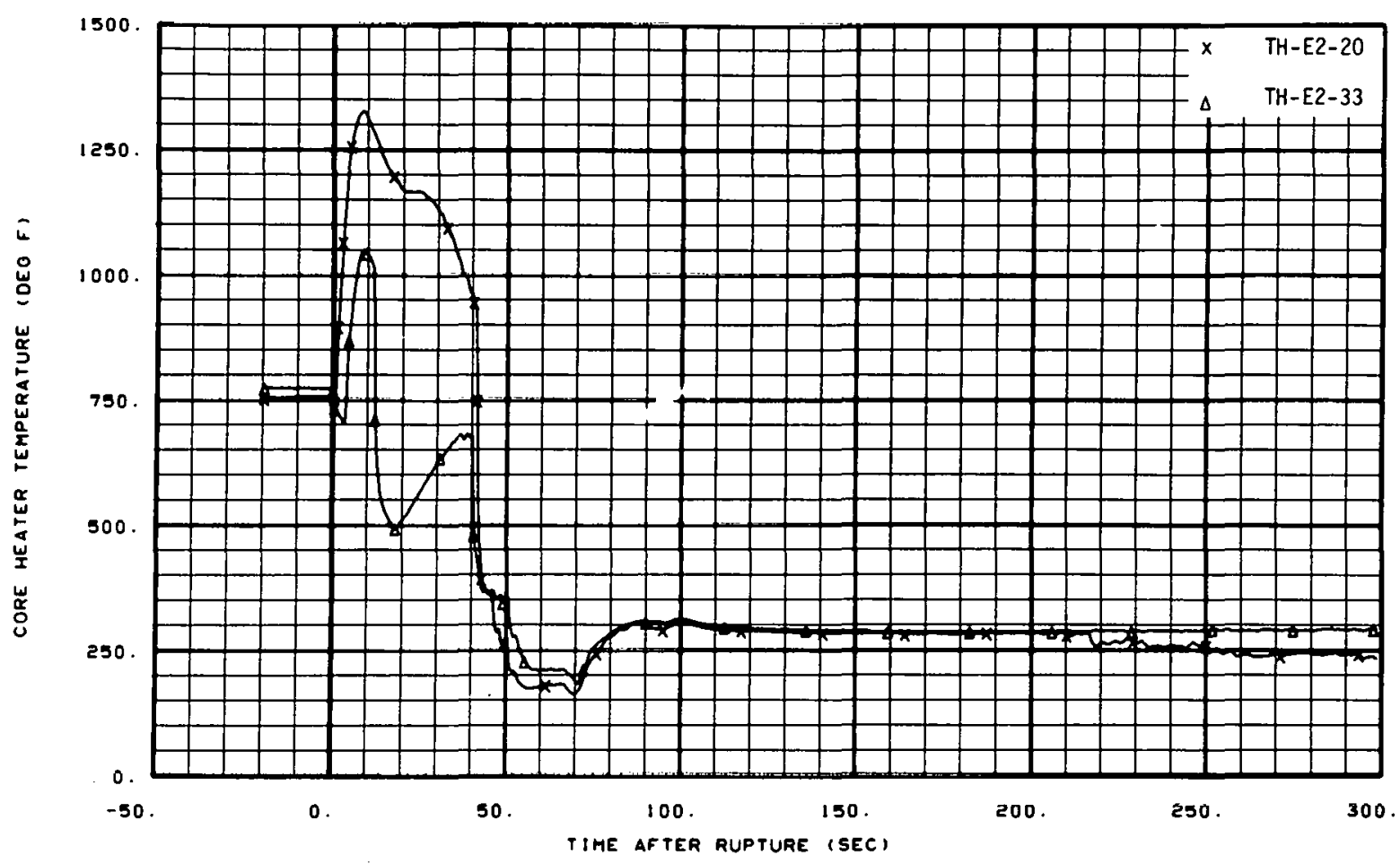

Fig. 99 Core heater temperature, Rod E-2 (TH-E2-20 and TH-E2-33), from -20 to 300 seconds.

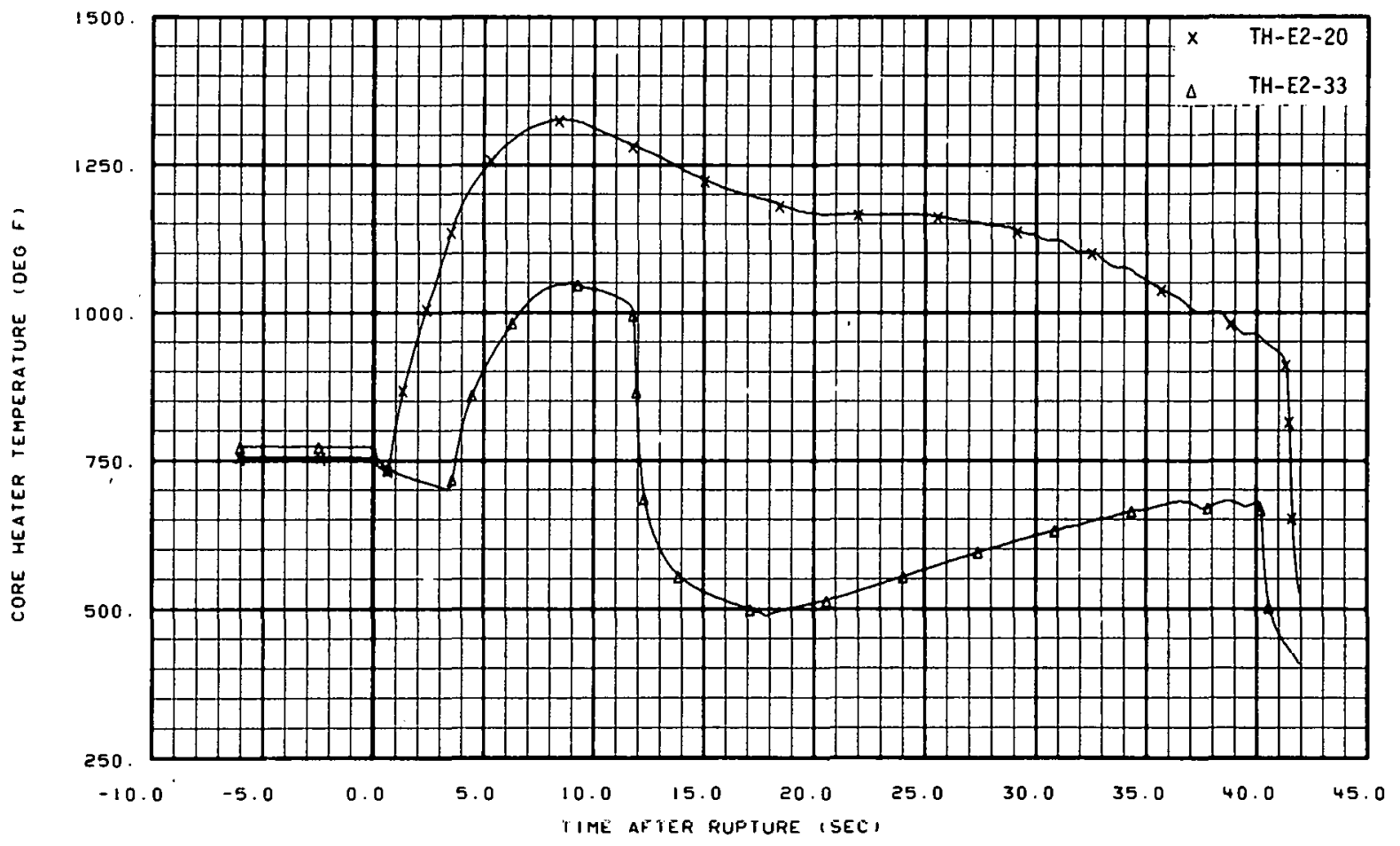

Fig. 100 Core heater temperature, Rod E-2 (TH-E2-20 and TH-E2-33), from -6 to 42 seconds. 


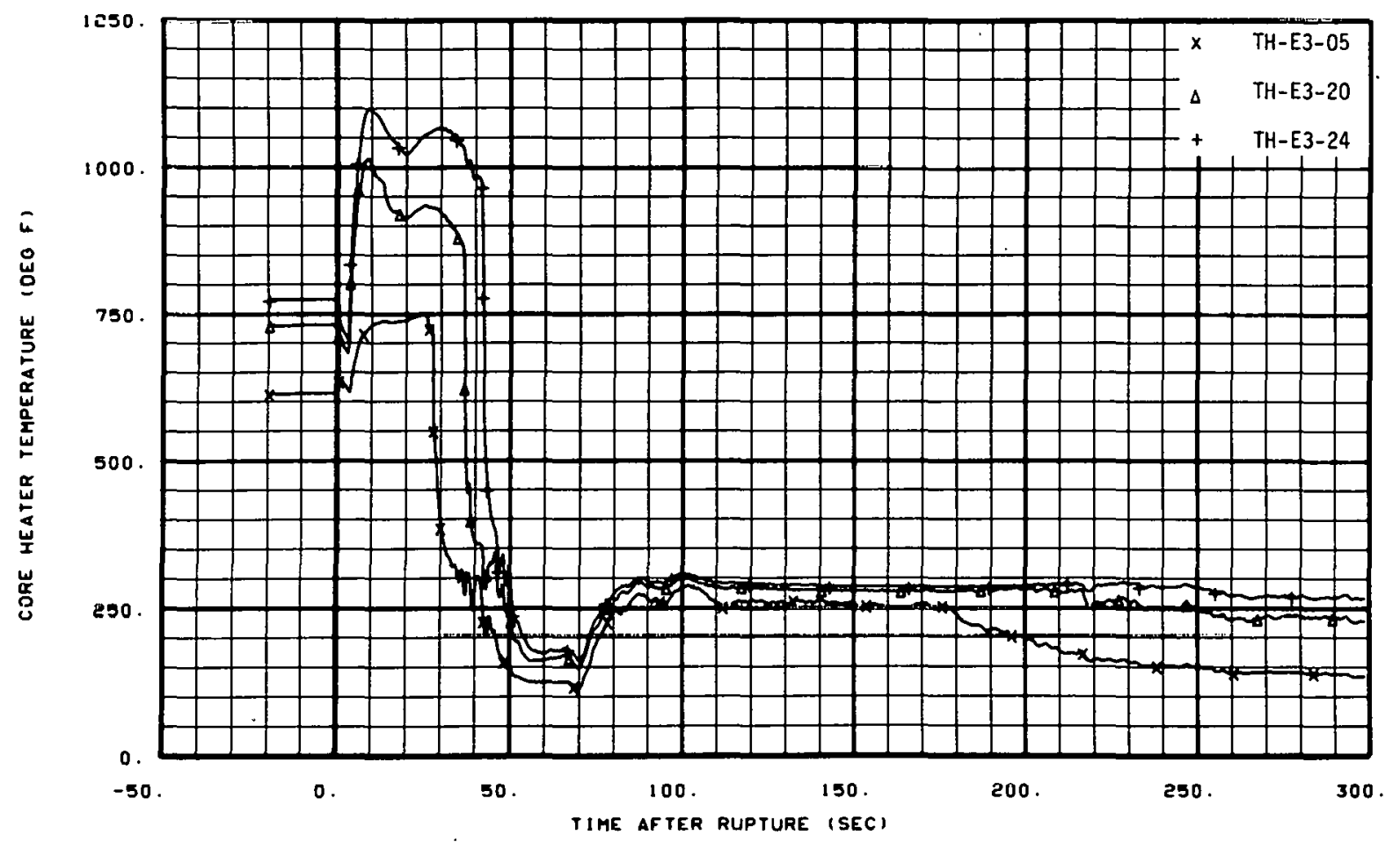

Fig. 101 Core heater temperature, Rod E-3 (TH-E3-05, TH-E3-20, and TH-E3-24), from -20 to 300 seconds.

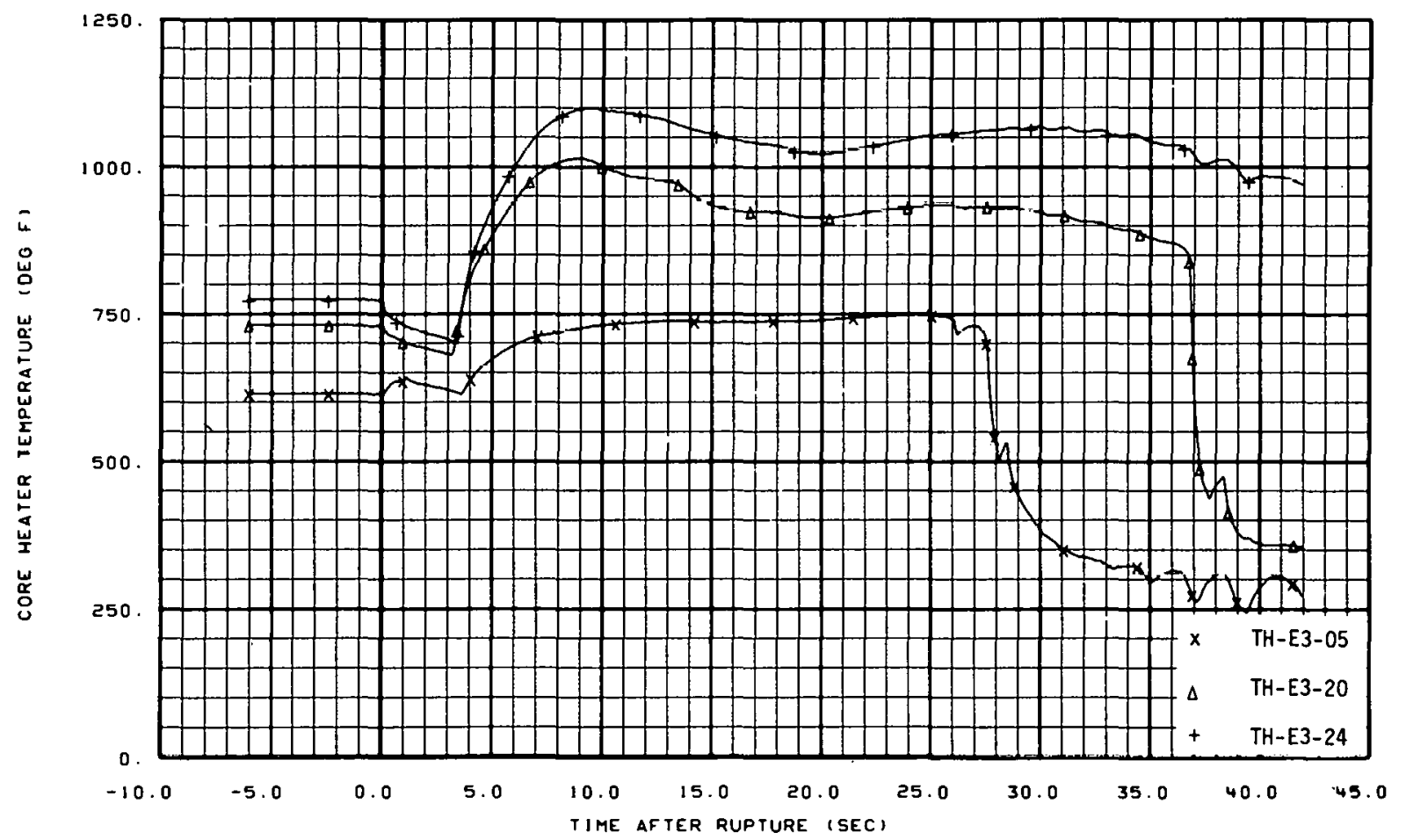

Fig. 102 Core heater temperature, Rod E-3 (TH-E3-05, TH-E3-20, and TH-E3-24), from -6 to 42 seconds. 


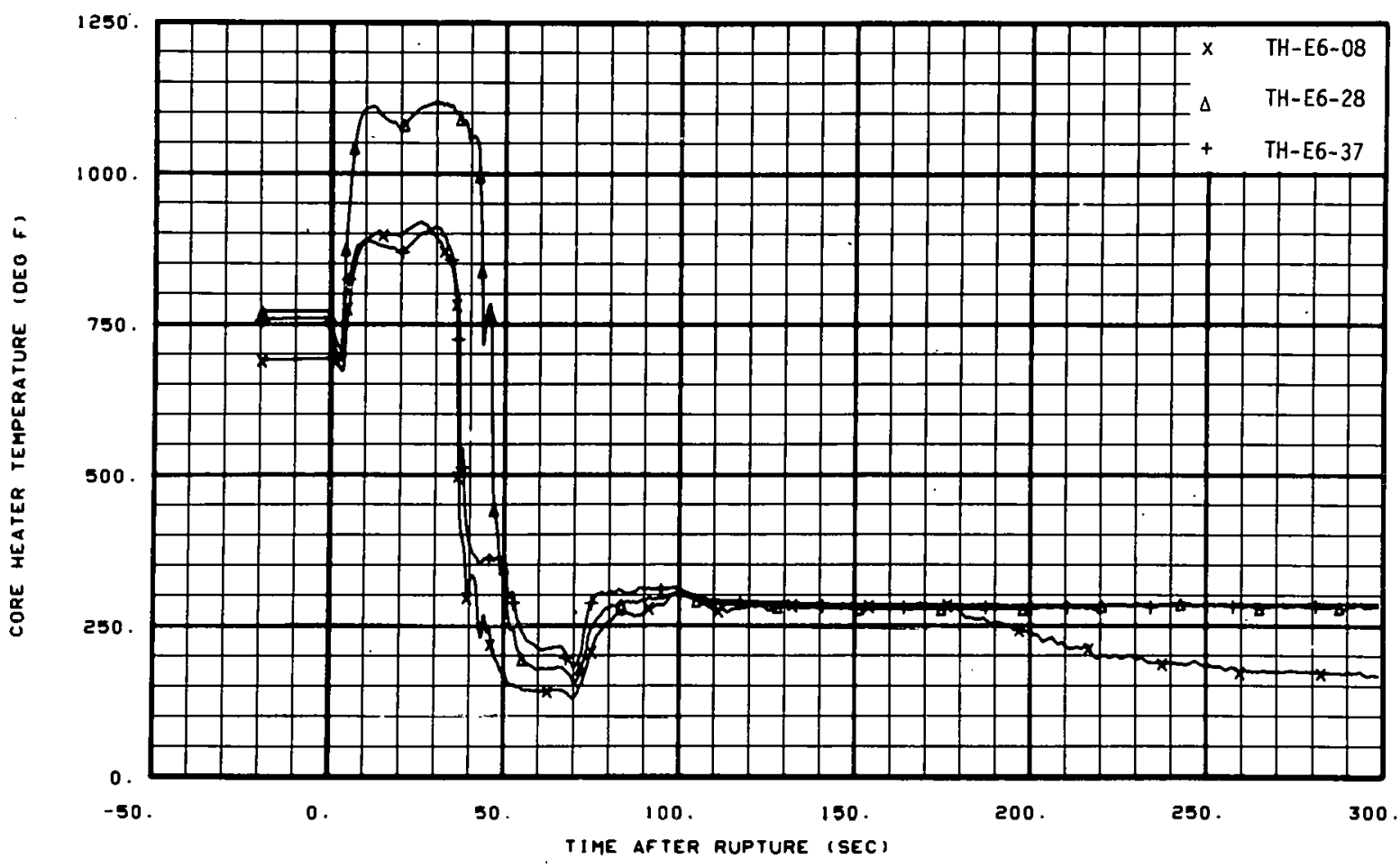

Fig. 103 Core heater temperature, Rod E-6 (TH-E6-08, TH-E6-28, and TH-E6-37), from -20 to 300 seconds.

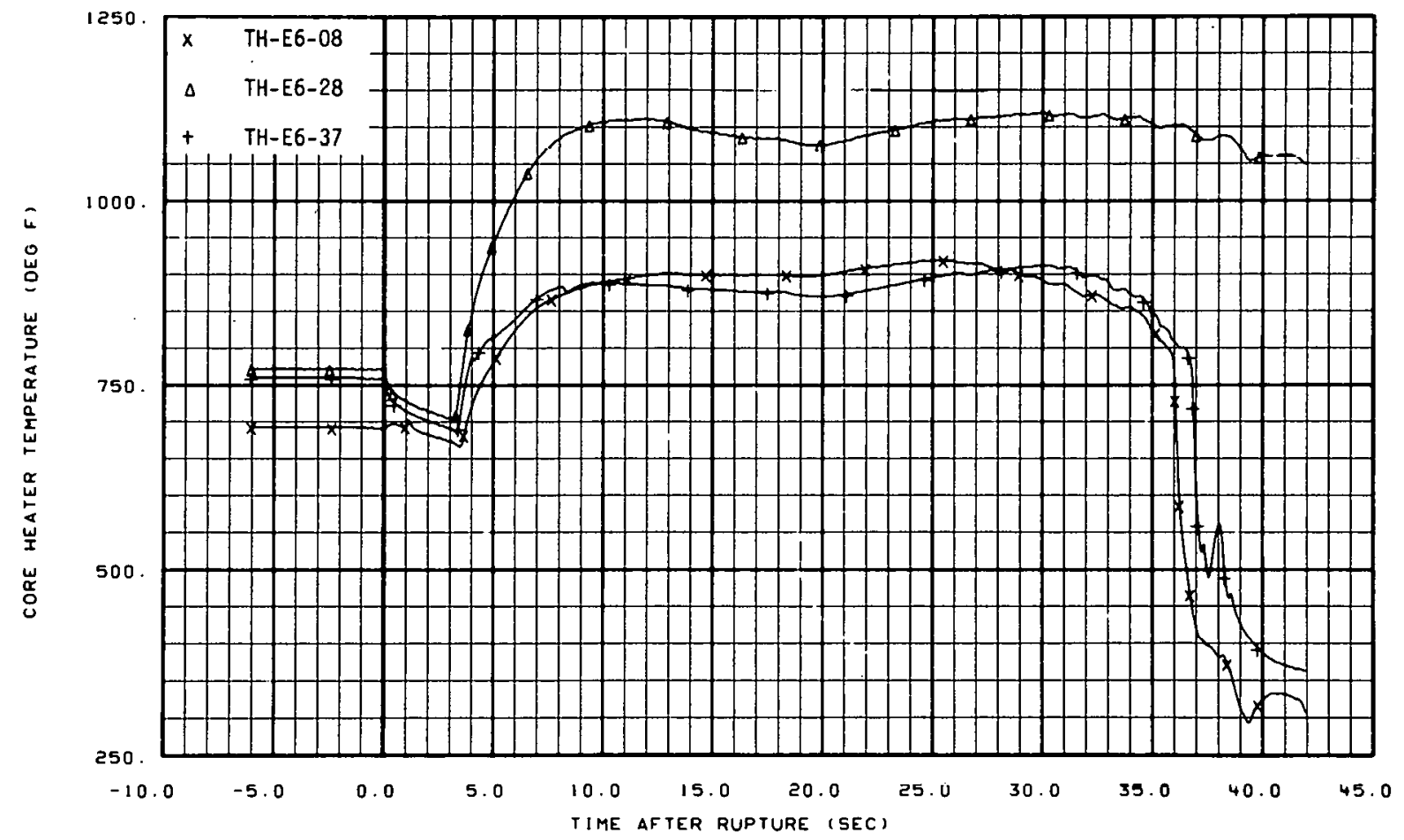

Fig. 104 Core heater temperature, Rod E-6 (TH-E6-08, TH-E6-28, and TH-E6-37), from -6 to 42 seconds. 


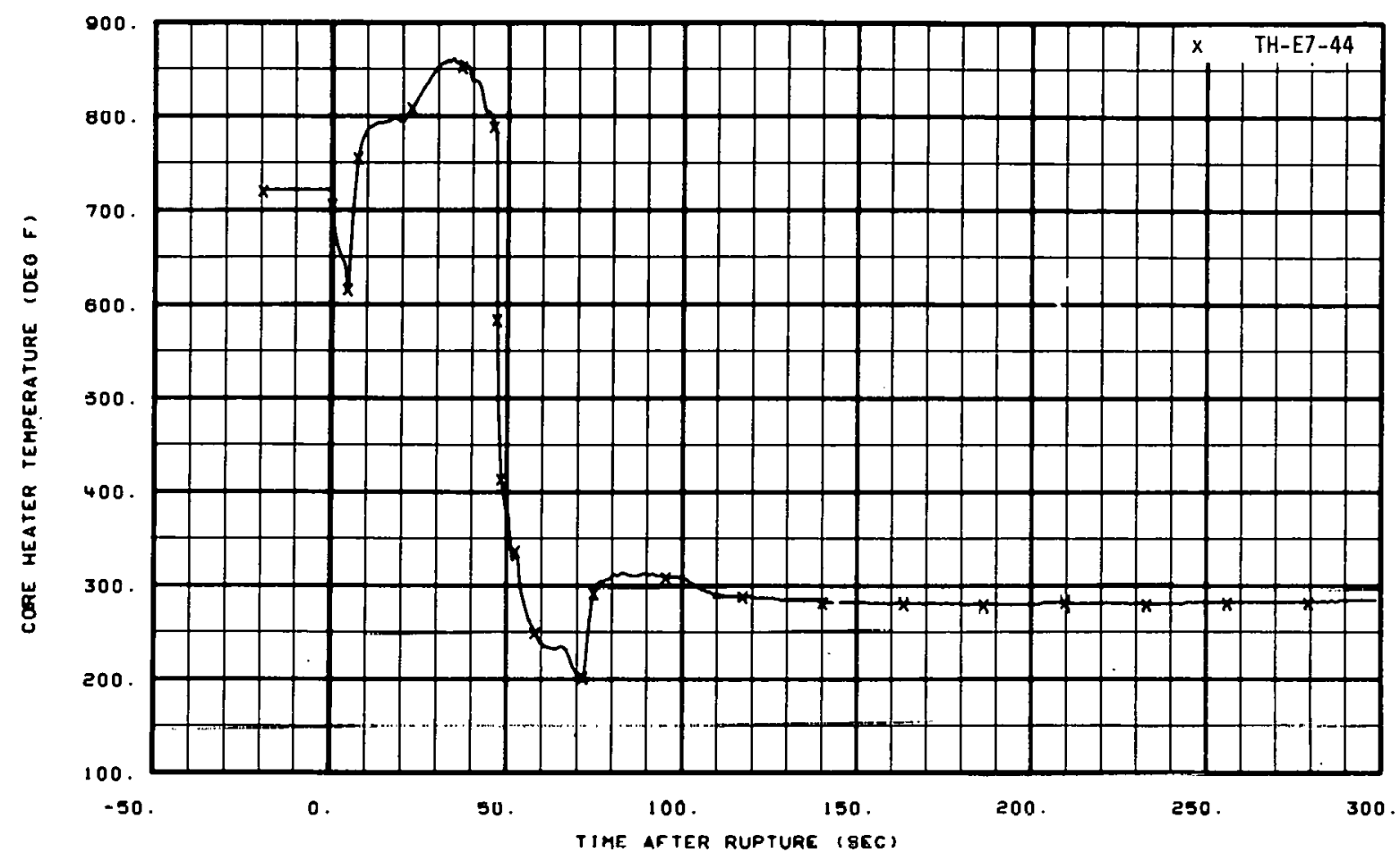

Fig. 105 Core heater temperature, Rod E-7 (TH-E7-44), from -20 to 300 seconds.

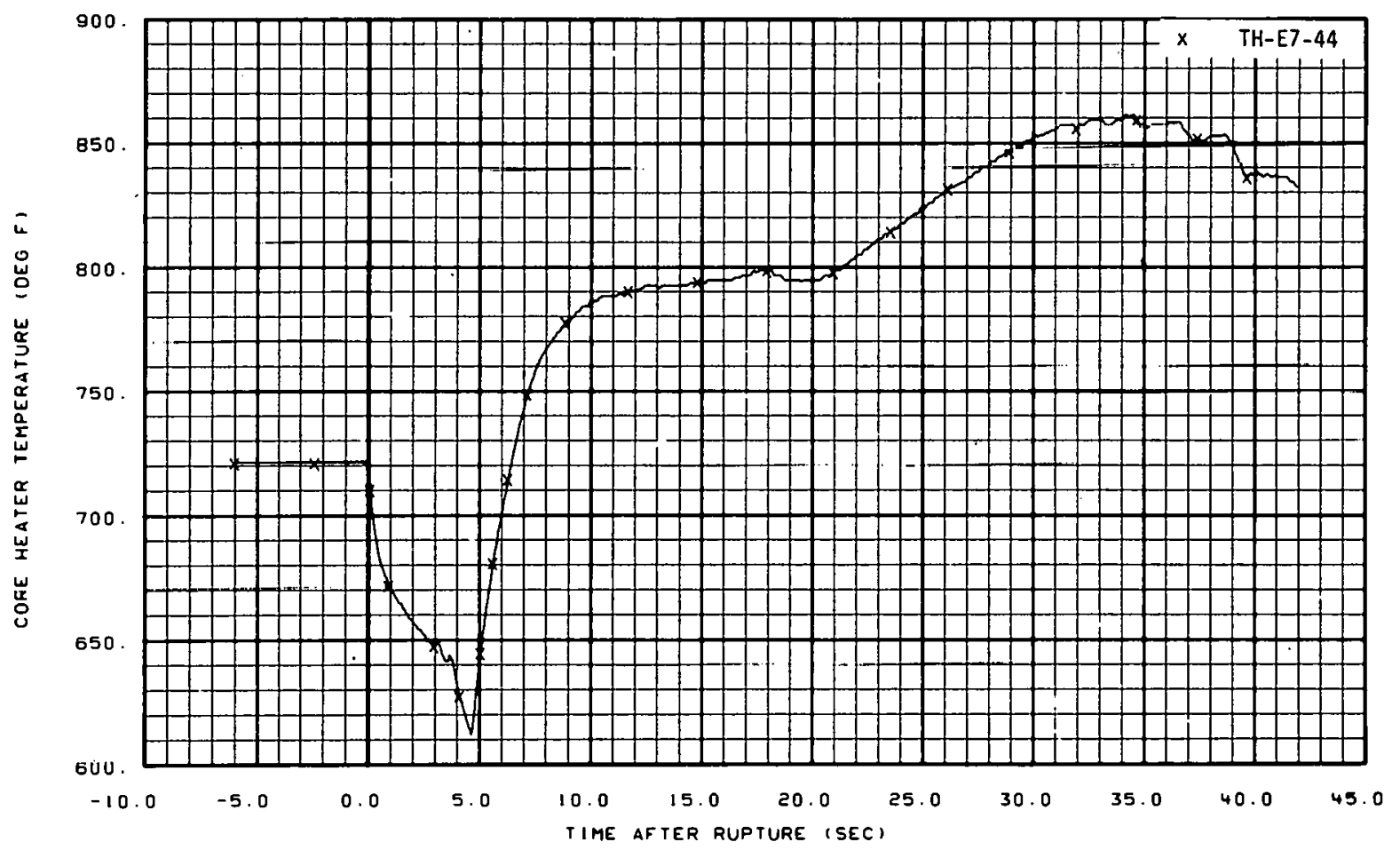

Fig. 106 Core heater temperature, Rod E-7 (TH-E7-44), from -6 to 42 seconds. 


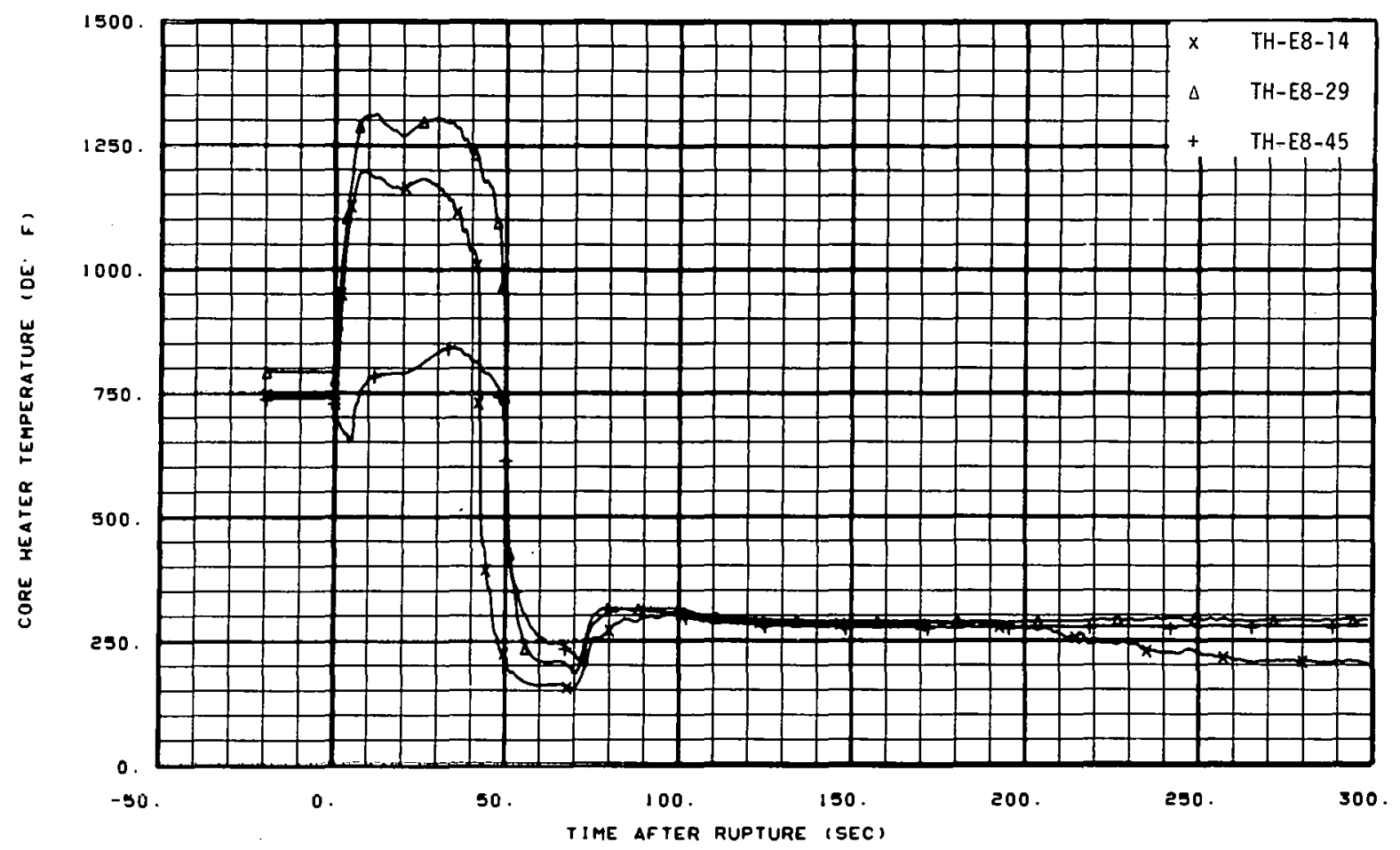

Fig. 107 Core heater temperature, Rod E-8 (TH-E8-14, TH-E8-29, and TH-E8-45), from -20 to 300 seconds.

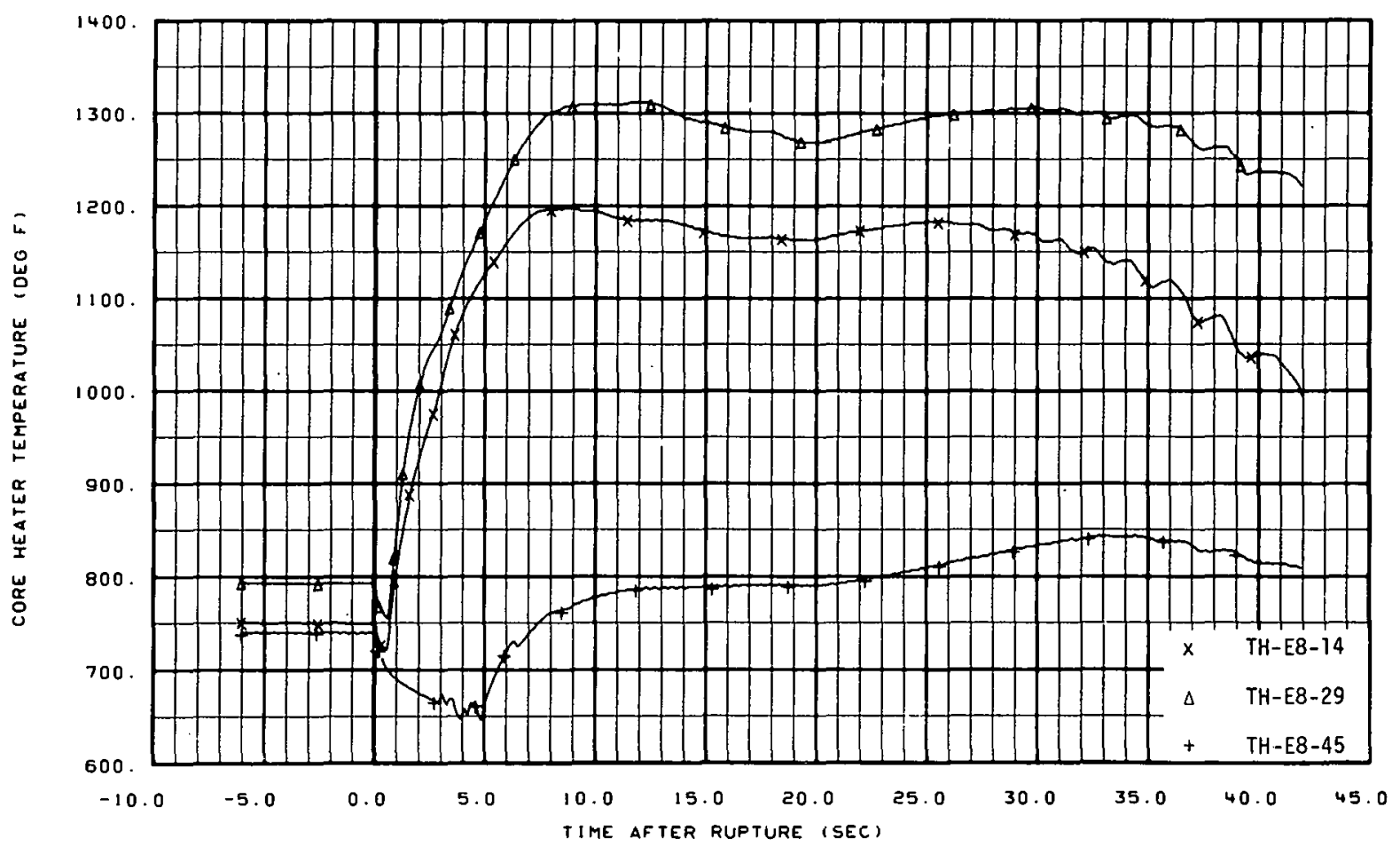

F1g. 108 Core heater temperature, Rod E-8 (TH-E8-14, TH-E8-29, and $T H-E 8-45)$, from -6 to 42 seconds. 


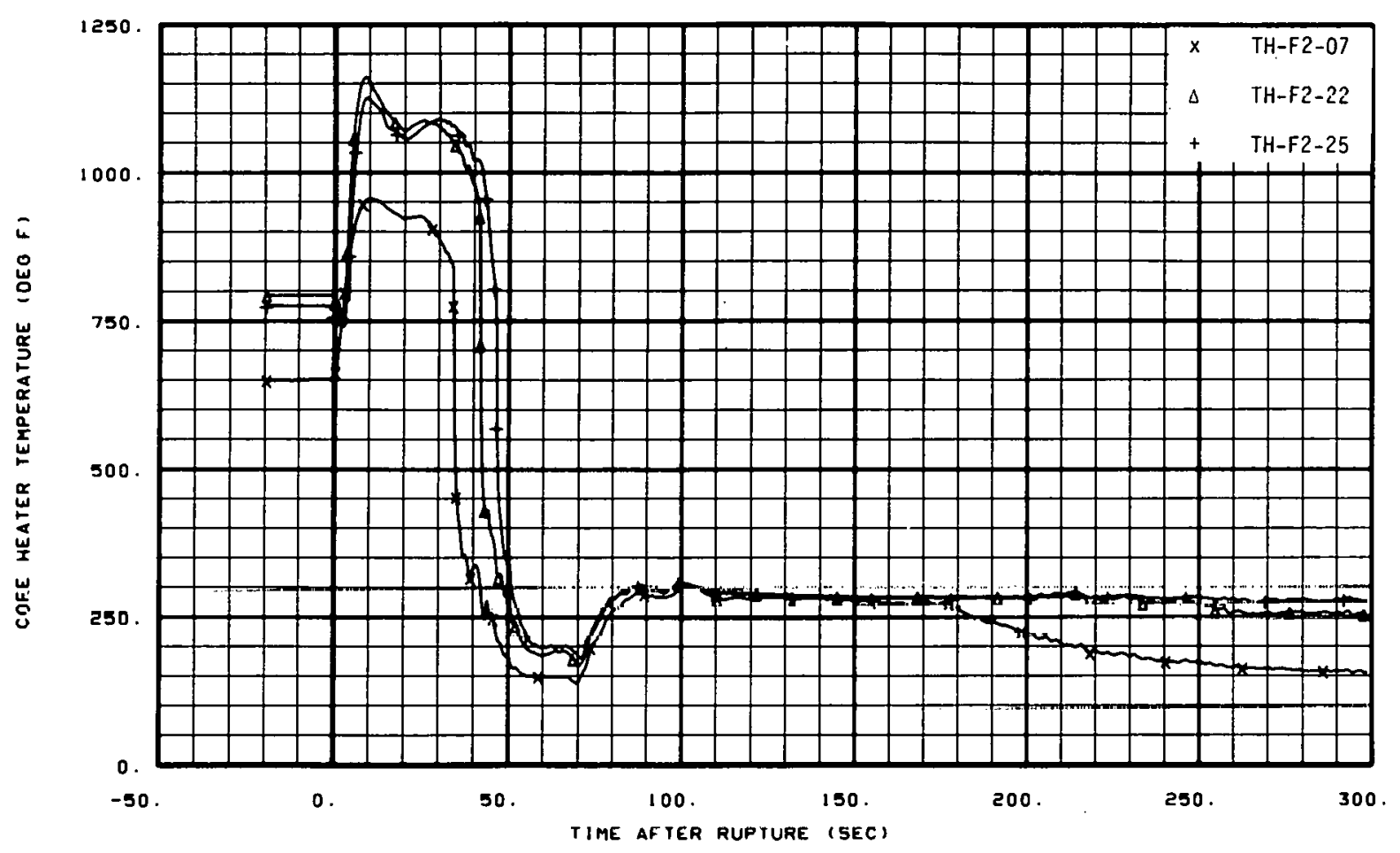

Fig. 109 Core heater temperature, Rod F-2 (TH-F2-07, TH-F2-22, and TH-F2-25), from -20 to 300 seconds.

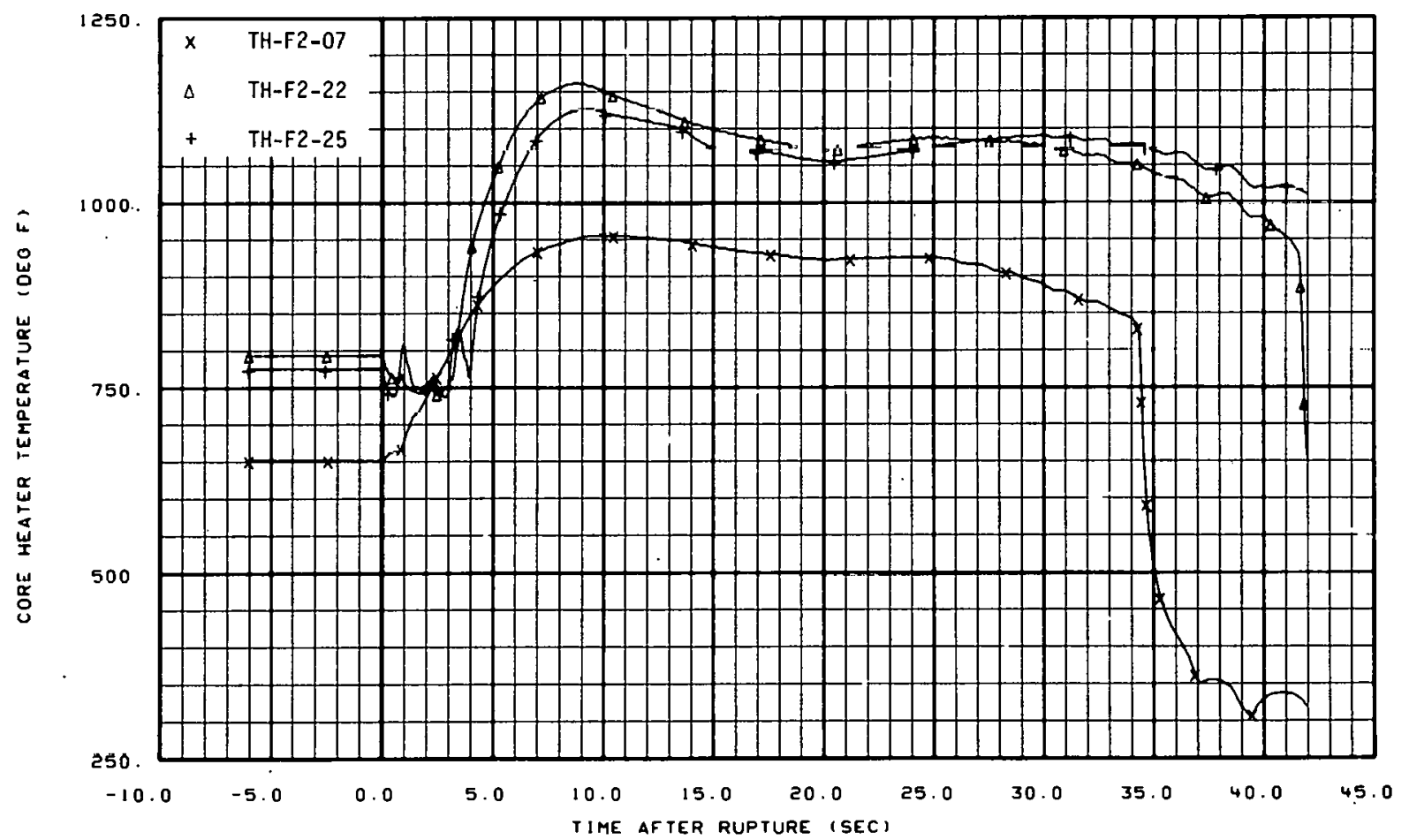

Fig. 110 Core heater temperature, Rod F-2 (TH-F2-07, TH-F2-22, and TH-F2-25), from -6 to 42 seconds. 


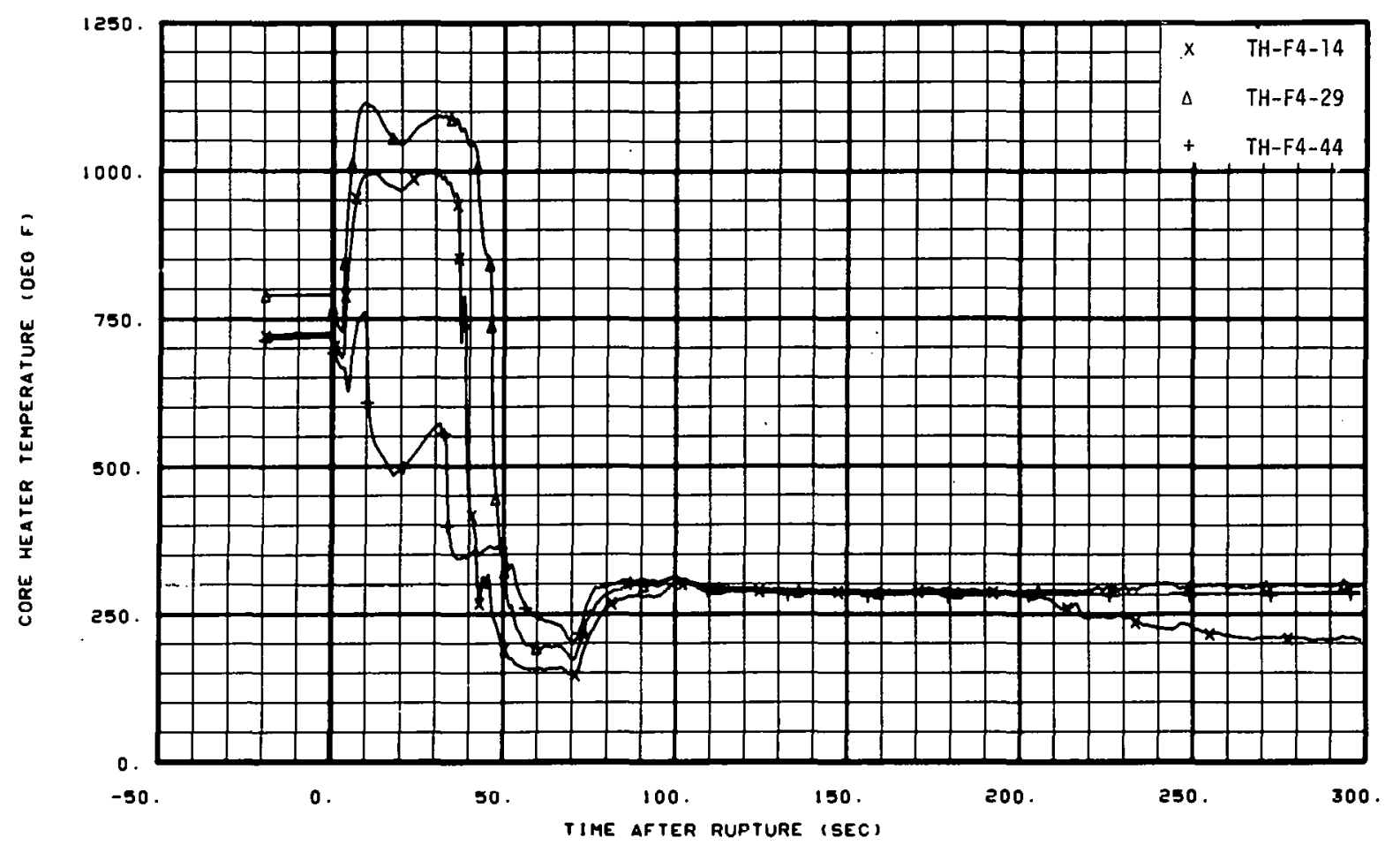

Fig. 111 Core heater temperature, Rod F-4 (TH-F4-14, TH-F4-29, and TH-F4-44), from -20 to 300 seconds.

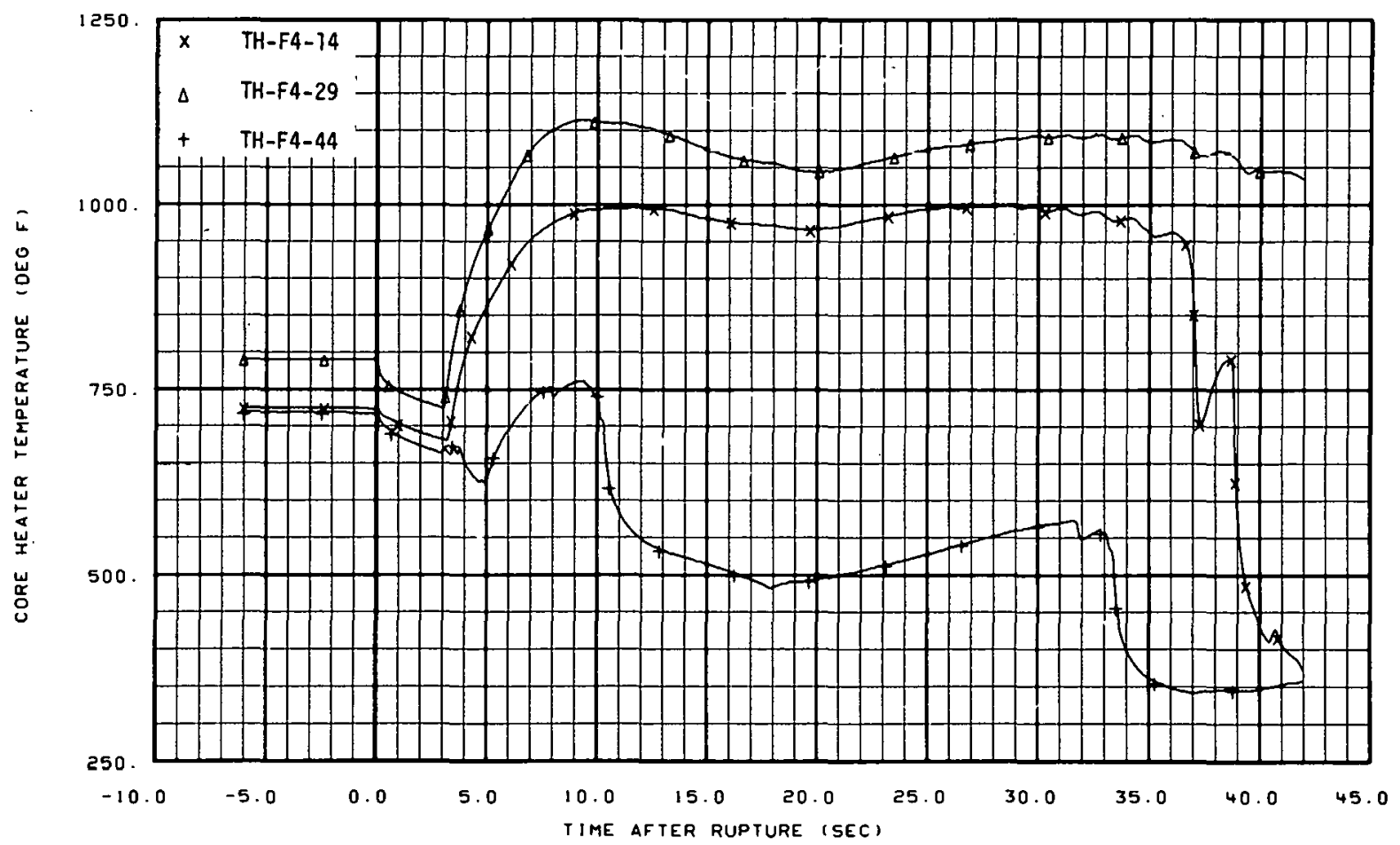

Fig. 112 Core heater temperature, Rod F-4 (TH-F4-74, TH-F4-29, drid TH-F4-44), from -6 to 42 seconds. 


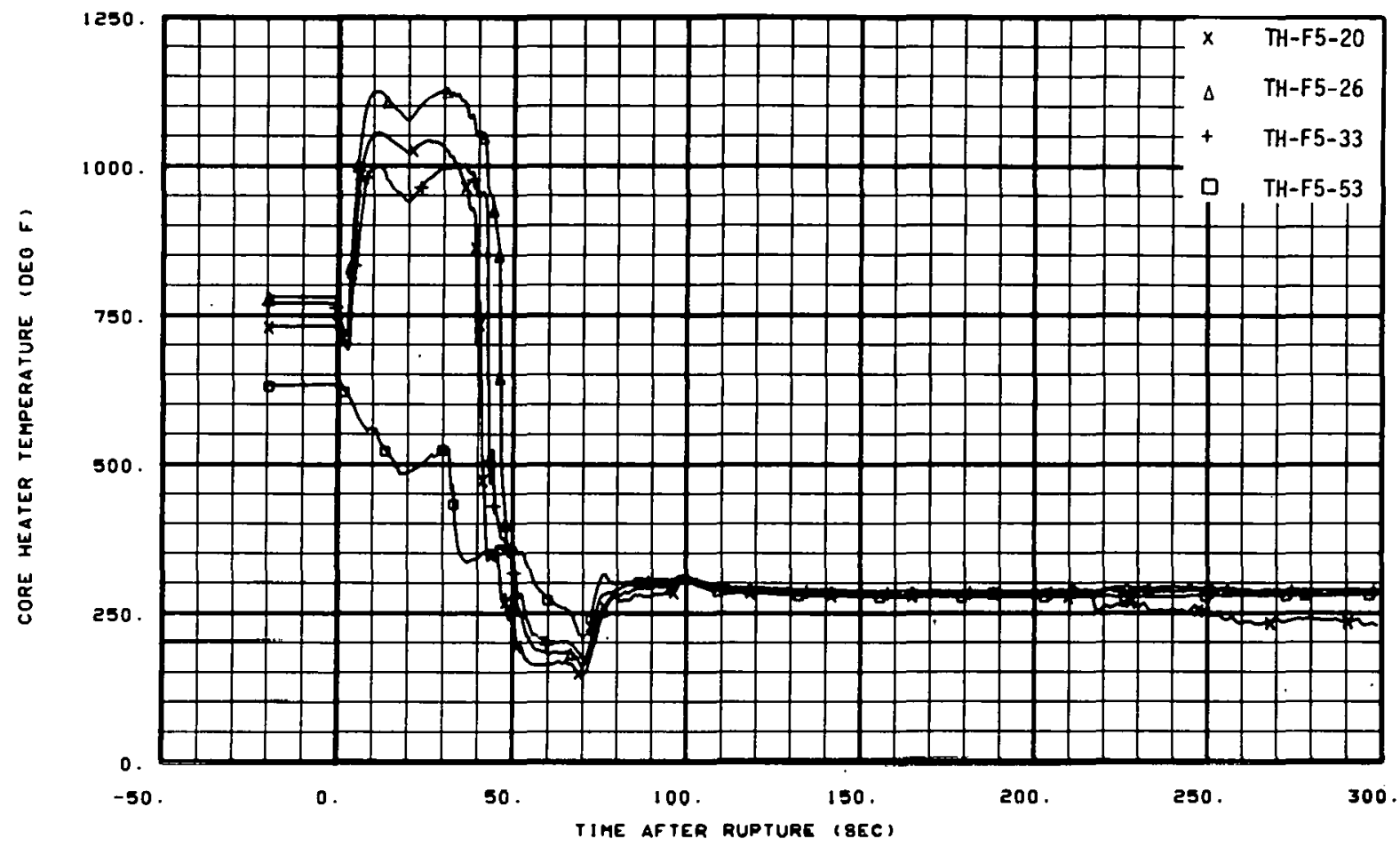

Fig. 113 Core heater temperature, Rod F-5 (TH-F5-20, TH-F5-26, TH-F5-33, and TH-F5-53), from -20 to 300 seconds.

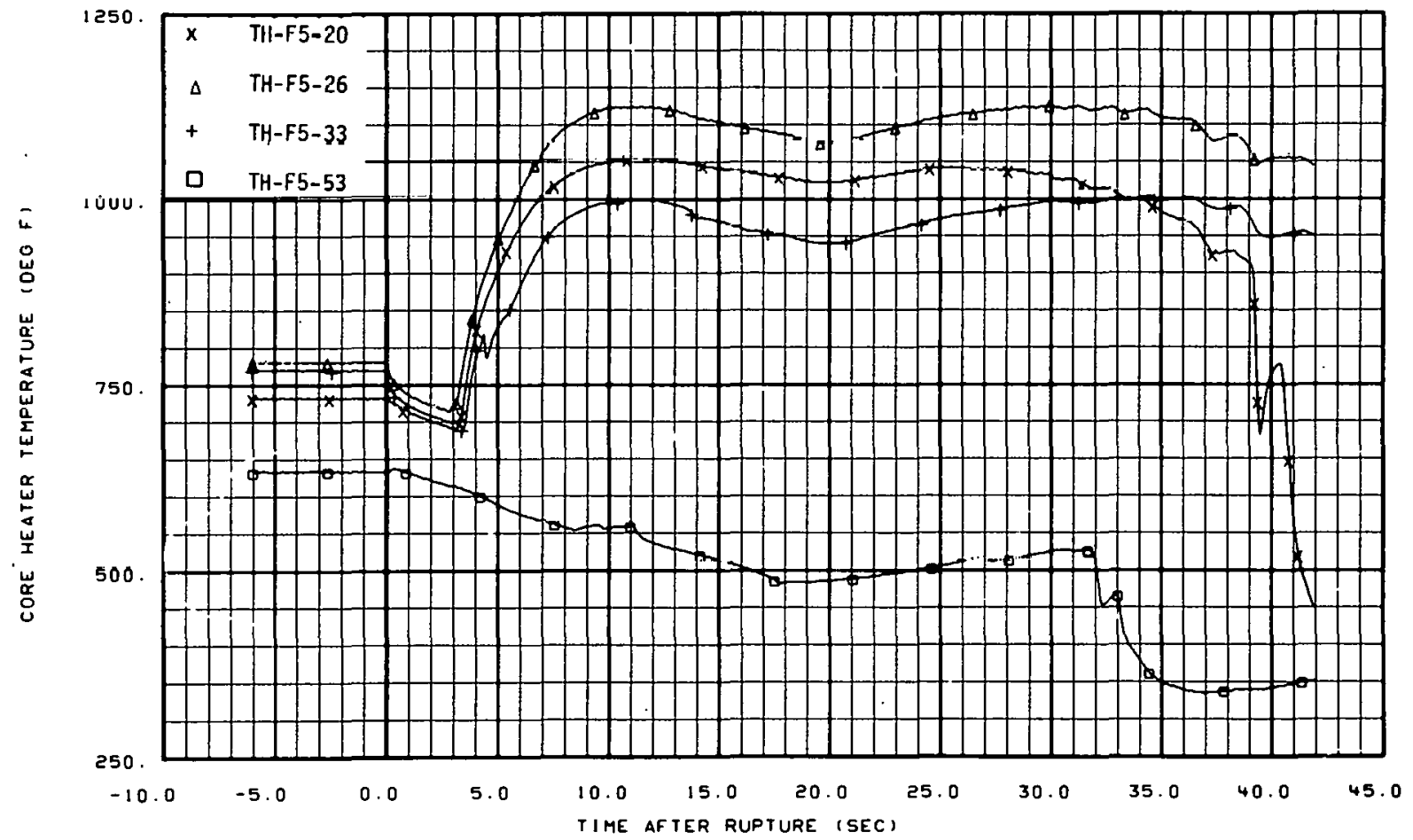

Fig. 114 Core heater temperature, Rod F-5 (TH-F5-20, TH-F5-26, TH-F5-33, and $T H-F 5-53$ ), from -6 to 42 seconds. 


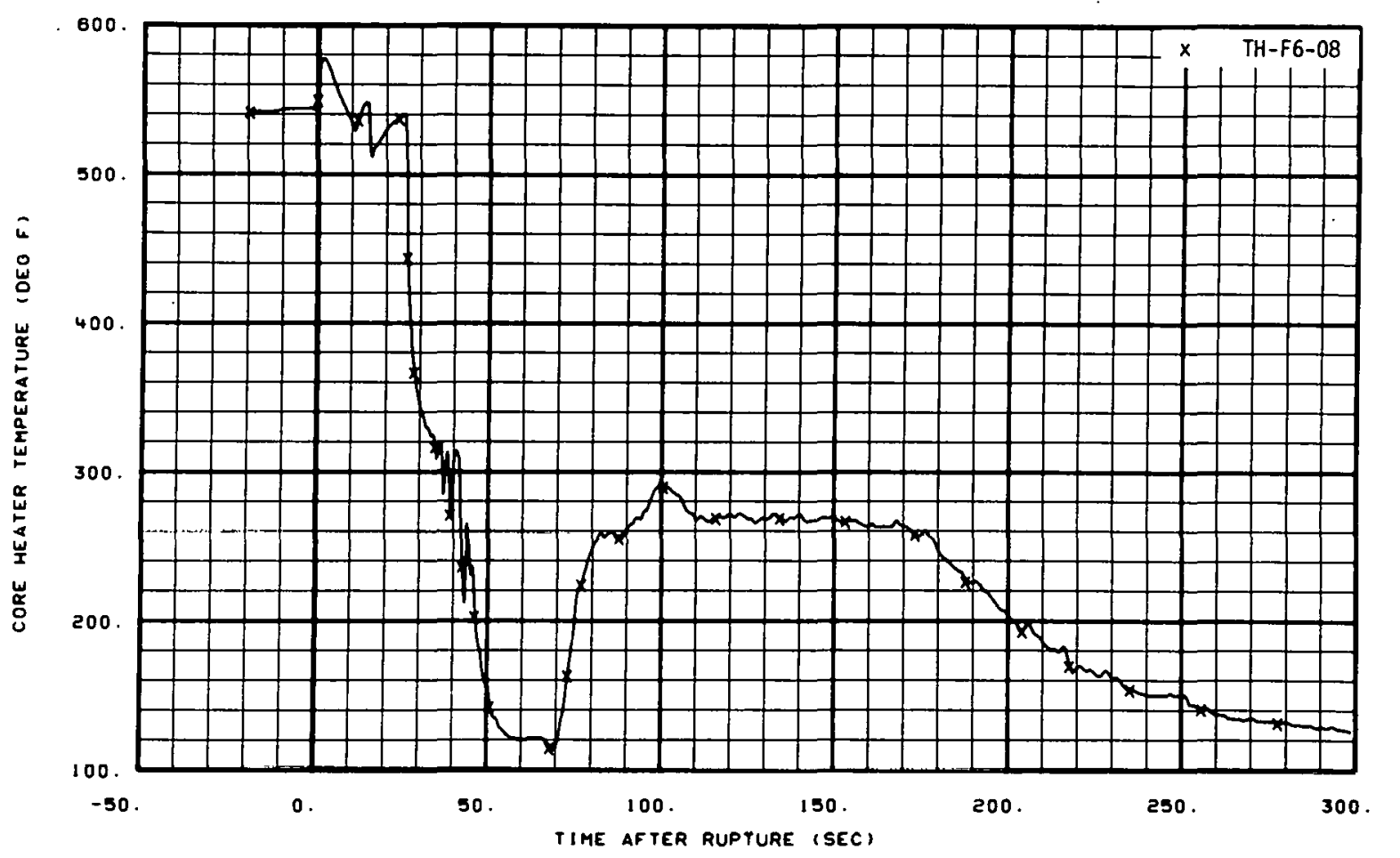

Fig. 115 Core heater temperature, Rod F-6 (TH-F6-08), from -20 to 300 seconds.

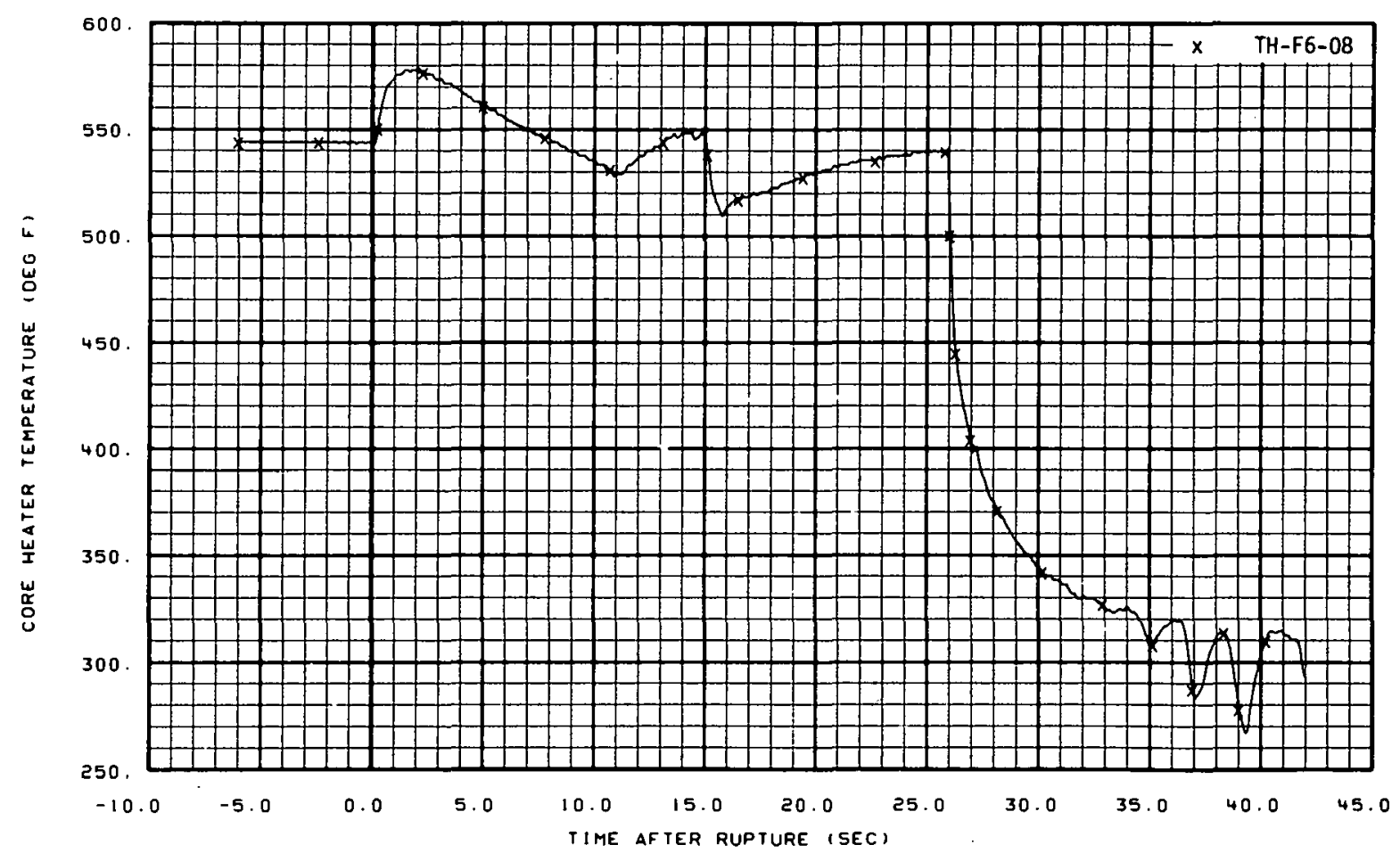

Fig. 116 Core heater temperature, Rod $F-6$ (TH-FG-08), from -6 to 42 seconds. 


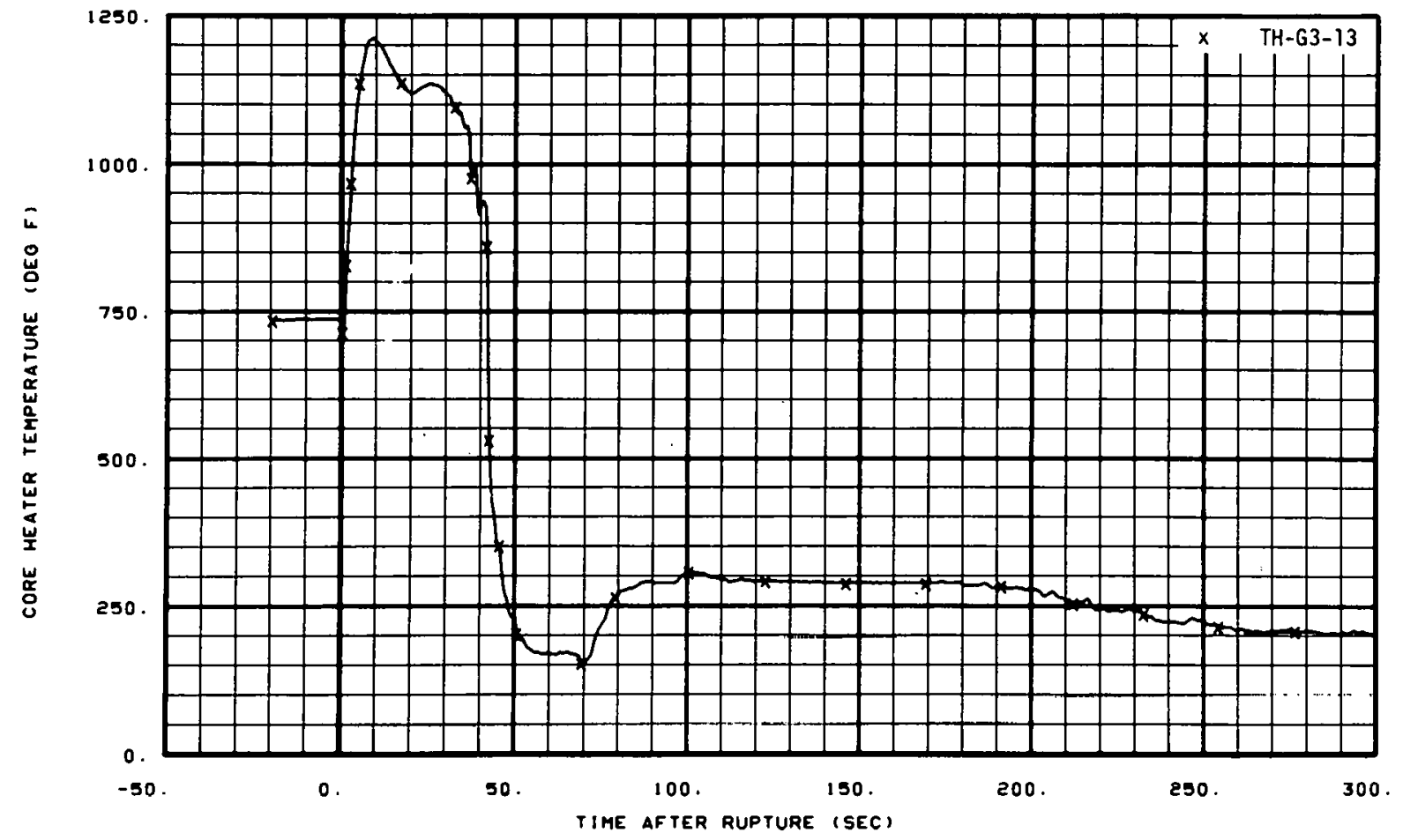

Fig. 117 Core heater temperature, Rod G-3 (TH-G3-13), from -20 to 300 seconds.

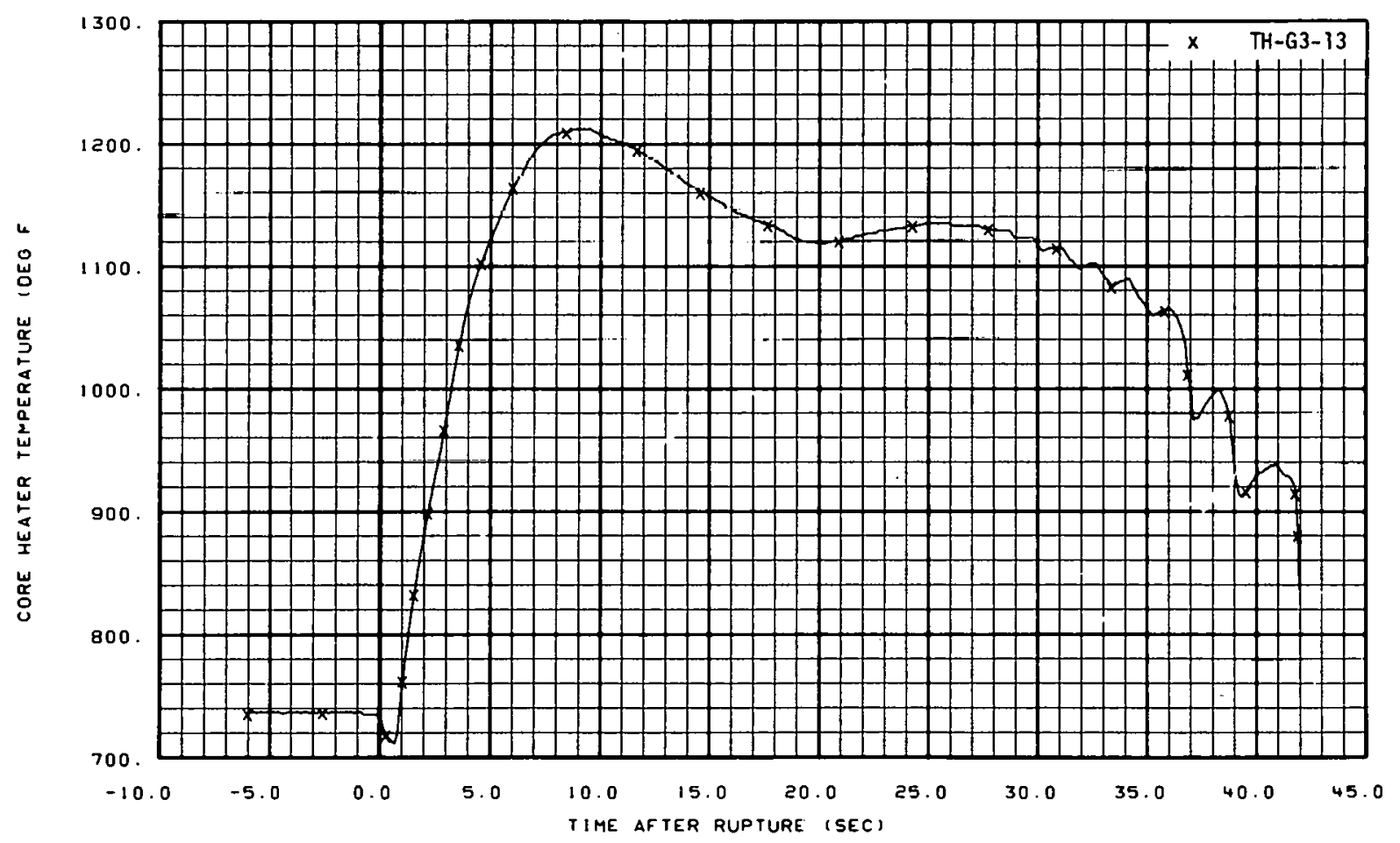

Fig. 118 Core heater temperature, Rod G-3 (TH-G3-13), from -6 to 42 seconds. 


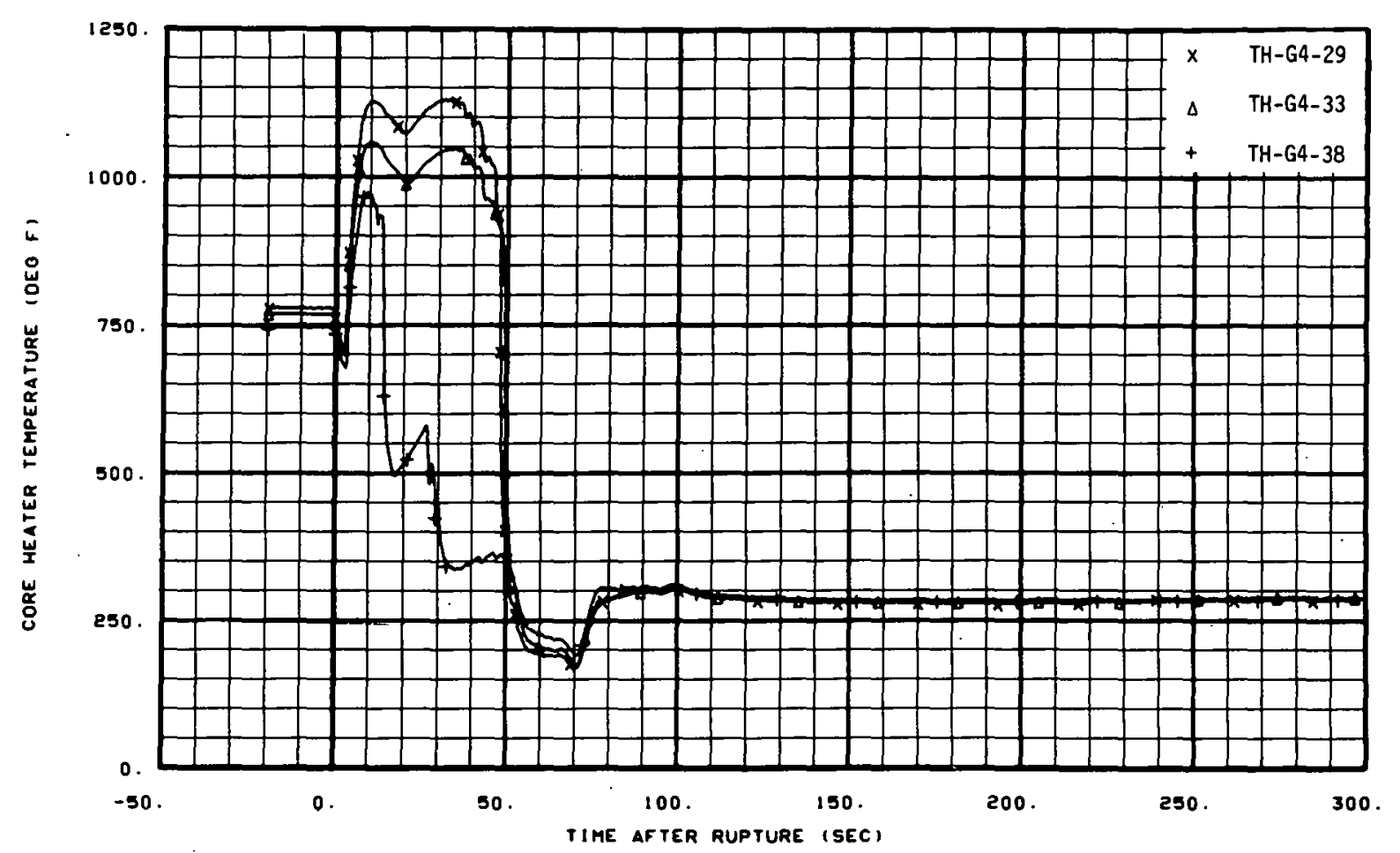

Fig. 119 Core heater temperature, Rod G-4 (TH-G4-29, TH-G4-33, and TH-G4-38), from -20 to 300 seconds.

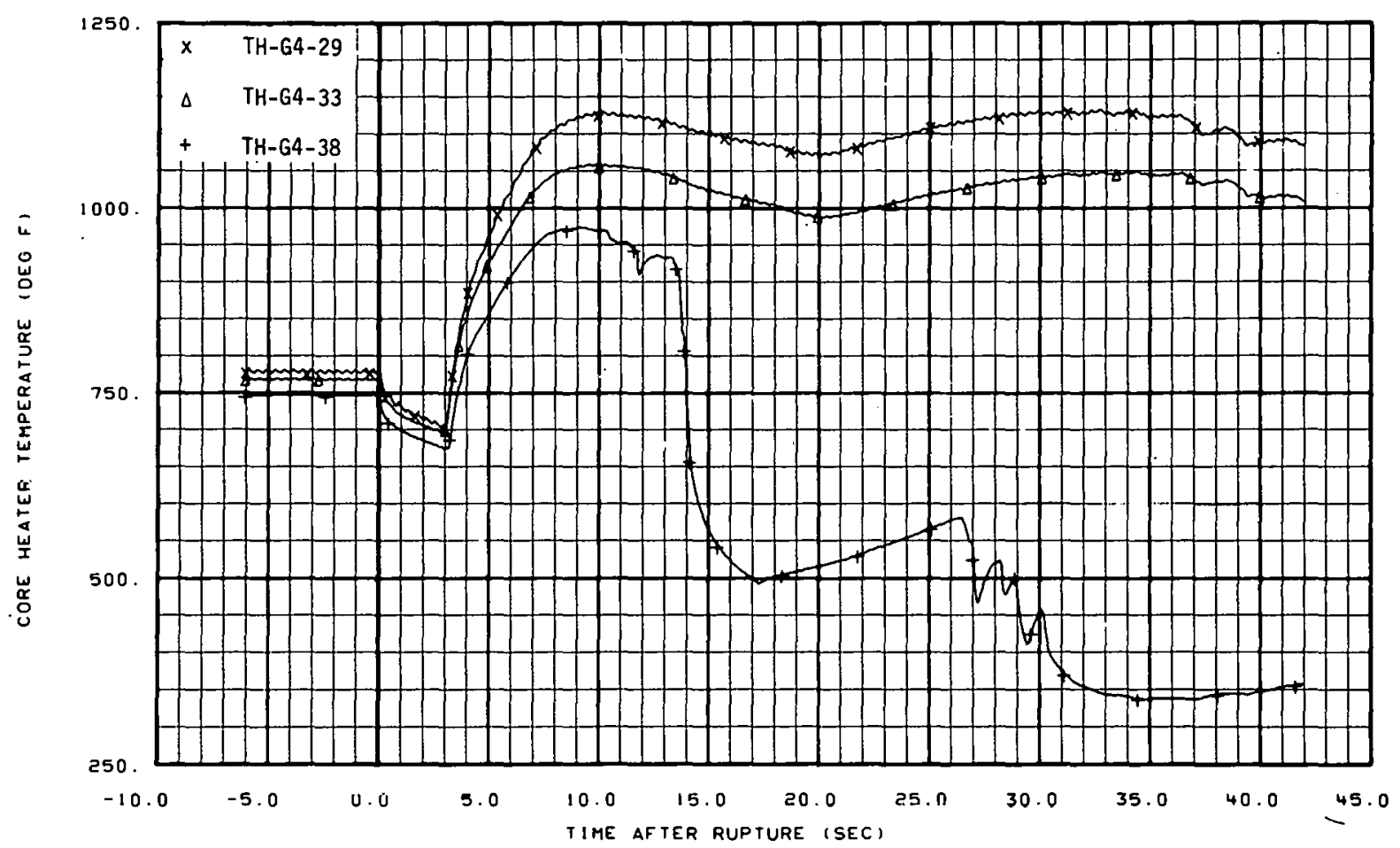

Fig. 120 rone heater temperature, Rod G-4 (TH-G4-29, TH-G4-33, and TH-G4-38), from -6 to 42 seconds. 


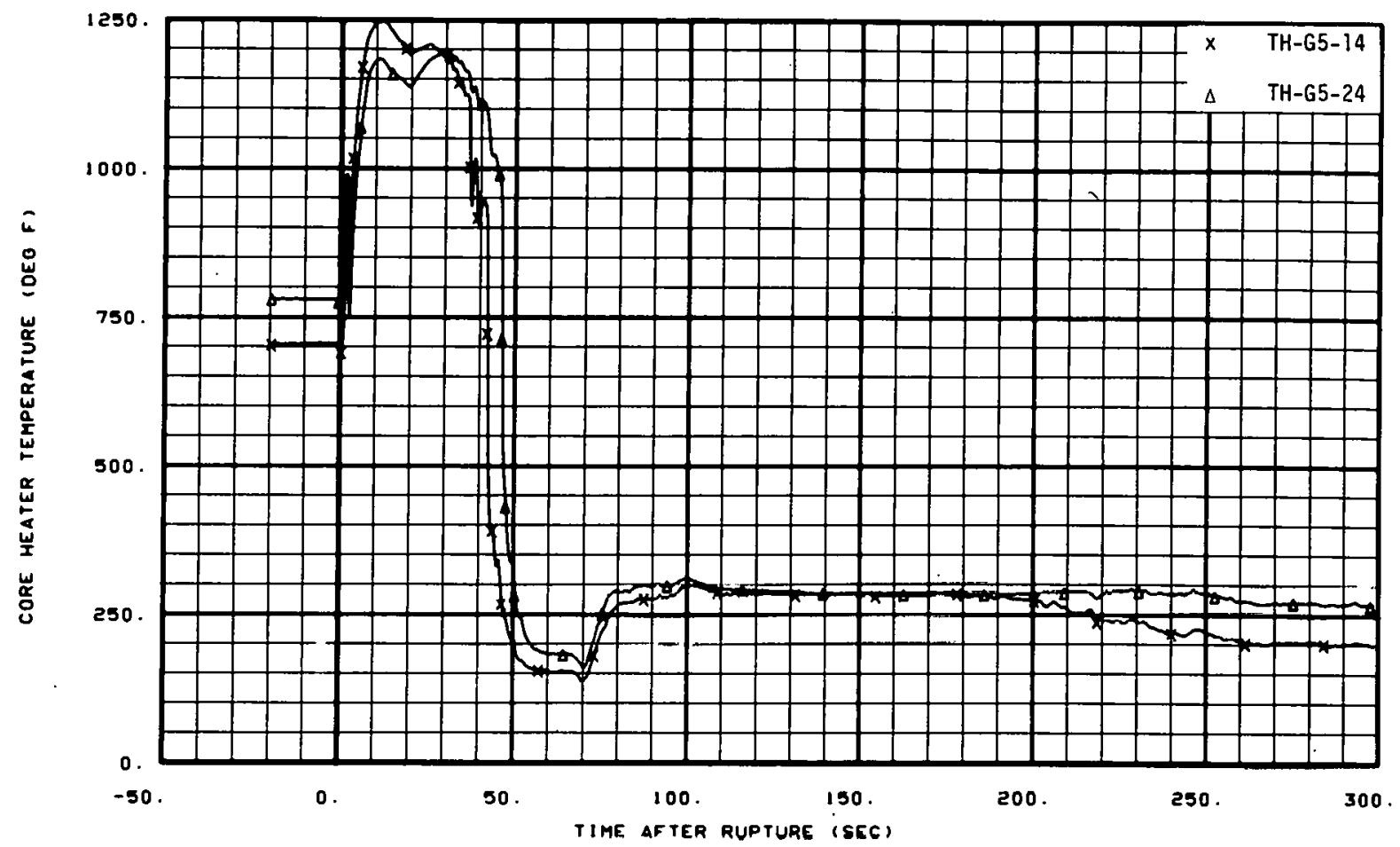

Fig. 121 Core heater temperature, Rod G-5 (TH-G5-14 and TH-G5-24), from -20 to 300 seconds.

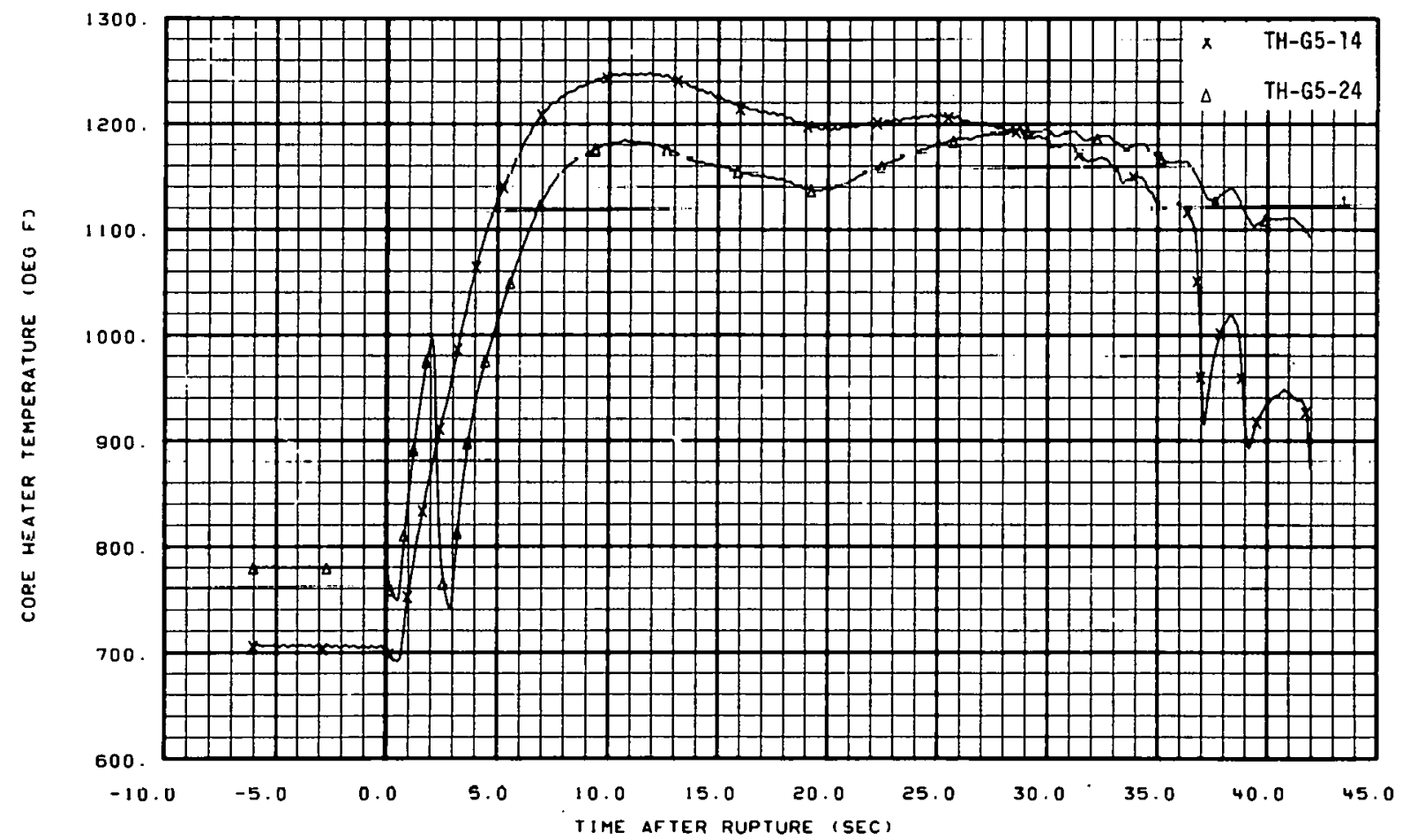

Fig. 122 Core heater temperature, Rod G-5 (TH-G5-14 and TH-G5-24), from -6 to 42 seconds. 


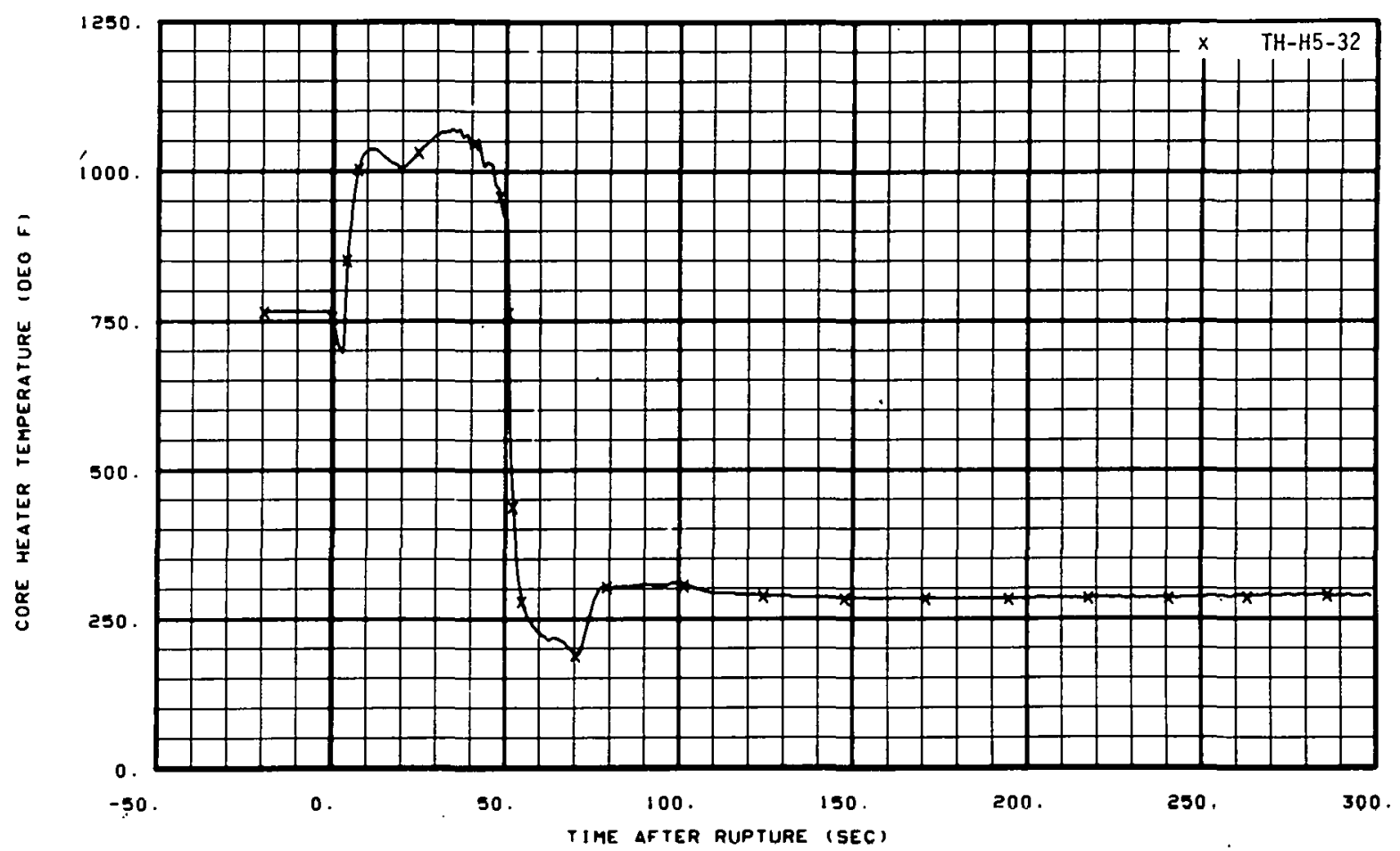

Fig. 123 Core heater temperature, Rod $\mathrm{H}-5$ ( TH-H5-32), from -20 to 300 seconds.

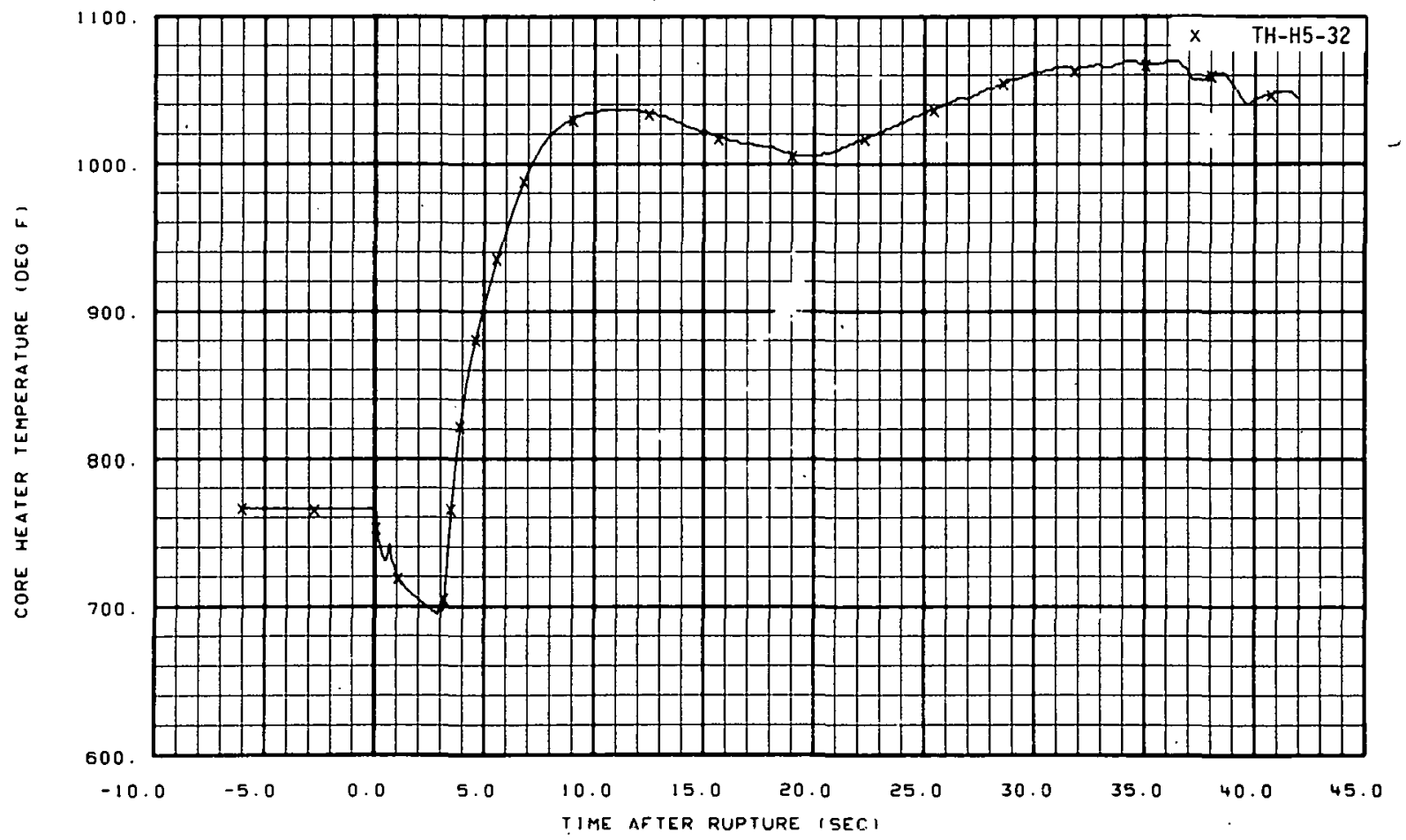

Fig. 124 Core heater temperature, Rod $\mathrm{H}-5$ ( TH-H5-32), from -6 to 42 seconds. 


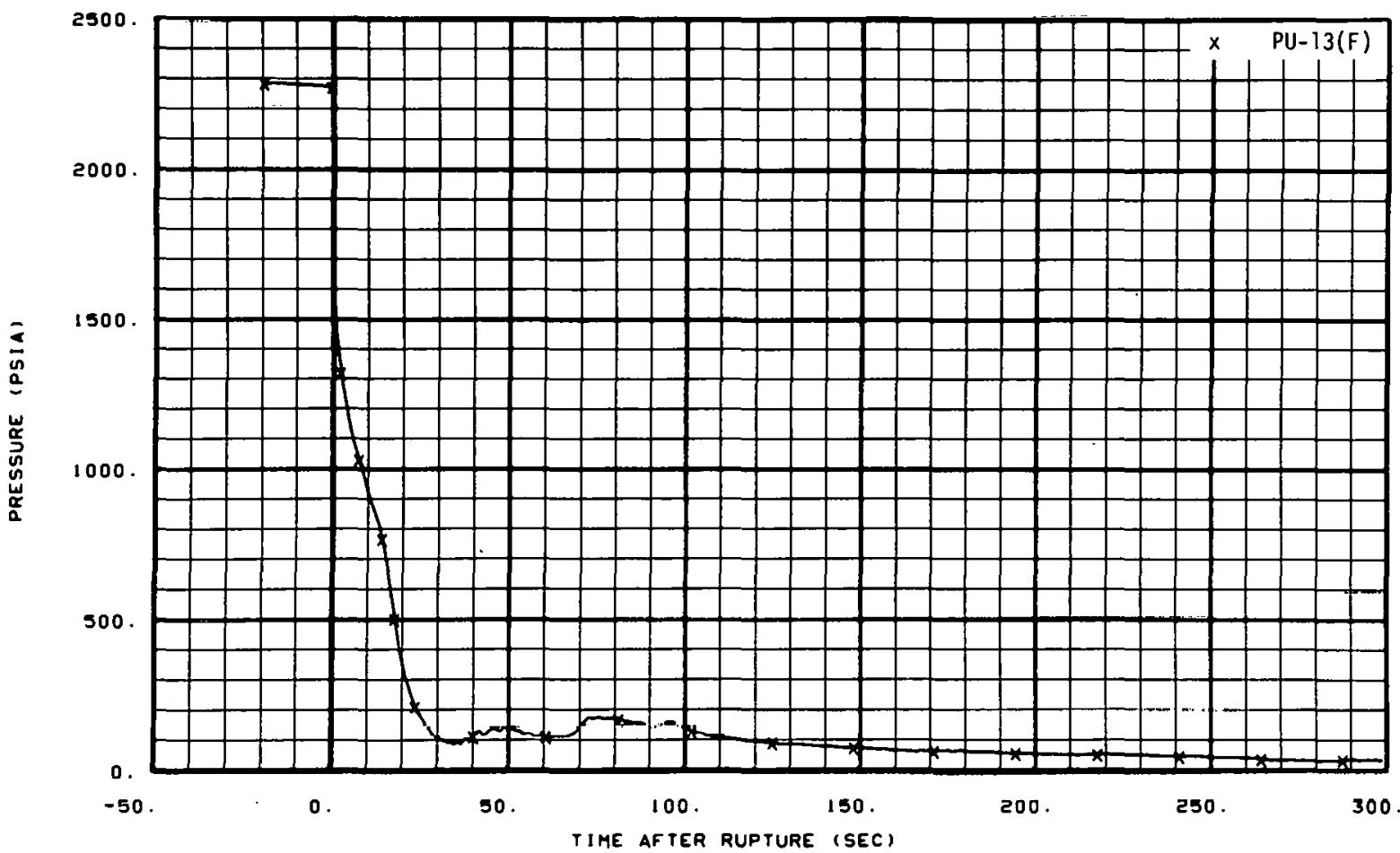

Fig. 125 Pressure in intact loop, Spool 13 PU-13(F), from -20 to 300 seconds.

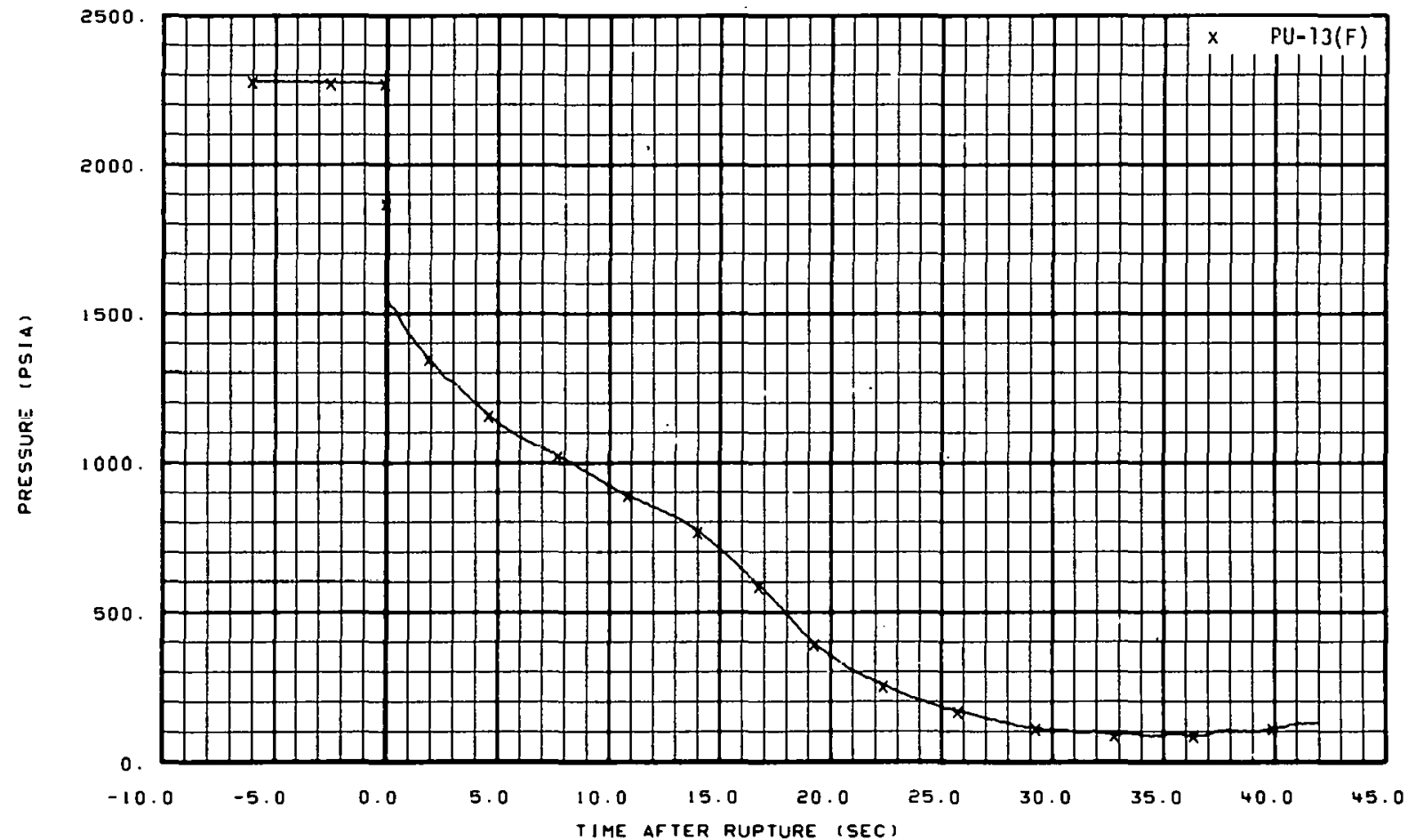

Fig. 126 Pressure in intact 10op, Spool 13 PU-13(F), from -6 to 42 seconds. 


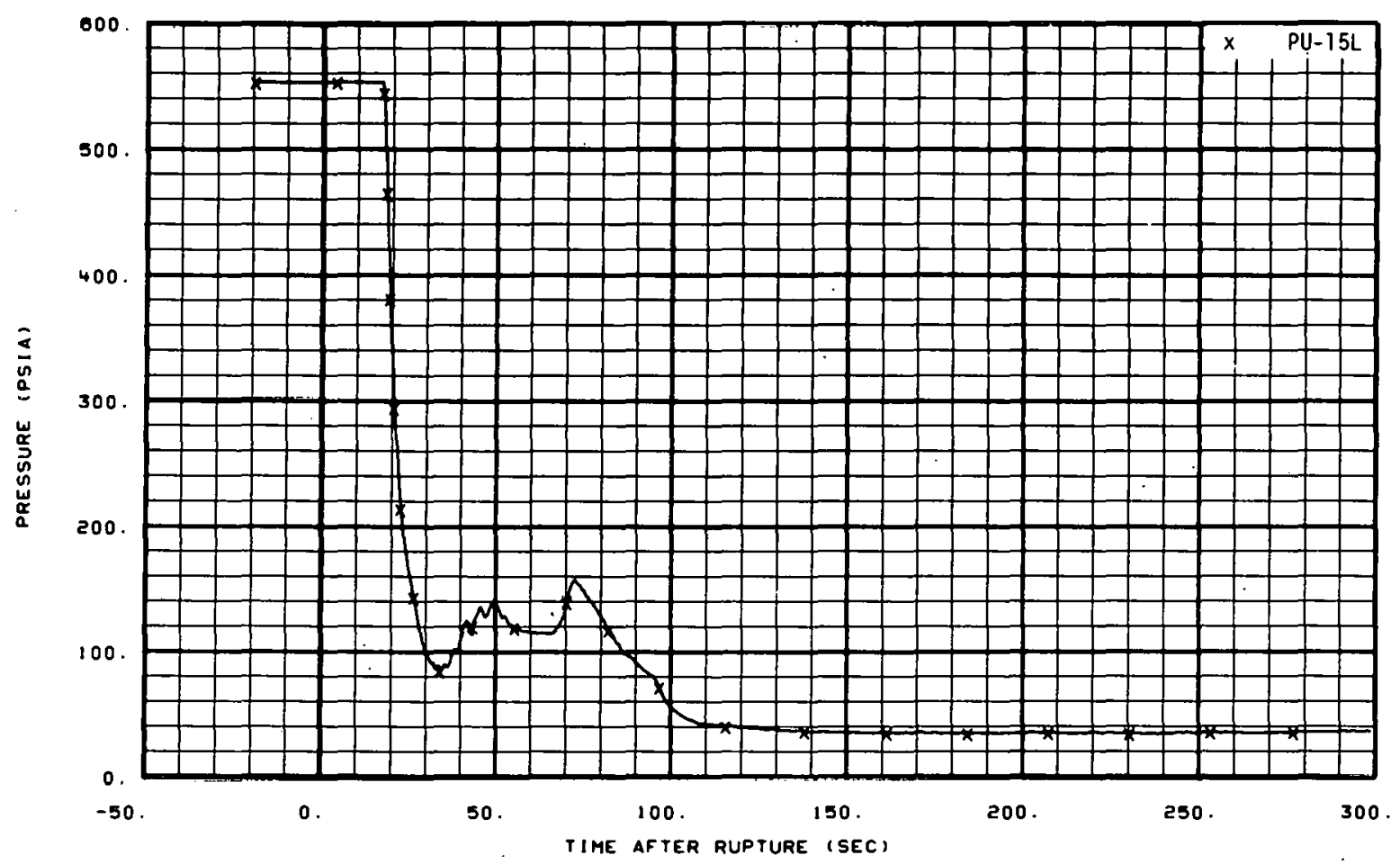

Fig. 127 Pressure in intact 10op, Spool 15, low range, (PU-15L), from -20 to 300 seconds.

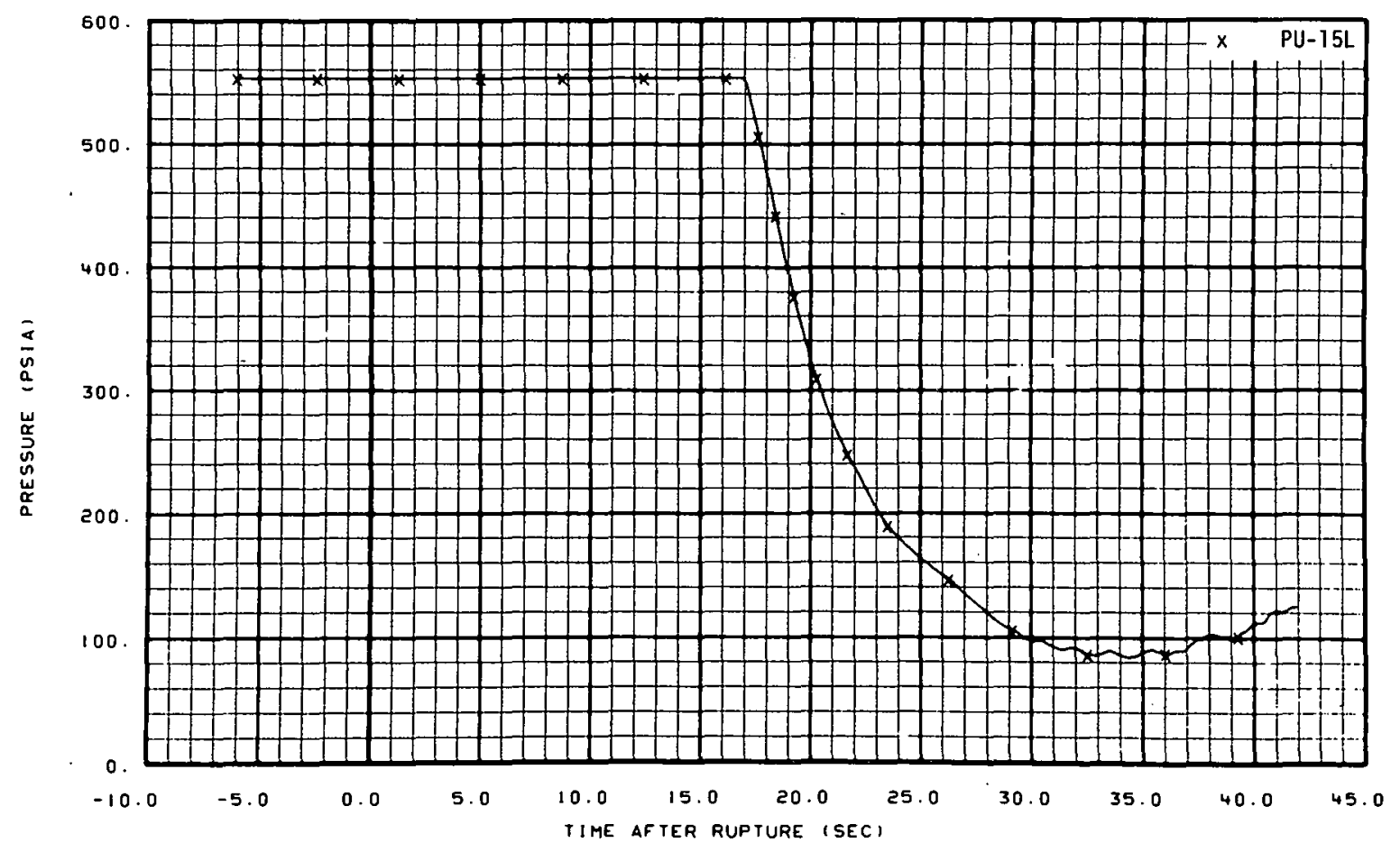

Fig. 128 Pressure in intact 10op, Spool 15, low range, (PU-15L), from -6 to 42 seconds. 


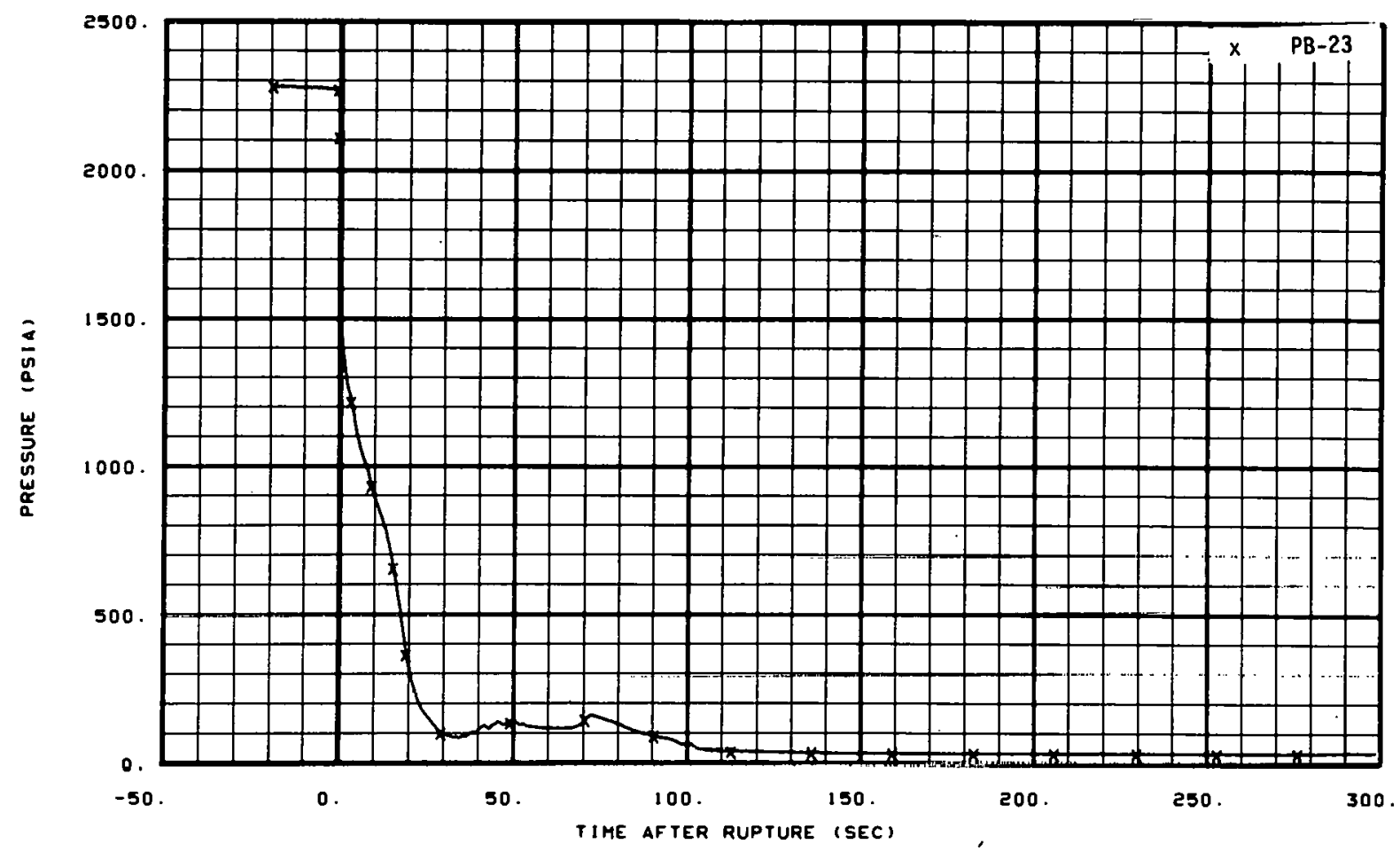

Fig. 129 Pressure in broken loop, vessel side, Spool 23 (PB-23), from -20 to 300 seconds.

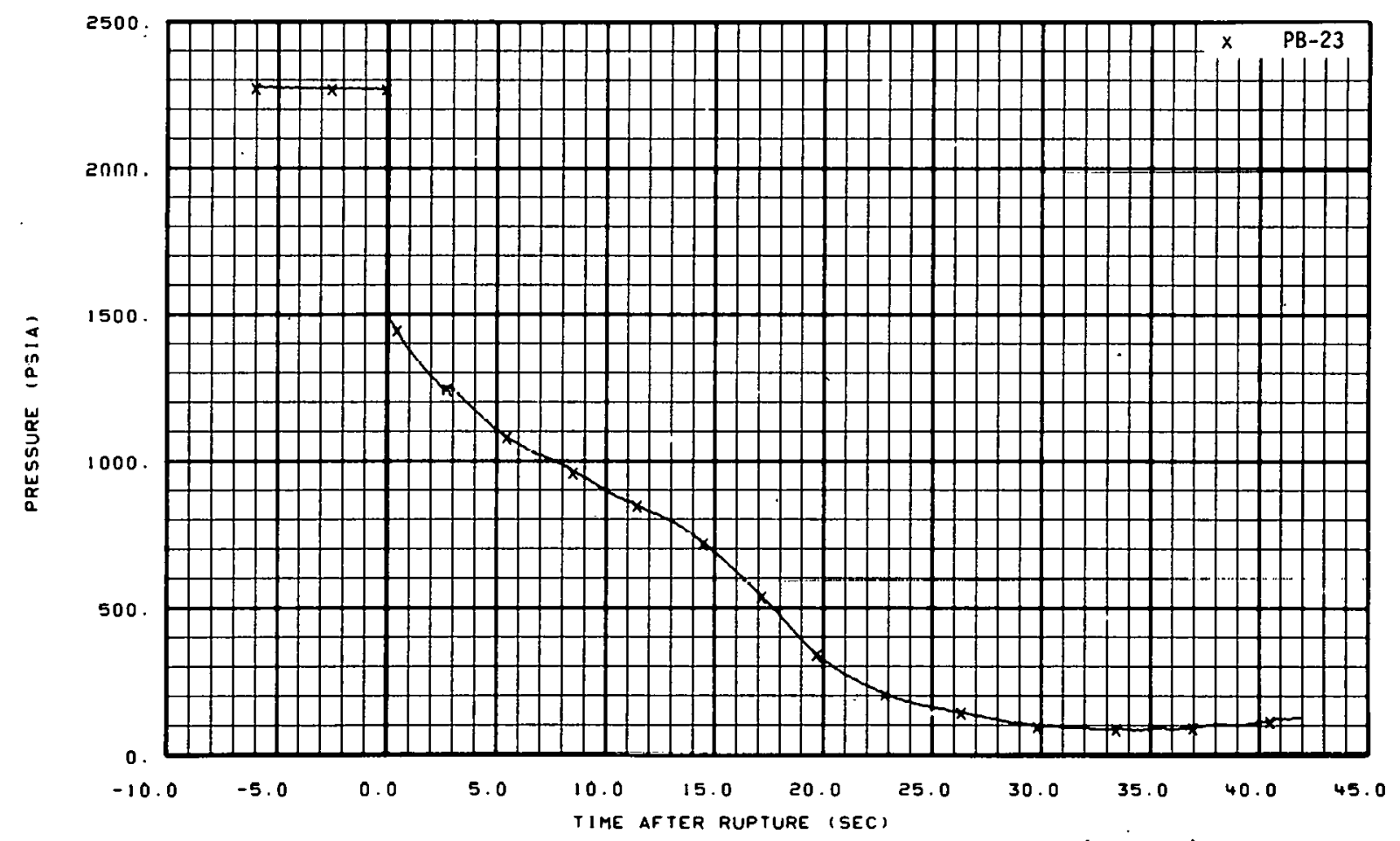

Fig. 130 Pressure in broken loop, vessel side, Spool 23 (PB-23), from -6 to 42 seconds. 


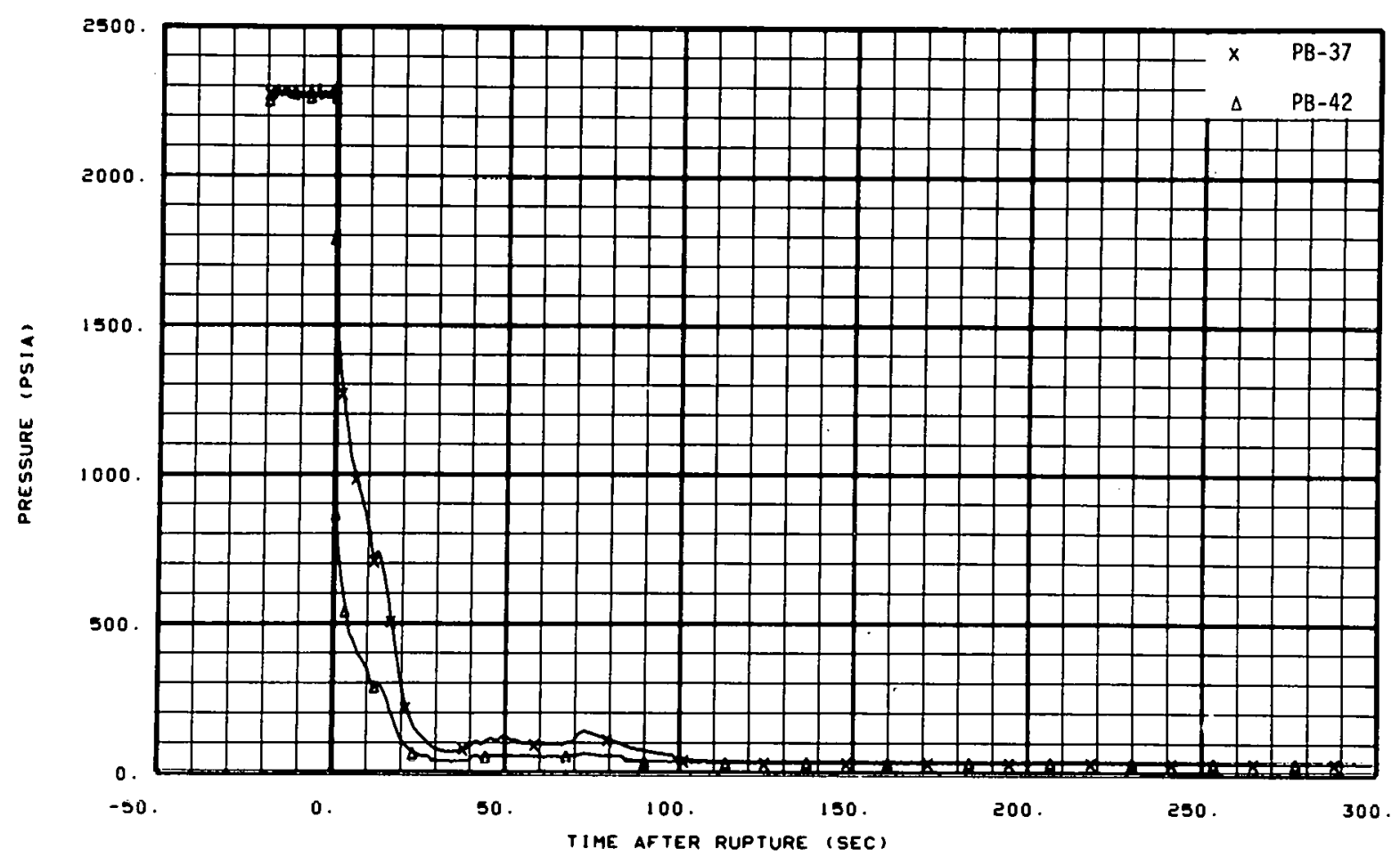

Fig. 131 Pressure in broken loop, pump side (PB-37 and PB-42), from -20 to 300 seconds.

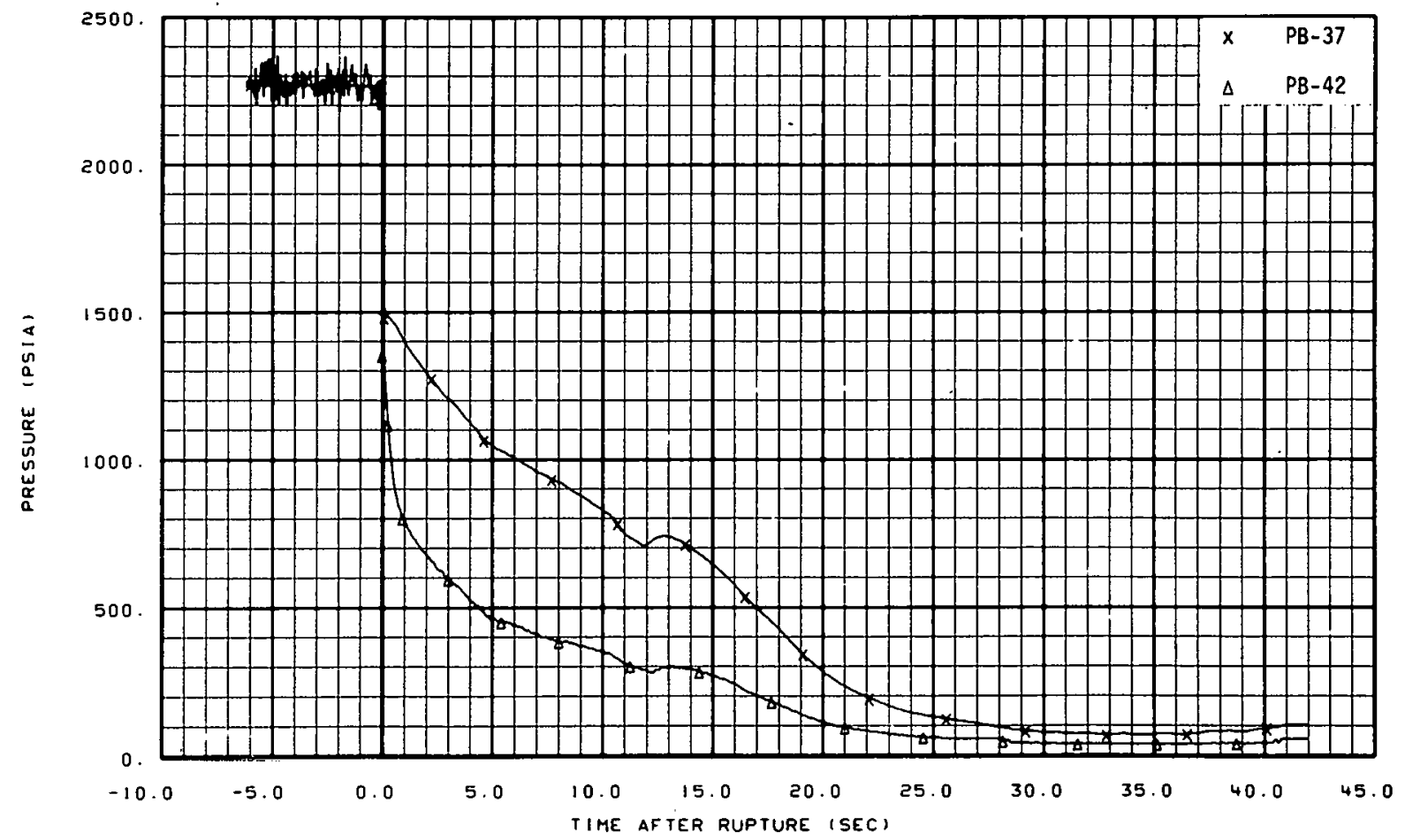

Fig. 132 Pressure in broken loop, pump side (PB-37 and PB-42), from -6 to 42 seconds. 


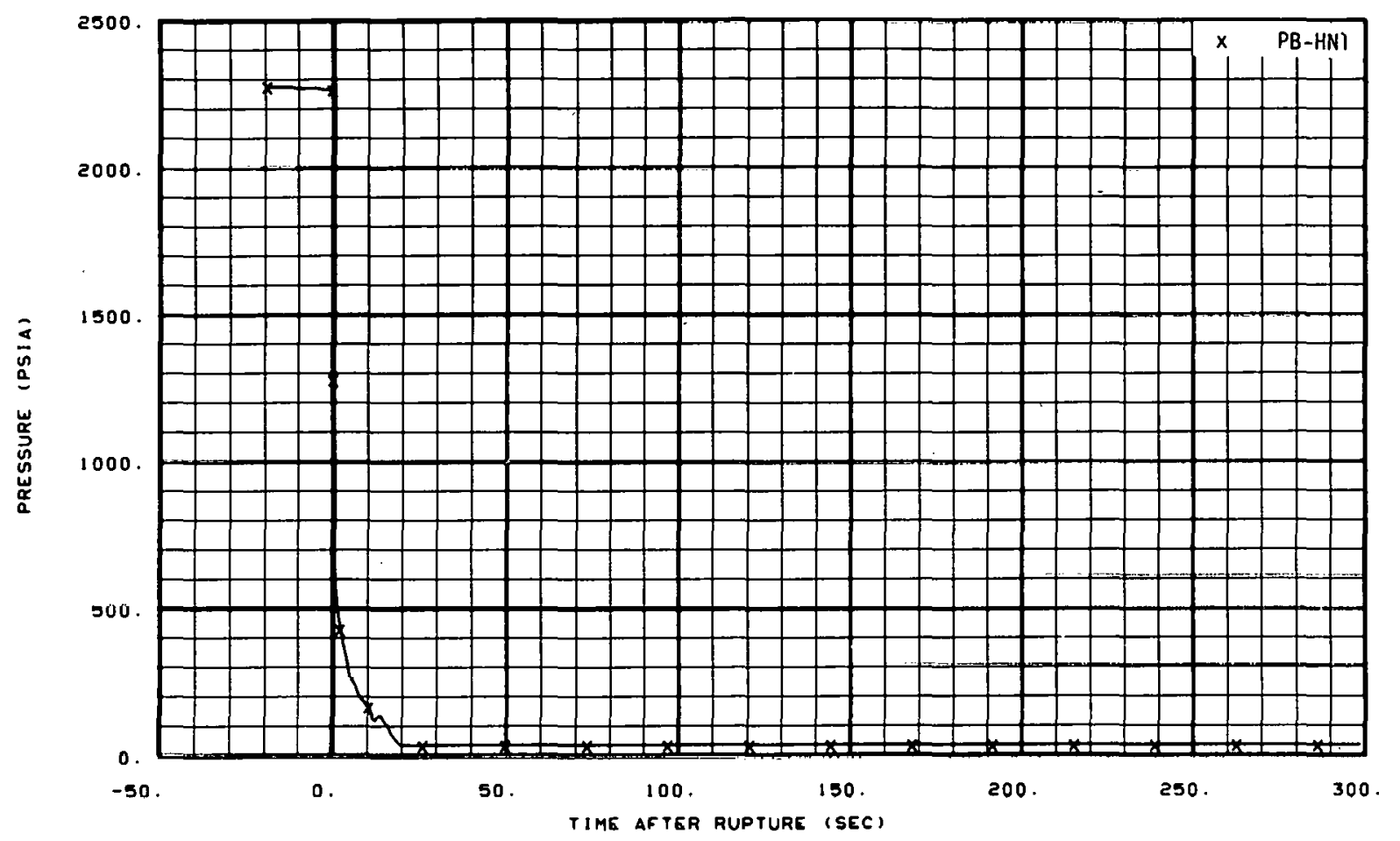

Fig. 133 Pressure in broken loop, pump-side nozzle (PB-HN1), from -20 to 300 seconds.

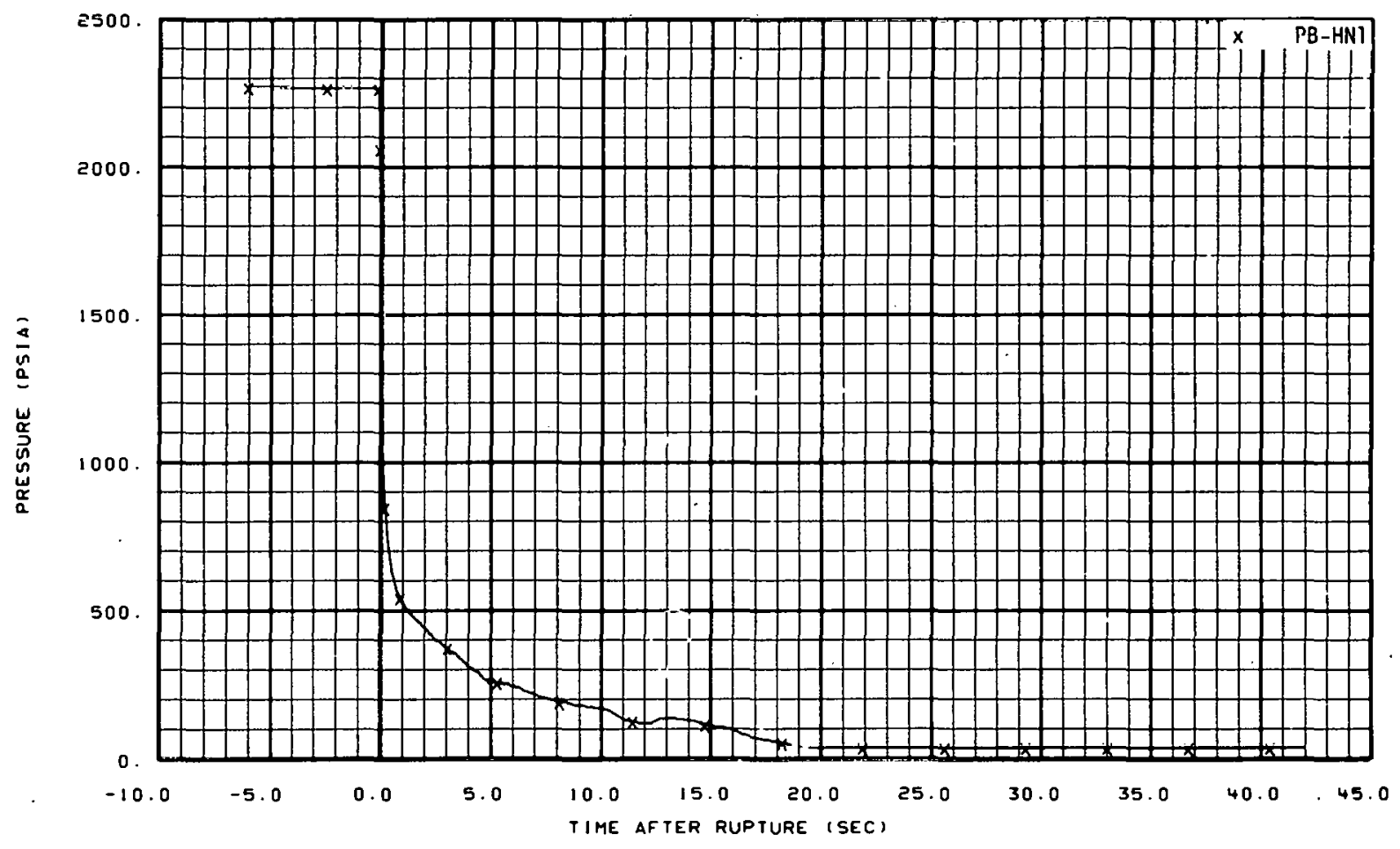

Fig. 134 Pressure in broken loop, pump-side nozzle (PB-HN1), from -6 to 42 seconds. 


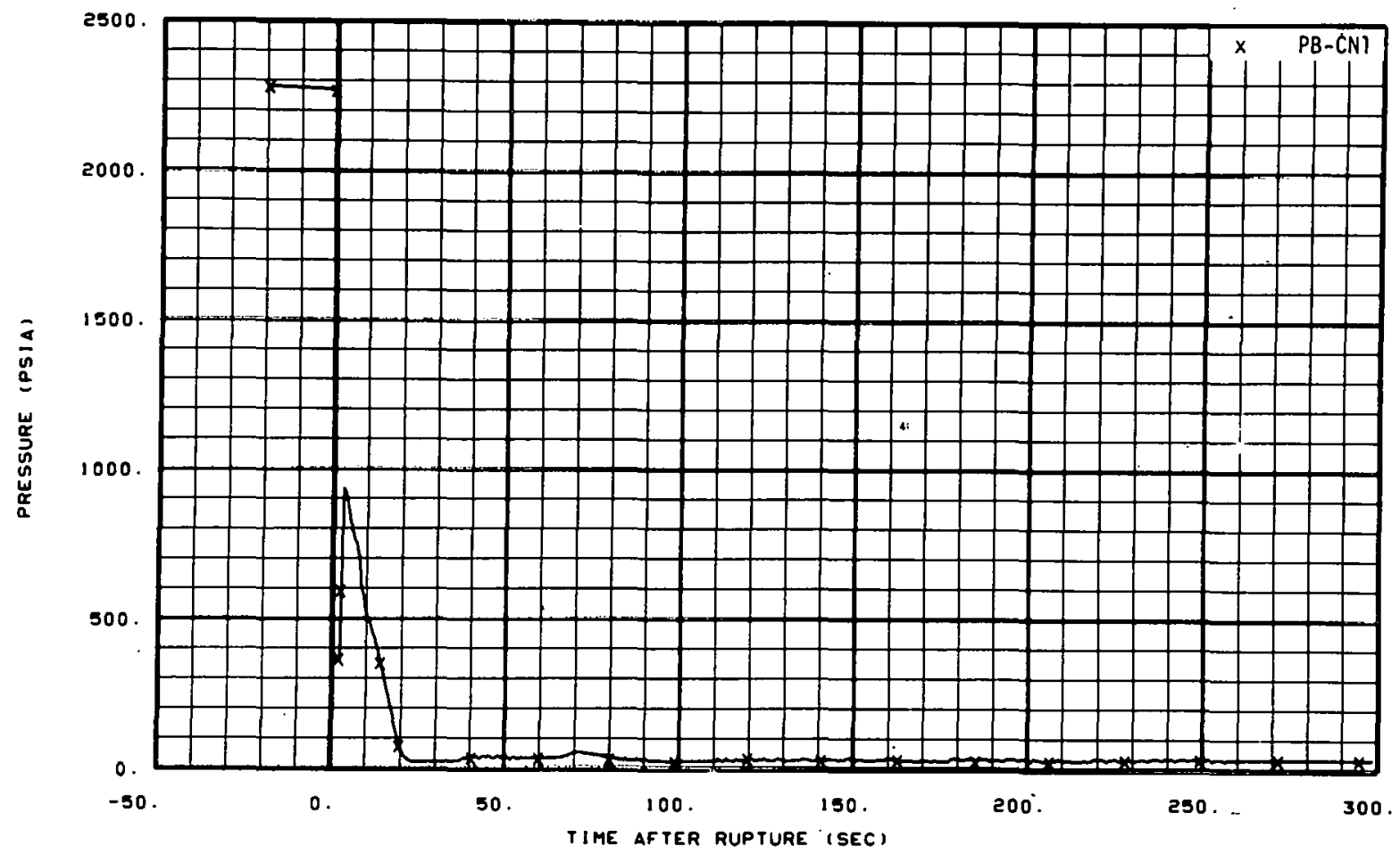

Fig. 135 Pressure in broken loop, vessel-side nozzle (PB-CN1), from -20 to 300 seconds.

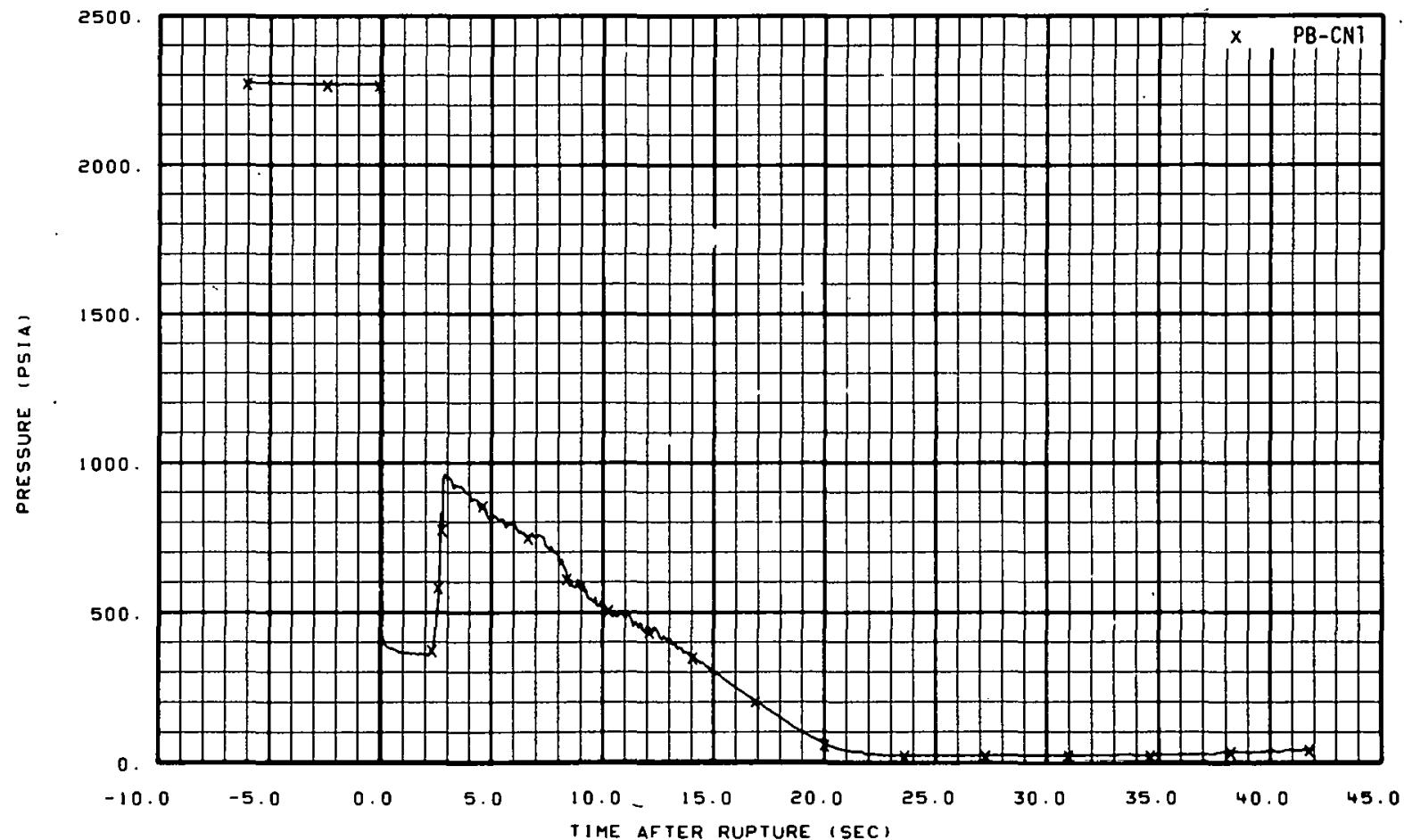

Fig. 136 Pressure in broken loop, vessel-side nozzle (PB-CN1), from -6 to 42 seconds. 


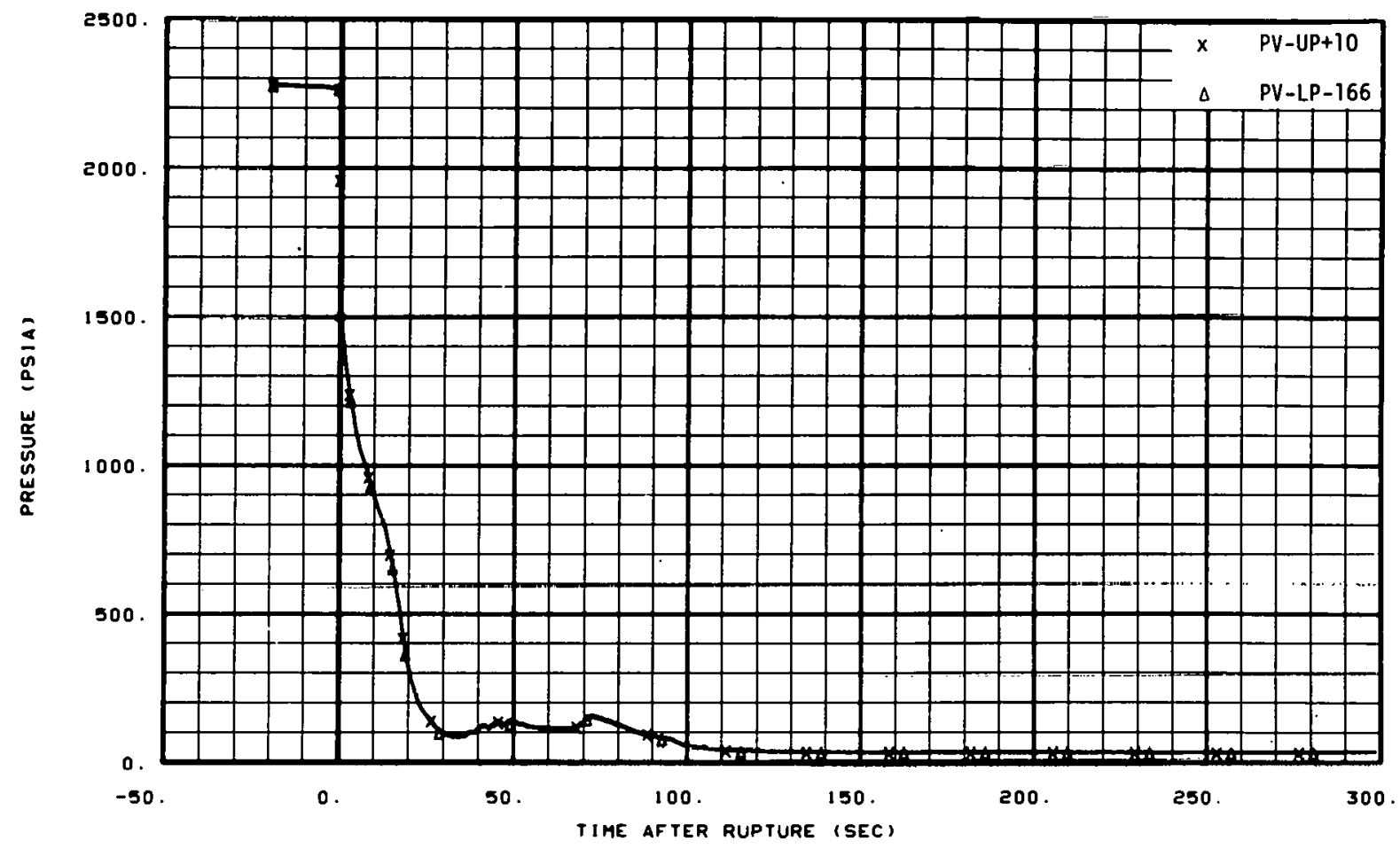

Fig. 137 Pressure in vessel (PV-UP+10 and PV-LP-166), from -20 to 300 seconds.

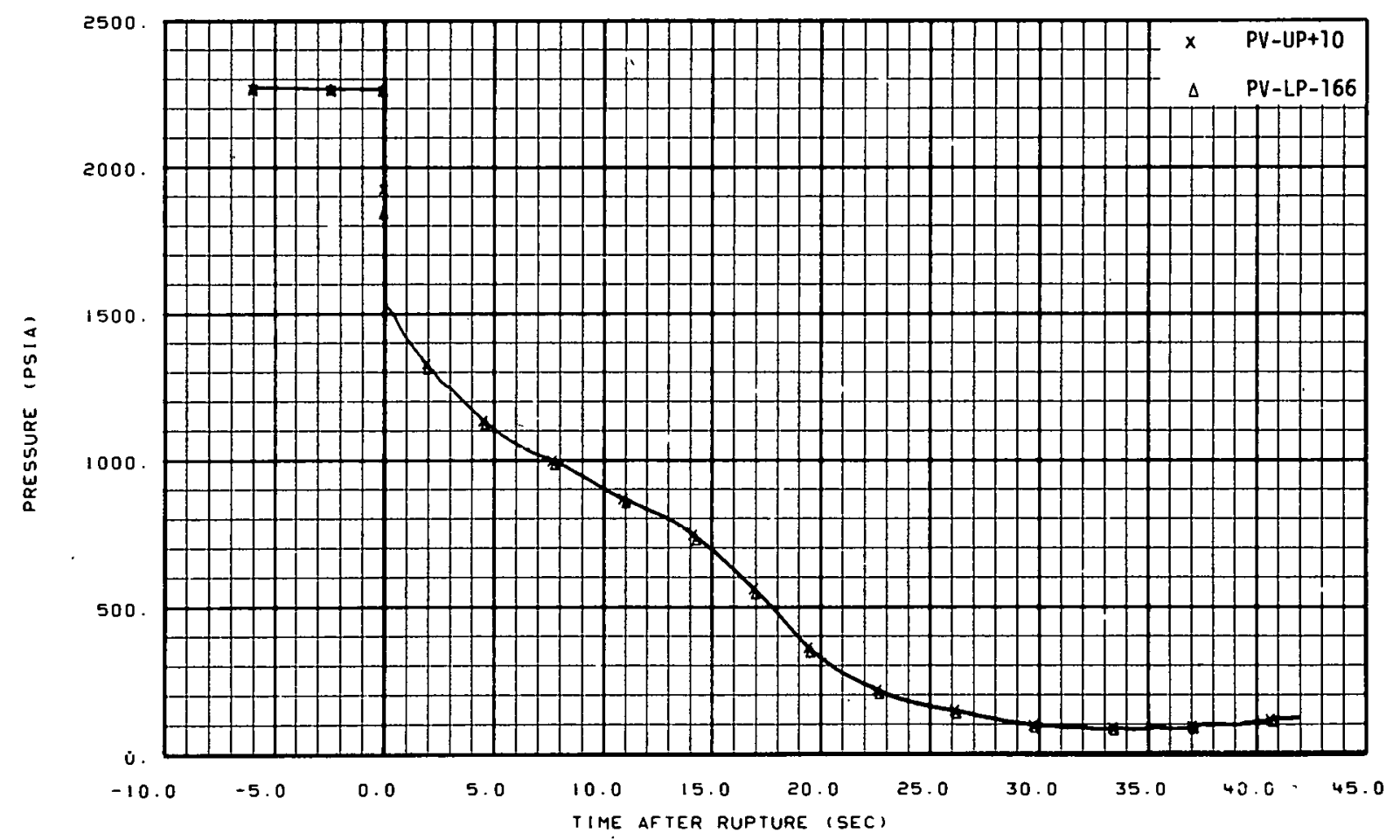

Fig. 138 Pressure in vessel (PV-UP+10 and PV-LP-166), from -6 to 42 seconds. 


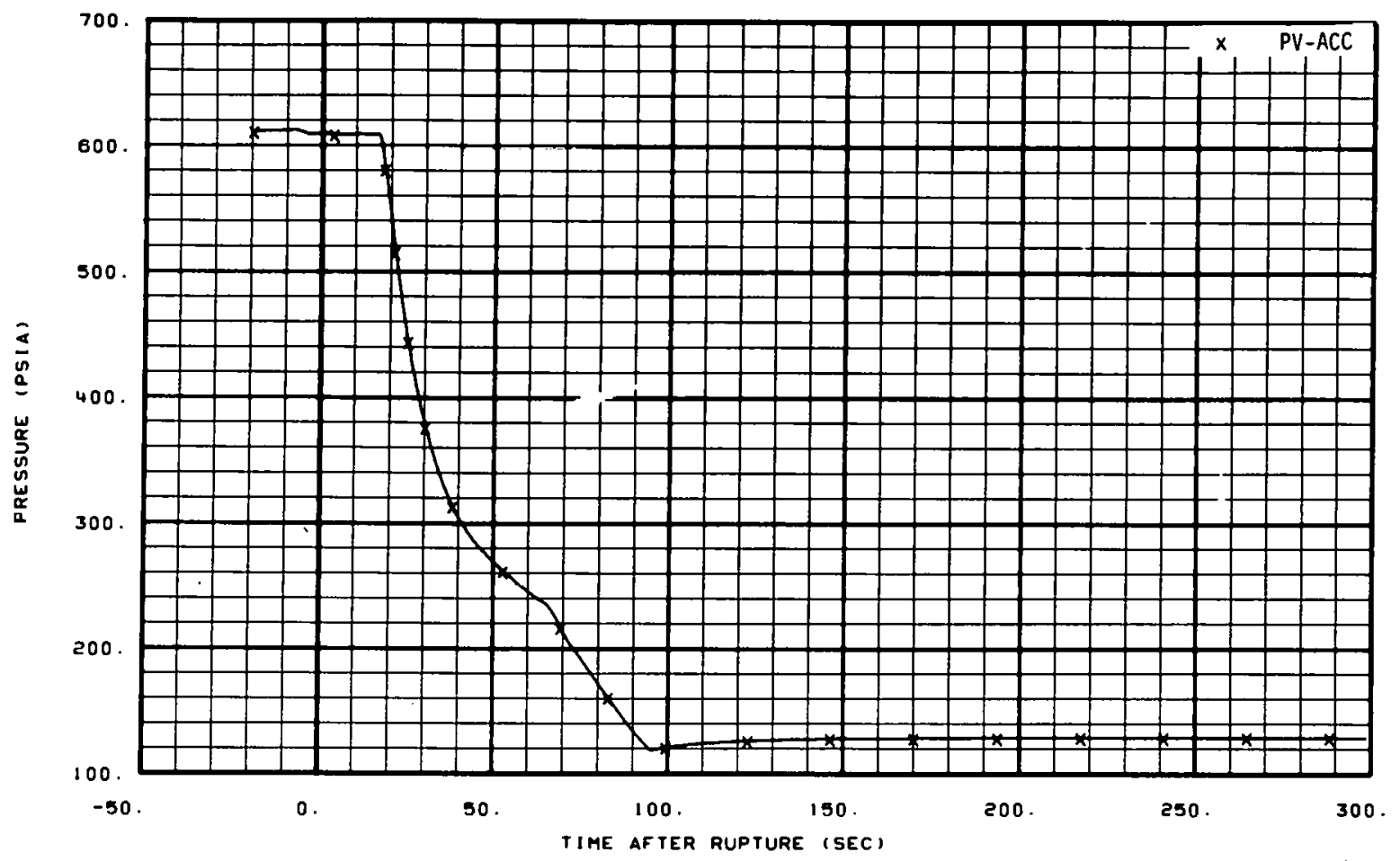

Fig. 139 Pressure in vessel accumulator (PV-ACC), from -20 to 300 seconds.

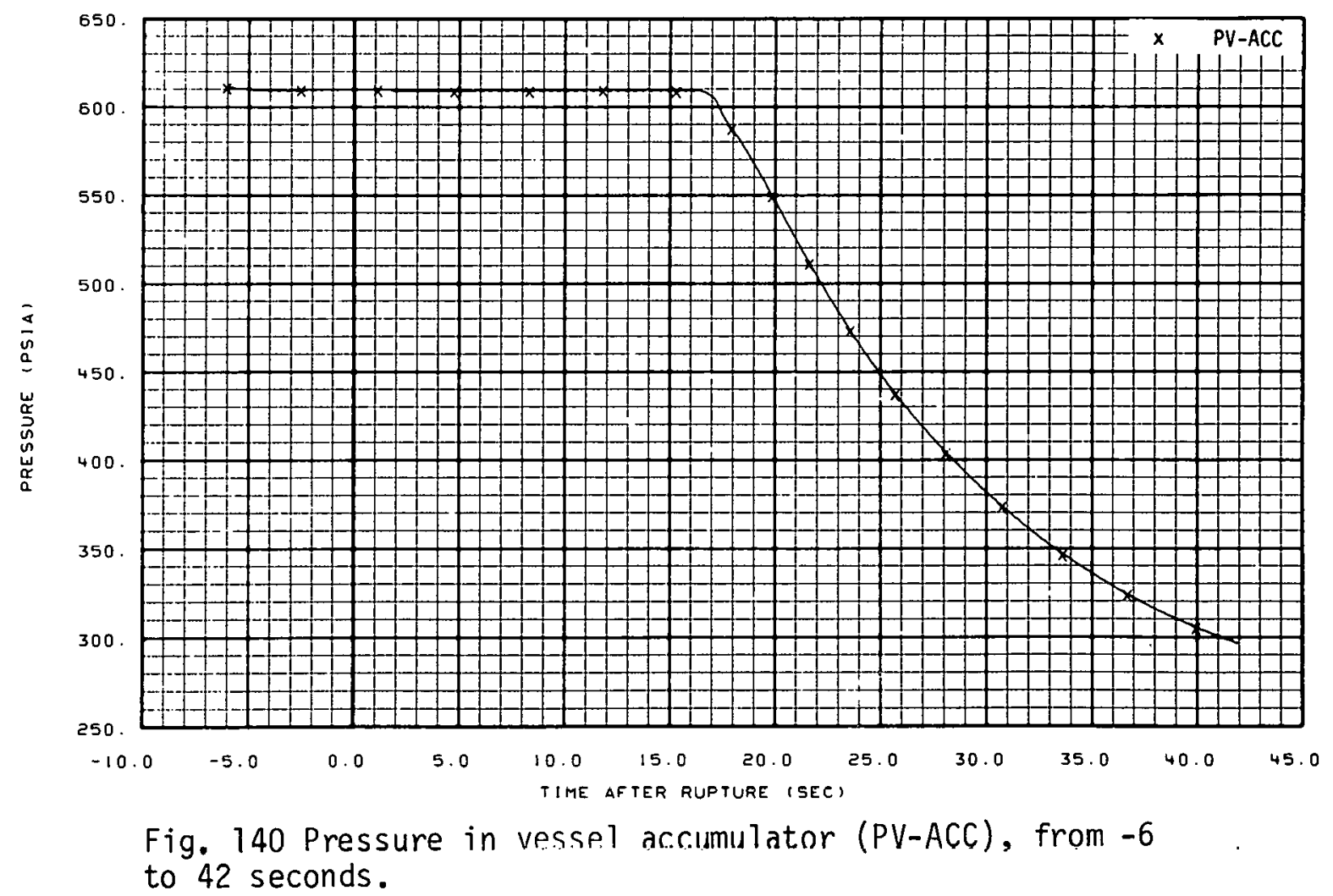




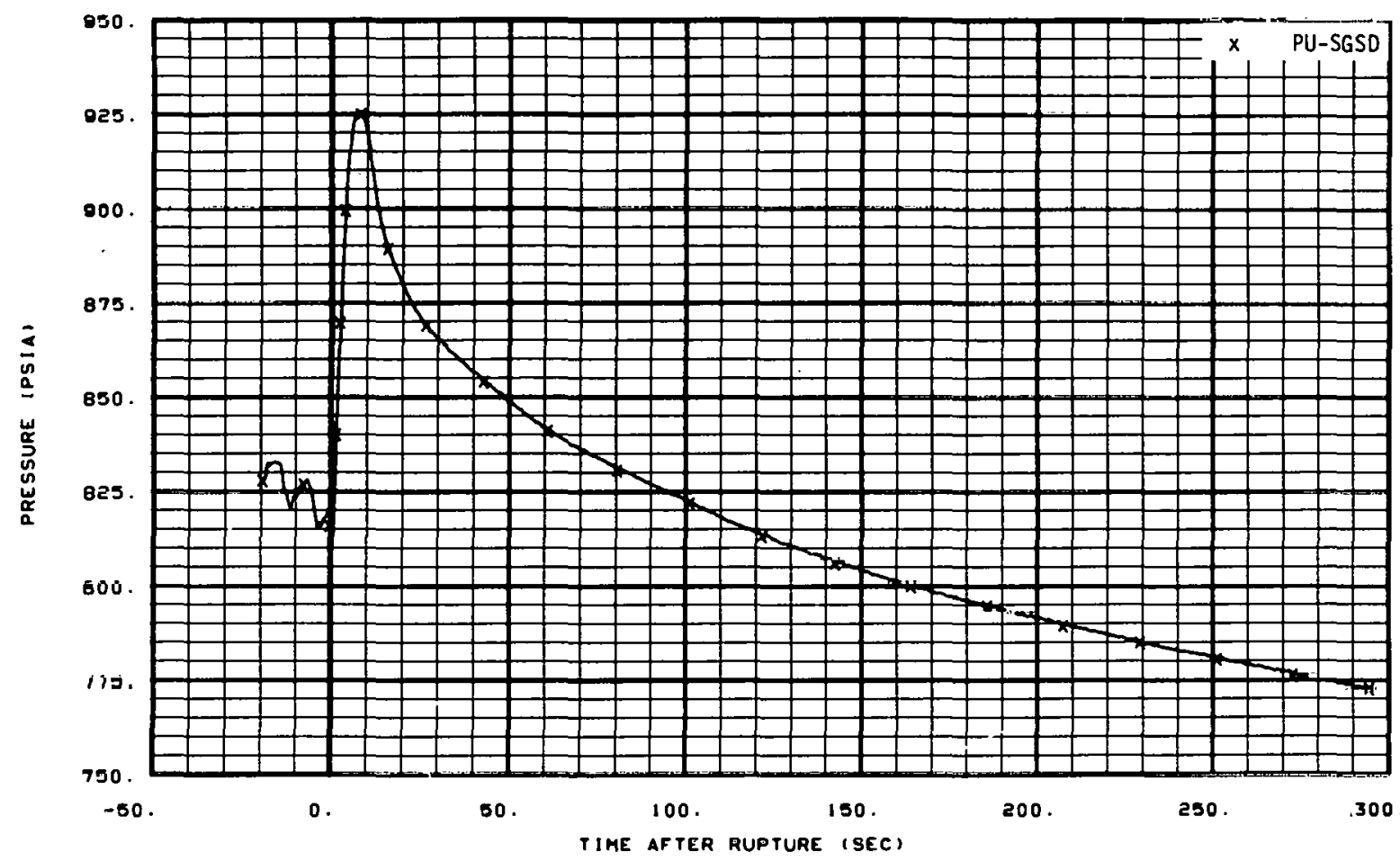

Fig. 141 Pressure in steam generator, secondary side (PU-SGSD), from -20 to 300 seconds.

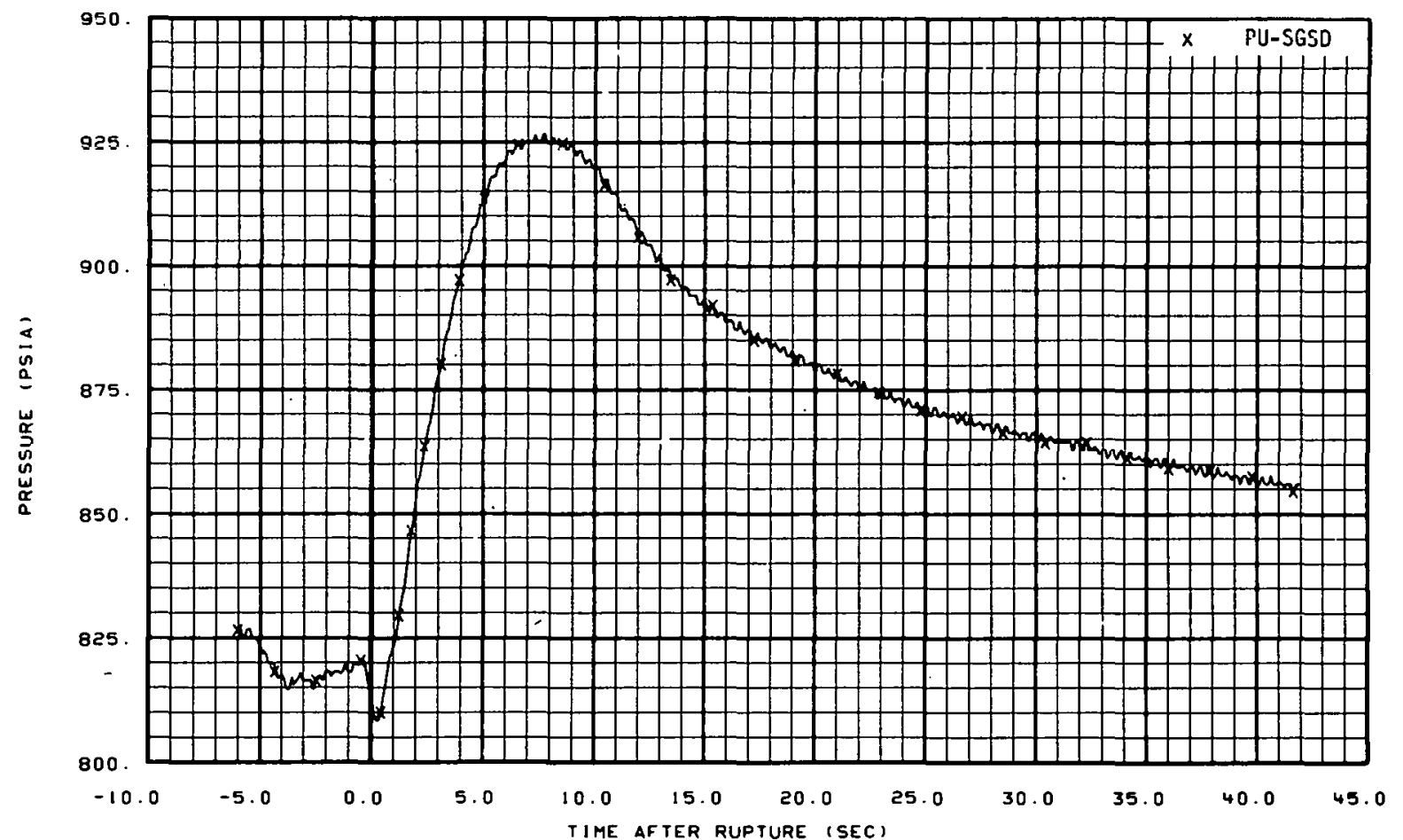

Fig. 142 Pressure in steam generator, secondary side (PU-SGSD), from -6 to 42 seconds. 


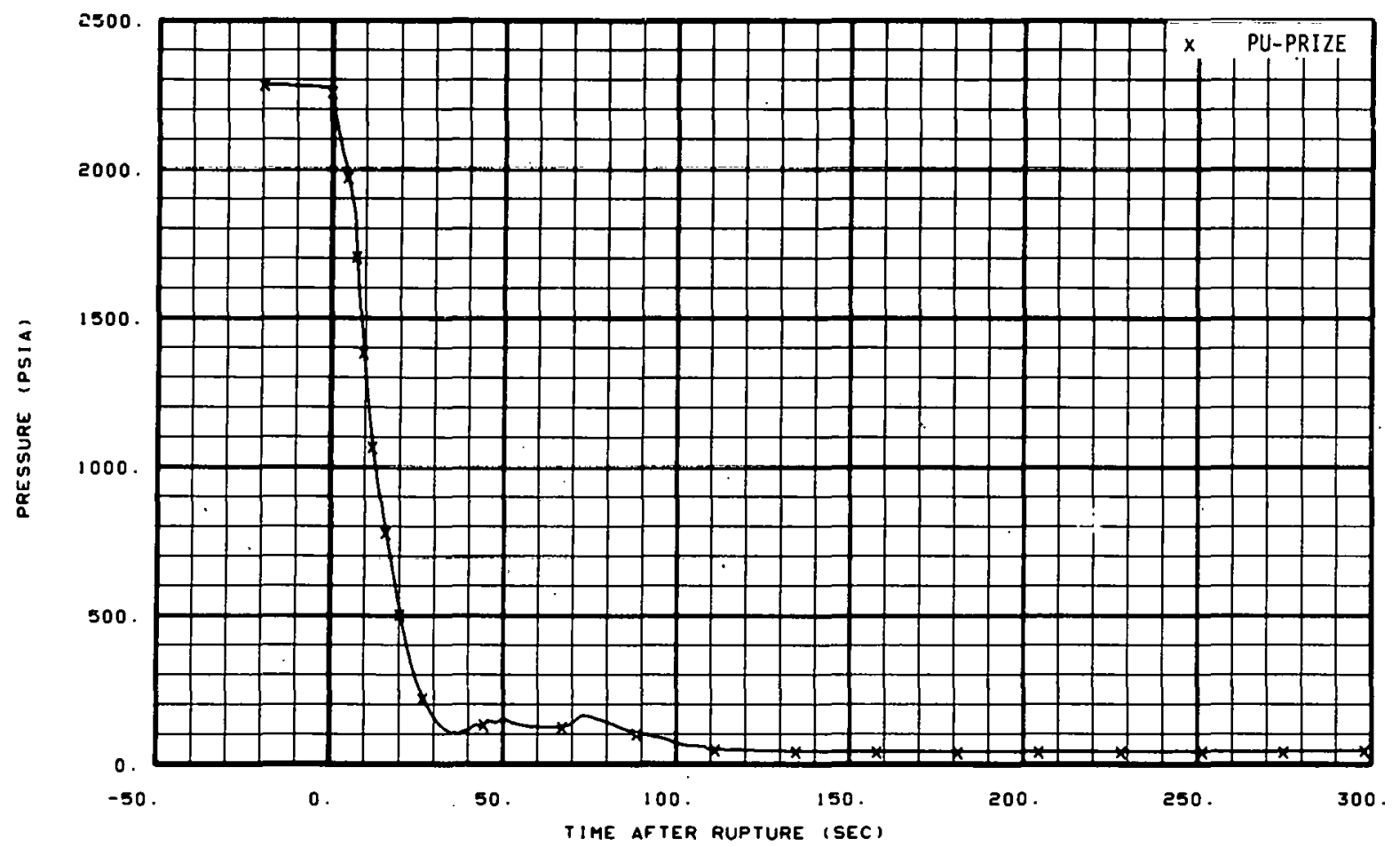

Fig. 143 Pressure in pressurizer (PU-PRIZE), from -20 to 300 seconds.

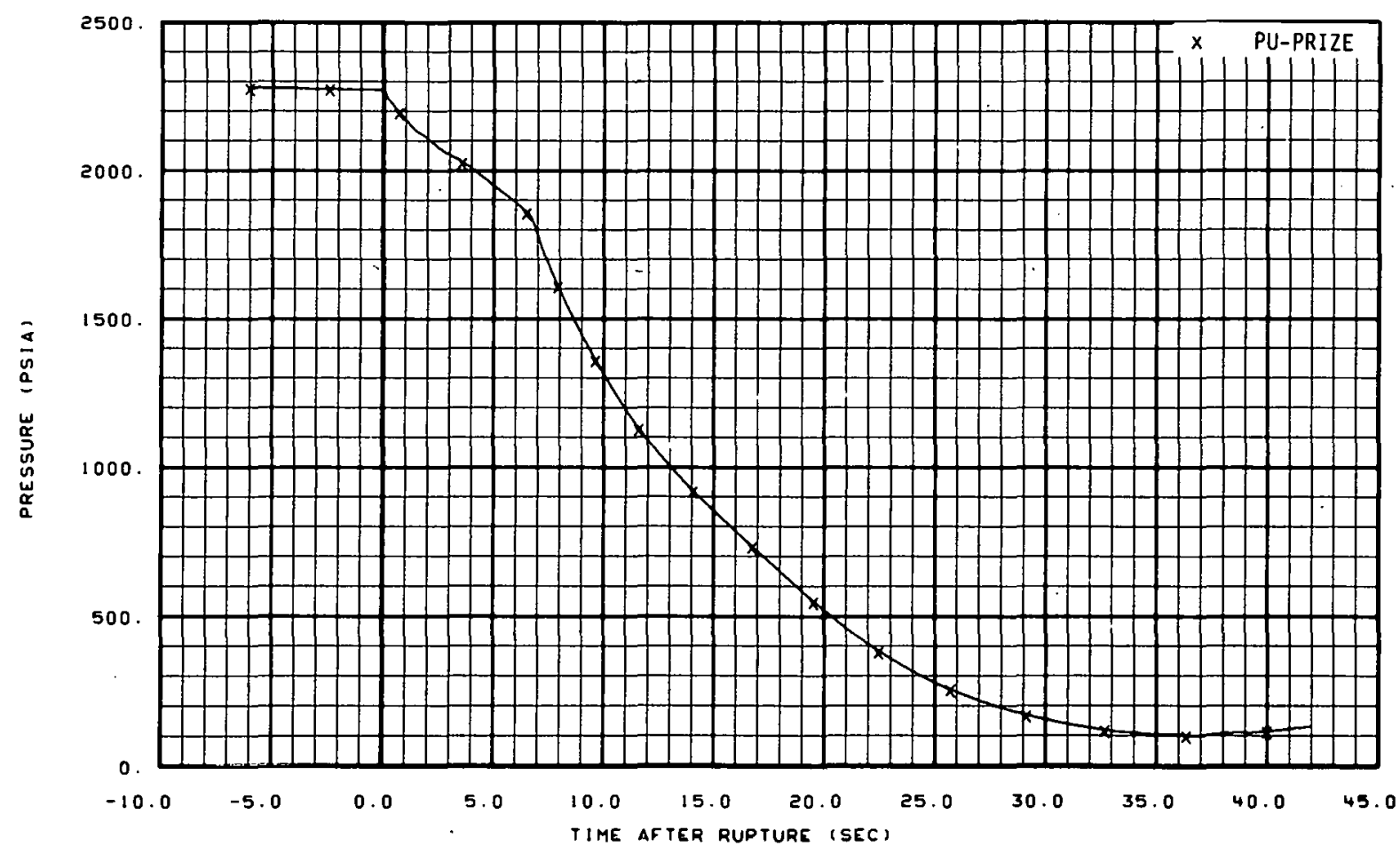

Fig. 144 Pressure in pressurizer (PU-PRIZE), from -6 to 42 seconds. 


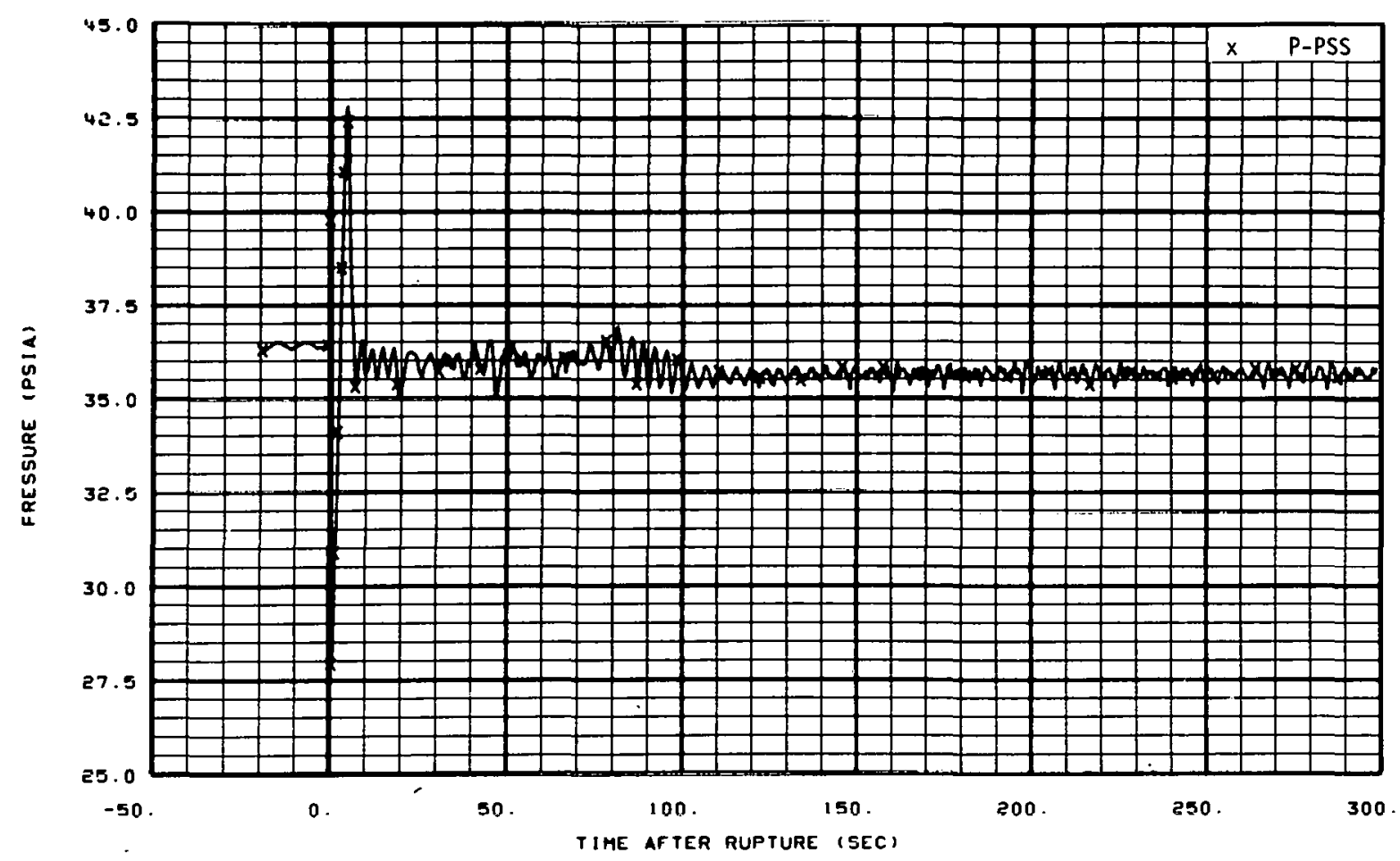

Fig. 145 Pressure in pressure suppression tank (P-PSS), from -20 to 300 seconds.

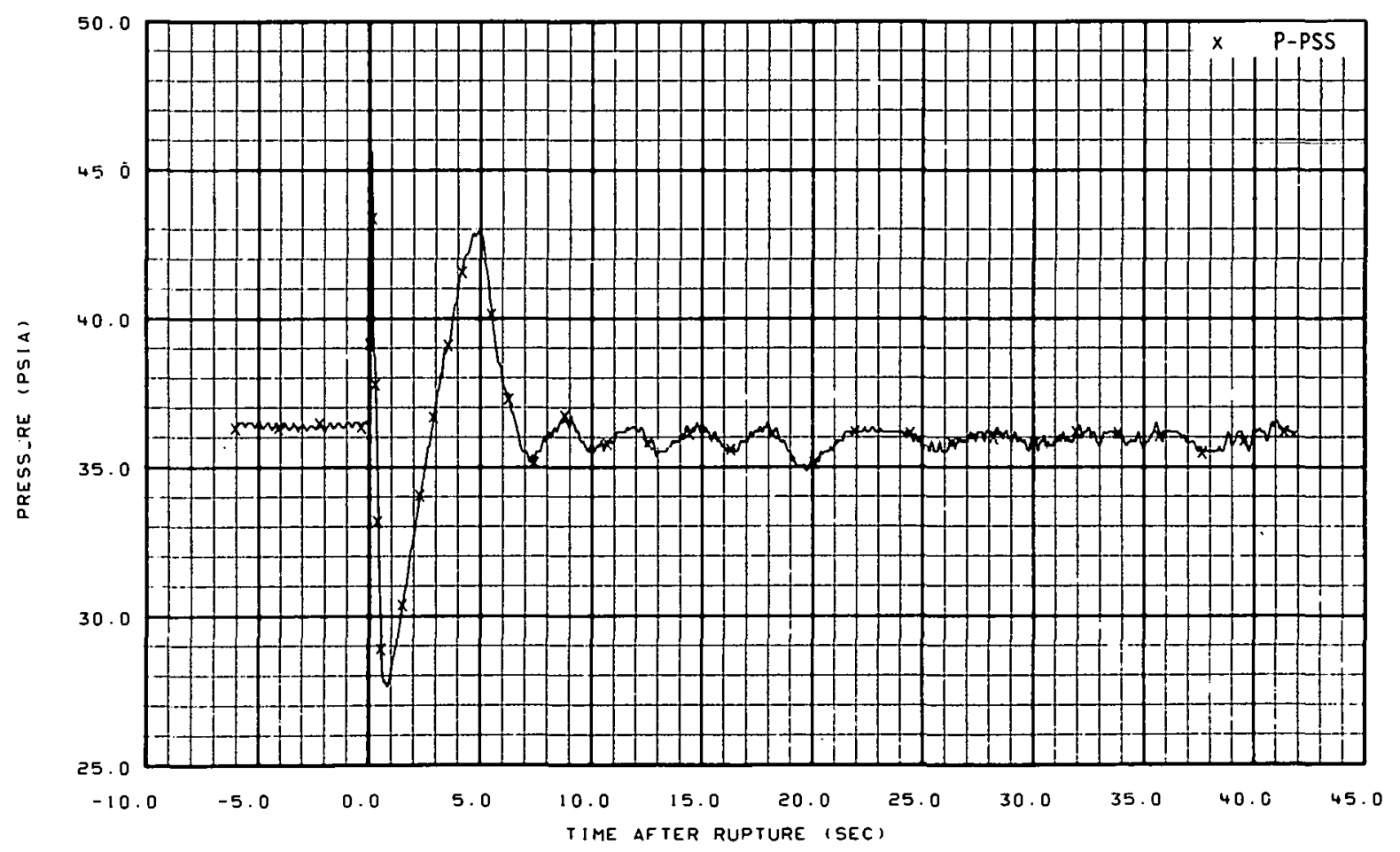

Fig. 146 Pressure in pressure suppression tank (P-PSS), from -6 to 42 seconds. 


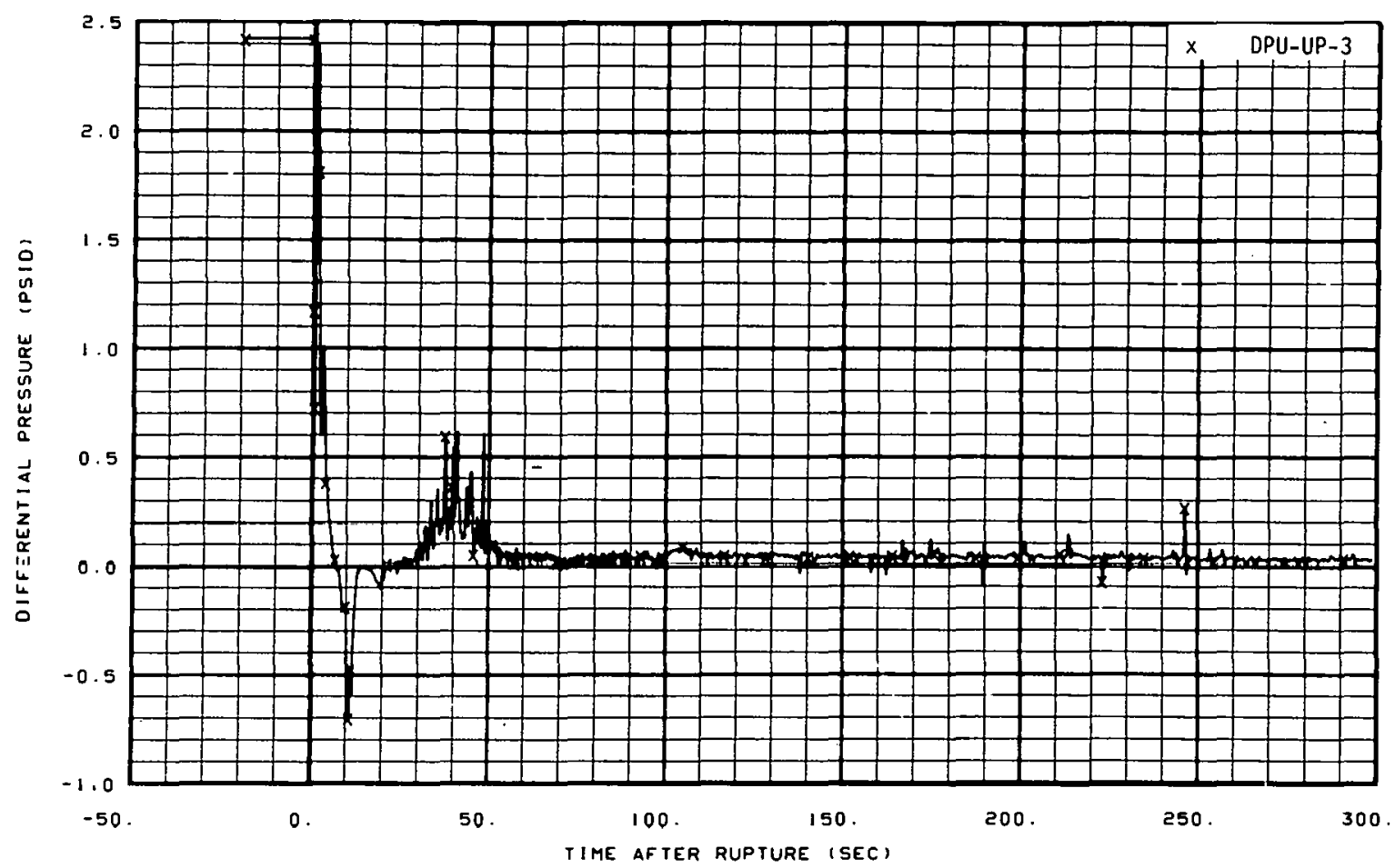

Fig. 147 Differential pressure in intact loop (DPU-UP-3), from -20 to 300 seconds.

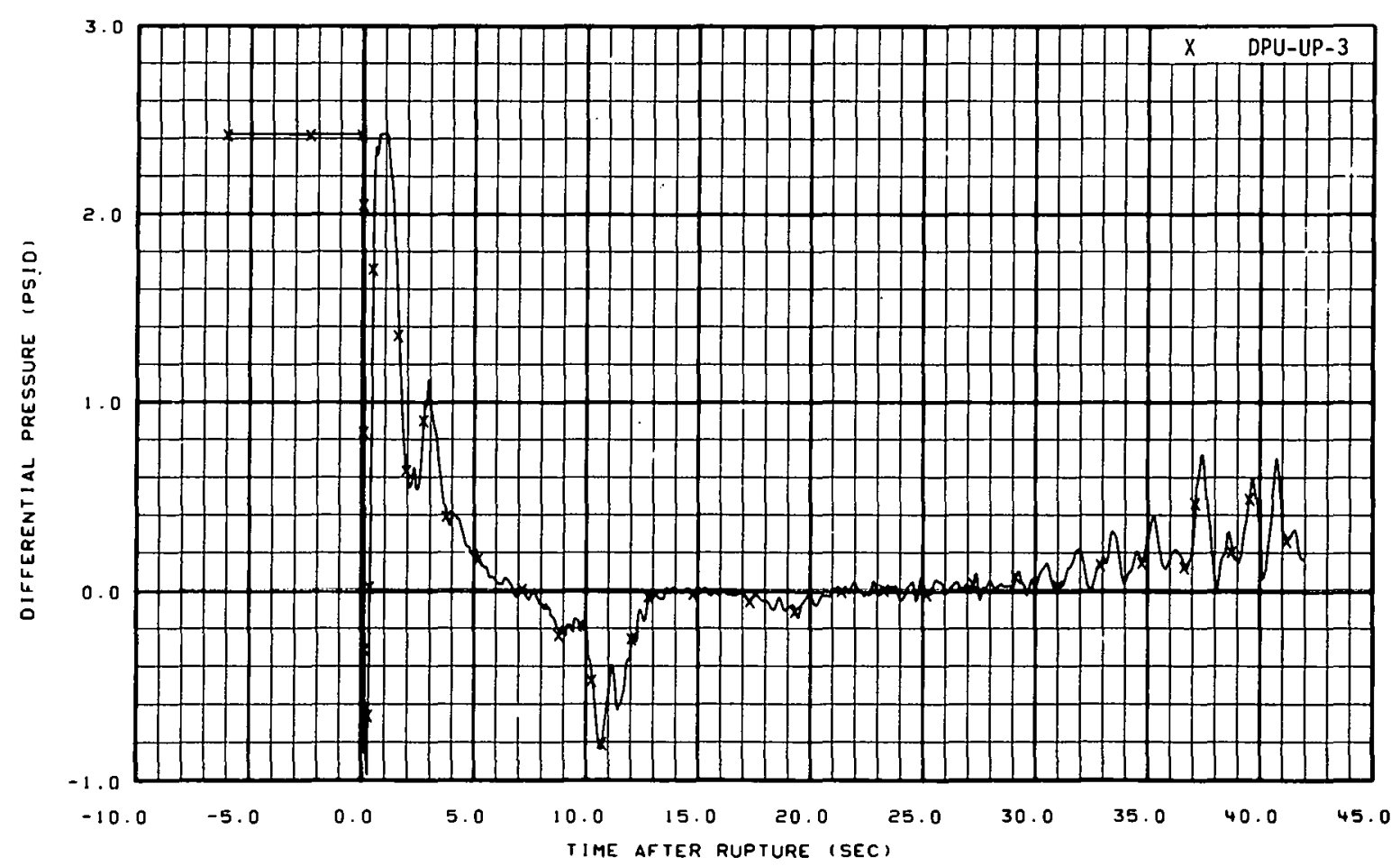

Fig. 118 Differential pressure in intact loop (DPU-UP-3), from -6 to 42 seconds. 


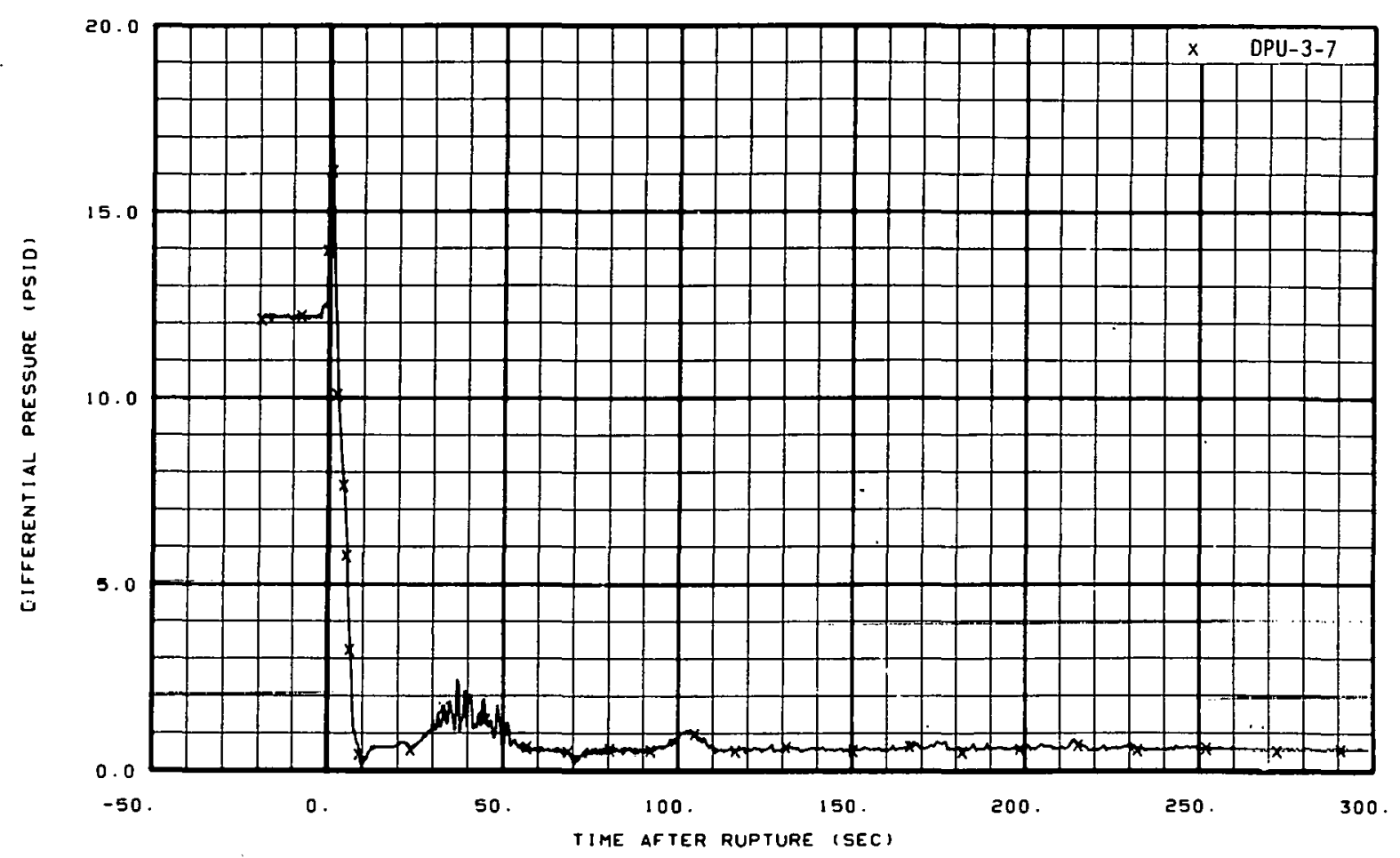

Fig. 149 Differential pressure in intact loop (DPU-3-7), from -20 to 300 seconds.

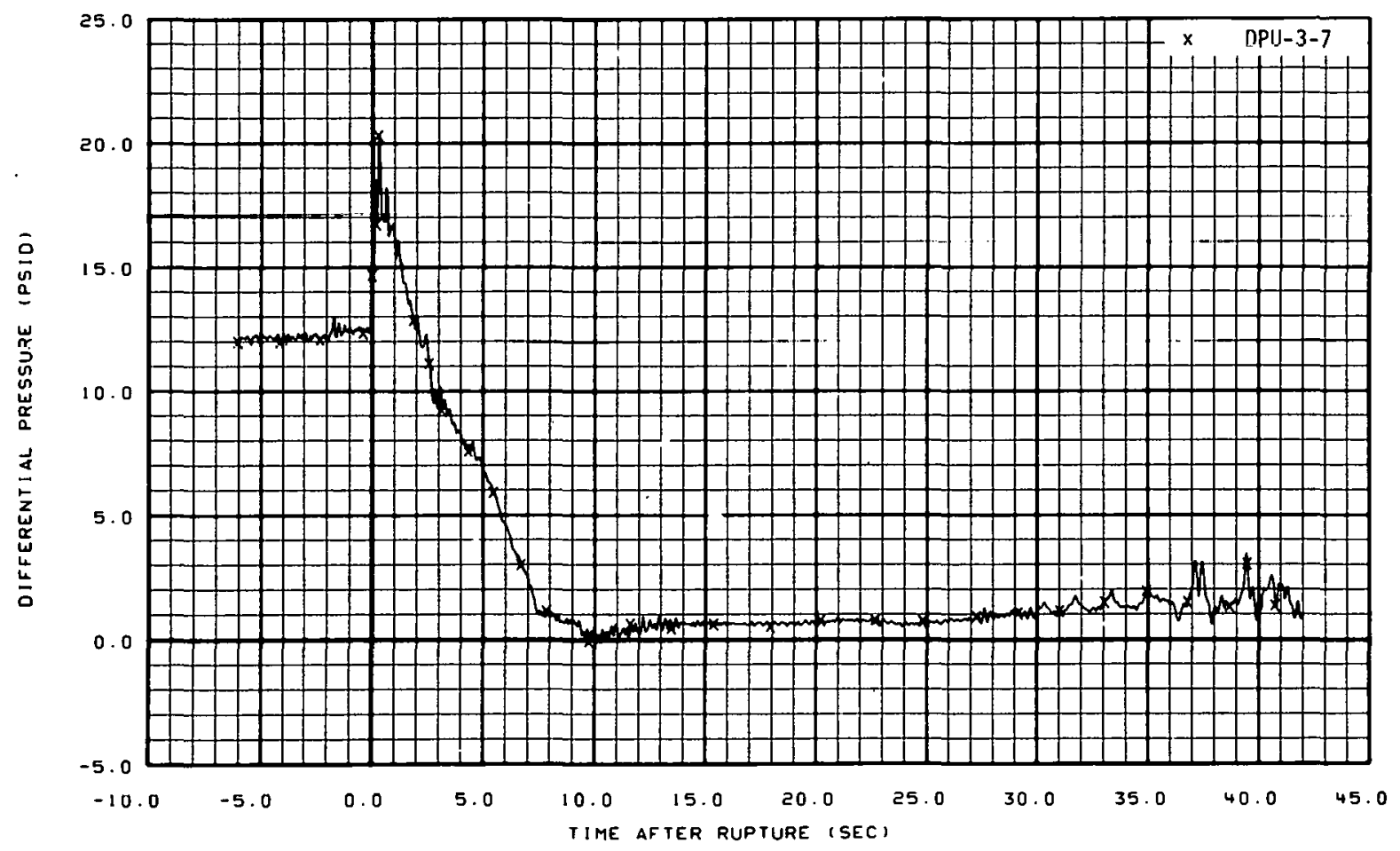

Fig. 150 Differential pressure in intact 100p (DPU-3-7), from -6 to 42 seconds. 


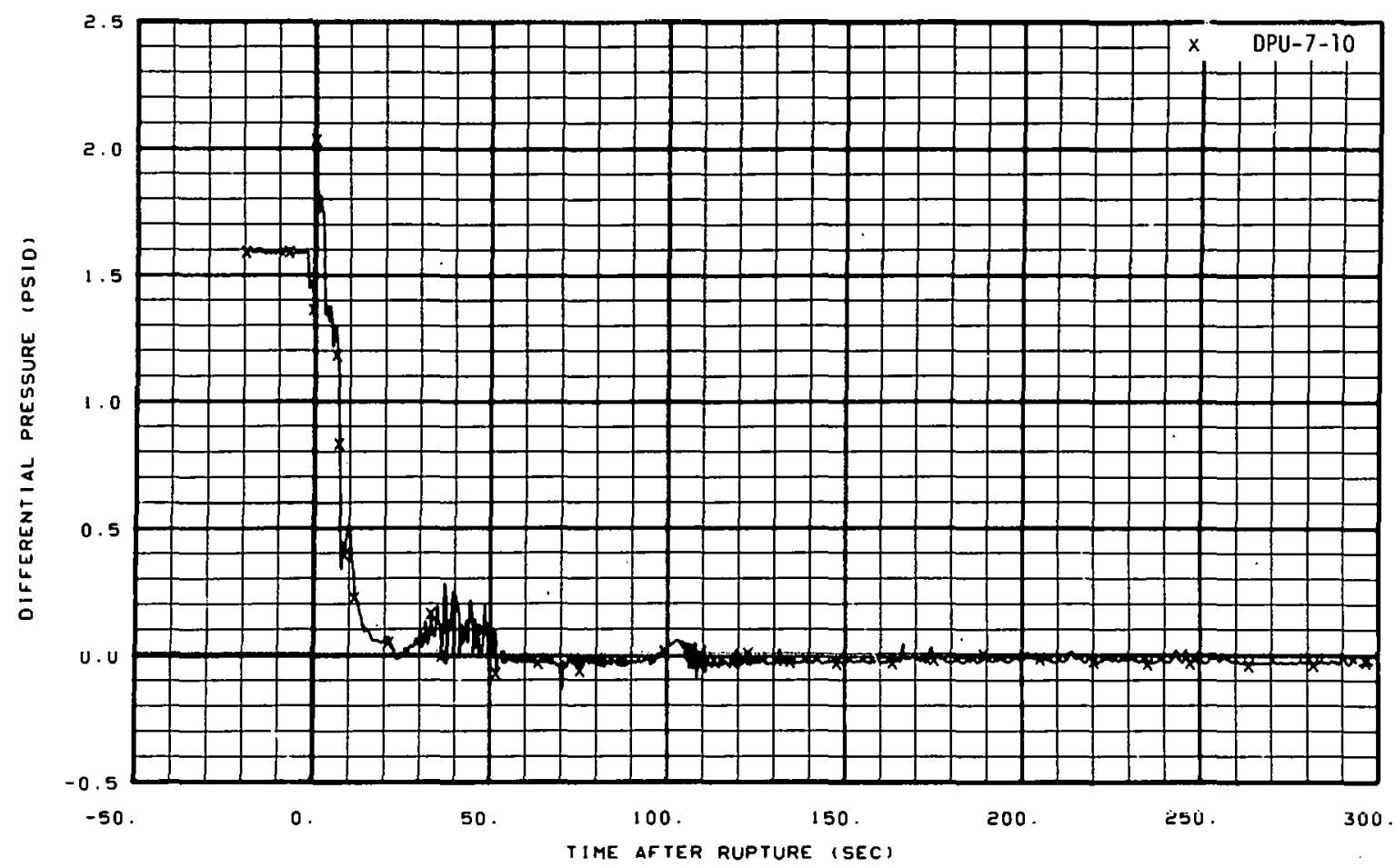

Fig. 151 Differential pressure in intact loop (DPU-7-10), from -20 to 300 seconds.

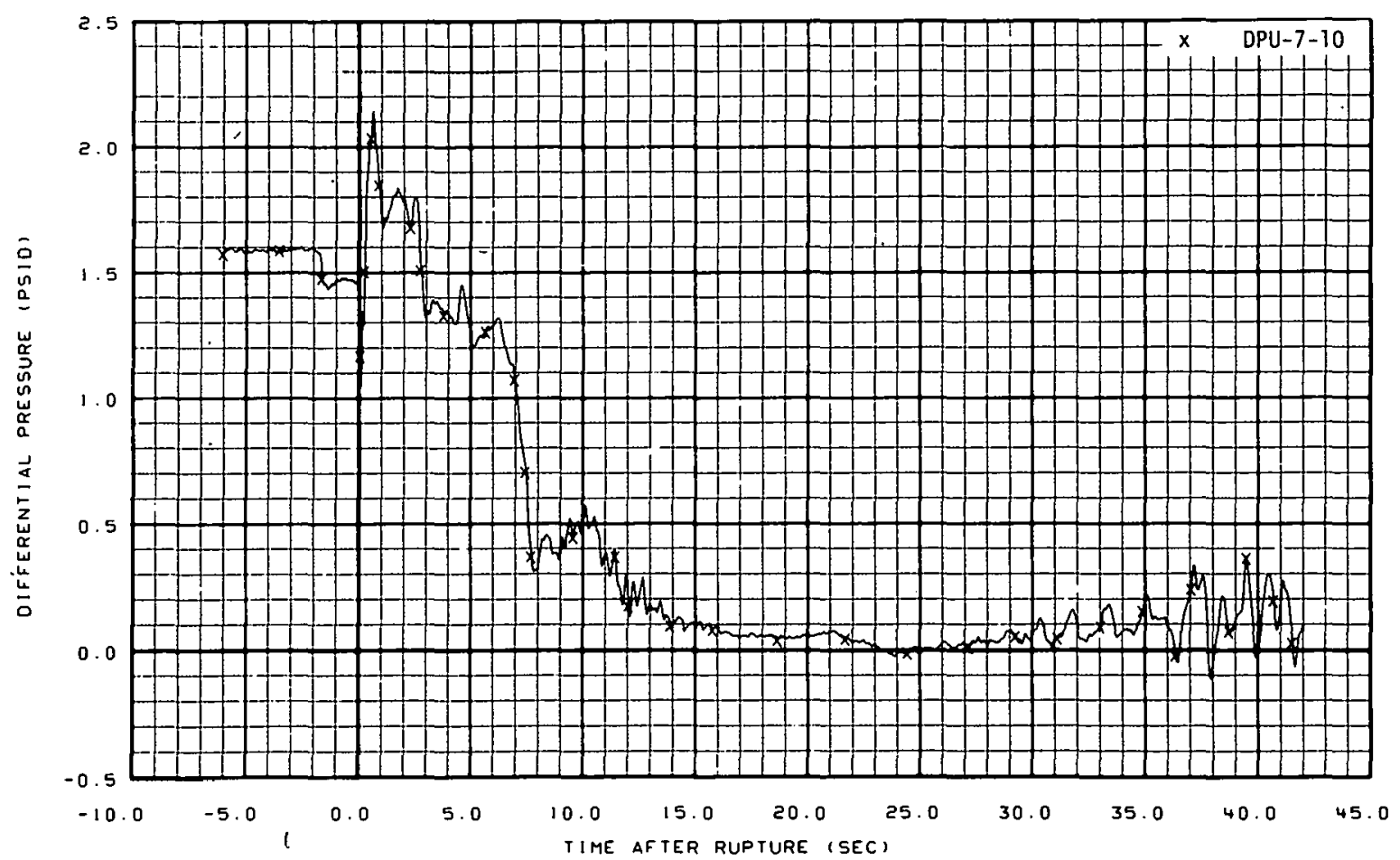

Fig. 152 Differential pressure in intact loop (DPU-7-10), from -6 to 42 seconds. 


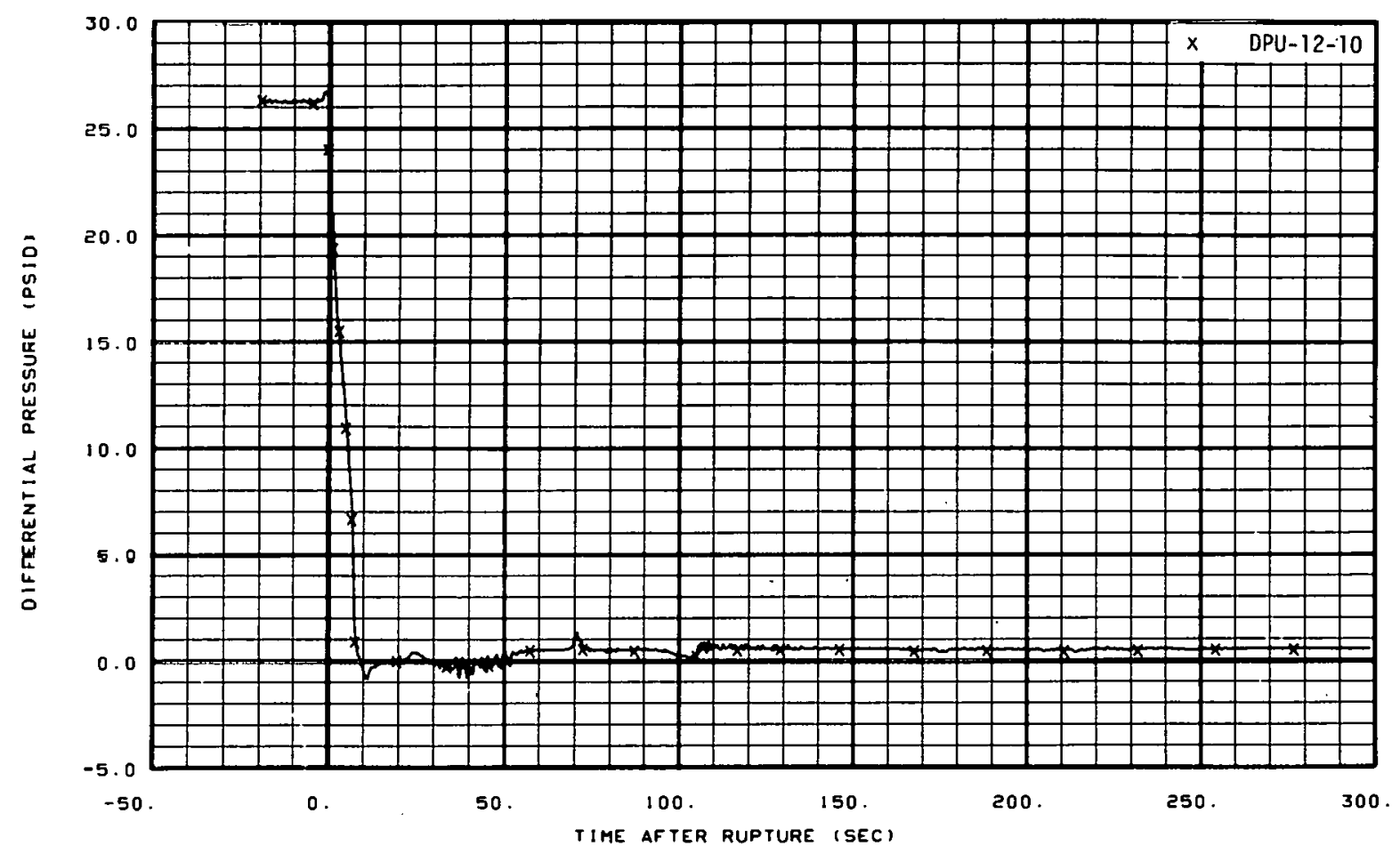

Fig. 153 Differential pressure in intact loop (DPU-12-10), from -20 to 300 seconds.

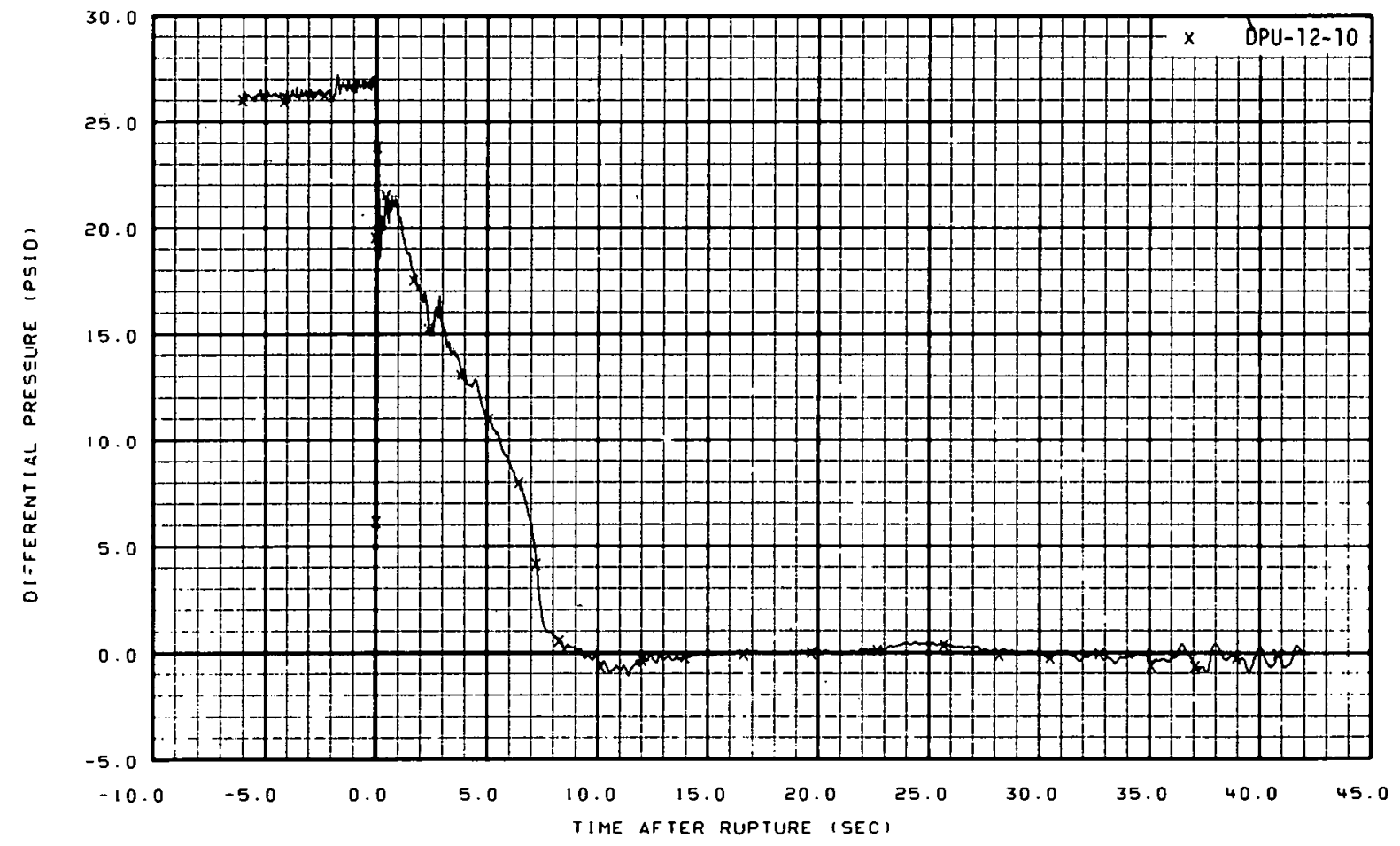

Fig. 154 Differential pressure in intact loop (DPU-12-10), from -6 to 42 seconds. 


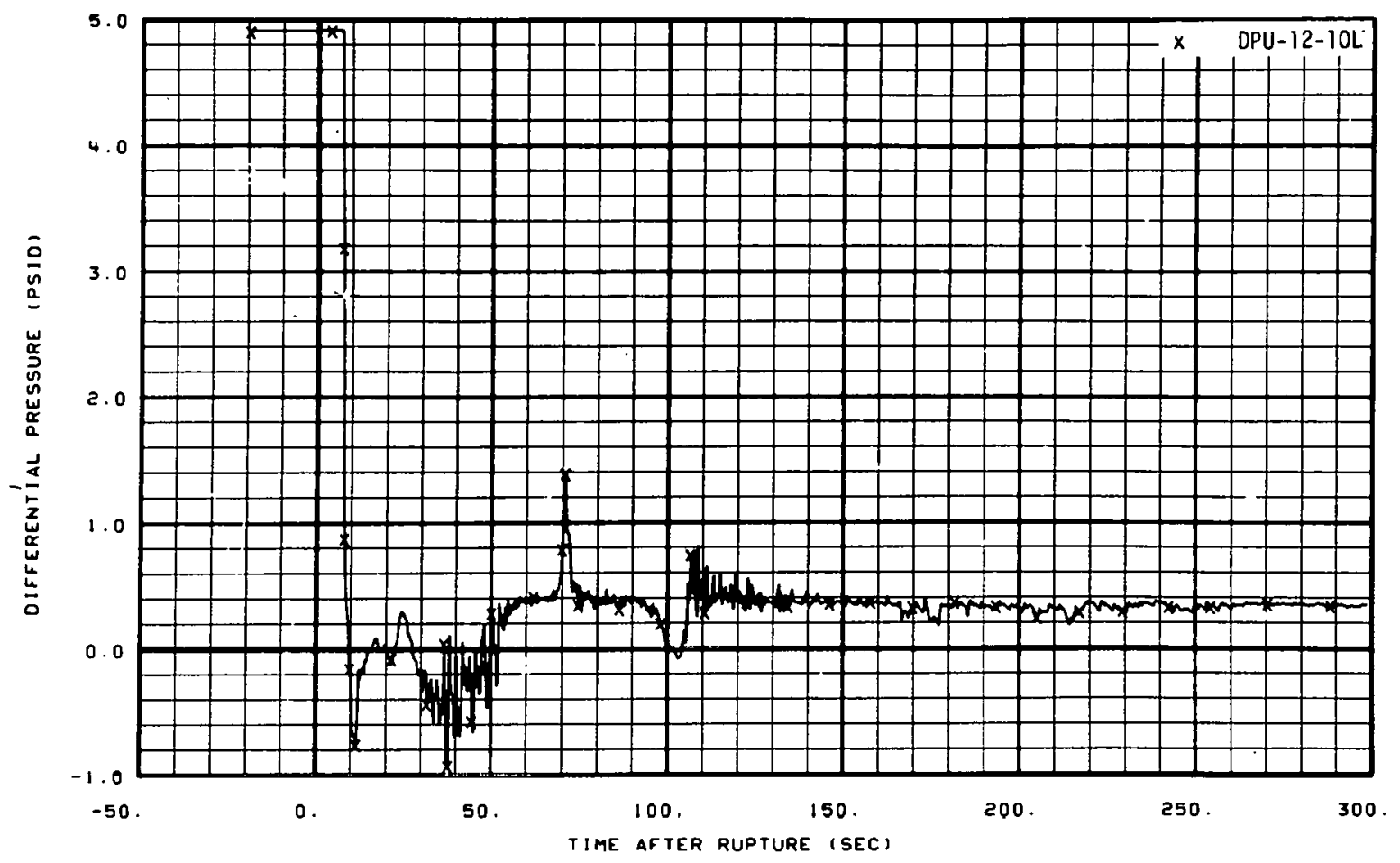

Fig. 155 Differential pressure in intact loop, low range (DPU-12-10L), from -20 to 300 seconds.

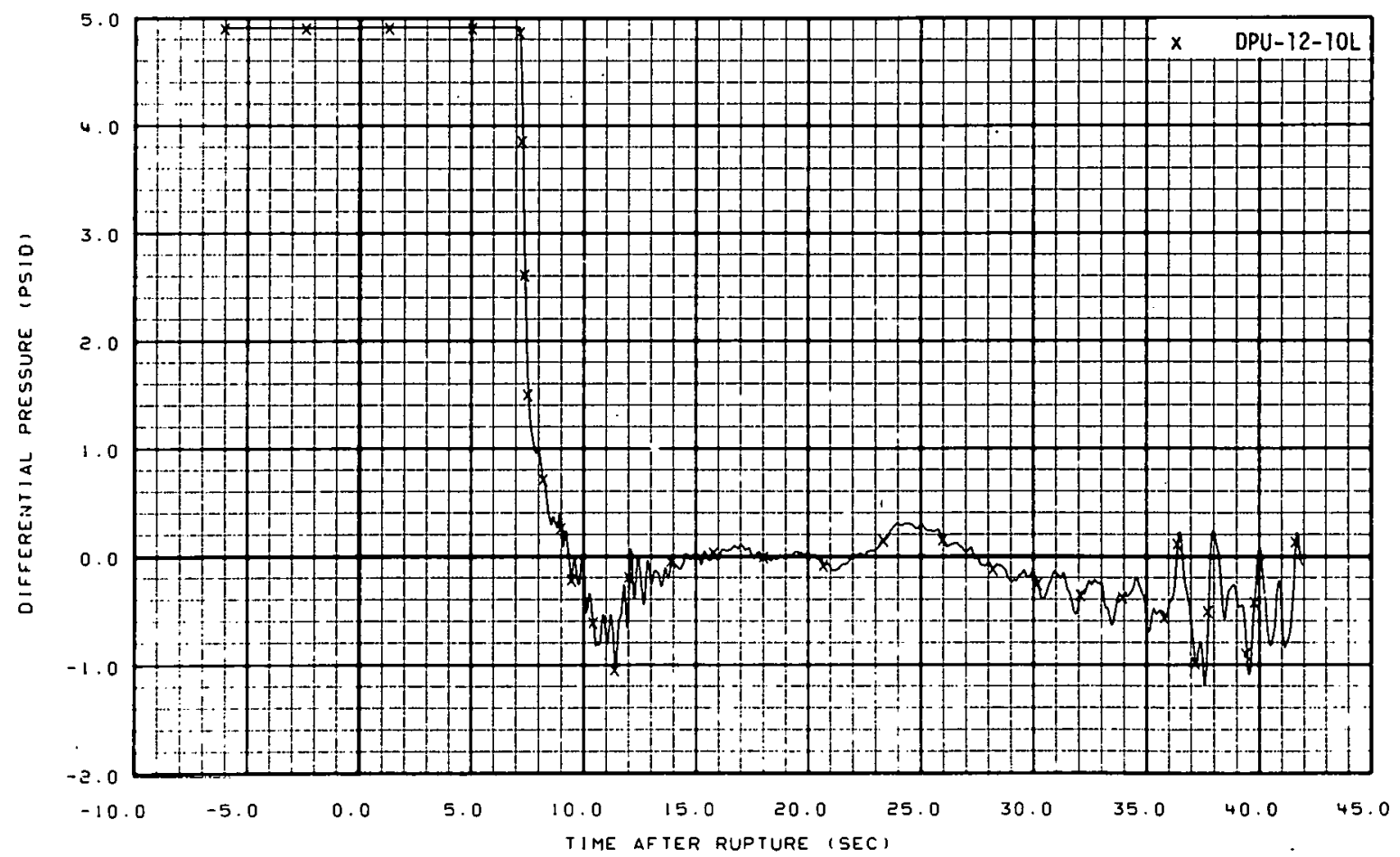

Fig. 156 Differential pressure in intact loop, low range (DPU-12-10L), from -6 to 42 seconds. 


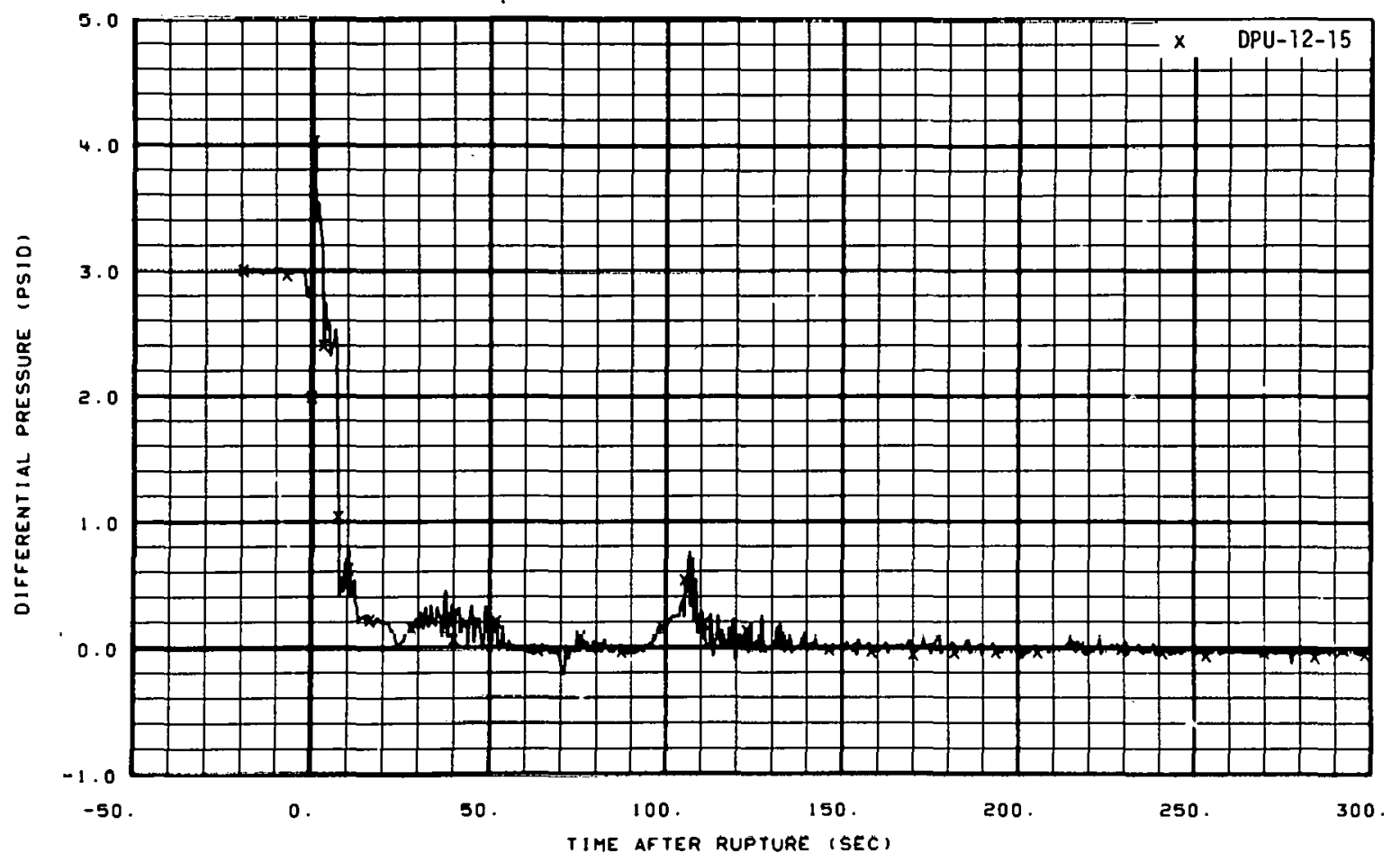

Fig. 157 Differential pressure in intact loop, (DPU-12-15), from -20 to 300 seconds.

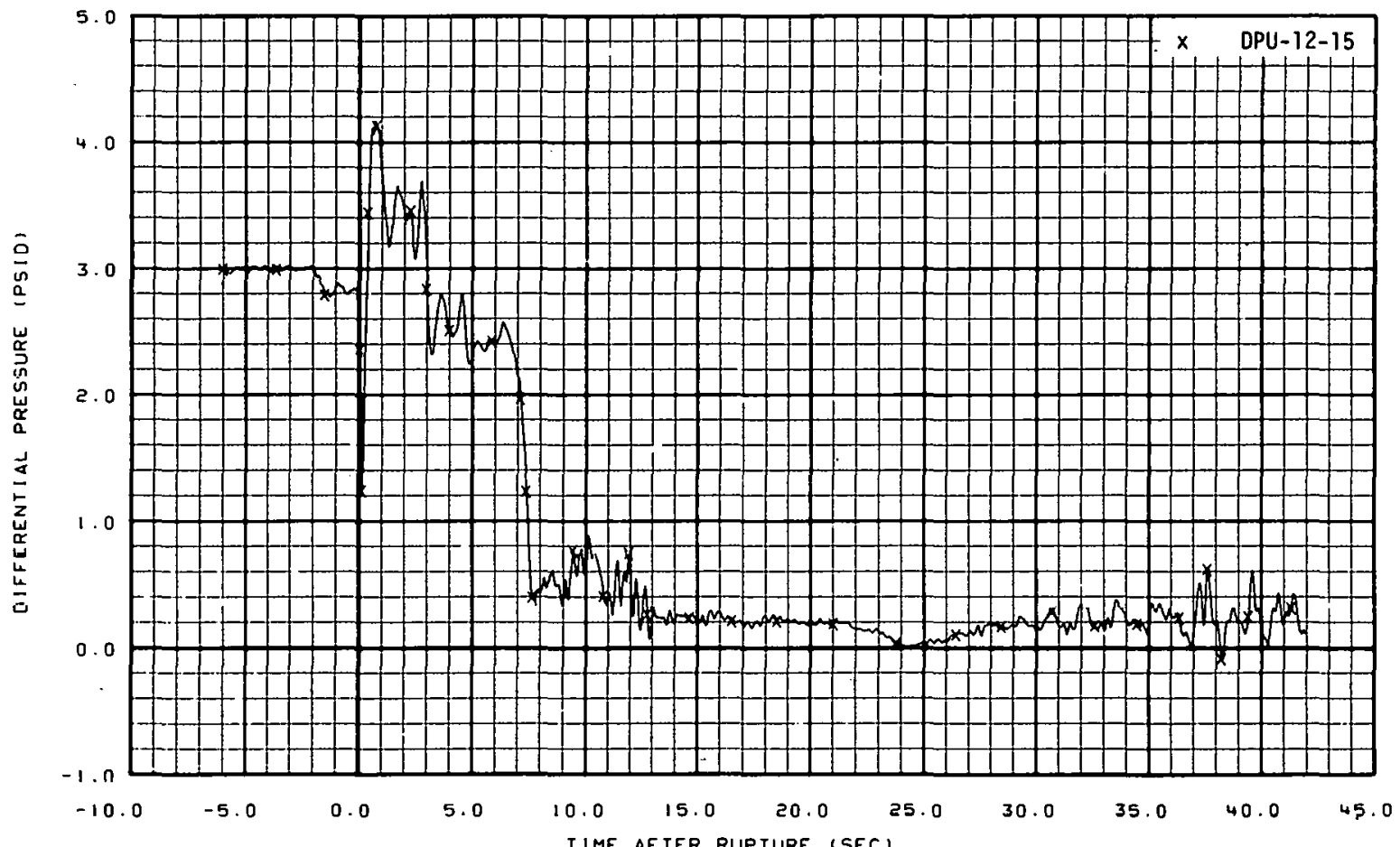

Fig. 158 Differential pressure in intact loop, (DPU-12-15), from -6 to 42 seconds. 


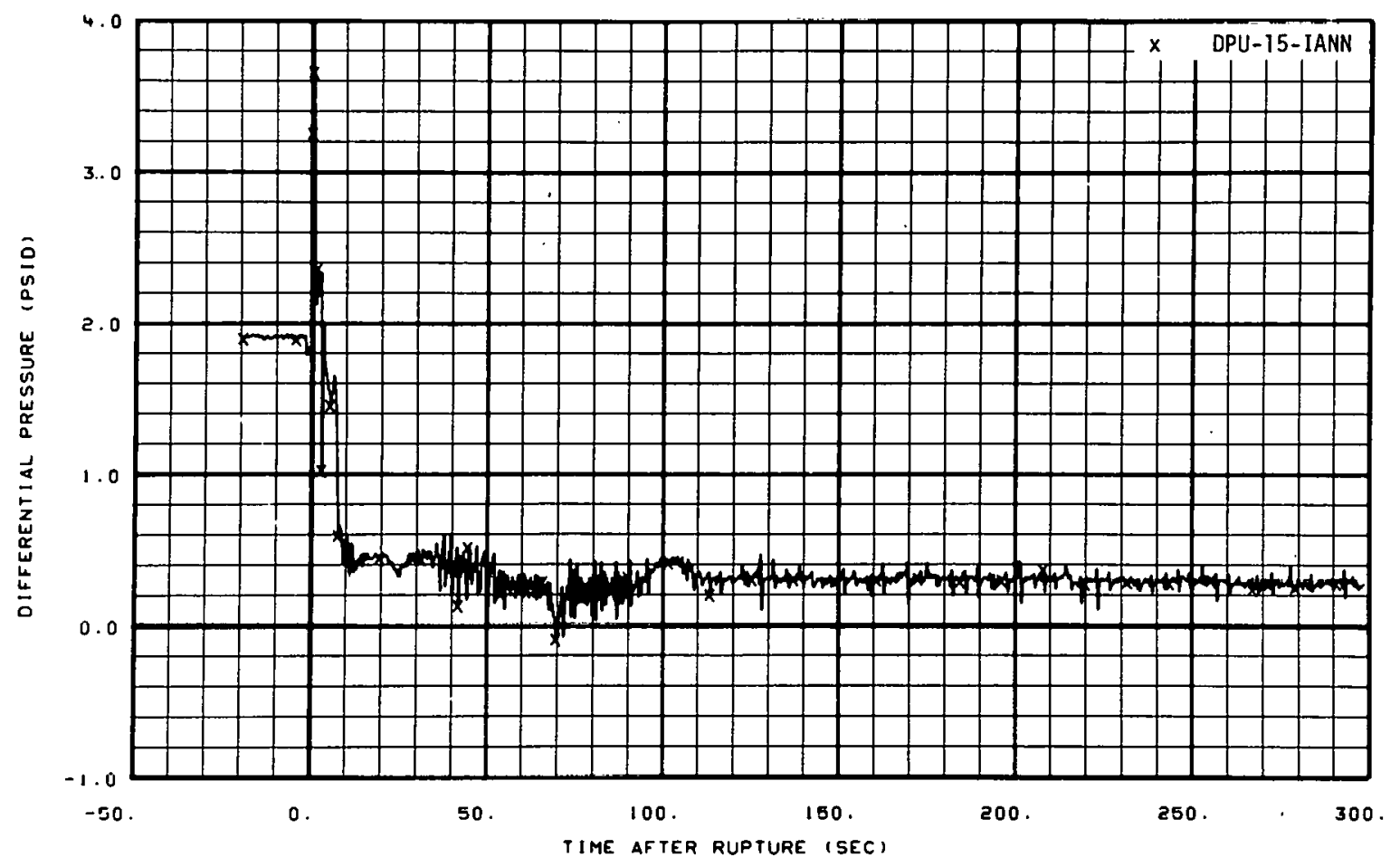

Fig. 159 Differential pressure in intact loop (DPU-15-IANN), from -20 to 300 seconds.

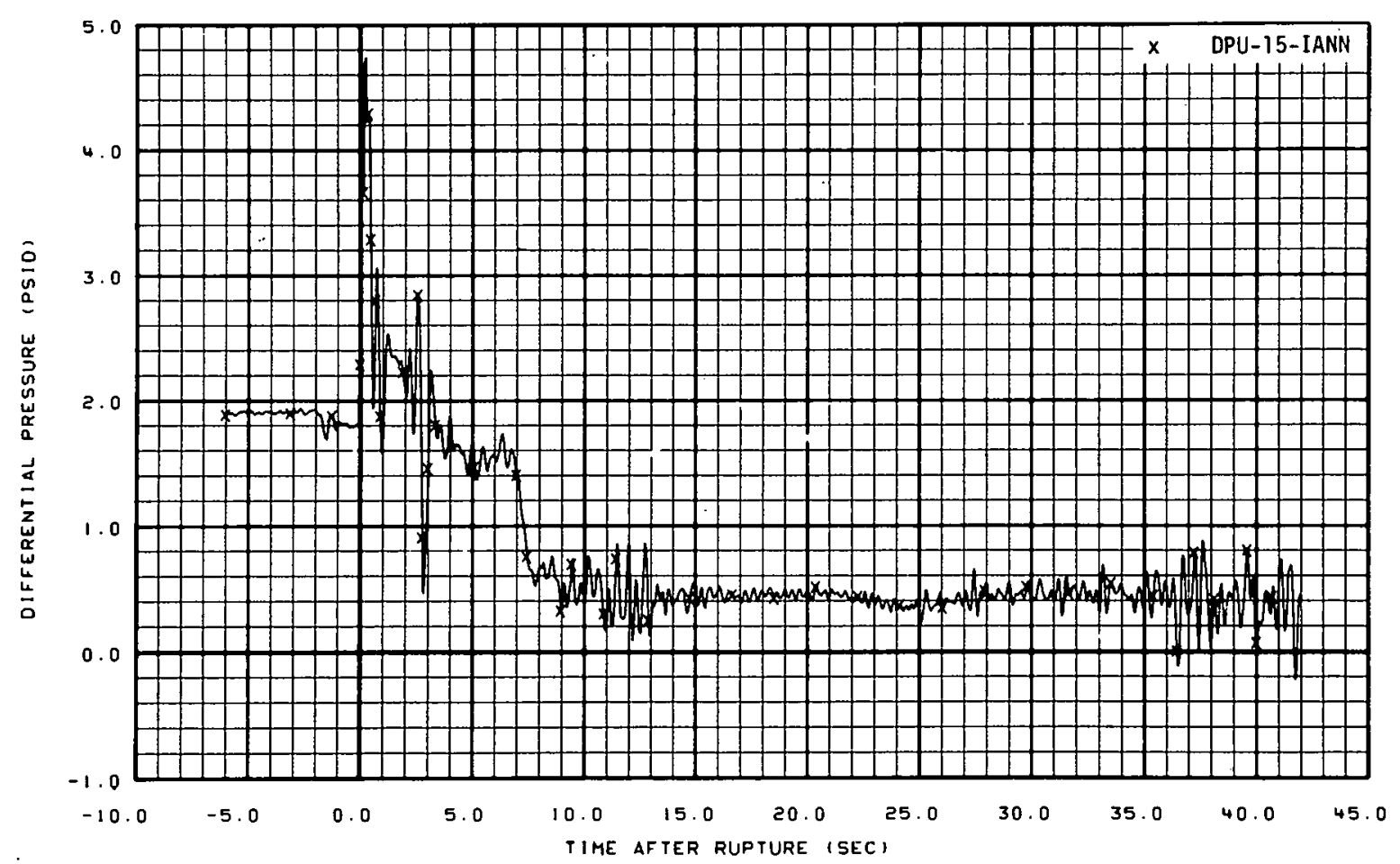

Fig. 160 Differential pressure in intact loop (DPU-15-IANN), from -6 to 42 seconds. 


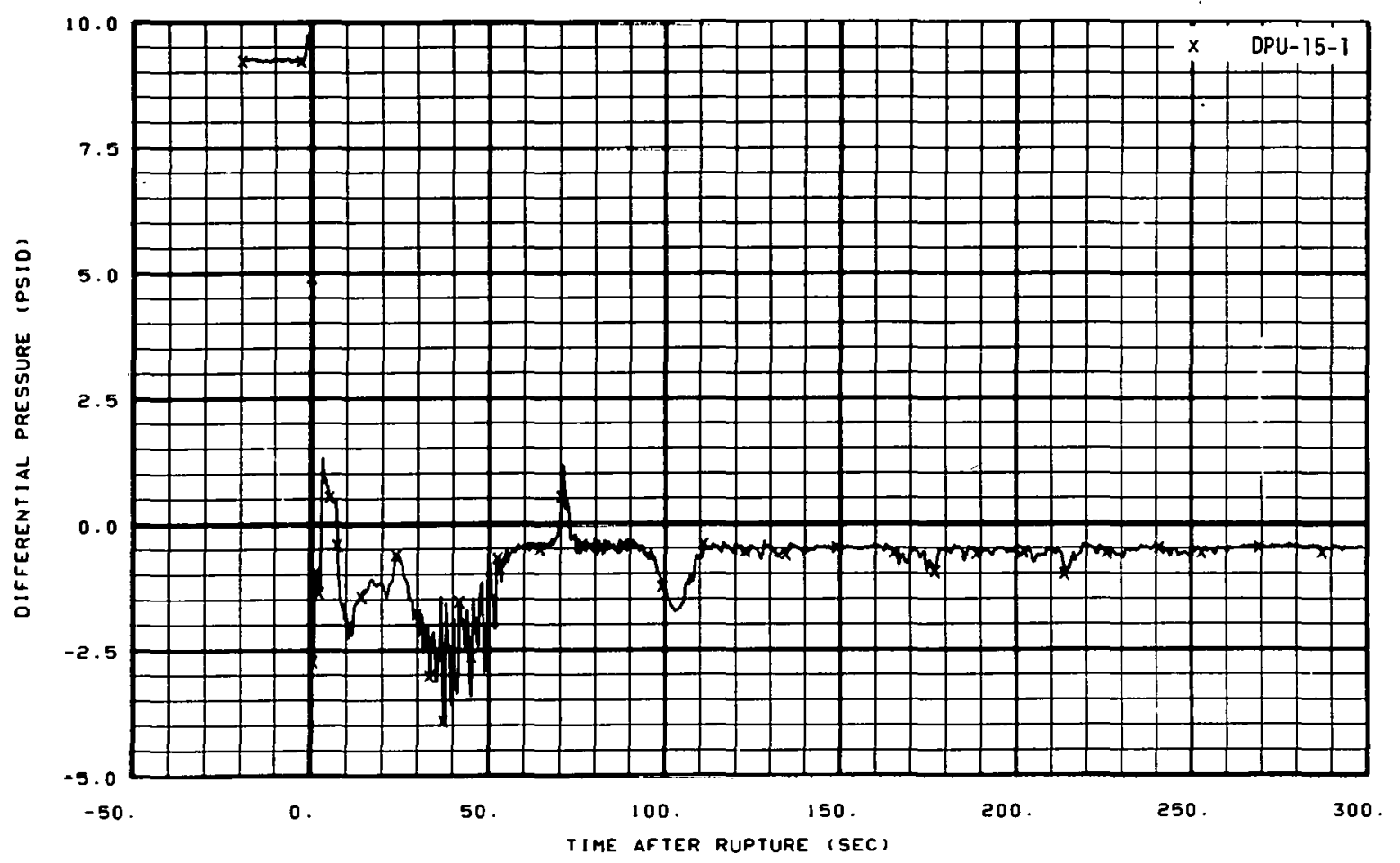

Fig. 161 Differential pressure in intact loop (DPU-15-1), from -20 to 300 seconds.

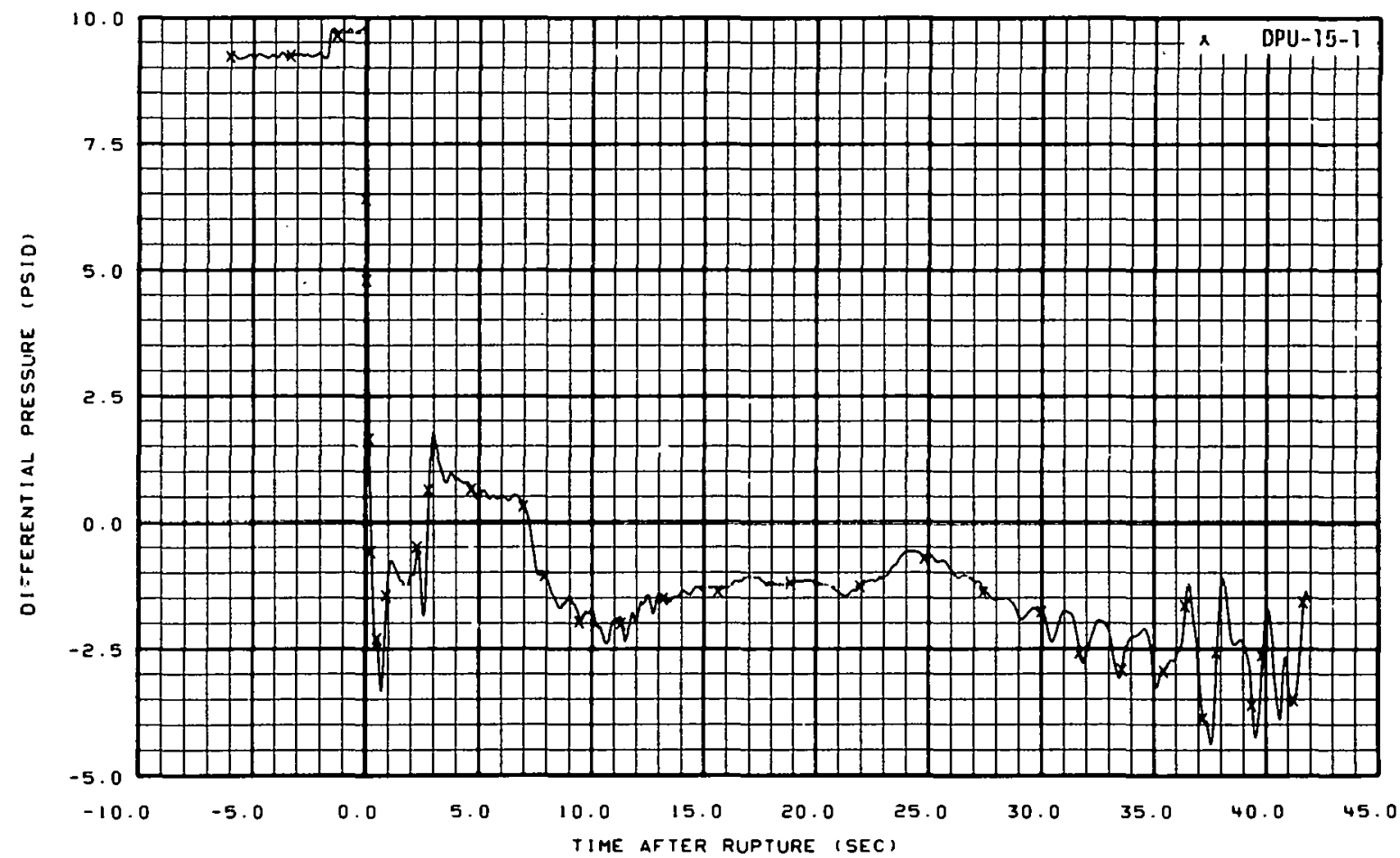

Fig. 162 Differential pressure in intact loop (DPU-15-1), from -6 to 42 seconds. 


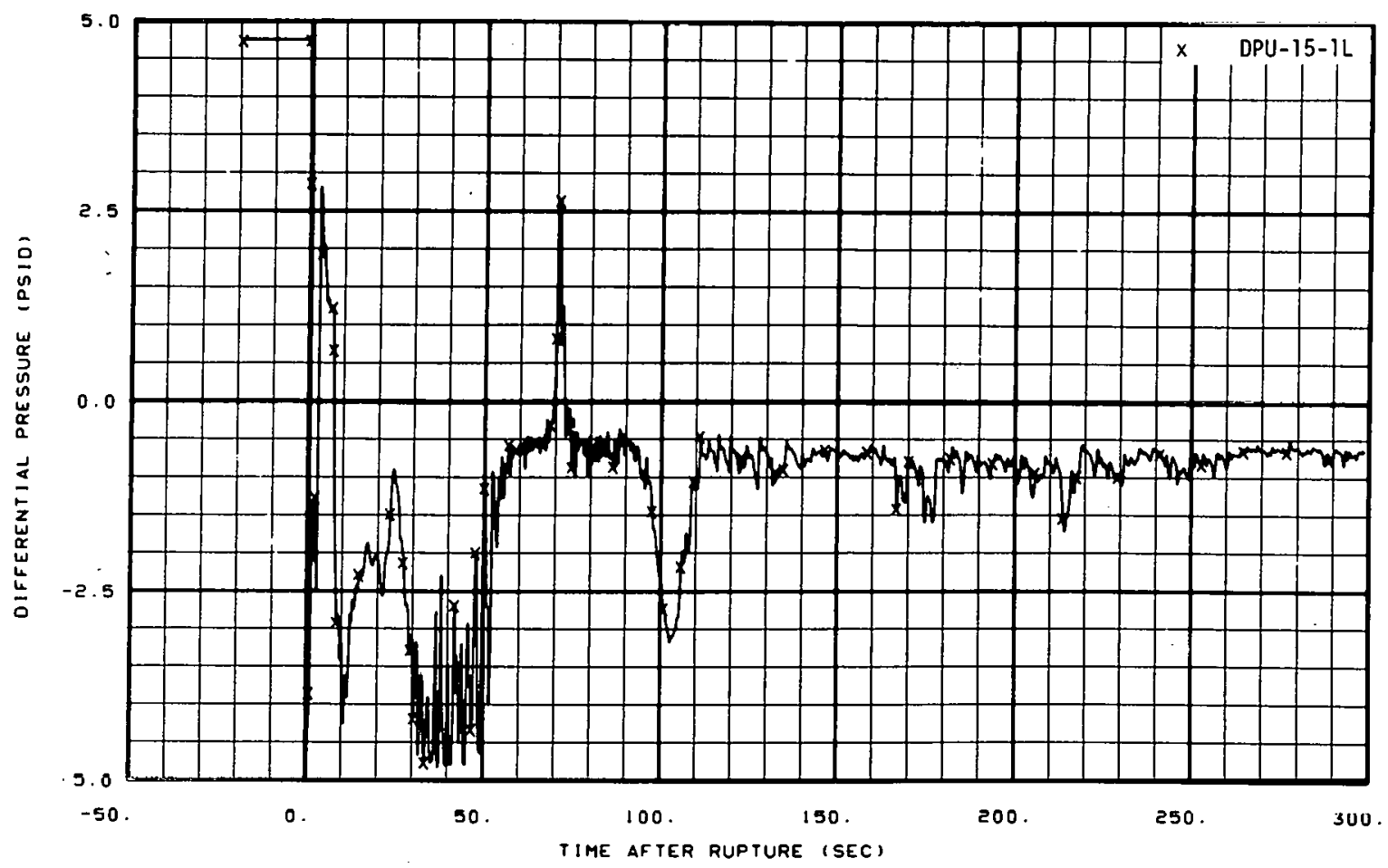

Fig. 163 Differential pressure in intact loop, low range (DPU-15-1L), from -20 to 300 seconds.

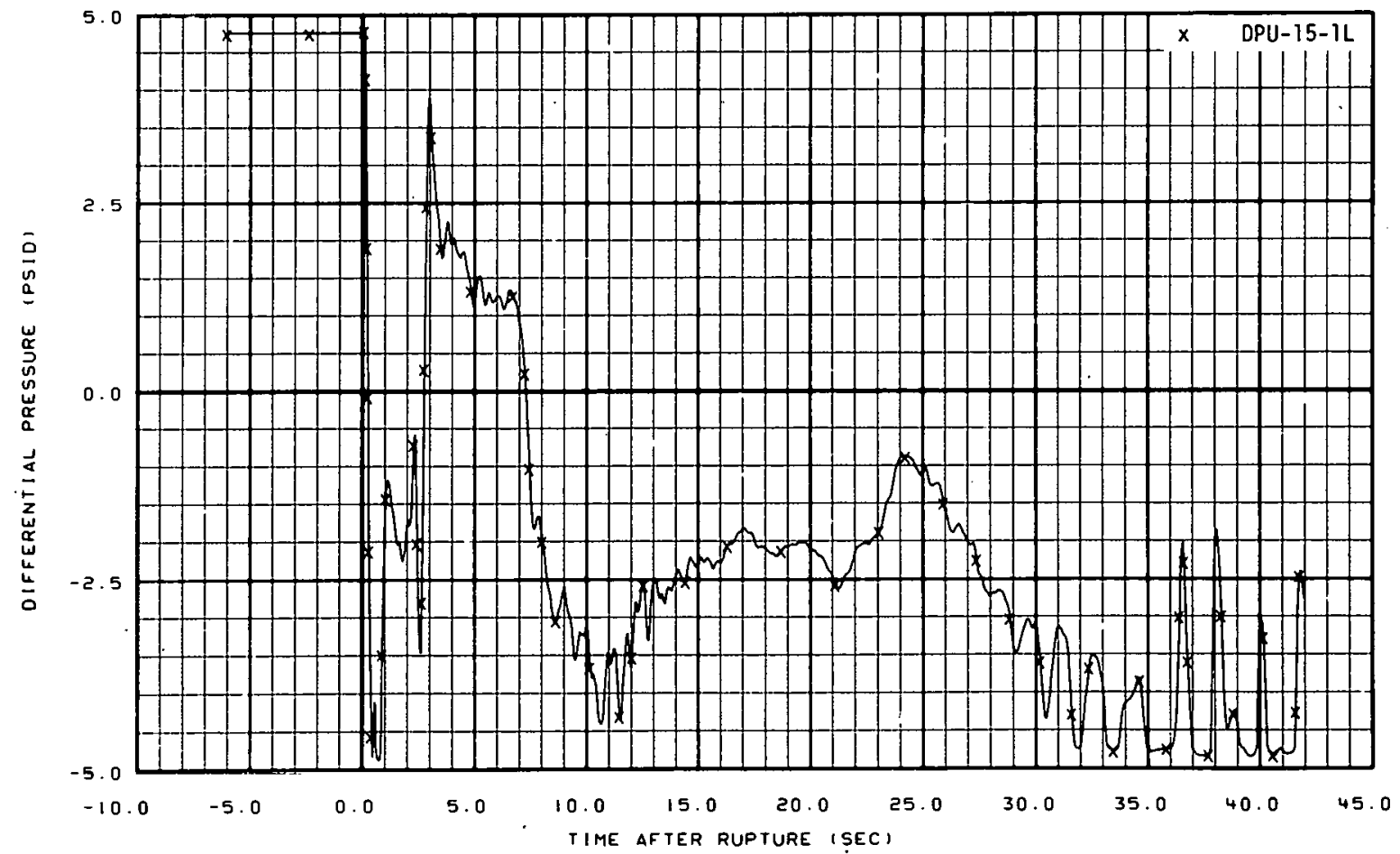

Fig. 164 Differential pressure in intact loop, low range (BPU-15-1L), from -6 to 42 seconds. 


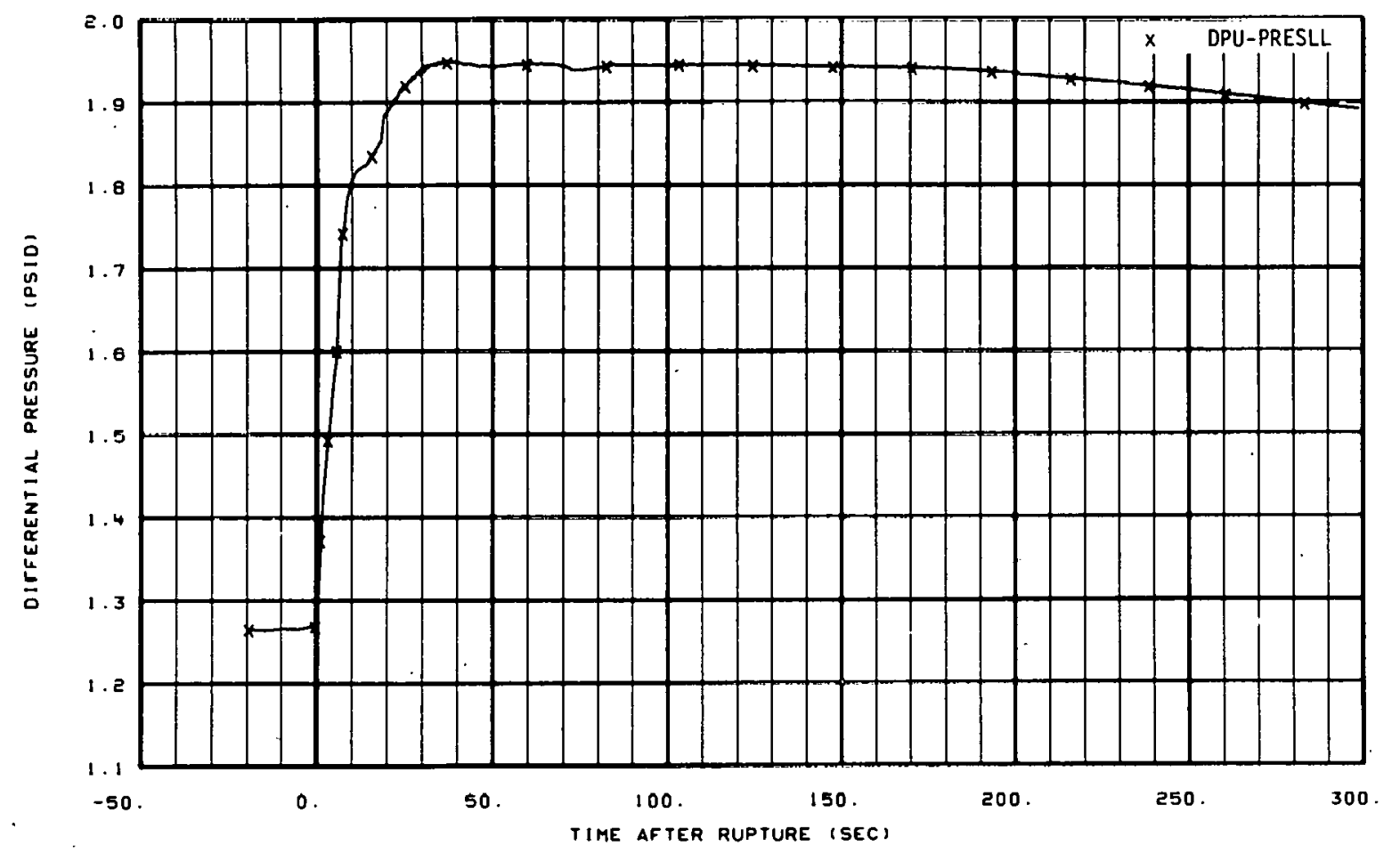

Fig. 165 Differential pressure in intact loop (DPU-PRESLL), from -20 to 300 seconds.

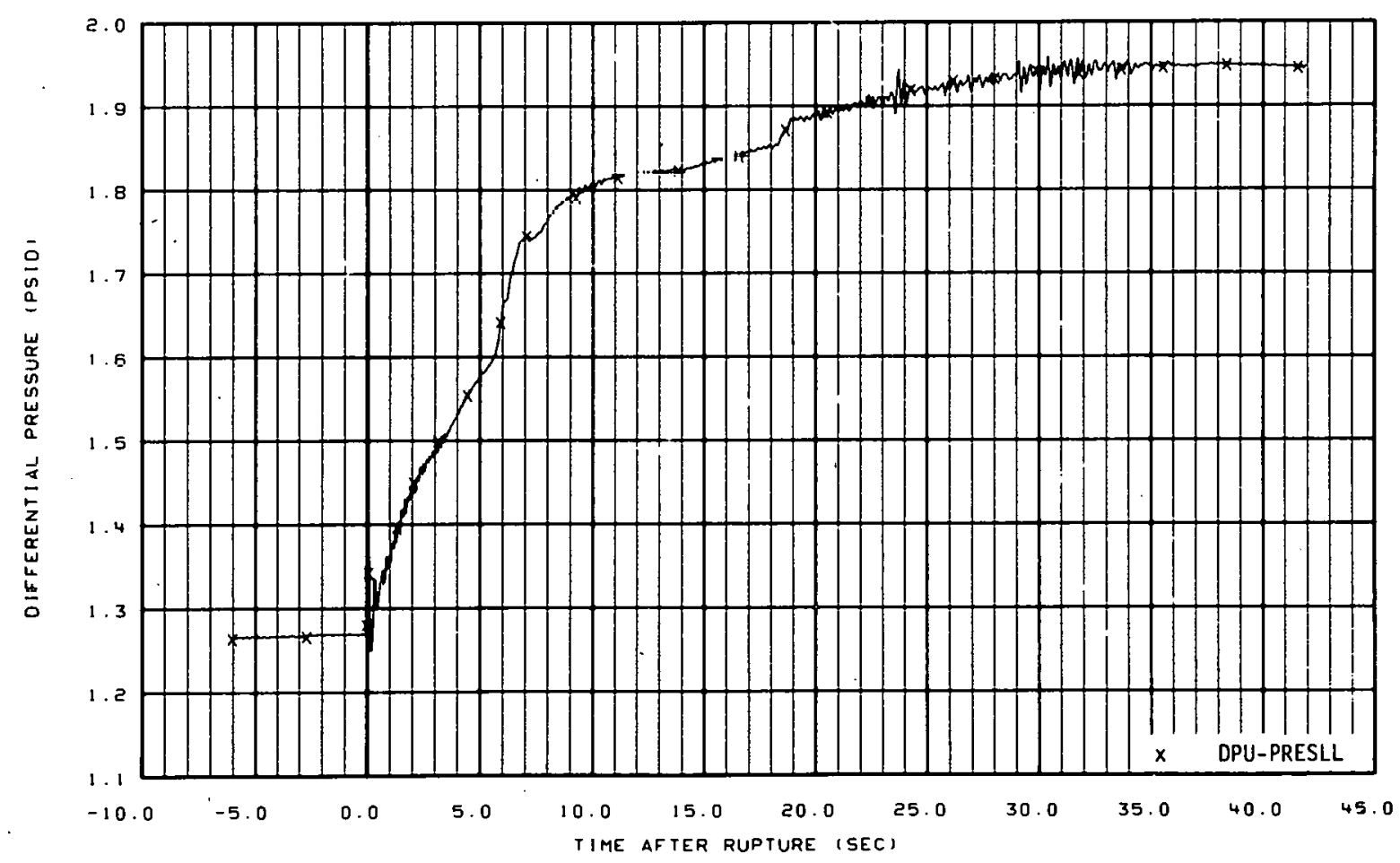

Fig. 166 Differential pressure in intact loop (DPU-PRESLL), from -6 - to 42 seconds. 


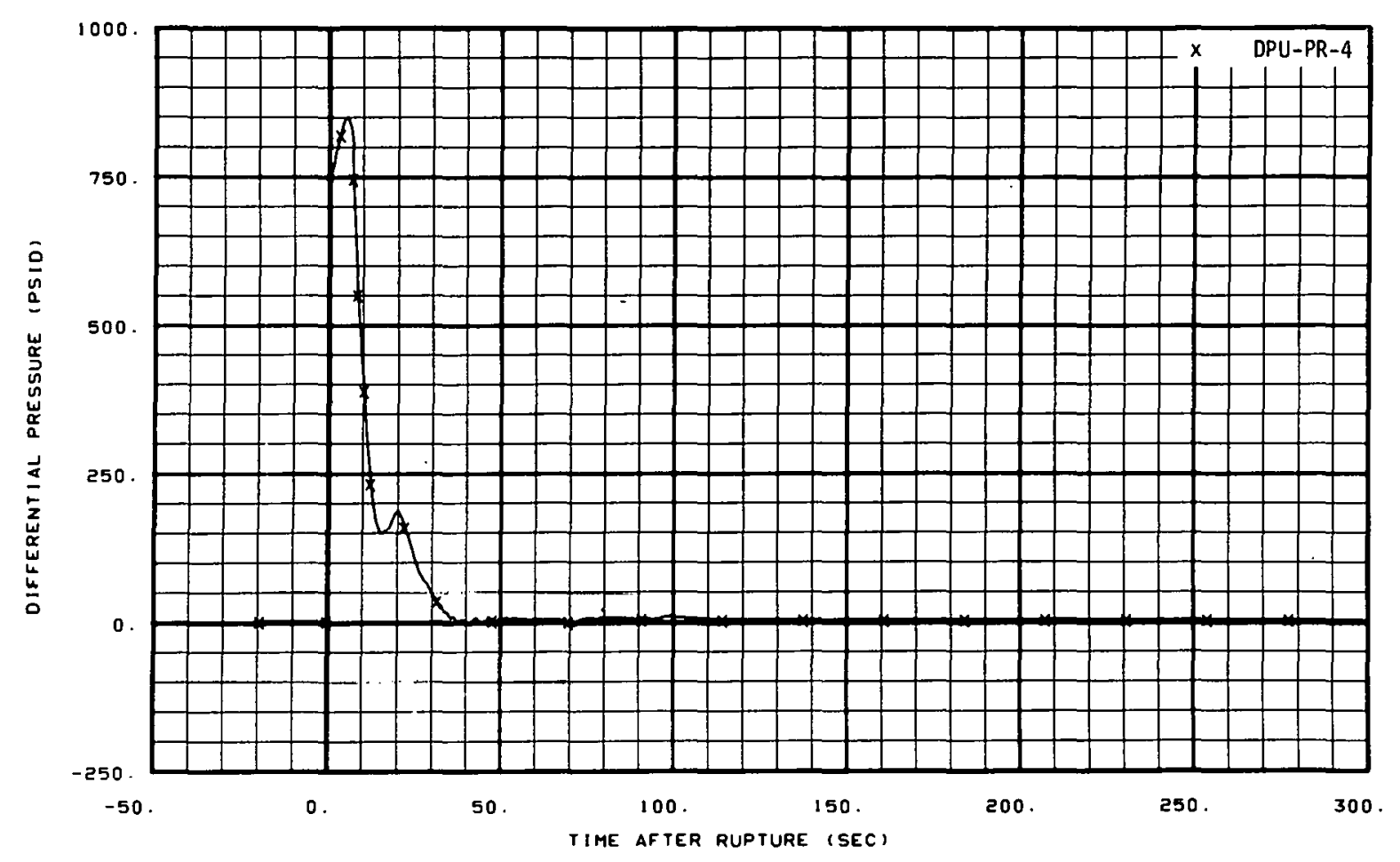

Fig. 167 Differential pressure in intact loop (DPU-PR-4), from -20 to 300 seconds.

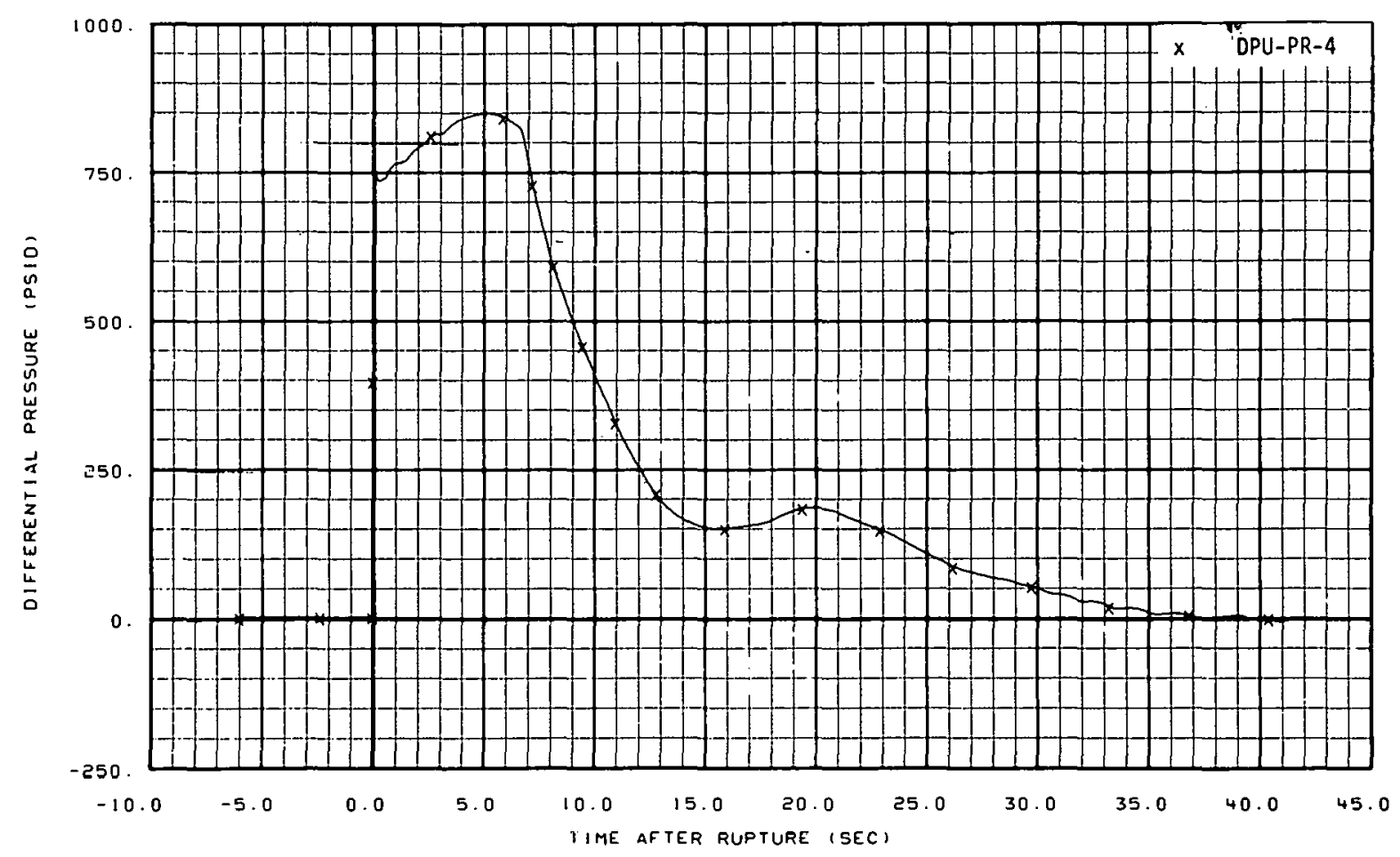

Fig. 168 Differential pressure in intact loop (DPU-PR-4), from -6 to 42 seconds. 


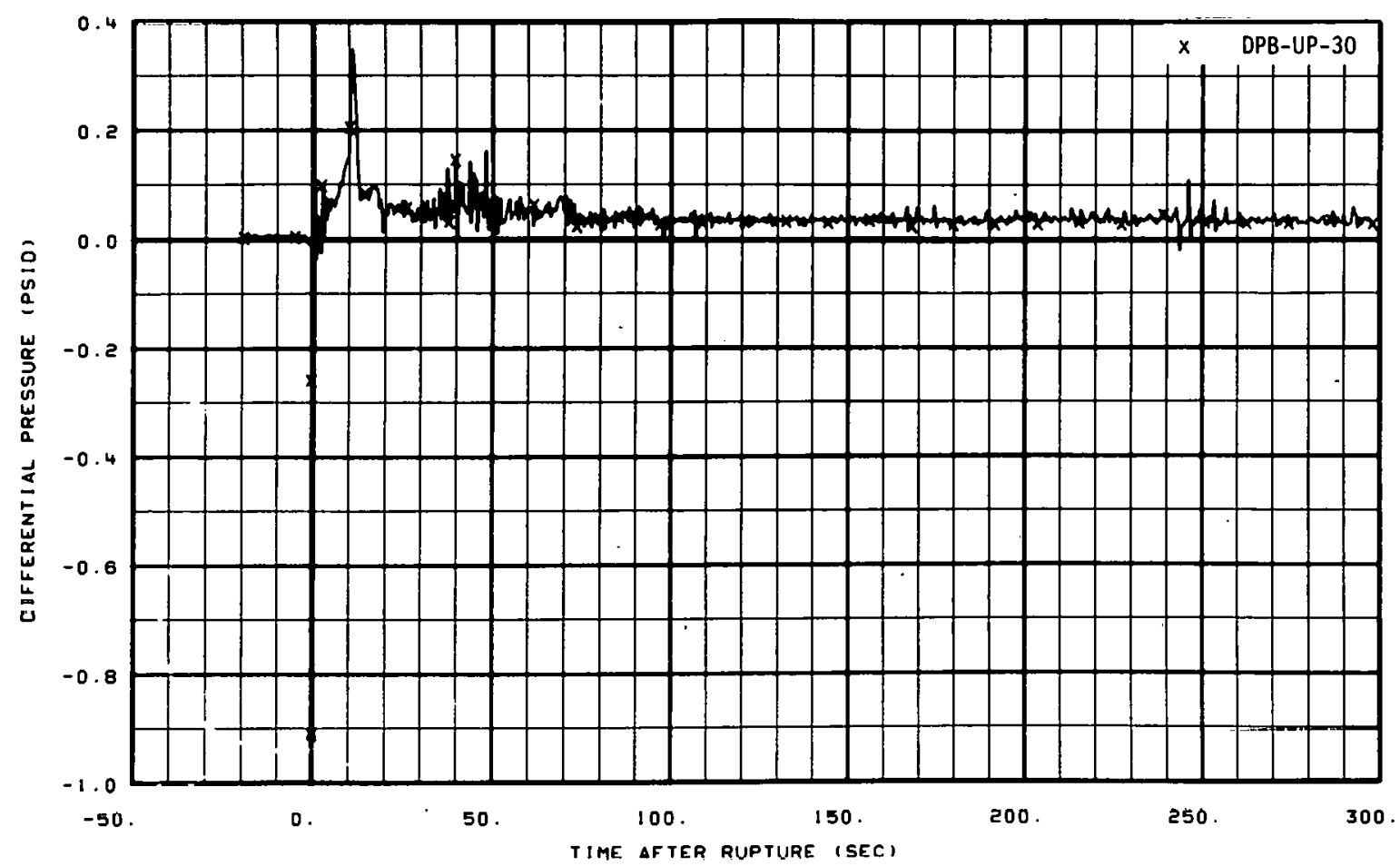

Fig. 169 Differential pressure in broken loop (UPB-UP-30), from -20 to 300 seconds.

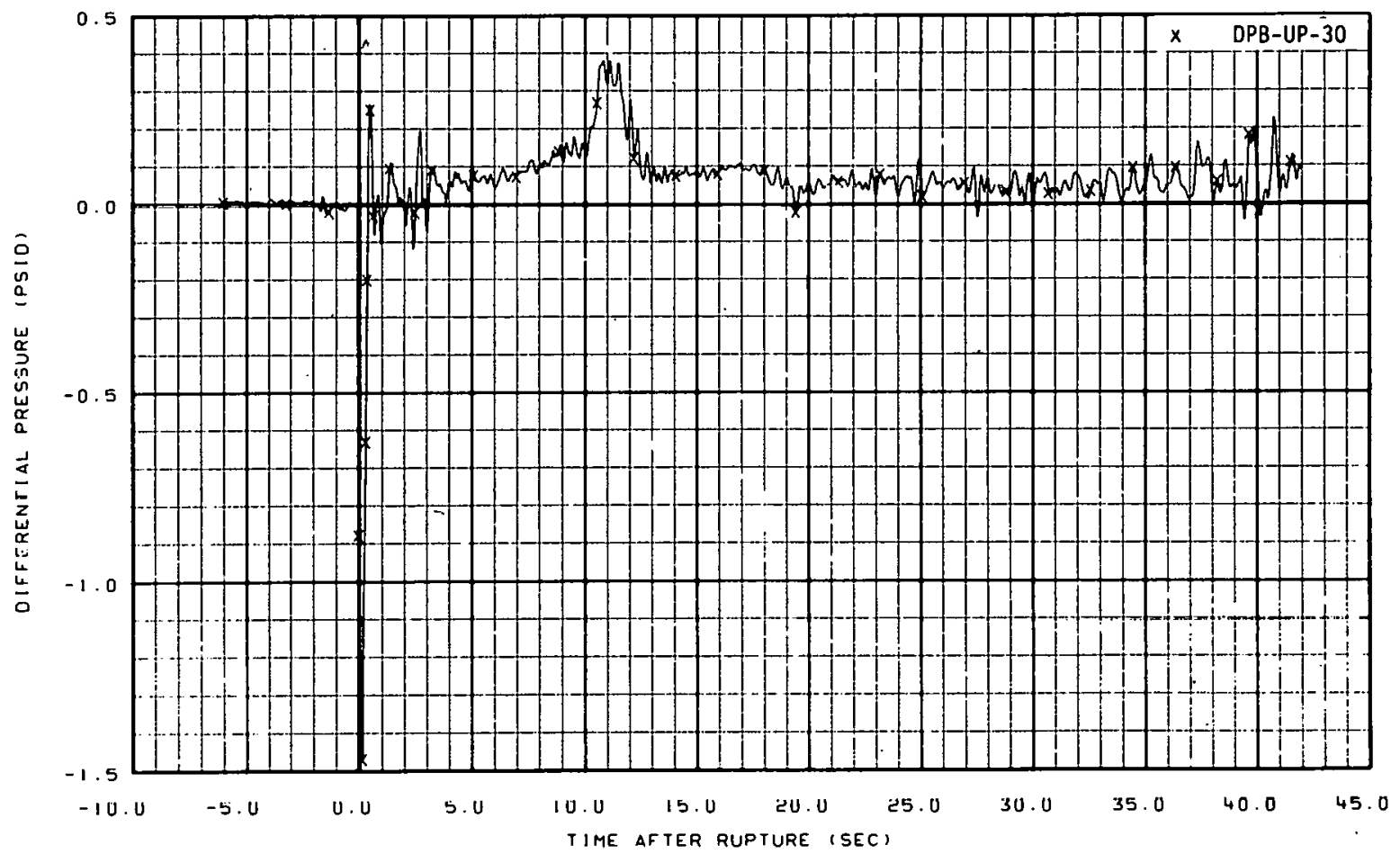

Fig. 170 Differential pressure in broken loop (DPB-UP-30), from -6 to 42 seconds. 


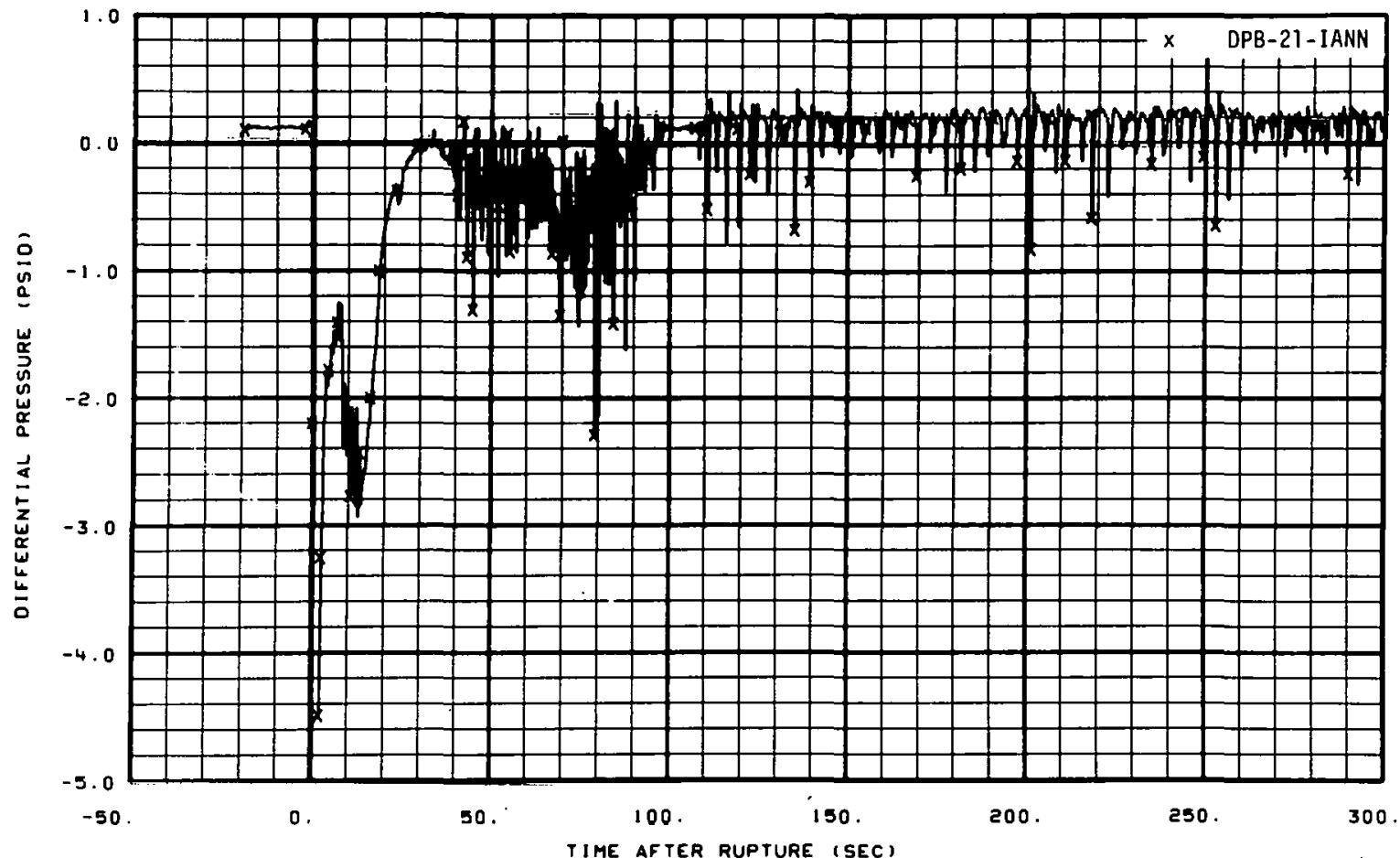

Fig. 171 Differential pressure in broken loop (DPB-21-IANN), from -20 to 300 seconds.

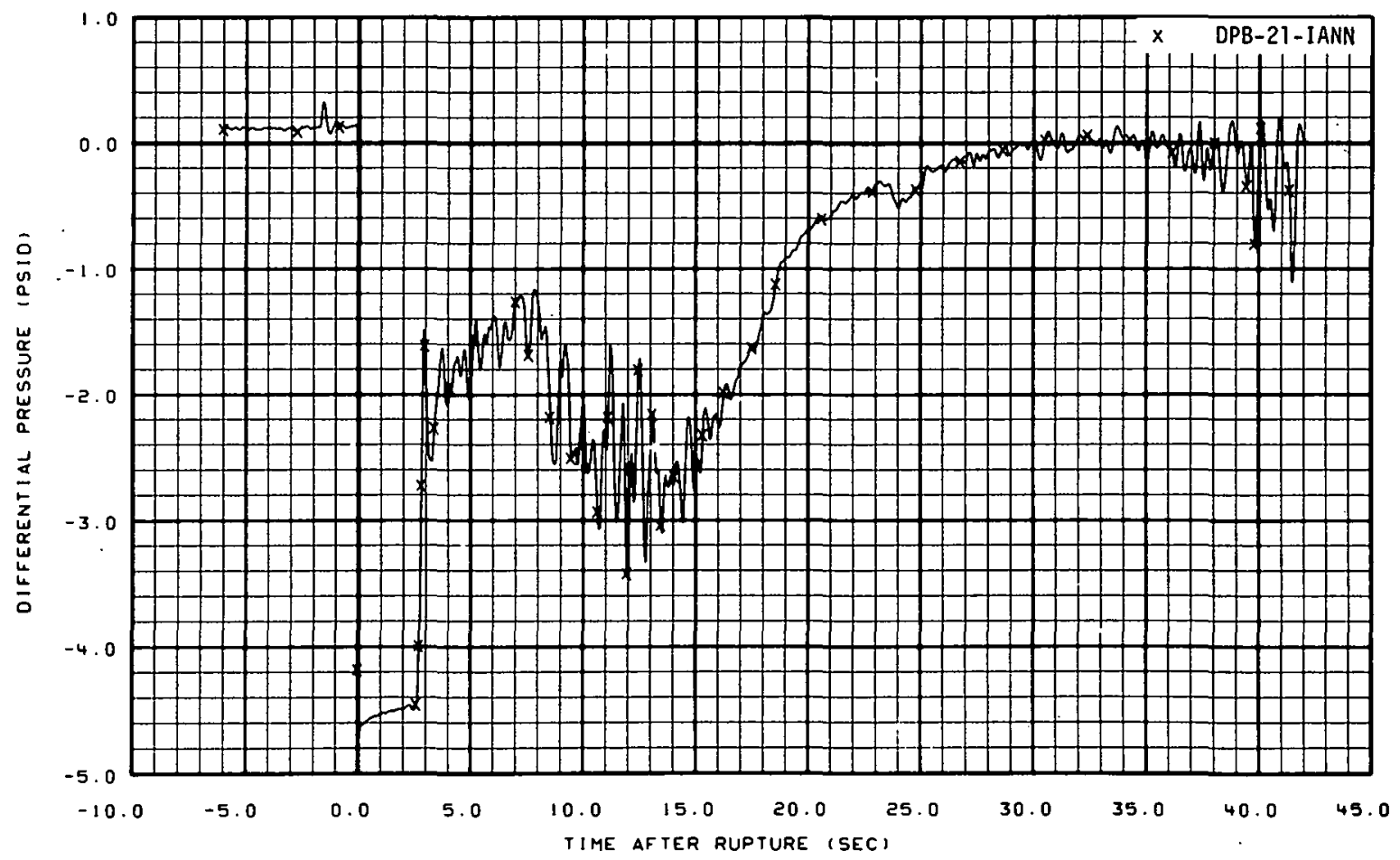

Fig, 172 Differential pressure in broken loop (DPB-21-IANN), from -6 to 42 seconds. 


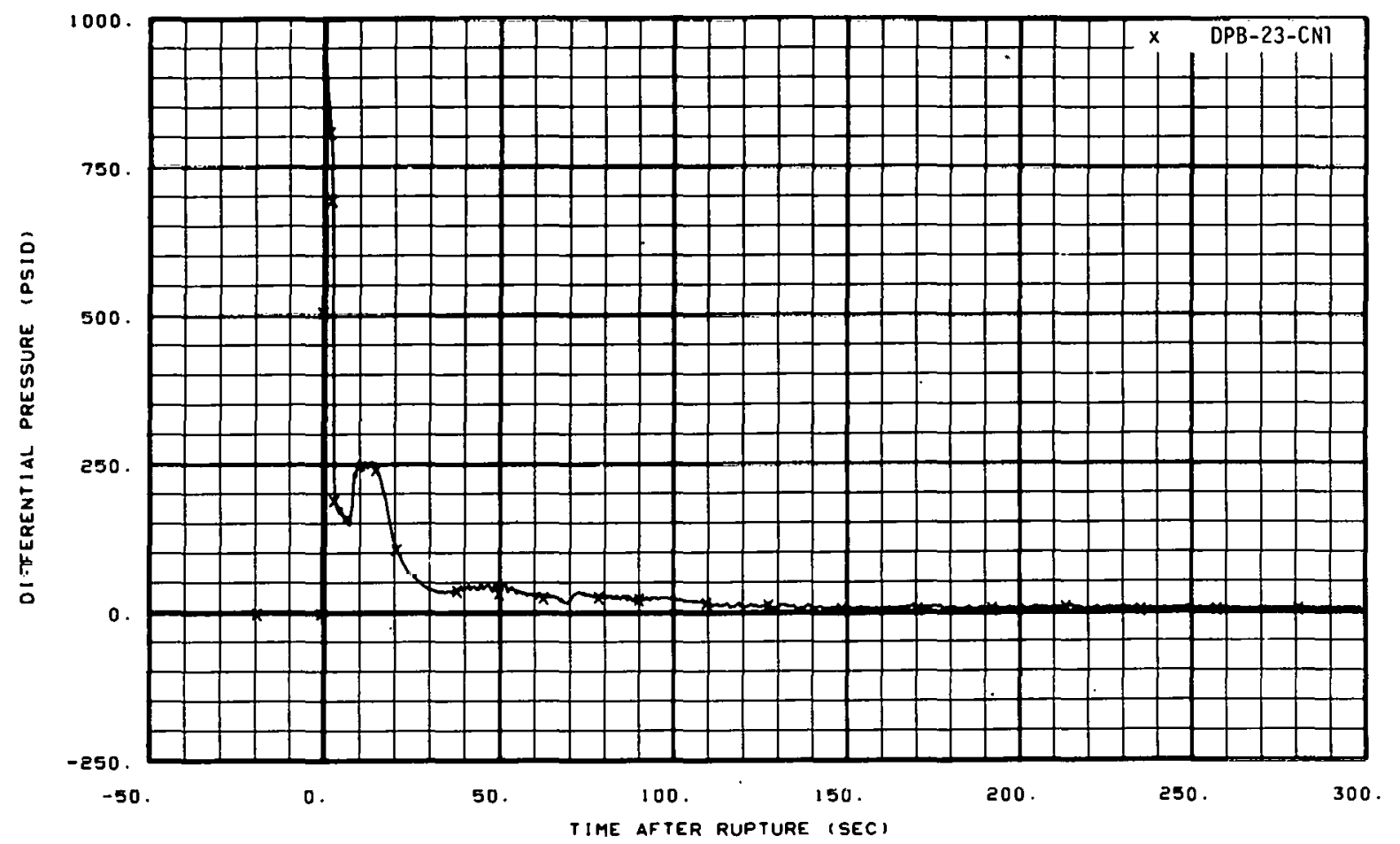

Fig. 173 Differential pressure in broken loop (DPB-23-CNI), from -20 to 300 seconds.

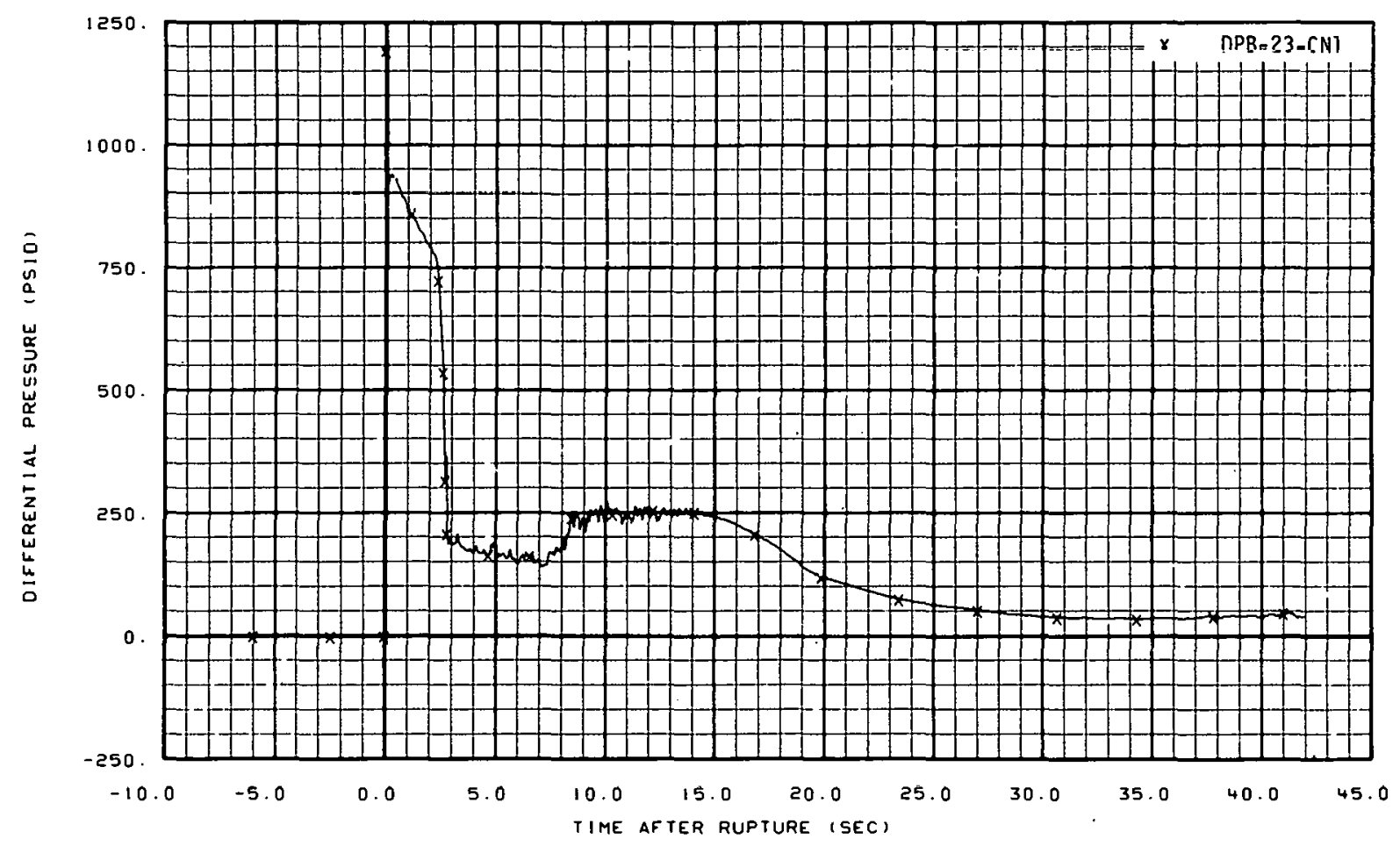

Fig. 174 Differential pressure in broken loop (DPB-23-CN1), from -6 to 42 seconds. 


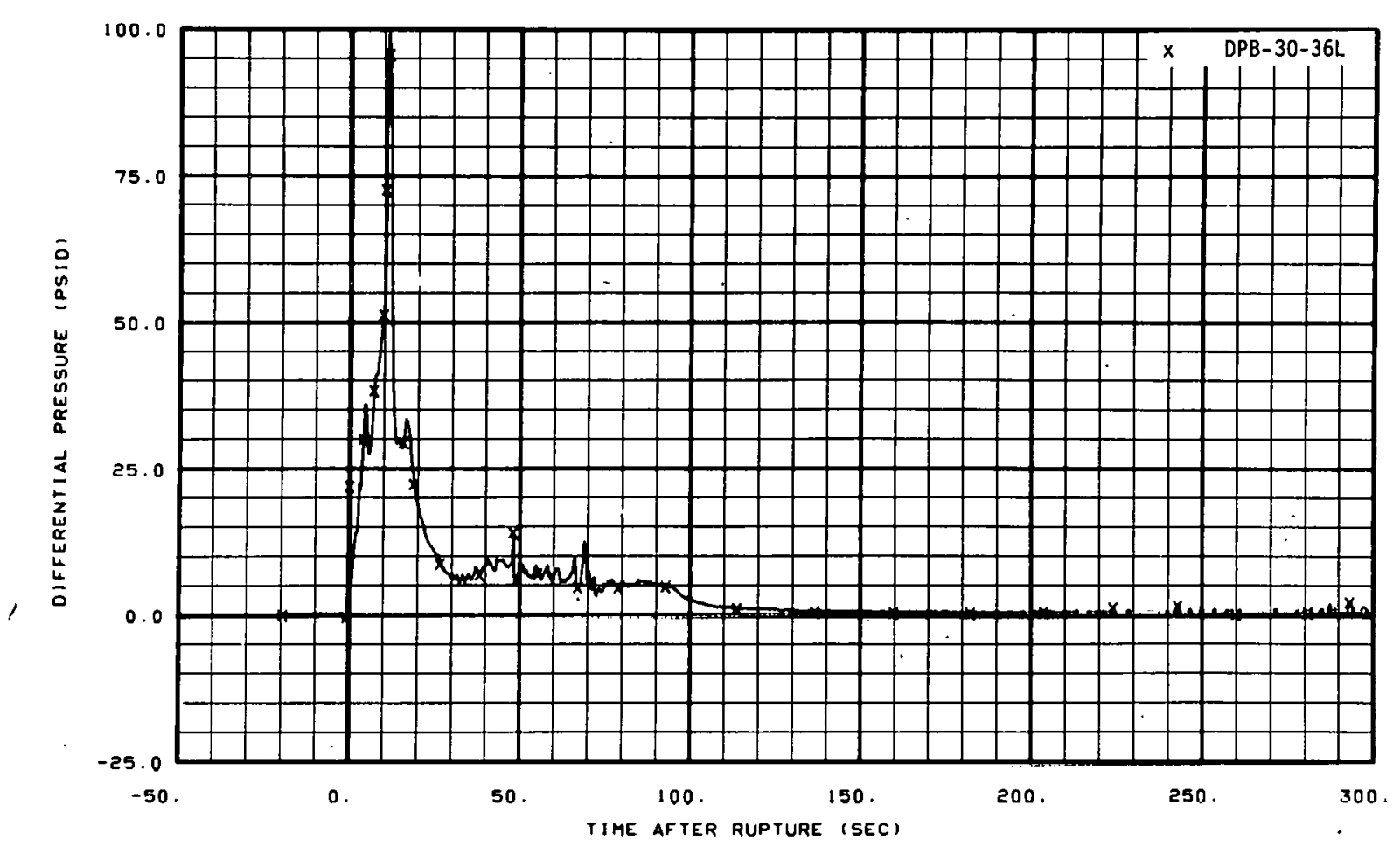

Fig. 175 Differential pressure in broken loop (DPB-30-36L), from -20 to 300 seconds.

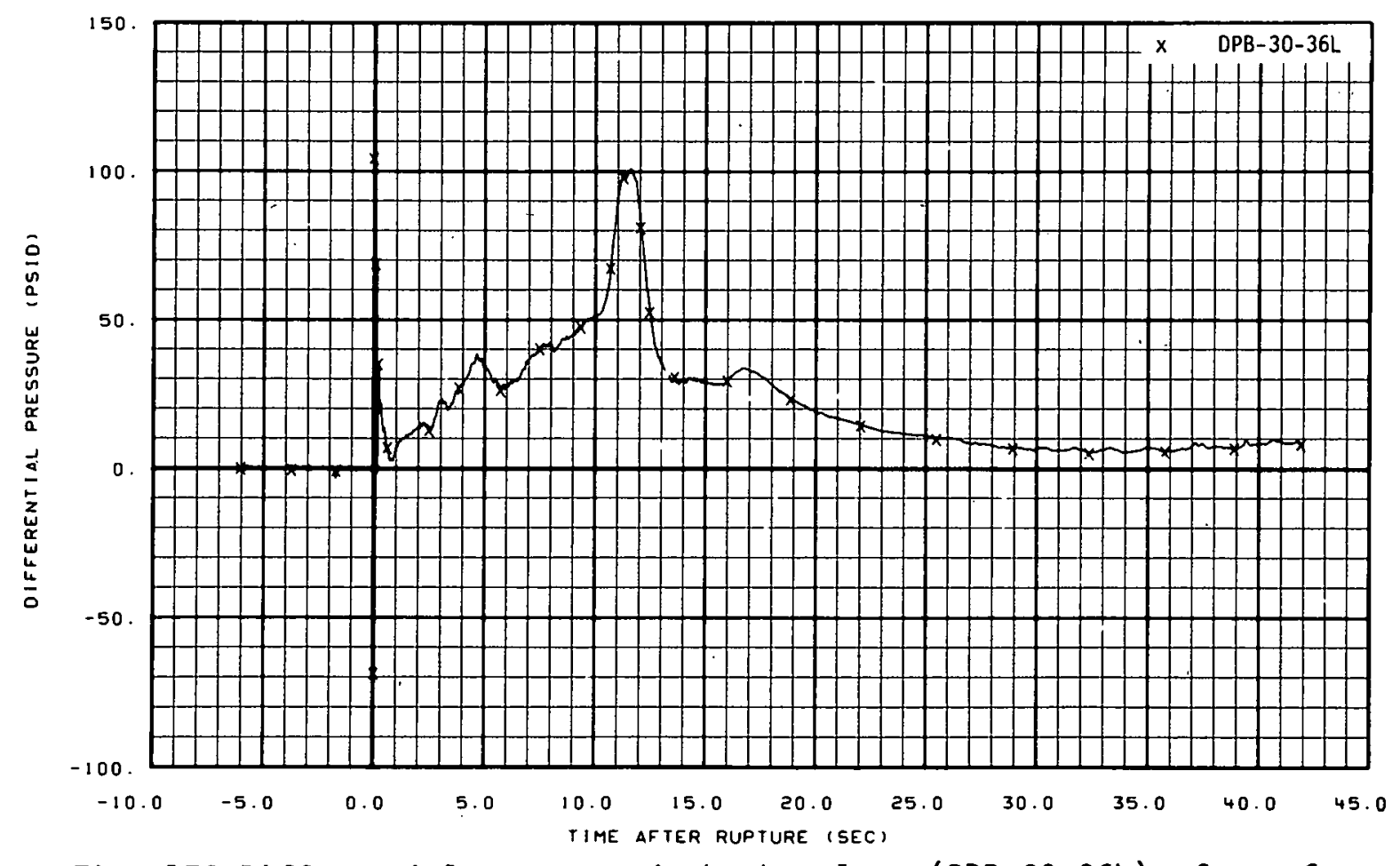

Fig. 176 Differential pressure in broken loop (DPB-30-36L), from -6 to 42 seconds. 


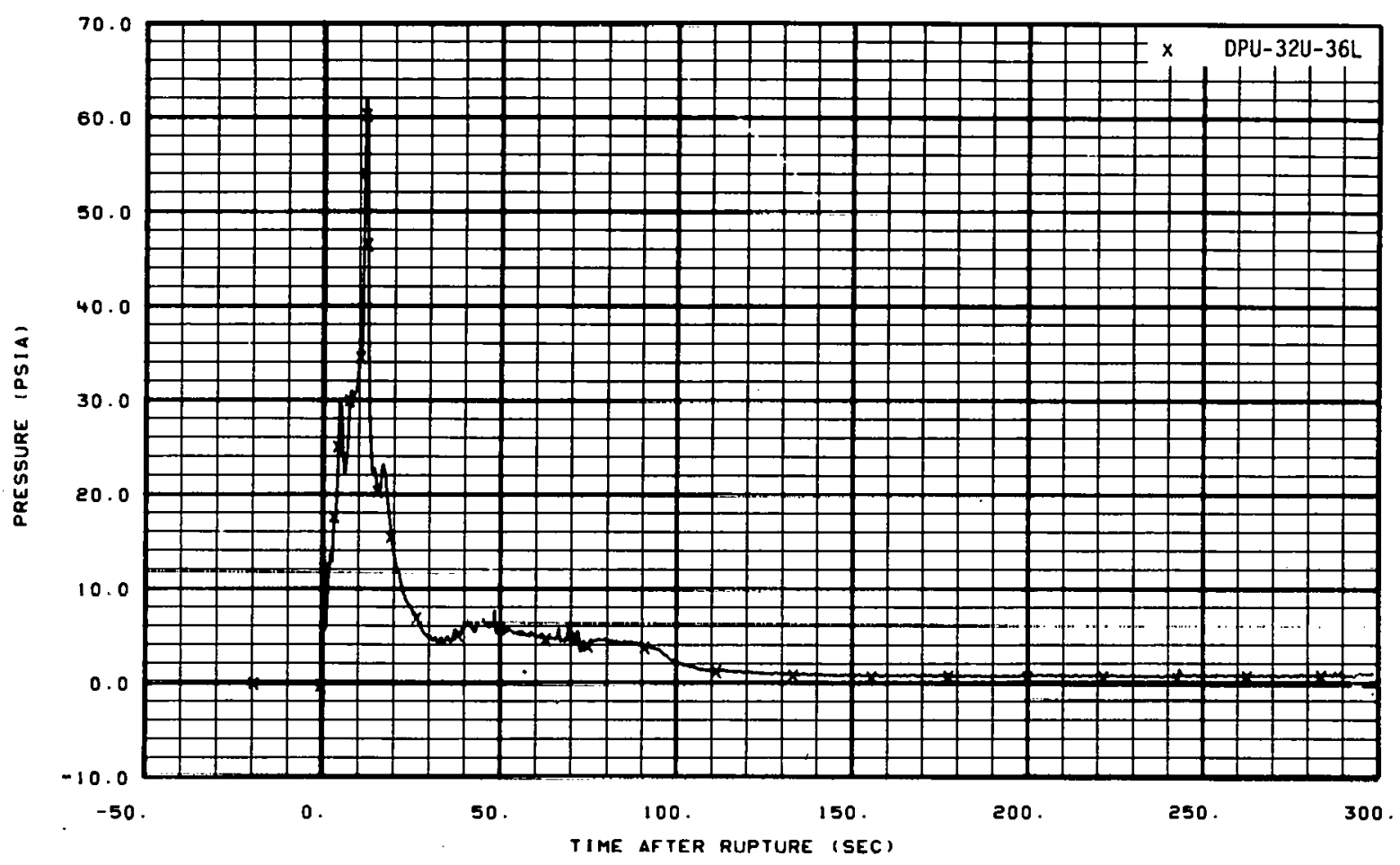

Fig. 177 Differential pressure in broken loop (DPB-32U-36L), from -20 to 300 seconds.

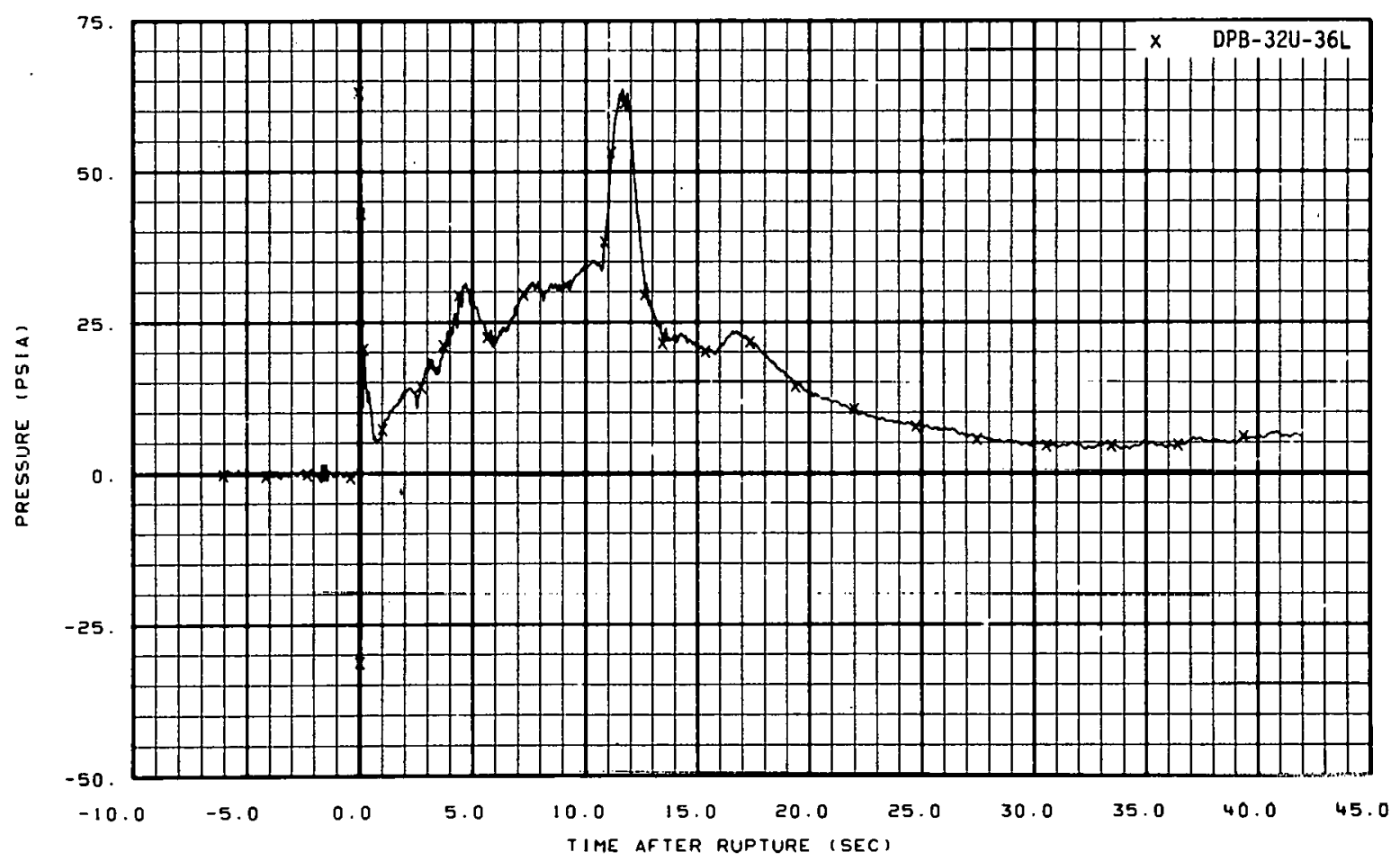

Fig. 178 Differential pressure in broken loop (DPB-32U-36L), from -6 to 42 seconds. 


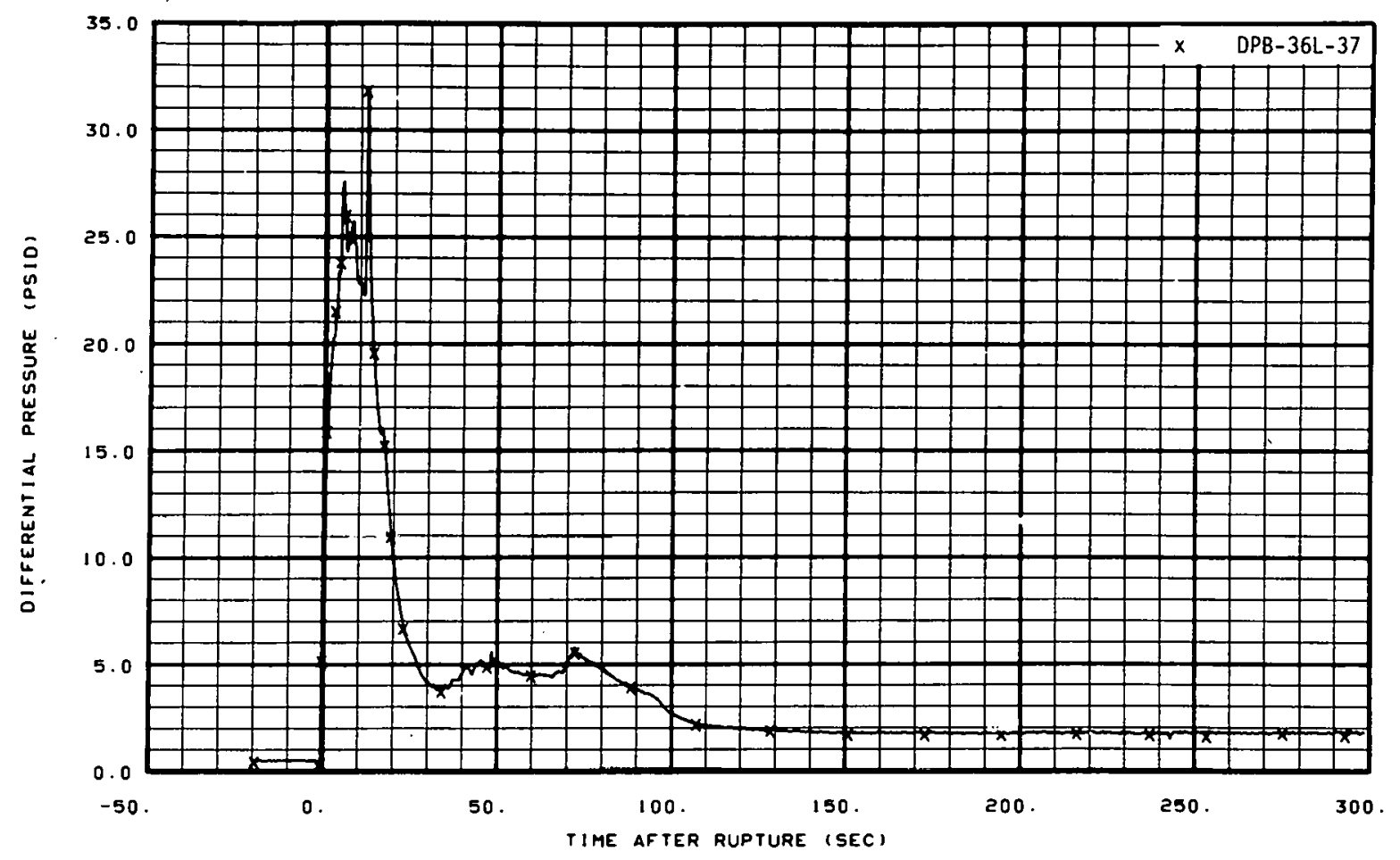

Fig. 179 Differential pressure in broken loop (DPB-36L-37), from -20 to 300 seconds.

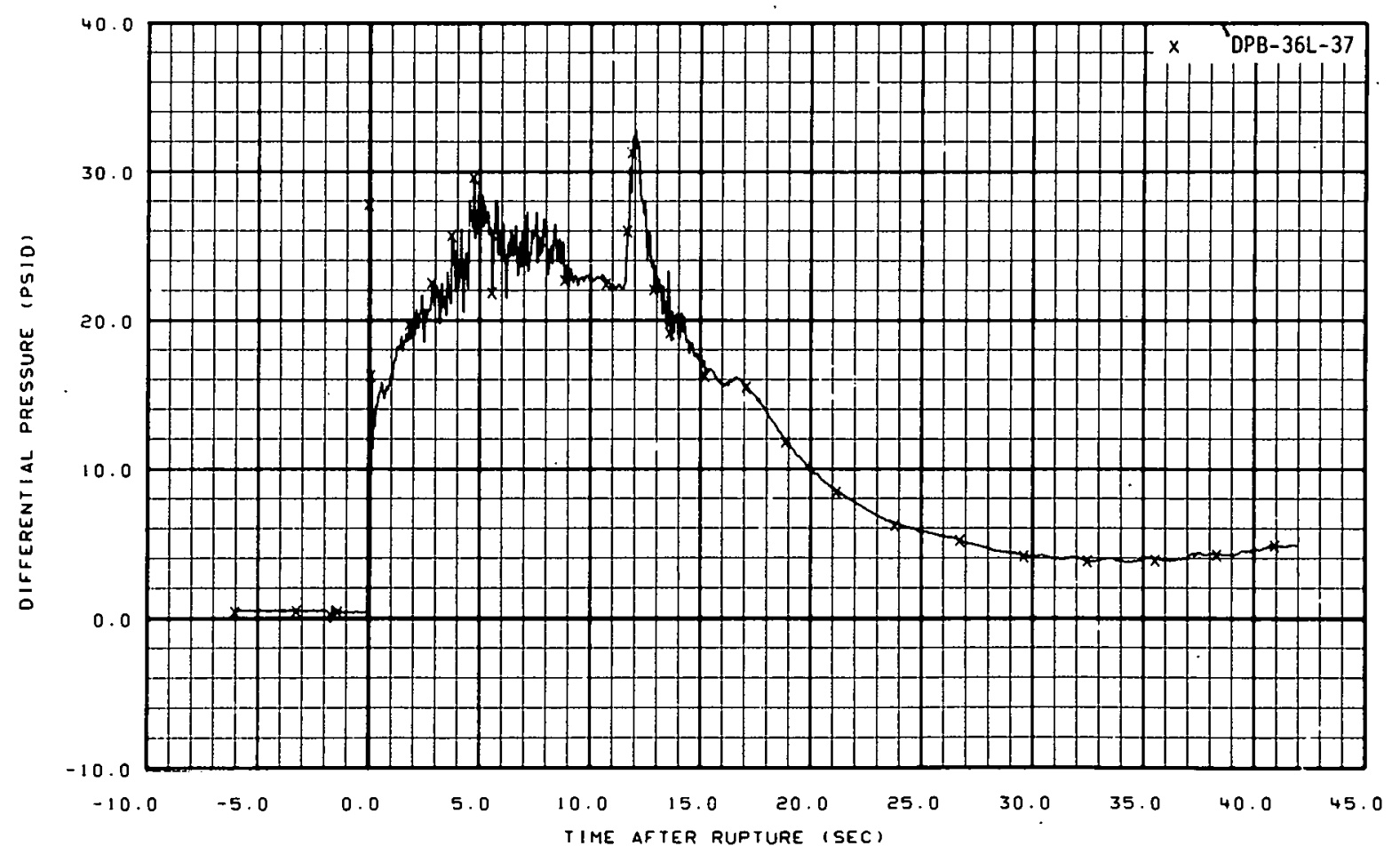

Fig. 180 Differential pressure in broken loop (DPB-36L -37), from -6 to 42 seconds. 


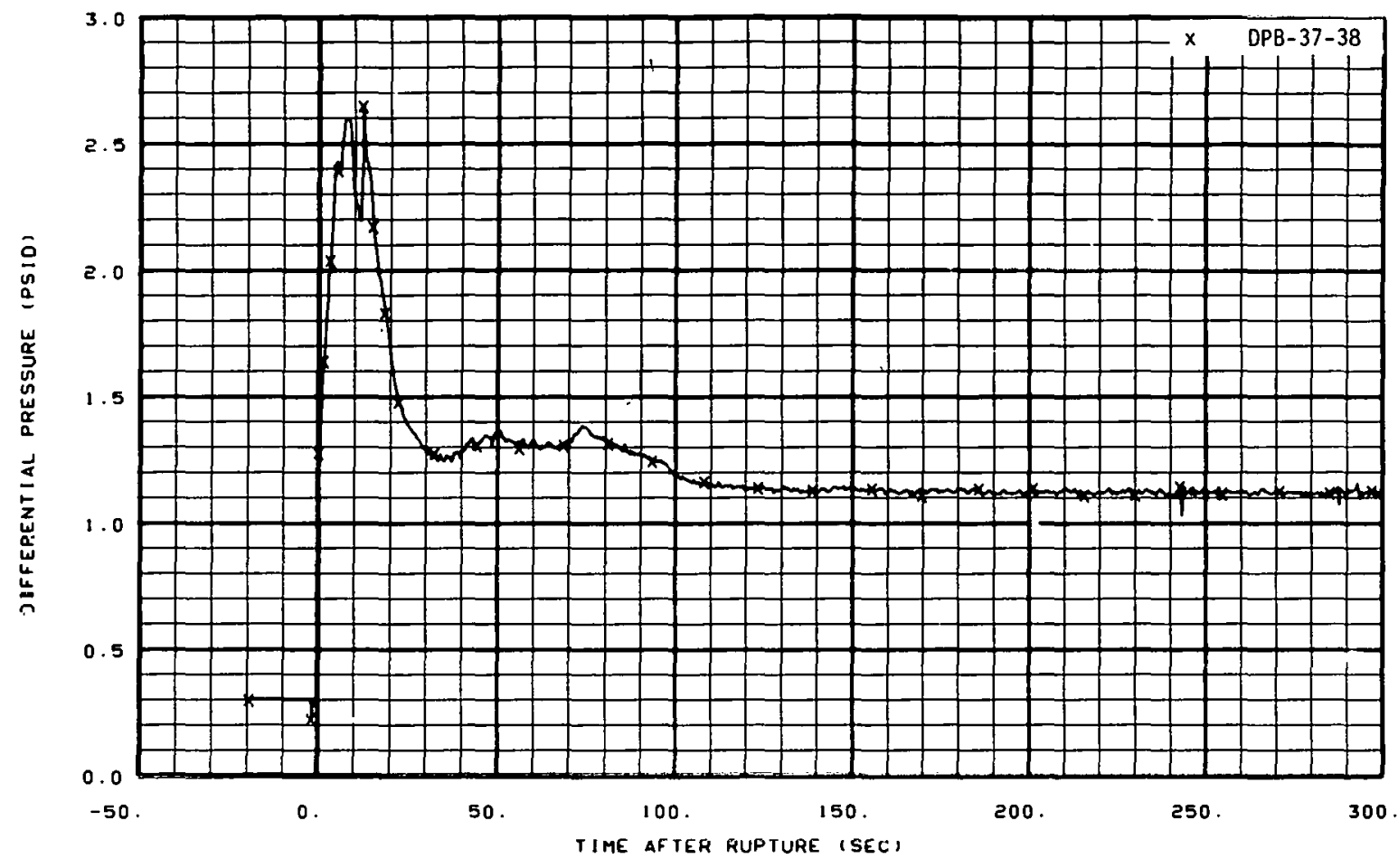

Fig. 181 Differential pressure in broken loop (DPB-37-38), from -20 to 300 seconds.

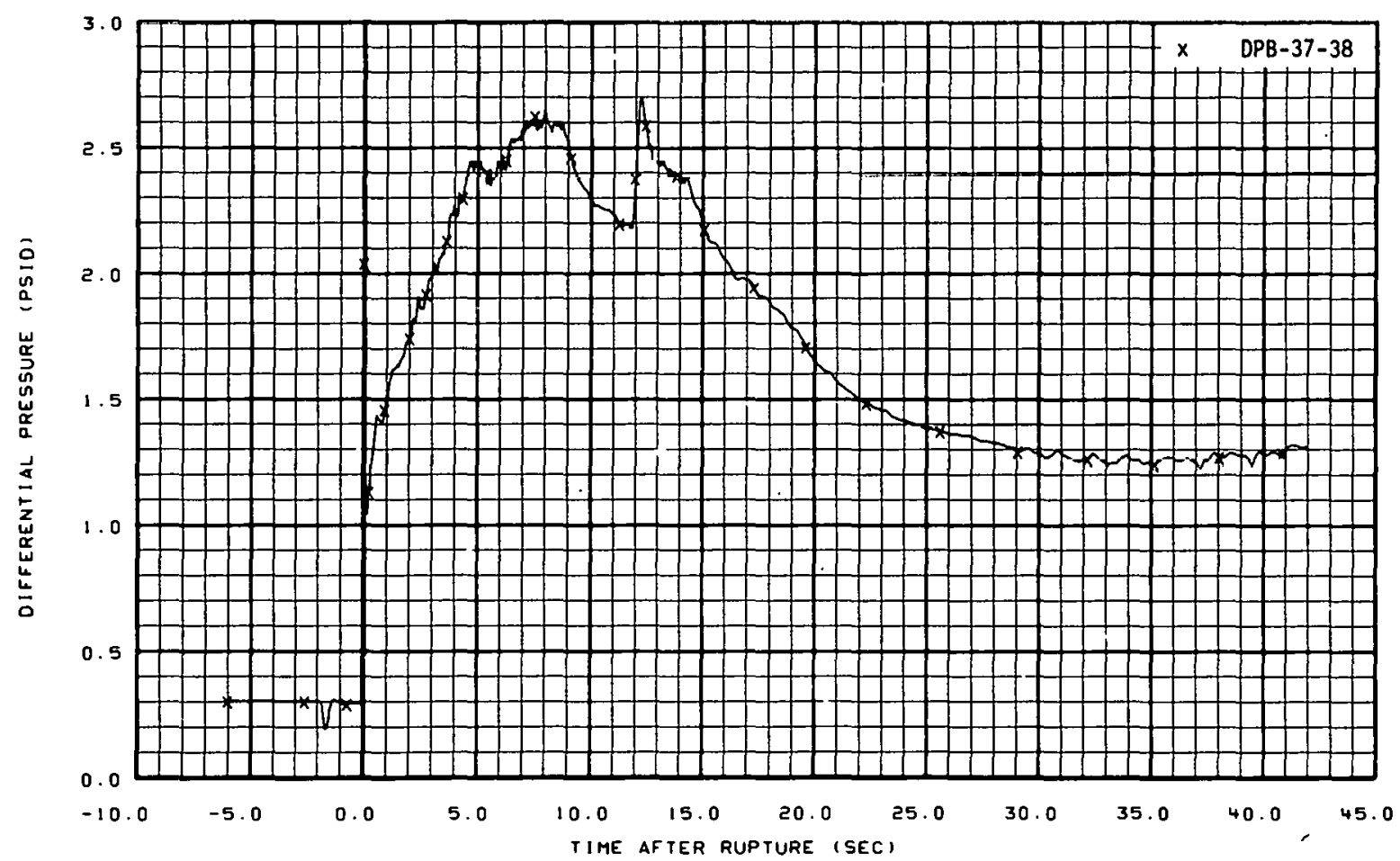

Fig. 182 Differential pressure in broken loop (DPB-37-38), from -6 to 42 seconds. 


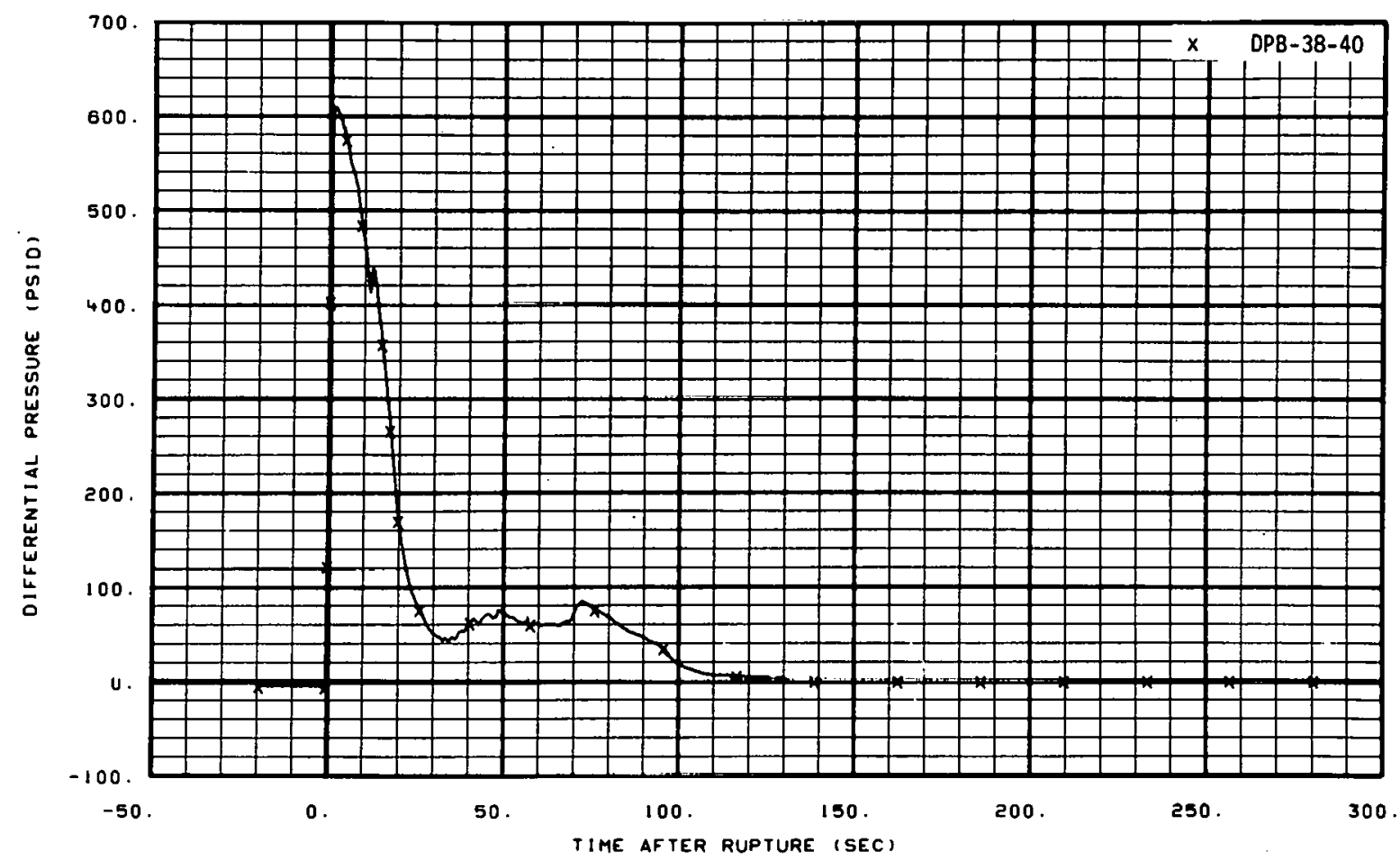

Fig. 183 Differential pressure in broken loop (DPB-38-40), from -20 to 300 seconds.

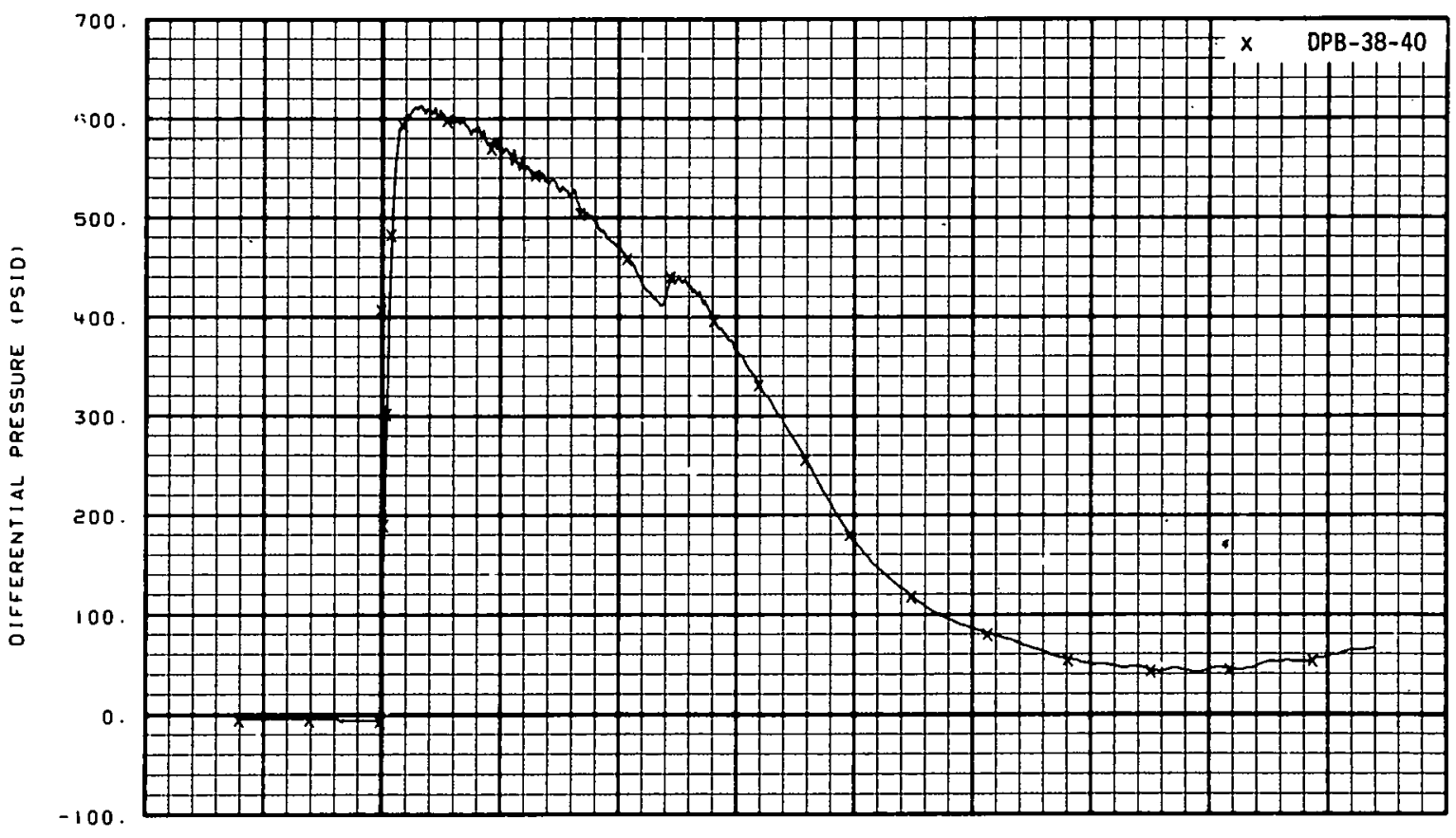

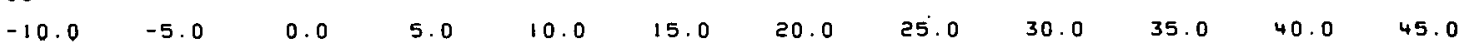

TIME AFTER RUPTURE (SEC)

Fig. 184 Differential pressure in broken loup (DPB-38-40), riulii-6 to 42 seconds. 


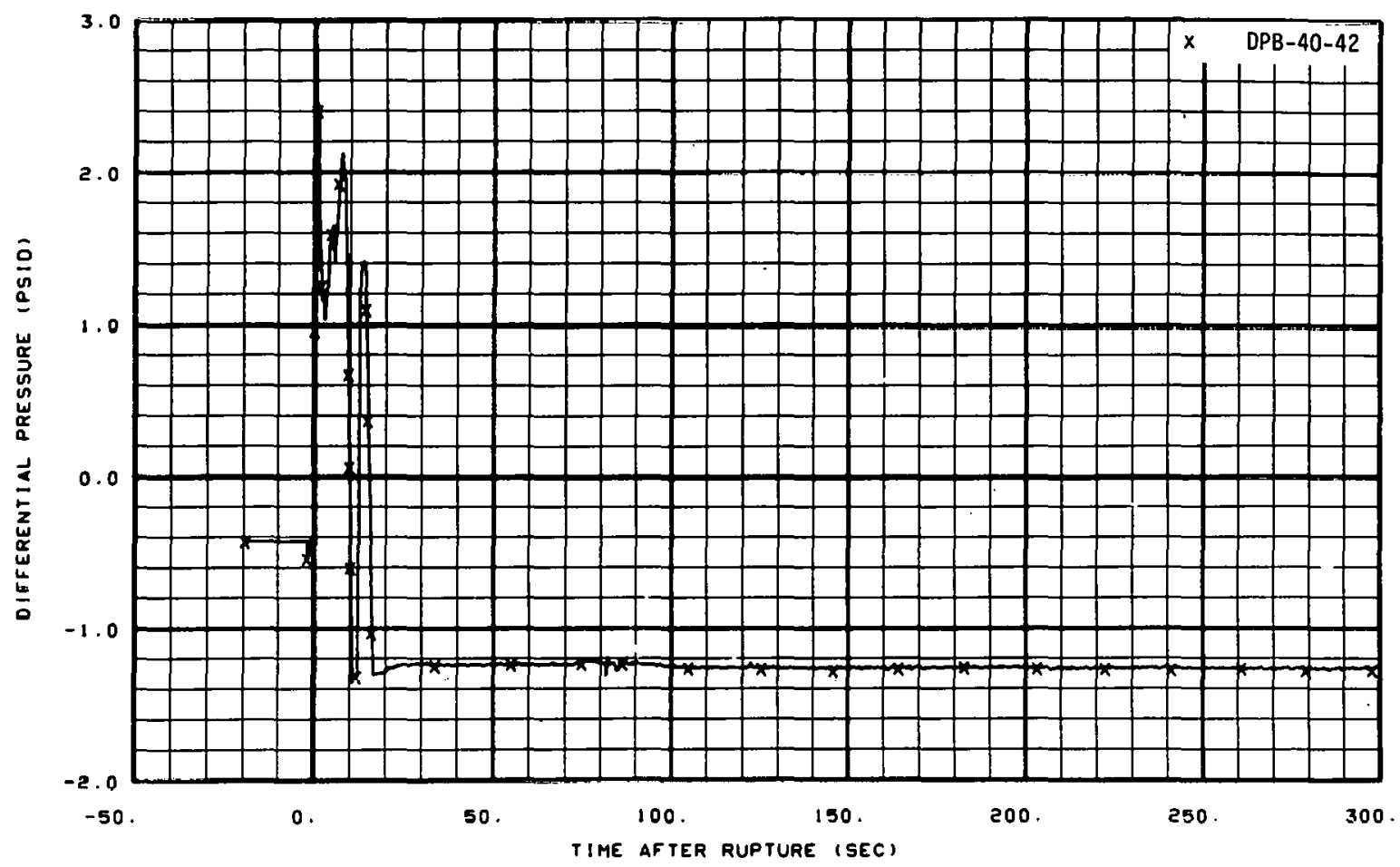

Fig. 185 Differential pressure in broken loop (DPB-40-42), from -20 to 300 seconds.

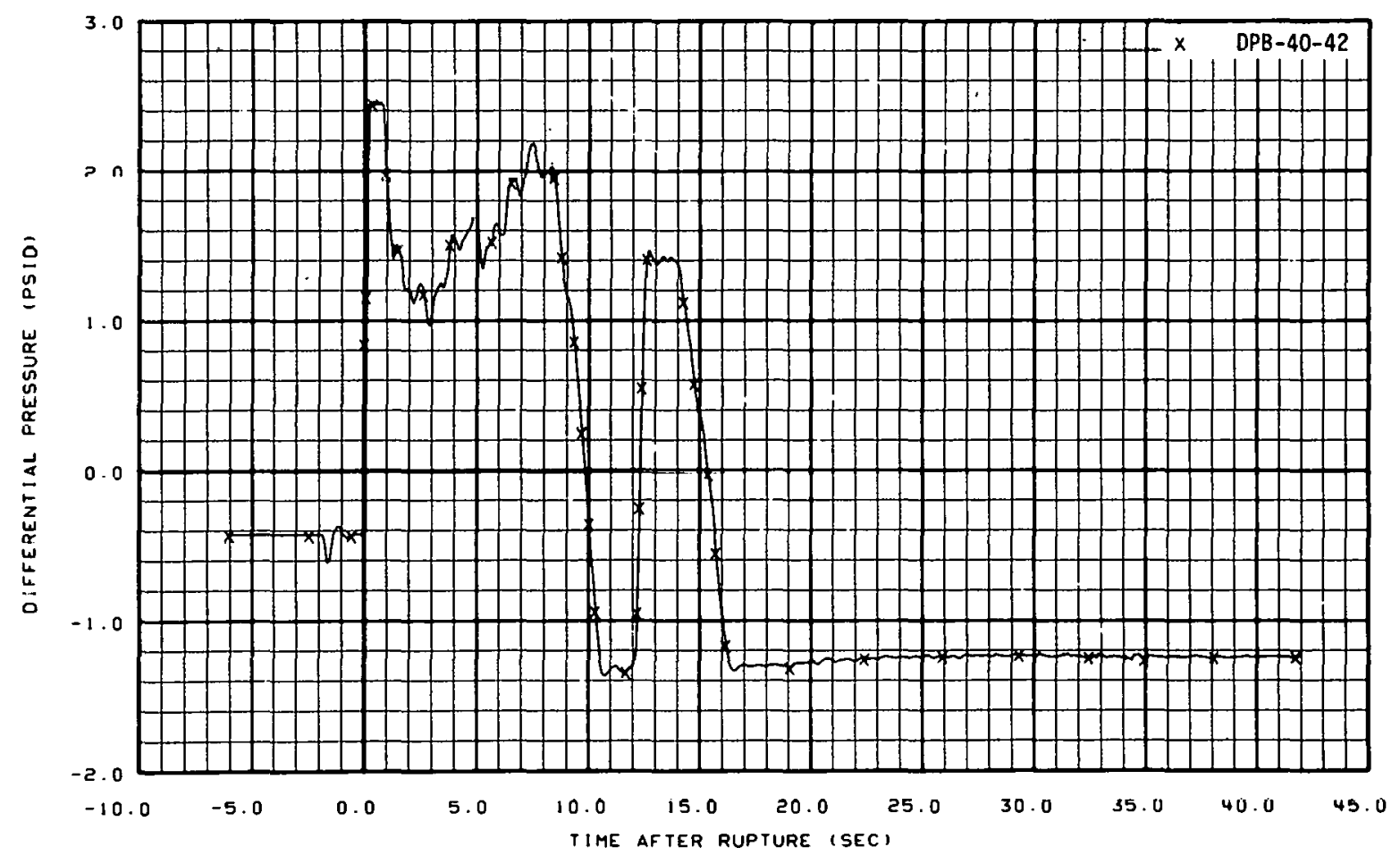

Fig. 186 Differential pressure in broken loop (DPB-40-42), from -6 to 42 seconds. 


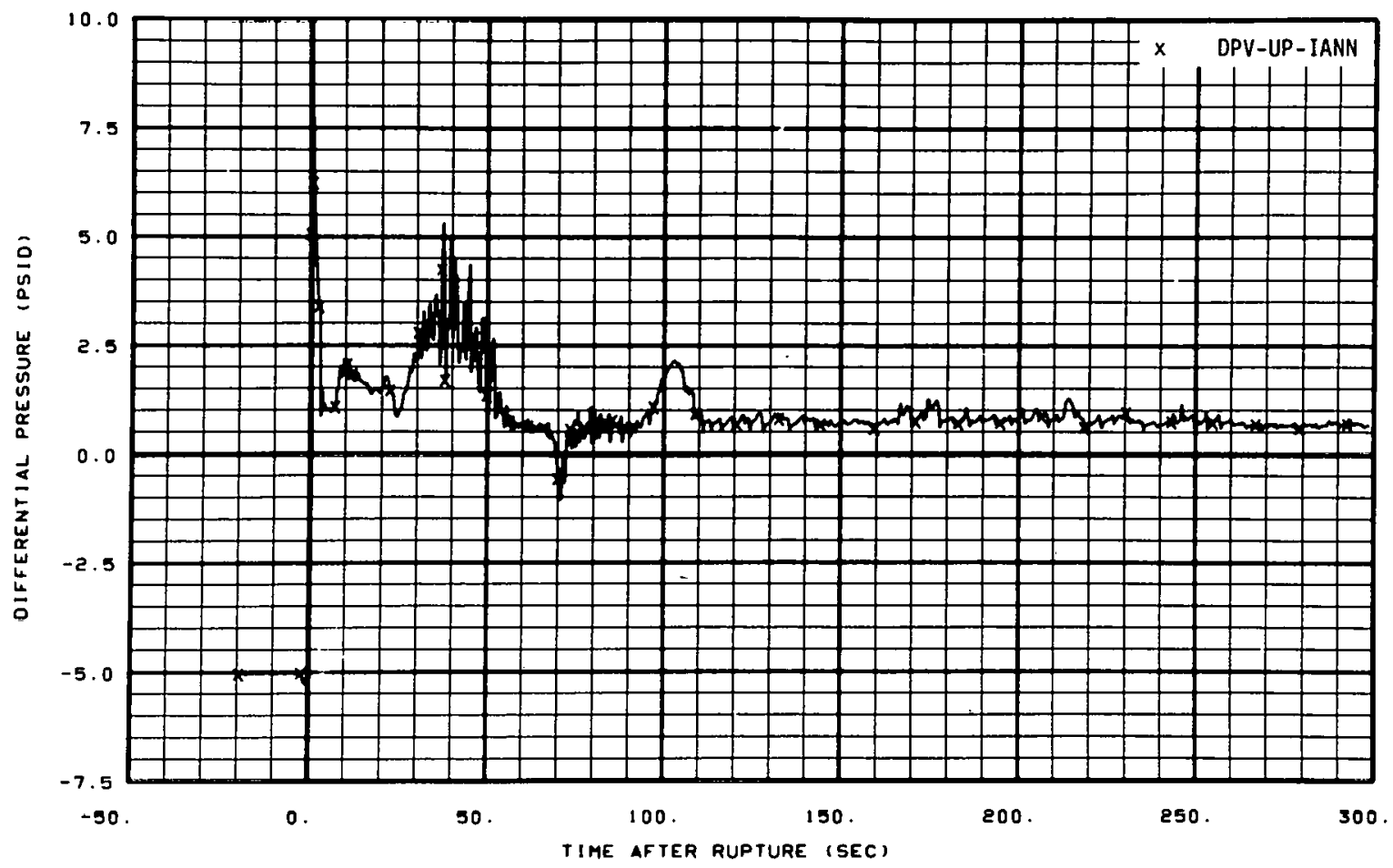

Fig. 187 Differential pressure in vessel (DPV-UP-IANN), from -20 to 300 seconds.

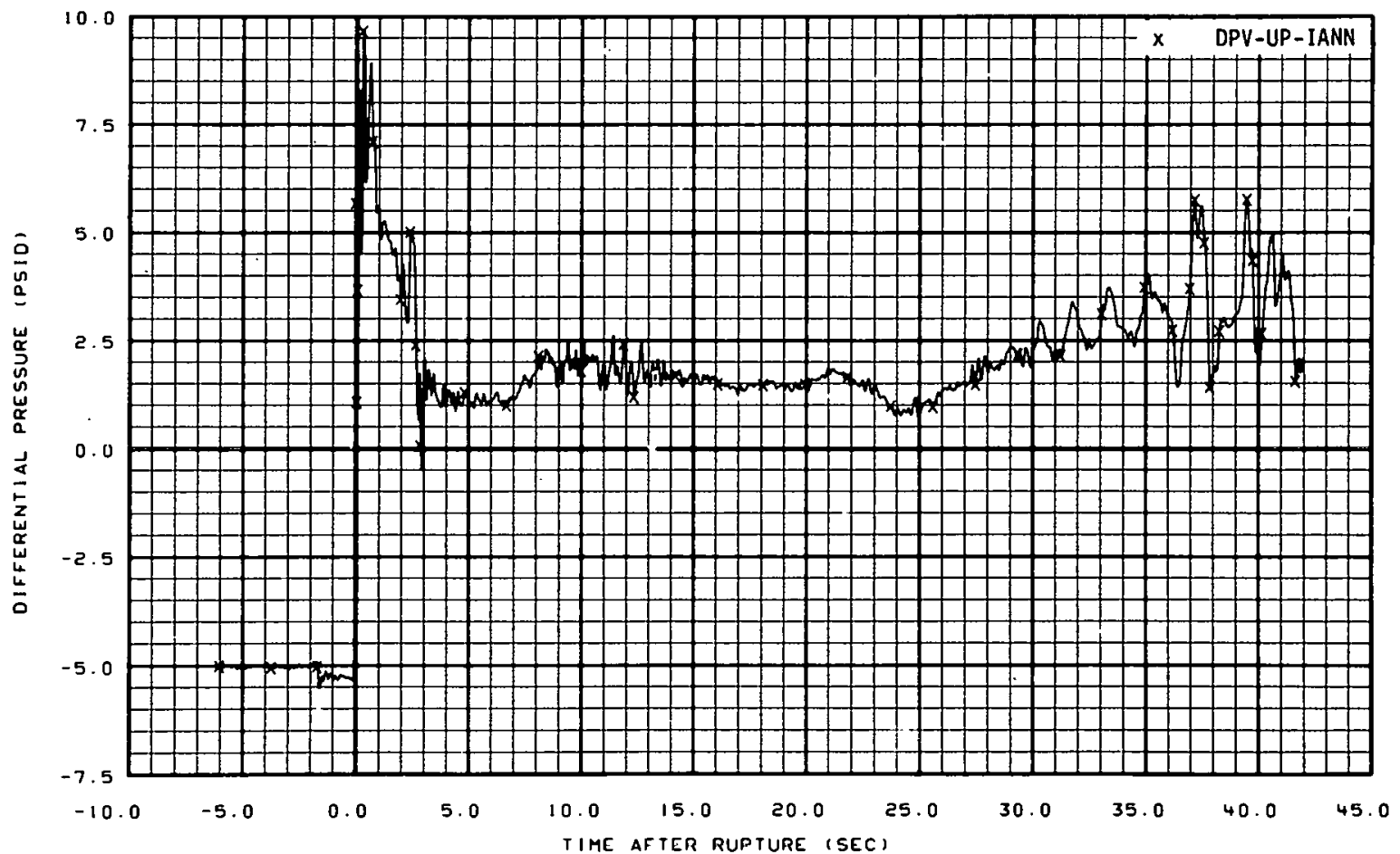

Fig. 188 Differential pressure in vessel (DPV-UP-IANN), from -6 to 42 seconds. 


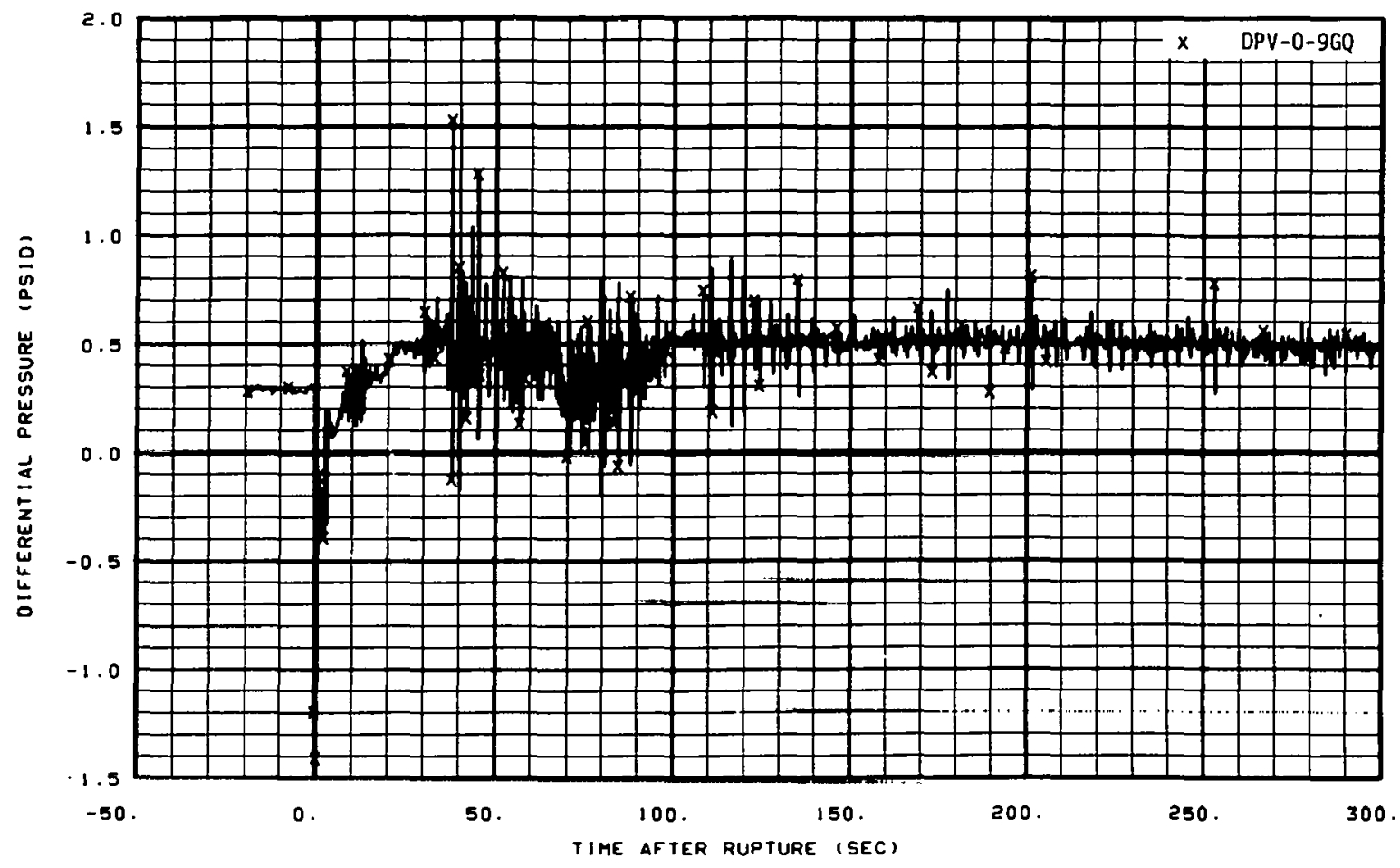

Fig. 189 Differential pressure in vesse1 (DPV-0-9GQ), from -20 to 300 seconds.

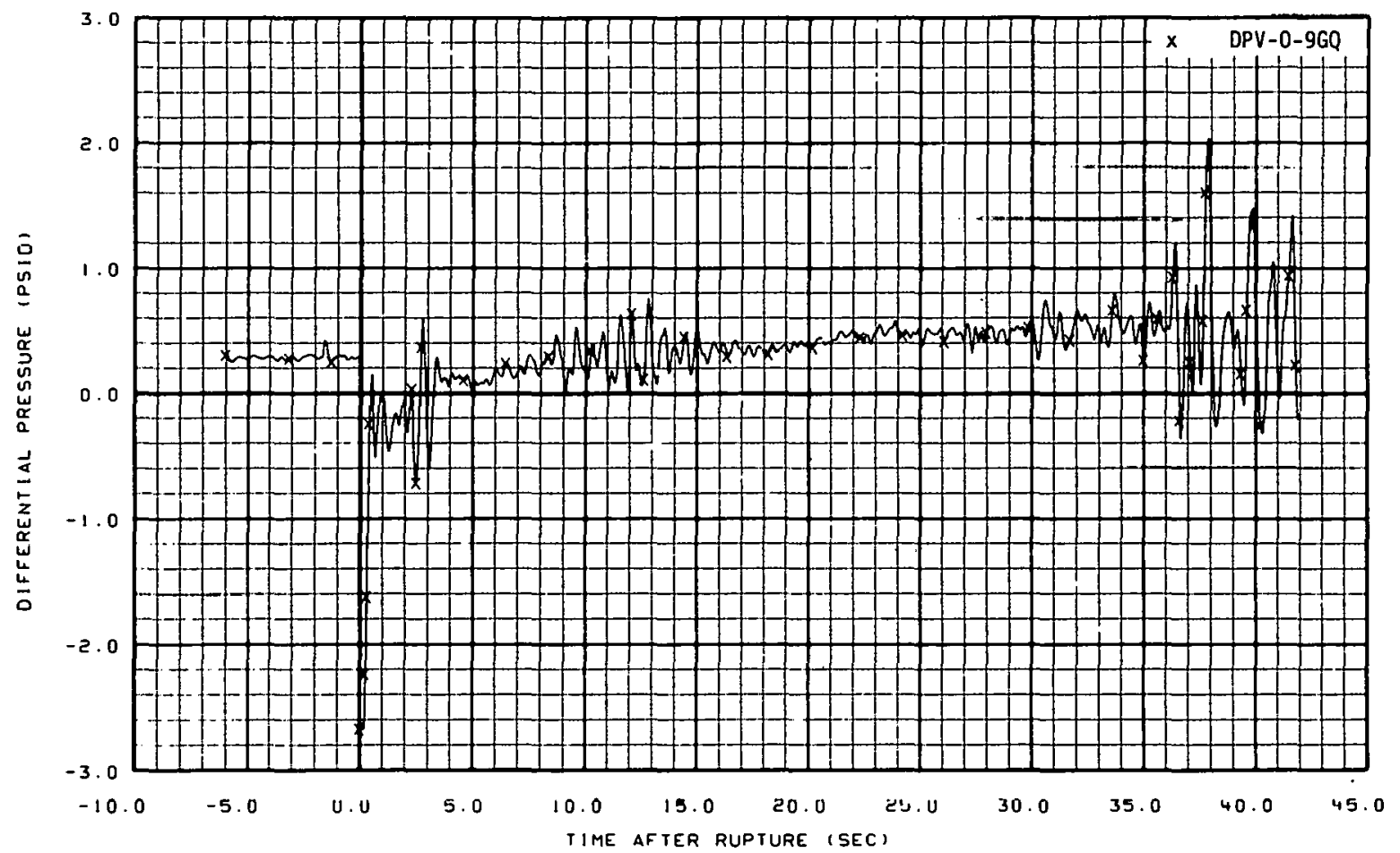

Fig. 190 Differential pressure in vessel (DPV-0-9GQ), from -6 to 42 seconds. 


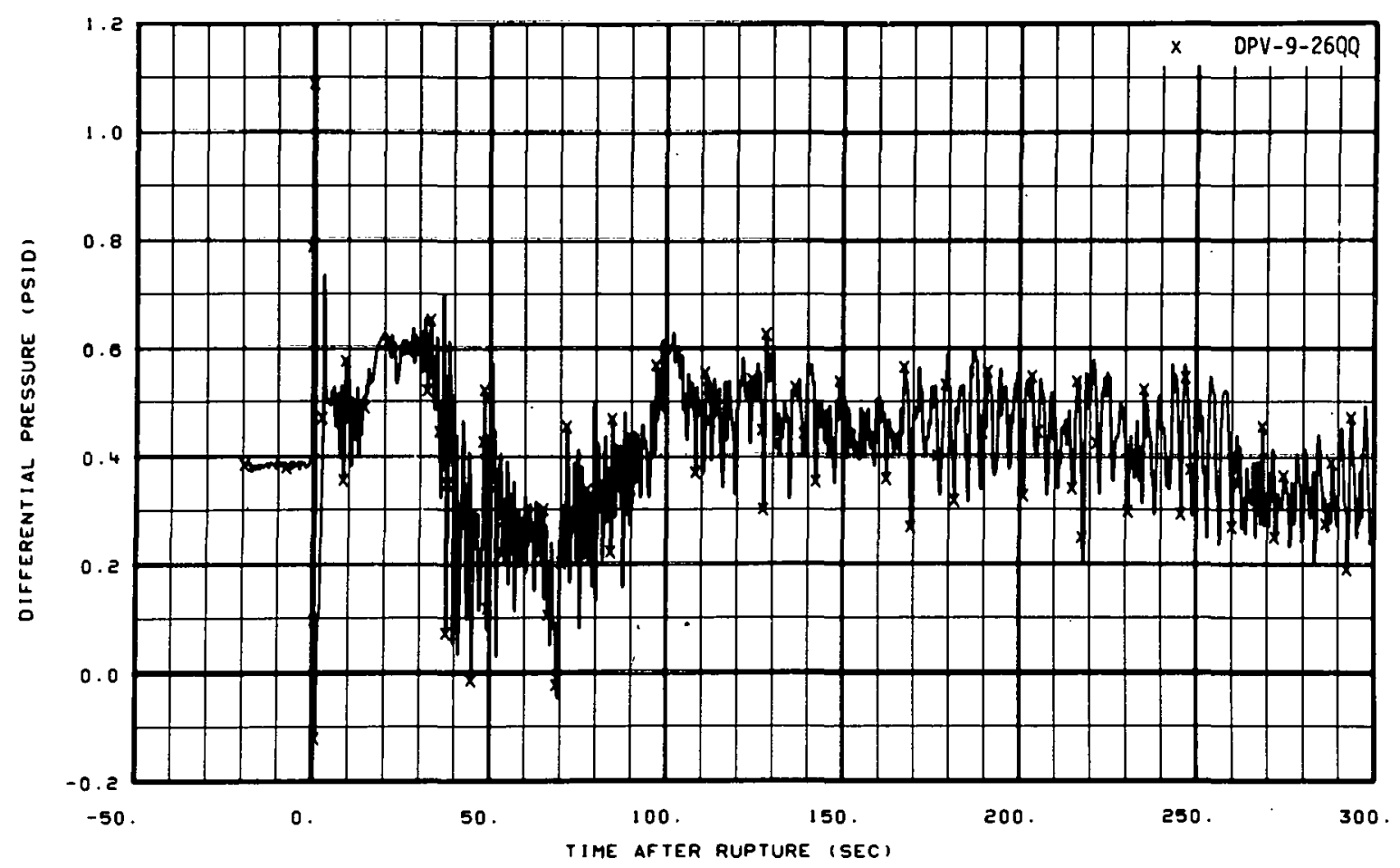

Fig. 191 Differential pressure in vessel (DPV-9-26QQ), from -20 to 300 seconds.

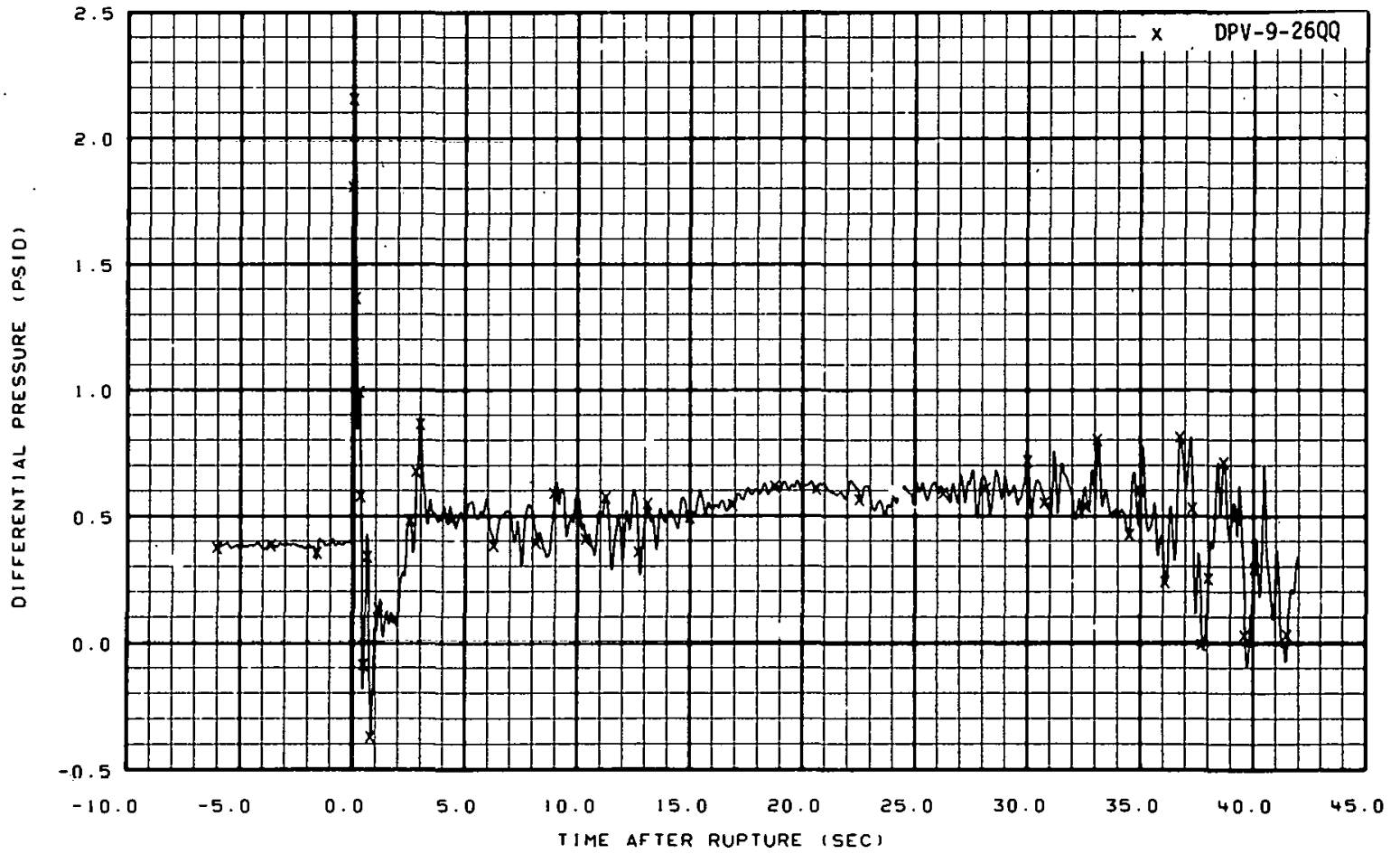

Fig. 192 Differential pressure in vesse1 (DPV-9-26nח), frmm - 6 t. 42 seconds. 


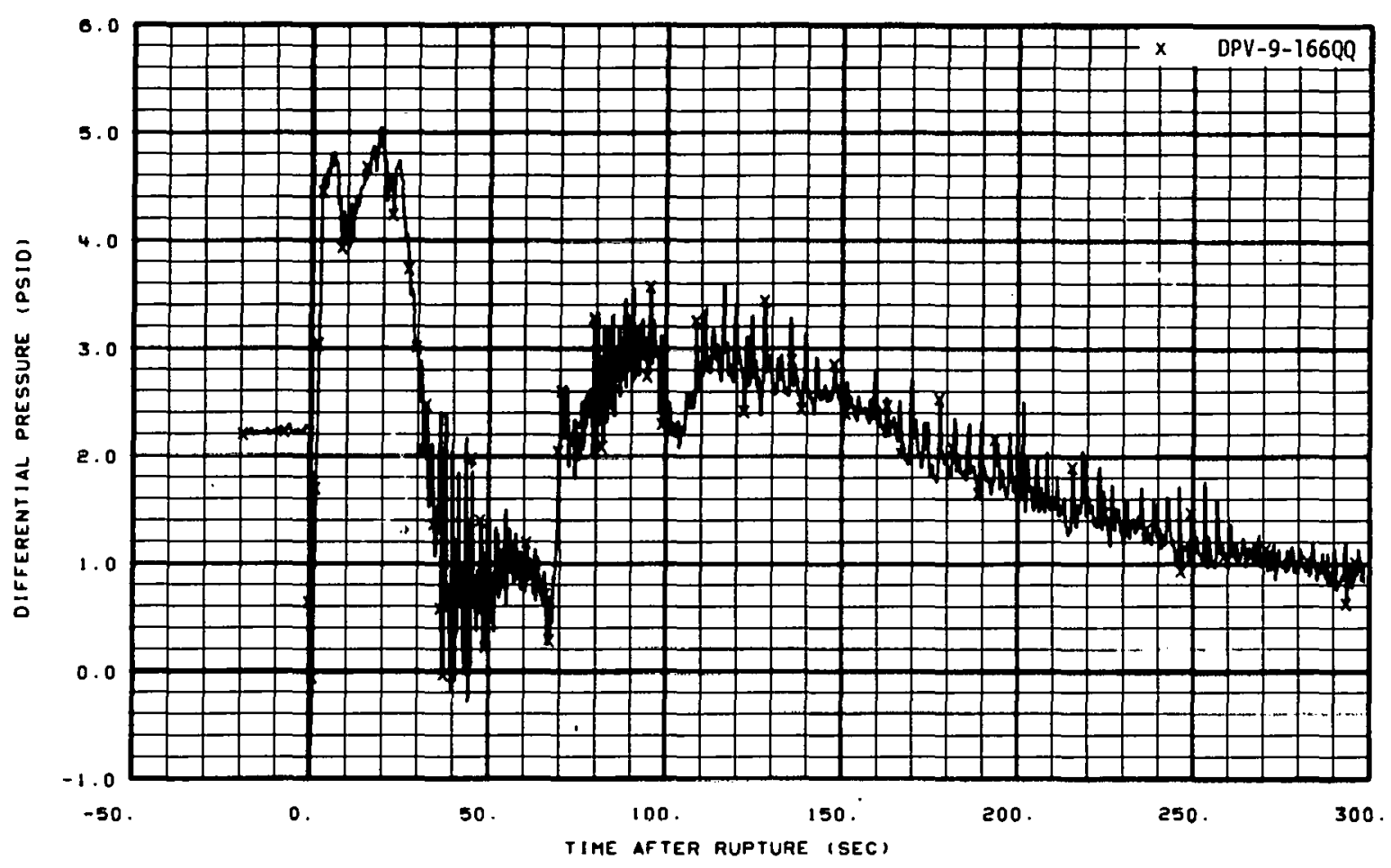

Fig. 193 Differential pressure in vessel (DPV-9-166QQ), from -20 to 300 seconds.

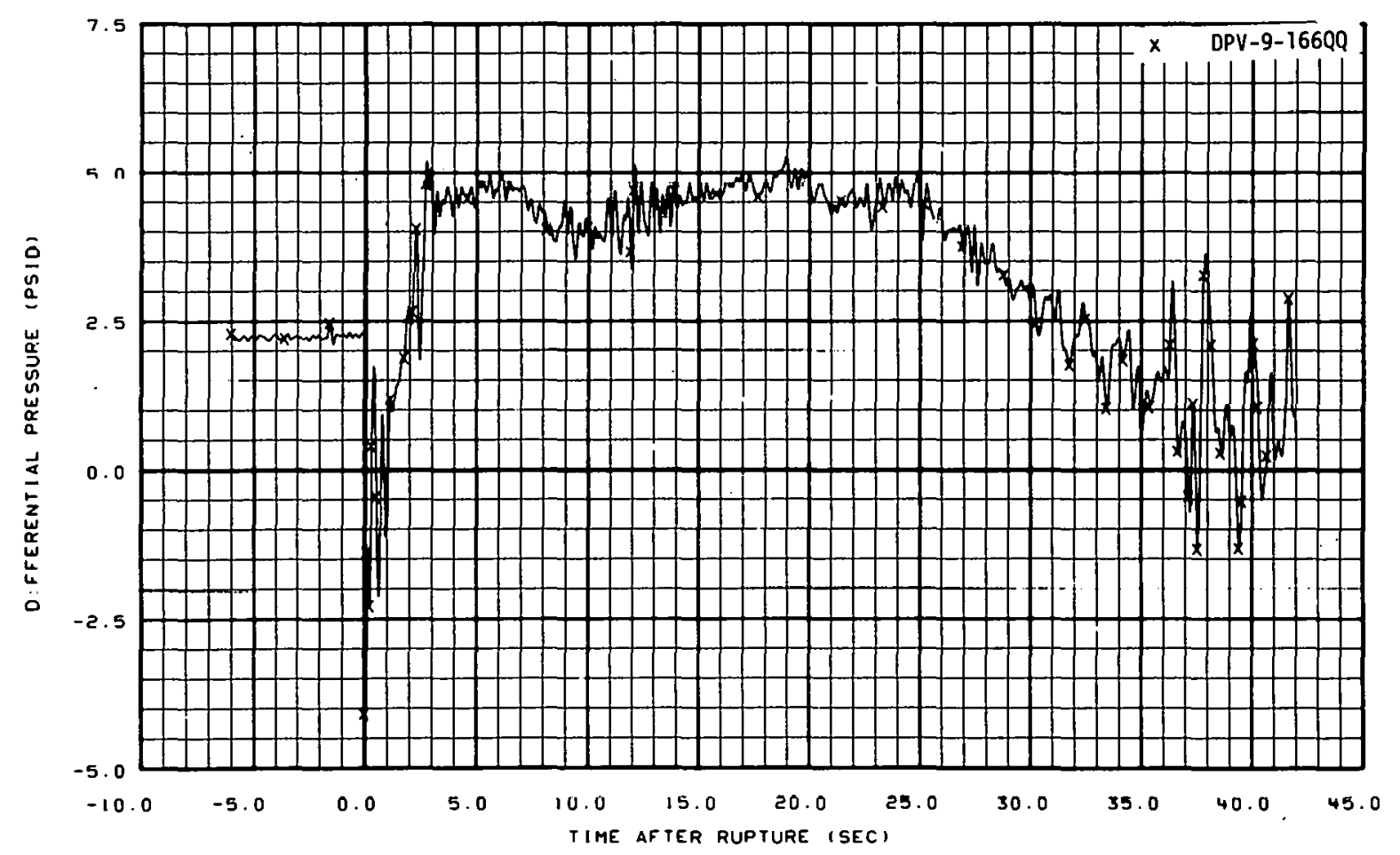

Fig. 194 Differential pressure in vessel (DPV-9-166QQ), from -6 to 42 seconds. 


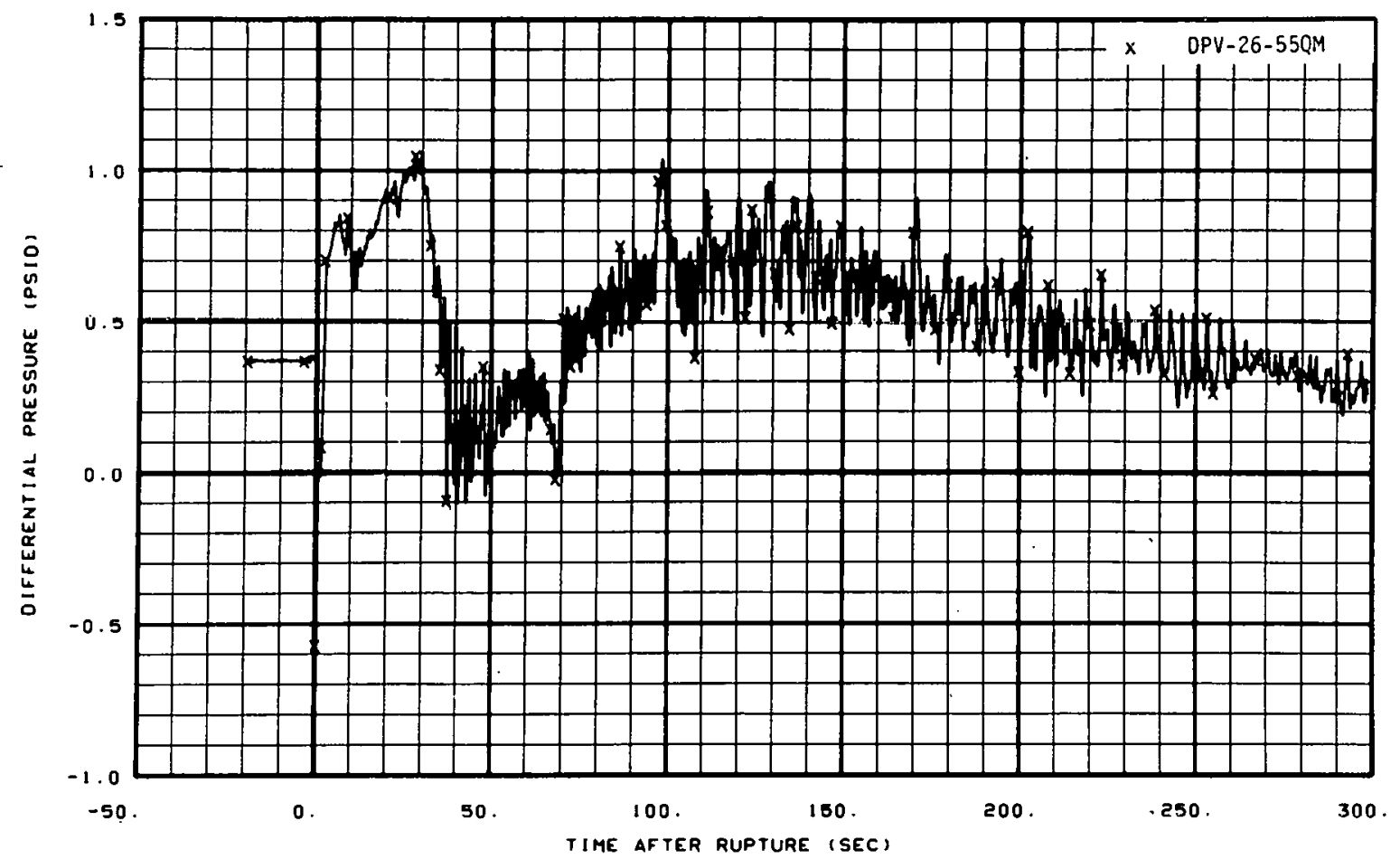

Fig. 195 Differential pressure in vessel (DPV-26-55QM), from -20 to 300 seconds.

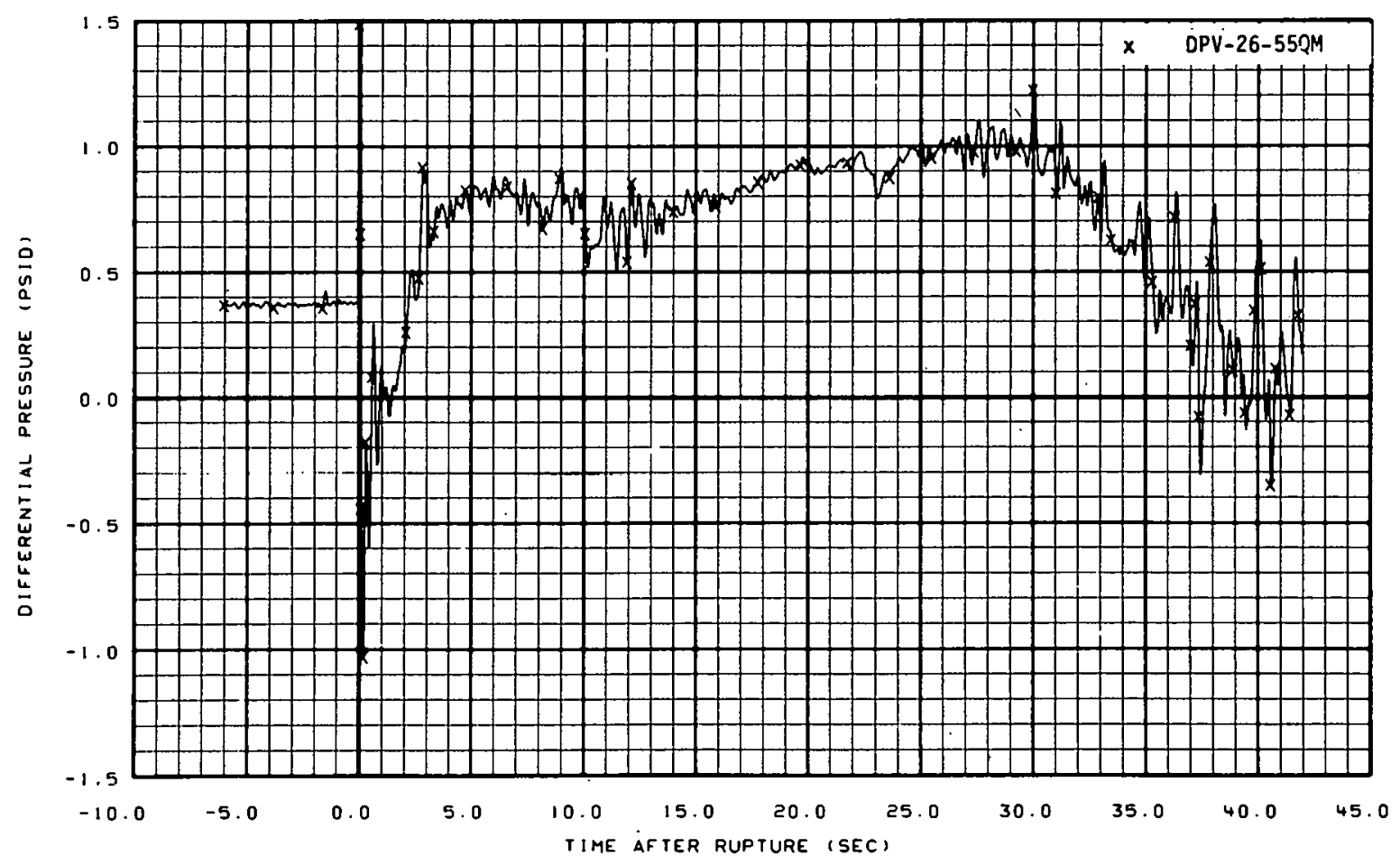

Fig. 196 Differential pressure in vessel (DPV-26-55QM), from -6 to 42 seconds. 


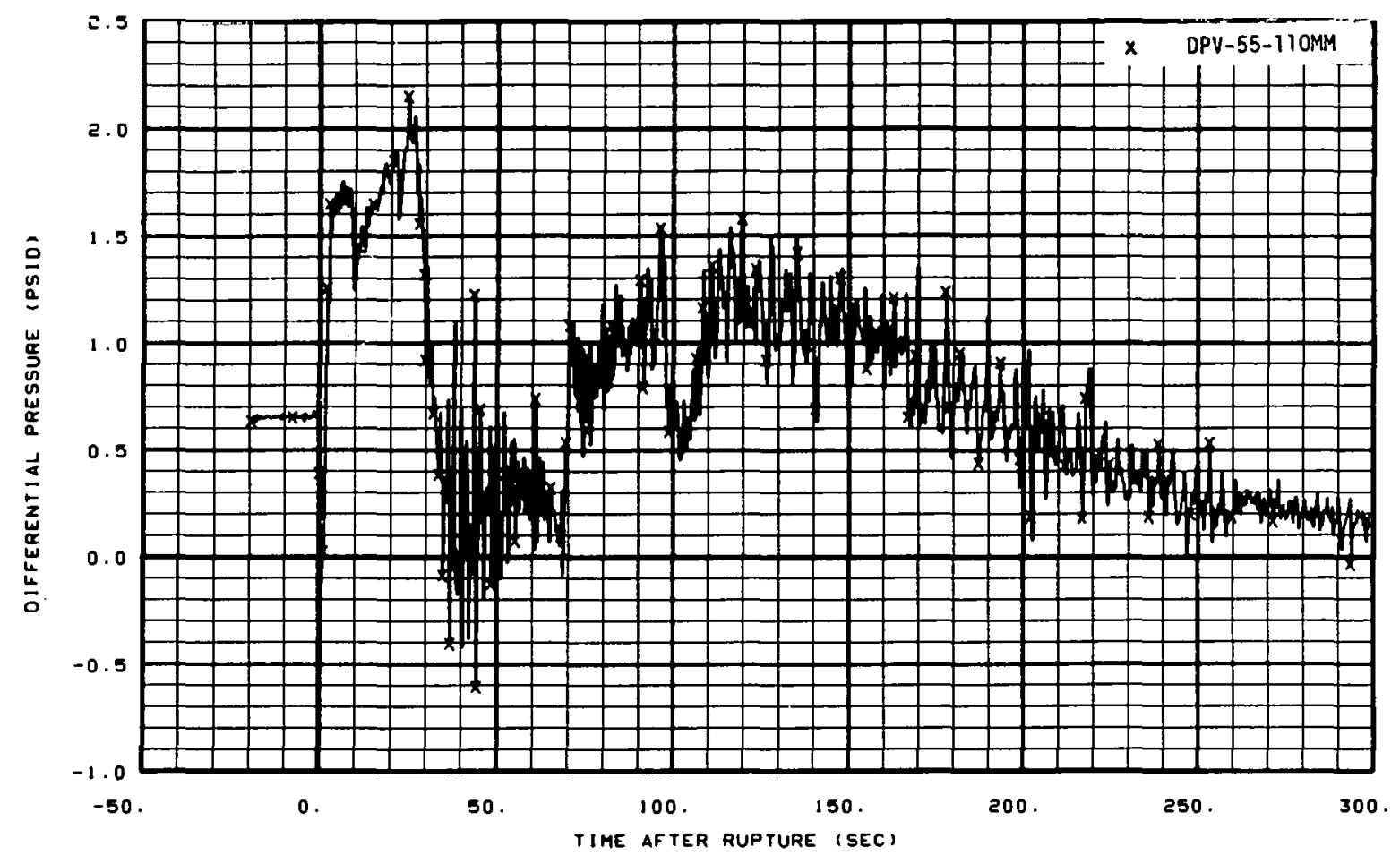

Fig. 197 Differential pressure in vessel (DPV-55-110MM), from -20 to 300 seconds.

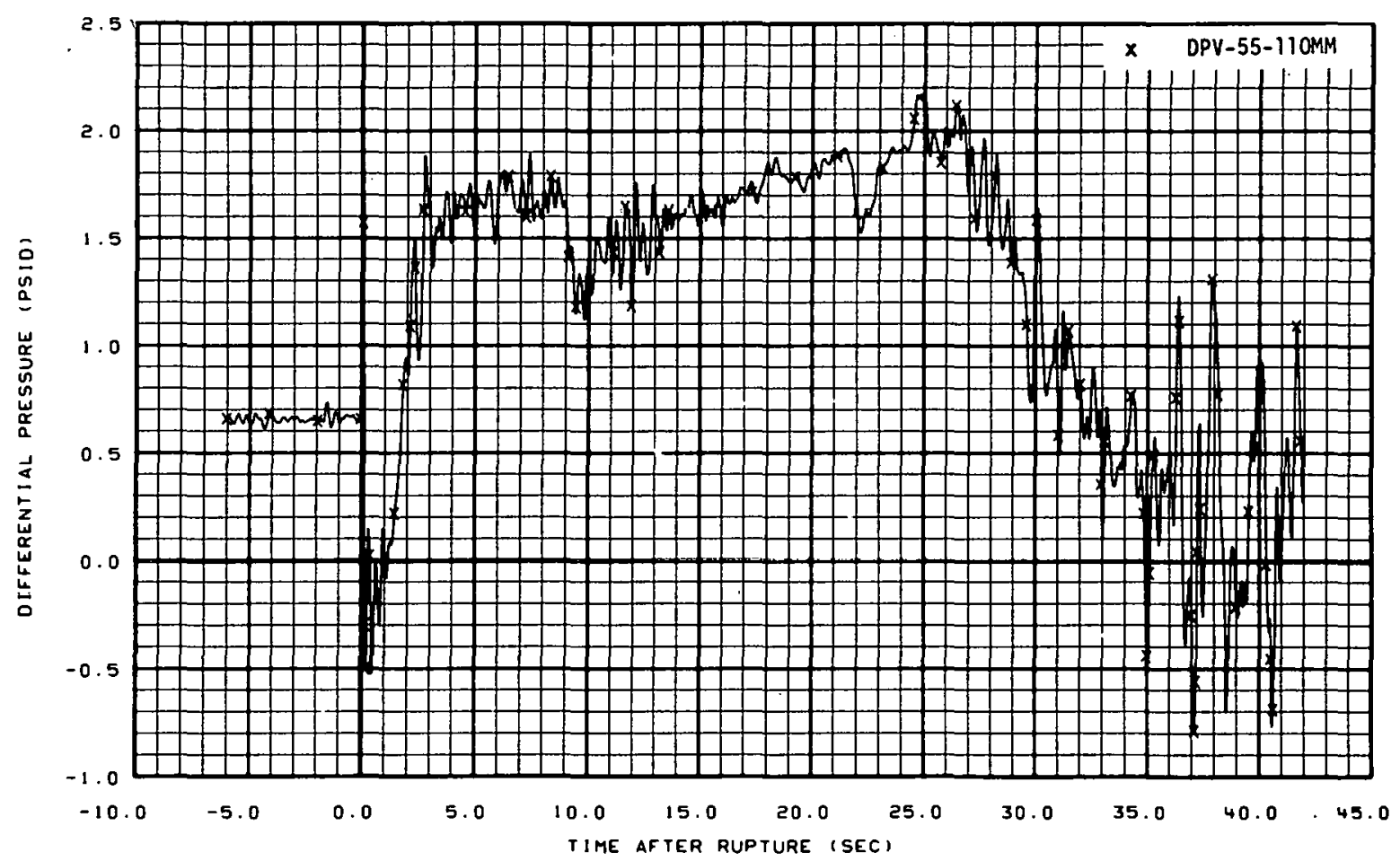

Fig. 198 Differential pressure in vessel (DPV-55-110/M), from -6 to 42 seconds. 


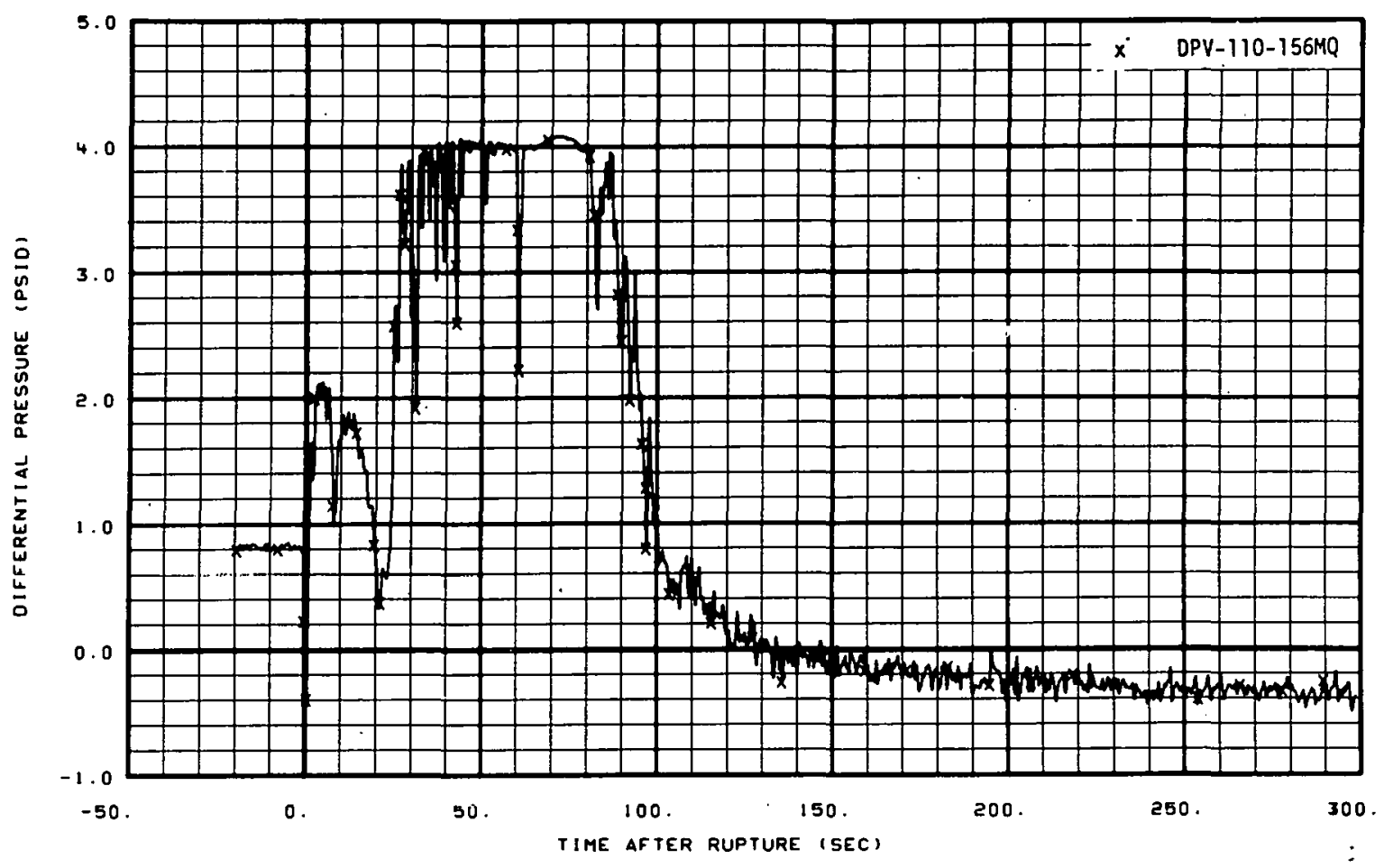

Fig. 199 Differential pressure in vessel (DPV-110-156MQ), from -20 to 300 seconds.

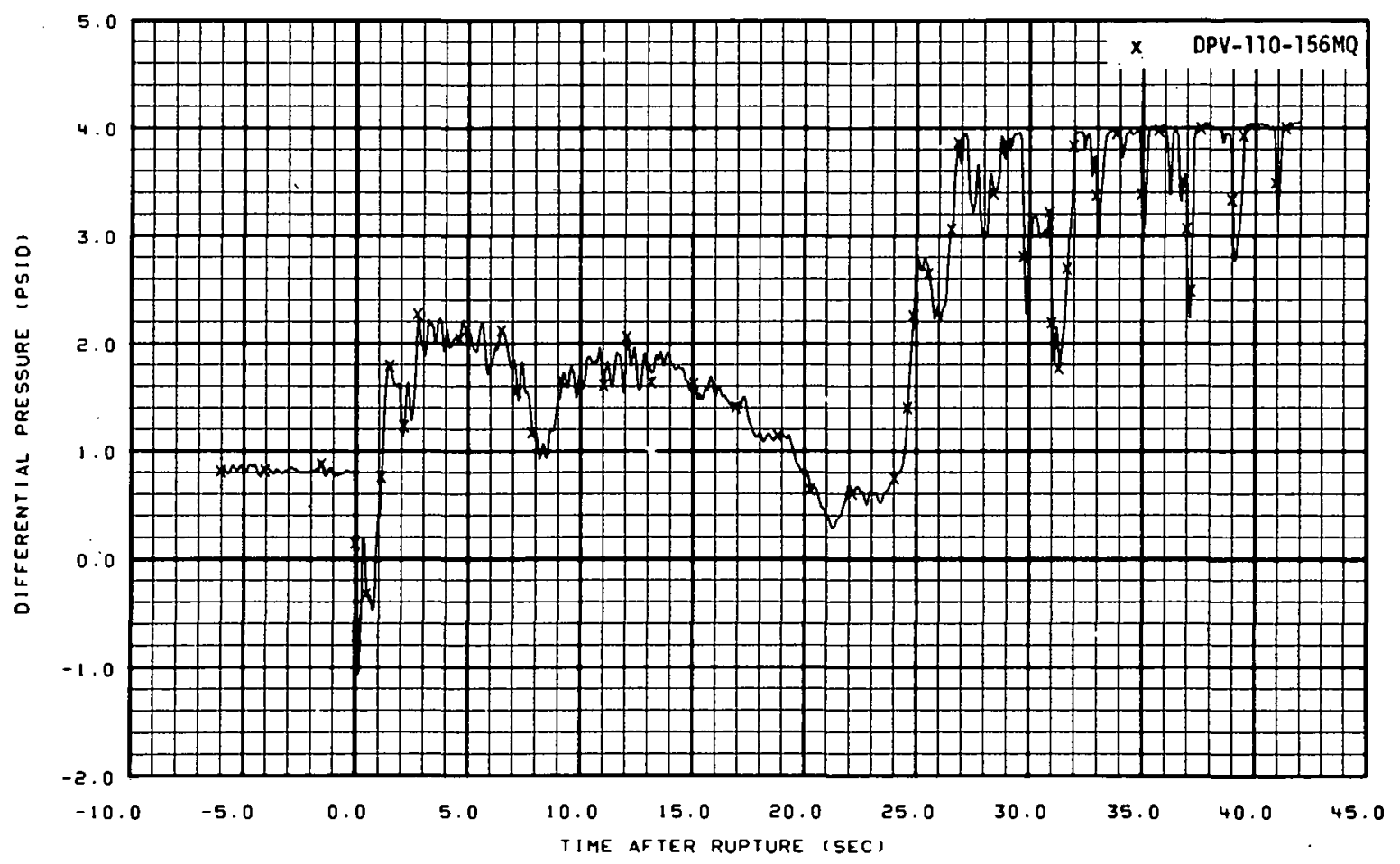

Fig. 200 Uifferential pressure in vesse1 (DPV-110-156MQ), fruil -6 lo 42 seconds. 


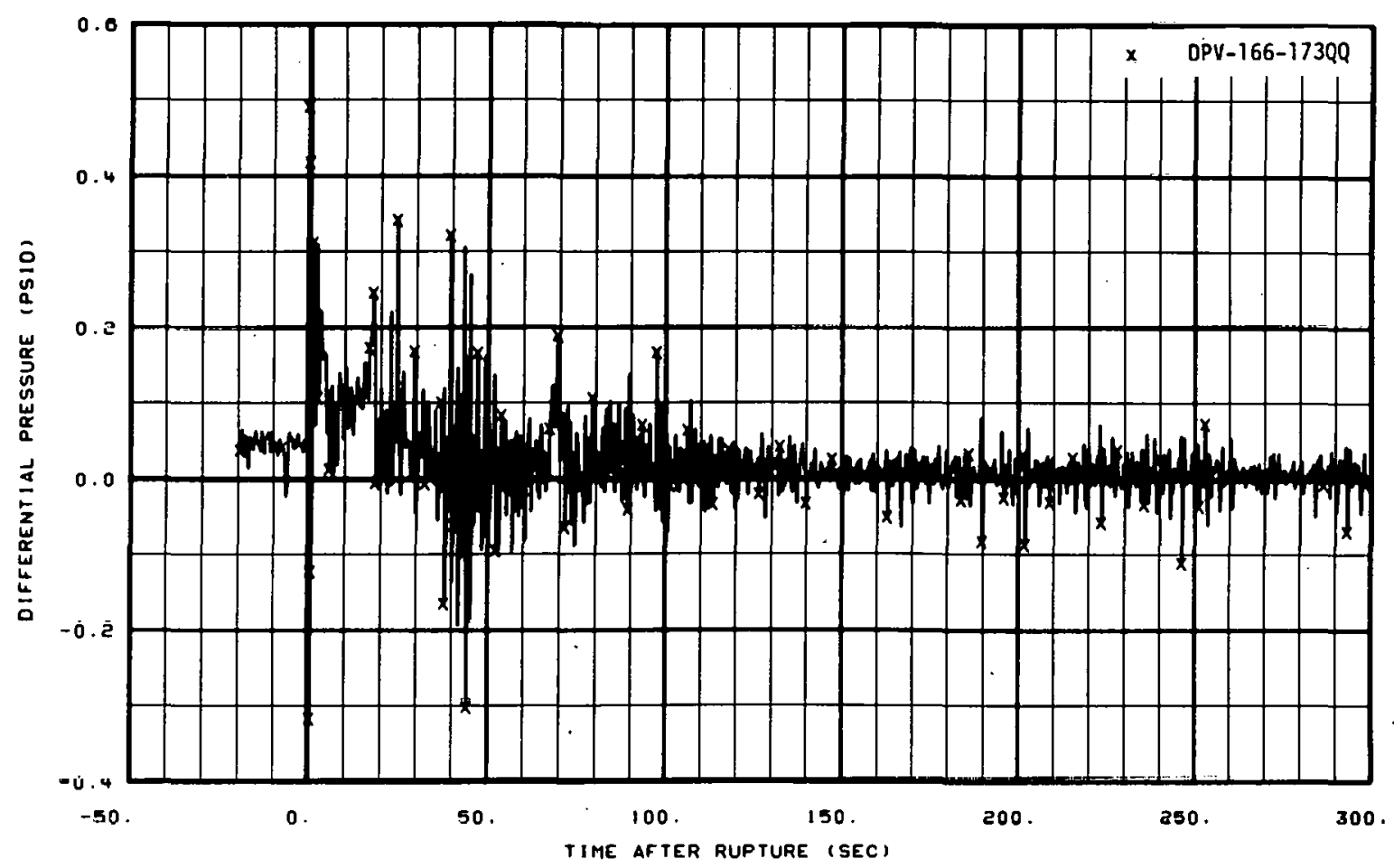

Fig. 201 Differential pressure in vessel (DPV-166-1730Q), from -20 to 300 seconds。

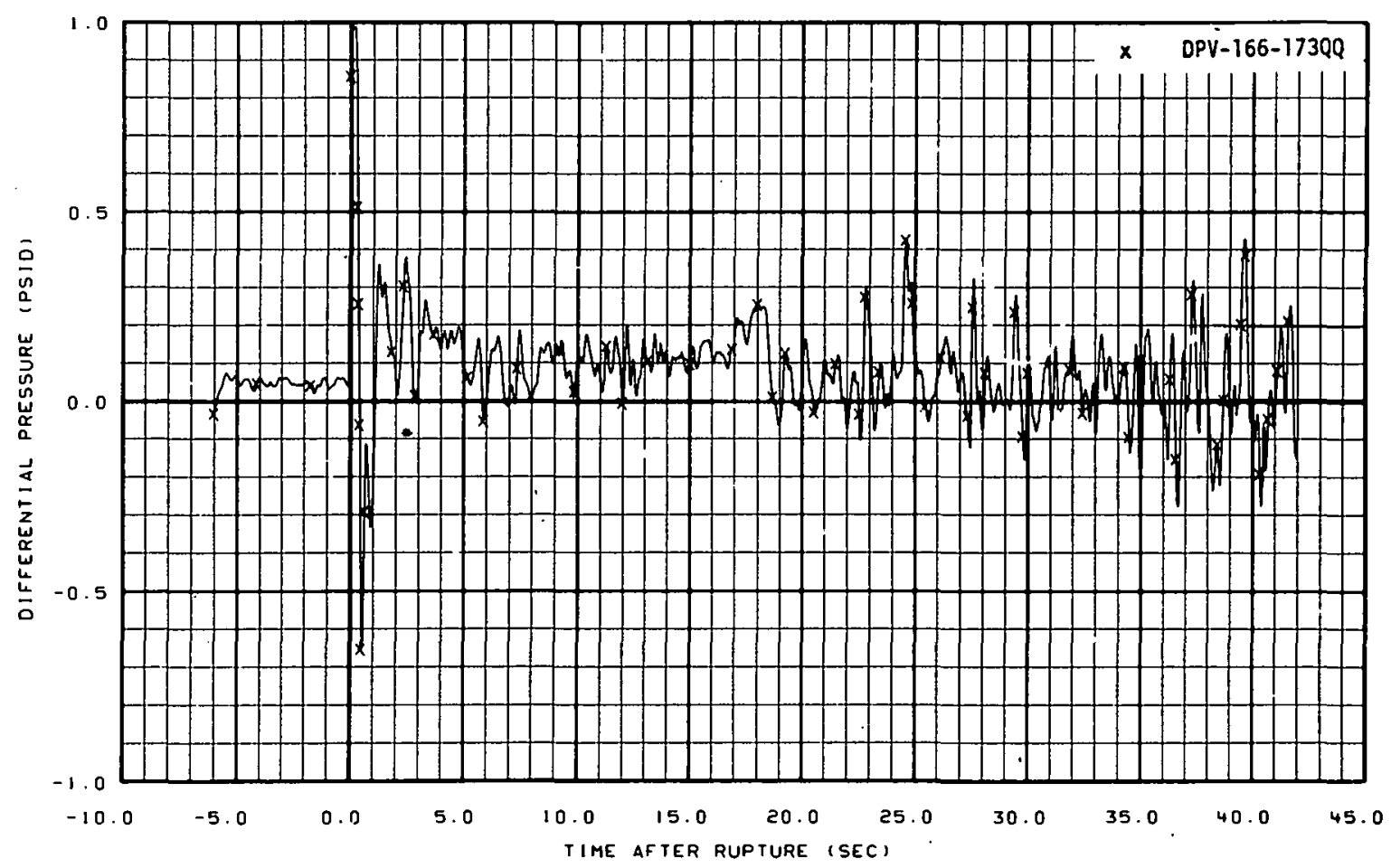

Fig. 202 Differential pressure in vessel (DPV-166-1730Q), from -6 to 42 seconds. 


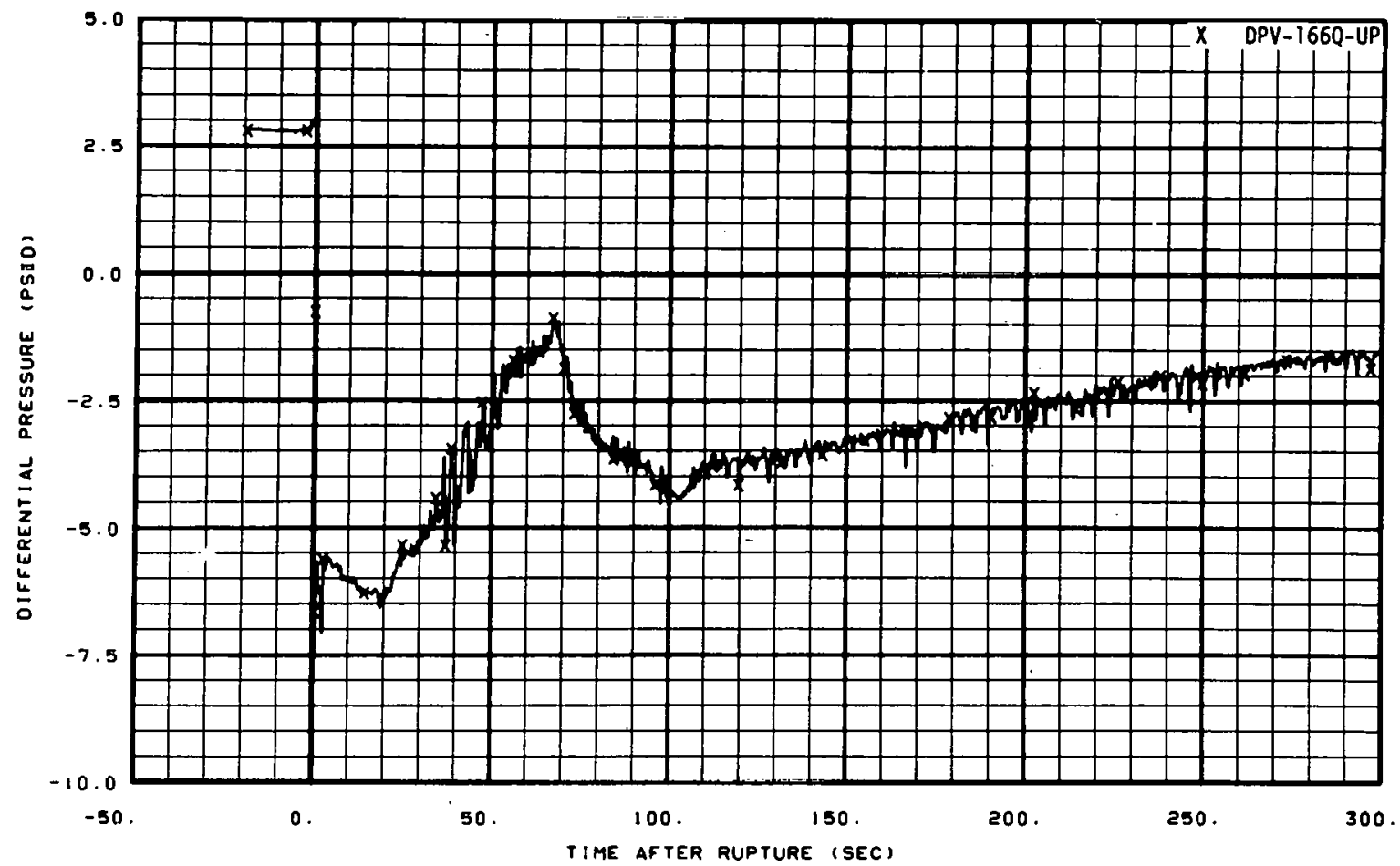

Fig. 203 Differential pressure in vessel (DPV-1660-UP), from -20 to 300 seconds.

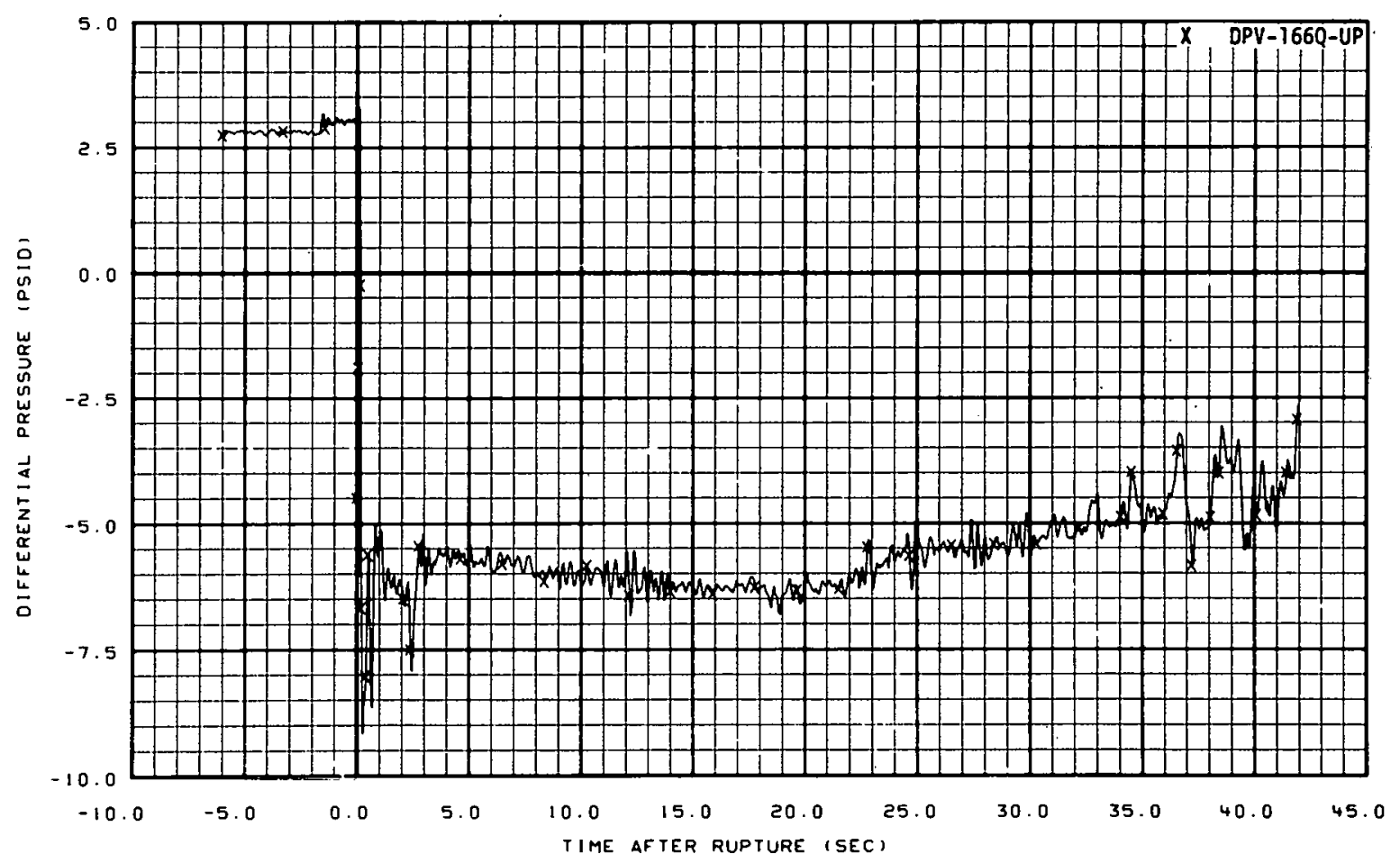

Fig. 204 Differential pressure in vessel (DPV-1660-UP), from -6 to 42 seconds. 


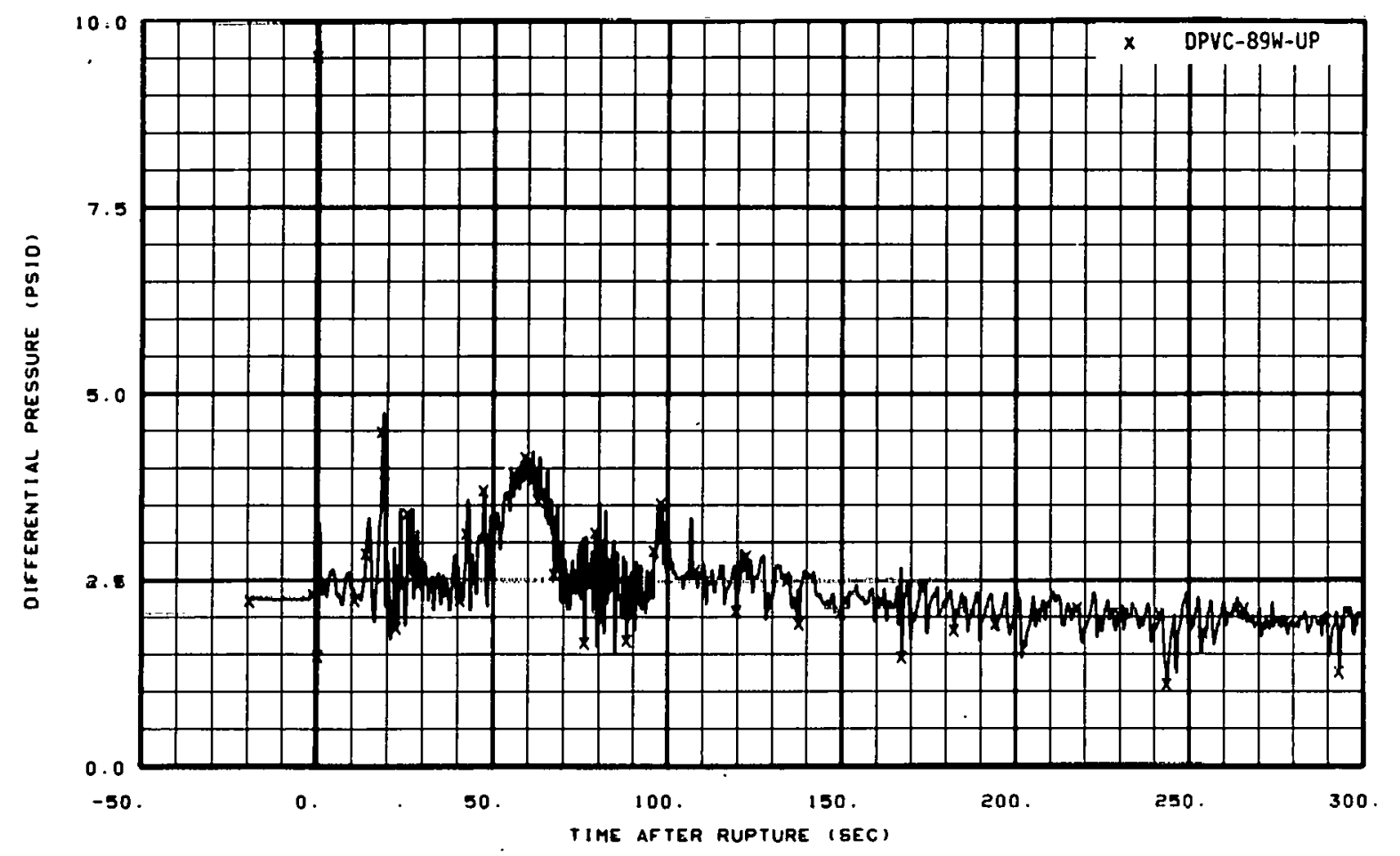

Fig. 205 Differential pressure in vessel core (DPVC-89W-UP), from -20 to 300 seconds.

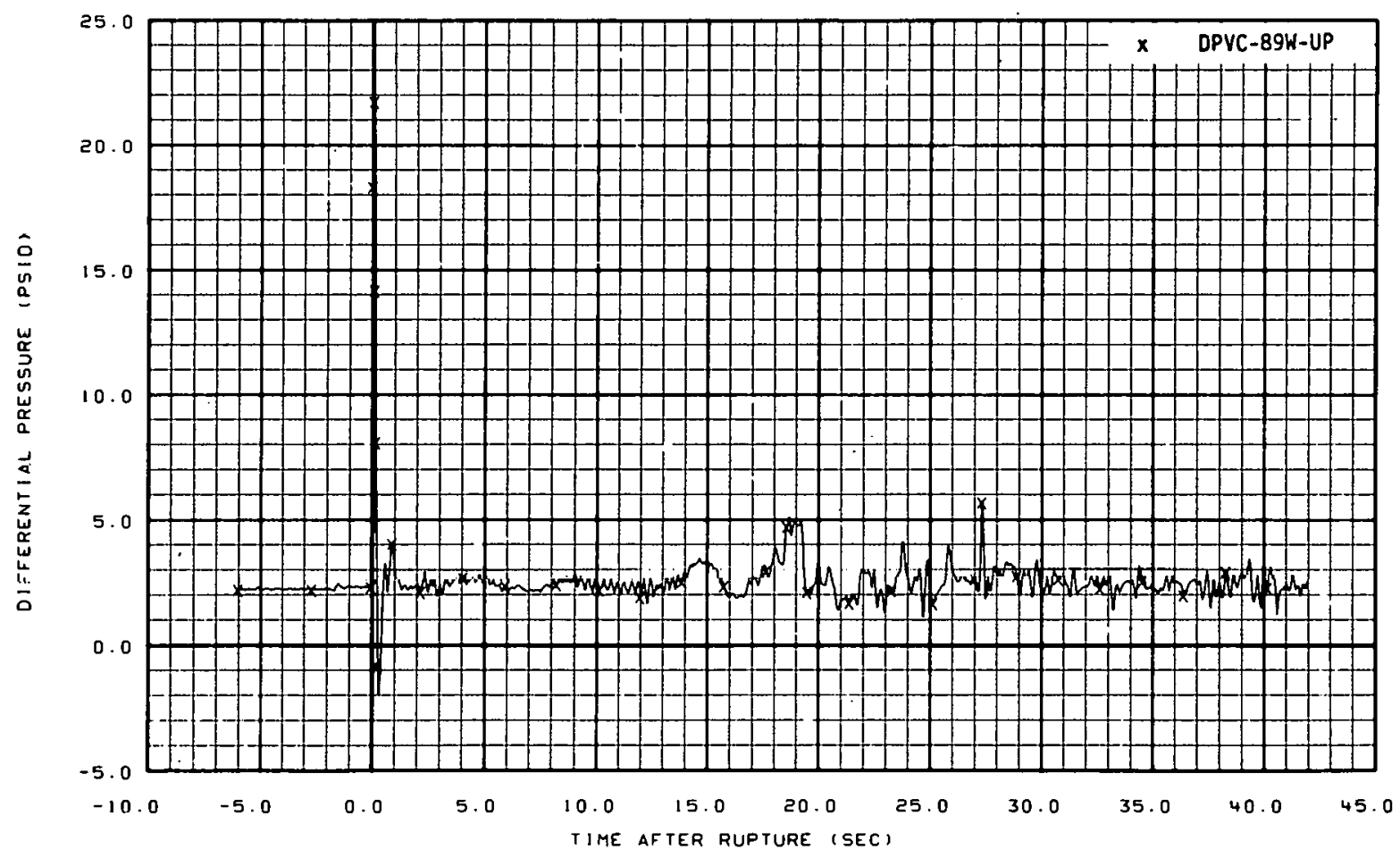

Fig. 206 Differential pressure in vessel core (DPVC-89W-UP), from -6 to 42 seconds. 


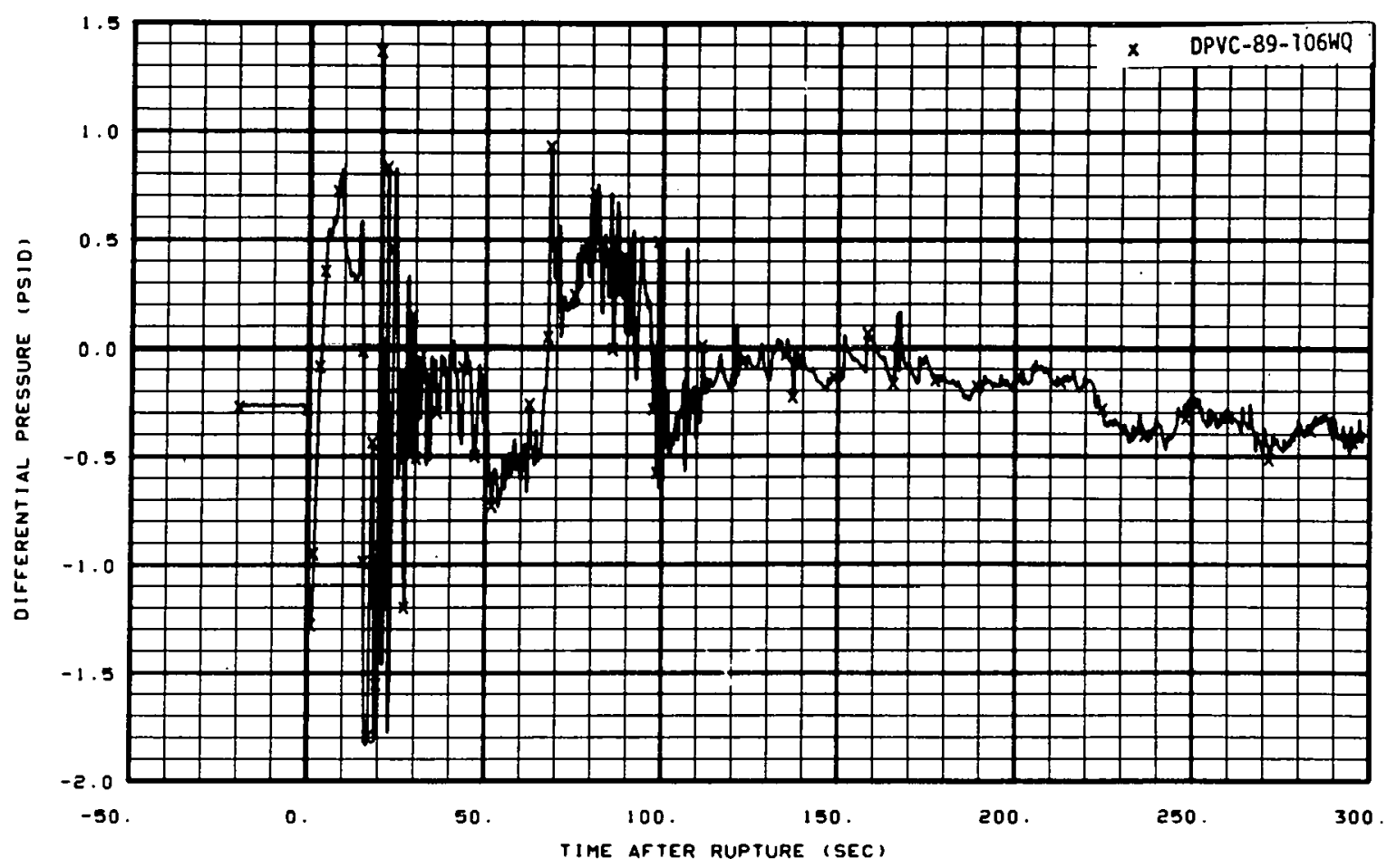

Fig. 207 Differential pressure in vessel core (DPVC-89-106WQ), from -20 to 300 seconds.

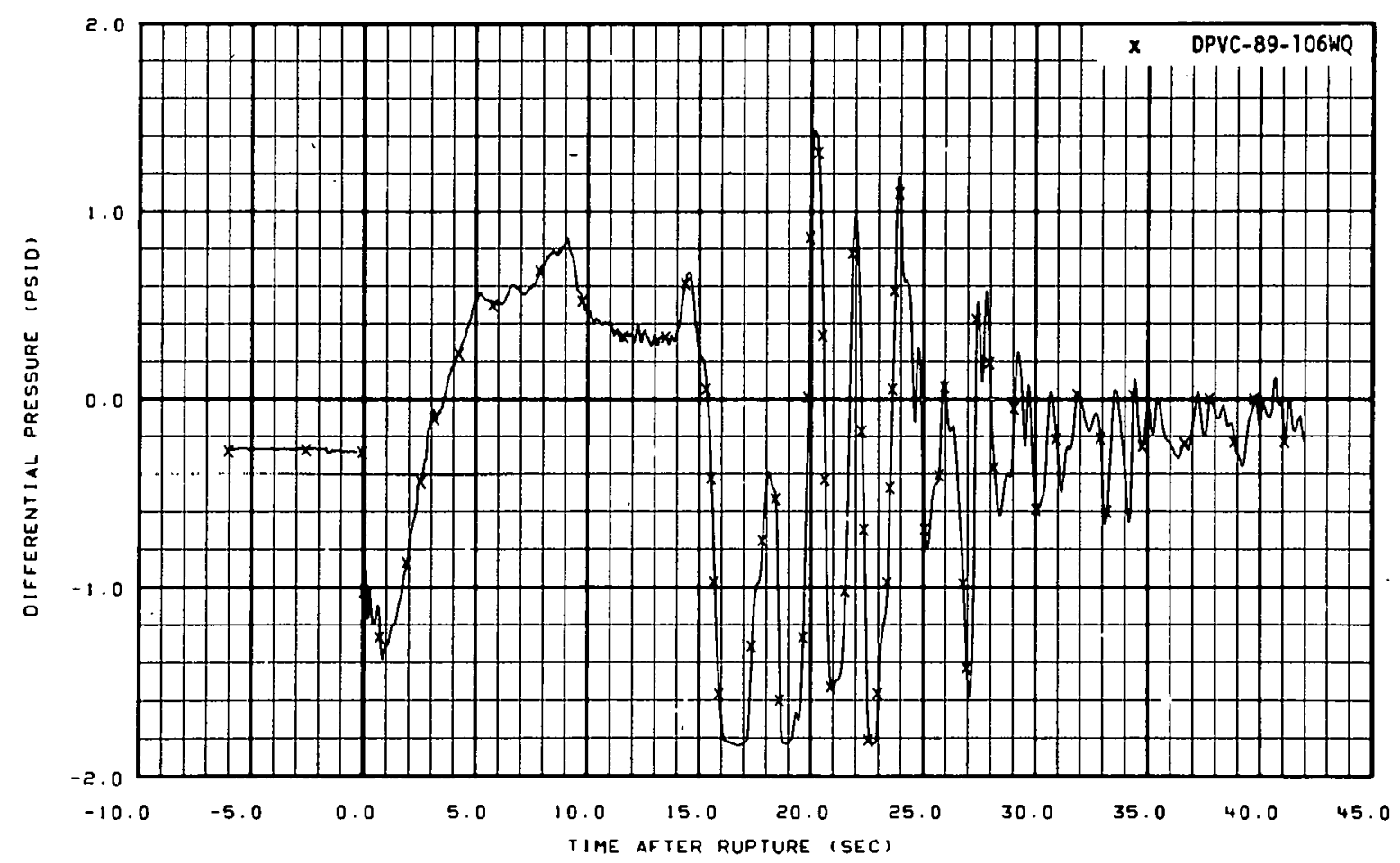

Fig. 208 Differential pressure in vessel core (DPVC-89-106WQ), from -6 to 42 seconds. 


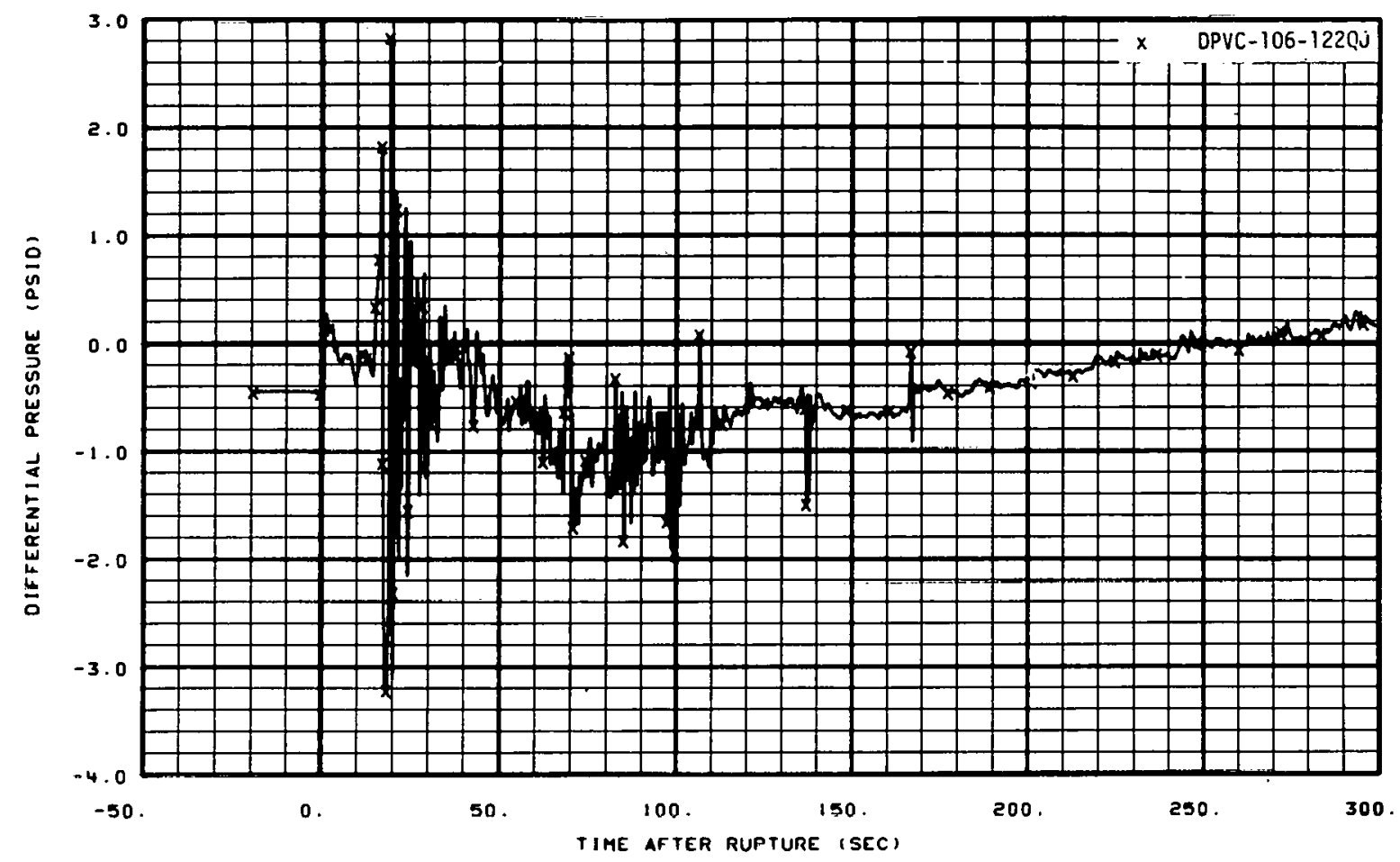

Fig. 209 Differential pressure in vessel core (DPVC-106-122QJ), from -20 to 300 seconds.

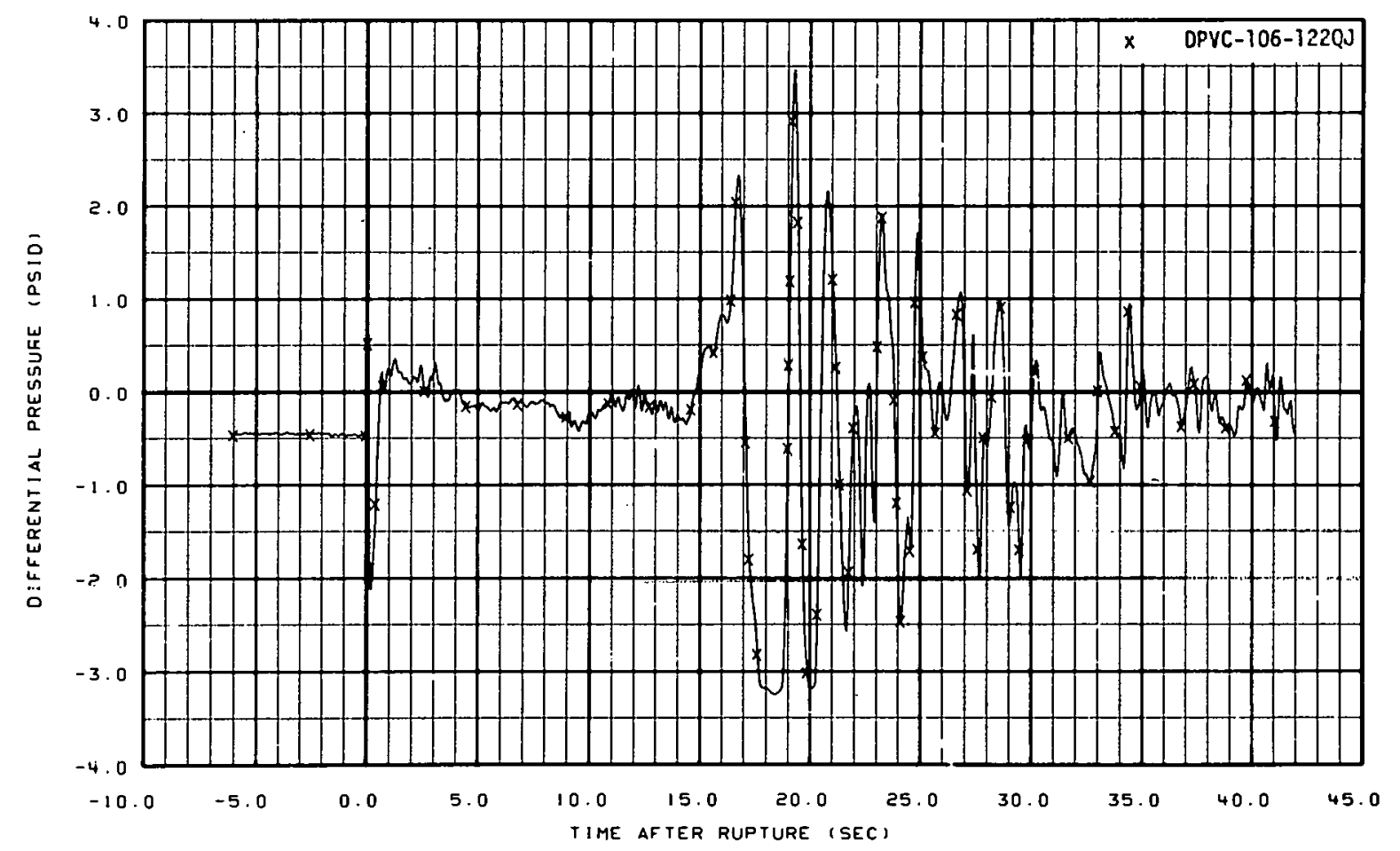

Fig. 210 Differential pressure in vessel core (DPVC-106-122QJ), from -6 to 42 seconds. 


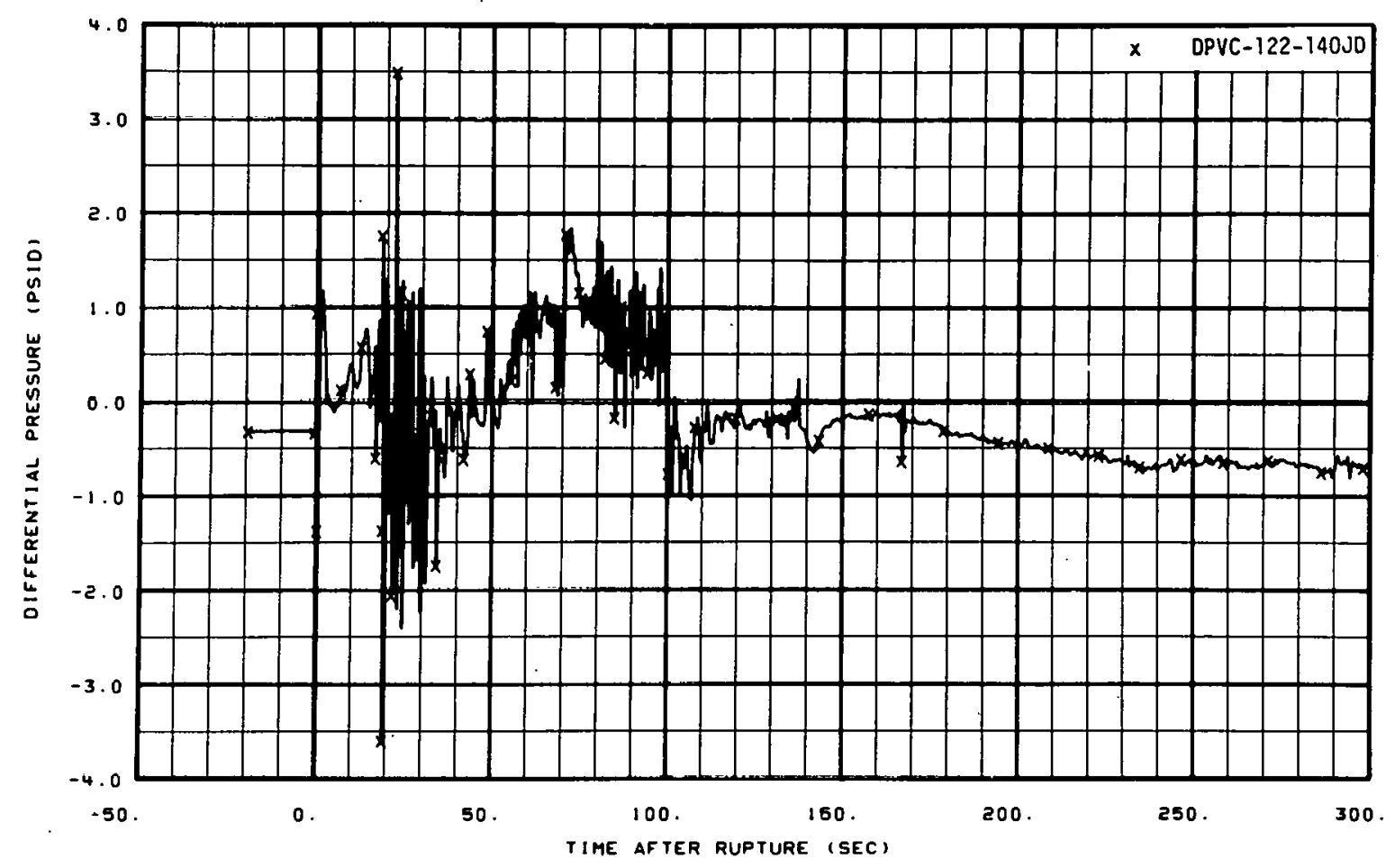

Fig. 211 Differential pressure in vessel core (DPVC-122-140JD), from -20 to 300 seconds.

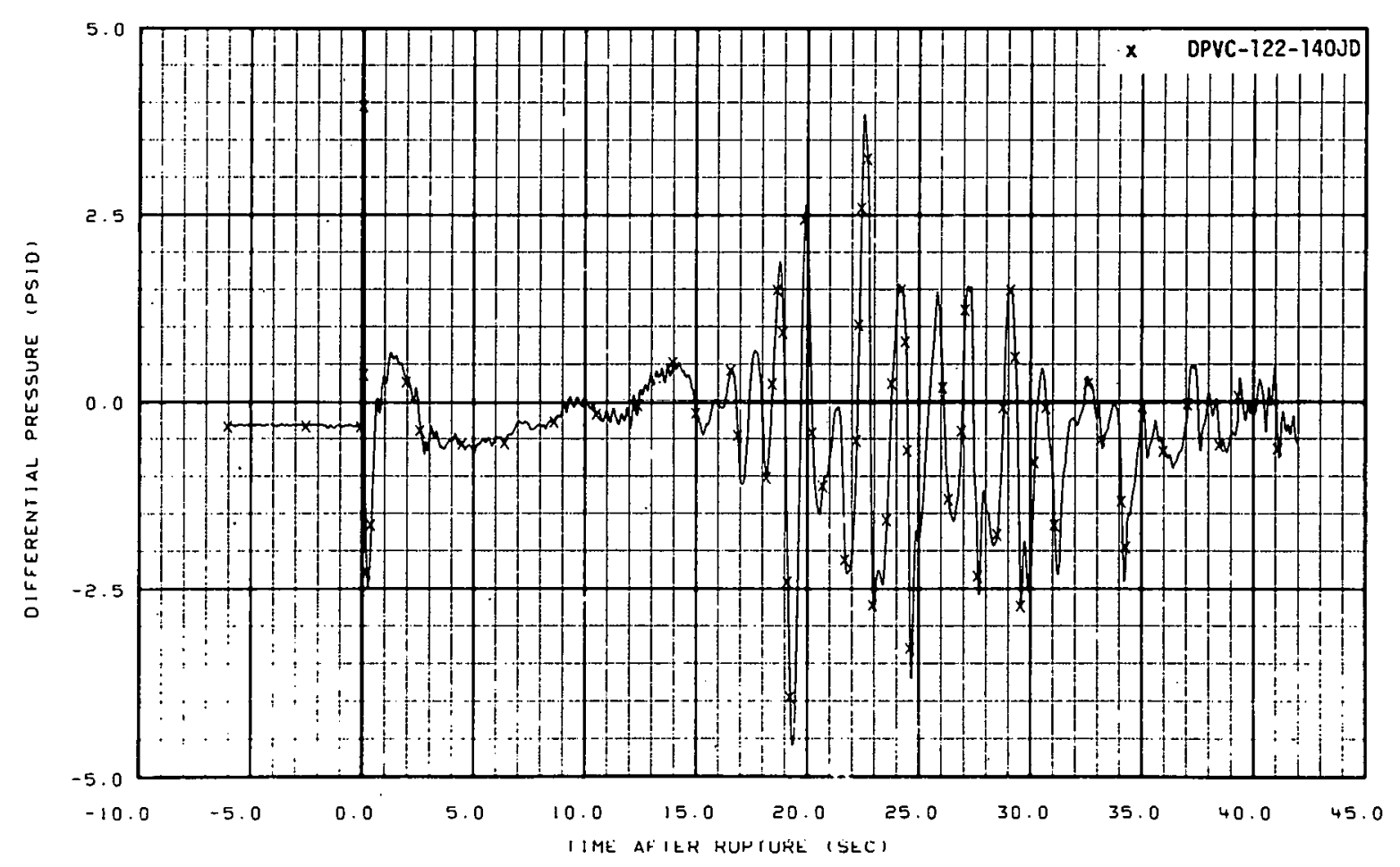

Fig. 212 Differential pressure in vessel core (DPVC-122-140JD), from -6 to 42 seconds. 


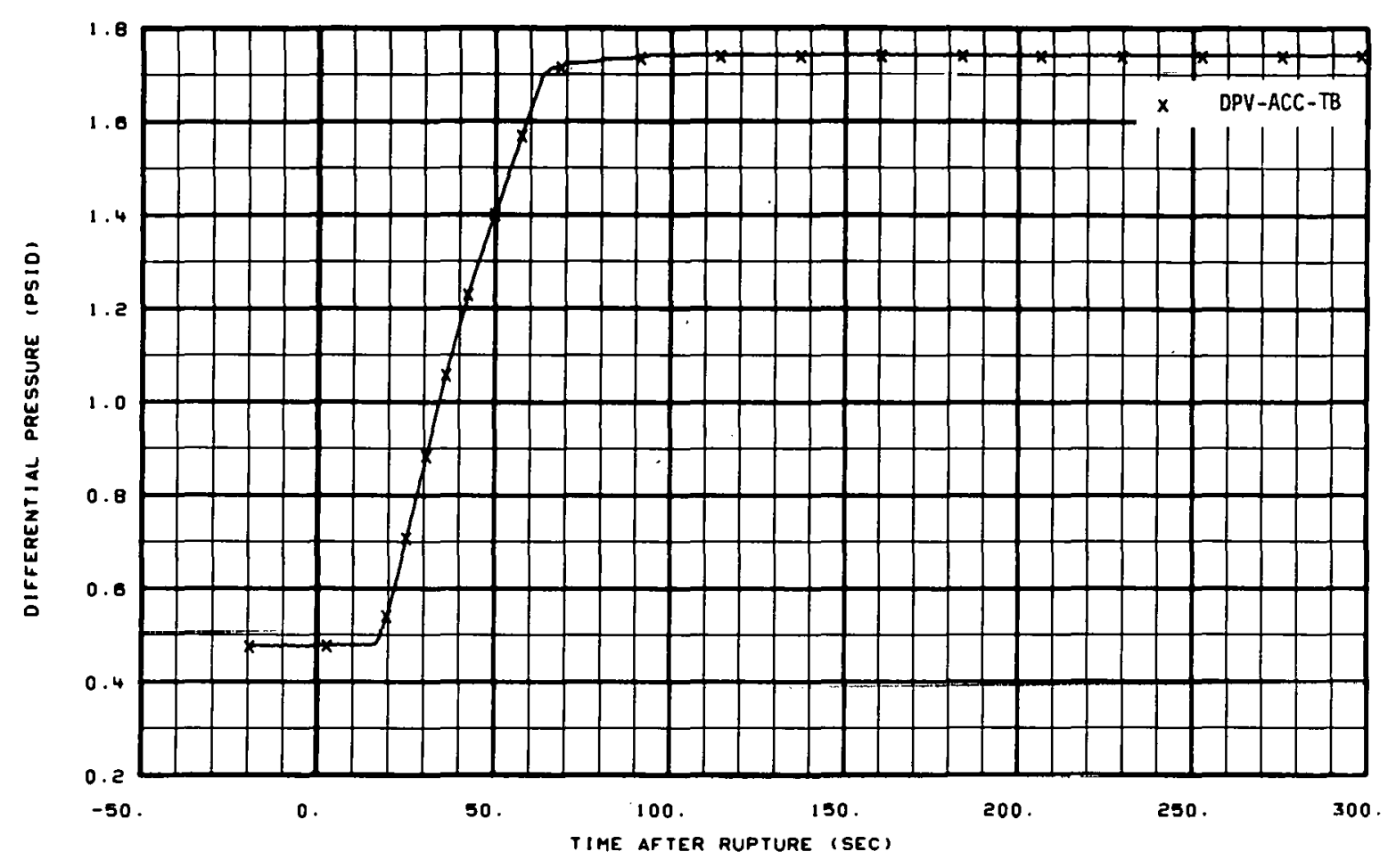

Fig. 213 Differential pressure in vessel accumulator (DPV-ACC-TB), from -20 to 300 seconds.

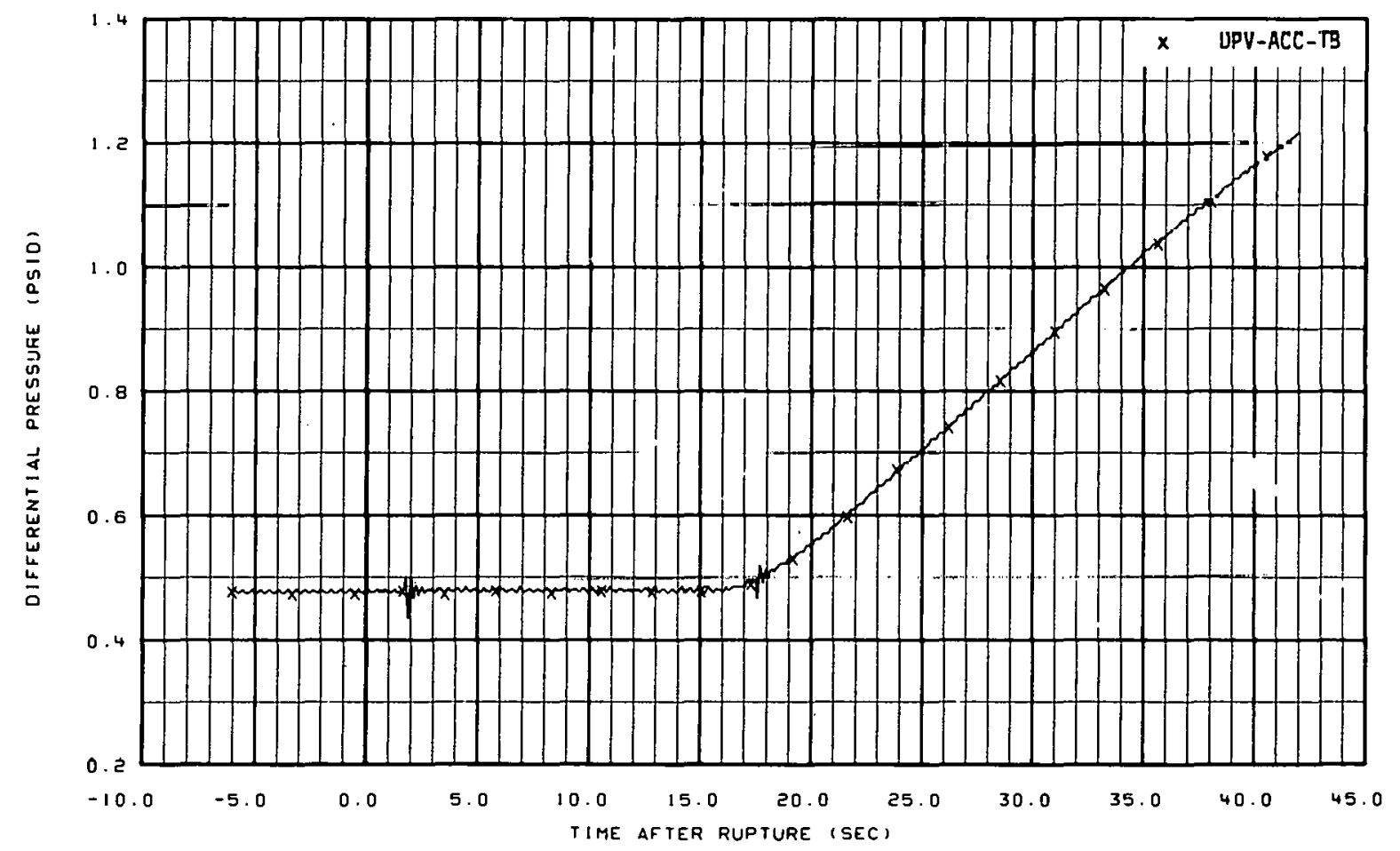

Fig. 214 Differential pressure in vessel accumulator (DPV-ACC-TB), from -6 to 42 seconds. 


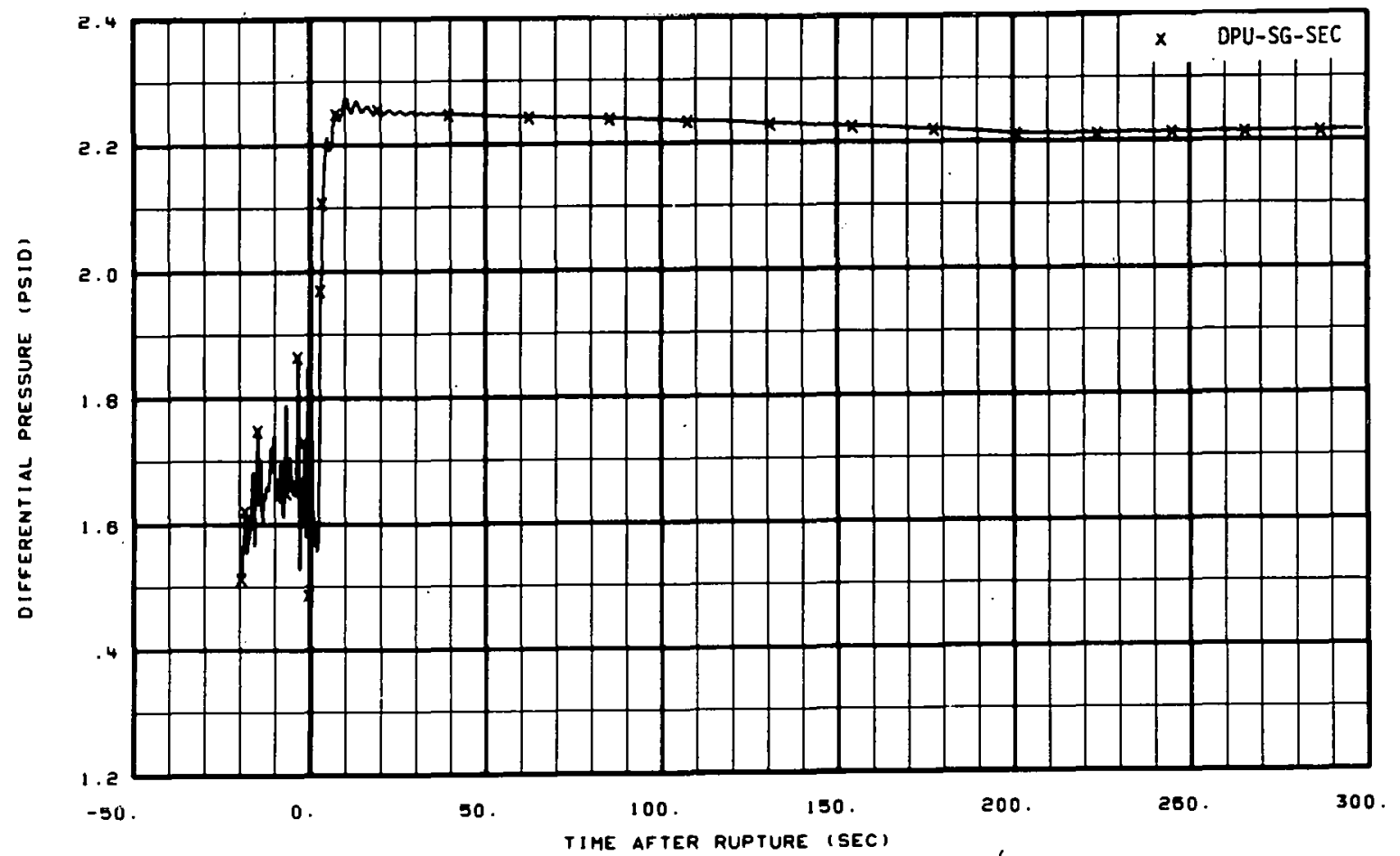

Fig. 215 Differential pressure in steam generator secondary (DPU-SG-SEC), from -20 to 300 seconds.

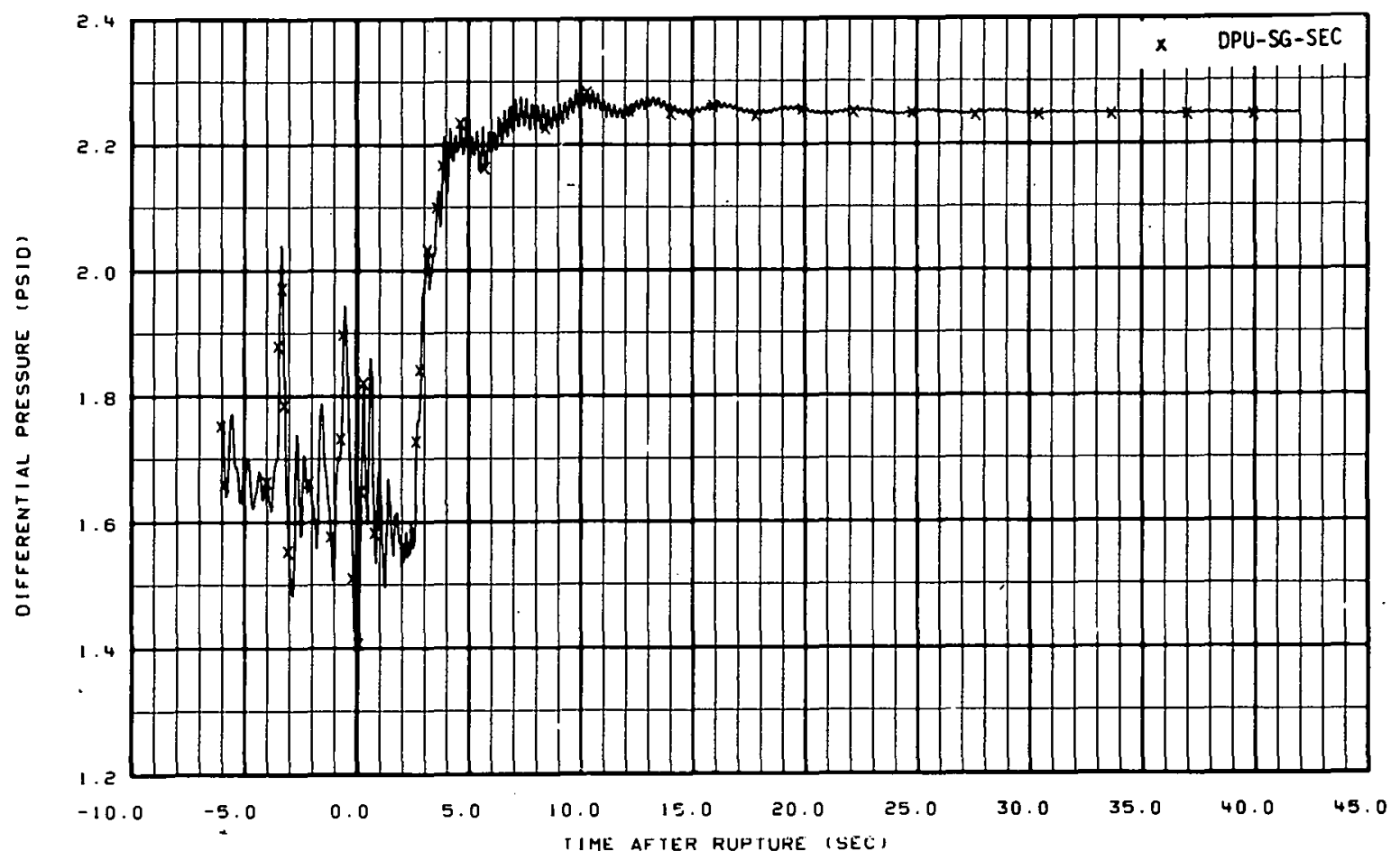

Fig. 216 Differential pressure in steam generator secondary (DPU-SG-SEC), from -6 to 42 seconds. 


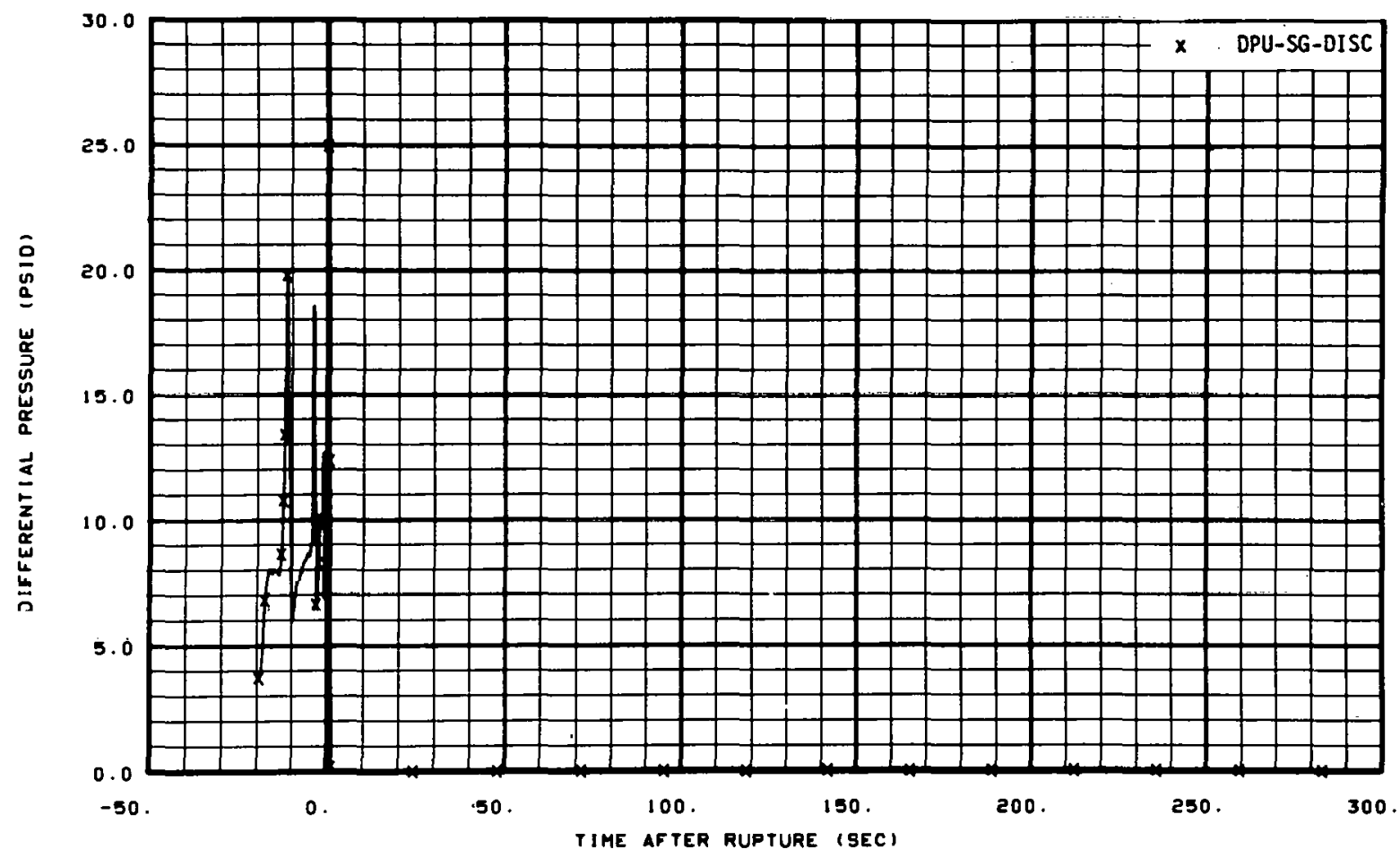

Fig. 217 Differential pressure across steam generator outlet orifice (DPU-SG-DISC), from -20 to 300 seconds.

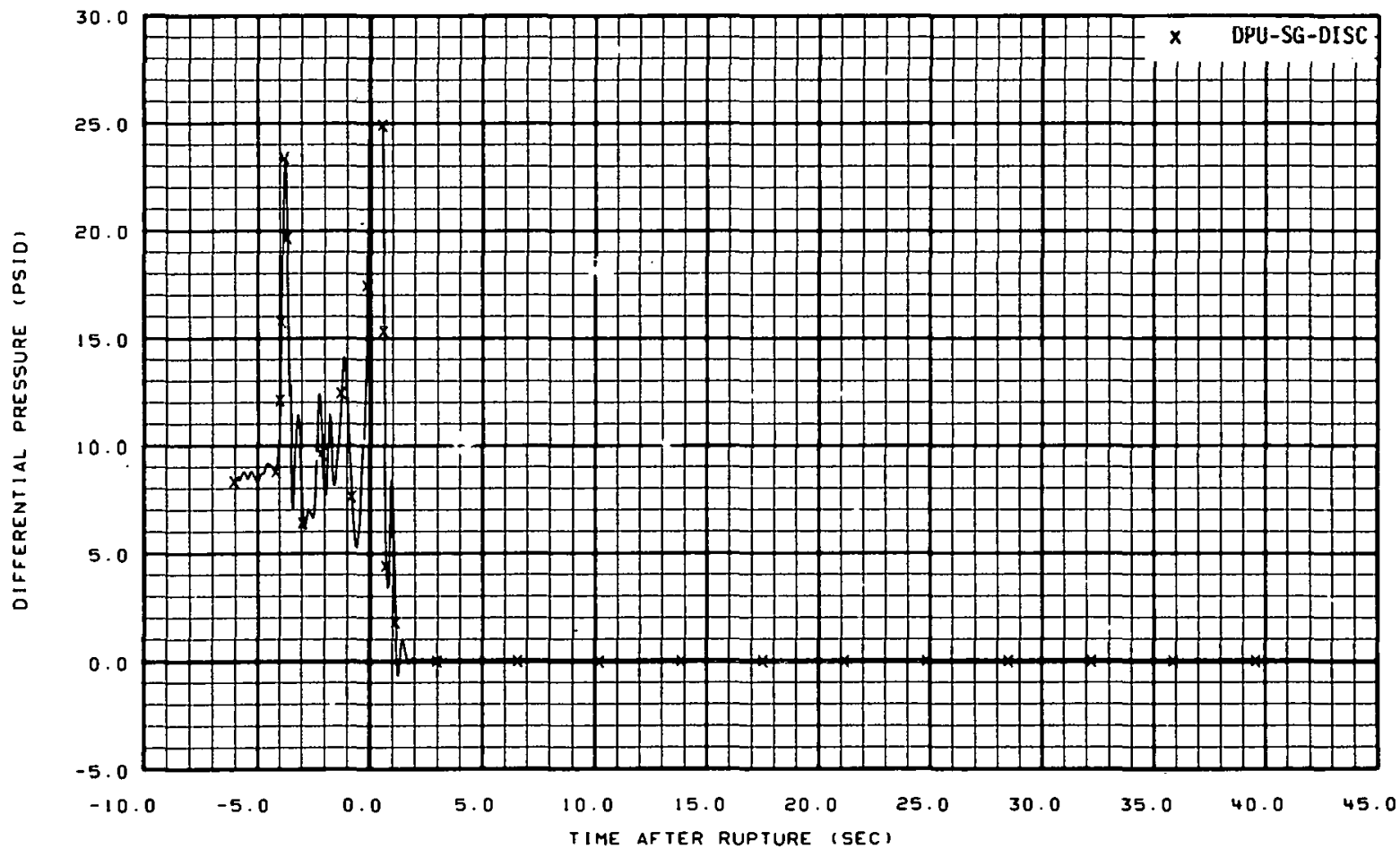

Fig. 218 Differential pressure across steam generator outlet orifice (DPU-S( 1 -DISC), from -6 to 42 seconds. 


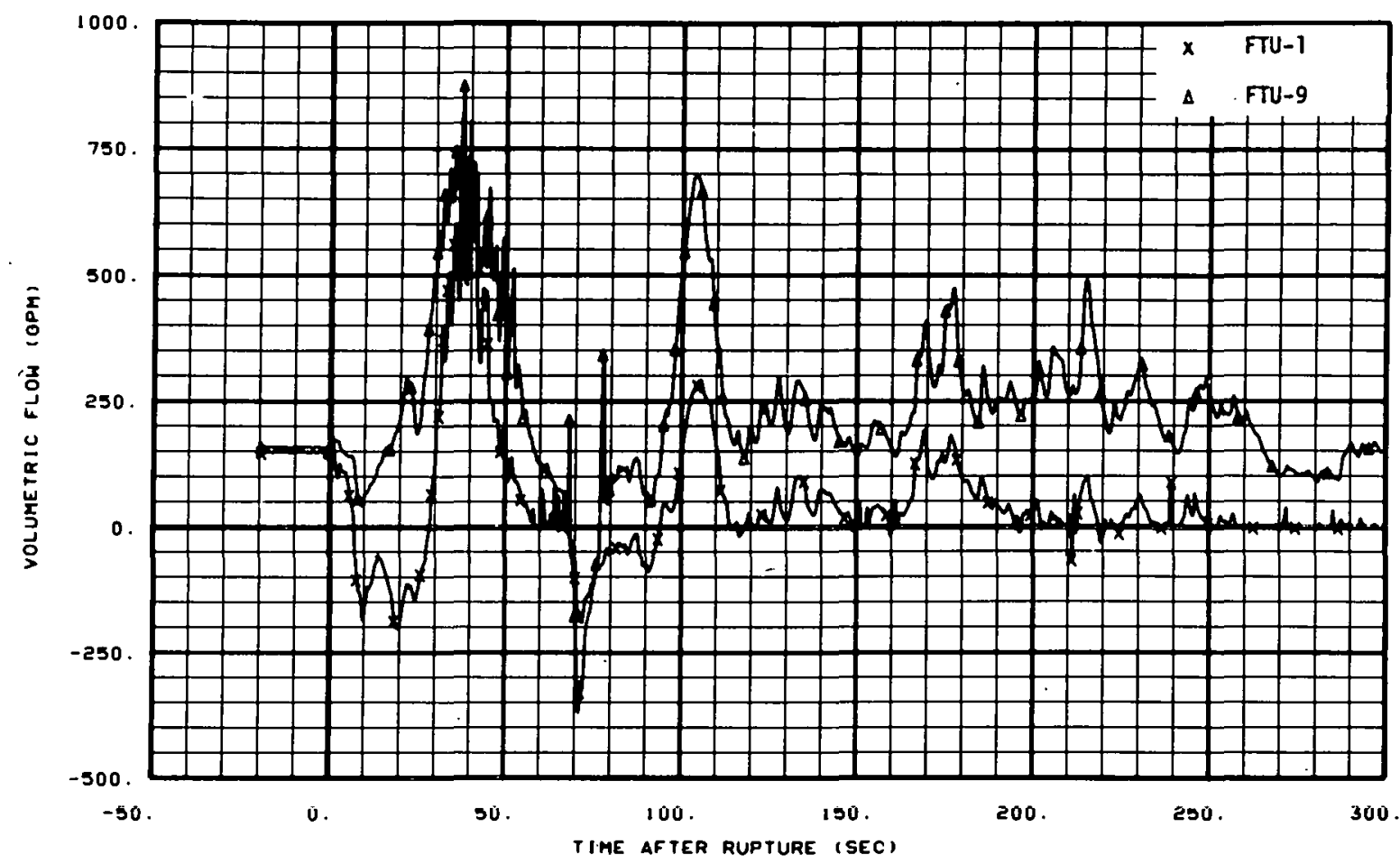

Fig. 219 Vol umetric flow in intact loop (FTU-1 and FTU-9), from -20 to 300 seconds.

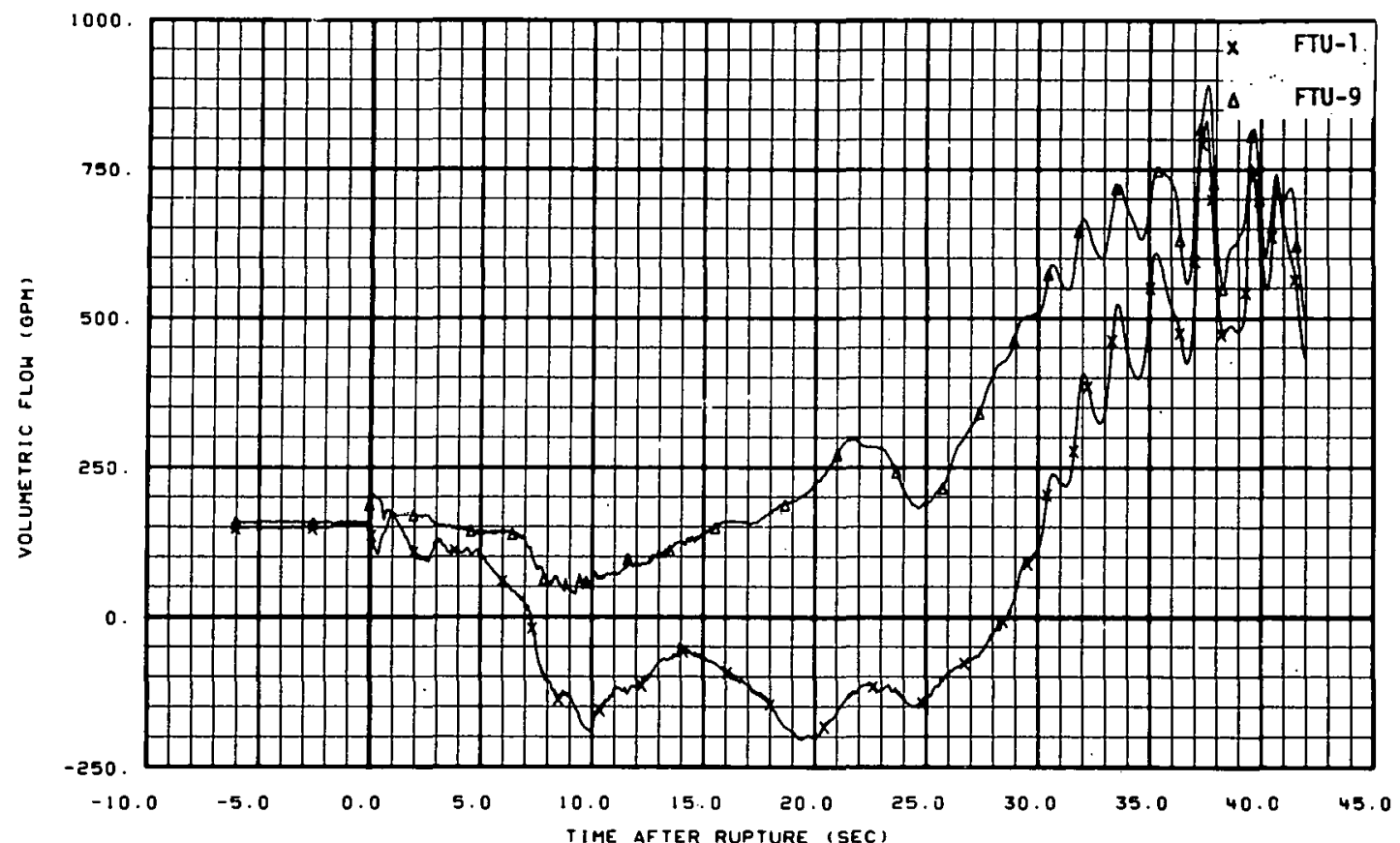

Fig. 220 Volumetric flow in intact loop (FTU- 1 and FTU-9), from -6 to 42 seconds. 


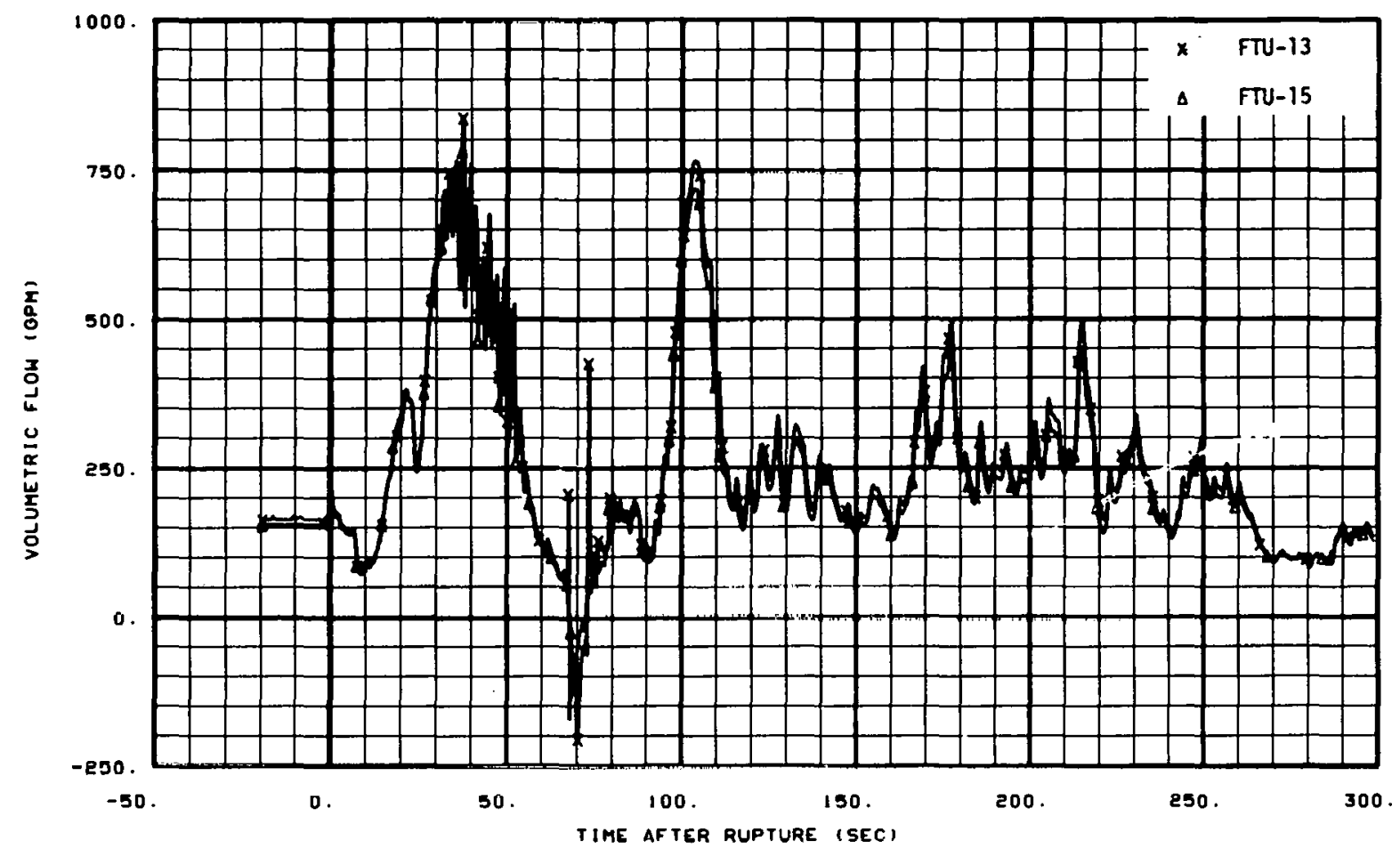

Fig. 221 Volumetric flow in intact loop (FTU-13 and FTU-15), from -20 to 300 seconds.

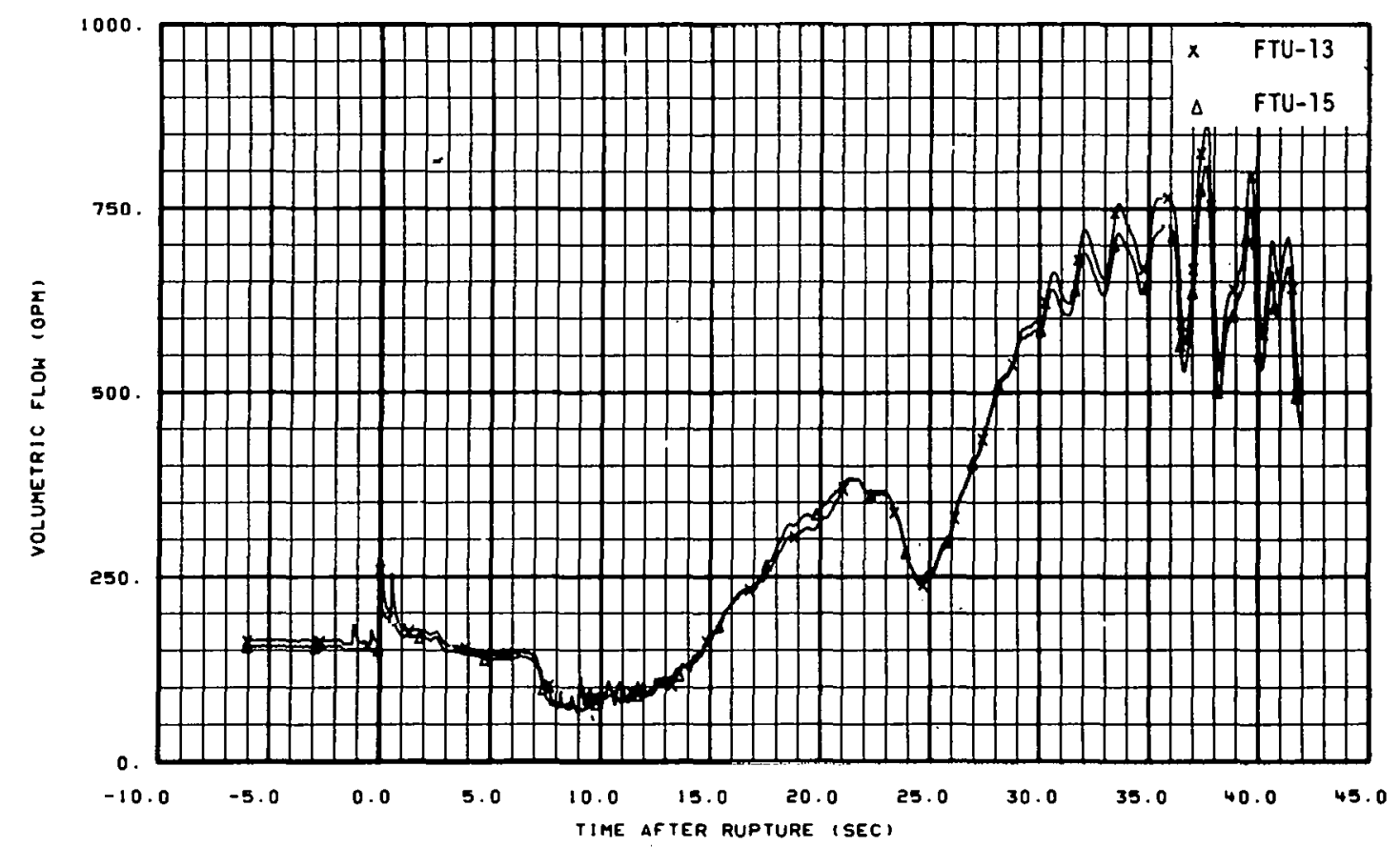

Fig. 222 Volumetric flow in intact loop (FTU-13 and FTU-15), from -6 to 42 seconds. 


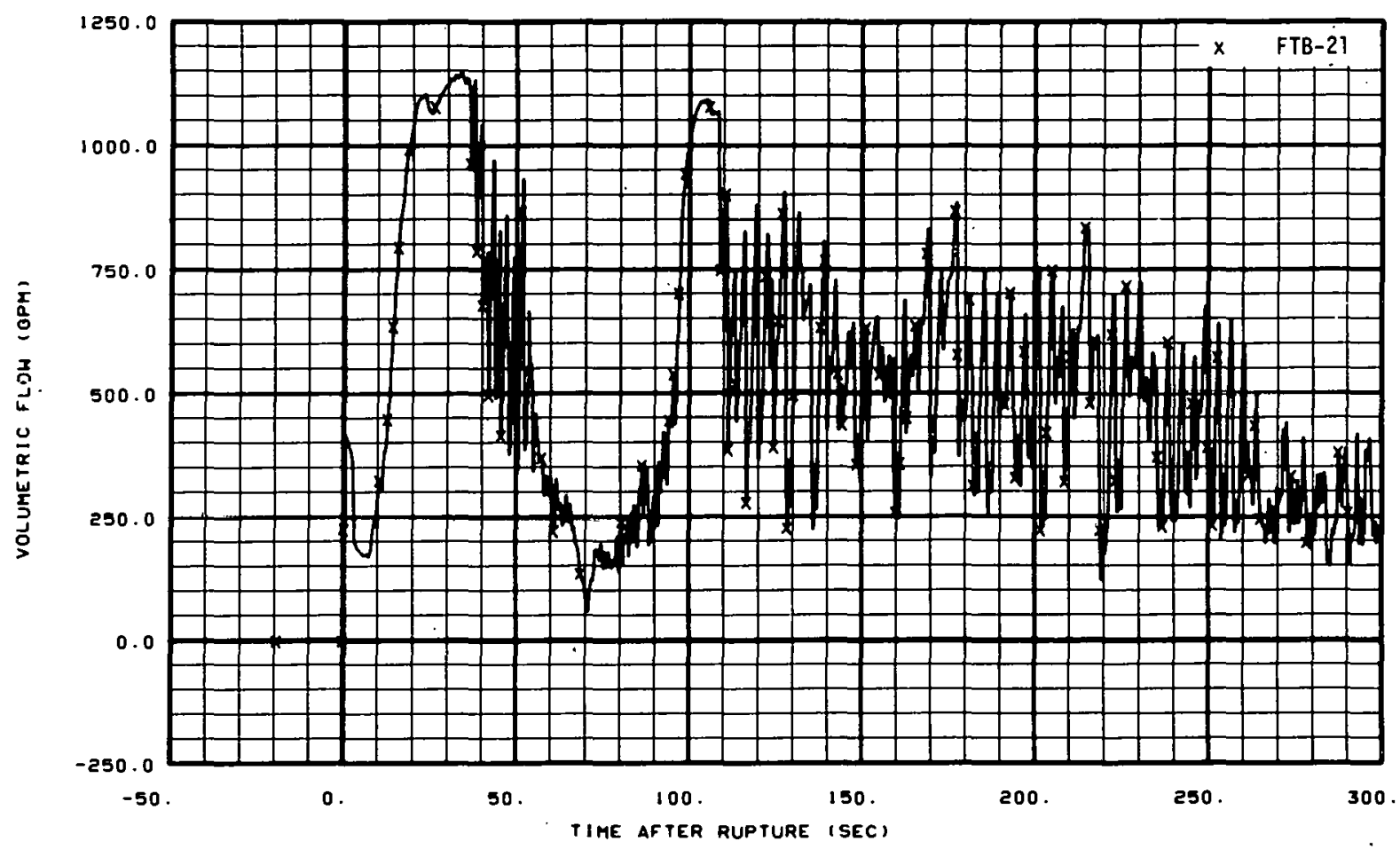

Fig. 223 Volumetric flow in broken loop (FTB-21), from -20 to 300 seconds.

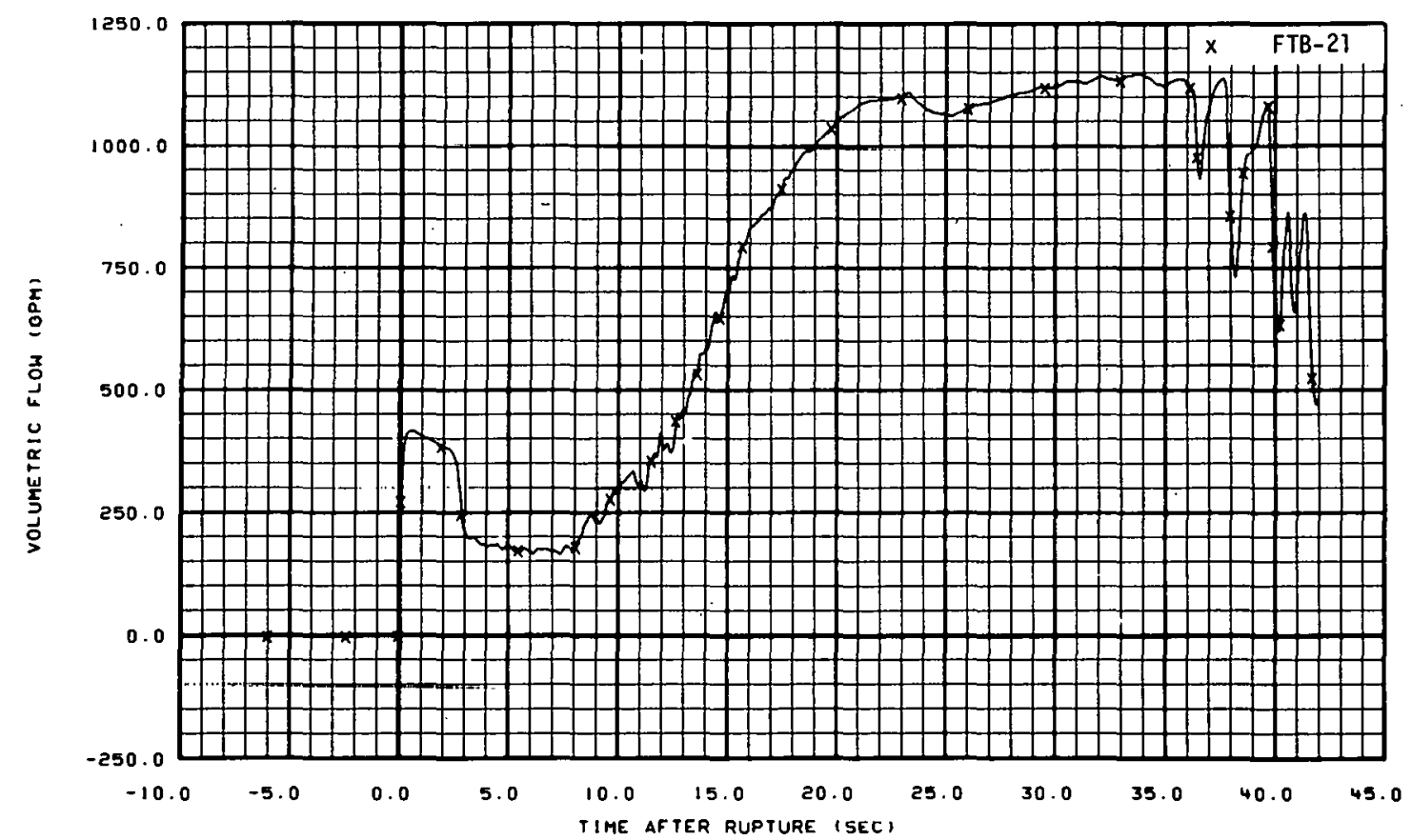

Fig. 224 Volumetric flow in broken loop (FTB-21), from -6 to 42 seconds. 


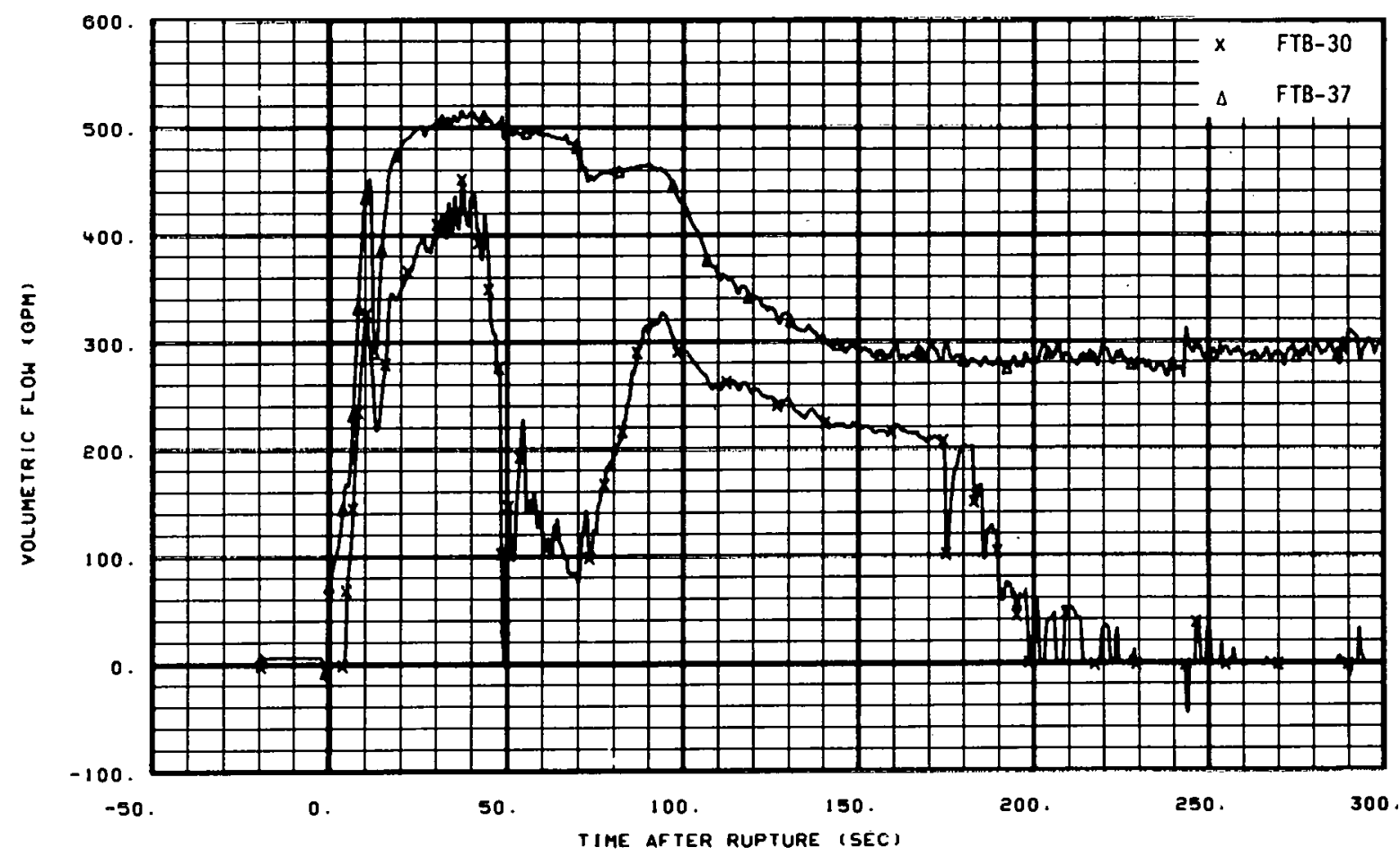

Fig. 225 Volumetric flow in broken loop (FTB-30 and FTB-37), from -20 to 300 seconds.

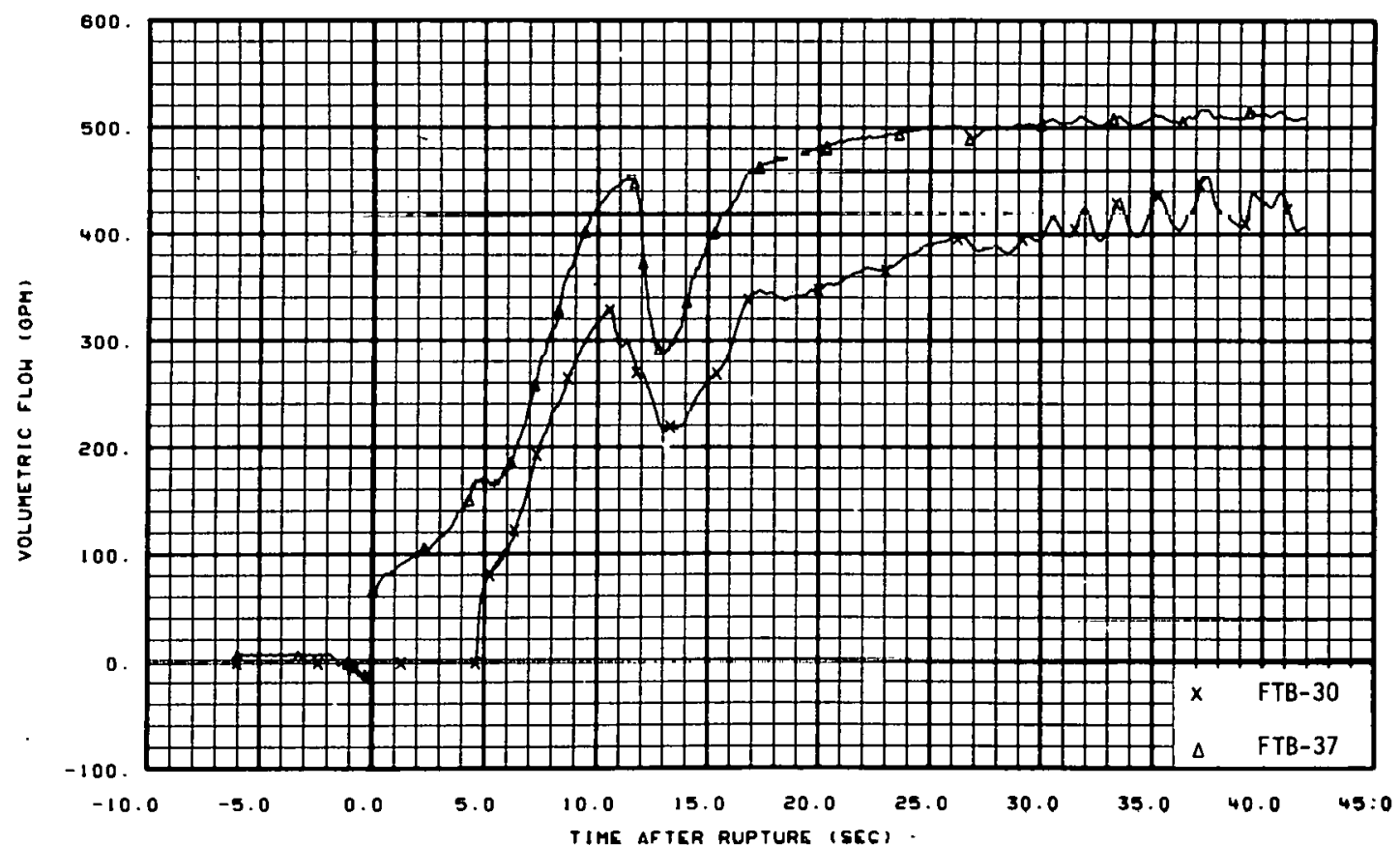

Fig. 226 Volumetric flow in broken loop (FTB-30 and FTB-37), from -6 to 42 seconds. 


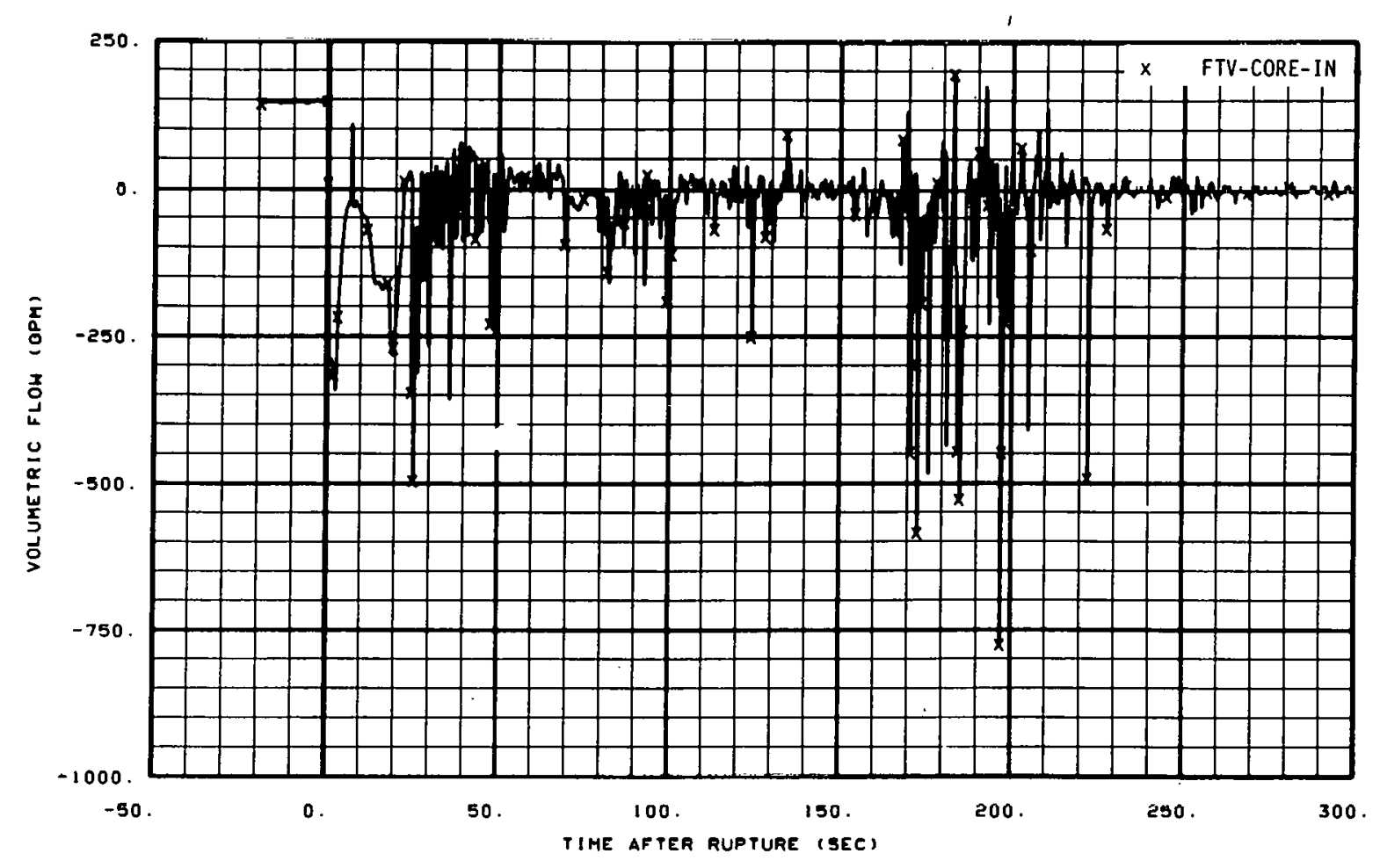

Fig. 227 Volumetric flow in core entrance (FTV-CORE-IN), from -20 to 300 seconds.

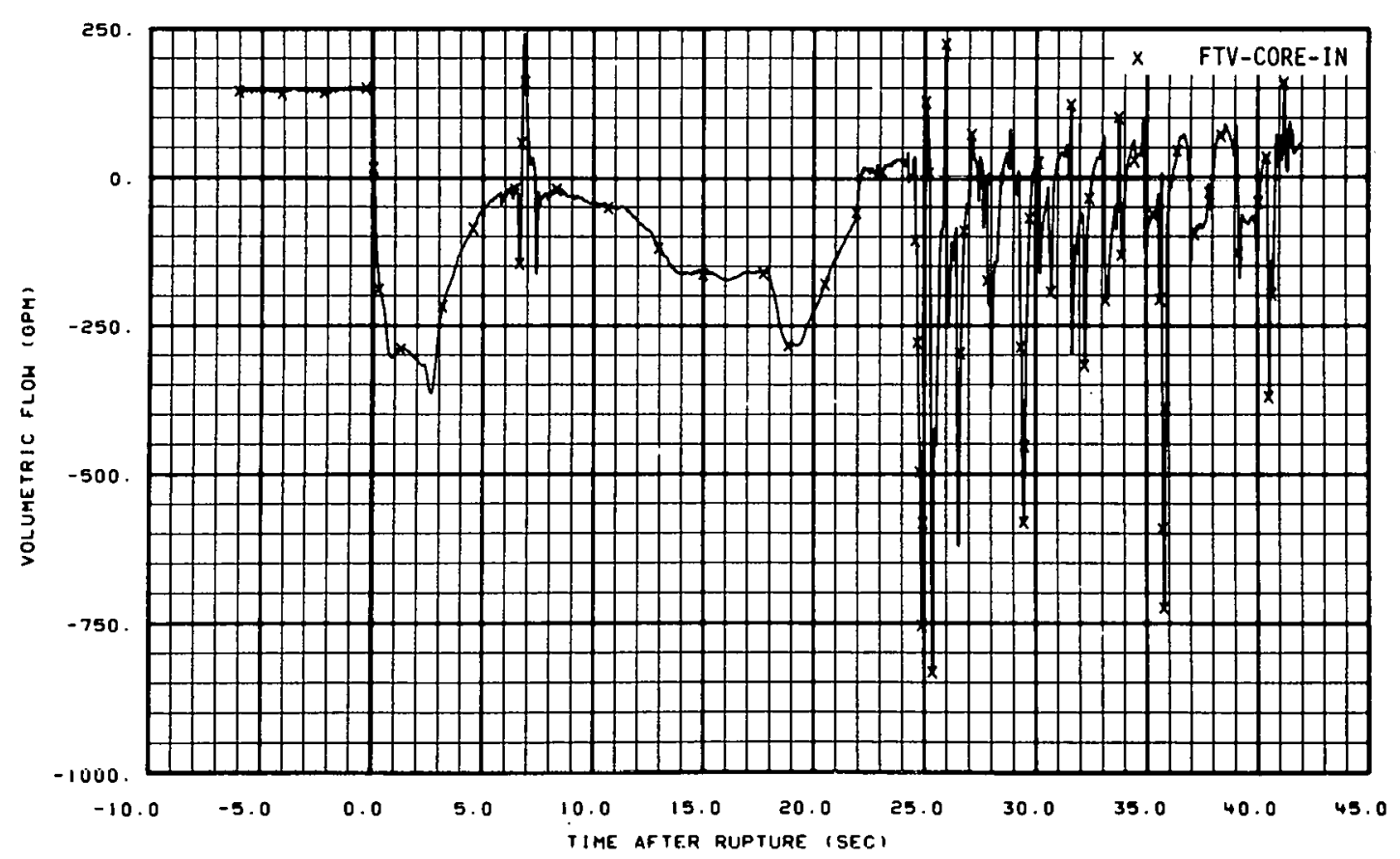

Fig. 228 Volumetric flow in core entrance (FTV-CORE-IN), from -6 to 42 seconds. 


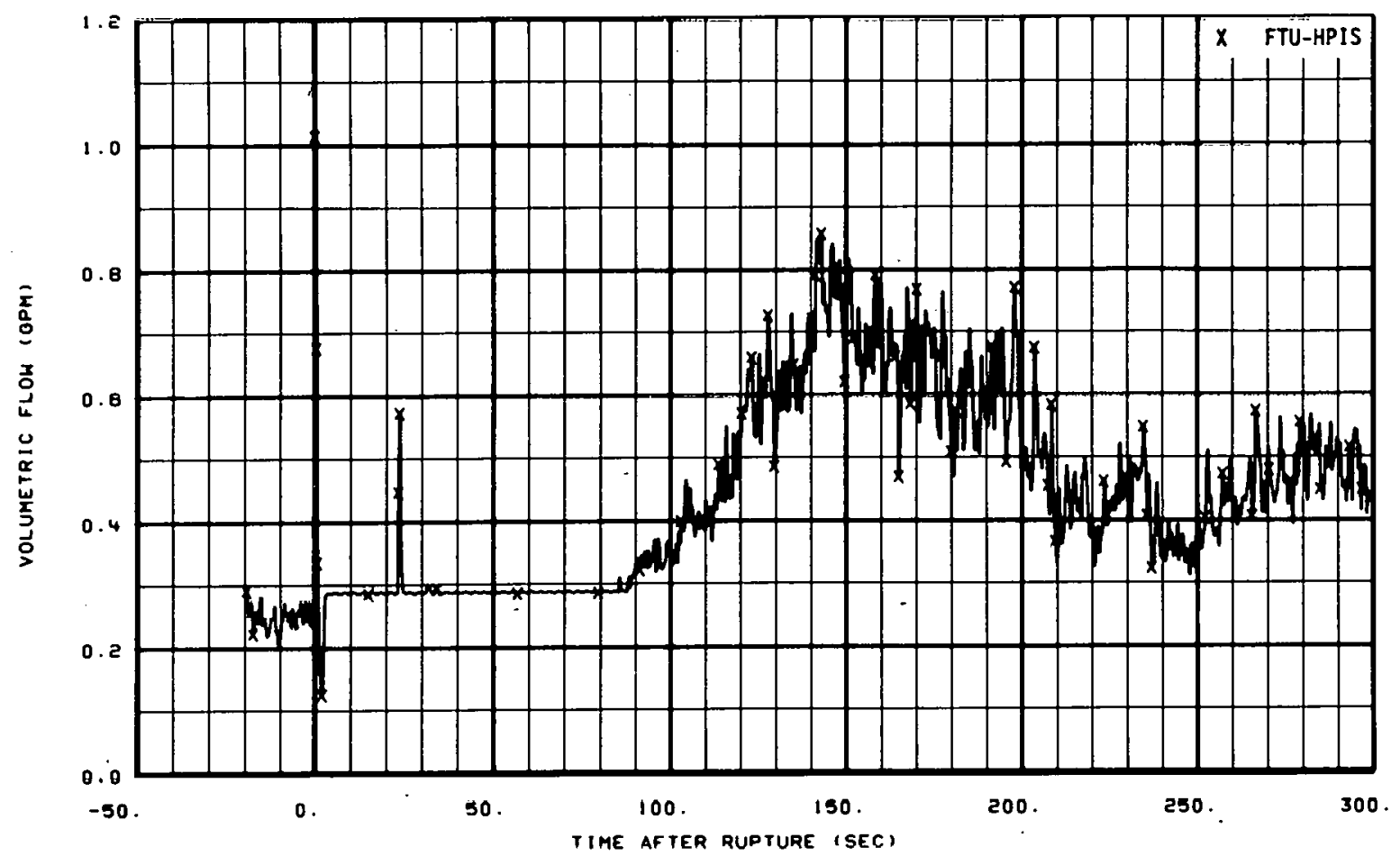

Fig. 229 Volumetric flow in intact loop high pressure injection line, to vessel (FTU-HPIS), from -20 to 300 seconds.

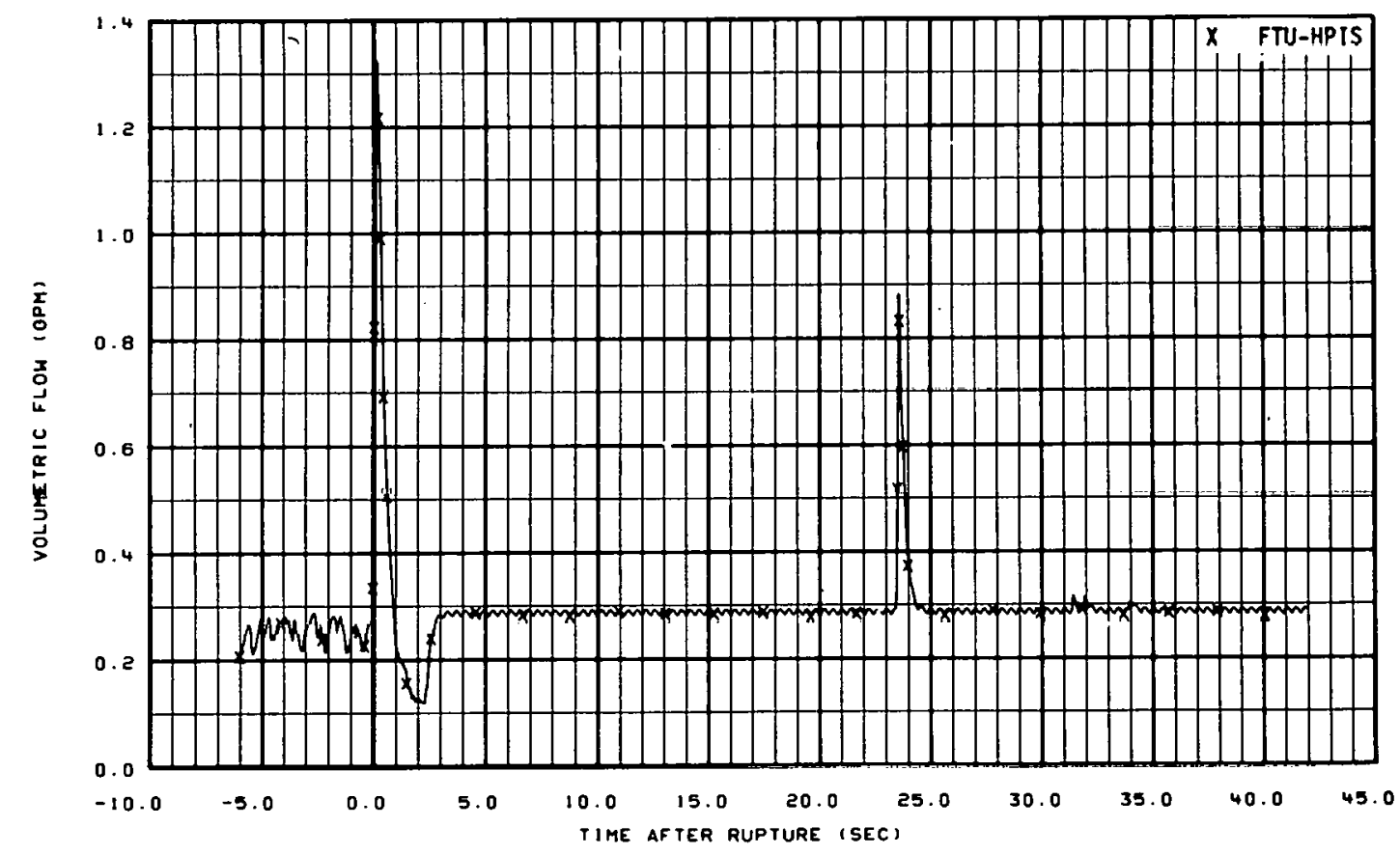

Fig. 230 Volumetric flow in intact loop high pressure injection line, to vessel (FTU-HPIS), from -6 to 42 seocnds. 


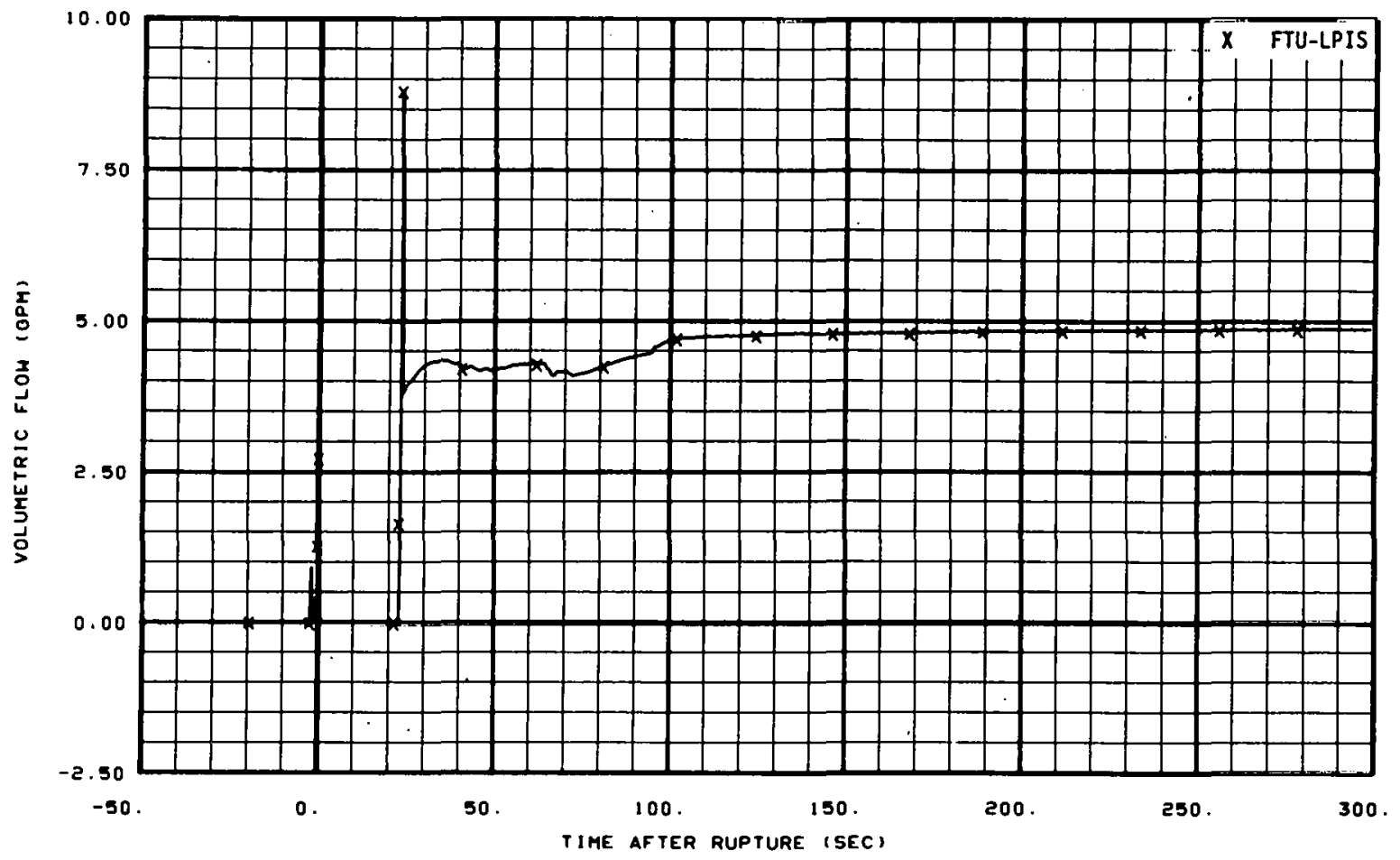

Fig. 231 Volumetric flow in intact loop low pressure injection line, to vessel (FTU-LPIS), from -20 to 300 seconds

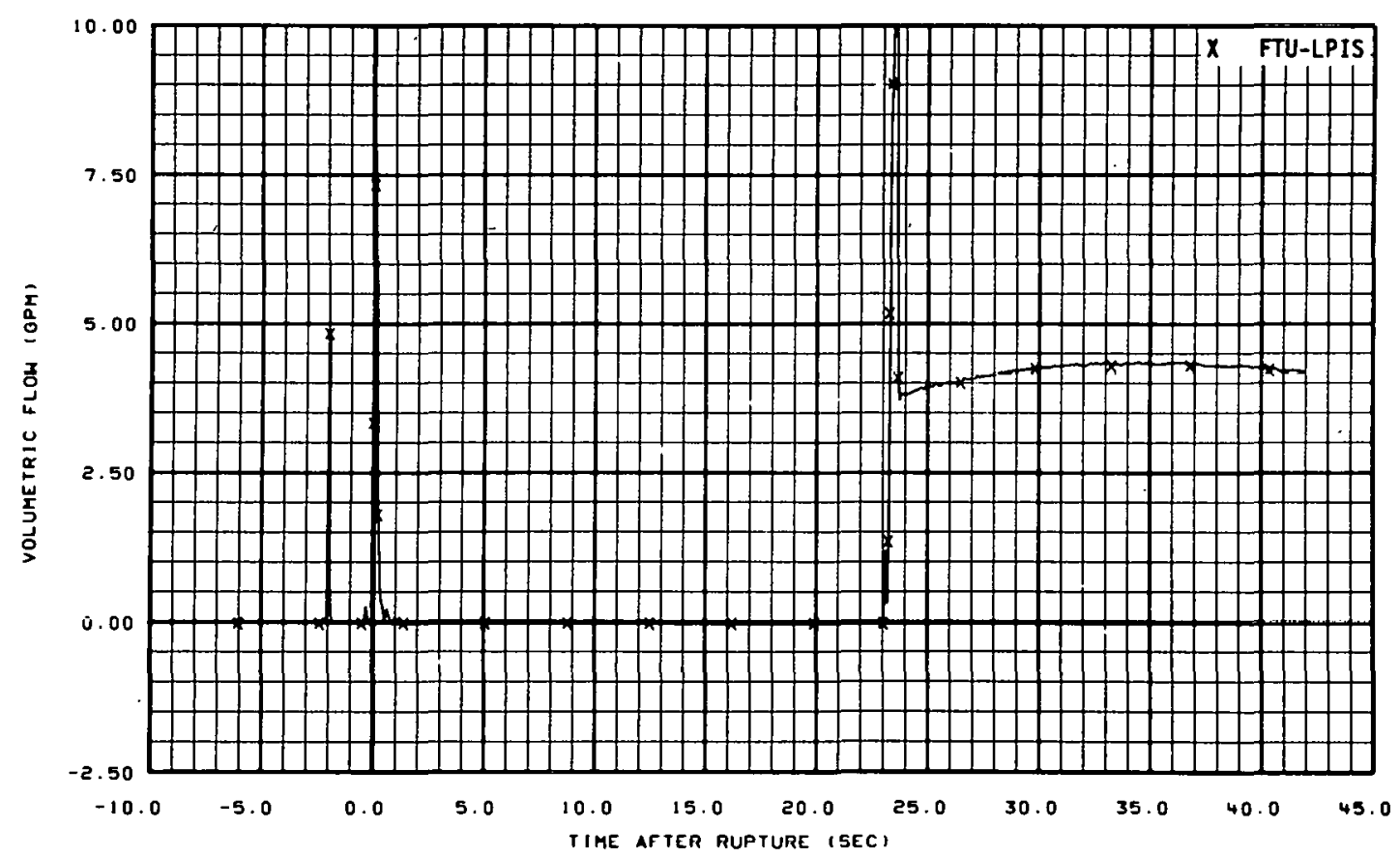

Fig. 232 Volumetric flow in intact loop low pressure injection line, to vessel (FTU-LPIS), from -6 to 42 seconds. 


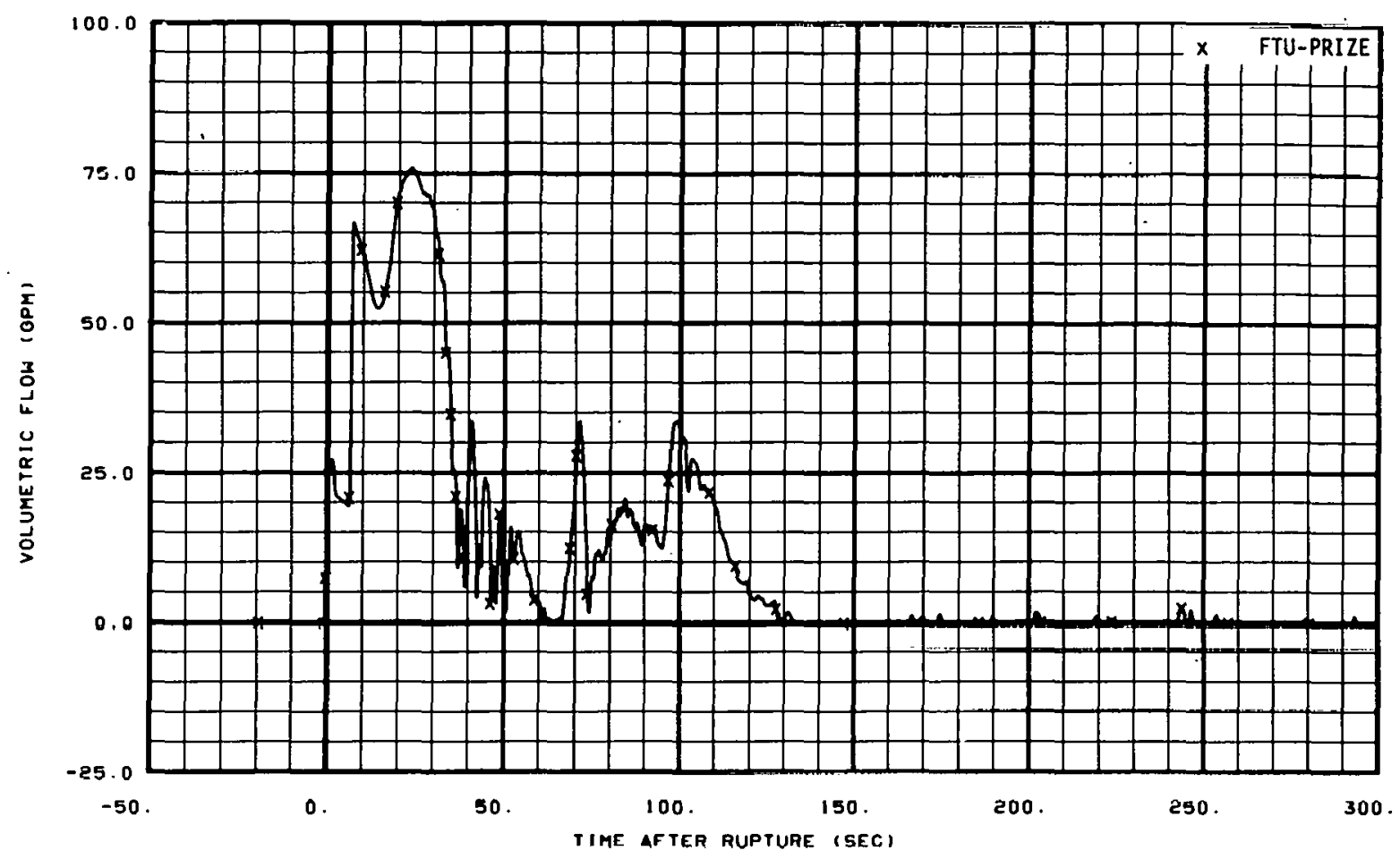

Fig. 233 Volumetric flow from pressurizer (FTU-PRIZE), from -20 to 300 seconds.

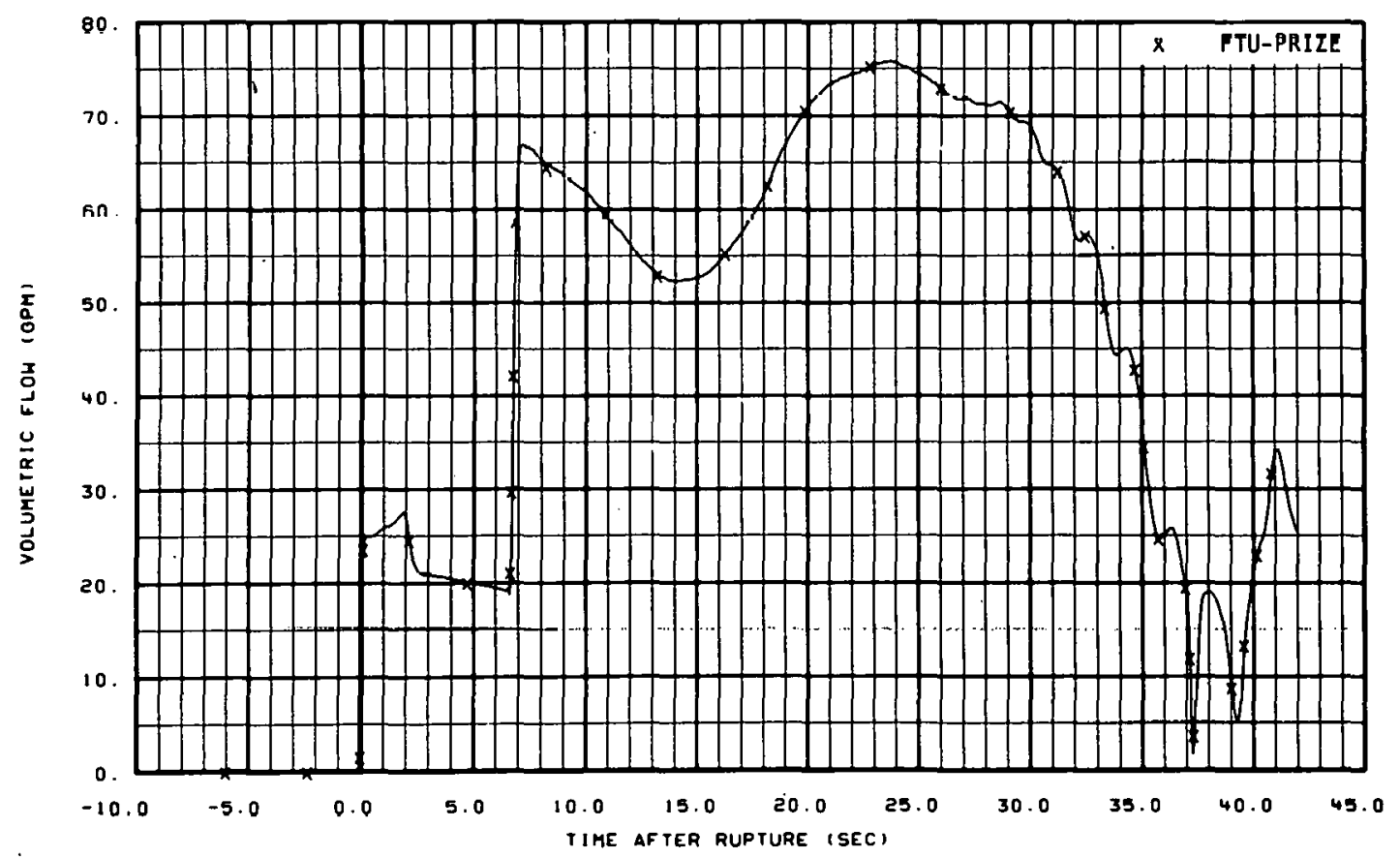

Fig. 234 Volumetric flow from pressurizer (FTU-PRIZE), from -6 to 42 seconds. 


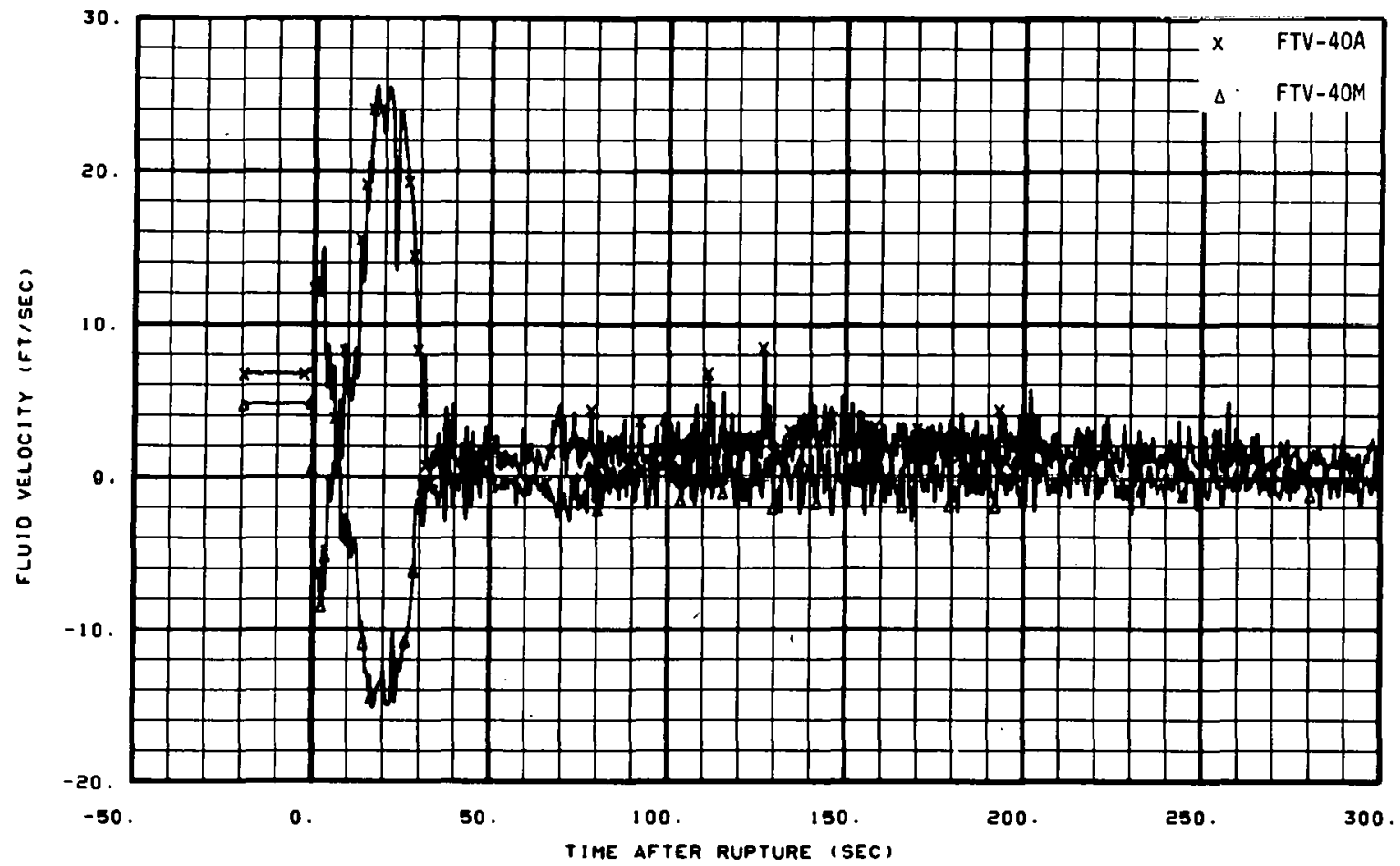

Fig. 235 Fluid velocity in vessel (FTV-40A and FTV-40M), from -20 to 300 seconds.

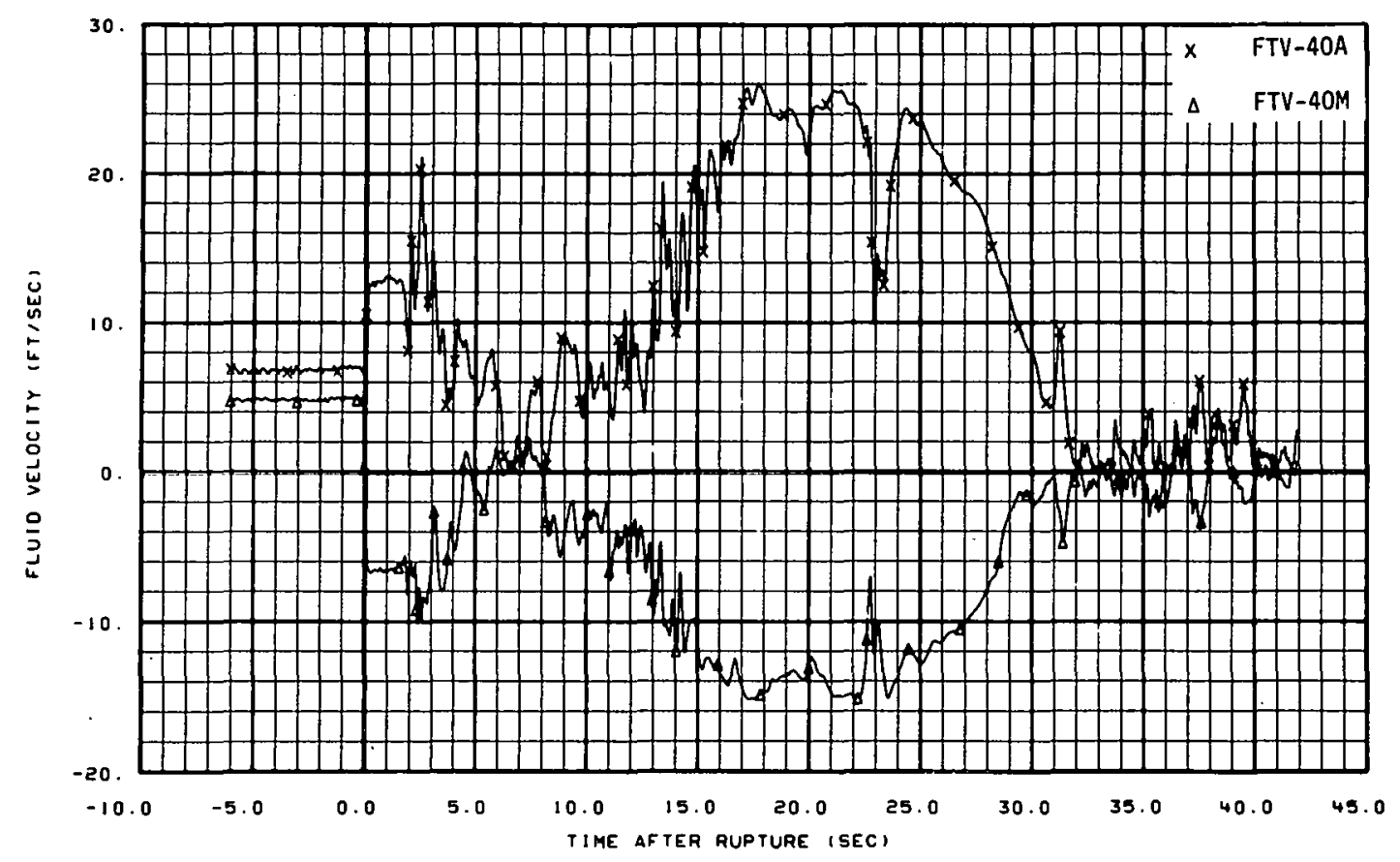

Fig. 236 Fluid velocity in vessel (FTV-40A and FTV-4014), from -6 to 42 seconds. 


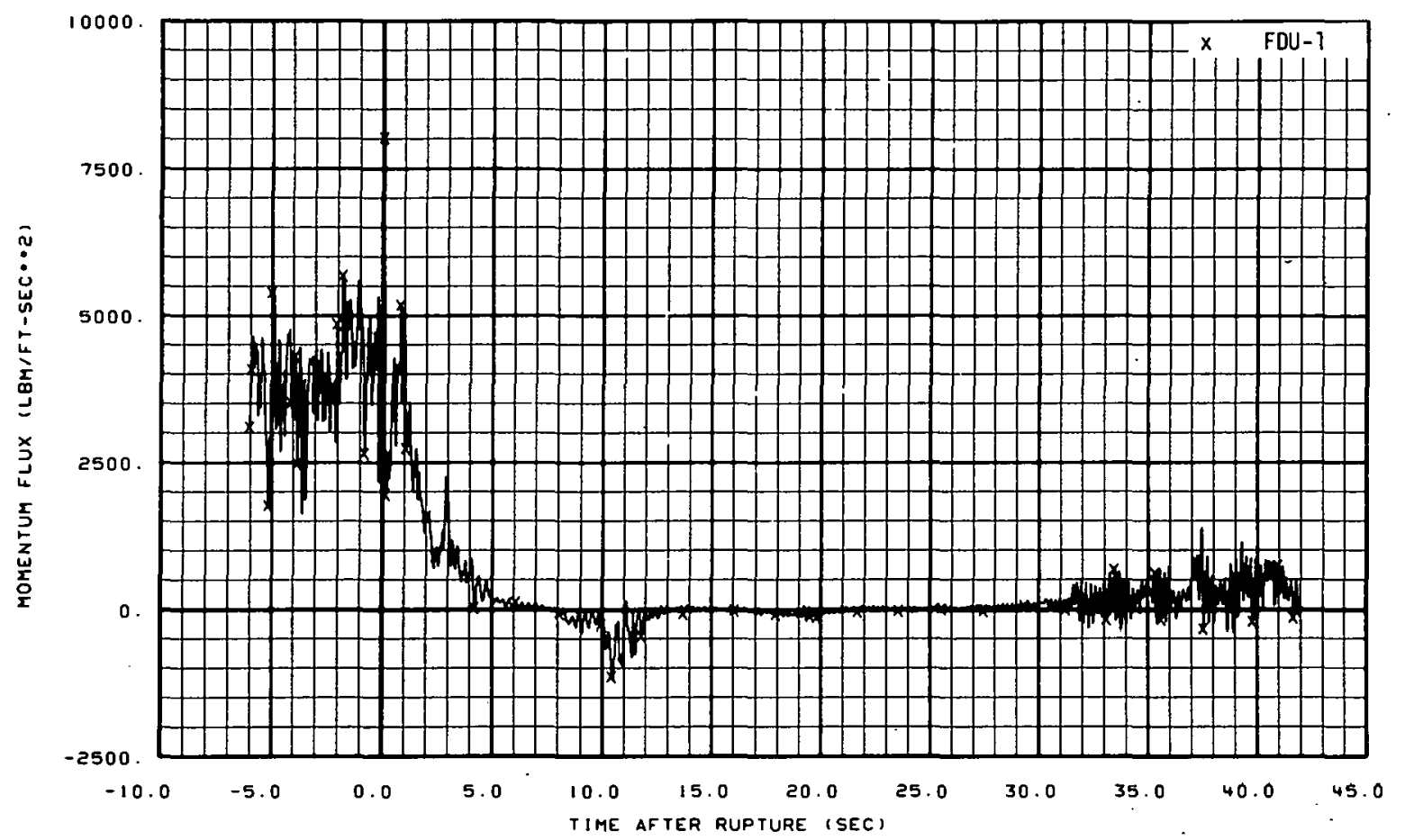

Fig. 237 Momentum flux in intact lópp (FDU-1), from -6 to 42 seconds.

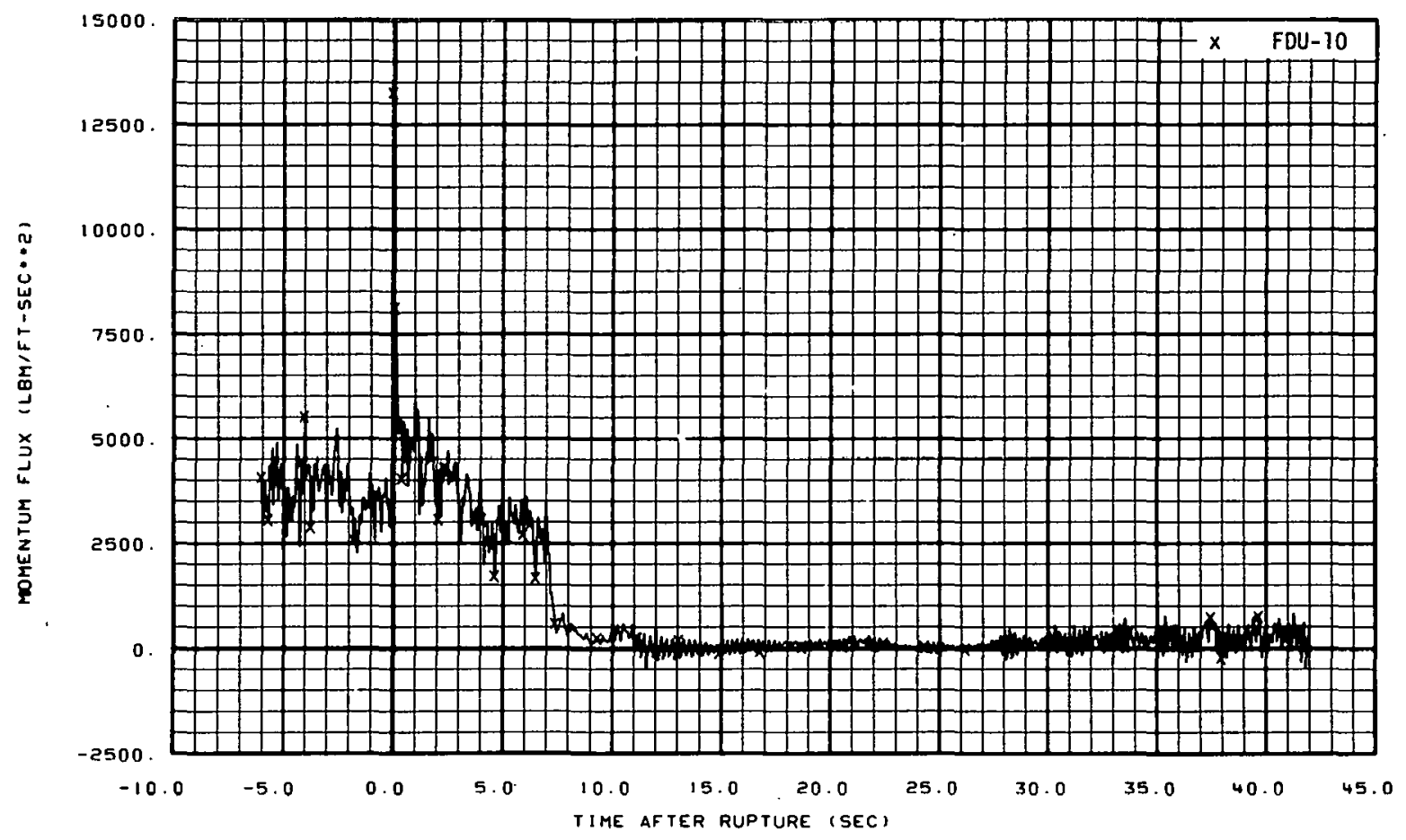

Fig. 238 Momentum flux in intact loop (FDU-10), from -6 to 42 seconds. 


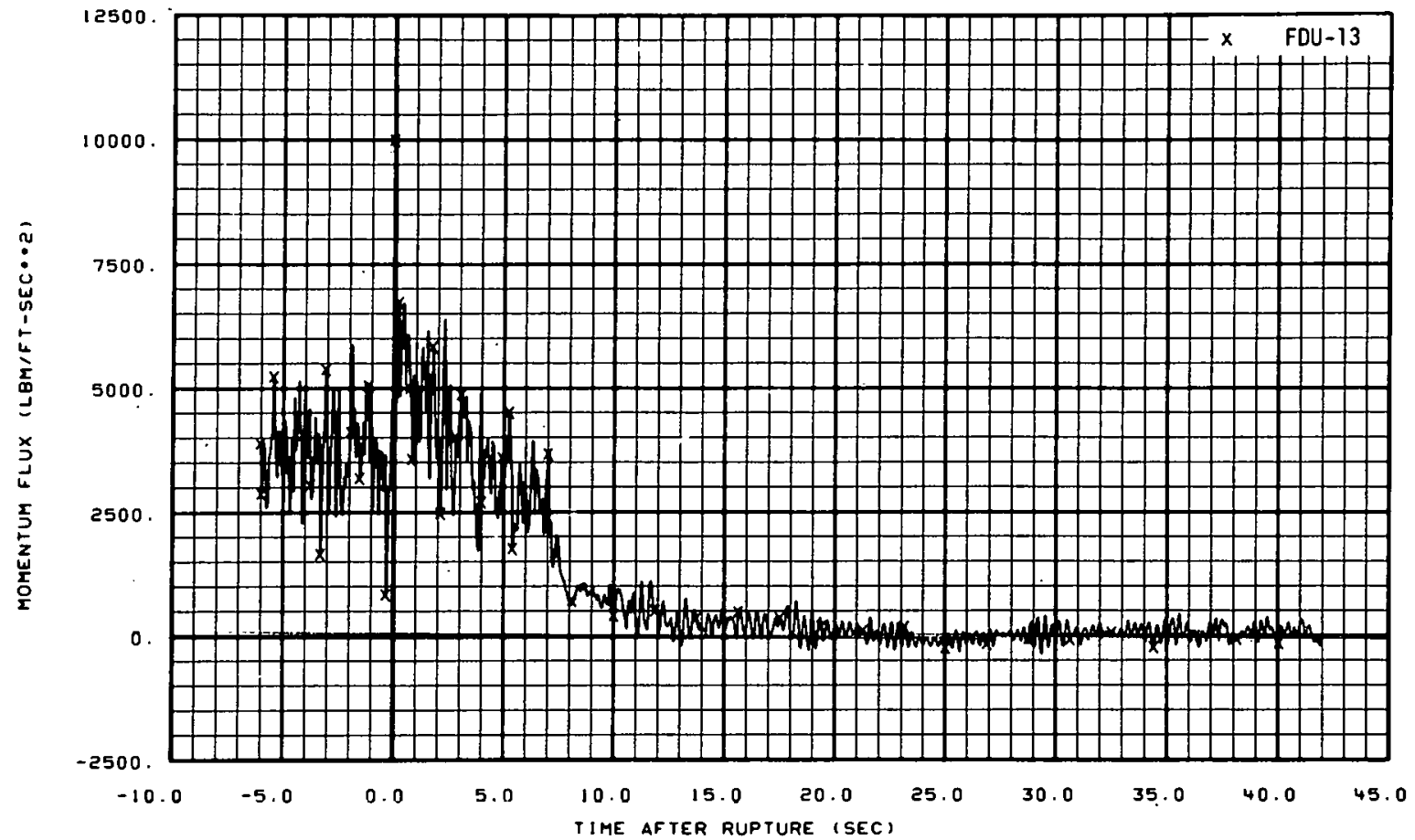

Fig. 239 Momentum flux in intact loiop (FDU-13), from -6 to 42 seconds.

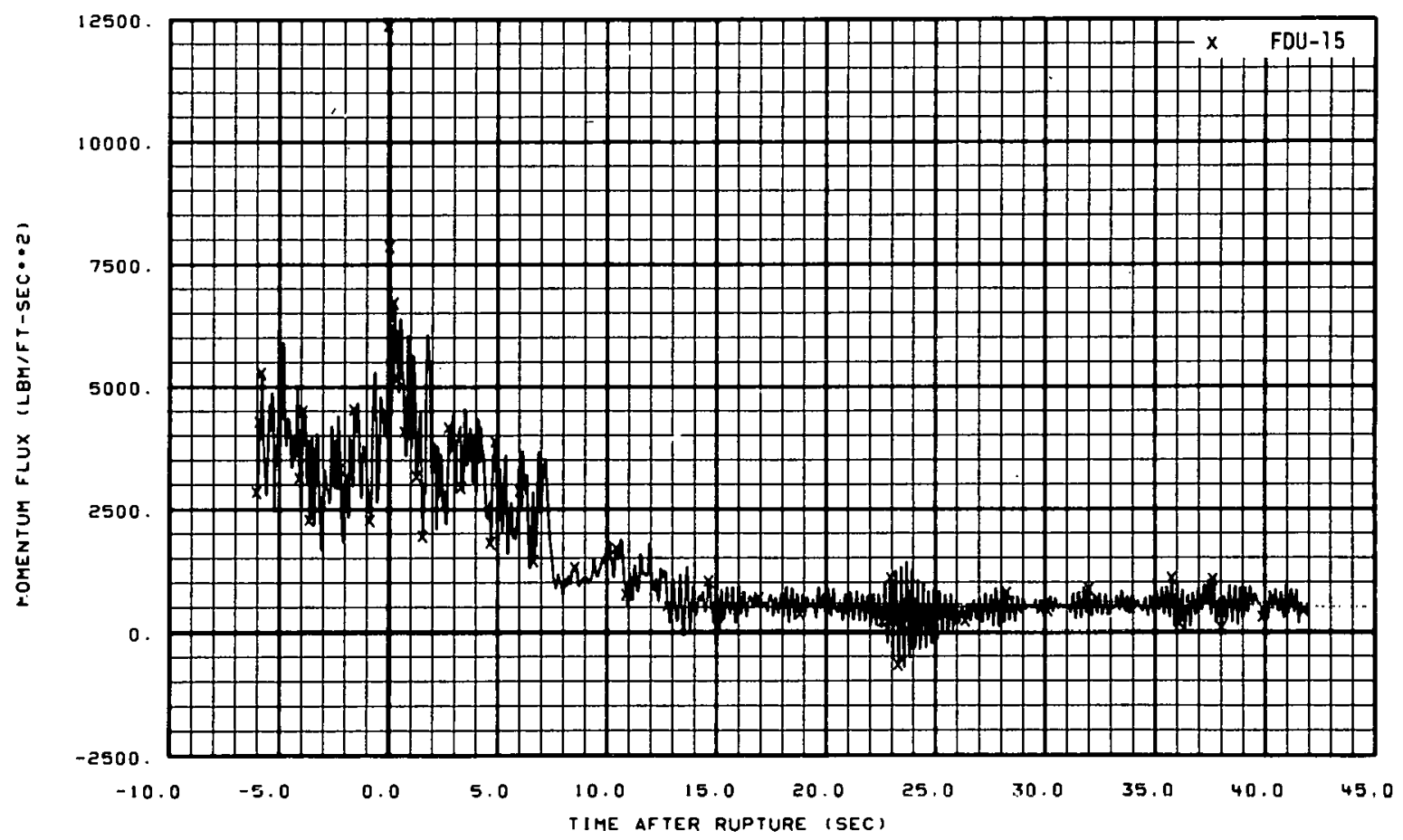

Fig. 240 Momentum flux in intact loop (FDU-75), from -6 to 42 seconds. 


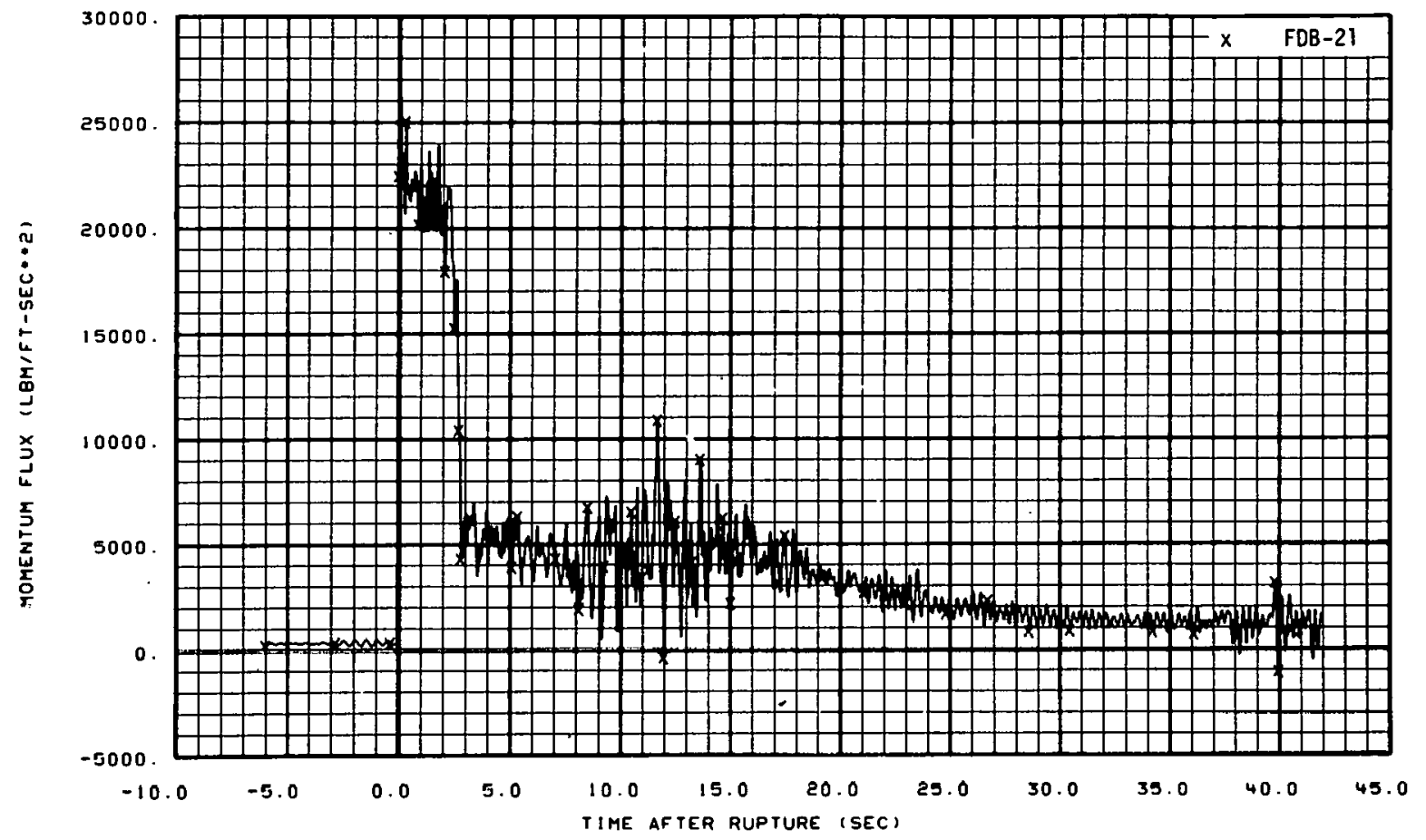

Fig. 241 Momentum f1ux in broken loop (FDB-21), from -6 to 42 seconds.

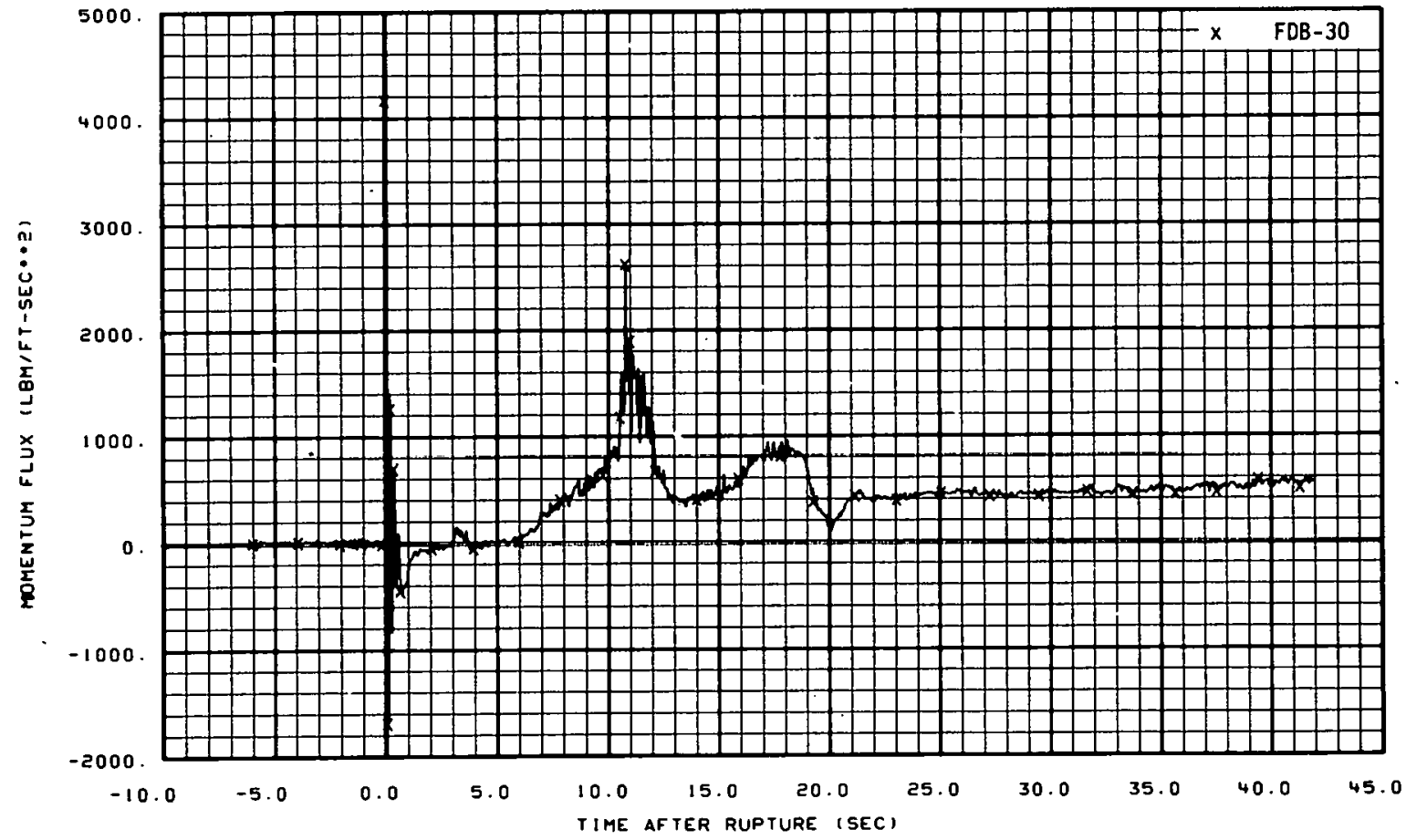

Fig. 242 Momentum flux in broken loop (FDB-30), from -6 to 42 seconds. 


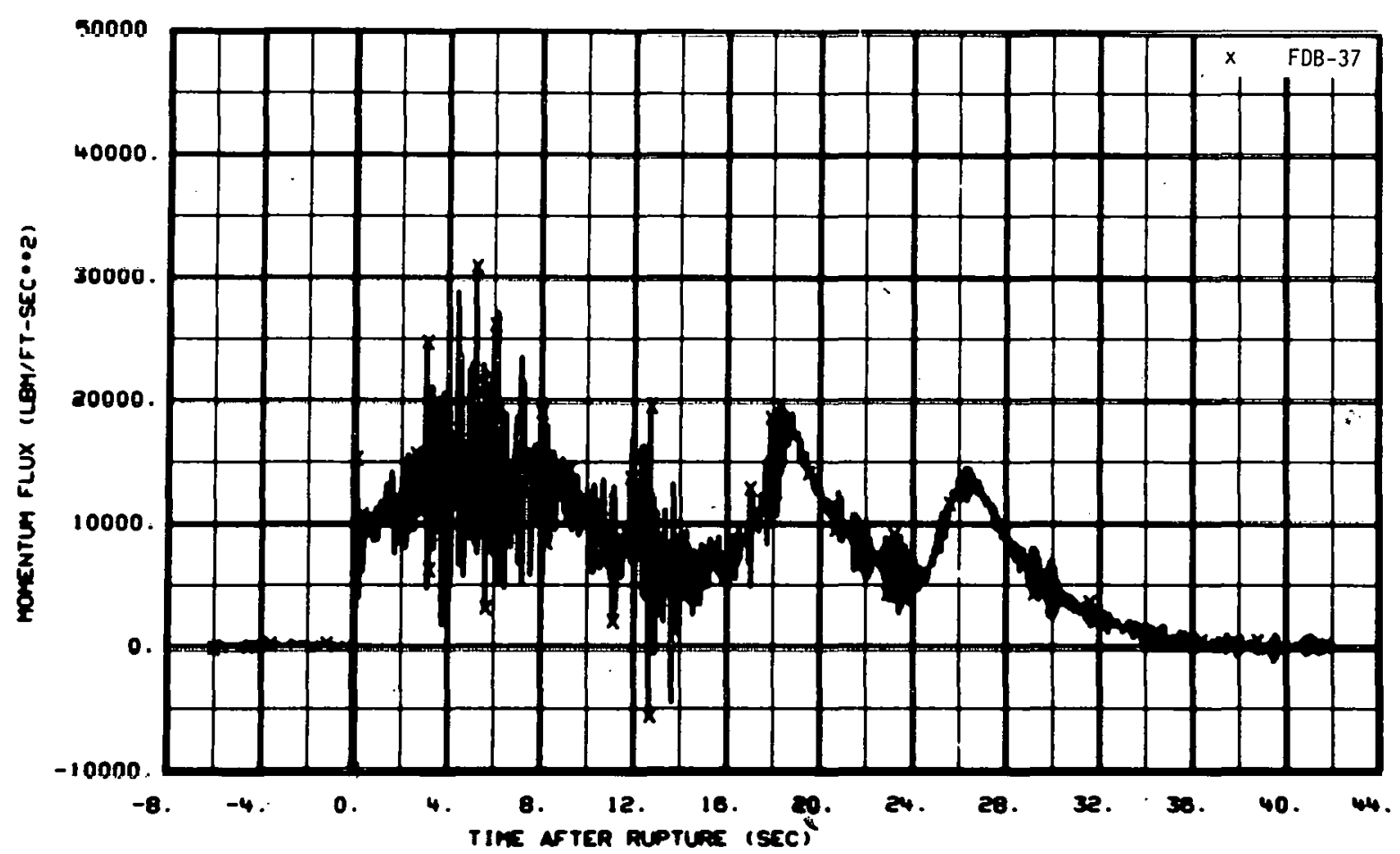

Fig. 243 Momentum flux in broken loop (FDB-37), from -6 to 42 seconds. 


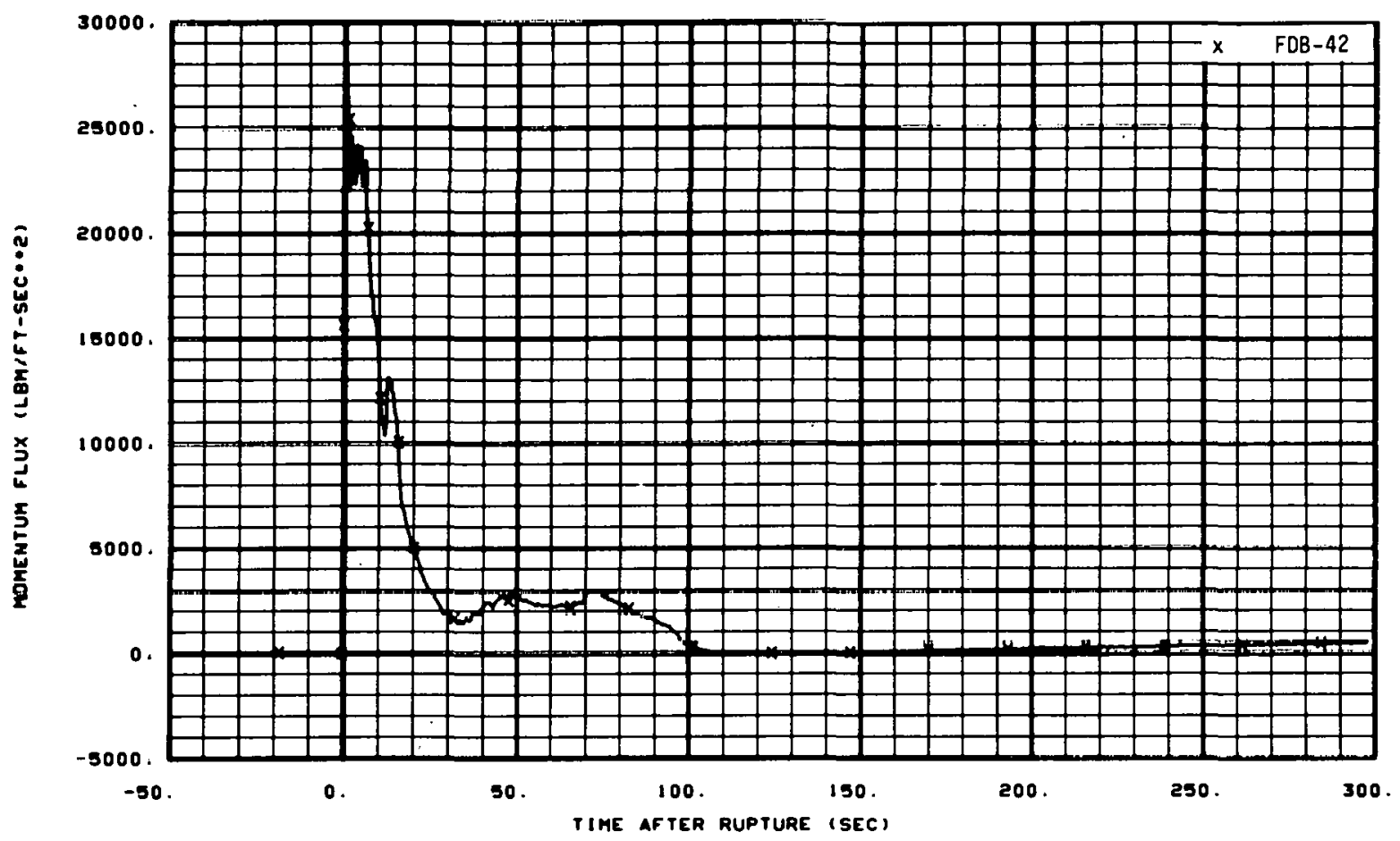

Fig. 244 Momentum flux in broken loop (FDB-42), from -20 to 300 seconds.

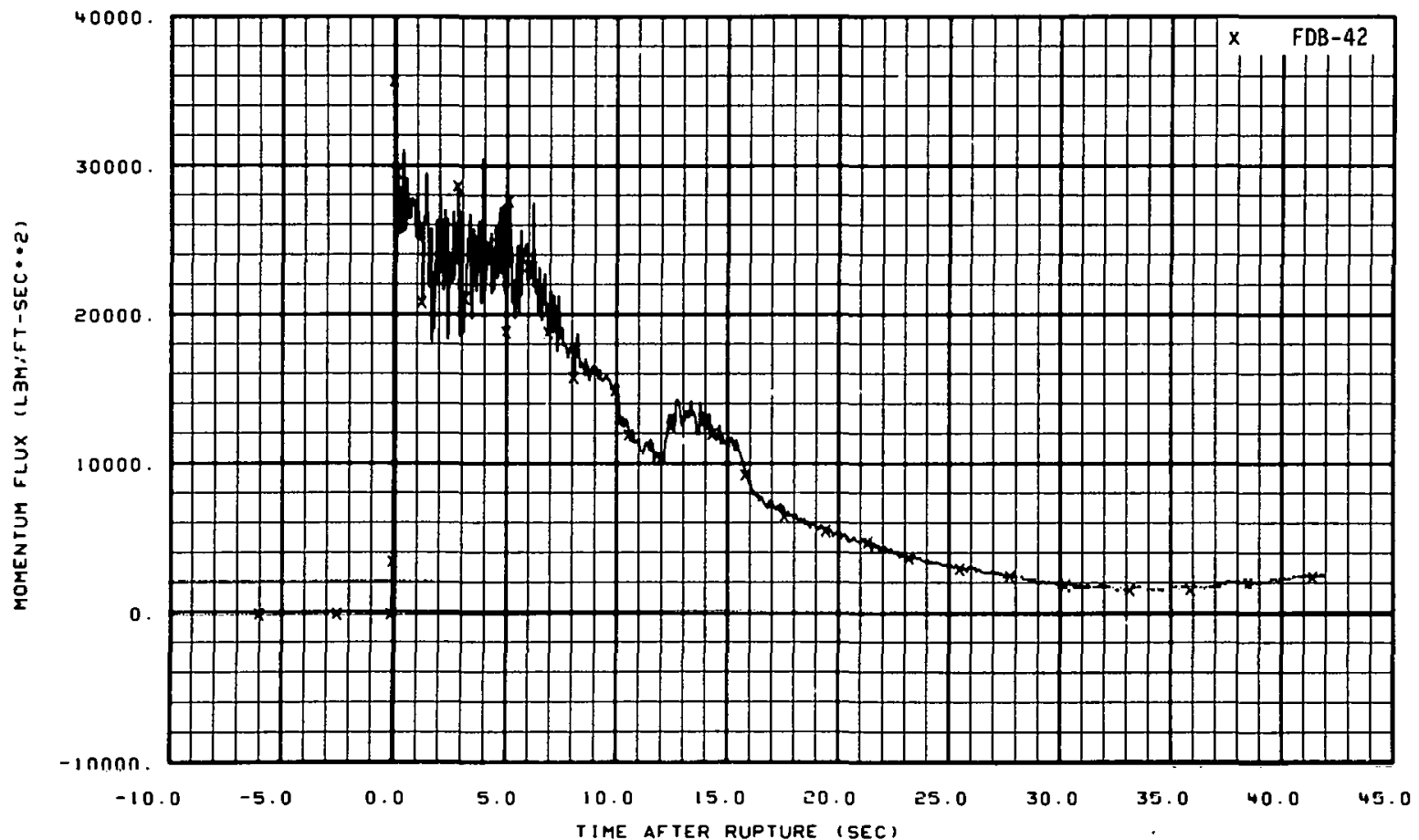

Fig. 245 Momentum flux in broken laop (FDB-42), from -6 to 42 seconds. 


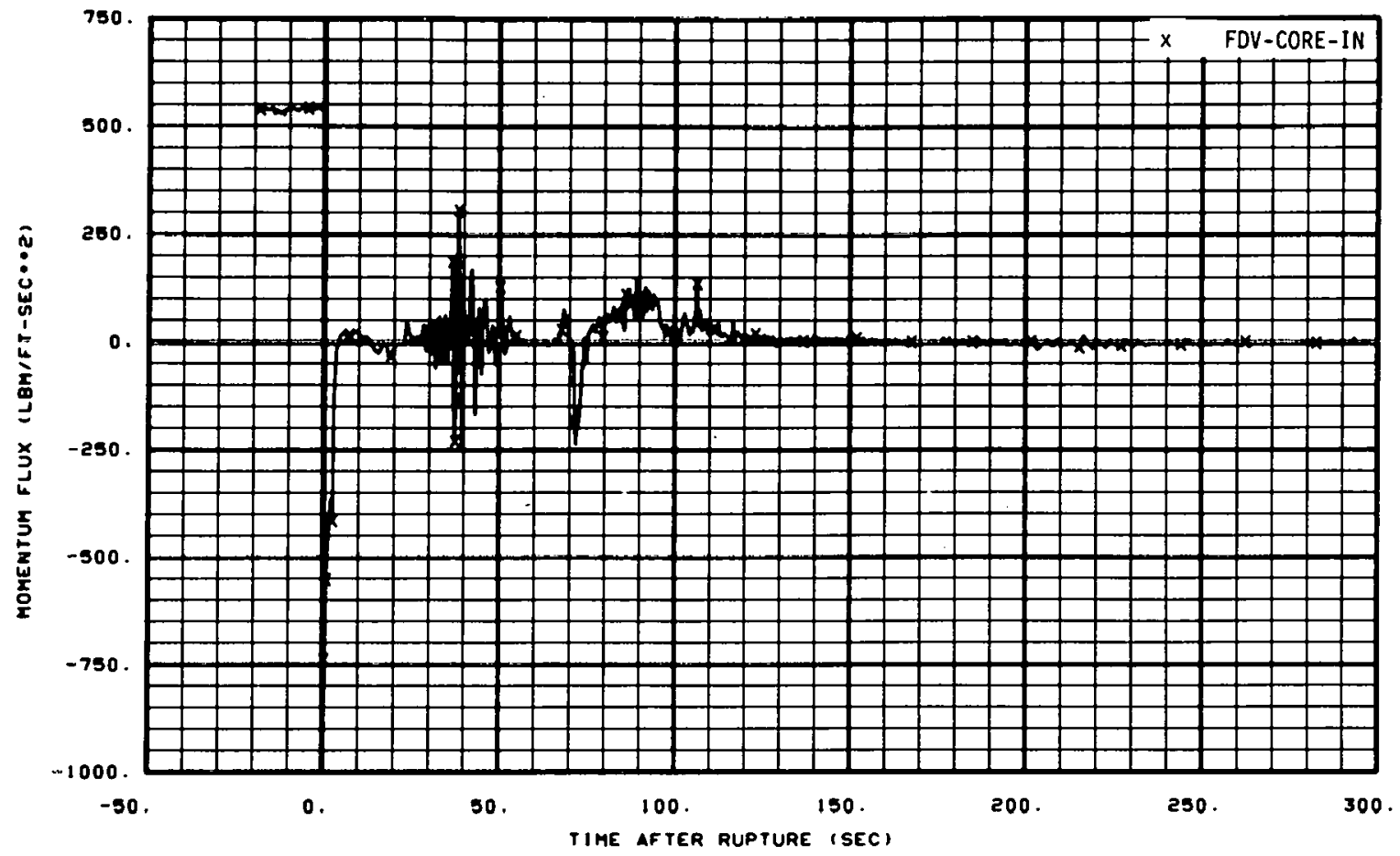

Fig. 246 Momentum flux in core entrance (FDV-CORE-IN), from -20 to 300 seconds.

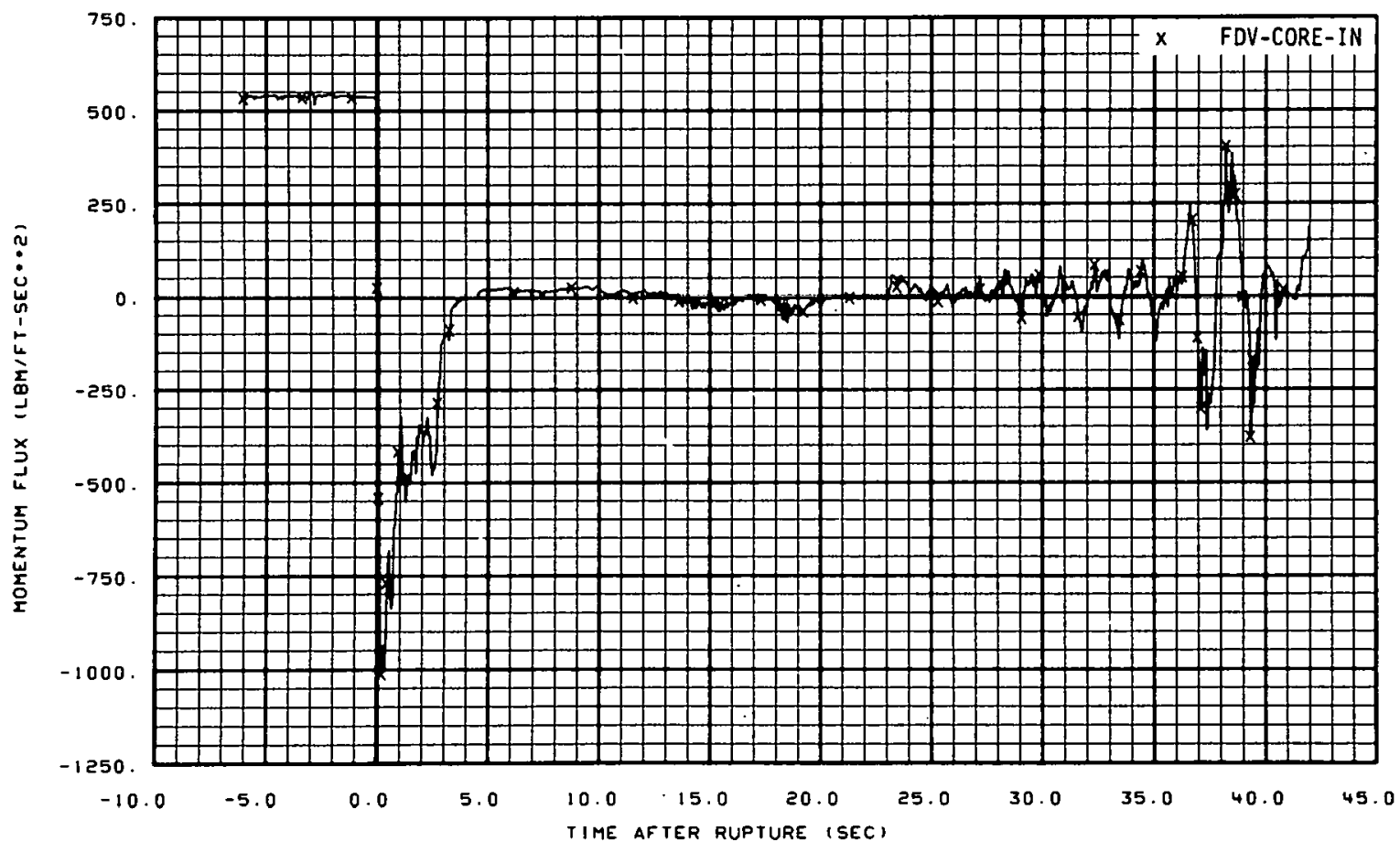

Fig. 247 Momentum flux in core enitrance (FDV-CORE-IN), from -6 to 42 sccunds. 


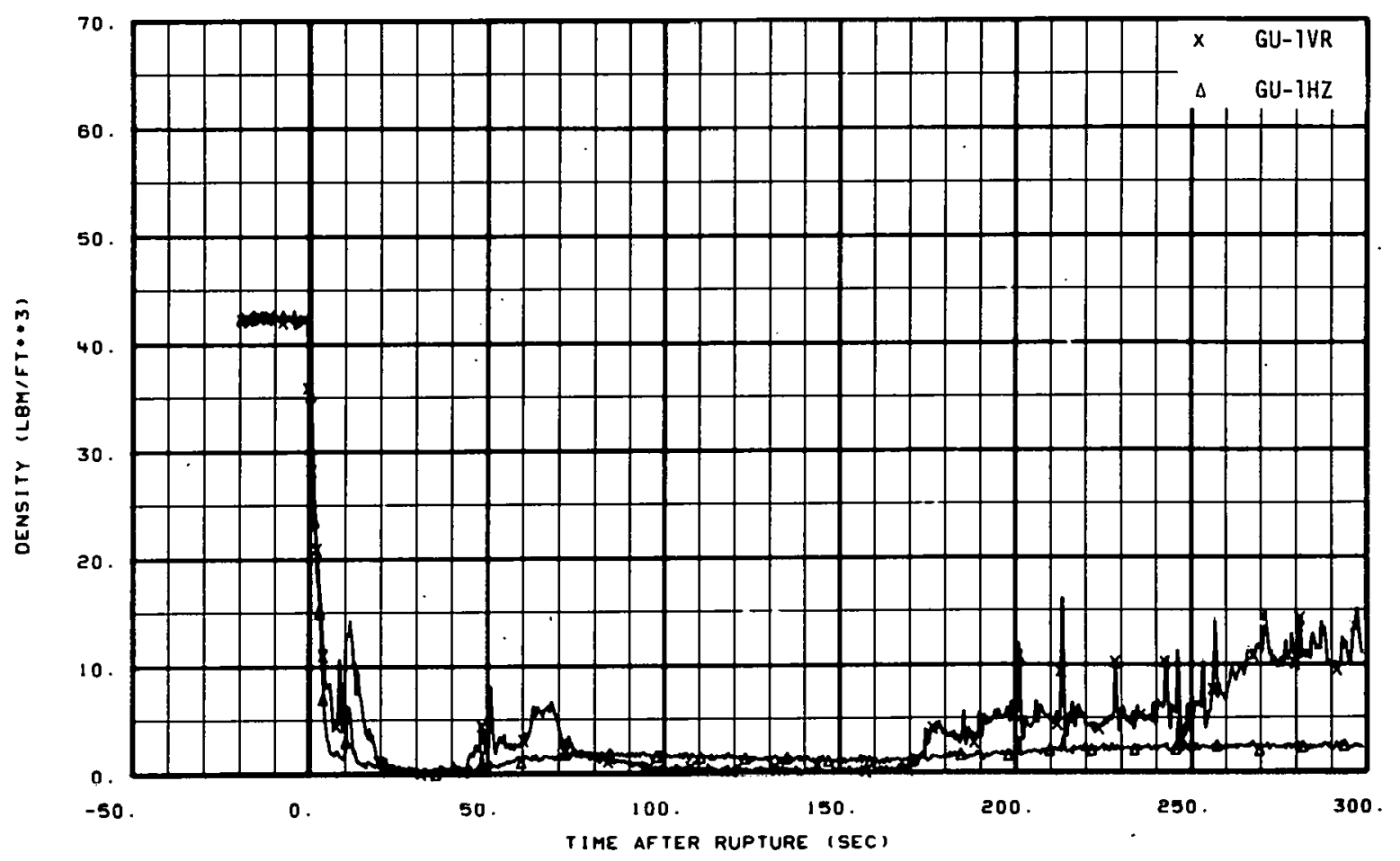

Fig. 248 Density in intact loop (GU-1VR and GU-1HZ), from -20 to 300 seconds.

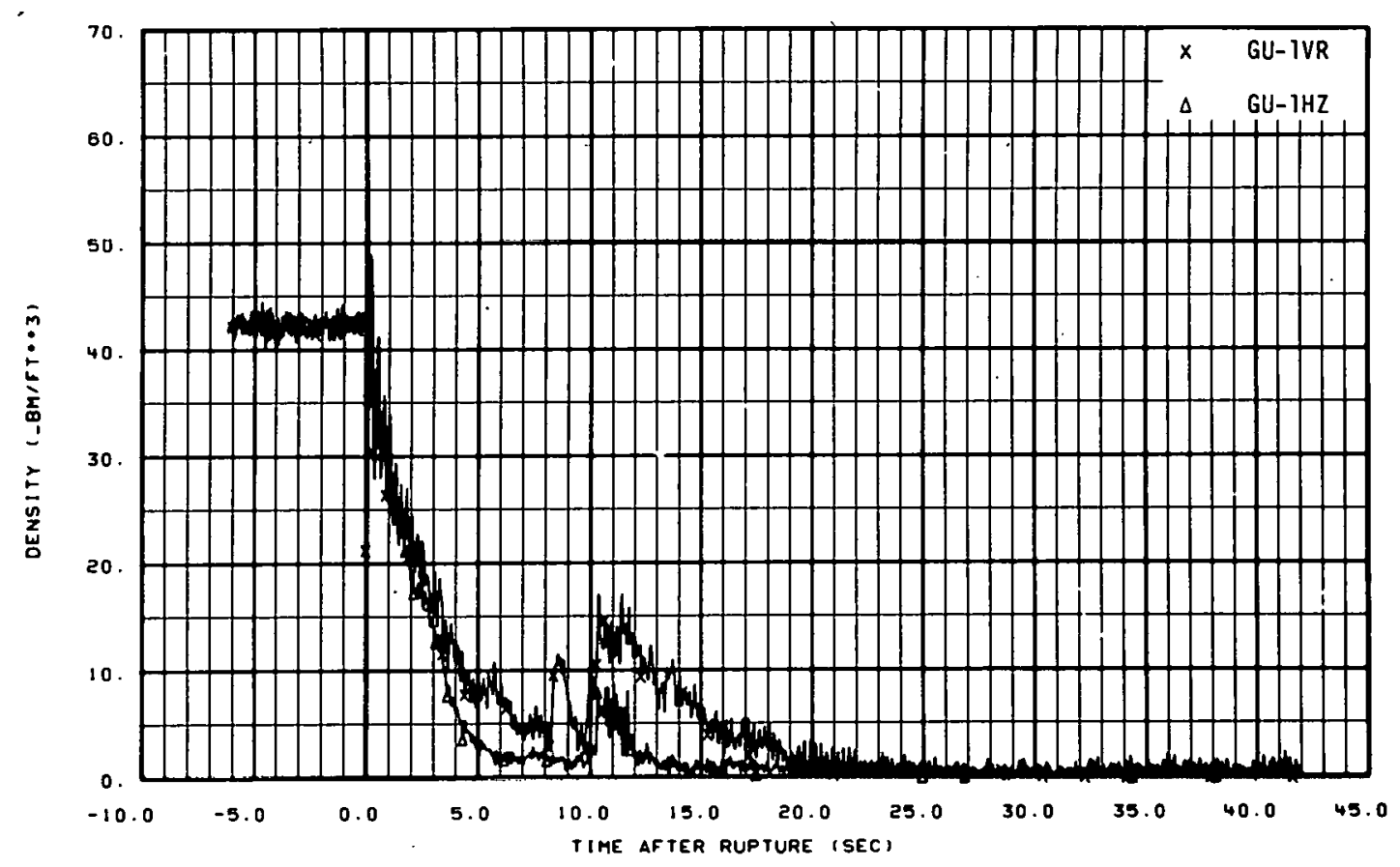

Fig. 249 Density in intact loop (GU-IVR and GU-1HZ), from -6 to 42 seconds. 


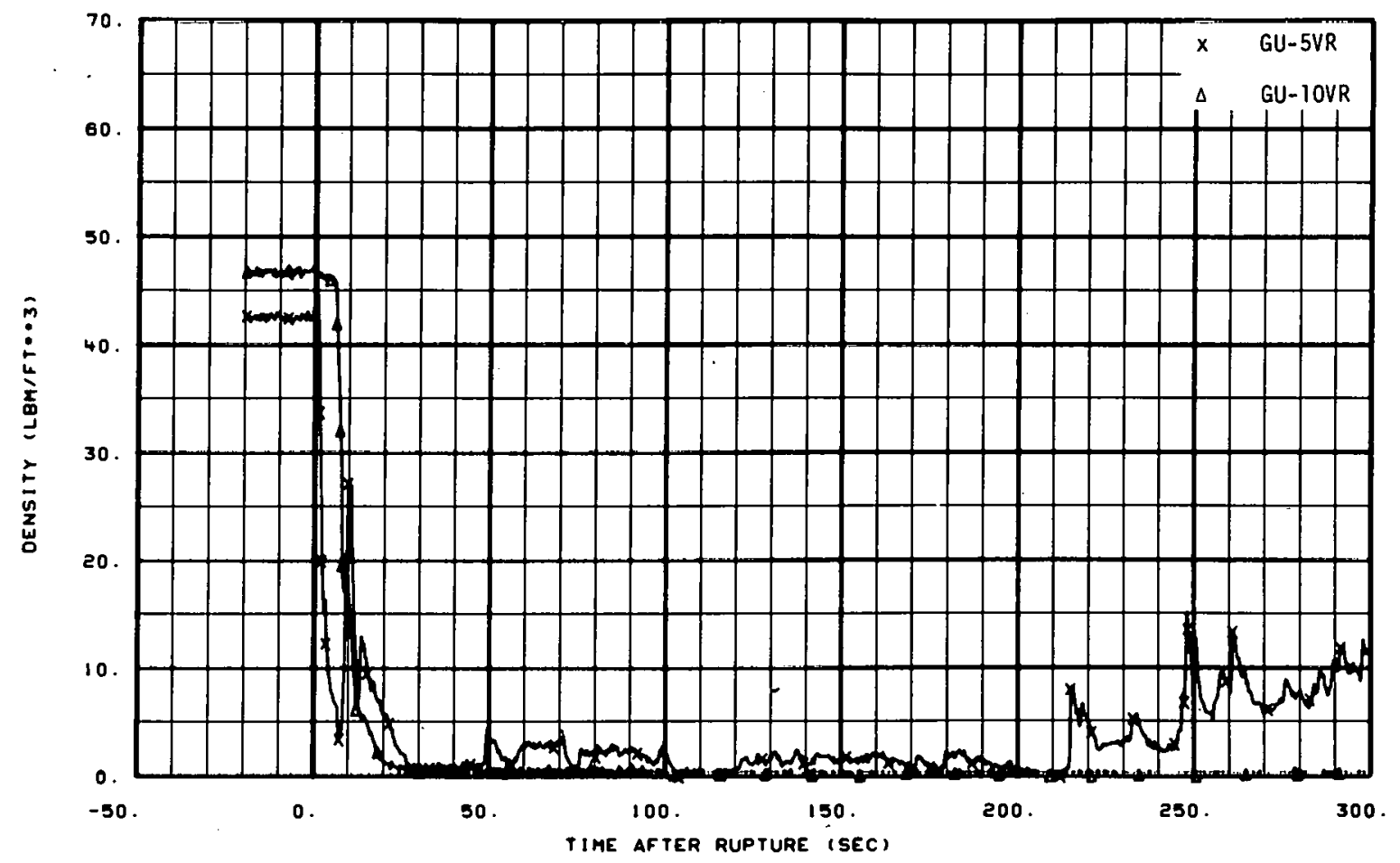

Fig. 250 Density in intact 10op (GU-5VR and GU-10VR), from -20 to 300 seconds.

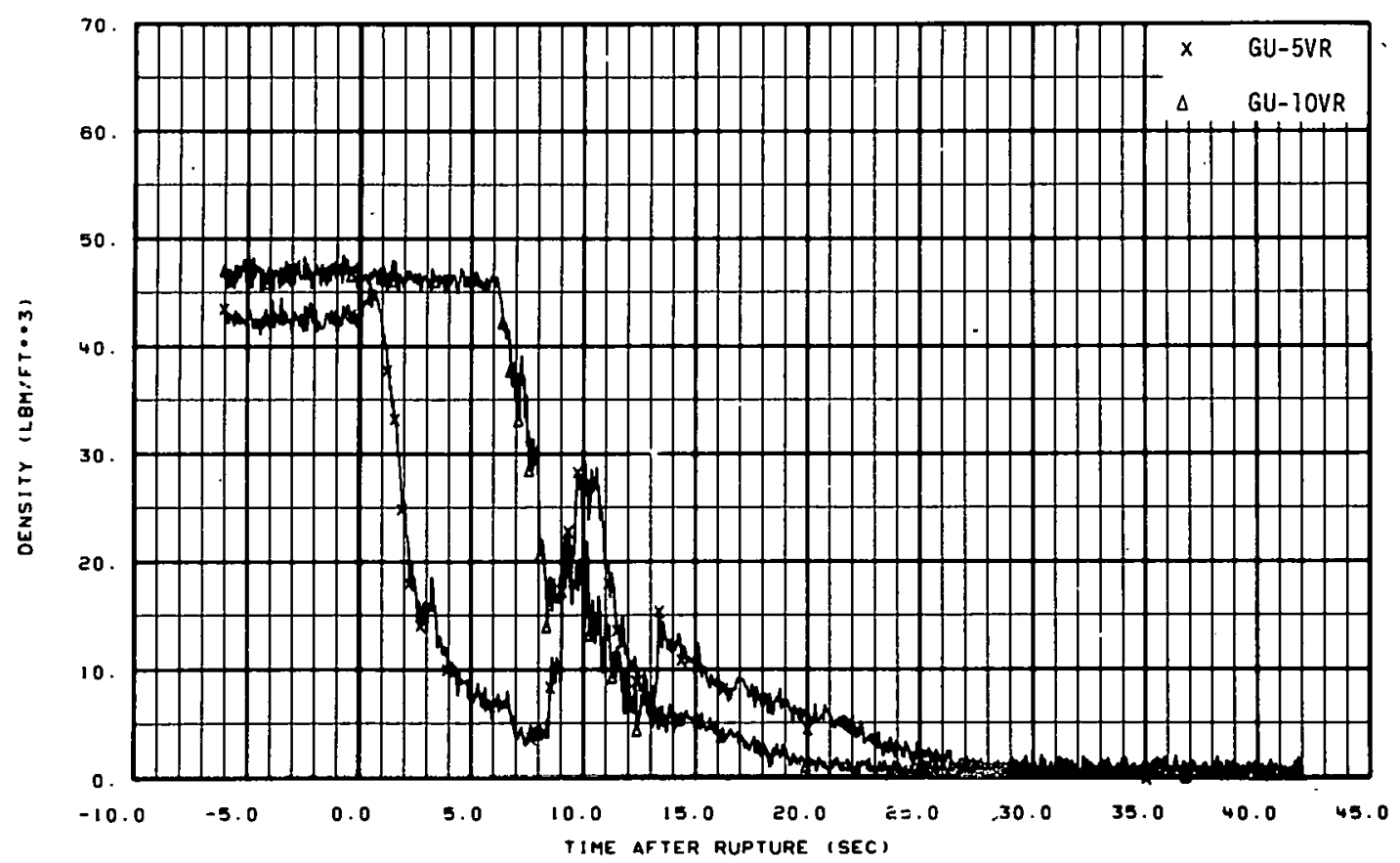

Fig. 251 Density in intact 100p (GU-5VR and GU-10VR), from -6 to 42 seconds. 


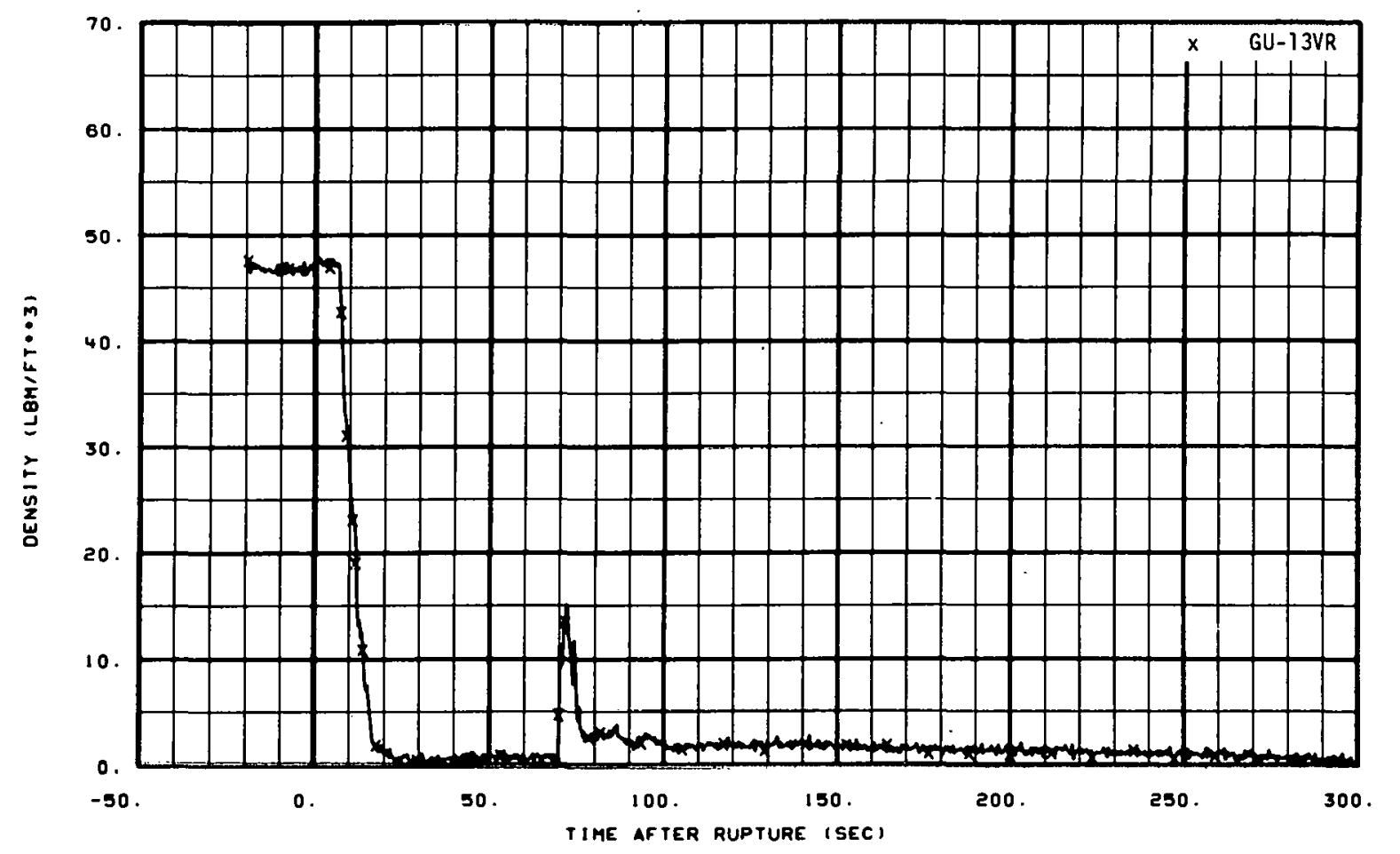

Fig. 252 Density in intact loop (GU-13VR), from -20 to 300 seconds.

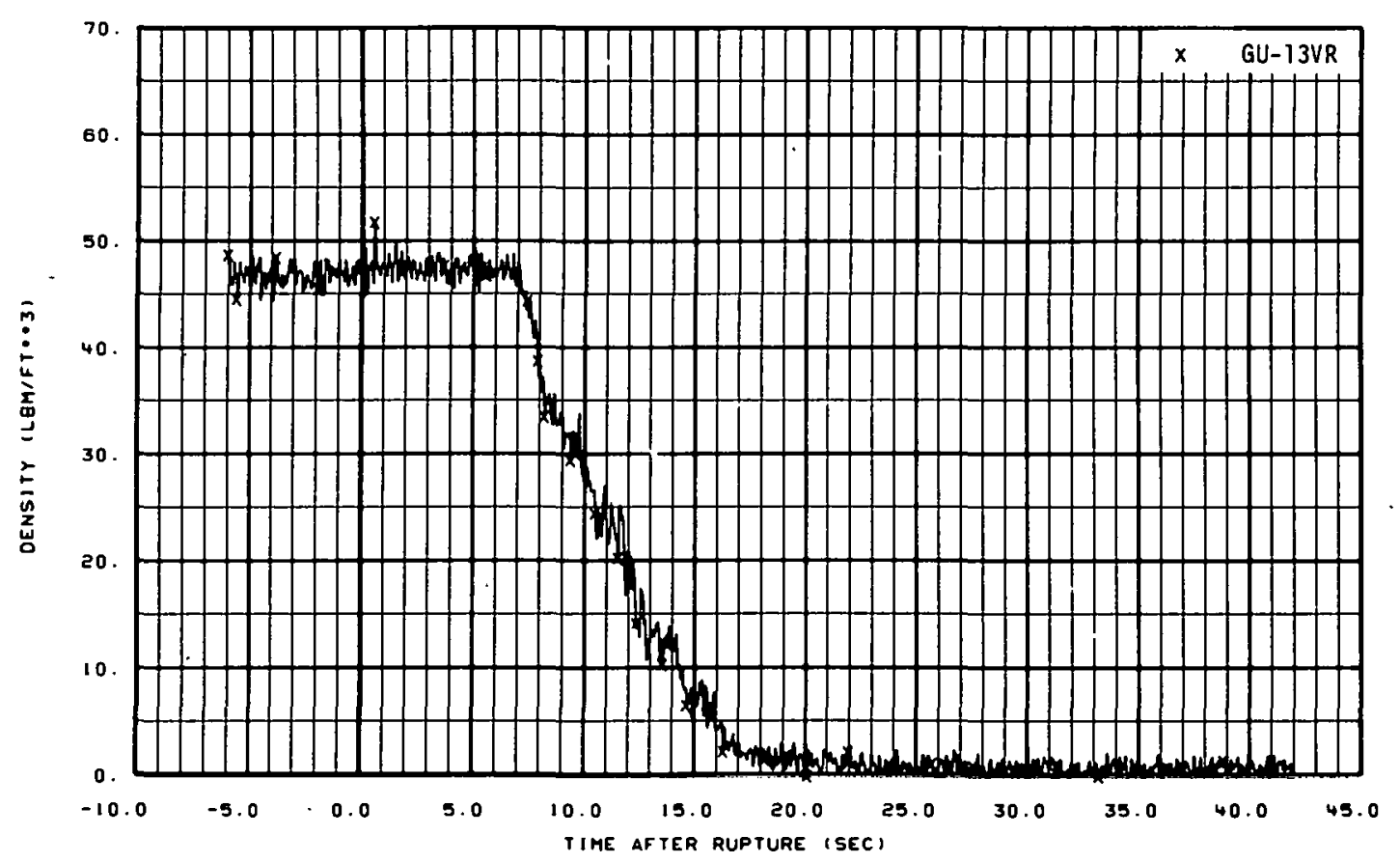

Fig. 253 Density in intact loop (GU-13VR), from -6 to 42 seconds. 


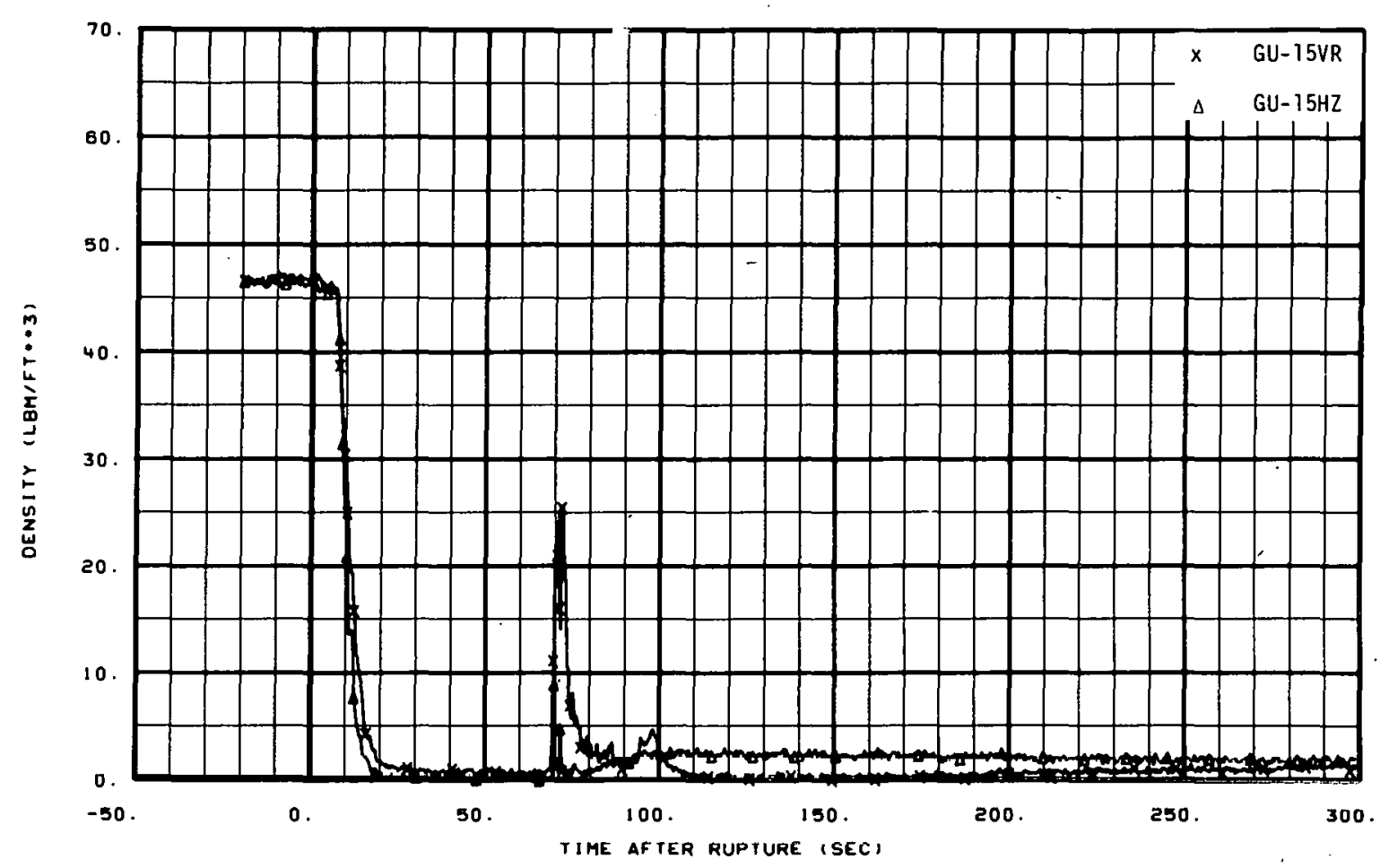

Fig. 254 Density in intact 100p (GU-15VR and GU-15HZ), from -20 to : 300 seconds.

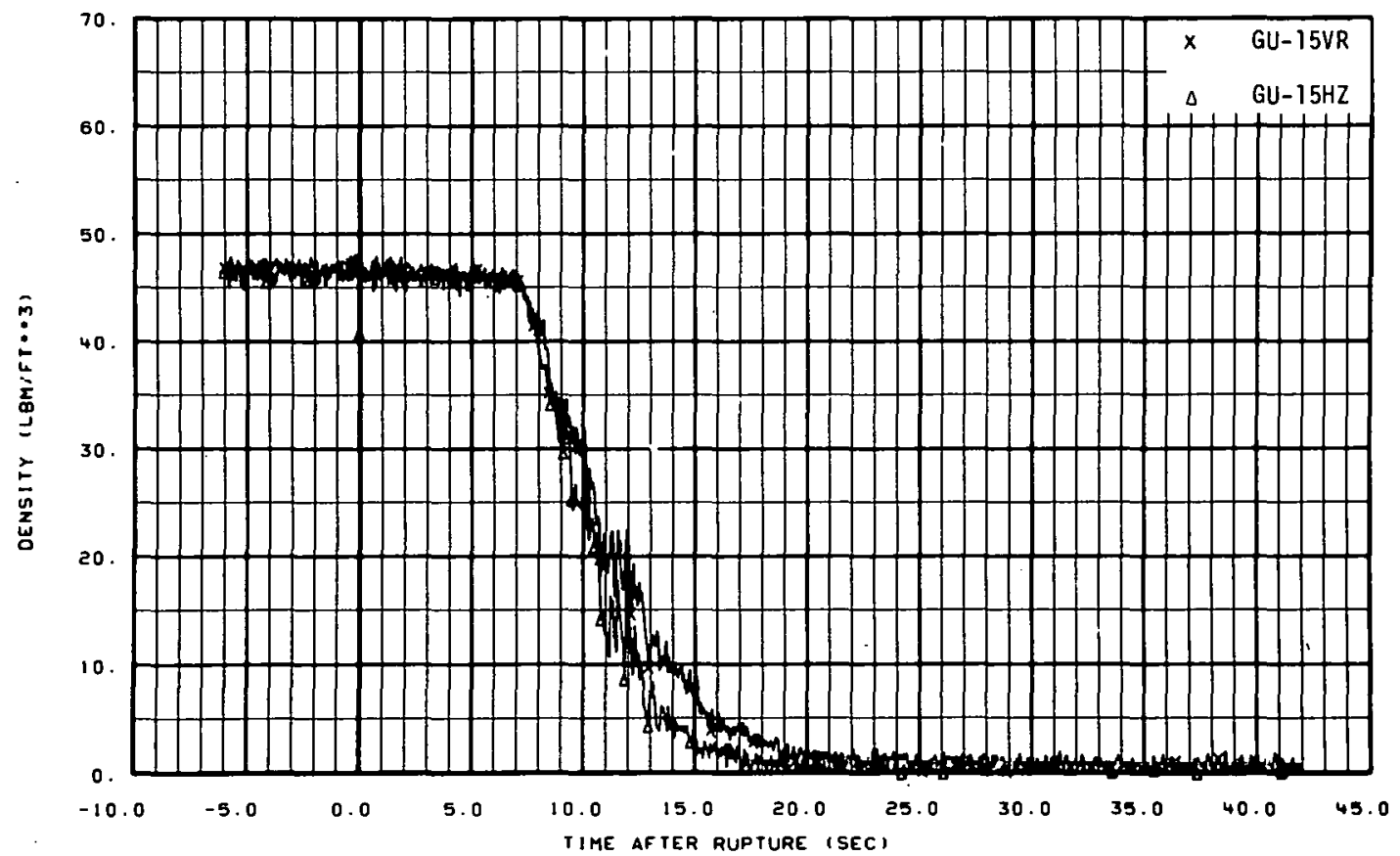

Fig. 255 Density in intact 1oop (GU-15VR and GU-15HZ), from -6 to 42 seconds. 


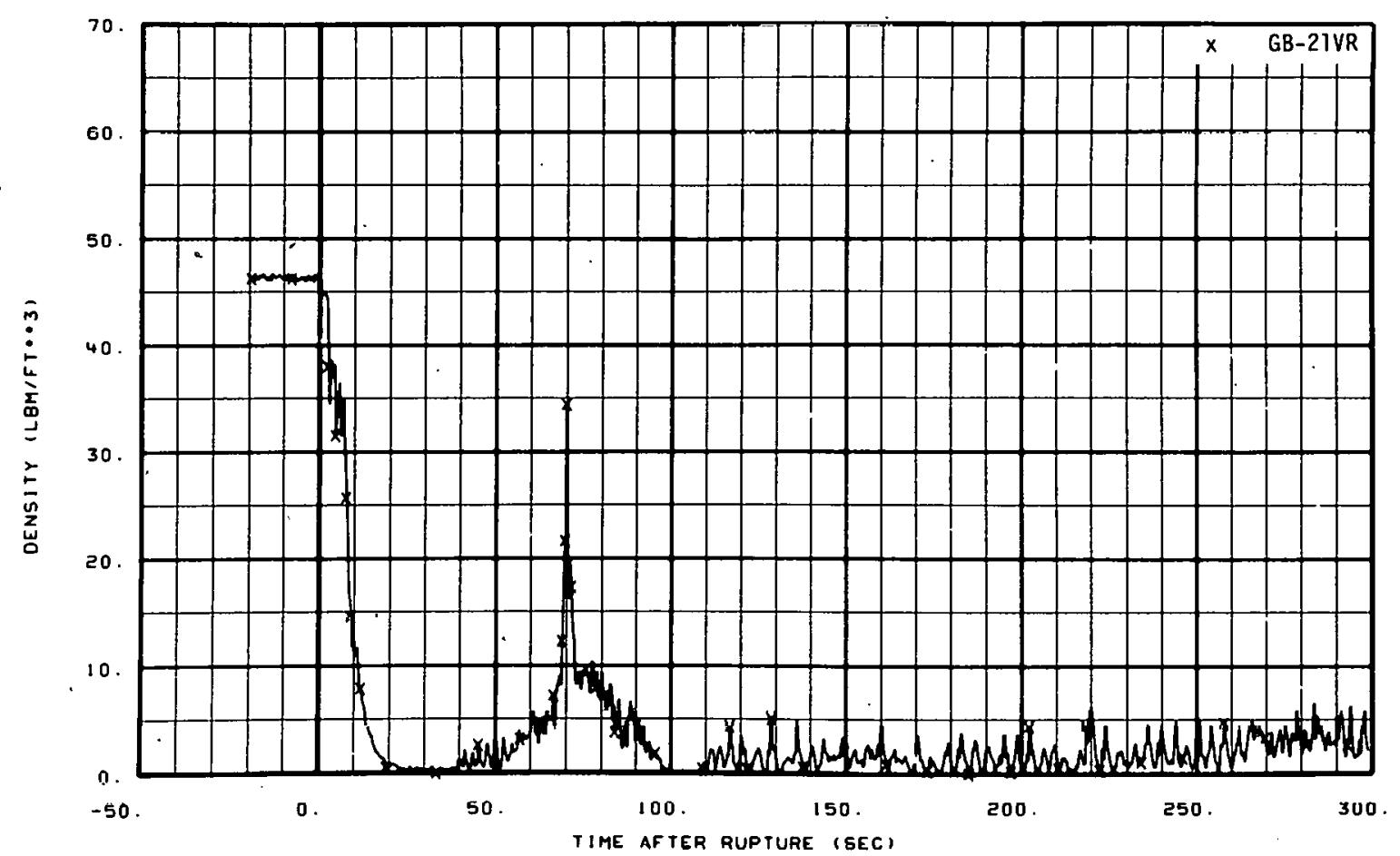

Fig. 256 Density in broken loop (GB-21VR), from -20 to 300 seconds.

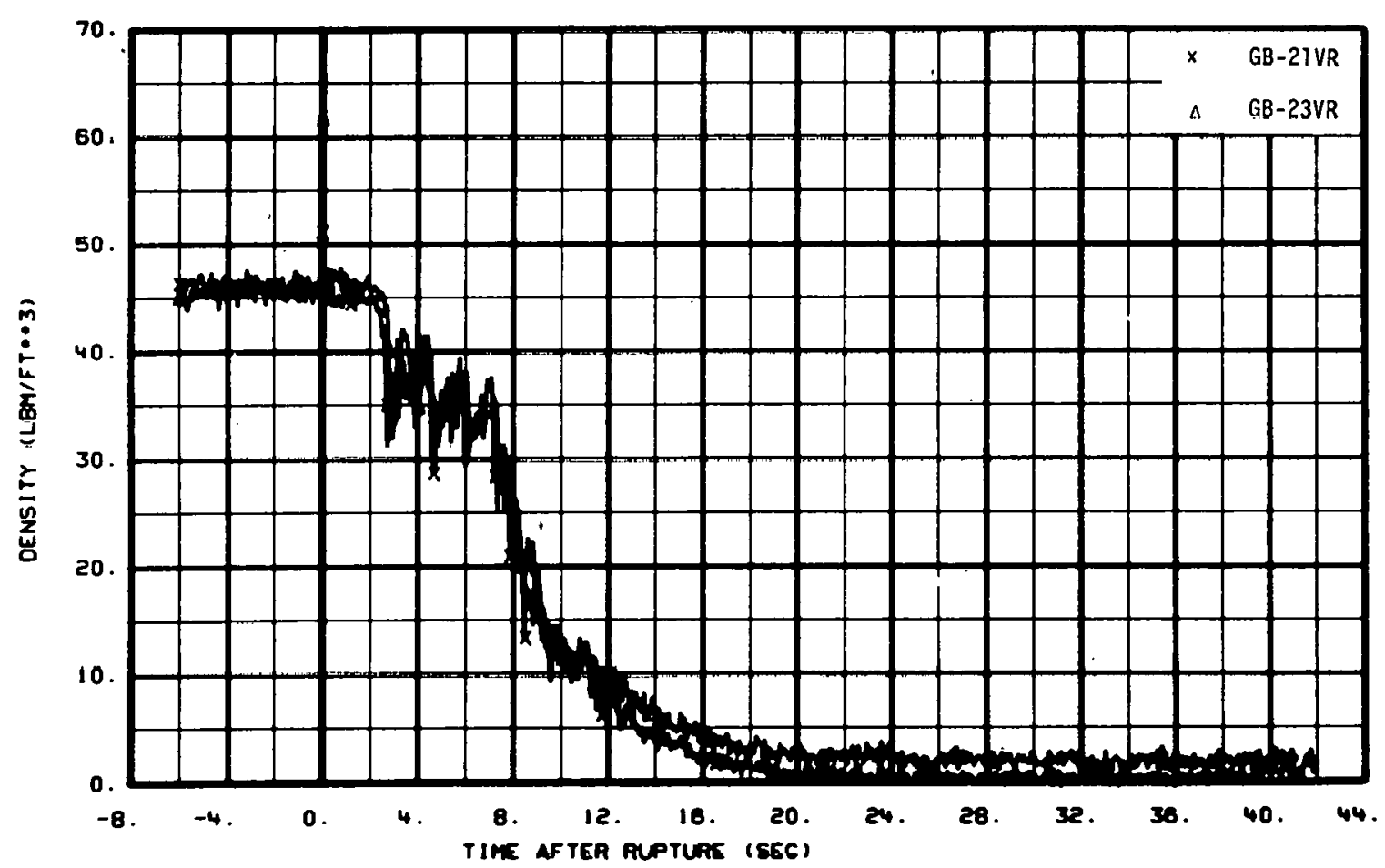

Fig. 257 Density in broken loop (GB-21VR and GB-23VR), from -6 to 42 seconds. 


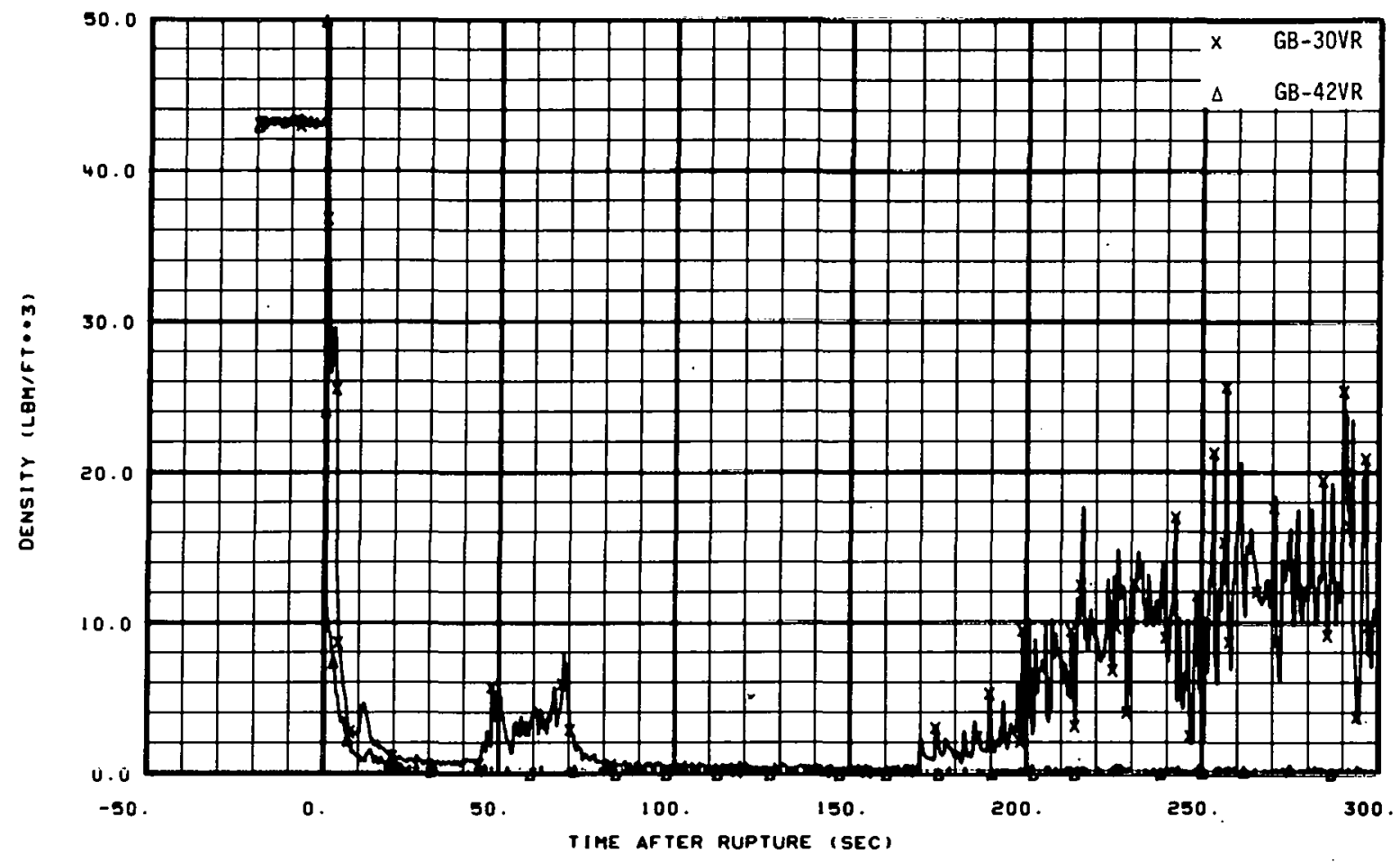

Fig. 258 Density in broken loop (GB-30VR and GB-42VR), from -20 to 300 seconds.

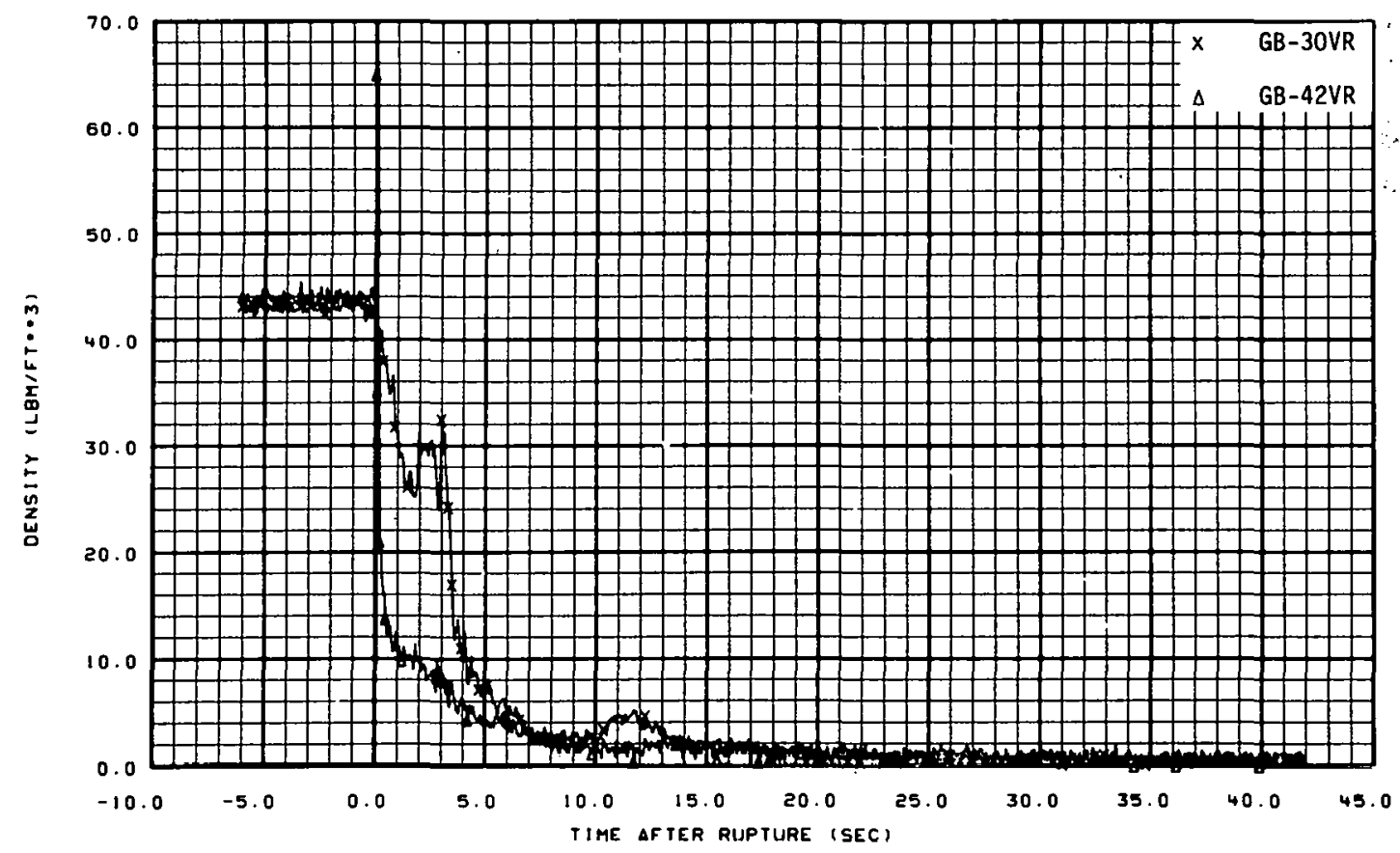

Fig. 259 Density in broken loop (GB-30VR and GB-42VR), from -6 to 42 seconds. 


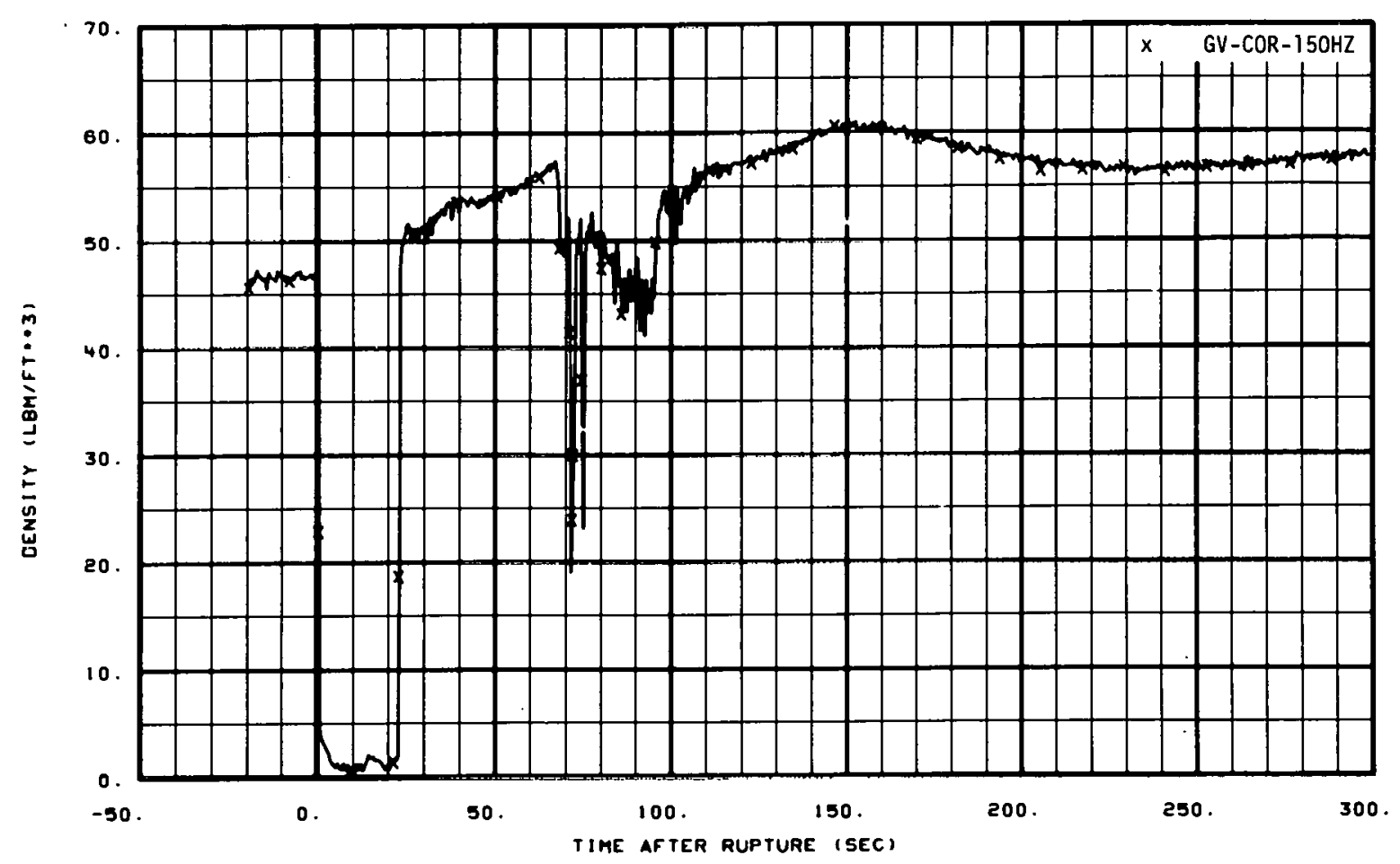

Fig. 260 Density in vesse (GV-COR-150HZ), from -20 to 300 seconds.

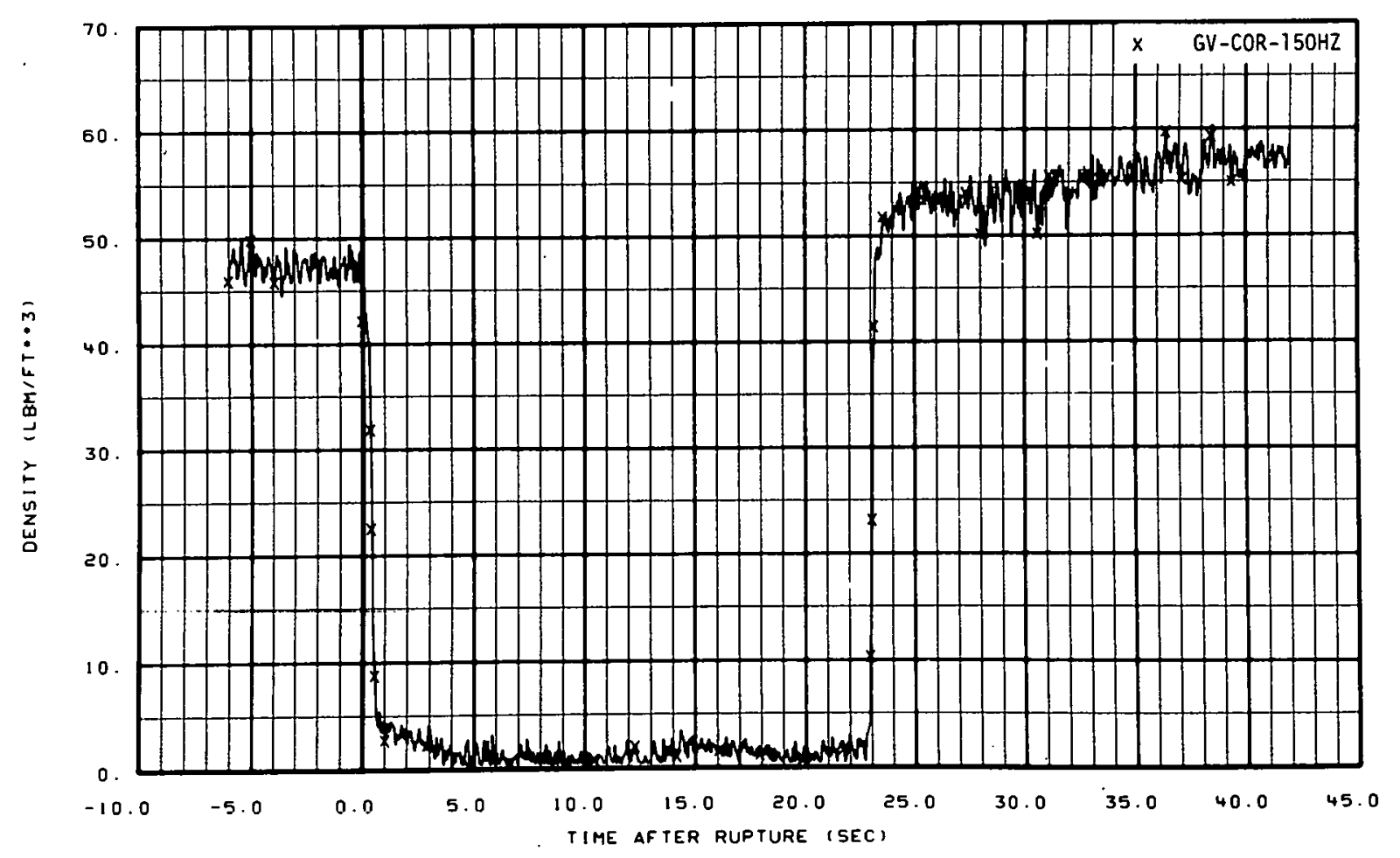

Fig. 261 Density in vessel (GV-COR-150HZ), from -6 to 42 seconds. 


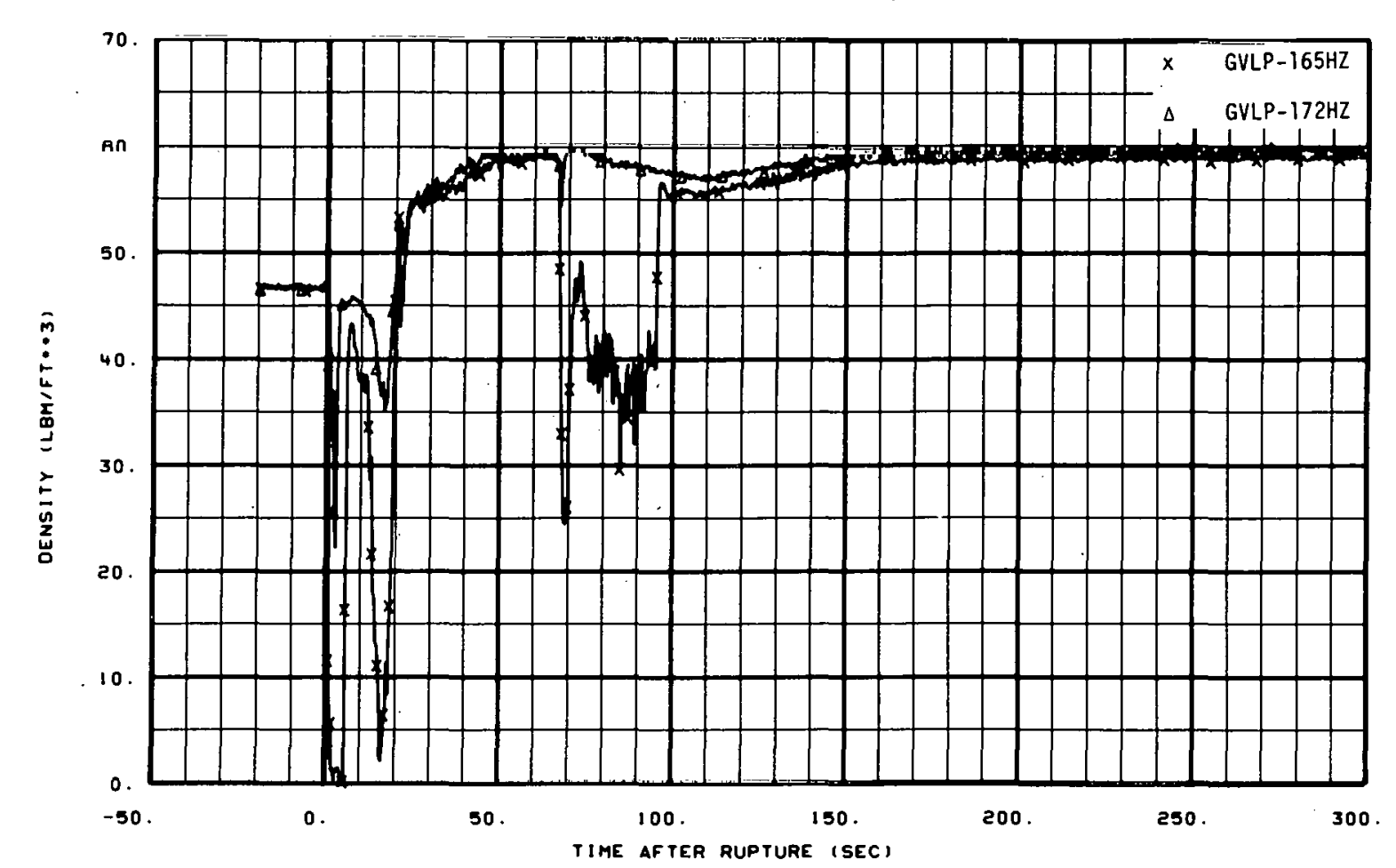

Fig. 262 Density in vessel (GVLP-165HZ and GVLP-172HZ), from -20 to 300 seconds.

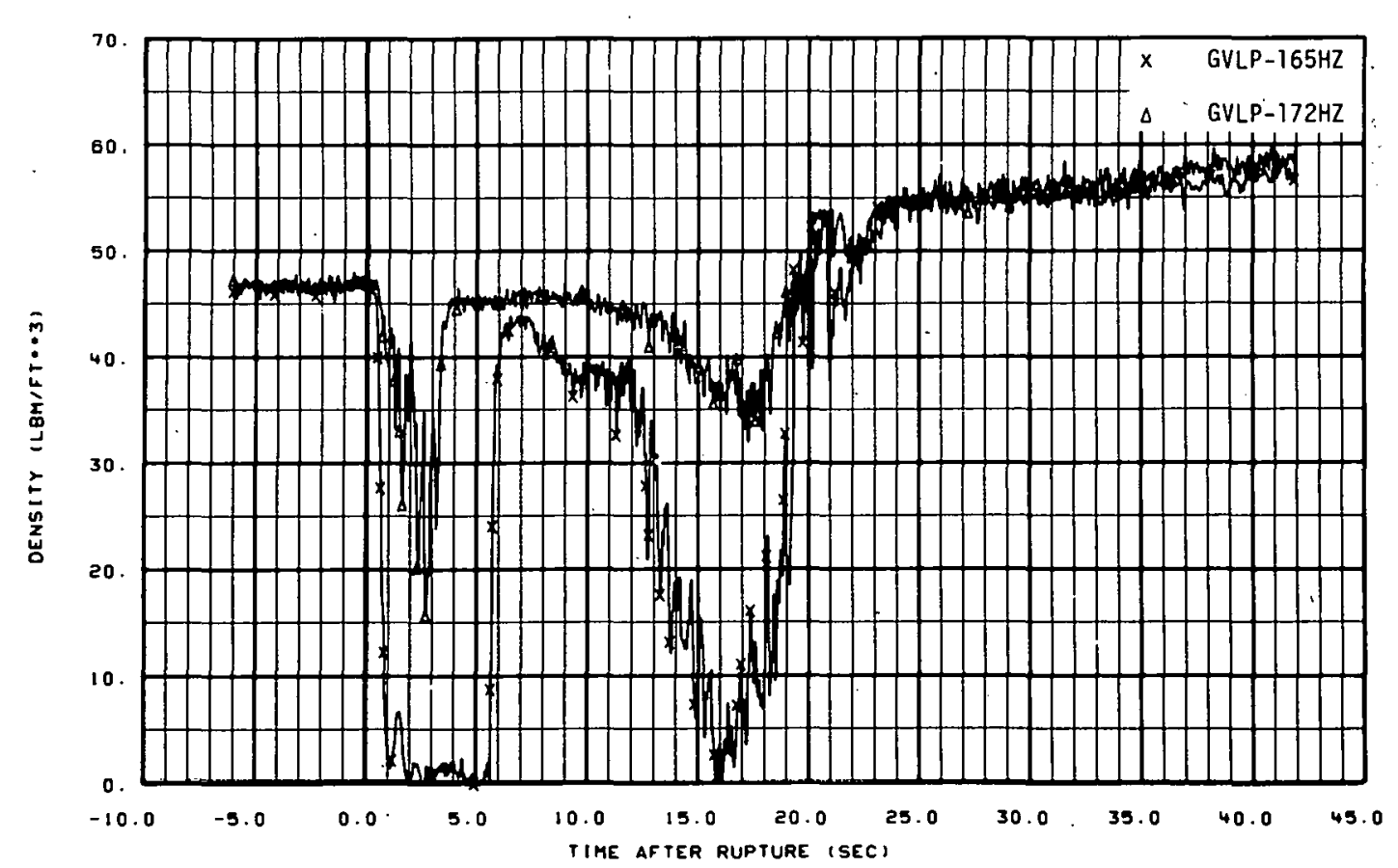

Fig. 263 Density in vessel (GVLP-165HZ and GVLP-172HZ), from -6 to 47 sernnts. 


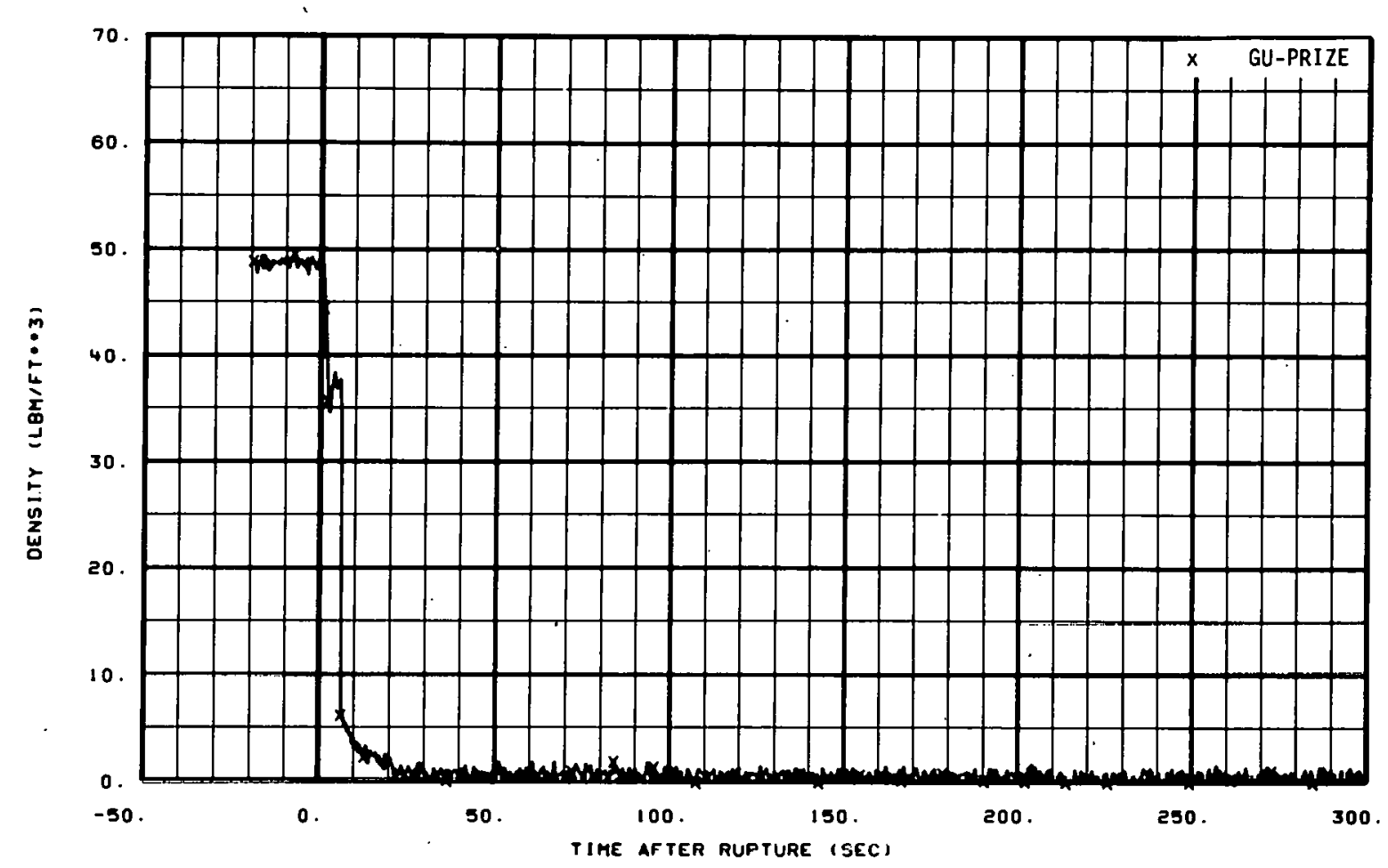

Fig. 264 Density in pressurizer (GU-PRIZE), from -20 to 300 seconds.

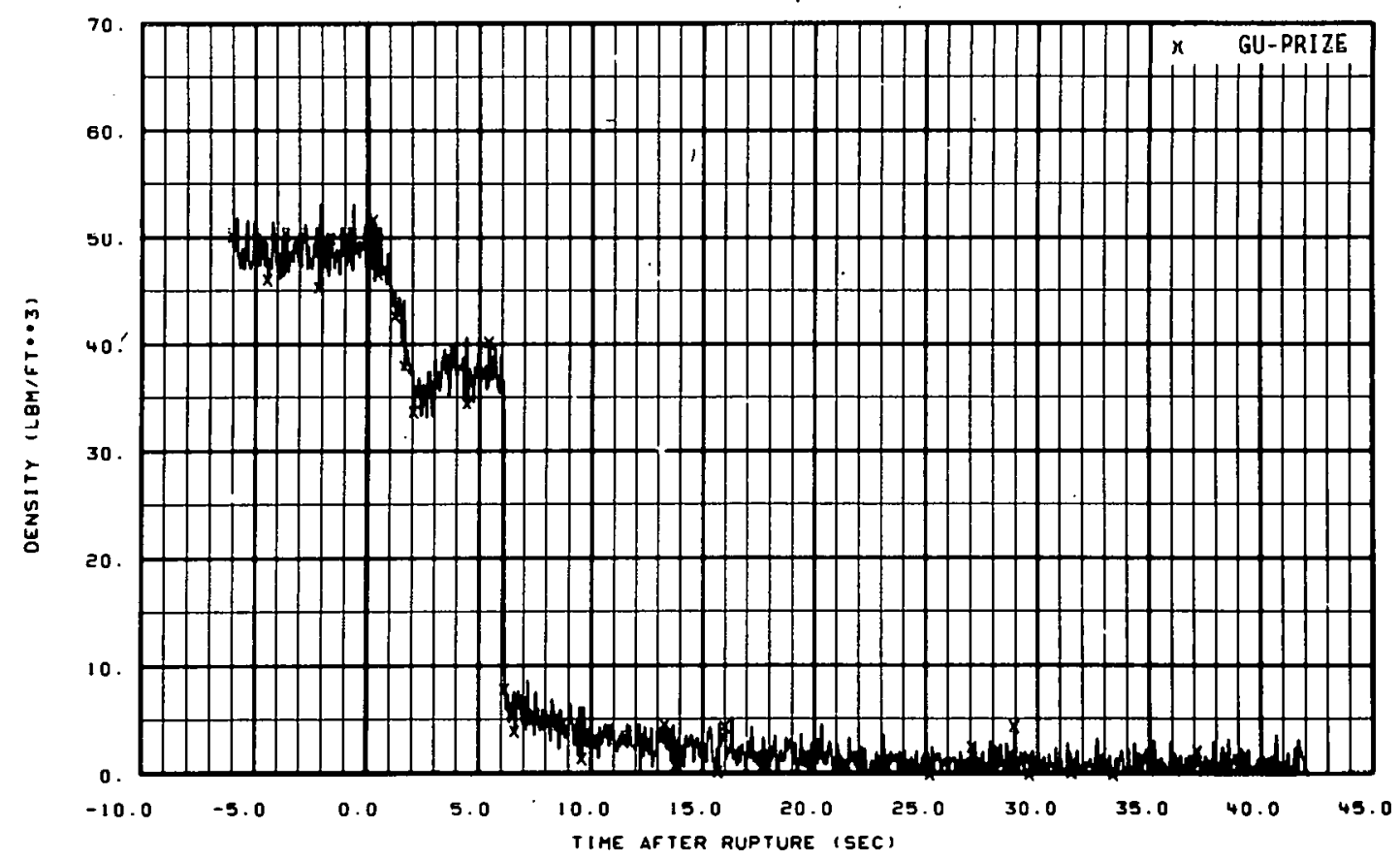

Fig. 265 Density in pressurizer ('GU-PRIZE), from -6 to 42 seconds. 


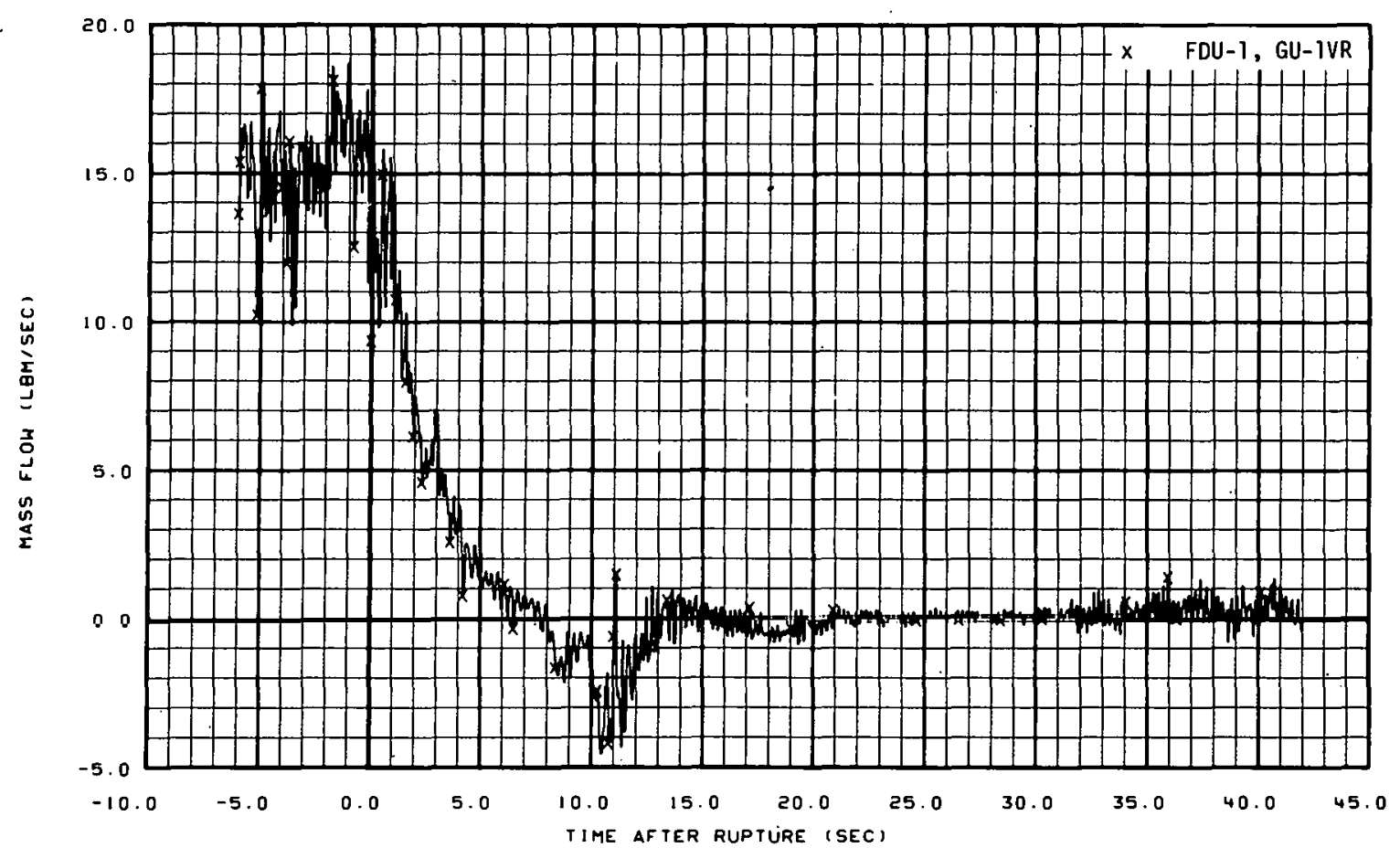

Fig. 266 Mass flow in intact loop (FDU-1 and GU-1VR), from -6 to 42 seconds. 


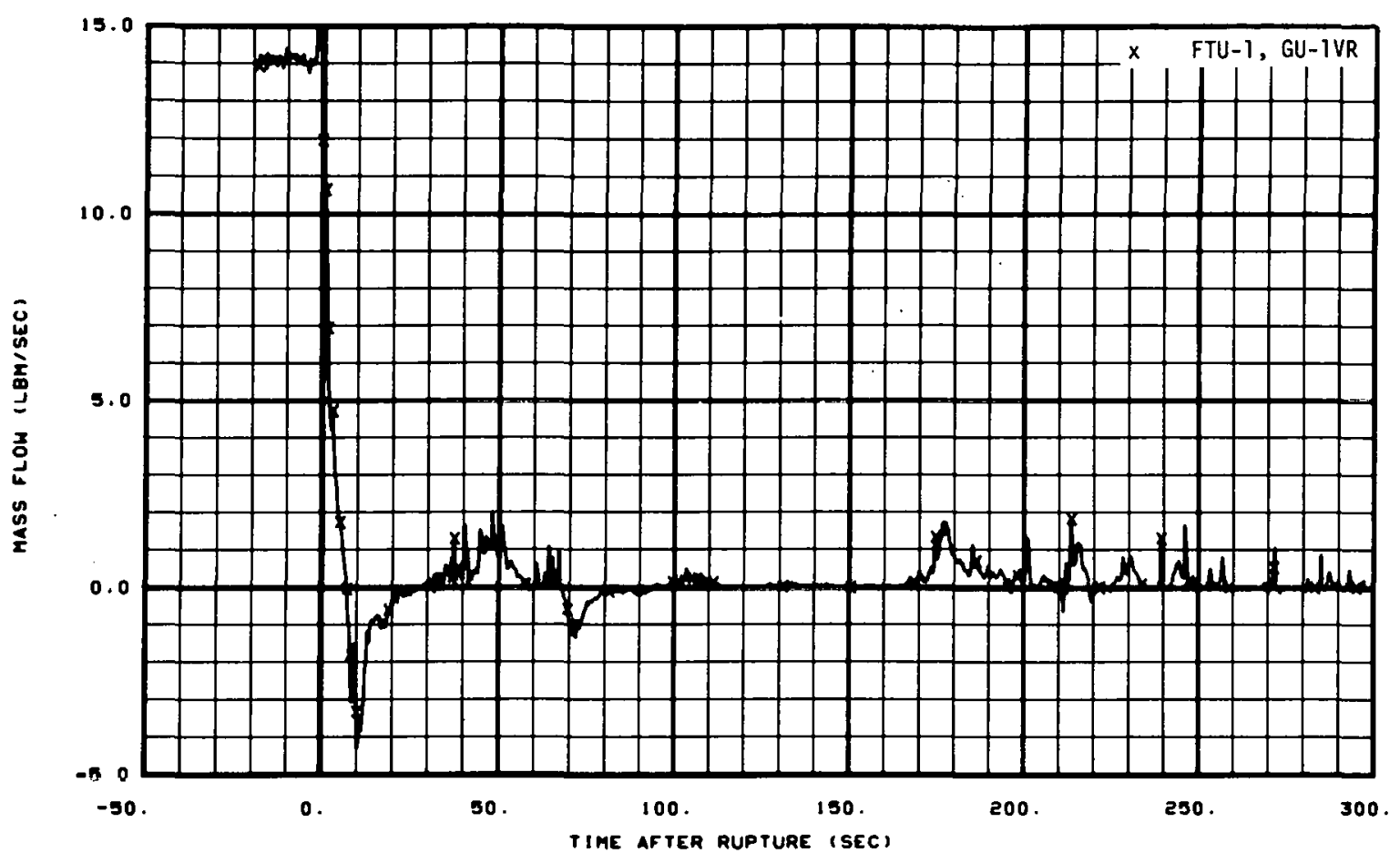

Fig. 267 Mass flow in intact loop (FTU-1 and GU-TVR), from -20 to 300 seconds.

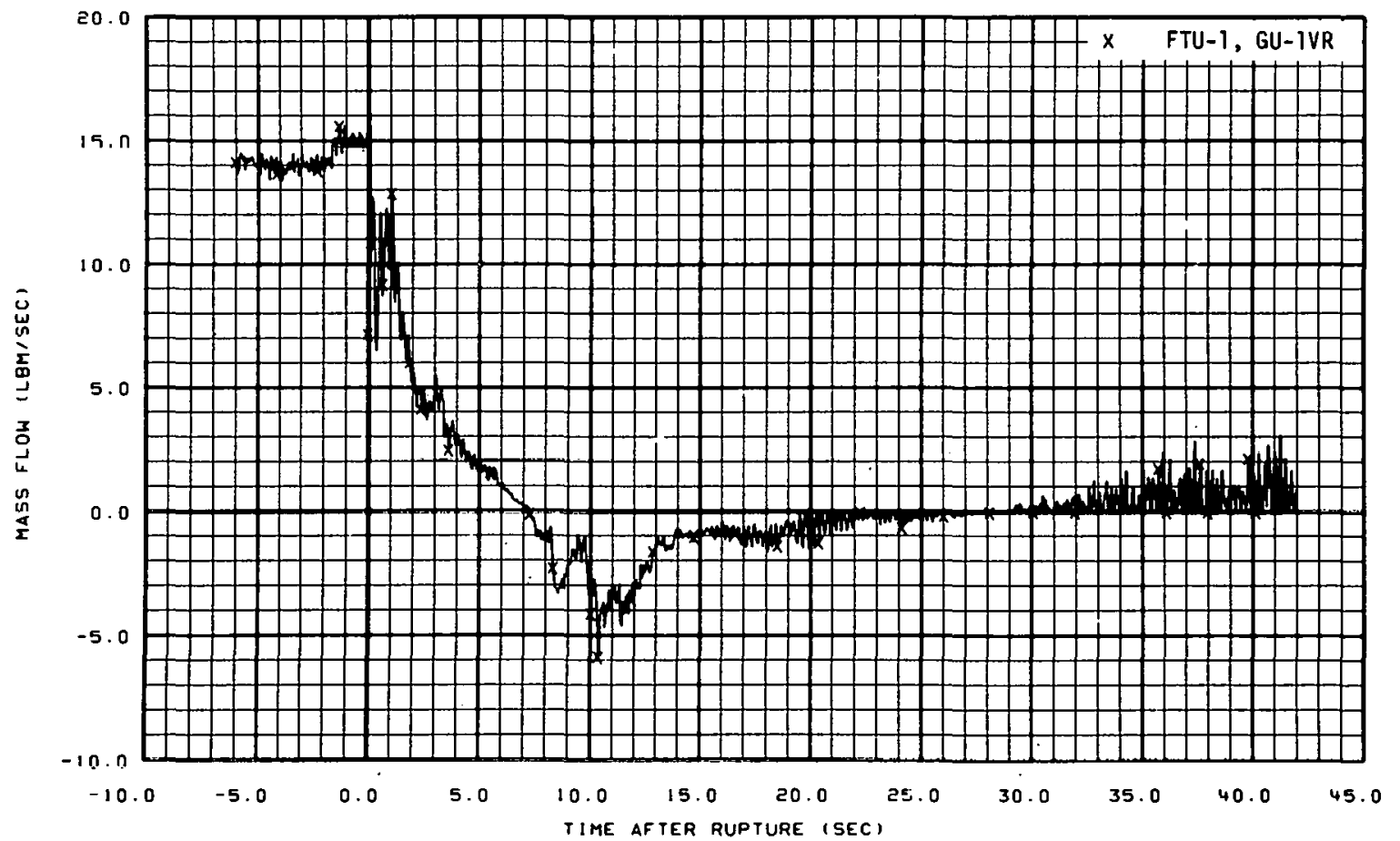

Fig. 268 Mass flow in intact loop (FTU- 1 and GU-1VR), from -6 to 42 seconds. 


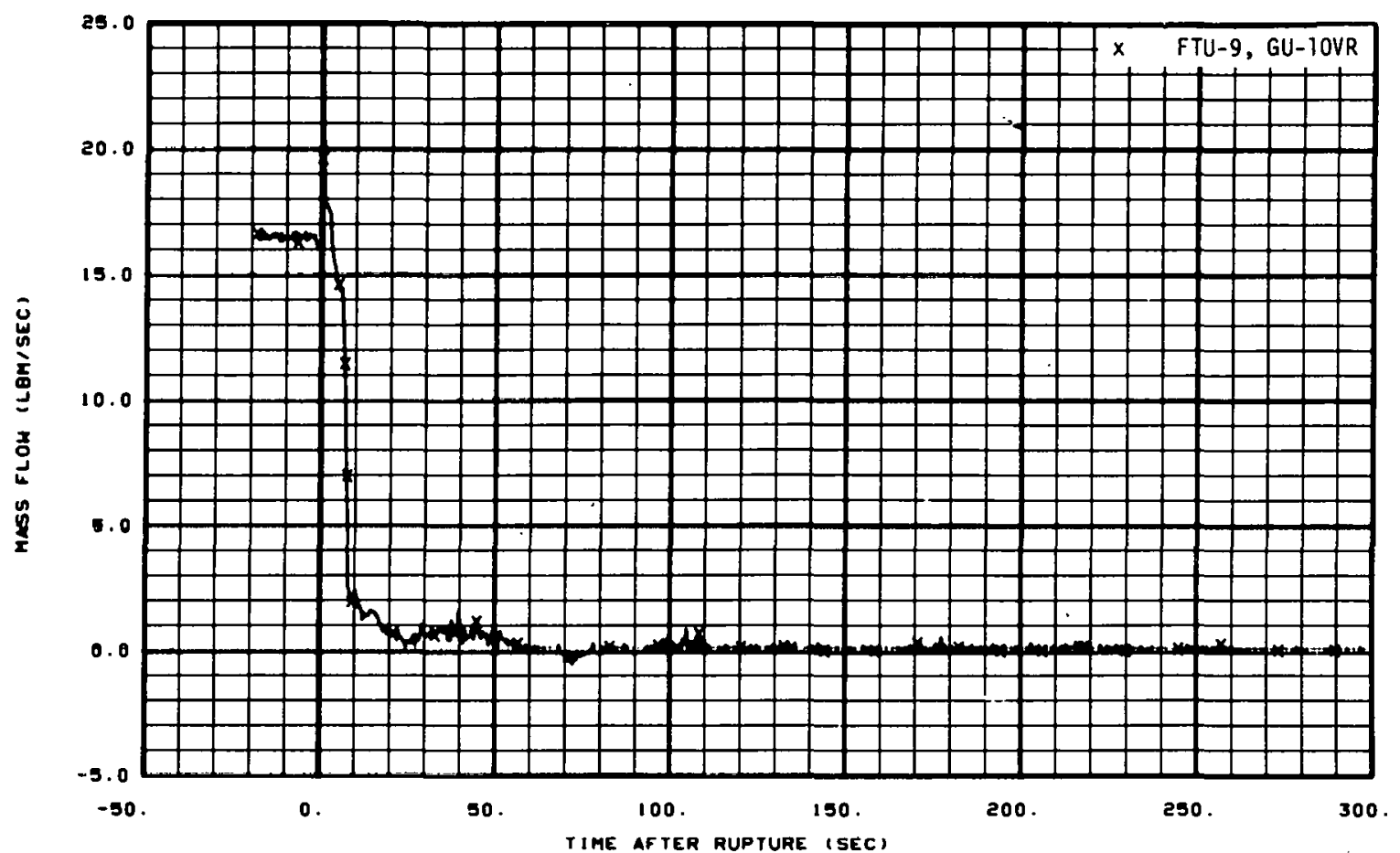

Fig. 269 Mass flow in intact loop (FTU-9 and GU-10VR), from -20 to 300 seconds.

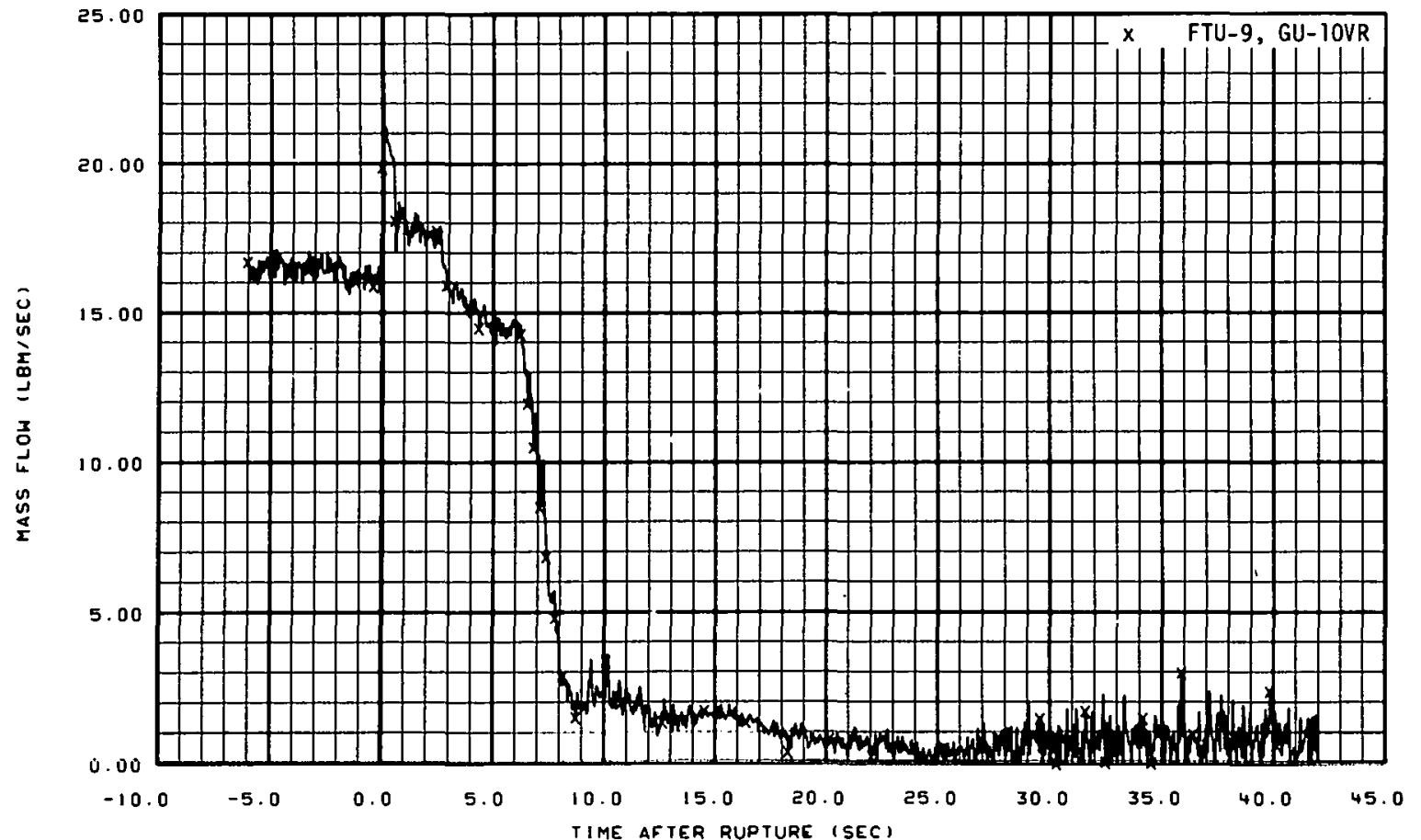

Fig. 270 Mass flow in intact 10op (FTU-9 and GU-10VR), from -6 to 42 seconds. 


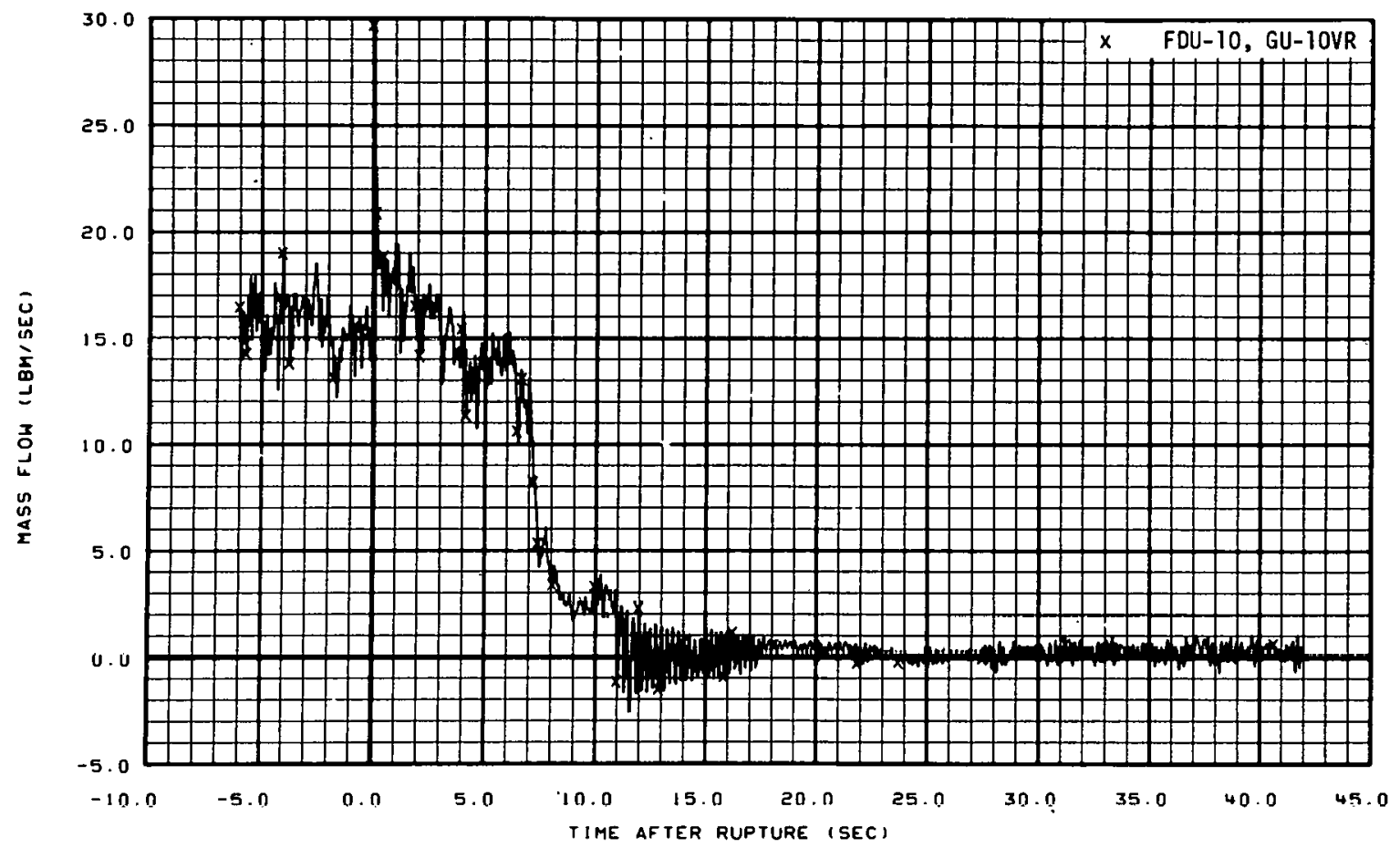

Fig. 271 Mass flow in intact loop' (FDU-10 and GU-10VR), from -6 to 42 seconds.

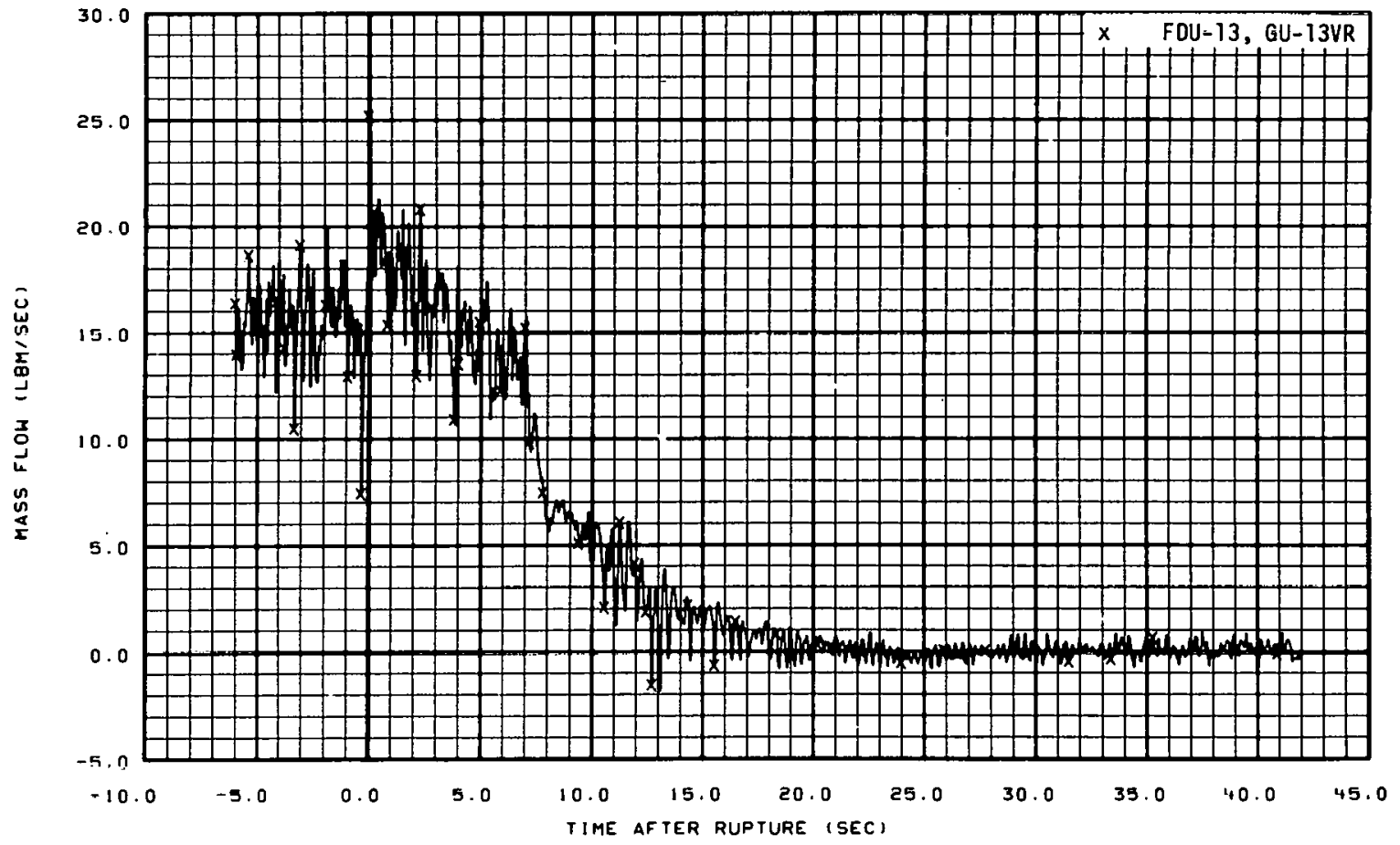

Fig. 272 Mass flow in intact loop (FDU-13 and FU-13VR), from -6 to 42 seconds. 


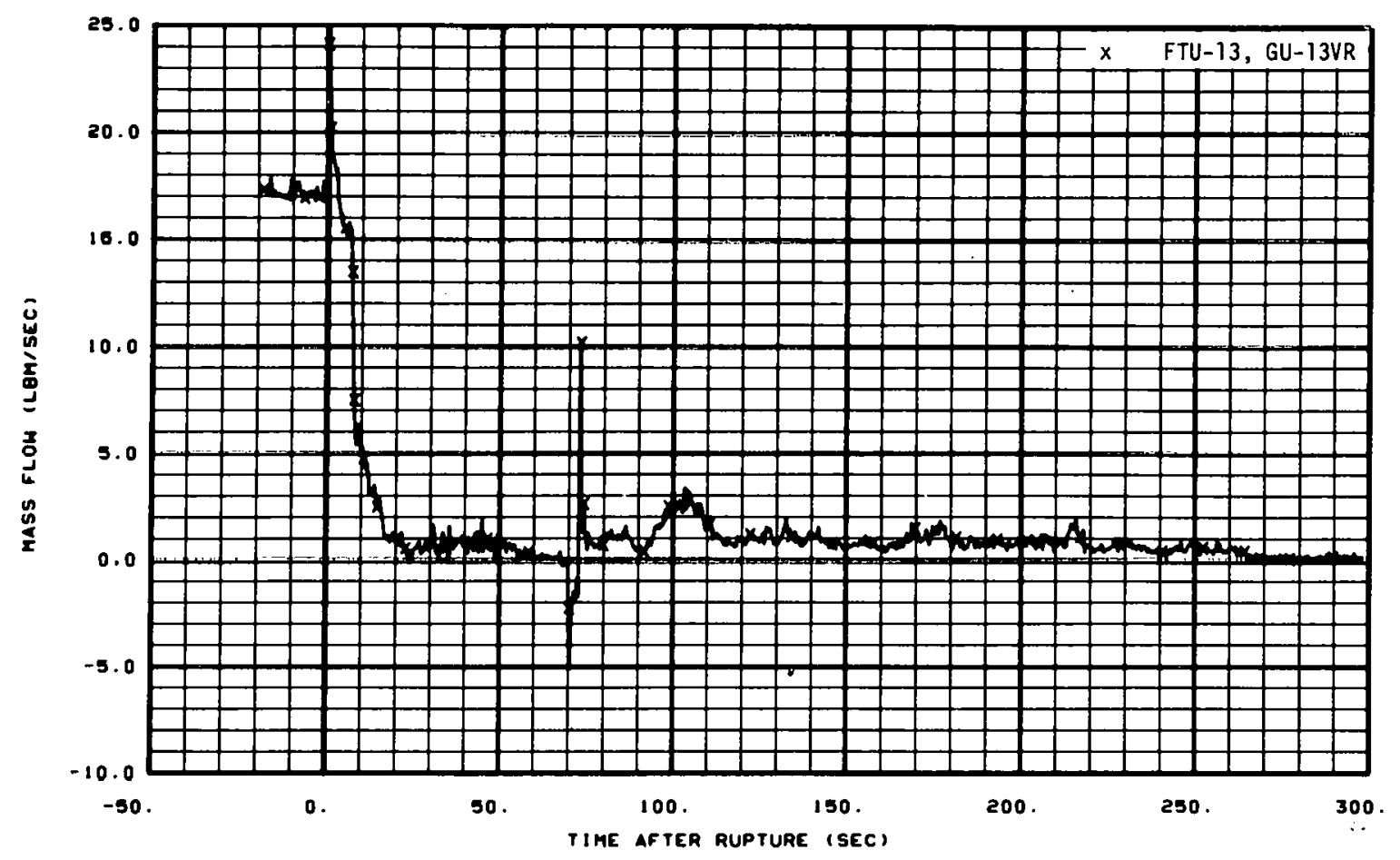

Fig. 273 Mass flow in intact loop (FTU-13 and GU-13VR), from -20 to 300 seconds.

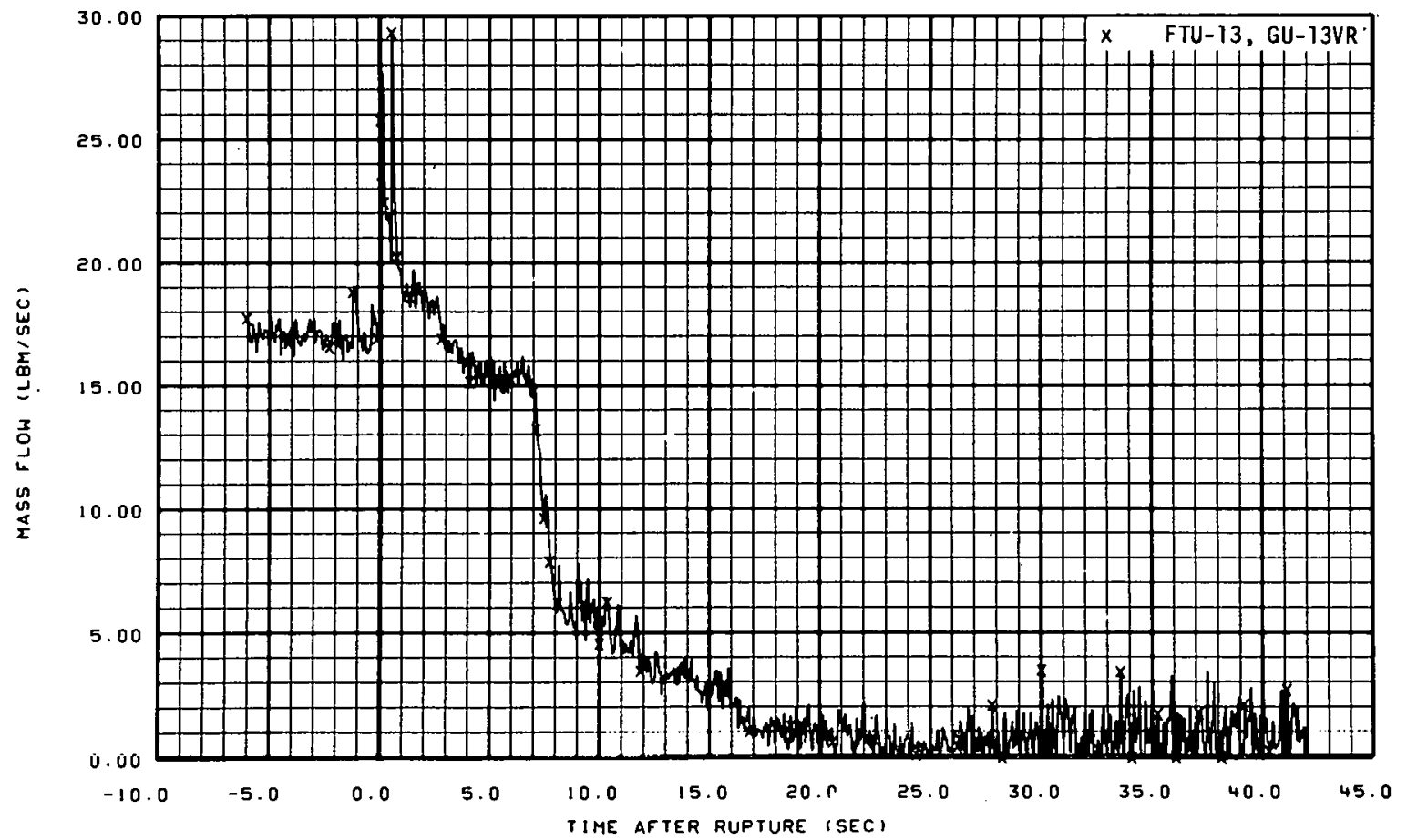

Fig. 274 Mass flow in intact loop (FTU-13 and GU-13VR), from -6 to 42 seconds. 


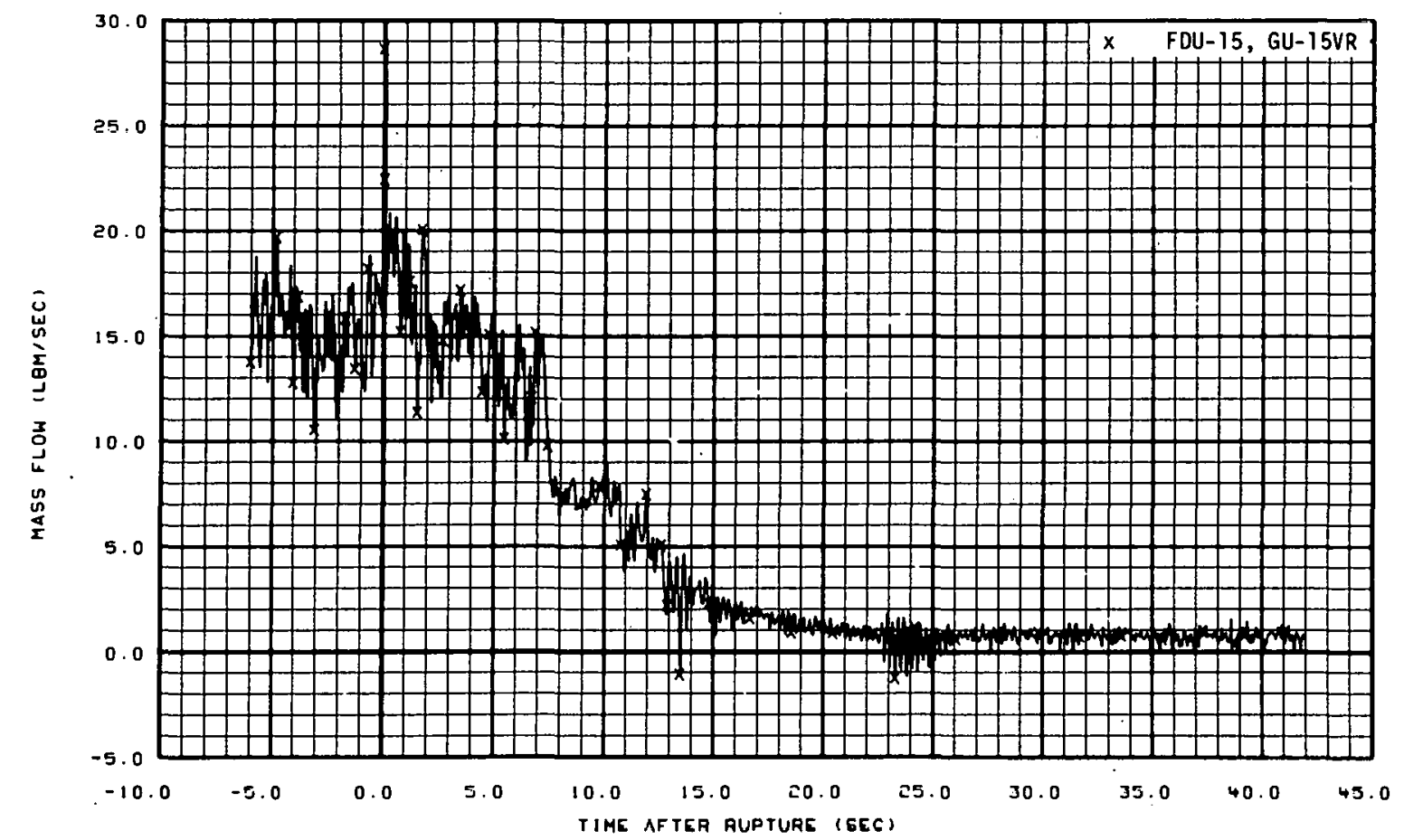

Fig. 275 Mass flow in intact loop (FDU-15 and GU-15VR), from -6 to 42 seconds. 


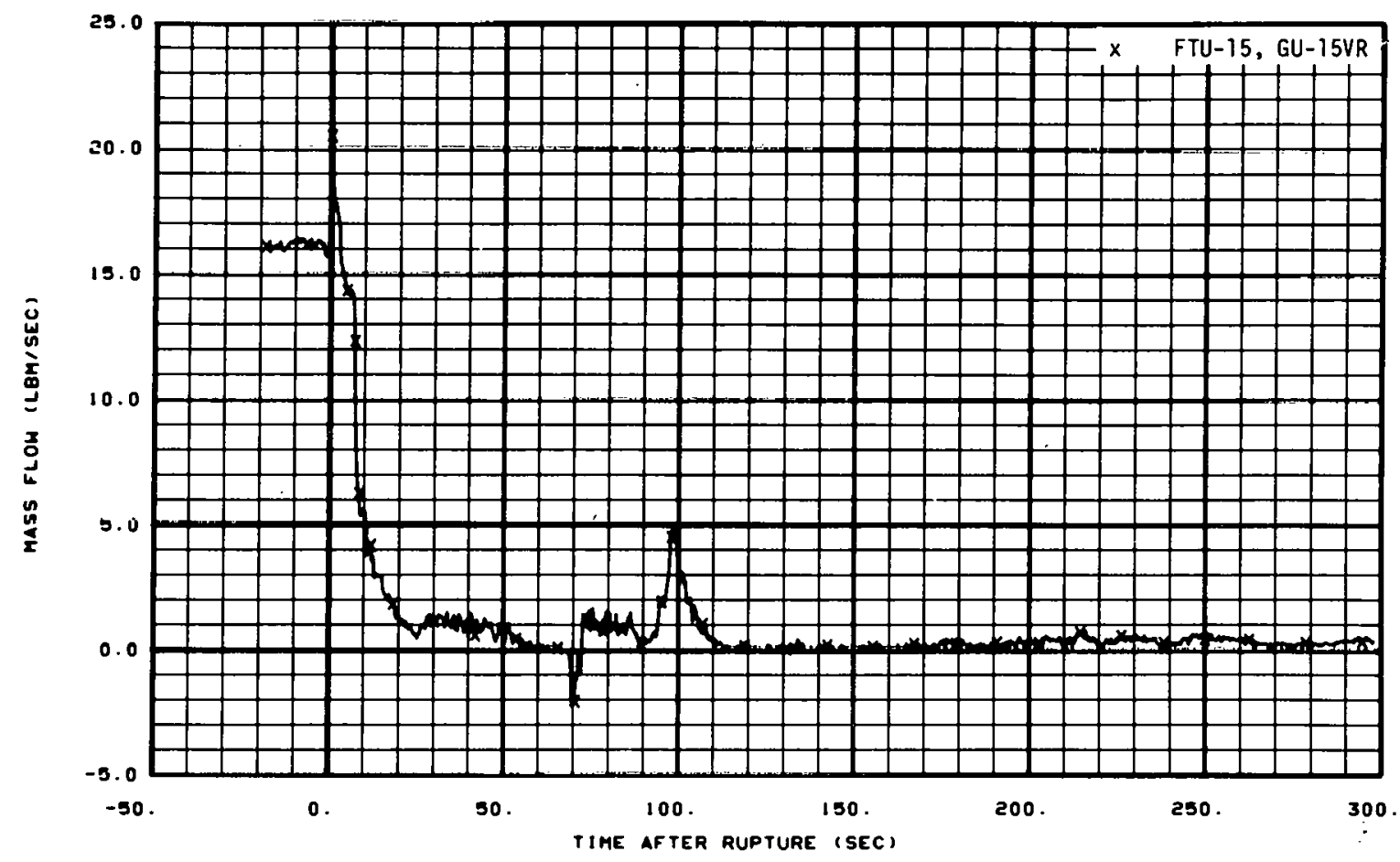

Fig. 276 Mass flow in intact loop (FTU-15 and GU-15VR), from -20 to 300 seconds.

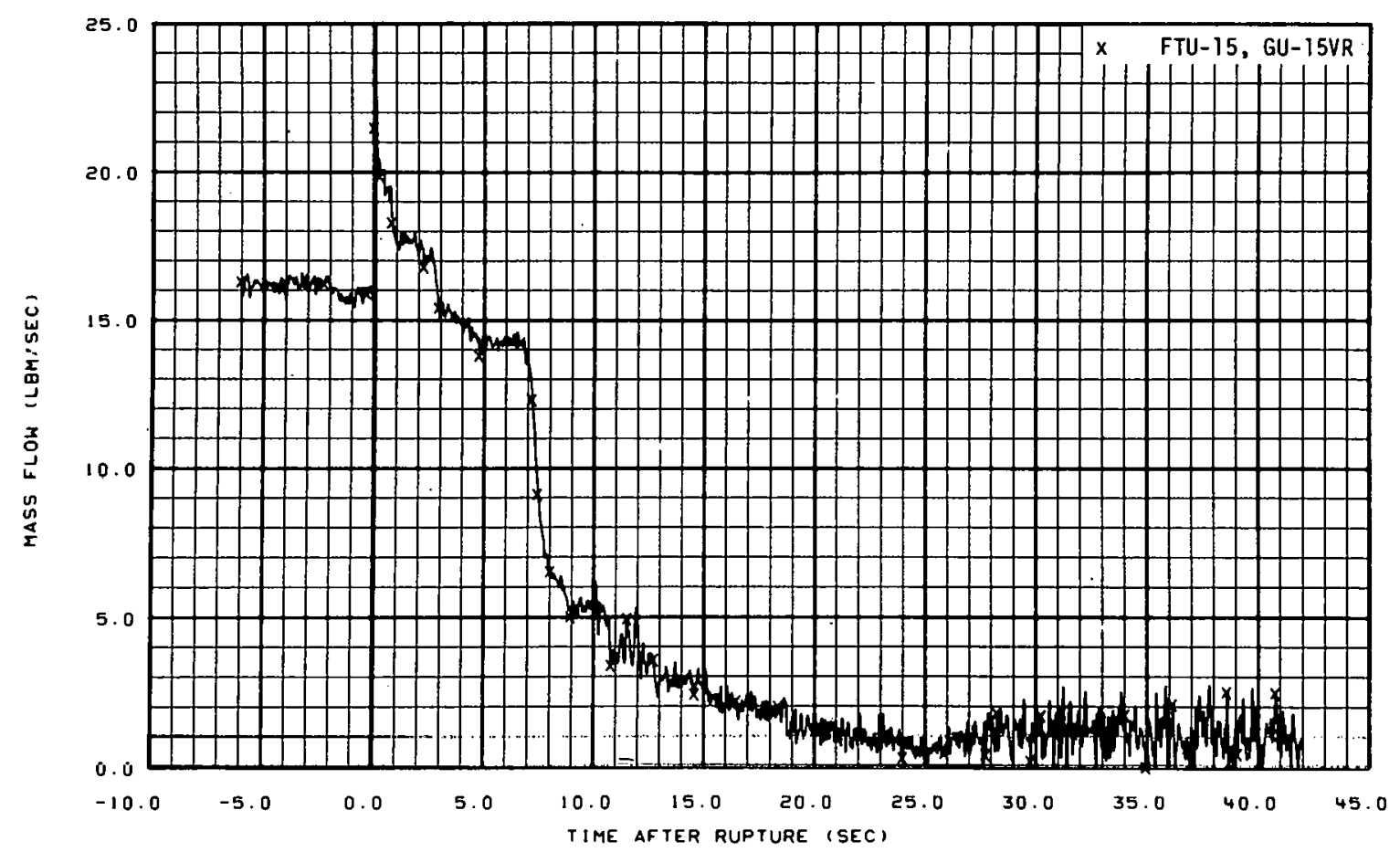

Fig. 277 Mass flow in intact loop (FTU-15 and GU-15VR), from -6 to 42 seconds. 


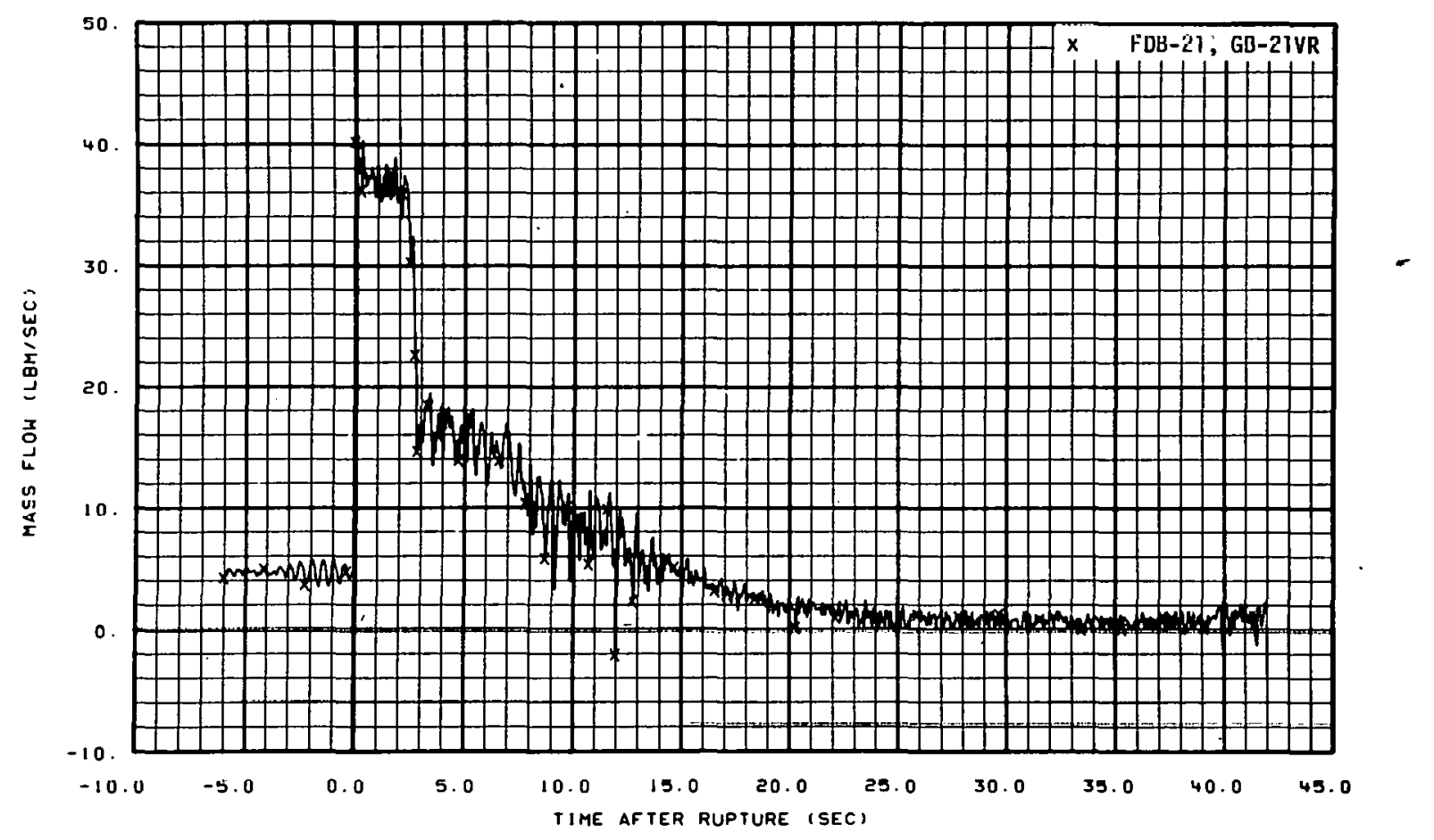

Fig. 278 Mass flow in broken loop (FDB-21 and GB-21VR), from -6 to 42 seconds. 


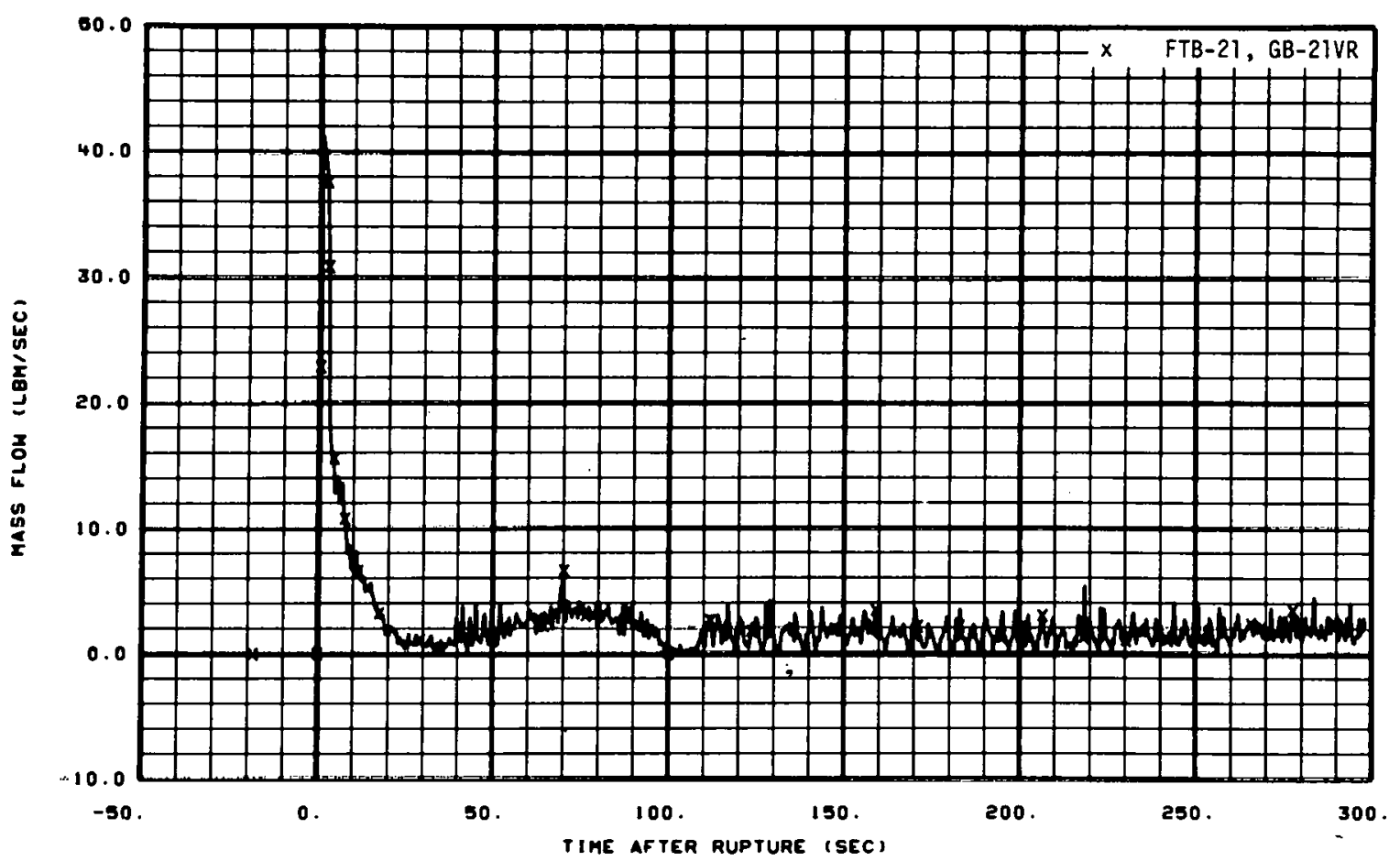

Fig. 279 Mass flow in broken loop (FTB-21 and GB-21VR), from -20 to 300 seconds.

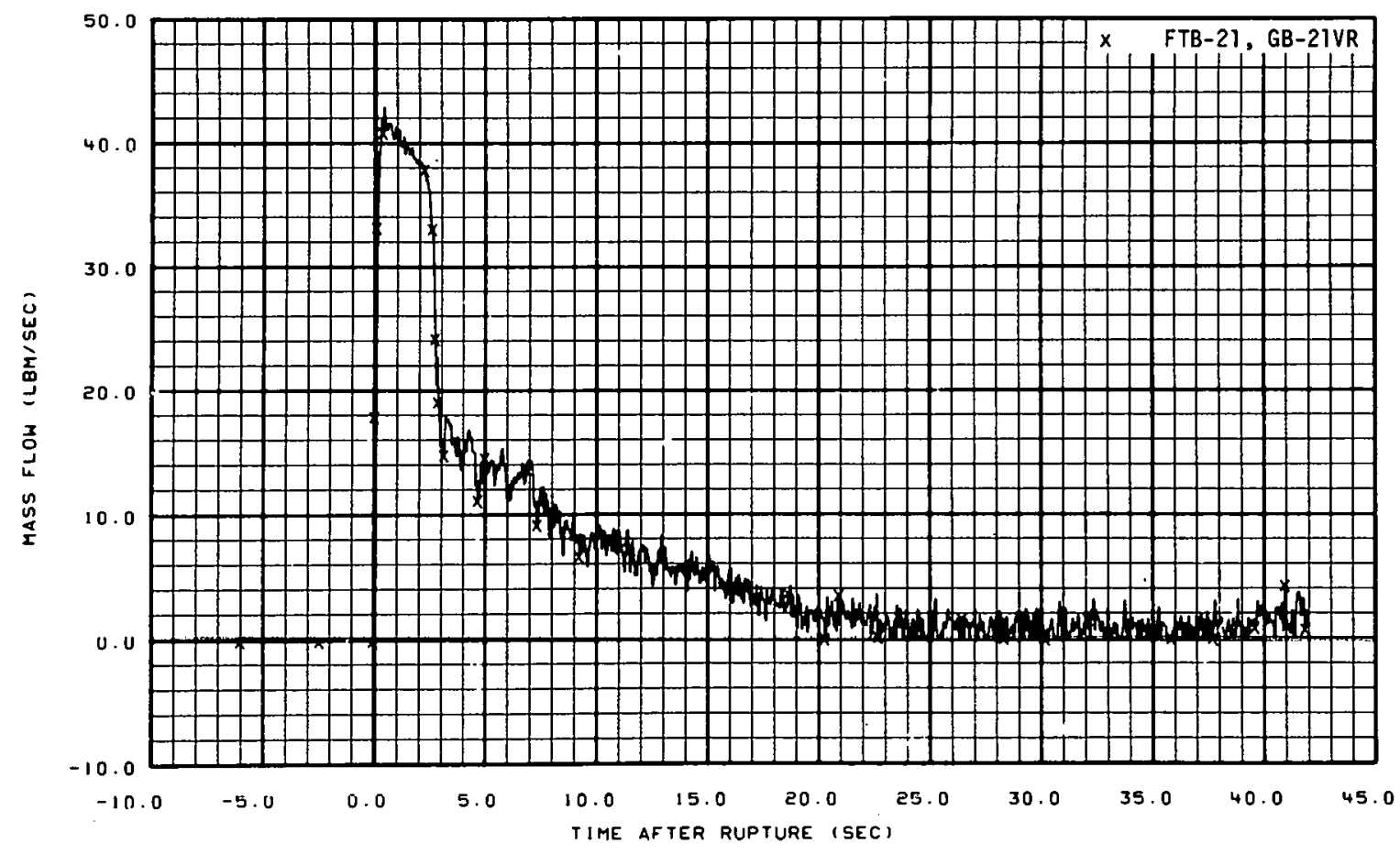

Fig. 280 Mass flow in broken loop (FTB-21 and GB-21VR), from -6 to 42 seconds. 
1

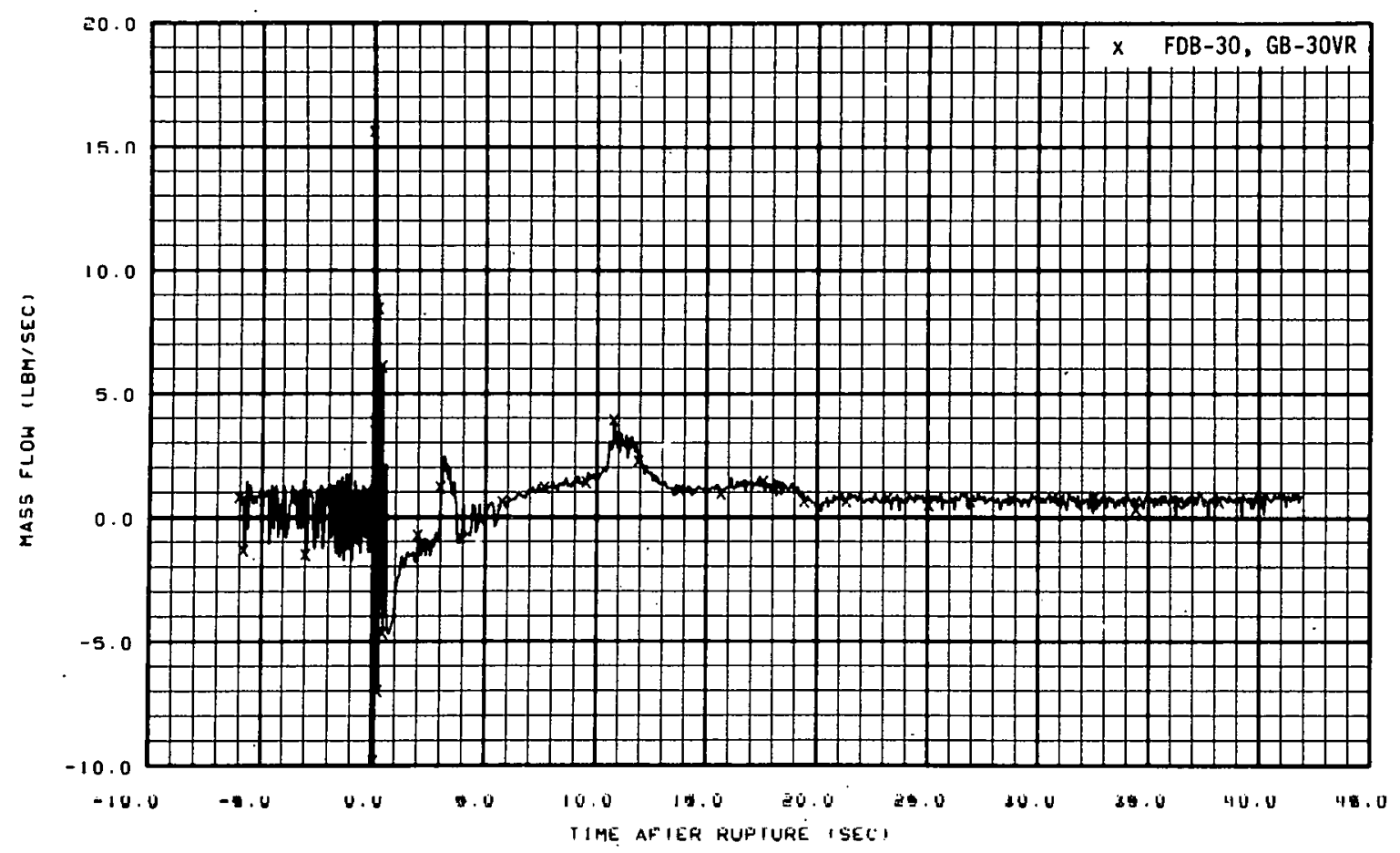

Fig. 281 Mass flow in broken loop (FDB-30 and GB-30VR), from -6 to 42 seconds. 


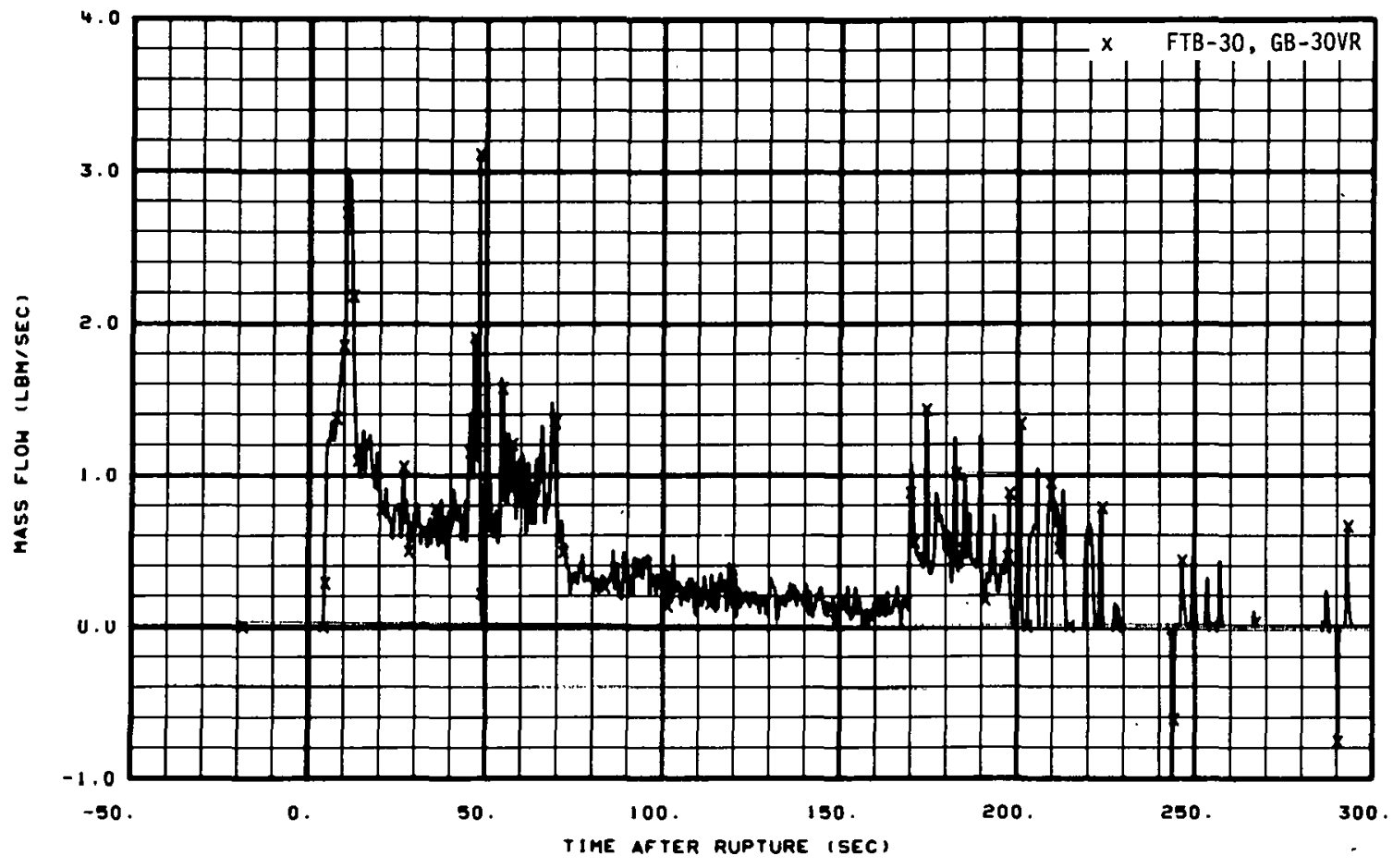

Fig. 282 Mass flow in broken 1oop (FTB-30 and GB-30VR), from -20 to 300 seconds.

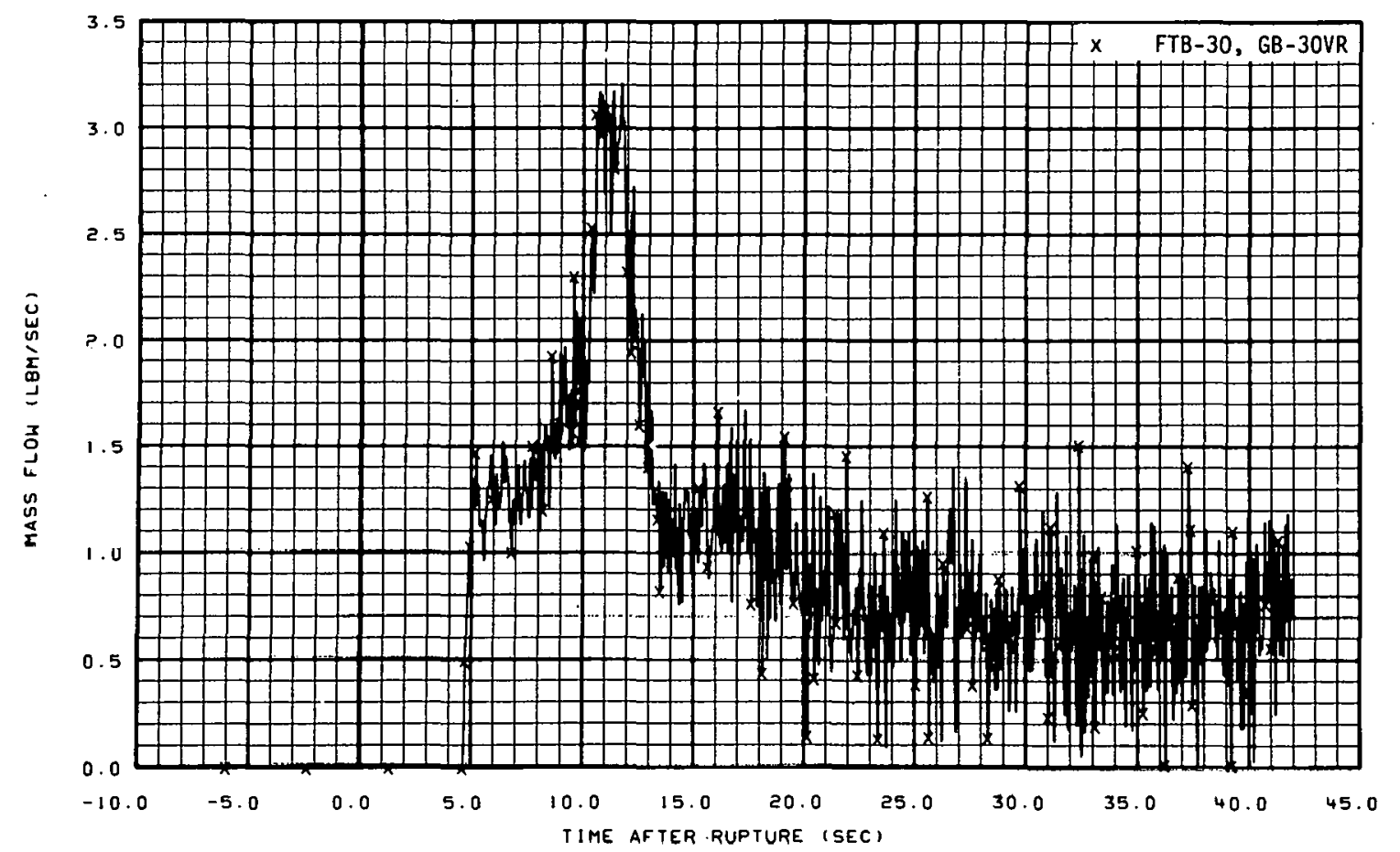

Fig. 283 Mass flow in broken loop (FTB-30 and GB-30VR), from -6 to 42 seconds. 


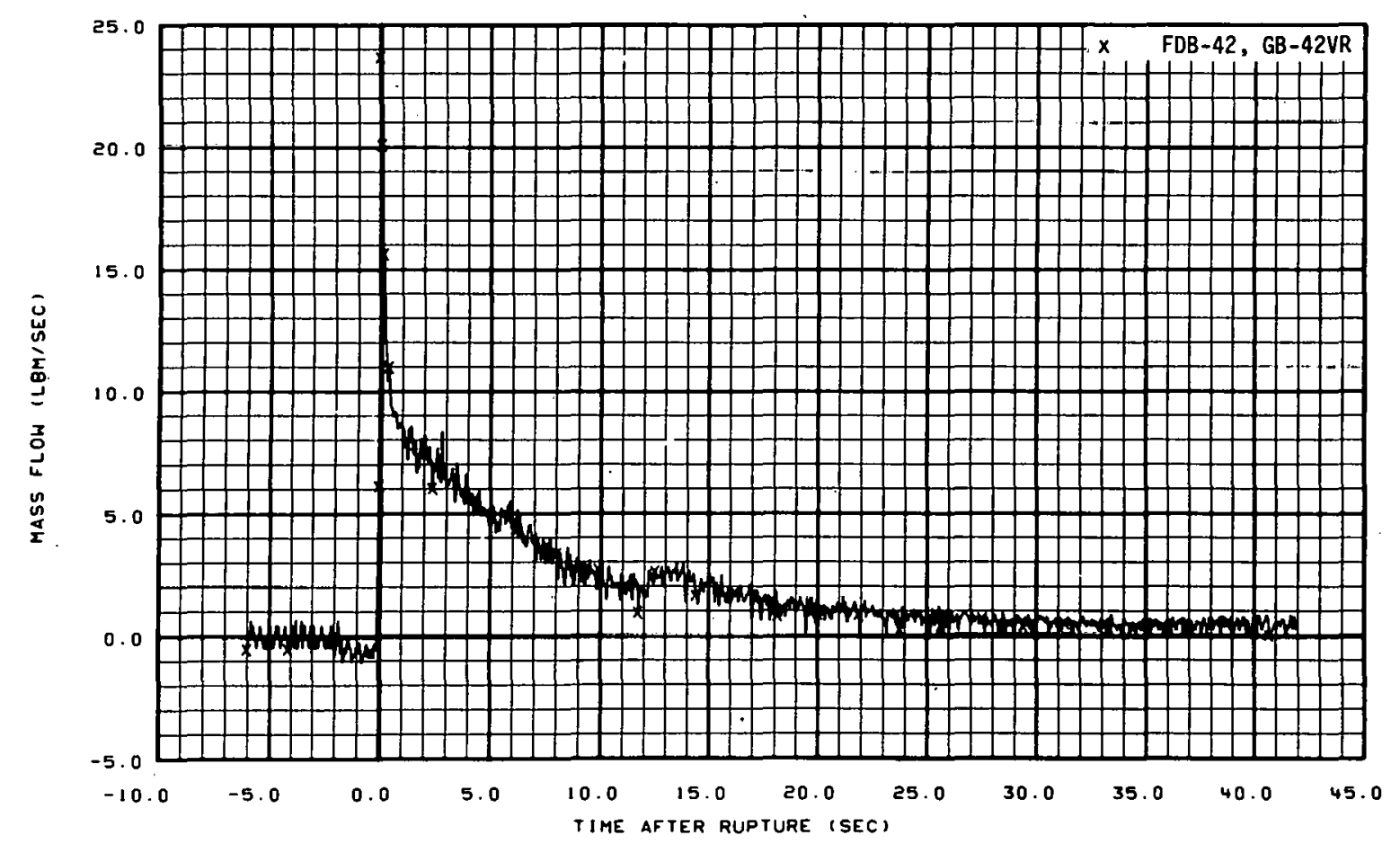

Fig. 284 Mass flow in broken 10op (FDB-42 and GB-42VR), from -6 to 42 seconds. 


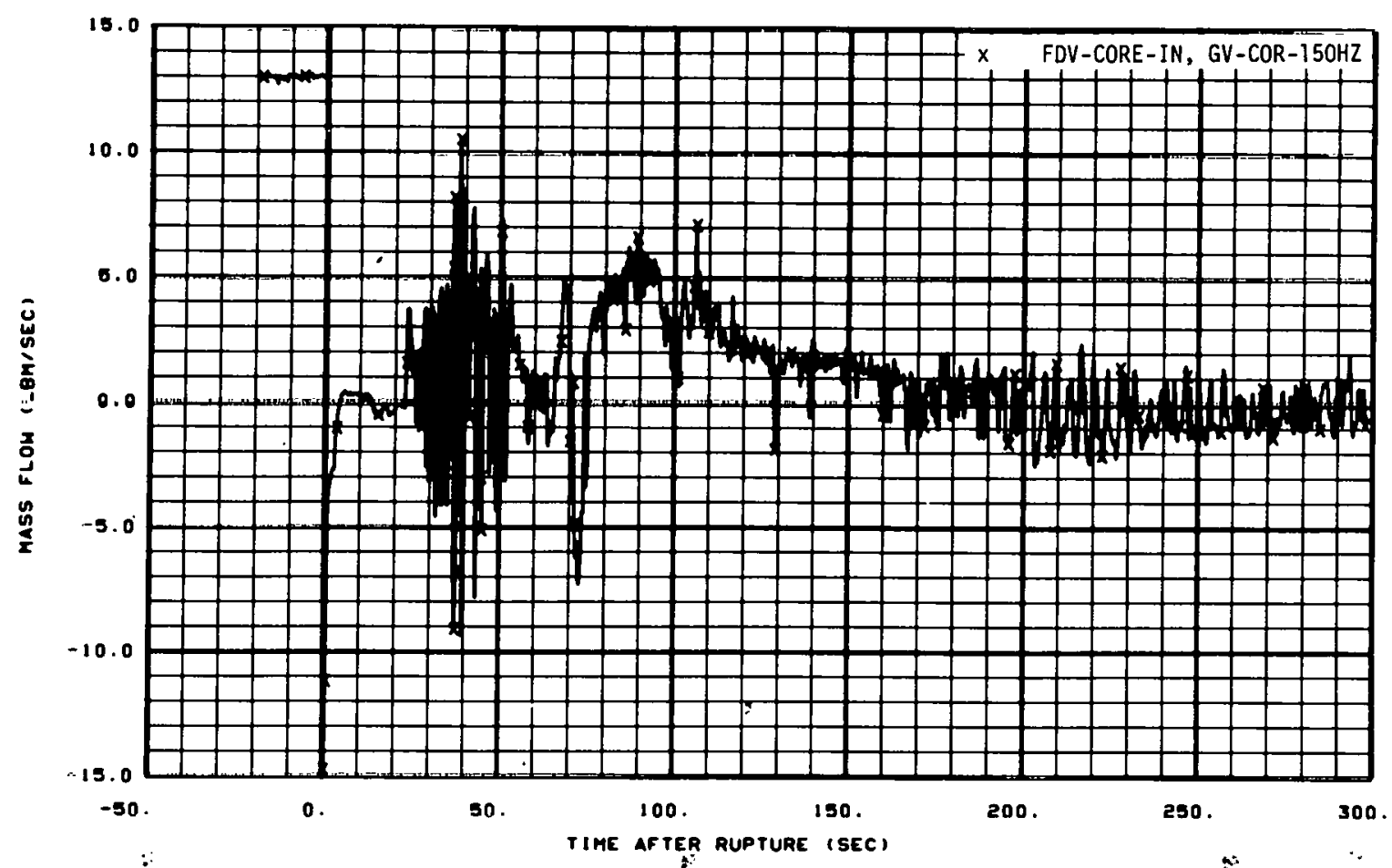

Fig. 285 Mass flow in vessel (FDV-CORE-IN and GV-COR-150HZ), from -20 to 300 seconds.

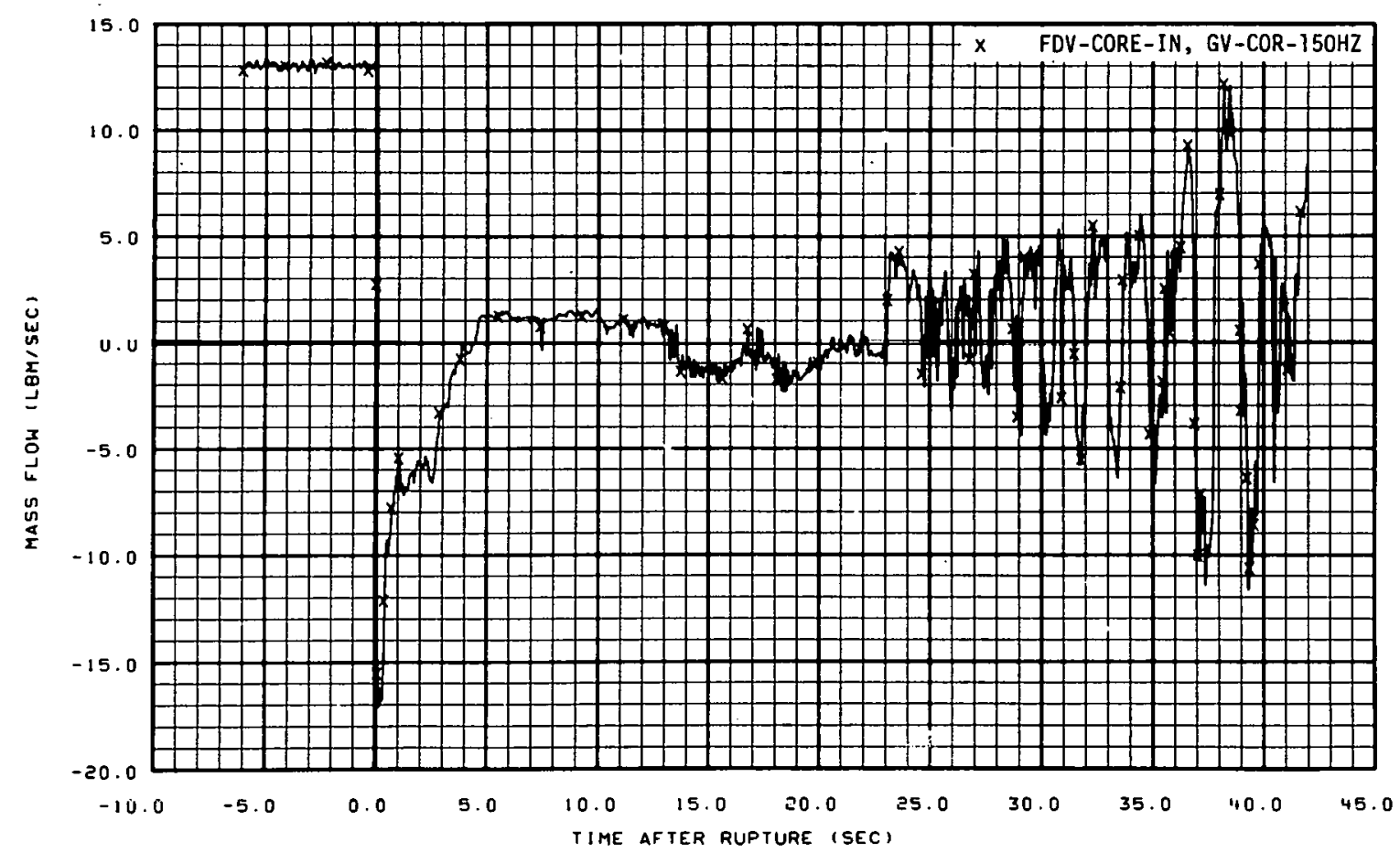

Fig. 286 Mass flow in vessel (FDV-CORE-IN and GV-COR-150HZ), from -6 to 42 seconds. 


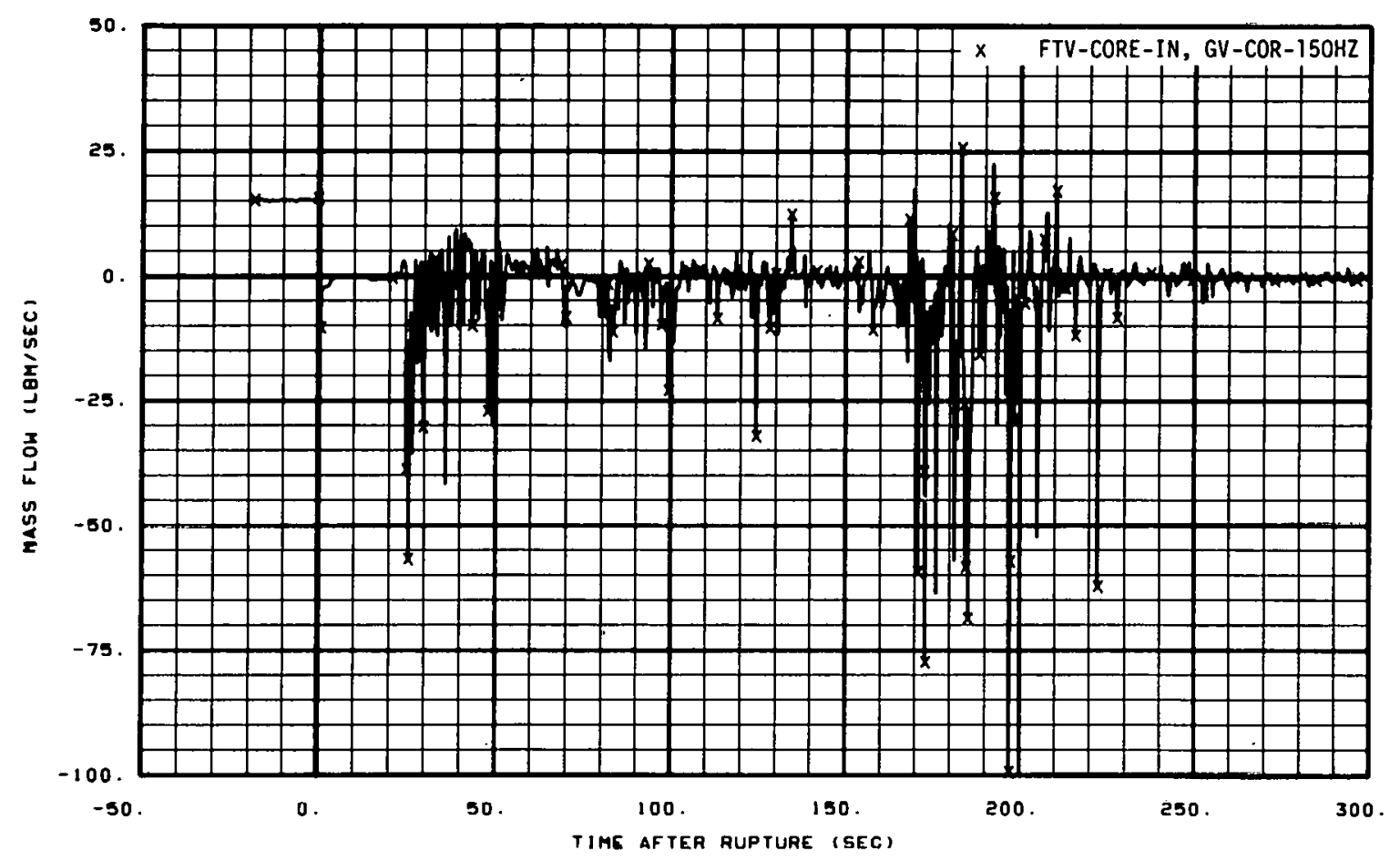

Fig. 287 Mass flow in vessel (FTV-CORE-IN and GV-COR-150HZ), from -20 to 300 seconds.

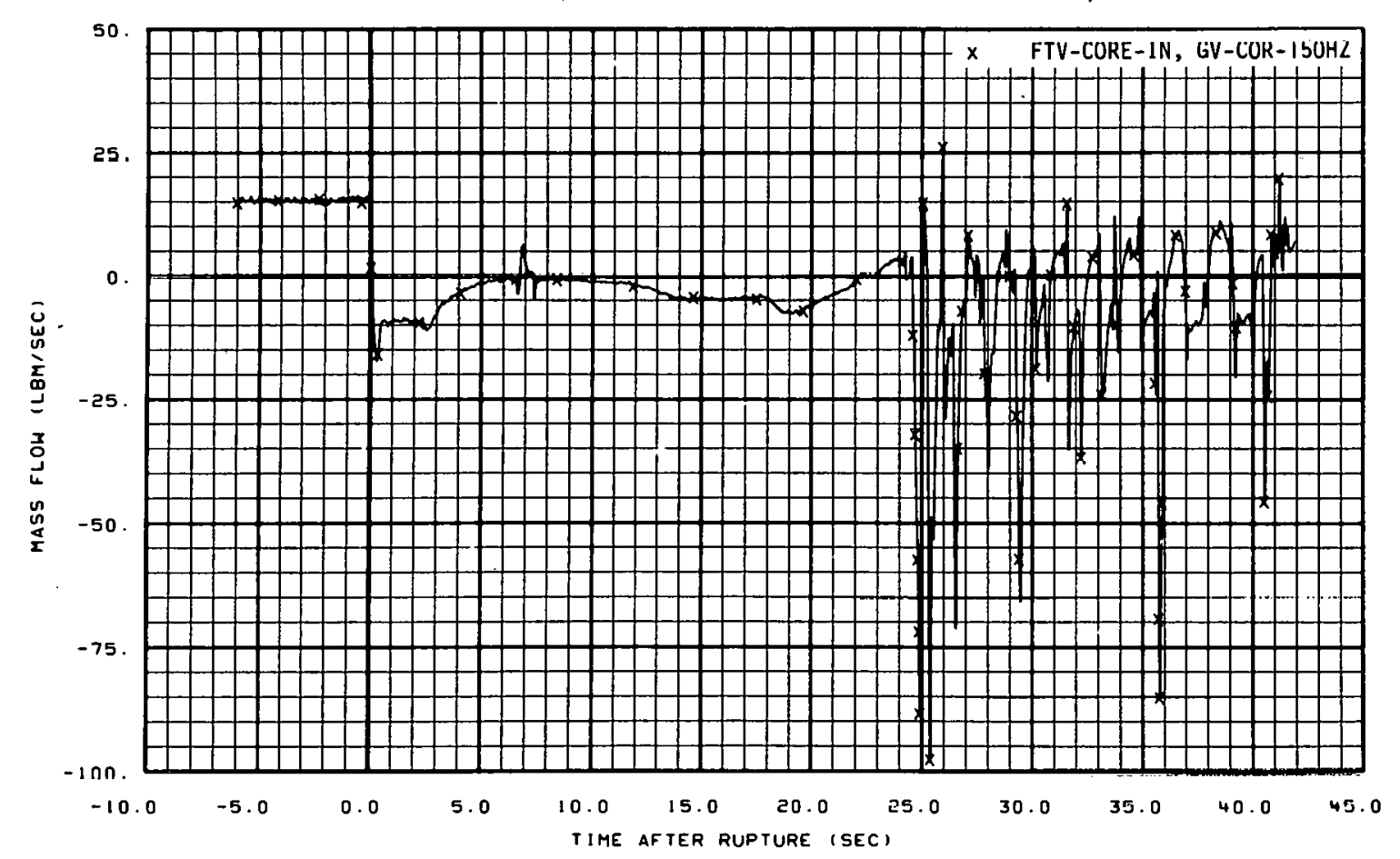

Fig. 288 Mass flow in vessel (FTV-CORE-IN and GV-COR-150HZ), from -6 to 42 seconds. 


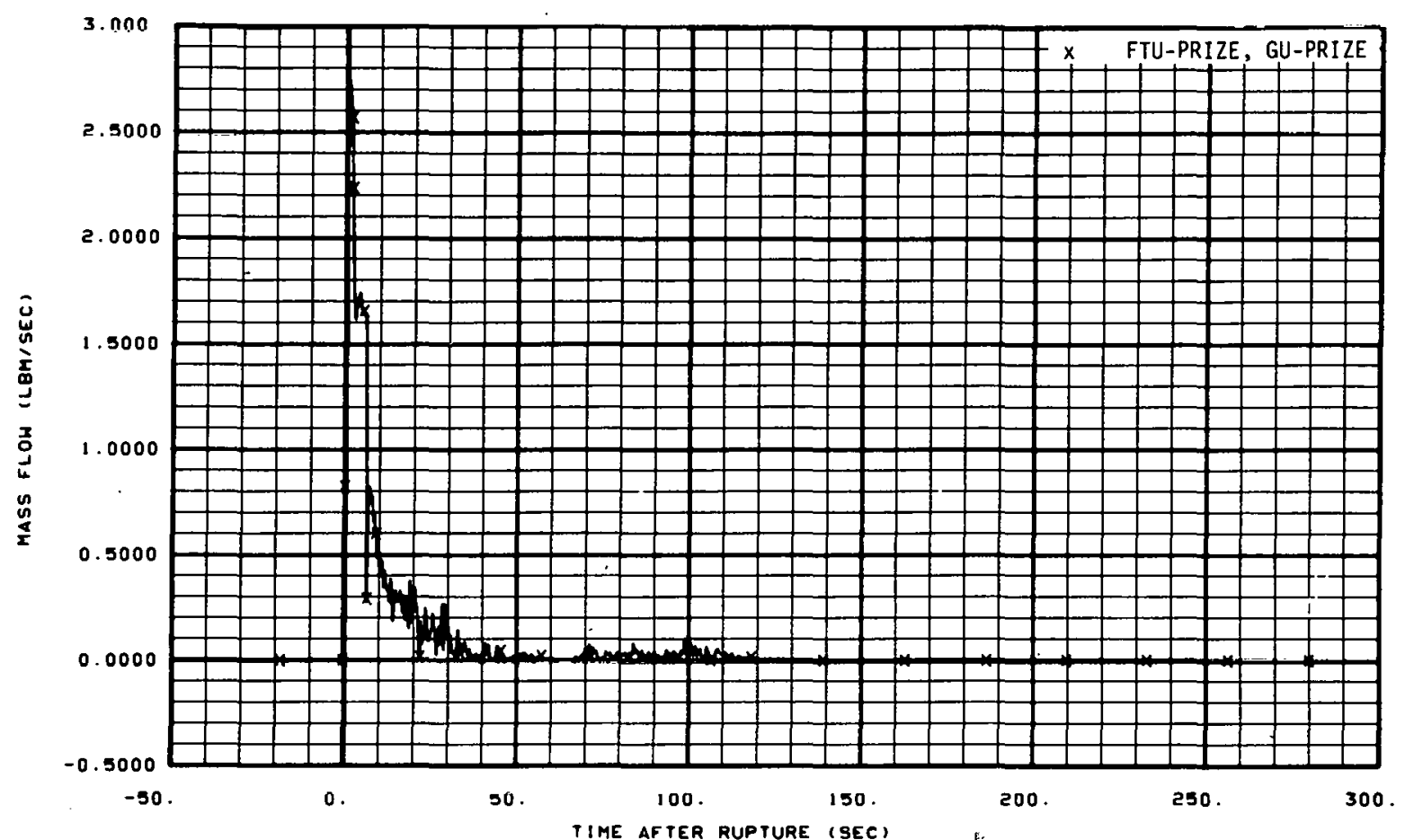

Fig. 289 Mass flow in pressurizer surge line (FTU-PRIZE and GU-PRIZE), from -20 to 300 seconds.

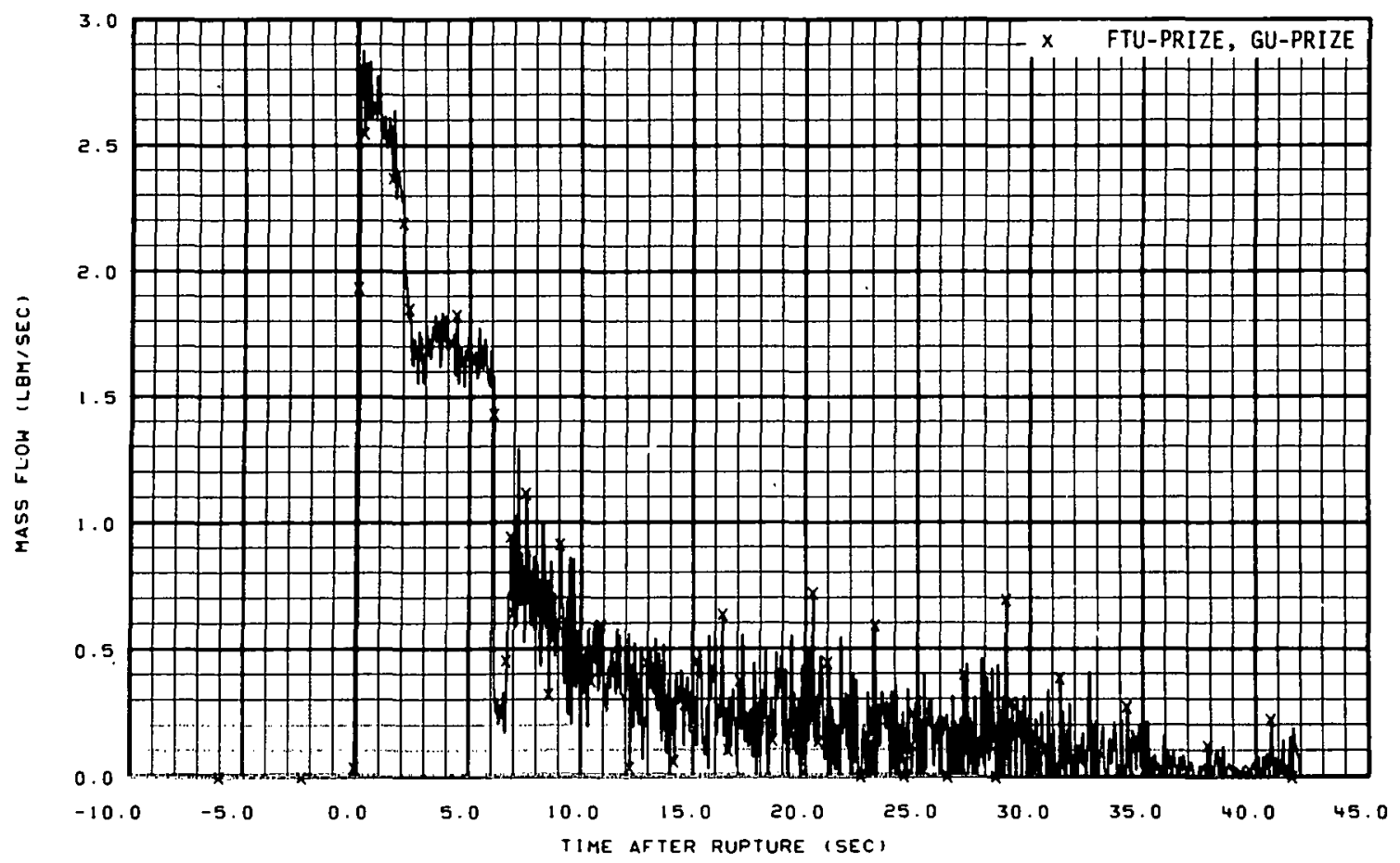

Fig. 290 Mass flow in pressurizer surge line (FTU-PRIZE and GU-PRIZE), from -6 to 42 seconds. 


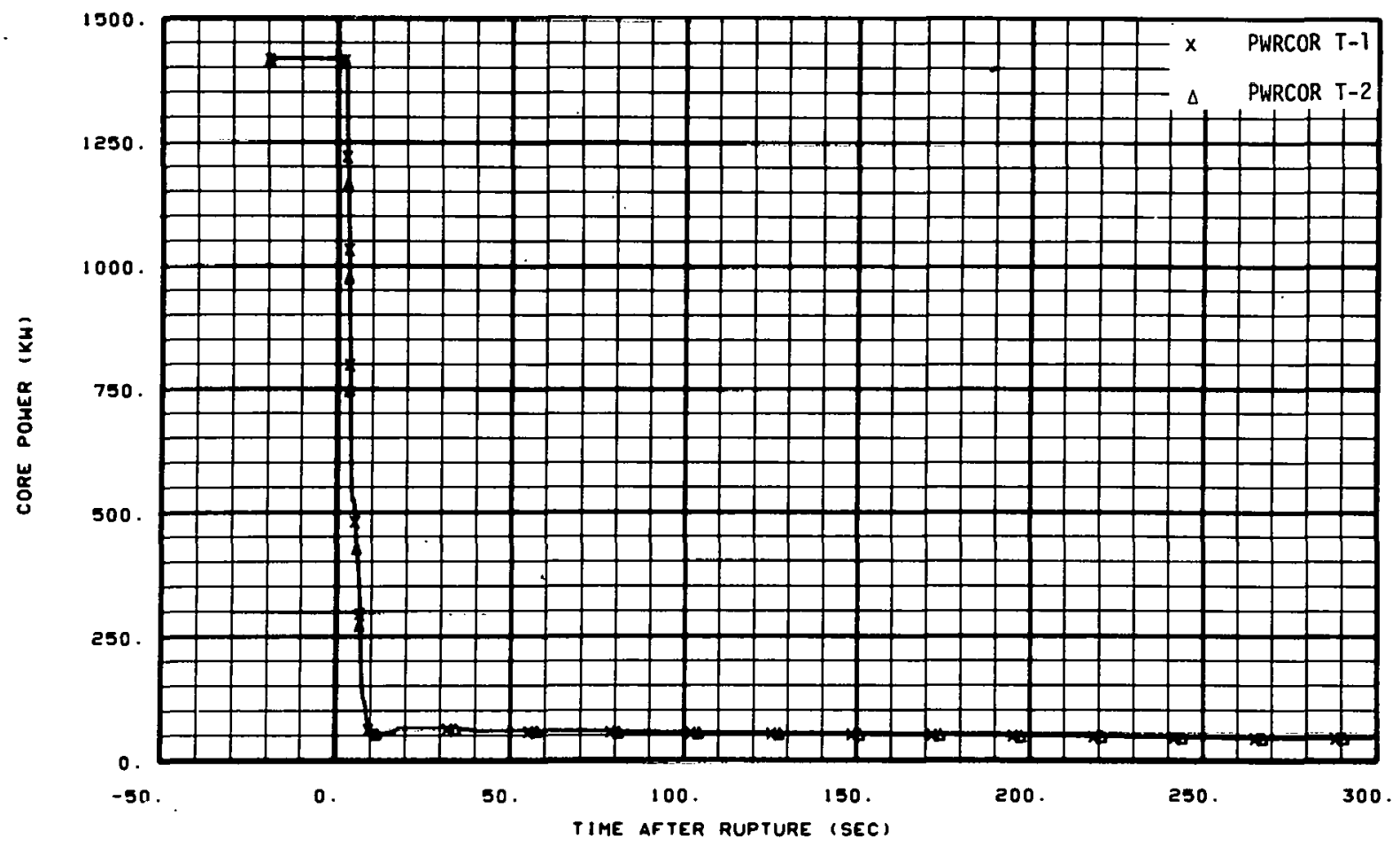

Fig. 291 Core heater pin total power (PWRCOR T-1 and PWRCOR T-2), from -20 to 300 seconds.

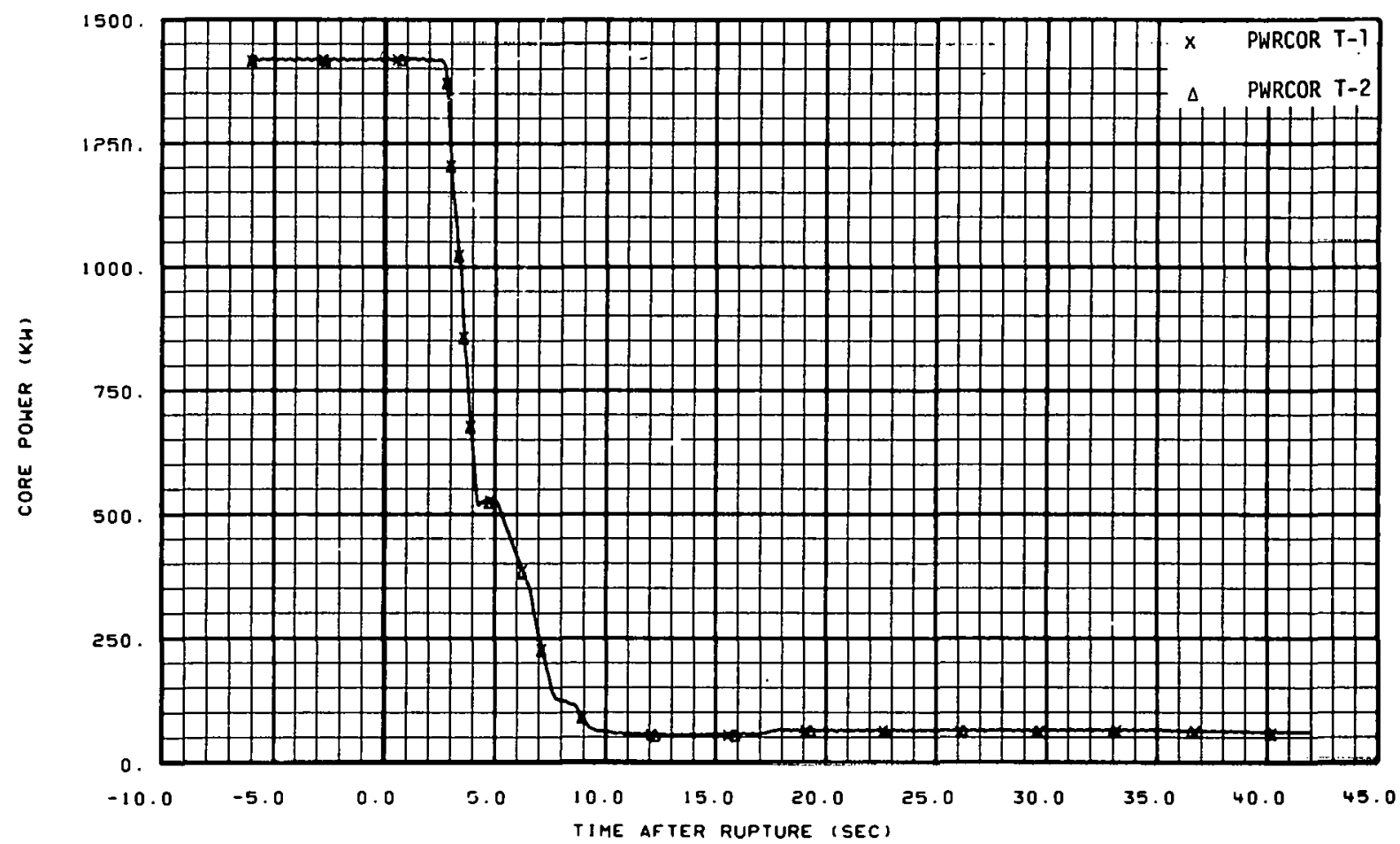

Fig. 292 Core heater pin total power (PWRCOR T-1 and PWRCOR T-2), from -6 to 42 seconds. 


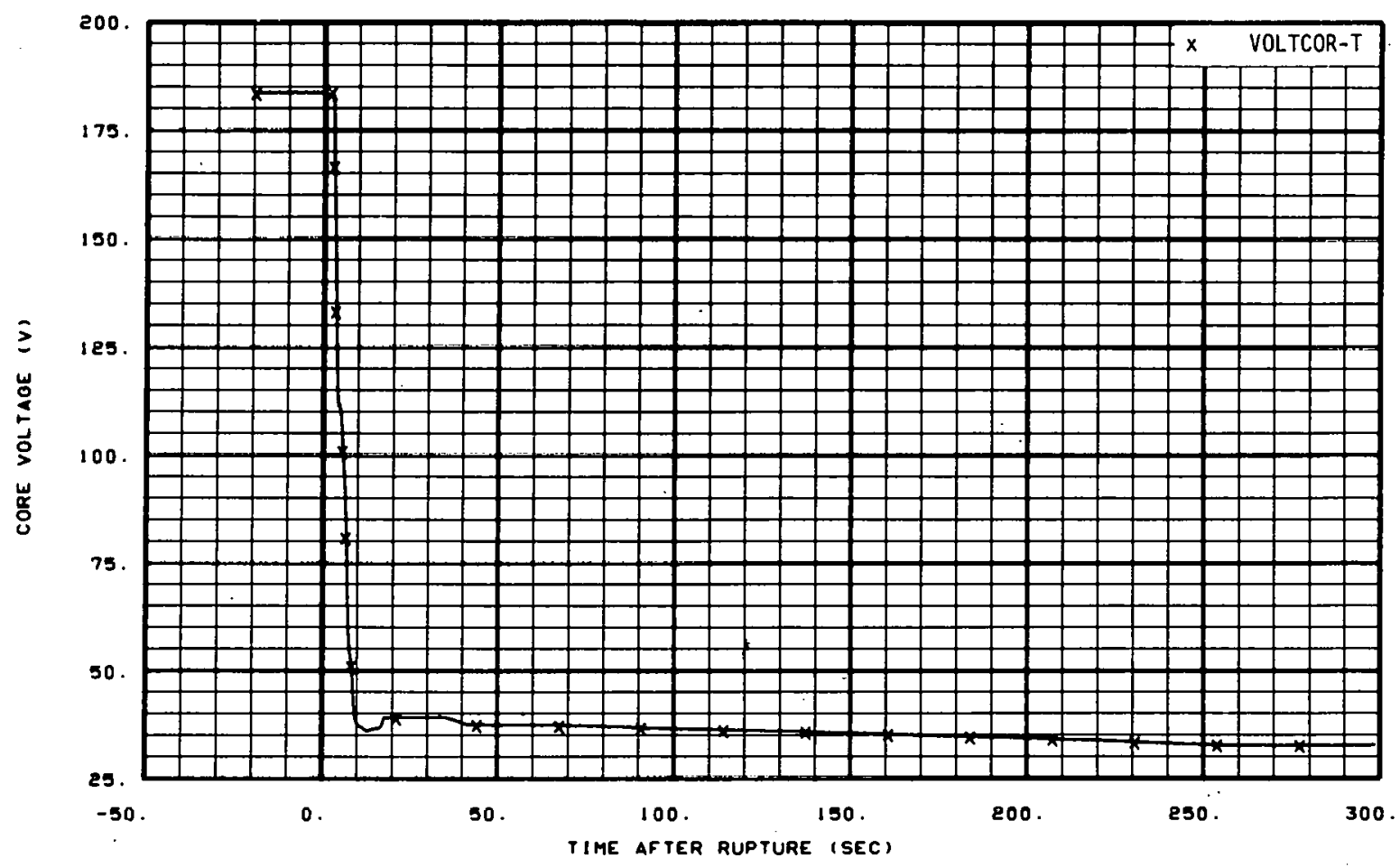

Fig. 293 Core heater voltage (VOLTCOR-T), from -20 to 300 seconds.

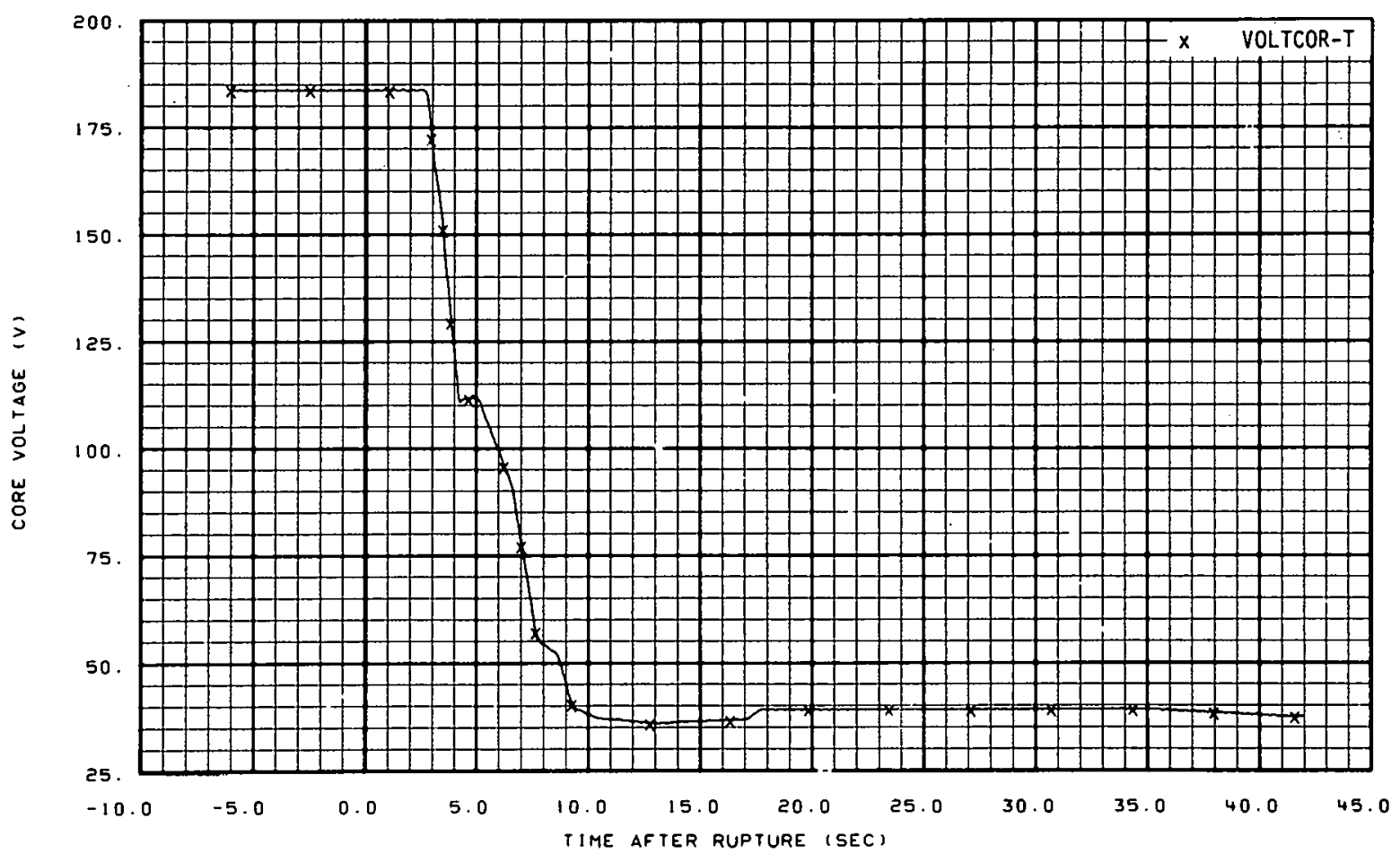

F1g. 294 Core heater vol laye (VOLTCOR-T), rroim -6 to 42 seconds. 


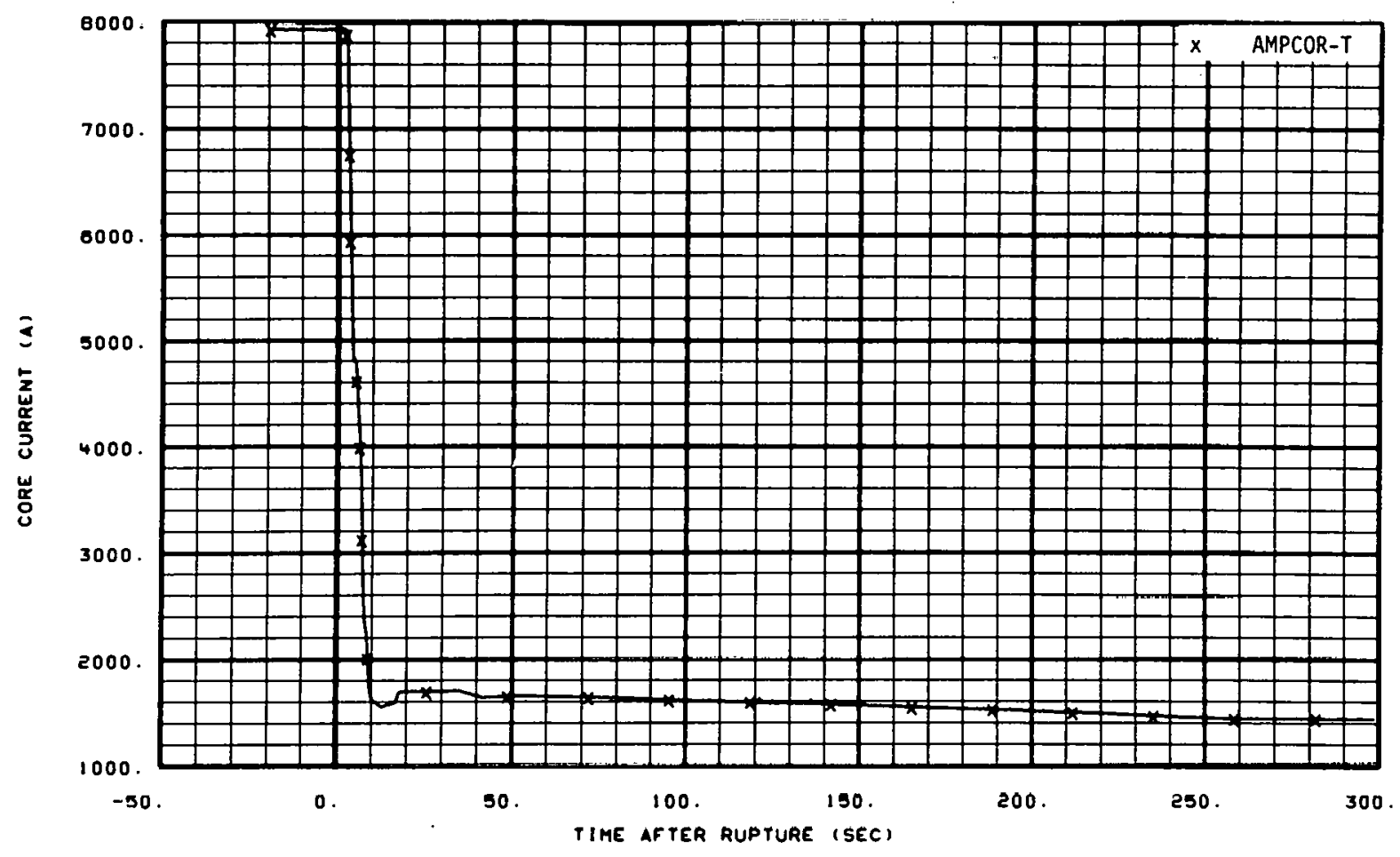

Fig. 295 Core heater total current (AMPCOR-T), from -20 to 300 seconds.

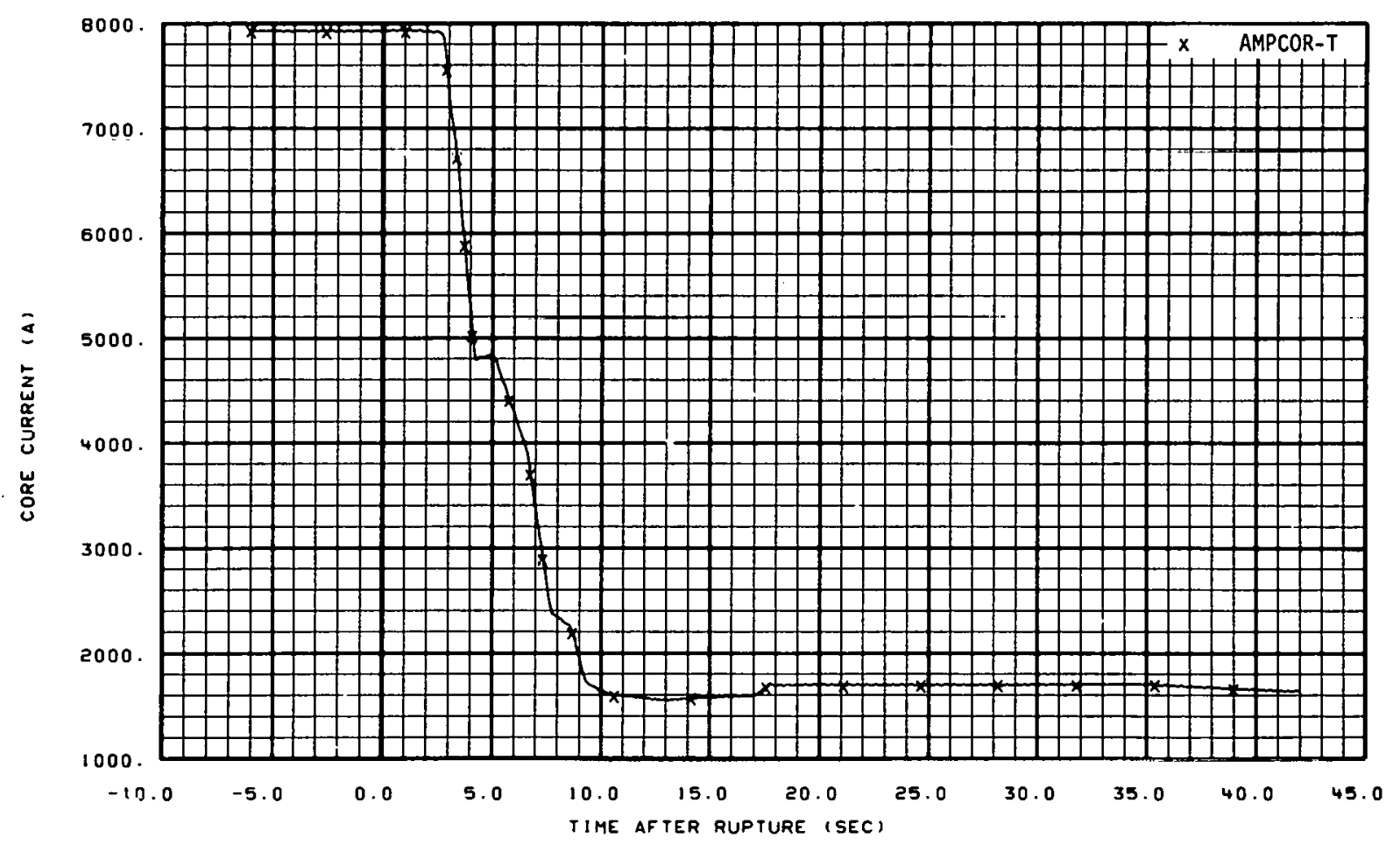

Fig. 296 Core heater total current (AMPCOR-T), from -6 to 42 seconds. 


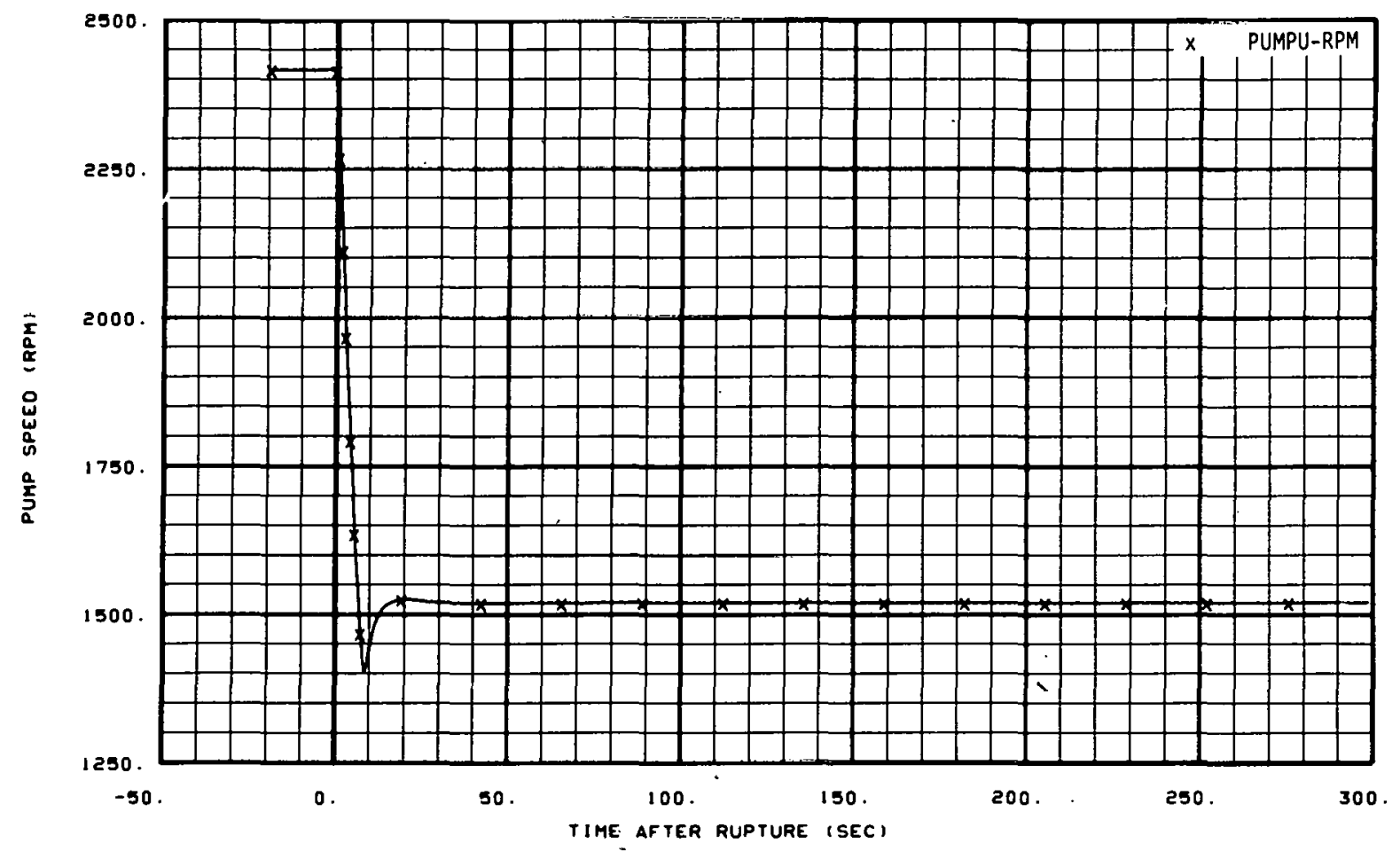

Fig. 297 Primary pump speed (PUMPU-RPM), from -20 to 300 seconds.

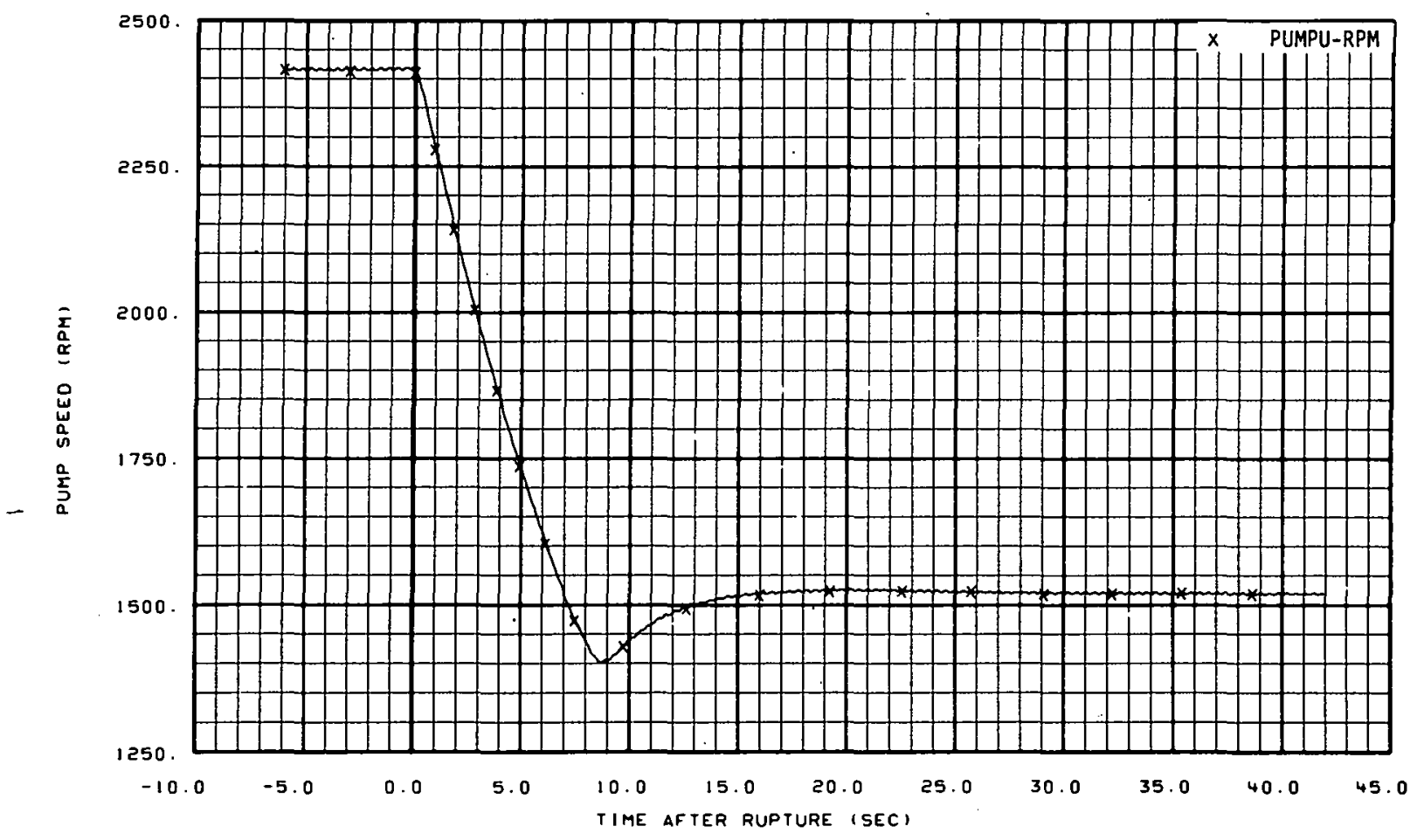

Fig. 298 Primary pump speed (PUMPU-RPM), from -6 to 42 seconds. 


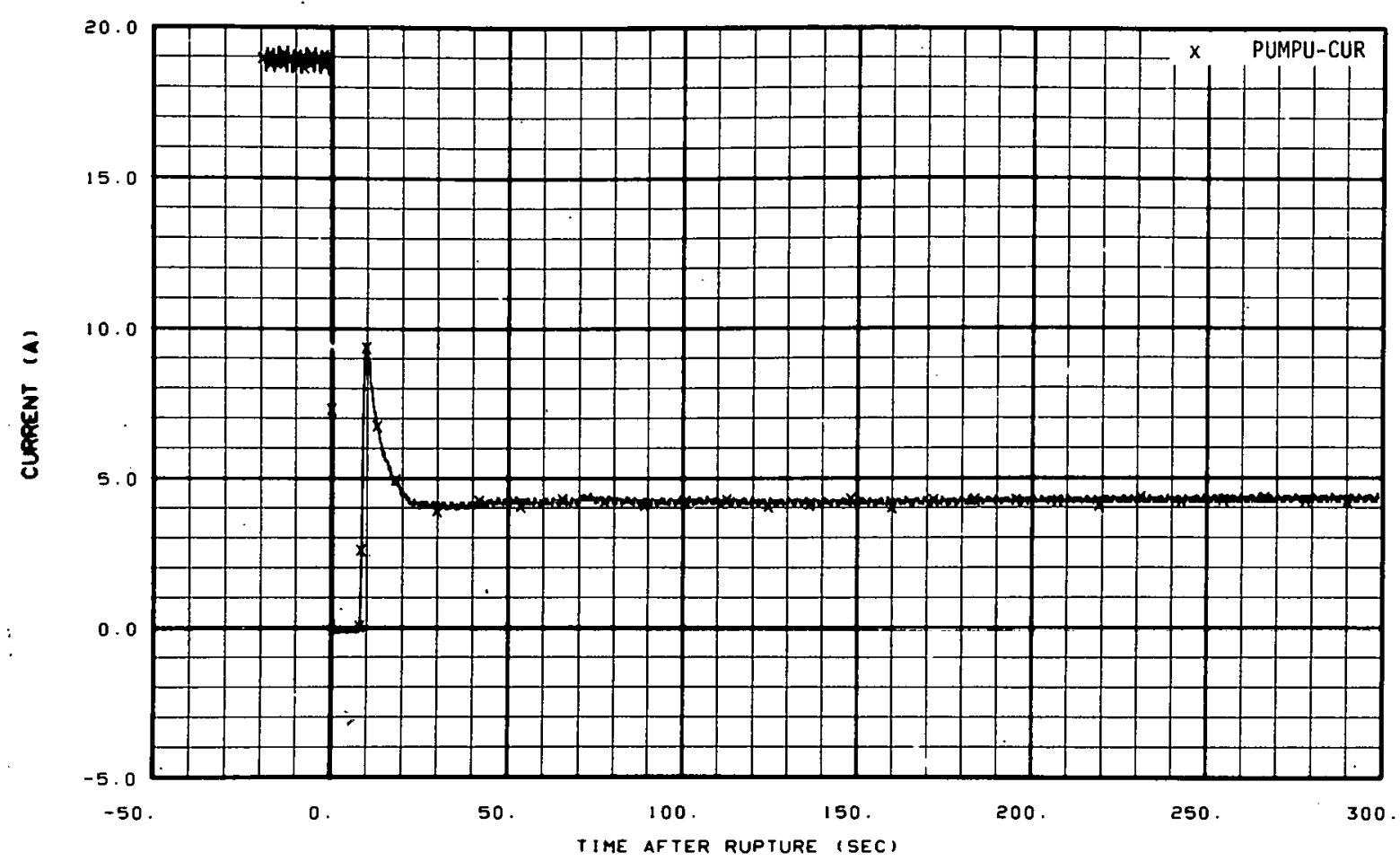

Fig. 299 Primary pump current (PUMPU-CUR), from -20 to 300 seconds.

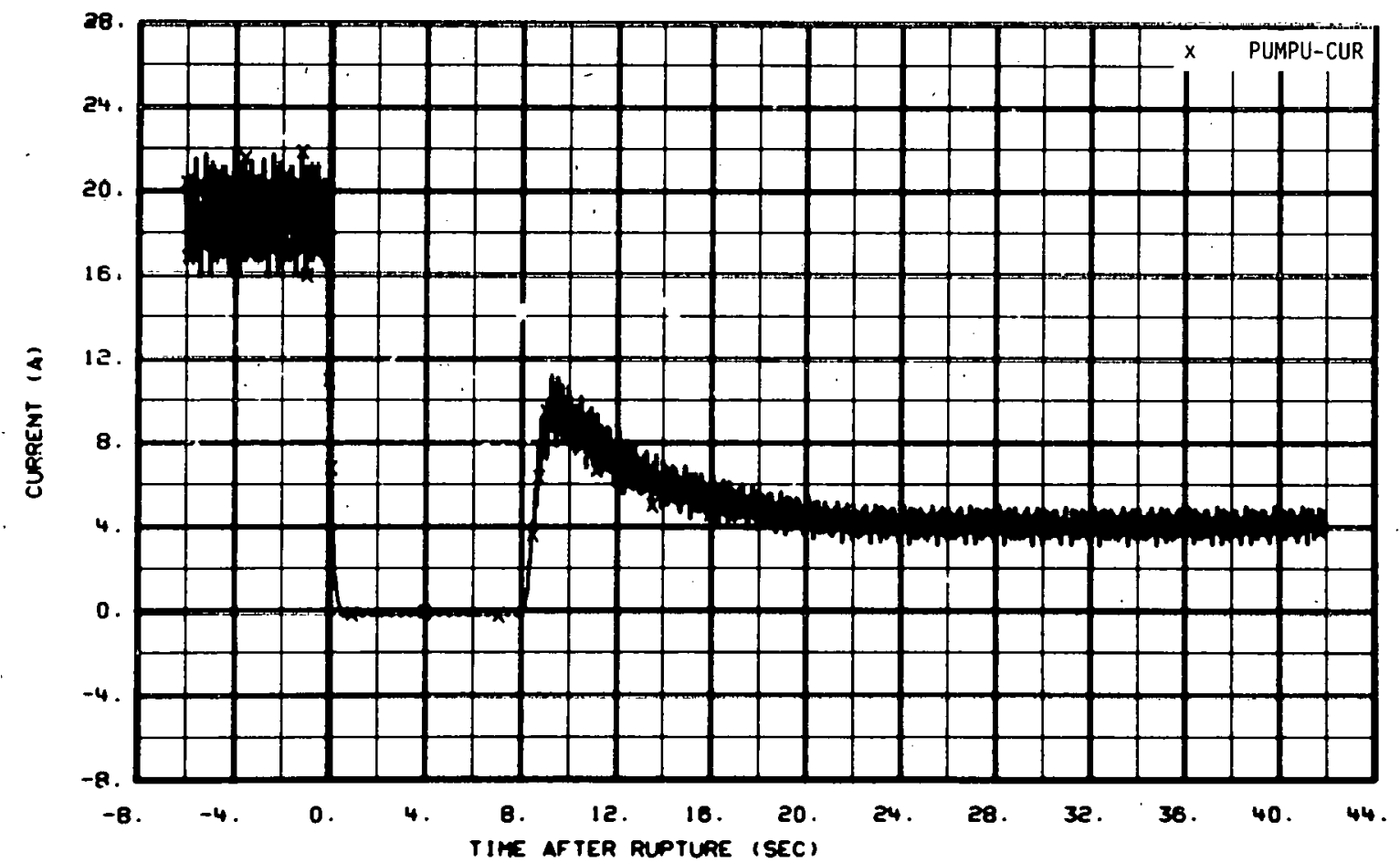

Fig. 300 Primary pump current (PUMPU-CUR), from -6 to 42 seconds. 


\section{REFERENCE}

1. E. M. Feldman and D. J. Olson, Semiscale Mod-1 Program and System Description for the Blowdown Heat Transfer Tests (Test Series 2), ANCR-1230 (August 1975). 


\section{THIS PAGE}

\section{WAS INTENTIONALLY LEFT BLANK}




\section{APPENDIX A}

POSTTEST ADJUSTMENTS TO DATA FROM

SEMISCALE MOD-1 TEST S-05-1 


\section{THIS PAGE WAS INTENTIONALLY LEFT BLANK}




\title{
APPENDIX A \\ POSTTEST ADJUSTMENTS TO DATA FROM
}

\author{
SEMISCALE MOD-1 TEST S-05-1
}

Many of the transducers used in the Semiscale Mod-1 system exhibit significant sensitivity to one or more spurious inputs. Strain gage bridge circuits used in pressure transducers, differential pressure transducers, and drag discs are sensitive to changes in ambient temperature. Differential pressure cells are also sensitive to changes in system pressure. Photomultiplier tubes used as gamma ray detectors in the density transducers are sensitive to temperature changes, as well as to random variations in the locations of the radiation sources. Core power measurements depend on a calibrated resistor, which changes in value as a function of time and power level as it heats up.

Although the errors introduced into the data by spurious secondary inputs generally do not excced the specified error ranges of the transducers, significant improvement in measurement accuracy can be achieved if the secondary sensitivity can be identified and removed. In the case of the drag discs, corrections are absolutely necessary because the signal due to temperature fluctuations can exceed that due to flow by several hundred percent. Since the exact values of the spurious inputs to which different transducers might be sensitive cannot often be easily predicted and are sometimes inconvenient to measure, secondary effects have been accounted for by correcting the data after the test rather than by using elaborate real time programs in the data acquisition system computer. The methods and results of the posttest data correction analysis for Test S-05-1 are presented in the following paragraphs and tables.

\section{PRESSURE MEASUREMENTS}

Corrections to pressure transducer measurements in the main system loop are based on data taken from the standard reference (Heise) gage at Spool 4, taken 15 seconds before initiation of blowdown and 300 seconds after initiation of blowdown. The pressurc rcadings are adjusted to account for pressure variations around the main loop, using the readings of nearby differential pressure cells. A linear correction is then applied to the pressure data to match the data to the calculated reference data at the two specified time points.

Correction of the steam generator secondary pressure (PU-SGSD) measurement is done in the same manner as for the main loop pressures using a Heise gage installed expressly for this purpose.

Pressure measurement corrections are performed using the data acquisition system (DAS) computer using the following equation: 
where

$$
F^{\prime}(t)=c_{0}+c_{1} \quad[F(t)]
$$

$\begin{array}{lll}F^{\prime}(t) & = & \text { corrected data } \\ F(t) & = & \text { raw data } \\ C_{0} & = & \text { offset } \\ C_{1} & = & \text { scaling factor. }\end{array}$

The exact values of $\mathrm{C}_{0}$ and $\mathrm{C}_{1}$ are given in Table $\mathrm{A}-\mathrm{I}$.

TABLE A-I

CONSTANTS FOR PRESSURE MEASUREMENT

CORRECTIONS (TEST S-05-1)

\begin{tabular}{lrr}
$\begin{array}{c}\text { Detector } \\
\text { Identification }\end{array}$ & \multicolumn{1}{c}{$C_{0}$} & $\frac{C_{1}}{1.0167}$ \\
\cline { 1 - 2 } PU-13(F) & -56.5 & 0.9820 \\
PU-SGSD & 57.7 & 0.9993 \\
PV-UP+10 & 1.4 & 0.9877 \\
PU-PRIZE & 10.4 & 0.9953 \\
PB-CN1 & -15.5 & 0.9950 \\
PB-23 & 8.0 & 0.9954 \\
HB-4Z & 5.3 & 0.9956 \\
PB-HN1 & -11.0 & 0.9943 \\
PB-37 & 10.6 & 0.9975 \\
PV-LP-166 & -4.2 &
\end{tabular}

\section{DIFFERENTIAL PRESSURE MEASUREMENTS}

Pressure, sensitivity in the differential pressure cells in the main system loop is determined from the pretest system pressure check. Digital data are recorded for all measurements at ambient temperature, with no system flow, at pressures of ambient, 200, $500,1000,1500,2000$, and 2250 psig. The output of the differential pressure cells is plotted against system pressure, with the resulting plots used to describe the pressure response of the transducers.

The response of the differential pressure cells due to ambient temperature is determined from a digital data scan taken at $500^{\circ} \mathrm{F}$ and $1750 \mathrm{psig}$, with no system flow. The measured transducer outputs are corrected for pressure and compared with the values 
calculated due only to the density difference between the water inside the loop (500\% $\mathrm{F}$ ) and outside the loop in the sense lines ( 80 to $100^{\circ} \mathrm{F}$ ).

The difference between the measured pressure, corrected value and the calculated value is the thermal drift. After the data scan at $500^{\circ} \mathrm{F}$ is made, no more opportunities exist to obtain data with the pump stopped and the system full of liquid; therefore, for lack of later data, the thermal drift calculated from the $500^{\circ} \mathrm{F}$ data is assumed to be constant throughout the test.

For some differential pressure measurements, the data scan at $500^{\circ} \mathrm{F}$ cannot be used as a reference for thermal drift, so other references are used. The liquid level measurements in the vessel accumulator (DPV-ACC-TB) and pressurizer (DPU-PRESLL) are referenced to calculated values based on geometrical considerations at the time when gas flow from the respective vessel is first noted. The reading from the steam generator discharge venturi (DPU-SGDISC) is shifted to read zero after flow is stopped. The steam generator secondary liquid level measurement (DPU-SG-SEC) is shifted to match the output of the process instrumentation prior to blowdown.

In correcting differential pressure data for pressure sensitivity, the corrections are calculated for various times during the test by referring to nearby system pressure transducers. The thermal drift correction is then added to each pressure sensitivity correction and the combined value is added to the raw data using a computer program that linearly interpolates the corrections between the specified time points. The corrections are performed according to the following equations:

$F^{\prime}(t)=K F(t)+C_{\eta}$ for $t<t_{\eta}$ or when no $t_{j}$ are listed

for time points $t$, where $t, \leqslant t \leqslant t_{n}$

$F^{\prime}(t)=K F(t)+c_{i}+\frac{t-t_{i}}{t_{i+1}-t_{i}}\left(c_{i+1}-c_{i}\right)$ for $t_{i} \leq t \leq t_{i+1}$ and where

$i$ takes on values 1 t. $n-1$

$F^{\prime}(t)=K F(t)+C_{n}$ for $t>t_{n}$

where

$\begin{array}{lll}\mathrm{t} & = & \text { time } \\ \mathrm{F}^{\prime}(\mathrm{t}) & = & \text { corrected data } \\ \mathrm{F}(\mathrm{t}) & = & \text { raw data } \\ \mathrm{K} & = & \text { scaling factor } . \\ \mathrm{C}_{\mathrm{i}} \text { and } \mathrm{t}_{\mathrm{i}} & = & \text { corrections and time points. }\end{array}$

The exact values of the constants are given in Table A-II. 
TABLE A-II

CONSTANTS FOR DIFFERENTIAL PRESSURE .

MEASUREMENT CORRECTIONS (TEST S-05-1)

\begin{tabular}{|c|c|c|c|c|c|c|c|}
\hline $\begin{array}{l}\text { Detector } \\
\text { Identification }\end{array}$ & K & $c_{1}$ & $\underline{t_{1}}$ & $\mathrm{C}_{2}$ & $t_{2}$ & $c_{3}$ & $\underline{t_{3}}$ \\
\hline DPV-ACC-TB & $2[a]$ & -1.64 & & & & & \\
\hline DPU-SGDISC & 1 & 0.5 & & & & & \\
\hline DPV-0-9GQ & 1 & -0.077 & 0 & -0.073 & 0.01 & -0.057 & 30 \\
\hline DPU-3-7 & 1 & 0.175 & 0 & 0.10 & 0.01 & -0.03 & 30 \\
\hline$D P B=30=36 L$ & 1 & 3.6 & $n$ & 2.5 & 0.01 & n.? & 30 \\
\hline DPU-PRESLL & 1 & $-0: 4$ & & & & & \\
\hline DPU-SG-SEC & $-7[b]$ & 3.06 & & & & & \\
\hline DPB-23-CNI & $-7^{[c]}$ & & & & & & \\
\hline DPB-32U-36L & 1 & 4.0 & 0 & 2.6 & 0.01 & 0 & 30 \\
\hline DPV-UP-IANN & 1 & 4.0 & 0 & 0.075 & 0.01 & 0.02 & 30 \\
\hline DPB-37-38 & 1 & 0.11 & 0 & 0.1 & 0.01 & 0.08 & 30 \\
\hline DPB-36L-37 & 1 & -0.3 & 0 & -0.2 & 0.01 & -0.03 & 30 \\
\hline DPU-15-1 & 1 & 0.24 & 0 & 0.16 & 0.01 & 0.02 & 30 \\
\hline DPU-15-1L & 1 & -0.065 & 0 & -0.04 & 0.01 & -0.0003 & 30 \\
\hline DPB-38-40 & $-1[c]$ & 3.7 & 0 & 2.5 & 0.01 & 0.3 & 30 \\
\hline DPB-40-42 & 1 & -0.035 & 0 & -0.033 & 0.01 & -0.023 & 30 \\
\hline DPB-21-IANN & 1 & -0.051 & 0 & -0.036 & 0.01 & -0.006 & 30 \\
\hline DPU-12-10 & 1 & 0.61 & 0 & 0.50 & 0.01 & 0.28 & 30 \\
\hline DPU-12-10L & 1 & 0.044 & 0 & 0.048 & 0.01 & 0.054 & 30 \\
\hline DPB-UP-30 & 1 & 0.03 & 0 & 0.022 & 0.0 .1 & 0 & 30 \\
\hline DPU-PR-4 & 1 & -9.3 & 0 & -7.4 & 0.01 & -4.6 & 30 \\
\hline DPV-9-26QQ & 1 & 0.027 & 0 & 0.015 & 0.01 & 0 & 30 \\
\hline DPV-26-55QM & 1 & -0.11 & 0 & -0.05 & 0.01 & 0.045 & 30 \\
\hline DrU-15-IANN & 1 & 0.038 & 0 & 0.021 & 0.01 & -0.006 & 30 \\
\hline DPU-7-10 & 1 & -0.045 & 0 & -0.033 & 0.01 & 0.01 & 30 \\
\hline DPVC-89-W-UP & 1 & 0.39 & 0 & 0.25 & 0.01 & 0.02 & 30 \\
\hline DPVC-9-166ญ२ & 1 & 0.55 & 0 & 0.42 & 0.01 & 0.14 & 30 \\
\hline DPVC-122-140JD & 1 & 0.04 & 0 & 0.065 & 0.01 & 0.10 & 30 \\
\hline DPVC-106-122QJ & 1 & -0.033 & 0 & -0.022 & 0.01 & 0 & 30 \\
\hline DPV-55-110MM & 1 & -0.08 & 0 & -0.065 & 0.01 & -0.04 & 30 \\
\hline
\end{tabular}


$\underline{\text { TABLE A-II (continued) }}$

\begin{tabular}{|c|c|c|c|c|c|c|}
\hline $\begin{array}{c}\text { Detector } \\
\text { Identification } \\
\end{array}$ & K & $\mathrm{C}_{1}$ & $t_{1}$ & $\mathrm{C}_{2}$ & $t_{2}$ & $\mathrm{C}_{3}$ \\
\hline DPV-166-173QQ & 1 & -0.02 & 0 & -0.013 & 0.01 & -0.001 \\
\hline DPV-110-136MQ & 1 & -0.75 & & & & \\
\hline
\end{tabular}

[a] Data acquisition computer used wrong multiplier:

[b] Transducer output was inverted and offset to show liquid level.

[c] Patch panel connections were reversed.

\section{MOMENTUM FLUX MEASUREMENTS (DRAG DISCS)}

The temperature sensitivity of drag discs is determined from pretest warmup data taken at 200 and $500^{\circ} \mathrm{F}$ with no system flow. The temperature sensitivity is removed from the data before the data are converted to momentum flux. The temperature of each transducer is taken from the signal of a nearby fluid or metal temperature thermocouple. Slight corrections for errors in setting the transducer output to zero at ambient conditions are also made at this time. Corrections are made using the following equation:

where

$$
F^{\prime}(t)=F(t)+D_{0}-D_{1} T(t)
$$

$$
\begin{aligned}
& F^{\prime}(t)=\text { corrected data } \\
& F(t)=\text { raw data } \\
& T(t)=\begin{array}{l}
\text { temperature data from the transducer used for temperature sensitivity } \\
\text { correction }
\end{array} \\
& D_{0}=\text { ambient offset } \\
& D_{1}=\text { temperature sensitivity. }
\end{aligned}
$$

Values of the constants are given in Table A-III.

The drag discs, FDB-30 and FDB-37, were partially filled with subcooled water during blowdown, giving them an unpredictable temperature response. Due to this problem, corrections to FDB-30 and FDB-37 are done only to set the transducer output to zero at 
TABLE A-I I I

CONSTANTS FOR MOMENTUM FLUX

MEASUREMENT CORRECTIONS (TEST S-05-1)

\begin{tabular}{|c|c|c|c|c|c|c|}
\hline \multicolumn{2}{|l|}{$\begin{array}{c}\text { Detector } \\
\text { Identification } \\
\end{array}$} & $D_{0}$ & & $D_{1}$ & & $T(t)^{[a]}$ \\
\hline FDV-CORE-IN & & -0.04 & & -0.000626 & & TFV-LP-7 \\
\hline FDU-10 & & . & & 0.000216 & & TMU-1T16 \\
\hline FDU -13 & & 0.01 & & 0.000729 & & TMU-15B16 \\
\hline FDB-21 & & & & -0.000748 & & TMB $-20 B 16$ \\
\hline$F D B-12$ & & & & ก.กกก787 & & TFB -42 \\
\hline FDU-1 & & 0.01 & & -0.000663 & & TMU-1T16. \\
\hline FDU-15 & & & & -0.001533 & & TMU $-15 B 16$ \\
\hline & $\underline{k}$ & & $c_{1}$ & $t_{1}$ & $\mathrm{C}_{2}$ & $\underline{t_{2}}$ \\
\hline FDB -30 & 1 & & 0.433 & . & & \\
\hline FDB -37 & 1. & & -0.265 & 0 & 0.05 & 40 \\
\hline $\begin{array}{l}\text { [a] } T(t) \text { is th } \\
\text { correction } \\
\text { which the }\end{array}$ & & $\begin{array}{l}\text { ure da } \\
\text { bols } \\
\text { obtair }\end{array}$ & $\begin{array}{l}\text { ta used } \\
\text { listed } i \\
\text { eed. }\end{array}$ & $\begin{array}{l}\text { or tempera } \\
\text { ntity the }\end{array}$ & $\begin{array}{l}\text { sens } \\
\text { nocouk }\end{array}$ & $\begin{array}{l}\text { tivity } \\
\text { les from }\end{array}$ \\
\hline
\end{tabular}

times when no flow occurs in the broken loop. Adjustments were made using the same time-based equations used for the differential pressure corrections described in Section A-2. Values of the constants are given in Table A-III.

\section{DENSITY MEASUREMENTS}

Density calculations are based on the voltage output of the photomultiplier tubes in the gamma-attenuation densitometer assemblies. The equation used for converting voltage to density is as follows

$$
\rho=(1 / C) \ln \{D /[A F(t)+B]\}
$$


where
$\rho=$ density in $1 \mathrm{bm} / \mathrm{ft}^{3}$
$\mathrm{C}=$ constant based on the length of the gamma beam path
$\mathrm{D}=$ theoretical voltage for zero attenuation inside the vessel
A $=$ amplification factor
B = biasing factor
$F(t)=$ transducer voltage output.

Constants $\mathrm{A}$ and $\mathrm{B}$ are adjusted to match the final data to density values calculated from measured pressure and temperature values at the preblowdown and postdrain conditions, effectively giving the data an in place calibration. The values of the constants for various transducers are given in Table A-IV.

The density measurement GVLP- $172 \mathrm{HZ}$ uses an amplifier which precalculates the logarithm function, and hence has a simpler conversion formula

$$
\rho=10-1.845 F(t) \text {. }
$$




\section{TABLE A-IV}

CONSTANTS FOR DENSITY MEASUREMENT

CONVERSIONS TO ENGINEERING UNITS (TEST S-05-1)

\begin{tabular}{|c|c|c|c|c|}
\hline $\begin{array}{c}\text { Detector } \\
\text { Identification }\end{array}$ & A & B & $C$ & $D$ \\
\hline GV $-\mathrm{COR}-150 \mathrm{~Hz}$ & 0.7376 & 0.528 & 0.014 & 4.1 \\
\hline$G B-30 V R$ & 1.027 & -0.137 & 0.0095 & 6.75 \\
\hline$G B-42$ & 0.907 & 0.593 & 0.006 & 6.1 \\
\hline GU-1VR & 1.087 & -0.194 & 0.0095 & 3.2 \\
\hline $\mathrm{GU}-1 \mathrm{~Hz}$ & 1.261 & -1.27 & 0.0095 & 5.3 \\
\hline GU-5VR & 1.153 & -0.861 & 0.0095 & 6.2 \\
\hline GU-10VR & 1.083 & -0.543 & 0.0095 & 7.2 \\
\hline GU-13VR & 1.281 & -0.765 & 0.0095 & 2.9 \\
\hline GU-15VR & 1.047 & -0.329 & 0.0095 & 7.2 \\
\hline GU-15Hz & 1.035 & -0.041 & 0.0095 & 1.75 \\
\hline$G B-21 V R$ & 1.015 & -0.079 & 0.0095 & 6.55 \\
\hline$G B-23 V R$ & 1.034 & -0.274 & 0.006 & 7.9 \\
\hline GU-PRIZE & 1.043 & -0.068 & 0.0095 & 2.3 \\
\hline GVLP-165Hz & 0.771 & 1.469 & 0.014 & 6.4 \\
\hline
\end{tabular}




\section{CORE POWER MEASUREMENTS}

Corrections to core power readings are determined from the core voltage and core current readings, with a slight adjustment for the power lost in setting the core radial peaking factor. The adjustments are as follows:

PWRCOR T-1: $\quad F^{\prime}(t)=0.9950 F(t)-1.06=[($ Voltage $)$ (Current) $(0.974)]$

PURCOR T-2: $\quad F^{\prime}(t)=0.9891 F(t)+4.85=\left[\left(V_{0}\right]\right.$ tage) (Current) $\left.(0.974)\right]$

where

$$
\begin{aligned}
& F^{\prime}(t)=\quad \text { core power in kilowatts } \\
& F(t)=\quad \text { raw core power reading. }
\end{aligned}
$$




\section{Internal Distribution}

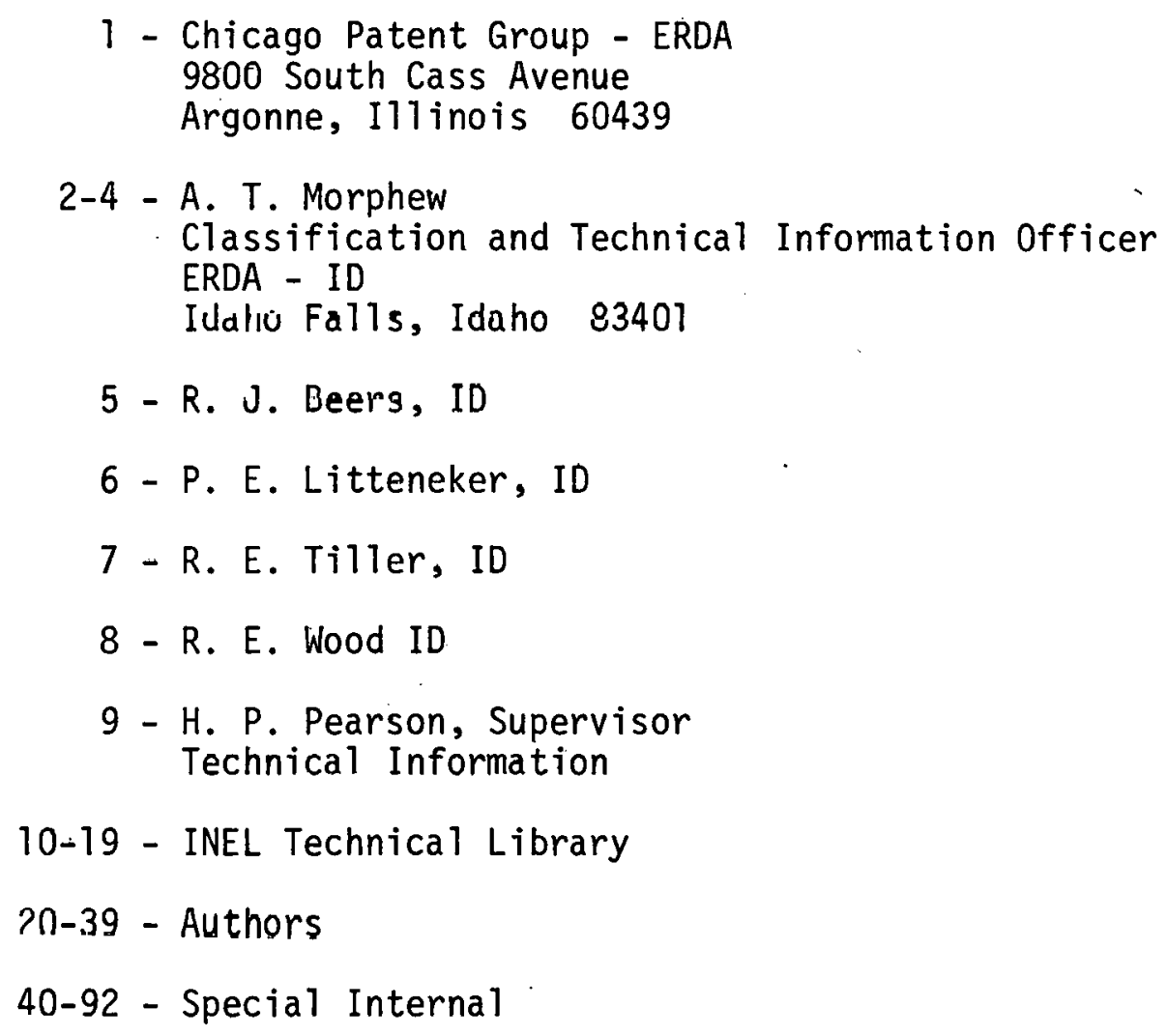

\section{External Distribution}

93-94 - Sául Levine, Dirreclur. Office of Nuclear Regulatory Research, NRC Washington, D. C. 20555

95-398 - Distribution under NRC-2, Water Reactor Safety Research Systems Engineering 